\title{
Baseline and Projected Future Carbon Storage and Greenhouse-Gas Fluxes in Ecosystems of the Eastern United States
}

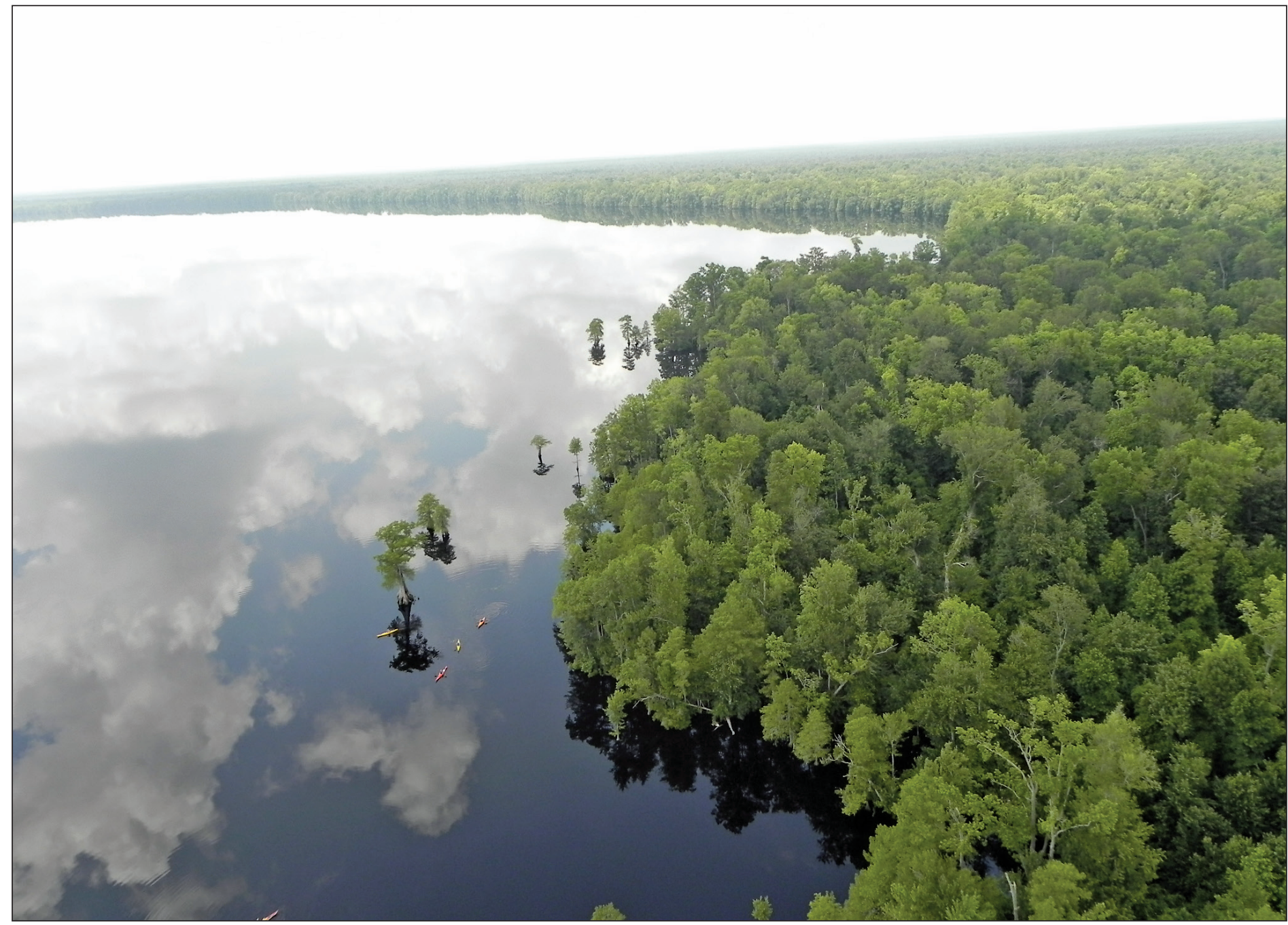

Professional Paper 1804 


\section{Baseline and Projected Future Carbon Storage and Greenhouse-Gas Fluxes in Ecosystems of the Eastern United States}

Edited by Zhiliang Zhu and Bradley C. Reed

Professional Paper 1804 


\title{
U.S. Department of the Interior SALLY JEWELL, Secretary
}

\section{U.S. Geological Survey \\ Suzette M. Kimball, Acting Director}

\author{
U.S. Geological Survey, Reston, Virginia: 2014
}

For more information on the USGS - the Federal source for science about the Earth, its natural and living resources, natural hazards, and the environment-visit http://www.usgs.gov or call 1-888-ASK-USGS.

For an overview of USGS information products, including maps, imagery, and publications, visit http://www.usgs.gov/pubprod/.

To order this and other USGS information products, visit http://store.usgs.gov/.

Any use of trade, firm, or product names is for descriptive purposes only and does not imply endorsement by the U.S. Government.

Although this information product, for the most part, is in the public domain, it also may contain copyrighted materials as noted in the text. Permission to reproduce copyrighted items must be secured from the copyright owner.

Suggested citation:

Zhu, Zhiliang, and Reed, B.C., eds., 2014, Baseline and projected future carbon storage and greenhouse-gas fluxes in ecosystems of the eastern United States: U.S. Geological Survey Professional Paper 1804, 204 p., http://dx.doi.org/10.3133/pp1804.

ISSN 1044-9612 (print) ISSN 2330-7102 (online) ISBN 978-1-4113-3794-7 


\section{Contents}

Executive Summary

By Zhiliang Zhu, Benjamin M. Sleeter, Ryan R. Reker, Todd J. Hawbaker,

Sarah Stackpoole, Brian A. Bergamaschi, and Shuguang Liu ...................................1

Chapter 1 Scope, Methodology, and Current Knowledge

By Zhiliang Zhu, Benjamin M. Sleeter, Terry L. Sohl, Todd J. Hawbaker,

Shuguang Liu, Sarah Stackpoole, Brian A. Bergamaschi, and

Ashwan D. Reddy

Chapter 2 Ecoregion and Scenario Framework

By Benjamin M. Sleeter, Glenn E. Griffith, Tamara S. Wilson, Rachel R. Sleeter, Christopher E. Soulard, Kristi L. Sayler, Ryan R. Reker, Michelle A. Bouchard, and Terry L. Sohl .

Chapter 3 Mapping and Modeling of Land Use and Land Cover in the Eastern United States From 1992 Through 2050

By Ryan R. Reker, Kristi L. Sayler, Aaron M. Friesz, Terry L. Sohl, Michelle A. Bouchard, Benjamin M. Sleeter, Rachel R. Sleeter, Tamara S. Wilson, Glenn E. Griffith, and Michelle L. Knuppe .

Chapter 4 Wildland Fire Occurrence and Emissions in the Eastern United States From 2001 Through 2050

By Todd Hawbaker and Zhiliang Zhu

Chapter 5 Carbon Sequestration, Transport, and Emission From Inland Aquatic Ecosystems in the Eastern United States

By Sarah Stackpoole, David Butman, David Clow, Cory McDonald, Edward Stets, and Robert Striegl

Chapter 6 Terrestrial Fluxes of Nutrients and Sediment to Coastal Waters and Their Effects on Coastal Carbon Storage in the Eastern United States By Brian A. Bergamaschi, Richard A. Smith, Michael J. Sauer, Jhih-Shyang Shih, and Lei Ji

Chapter 7 Baseline and Projected Future Carbon Storage, Carbon Sequestration, and Greenhouse-Gas Fluxes in Terrestrial Ecosystems of the Eastern United States

By Shuguang Liu, Jinxun Liu, Yiping Wu, Claudia J. Young,

Jeremy M. Werner, Devendra Dahal, Jennifer Oeding, and

Gail L. Schmidt. .115

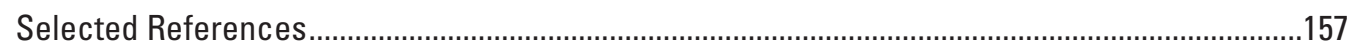

Appendix 1. The Erosion Deposition Carbon Model ................................................................180

Appendix 2. The Land Greenhouse-Gas Accounting Tool..........................................................182

Appendix 3. Coefficients of Forest Partial Cutting and Biomass Mortality.....................................184

Appendix 4. Optimized Maximum Monthly Gross Primary Production ..........................................189

Appendix 5. Comparison of Sampling-Based and Per-Pixel Model Runs......................................190

Appendix 6. Emission Factors of Nitrous Oxide and Methane in the Eastern United States .......193 
Conversion Factors

\begin{tabular}{|c|c|c|}
\hline Multiply & By & To obtain \\
\hline \multicolumn{3}{|c|}{ Length } \\
\hline centimeter $(\mathrm{cm})$ & 0.3937 & inch (in.) \\
\hline millimeter (mm) & 0.03937 & inch (in.) \\
\hline meter $(\mathrm{m})$ & 3.281 & foot $(\mathrm{ft})$ \\
\hline kilometer $(\mathrm{km})$ & 0.6214 & mile (mi) \\
\hline \multicolumn{3}{|c|}{ Area } \\
\hline hectare (ha) & 2.471 & acre \\
\hline square meter $\left(\mathrm{m}^{2}\right)$ & 10.76 & square foot $\left(\mathrm{ft}^{2}\right)$ \\
\hline square centimeter $\left(\mathrm{cm}^{2}\right)$ & 0.1550 & square inch $\left(\mathrm{ft}^{2}\right)$ \\
\hline square kilometer $\left(\mathrm{km}^{2}\right)$ & 0.3861 & square mile $\left(\mathrm{mi}^{2}\right)$ \\
\hline \multicolumn{3}{|c|}{ Volume } \\
\hline cubic centimeter $\left(\mathrm{cm}^{3}\right)$ & 0.06102 & cubic inch $\left(\right.$ in $\left.^{3}\right)$ \\
\hline cubic meter $\left(\mathrm{m}^{3}\right)$ & 35.31 & cubic foot $\left(\mathrm{ft}^{3}\right)$ \\
\hline \multicolumn{3}{|c|}{ Flow rate } \\
\hline cubic meter per second $\left(\mathrm{m}^{3} / \mathrm{s}\right)$ & 35.31 & cubic foot per second $\left(\mathrm{ft}^{3} / \mathrm{s}\right)$ \\
\hline cubic meter per day $\left(\mathrm{m}^{3} / \mathrm{d}\right)$ & 264.2 & gallon per day $(\mathrm{gal} / \mathrm{d})$ \\
\hline $\begin{array}{l}\text { cubic meter per day per square kilometer } \\
{\left[\left(\mathrm{m}^{3} / \mathrm{d}\right) / \mathrm{km}^{2}\right]}\end{array}$ & 684.28 & gallon per day per square mile $\left[(\mathrm{gal} / \mathrm{d}) / \mathrm{mi}^{2}\right]$ \\
\hline millimeter per year $(\mathrm{mm} / \mathrm{yr})$ & 0.03937 & inch per year (in/yr) \\
\hline \multicolumn{3}{|c|}{ Mass } \\
\hline gram $(\mathrm{g})$ & 0.03527 & ounce, avoirdupois (oz) \\
\hline kilogram (kg) & 2.205 & pound avoirdupois (lb) \\
\hline \multicolumn{3}{|c|}{ Pressure } \\
\hline atmosphere, standard (atm) & 101.3 & kilopascal $(\mathrm{kPa})$ \\
\hline \multicolumn{3}{|c|}{ Hydraulic conductivity } \\
\hline meter per day $(\mathrm{m} / \mathrm{d})$ & 3.281 & foot per day $(\mathrm{ft} / \mathrm{d})$ \\
\hline \multicolumn{3}{|c|}{ Transmissivity* } \\
\hline meter squared per day $\left(\mathrm{m}^{2} / \mathrm{d}\right)$ & 10.76 & foot squared per day $\left(\mathrm{ft}^{2} / \mathrm{d}\right)$ \\
\hline \multicolumn{3}{|c|}{ Application rate } \\
\hline kilograms per hectare per year [(kg/ha)/yr] & 0.8921 & pounds per acre per year [(lb/acre)/yr] \\
\hline
\end{tabular}

\section{Datums and Supplemental Information}

Vertical coordinate information is referenced to the North American Vertical Datum of 1988 (NAVD 88).

Horizontal coordinate information is referenced to the North American Datum of 1983 (NAD 83). Altitude, as used in this report, refers to distance above the vertical datum.

Temperature in degrees Celsius $\left({ }^{\circ} \mathrm{C}\right)$ may be converted to degrees Fahrenheit $\left({ }^{\circ} \mathrm{F}\right)$ as

$$
{ }^{\circ} \mathrm{F}=\left(1.8 \times{ }^{\circ} \mathrm{C}\right)+32 \text {. }
$$

The resolution of pixels in spatial datasets follows the conventions used in the spatial data and modeling communities. The format is "n-meter resolution," where $n$ is a numerical value for the length. The usage translates into a pixel with a length of $n$ on all sides that covers an area of $\mathrm{n}$ meters $\times \mathrm{n}$ meters.

\section{Abbreviations}

$\begin{array}{ll}{ }^{\circ} \mathrm{C} & \text { degrees Celsius } \\ \mu \mathrm{atm} & \text { microatmospheres }\end{array}$




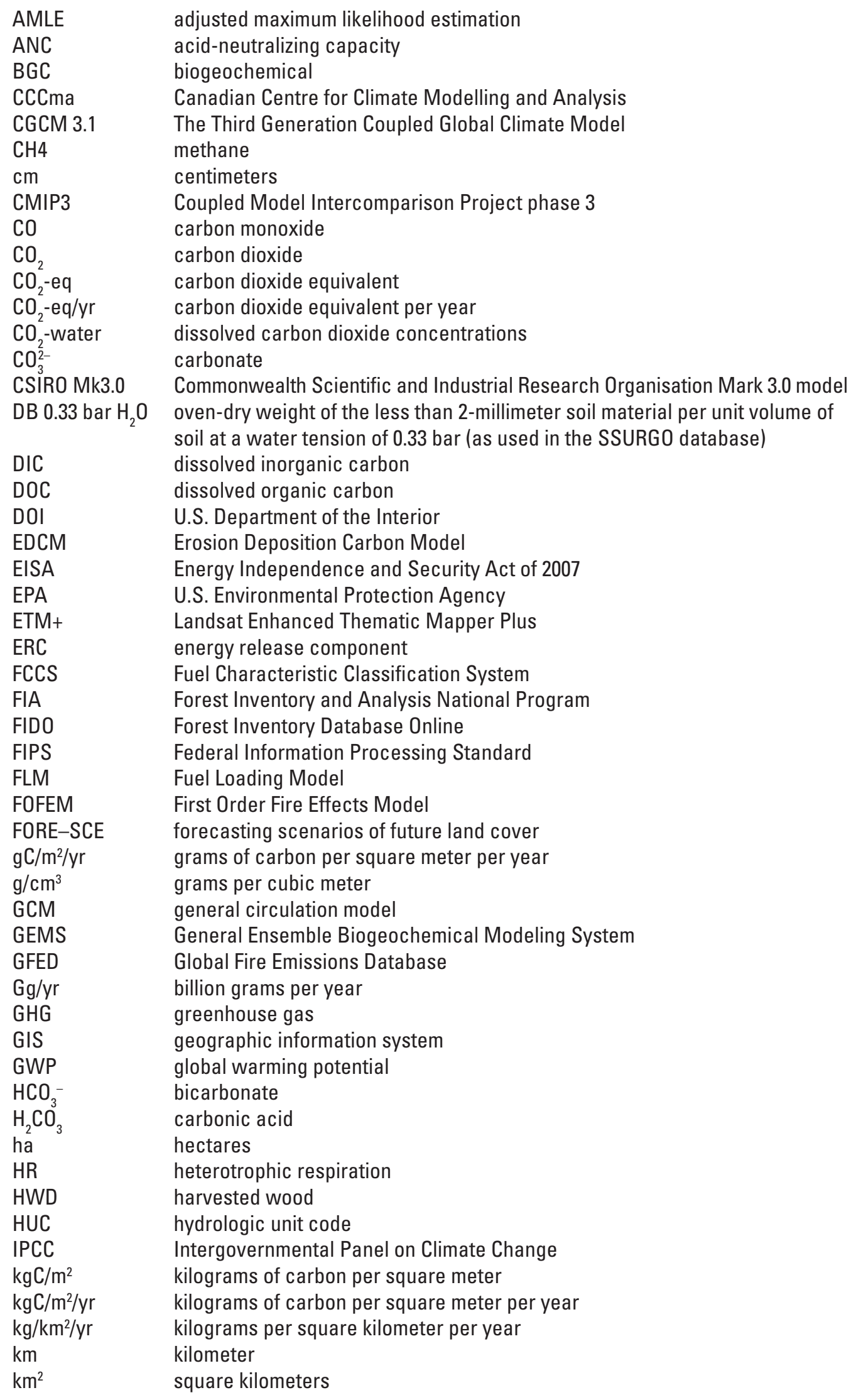




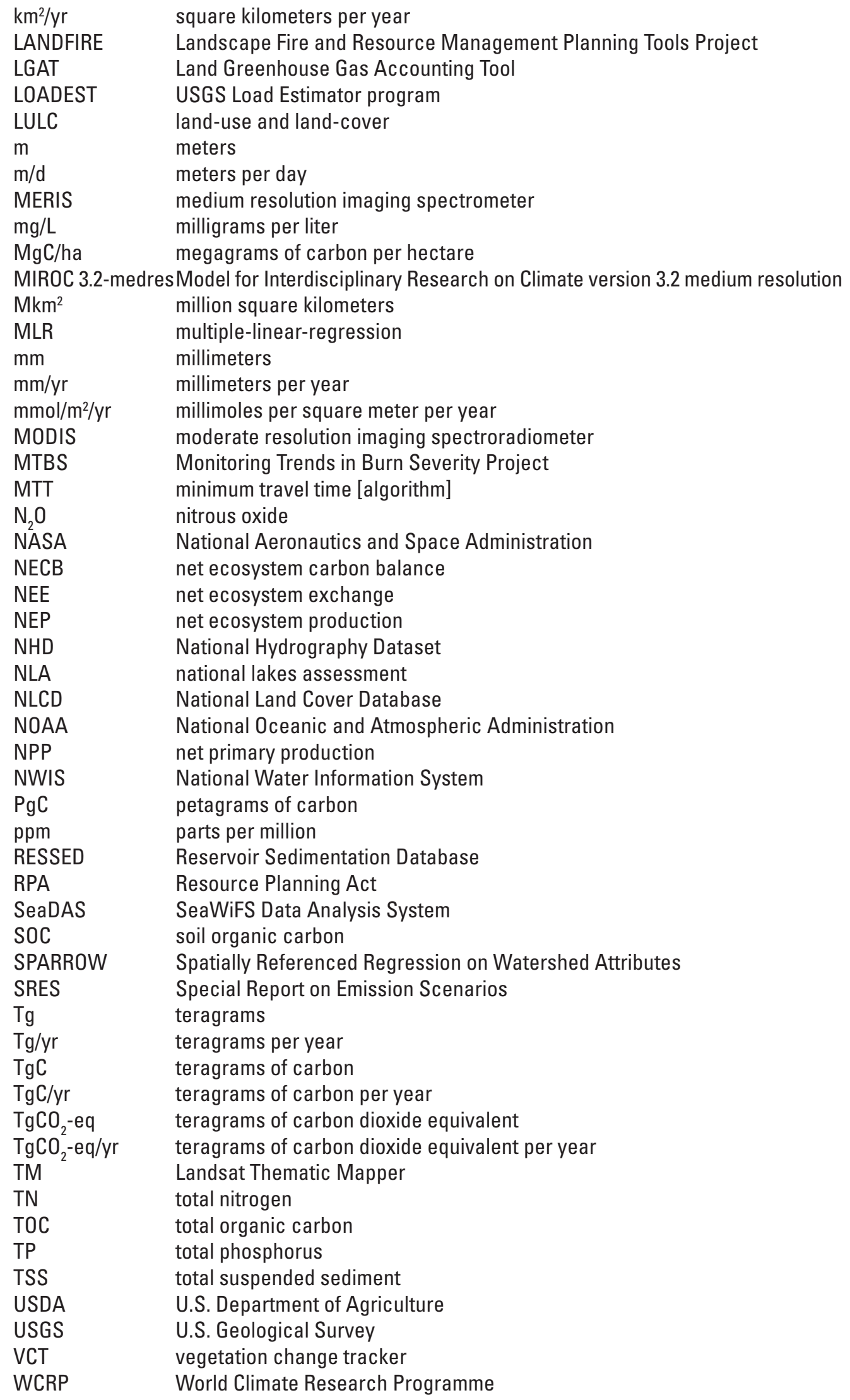




\title{
Baseline and Projected Future Carbon Storage and Greenhouse-Gas Fluxes in Ecosystems of the Eastern United States-Executive Summary
}

\author{
By Zhiliang Zhu, ${ }^{1}$ Benjamin M. Sleeter, ${ }^{1}$ Ryan R. Reker, ${ }^{2}$ Todd J. Hawbaker, ${ }^{1}$ Sarah Stackpoole, \\ Brian A. Bergamaschi, ${ }^{1}$ and Shuguang Liu'
}

\section{Introduction}

This is the third in a series of reports produced by the U.S. Geological Survey (USGS) to fulfill the requirements of section 712 of the Energy Independence and Security Act (EISA) of 2007 and to conduct a comprehensive national assessment of storage and flux (flow) of carbon and the fluxes of other greenhouse gases (GHGs, including carbon dioxide $\left(\mathrm{CO}_{2}\right)$, methane $\left(\mathrm{CH}_{4}\right)$, and nitrous oxide $\left.\left(\mathrm{N}_{2} \mathrm{O}\right)\right)$. These carbon and GHG variables were examined for major terrestrial ecosystems (forests, grasslands/shrublands, agricultural lands, and wetlands) and aquatic ecosystems (rivers, streams, lakes, estuaries, and coastal waters) in the Eastern United States in two time periods: baseline (from 2001 through 2005) and future (projections from the end of the baseline through 2050). The Great Lakes were not included in this assessment due to a lack of input data. Chapter 1 of this report provides an overview of the general methodology. Topics of this report include the storage and fluxes of carbon estimated based on data included in maps of classes of land-use and landcover (LULC) change, climate change, land management, and wildland fire. Changes in storage and fluxes of carbon estimated based on potential changes in natural vegetation and future potential vegetation change due to climate change were not included in this report.

This regional assessment was conducted to achieve two primary objectives: (1) to contribute to the EISA mandate for a national assessment of carbon sequestration and GHG fluxes, and (2) to help improve the understanding of carbon cycling at a regional scale by focusing on different ecosystems and their relations with natural and anthropogenic controlling processes (such as climate change, LULC, land management, and wildland fires). To meet the objectives, the assessment was designed to provide answers to such questions as "How much

\footnotetext{
${ }^{1}$ U.S. Geological Survey
}

${ }^{2}$ ASRC Federal InuTeq carbon was stored in ecosystems of the Eastern United States and how would storage of carbon change over space and time?" and "How might the stored carbon and carbon fluxes be affected by the natural and anthropogenic processes that affect the region?"

The assessment covered an area of 3.05 million square kilometers in the Eastern United States, which is divided into in seven level II ecoregions (as defined by the U.S. Environmental Protection Agency, 2013): the Mixed Wood Shield, Atlantic Highlands, Mixed Wood Plains, Central USA Plains, Southeastern USA Plains, Ozark, Ouachita-Appalachian Forests, and Mississippi Alluvial and Southeast USA Coastal Plains ecoregions. Further description of the ecoregional framework is provided in detail in chapters 1 and 2. The assessment was based on measured and remotely sensed data collected by the USGS and many other agencies and organizations, combined with statistical methods and simulation models. Specific input data used in different components of the assessment methodology are described in chapters 3 through 7 . The major findings are discussed in this executive summary.

\section{Baseline and Projected Future Land-Use and Land-Cover Change}

In 2005, the total area of the Eastern United States (3.05 million square kilometers) included the following ecosystems: forests (47.9 percent), agricultural lands (31.2 percent), wetlands ( 8.9 percent), open water (lakes, reservoirs, rivers, and streams; 5.4 percent), grasslands/ shrublands (1.7 percent), and other land types (5 percent). Between 1992 and 2005, changes in land use (such as croplands) and land cover (such as wetlands) in the Eastern United States affected 8.9 percent of that land area (compared with 2.9 percent in the Western United States) and were driven primarily by demands for forest products and urban development. 
The projected changes (to 2050) in both LULC and climate were used in this assessment to support the projection of future potential storage and fluxes of carbon in relation to ecological and economic processes. The projections in LULC were highly variable across the seven ecoregions of the Eastern United States, as were the assumptions that were made. For the Eastern United States as a whole, the total projected change ranged from 17.2 to 22.9 percent between different scenarios, including changes between different LULC categories such as forests, agriculture, and developed lands. The most active ecoregion in terms of projected LULC change was the Southeastern USA Plains ecoregion, averaging 31 percent of change between the different LULC types over the projection years.

\section{Baseline Carbon Storage and Greenhouse Gas Fluxes}

Main findings from this assessment for baseline years are described in paragraphs below and are summarized in table E1. The average total storage of carbon in the terrestrial ecosystems of the Eastern United States in 2005 was estimated to be 26,962 teragrams of carbon $(\mathrm{TgC})$, ranging between a low of 25,069 and a high of $28,497 \mathrm{TgC}$. The total carbon stock was distributed in forests (68.1 percent), wetlands (15.1 percent), agricultural lands (14.7 percent), grasslands/shrublands ( 0.9 percent), and other lands (1,1 percent). Geographically, the estimated total carbon stocks ranged from 1,499.5 $\mathrm{TgC}$ in the Central USA Plains ecoregion to 4,791 $\mathrm{TgC}$ in the Ozark, Ouachita-Appalachian Forests ecoregion, and the per-unit-of-area carbon stocks ranged from 6.3 kilograms of carbon per square meter $\left(\mathrm{kgC} / \mathrm{m}^{2}\right)$ in the Central USA Plains ecoregion to $16.1 \mathrm{kgC} / \mathrm{m}^{2}$ in the Atlantic Highlands ecoregion. On average, the wetlands maintained the largest stock of carbon per unit of area among all the ecosystems in the Eastern United States with $15 \mathrm{kgC} / \mathrm{m}^{2}$, followed by forests $\left(12.6 \mathrm{kgC} / \mathrm{m}^{2}\right)$, grasslands $/$ shrublands $\left(4.7 \mathrm{kgC} / \mathrm{m}^{2}\right)$, agricultural lands $\left(4.2 \mathrm{kgC} / \mathrm{m}^{2}\right)$, and other land types $\left(1 \mathrm{kgC} / \mathrm{m}^{2}\right)$. Overall, live biomass accounted for 42 percent of the total carbon stock, and soil organic carbon (SOC; assessed in the top 20-centimeter-thick layer only) accounted for 43 percent of the total carbon stock; woody debris and other surface carbon pools represented the remaining 15 percent.

The net flux of carbon was calculated as the change of carbon stock between two points in time. A negative number indicates carbon uptake, carbon sequestration, or a carbon sink; a positive number indicates a carbon emission or a carbon source. From 2001 to 2005, an average annual net flux of $-279.4 \mathrm{TgC} / \mathrm{yr}$, ranging from a low of $-405.5 \mathrm{TgC} / \mathrm{yr}$ to a high of $-112.5 \mathrm{TgC} / \mathrm{yr}$, was estimated for all the terrestrial ecosystems in the Eastern United States. Most of the net carbon flux in the study area was in forests (81 percent, -154.8 grams of carbon per square meter per year $\left.\left(\mathrm{gC} / \mathrm{m}^{2} / \mathrm{yr}\right)\right)$, followed by wetlands ( 12.8 percent, $-132.2 \mathrm{gC} / \mathrm{m}^{2} / \mathrm{yr}$ ), agricultural lands ( 4.1 percent, $-12.1 \mathrm{gC} / \mathrm{m}^{2} / \mathrm{yr}$ ), and grasslands/ shrublands ( 0.8 percent, $\left.-40.9 \mathrm{gC} / \mathrm{m}^{2} / \mathrm{yr}\right)$. Of the total carbon sink, live biomass accounted for 67.6 percent, SOC accounted for 23.4 percent, and dead biomass accounted for 9 percent.

For comparison with the estimated net carbon flux in this study, a recent study found that the net carbon flux from LULC change and forestry was $-246.8 \mathrm{TgC}$ in 2011 for the area of the conterminous United States (U.S. Environmental Protection Agency, 2013b). In a separate assessment for the Western United States (Liu and others, 2012), using the same method as described in this report, the per-unit-area net carbon flux for forests was estimated to be $-72.1 \mathrm{gC} / \mathrm{m}^{2} / \mathrm{yr}$. Net forest carbon flux was $-93 \mathrm{gC} / \mathrm{m}^{2} / \mathrm{yr}$ for the United States as a whole (Pan and others, 2011).

Between 2001 and 2008 in the Eastern United States, 875 to 4,842 square kilometers per year was burned, releasing 1.8 to 20.5 teragrams of $\mathrm{CO}_{2}$-equivalent per year $\left(\mathrm{TgCO}_{2}\right.$-eq/yr) ( 0.5 to $5.6 \mathrm{TgC} / \mathrm{yr})$, mostly along the Atlantic coast in the Mississippi Alluvial and Southeast USA Coastal Plains ecoregion, which includes the Everglades and Texas-Louisiana Coastal Plains ecoregions. The average annual GHG emission from the fires was $5.9 \mathrm{TgCO}_{2}$-eq/yr $(1.6 \mathrm{TgC} / \mathrm{yr})$.

Removal of carbon from forest ecosystems in the Eastern United States was estimated for forest harvesting (clearcutting and partial cutting, with forests remaining as forests) and forests converting to other uses (including agriculture, developed, and other land uses). Carbon removal from forest harvesting was estimated to be an average of $41 \mathrm{TgC} / \mathrm{yr}$ from 2001 through 2005, whereas from land use conversions, the average was $7.3 \mathrm{TgC} / \mathrm{yr}$.

Using data collected between the 1970s and the present, rivers and streams throughout the Eastern United States were estimated to transport $36.5 \mathrm{TgC} / \mathrm{yr}$ (or an average of $6.4 \mathrm{gC} / \mathrm{m}^{2} / \mathrm{yr}$ in yield per unit of area), ranging from 28.1 to $44.8 \mathrm{TgC} / \mathrm{yr}$ (or an average of 5 to $7.9 \mathrm{gC} / \mathrm{m}^{2} / \mathrm{yr}$ ) of dissolved inorganic and total organic carbon from upstream sources to estuaries and the coastal oceans. The emissions of carbon dioxide to the atmosphere from inland waters of the Eastern United States were $51.3 \mathrm{TgC} / \mathrm{yr}$ (or an average of $5.2 \mathrm{gC} / \mathrm{m}^{2} / \mathrm{yr}$ in yield per unit of area), ranging from 34.3 to $71.4 \mathrm{TgC} / \mathrm{yr}$ (or an average of 3.8 to $6.3 \mathrm{gC} / \mathrm{m}^{2} / \mathrm{yr}$ in yield per unit of area); 81 percent of the total emissions was from rivers and streams, and 19 percent was from lakes and reservoirs.

The rate of carbon burial (sequestration) in the sediments in the lakes and reservoirs was estimated to be $-9.2 \mathrm{TgC} / \mathrm{yr}$ (or an average of $-3.1 \mathrm{gC} / \mathrm{m}^{2} / \mathrm{yr}$ in yield per unit of area), ranging from -4.6 to $-13.8 \mathrm{TgC} / \mathrm{yr}$ (or an average of -1.6 to $-4.7 \mathrm{gC} / \mathrm{m}^{2} / \mathrm{yr}$ in yield per unit of area). The estimates of carbon fluxes in aquatic ecosystems were highly variable because of differences in precipitation, topography, lithology, and other controlling processes (Pacala and others, 2001).

Carbon is also stored in coastal waters in the Eastern United States through burial in coastal sediments and through transport of carbon from the surface into the deep ocean. The contribution of terrestrial processes to the total annual rate of carbon storage in coastal waters was estimated to be $-7.8 \mathrm{TgC} / \mathrm{yr}$, ranging from -1.8 to $-22.4 \mathrm{TgC} / \mathrm{yr}$, similar in the ranges of values of estimated burial of carbon in lakes and 
Table E1. Baseline estimates by ecosystems in the Eastern United States.

[gC/m²/yr, grams of carbon per square meter per year; $\mathrm{kgC} / \mathrm{m}^{2}$, kilograms of carbon per square meter; $\mathrm{TgC}$, teragrams of carbon; $\mathrm{TgC} / \mathrm{yr}$, teragrams of carbon per year; $\mathrm{TgCO}_{2}$-eq/yr, teragrams of carbon dioxide-equivalent per year]

\begin{tabular}{|c|c|c|}
\hline Variable & Ecosystem & Mean (range if available) \\
\hline Total carbon stock & All terrestrial ecosystems & $26,961.8(25,068.8$ to $28,497.0) \mathrm{TgC}$ \\
\hline \multirow[t]{3}{*}{ Per unit area carbon stock } & Forests & $12.6 \mathrm{kgC} / \mathrm{m}^{2}$ \\
\hline & Wetlands & $15.0 \mathrm{kgC} / \mathrm{m}^{2}$ \\
\hline & Agricultural lands & $4.2 \mathrm{kgC} / \mathrm{m}^{2}$ \\
\hline Average annual net carbon flux & All terrestrial ecosystems & $-279.4(-405.5$ to -112.5$) \mathrm{TgC} / \mathrm{yr}$ \\
\hline \multirow[t]{3}{*}{ Per unit area net carbon flux } & Forests & $-154.8 \mathrm{gC} / \mathrm{m}^{2} / \mathrm{yr}$ \\
\hline & Agricultural lands & $-12.1 \mathrm{gC} / \mathrm{m}^{2} / \mathrm{yr}$ \\
\hline & Grasslands/shrublands & $-40.9 \mathrm{gC} / \mathrm{m}^{2} / \mathrm{yr}$ \\
\hline Wildland fire emissions & Forests, wetlands & $1.6(0.5$ to 5.6$) \mathrm{TgC} / \mathrm{yr}$ \\
\hline Carbon removal from harvest & Forests & $41.0 \mathrm{TgC} / \mathrm{yr}$ \\
\hline Carbon removal from forest conversions & Forests converting to nonforest land use & $7.3 \mathrm{TgC} / \mathrm{yr}$ \\
\hline Coastal storage & Coastal waters & $15,000 \mathrm{TgC}$ \\
\hline Total methane emissions & All terrestrial ecosystems & 193.0 (191.7 to 195$) \mathrm{TgCO} 2-\mathrm{eq} / \mathrm{yr}$ \\
\hline Total nitrous oxide emissions & All terrestrial ecosystems & 174.7 (173.0 to 176.6 ) TgCO2-eq/yr \\
\hline
\end{tabular}

reservoirs. However, coastal sediments and deep ocean waters represent an important long-term reservoir for carbon storage, amounting to storage of more than $15,000 \mathrm{TgC}$ over millennial time scales under modeled conditions, or approximately 60 percent of the total terrestrial carbon pool.

In addition to the baseline net terrestrial carbon flux estimates $(-279.4 \mathrm{TgC} / \mathrm{tr}$, ranging from -405.5 to $-112.5 \mathrm{TgC} / \mathrm{yr}$, or $-1,024.6 \mathrm{TgCO}_{2}$-eq/yr, ranging from $-1,487$ to $-412.9 \mathrm{TgCO}_{2}$-eq/yr), the baseline flux rates of $\mathrm{CH}_{4}$ and $\mathrm{N}_{2} \mathrm{O}$ were estimated to be relatively low and highly variable among ecosystems and ecoregions. Overall, the estimated flux rate of $\mathrm{CH}_{4}$ during the baseline years was $193 \mathrm{TgC} / \mathrm{yr}$, ranging from 191.7 to $195 \mathrm{TgCO}_{2}$-eq/yr. The estimated flux rate of $\mathrm{N}_{2} \mathrm{O}$ was $174.7 \mathrm{TgCO}_{2}$-eq/yr, ranging from 173 to $176.6 \mathrm{TgCO}_{2}$-eq/yr.

\section{Projected Future Carbon Storage and Greenhouse Gas Fluxes}

In order to project the future potential carbon storage amounts and flux rates, combinations of LULC scenarios and climate projections, developed on an annual basis for 2006 through 2050, were used for the assessment along with multiple biogeochemical models. The results of these combinations led to a range of estimates for storage and flux of carbon under a range of projected future conditions. The results of projected future potential stocks and flux of carbon were highly variable among multiple model runs, ecoregions, and ecosystems

The total amount of carbon that potentially could be stored in the terrestrial ecosystems of the Eastern United States in 2050 was projected to be $37,082 \mathrm{TgC}$, ranging from 25,512 to $46,002 \mathrm{TgC}$, which is an increase of $10,121 \mathrm{TgC}$ or 37.5 percent in total carbon stock from the stocks stored in the baseline period. Seventy percent of the increase is in forest ecosystems of the study area.

The potential mean annual net carbon flux between 2006 and 2050 was projected to be $-224.9 \mathrm{TgC} / \mathrm{yr}$, ranging from -403.7 to $1.4 \mathrm{TgC} / \mathrm{yr}$. When compared with the $-279.4 \mathrm{TgC} / \mathrm{yr}$ net carbon flux estimates for the baseline period, ranging from -405.5 to $-112.5 \mathrm{TgC} / \mathrm{yr}$, the projected rates of future carbon sequestration in the Eastern United States represented a potential decrease of $54.5 \mathrm{TgC} / \mathrm{yr}$, ranging from 1.8 to $113.9 \mathrm{TgC} / \mathrm{yr}$. The projected decrease was largely driven by a potential decrease in the rate of sequestration in forest lands; the rates of carbon sequestration of agricultural lands and wetlands were projected to increase.

Under future projections of climate change, the area burned by wildland fires was projected to increase by 17 to 51 percent, and the GHG combustion emissions from wildland fires were projected to increase by 1 to 41 percent, relative to baseline conditions. Under extreme climate conditions, wildland fire emissions were projected to increase by 43 to 122 percent relative to baseline conditions. Carbon stored in wetlands of the Atlantic coast may be especially vulnerable to wildland-fire emissions because most of the 
fire activities were projected to be concentrated in the coastal regions where years of land use have altered some characteristics of hydrologic and fire regimes, such as exposed peat soils, and increased fire frequency.

Rates of carbon storage in coastal and estuarine waters were projected to increase by 19 to 25 percent between 2005 and 2050, largely a result of projected changes in nutrient and sediment supply to coastal waters. The environmental scenario showed the lowest projected change, whereas the economic scenario where energy development was not based on any one particular source (renewable technologies played an equal part in the energy mix as fossil fuels) had the greatest projected change. Nevertheless, the annual rate of coastal carbon storage represents less than 5 percent of those projected for the terrestrial system, so the increased rates projected for coastal waters will do little to offset the decreases seen in the terrestrial estimates.

\section{Limitations of the Assessment Report}

The known limitations of the assessment report include the following:

- LULC change was used as the geographic foundation of the assessment, but specific effects of LULC change on stocks and flux of carbon were not fully quantified and analyzed in this report.

- Future climate projections were used to project future ecosystem storage and fluxes of carbon, but the specific effects of the future climate projections on ecosystem carbon balance were not fully quantified and analyzed in this report.

- Wildland-fire combustion emissions were estimated, but the long-term effects of wildland fires on the production of carbon in ecosystems were not analyzed separately in this report.

- Other ecosystem disturbances, such as insect-caused forest mortalities or windstorms were not included in the assessment.

- Fluxes of $\mathrm{CH}_{4}$ and $\mathrm{N}_{2} \mathrm{O}$ were projected to future years based on a set of LULC scenarios without considering the effects of climate projections.

- The baseline carbon fluxes were estimated for the first time for aquatic ecosystems, but the existing carbon storage in the sediments of the aquatic ecosystems was not estimated.

- The SOC pool estimated and mapped in this assessment only represented available data for soil profile up to 20 centimeters deep. These data should not be compared with other SOC results produced at profiles deeper than 20 centimeters.
- Uncertainties from model runs of different components of the assessment were quantified using simple statistical methods to account for the spread of the estimates.

Other sources of uncertainties were described in the report but were not quantified. As a result, the total uncertainty of the assessment is unknown. In addition, there were limitations resulting from the methodology used for the assessment; specifically, the mapping and modeling of major components (such as LULC and wildland fires) of the assessment were not coupled in a completely integrative modeling system.

\section{Selected References}

Liu, Shuguang, Liu, Jinxun, Young, C.J., Werner, J.M., Wu, Yiping, Li, Zhengpeng, Dahal, Devendra, Oeding, Jennifer, Schmidt, G.L., Sohl, T.L., Hawbaker, T.J., and Sleeter, B.M., 2012, Baseline carbon storage, carbon sequestration, and greenhouse-gas fluxes in terrestrial ecosystems of the western United States, chap. 5 of Zhu, Zhiliang, and Reed, B.C., eds., Baseline and projected future carbon storage and greenhouse-gas fluxes in ecosystems of the western United States: U.S. Geological Survey Professional Paper 1797, p. 45-63. (Also available at http://pubs.usgs/gov/pp/1797/.)

Pacala, Stephen, Birdsey, R.A., Bridgham, S.D., Conant, R.T., Davis, Kenneth, Hales, Burke, Houghton, R.A., Jenkins, J.C., Johnston, Mark, Marland, Gregg, Paustian, Keith, Caspersen, John, Socolow, Robert, and Tol, R.S.J., 2007, The North American carbon budget past and present, chap. 3 of King, A.W., Dilling, Lisa, Zimmerman, G.P., Fairman, D.M., Houghton, R.A., Marland, Gregg, Rose, A.Z., and Wilbanks, T.J., eds., The first state of the carbon cycle report (SOCCR)-The North American carbon budget and implications for the global carbon cycle, U.S. Climate Change Committee Synthesis and Assessment Product 2.2: Asheville, North Carolina, National Oceanic and Atmospheric Administration, p. 29-36, accessed November 7, 2013, at http://downloads.globalchange.gov/ sap/sap2-2/sap2-2-final-all.pdf.

Pan, Yude, Birdsey, R.A., Fang, Jingyun, Houghton, Richard, Kauppi, P.E., Kurz, W.A., Phillips, O.L., Shvidenko, Anatoly, Lewis, S.L., Canadell, J.G., Ciais, Philippe, Jackson, R.B., Pacala, S.W., McGuire, A.D., Piao, Shilong, Rautiainen, Aapo, Sitch, Stephen, and Hayes, Daniel, 2011, A large and persistent carbon sink in the world's forests: Science, v. 333 , no. 6045 , p. 988-993, accessed October 31, 2013, at $h t t p: / / d x$.doi.org/10.1126/science. 1201609.

U.S. Congress, 2007, Energy independence and security act of 2007-Public Law 110-140: U.S. Congress, 311 p., accessed November 7, 2013, at http://frwebgate.access.gpo.gov/ cgi-bin/getdoc.cgi? dbname $=110 \_$cong_public_laws\&docid $=f$ : publ140.110.pdf. 
accessed November 13, 2013, at http://www.epa.gov/wed/ pages/ecoregions/na_eco.htm.

U.S. Environmental Protection Agency, 2013b, Inventory of U.S. greenhouse gas emissions and sinks - 1990-2011:

U.S. Environmental Protection Agency EPA 430-R13-001, [variously paged], accessed April 29, 2013, at http://www.epa.gov/climatechange/Downloads/ ghgemissions/US-GHG-Inventory-2013-Main-Text.pdf.

Zhu, Zhiliang, and Reed, B.C., eds., 2012, Baseline and projected future carbon storage and greenhouse-gas fluxes in ecosystems of the western United States: U.S. Geological Survey Professional Paper 1797, 192 p. (Also available at http://pubs.usgs.gov/pp/1797/.)

Zhu, Zhiliang, ed., Bergamaschi, Brian, Bernknopf, Richard, Clow, David, Dye, Dennis, Faulkner, Stephen, Forney, William, Gleason, Robert, Hawbaker, Todd, Liu, Jinxun, Liu, Shuguang, Prisley, Stephen, Reed, Bradley, Reeves, Matthew, Rollins, Matthew, Sleeter, Benjamin, Sohl, Terry,
Stackpoole, Sarah, Stehman, Stephen, Striegl, Robert, Wein, Anne, and Zhu, Zhiliang, 2010, A method for assessing carbon stocks, carbon sequestration, and greenhouse-gas fluxes in ecosystems of the United States under present conditions and future scenarios: U.S. Geological Survey Scientific Investigations Report 2010-5233, 190 p. (Also available at $h t t p: / / p u b s . u s g s . g o v /$ sir/2010/5233/.) (Supersedes U.S. Geological Survey Open-File Report 2010-1144.)

Zhu, Zhiliang, ed., Bouchard, Michelle, Butman, David, Hawbaker, Todd, Li, Zhengpeng, Liu, Jinxun, Liu, Shuguang, McDonald, Cory, Reker, Ryan, Sayler, Kristi, Sleeter, Benjamin, Sohl, Terry, Stackpoole, Sarah, Wein, Anne, and Zhu, Zhiliang, 2011, Baseline and projected future carbon storage and greenhouse-gas fluxes in the Great Plains region of the United States: U.S. Geological Survey Professional Paper 1787, 28 p. (Also available at $h t t p: / / p u b s . u s g s . g o v / p p / 1787 /$.) 



\title{
Chapter 1. Scope, Methodology, and Current Knowledge
}

\author{
By Zhiliang Zhu, Benjamin M. Sleeter, Terry L. Sohl, Todd J. Hawbaker, Shuguang Liu, Sarah Stackpoole, \\ Brian A. Bergamaschi, and Ashwan D. Reddy
}

\subsection{Scope and General Methodology}

This is the third in a series of reports produced by the U.S. Geological Survey (USGS) for a national assessment of carbon sequestration and greenhouse-gas (GHG) fluxes in ecosystems. The first two reports covered ecosystems of the Great Plains (Zhu and others, 2011) and Western (Zhu and Reed, 2012) regions of the United States. This report covers ecosystems in the Eastern United States, an area of about 3.05 million square kilometers $\left(\mathrm{Mkm}^{2}\right.$; fig. $\left.1-1\right)$ that extends from the Great Lakes, the Mississippi flood plains, and the Appalachian Mountains to the plains of the coasts of the Atlantic Ocean and the Gulf of Mexico.

The Eastern United States is a region largely dominated by forests. Conifer and deciduous forests span the Northeast and the areas near and around the Great Lakes, and plantationstyle forestry is prevalent in the southern coastal region. In the Southeast, forest land use is dynamic and involves management and short harvest cycles. In other regions of the Eastern United States, the pattern of forest lands decreasing in area because of urbanization but gaining in area from abandoned agricultural lands is prevalent. There is a substantial amount of agriculture in the Eastern United States; at the same time, the region is highly urbanized in areas along the eastern seaboard and around the southern coast of the Great Lakes. Some of the major population centers within the United States are in the East, and these centers are proving to be a key driver of land-use change from forest and agriculture. Wetlands have a large presence along the Atlantic and the gulf coasts as well as in the Great Lakes region, representing the majority of wetland areas in the conterminous United States.

This assessment of carbon stocks and sequestration and GHG fluxes was part of a national assessment required by the Energy Independence and Security Act of 2007 (EISA; U.S. Congress, 2007), which mandated that the U.S. Department of the Interior provide estimates of (1) the amount of carbon stored in ecosystems, (2) the capacity of ecosystems to sequester carbon, (3) the rate of GHG fluxes in and out of the ecosystems, and (4) the effects of the natural and anthropogenic processes that control ecosystem carbon balances and GHG fluxes. The GHGs considered in this assessment were carbon dioxide $\left(\mathrm{CO}_{2}\right)$, carbon monoxide $(\mathrm{CO}$, from wildland fires only), dissolved inorganic carbon (DIC), methane $\left(\mathrm{CH}_{4}\right)$, and nitrous oxide $\left(\mathrm{N}_{2} \mathrm{O}\right)$.

This regional assessment was conducted to (1) contribute to the EISA mandate for a national assessment of carbon sequestration and GHG fluxes and (2) help improve the understanding of carbon cycling at a regional scale by focusing on different ecosystems and their relations with natural and anthropogenic controlling processes (such as climate change, land use, land management, and wildland fires). To meet these objectives, the assessment was designed to provide answers to questions including the following: How much carbon was stored in ecosystems of the Eastern United States and how may it change over space and time? How might the stored carbon and carbon fluxes be affected by the natural and anthropogenic processes that control their storage and release in the ecosystems of the Eastern United States? Results and analyses provided in this report, as well as the previous two reports covering the Great Plains (Zhu and others, 2011) and Western (Zhu and Reed, 2012) regions of the United States, pertain to the first question and parts of the second question (because not all processes were exhaustively analyzed and presented). Results pertaining to the natural vegetation change under future climate change are not within the purview of this report.

The major ecosystems evaluated in this study are classified as terrestrial (forests, wetlands, grasslands/shrublands, and agricultural lands) or aquatic (rivers, lakes, estuaries, and coastal waters). The thematic definitions of the ecosystems and their spatial boundaries are outlined in table 1-1 and in Zhu and others (2010). The definitions are largely based on the National Land Cover Database (NLCD; Vogelmann and others, 2001; Homer and others, 2007), which was the primary source of initial land-use and land-cover (LULC) data for this assessment. The LULC data, derived from Landsat remote sensing data, were used to define the spatial boundaries of the ecosystems that were assessed in this study. Because the remote-sensing data allowed for complete coverage of the Eastern United States, the resulting spatially and temporally explicit data products provided a convenient and comprehensive basis for deriving carbon and GHG estimates.

Within the NLCD database, land-use (for example, mechanically disturbed classes (that is, forest clearcuts)) and land-cover (for example, forests) classes were mapped using data acquired from Landsat satellites. Because of the input data and the remote sensing methods used, areas in urban centers with significant tree cover, as determined by the NLCD, were treated as forest cover in this study. LULC change refers to changes between the LULC classes, including land conversions (such as from forest to developed lands) and cover change as the result of forest clearcuts. 


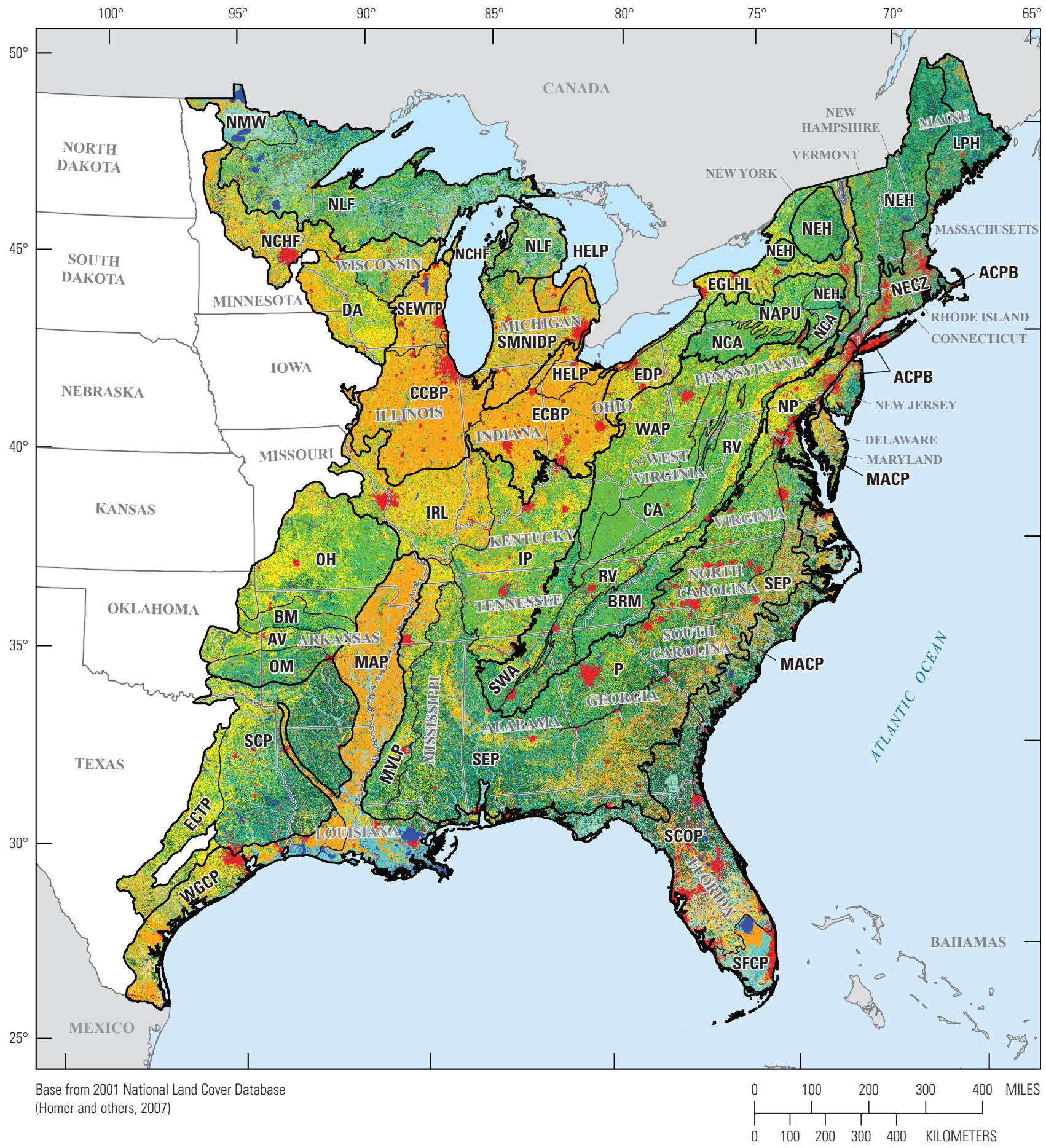

Figure 1-1. Map showing the spatial extent of the assessment of carbon storage and fluxes in the Eastern United States. The region consists of seven level II ecoregions (modified from U.S. Environmental Protection Agency, 2013a). The total area of the Eastern United States is about 3.05 million square kilometers (table 2-2). The land-use and land-cover classes shown on the map represent conditions that existed in 2005 , the year that was chosen as the baseline for this assessment. 


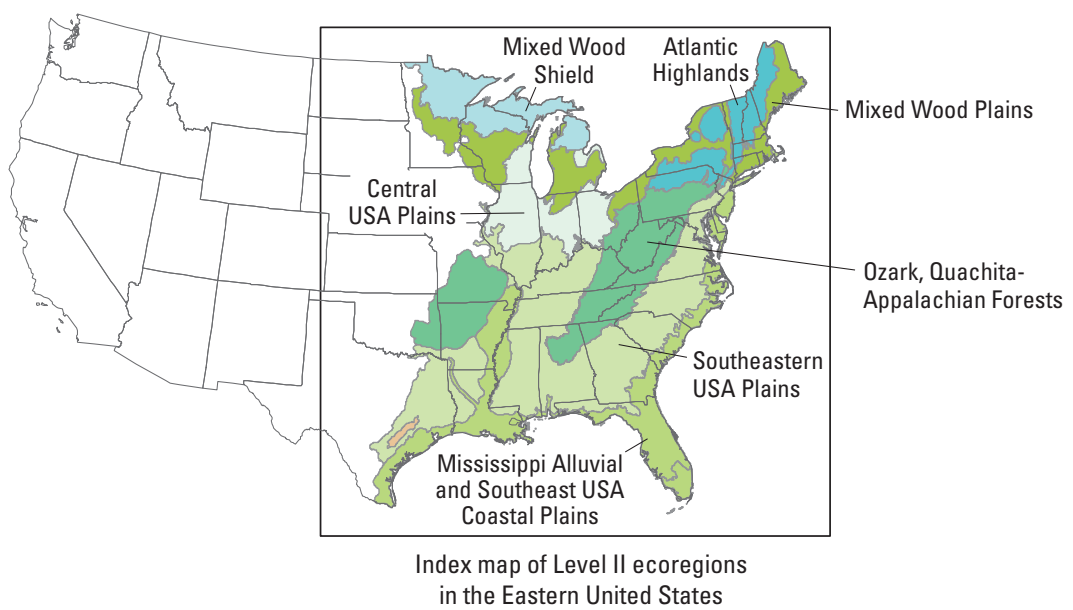

\section{EXPLANATION}

\section{Land cover}

Water

Developed

Mechanically disturbed national forest

Mechanically disturbed other public land

Mechanically disturbed private land

Mining

Barren

Deciduous forest

Evergreen forest

Mixed forest

Grassland

Shrubland

Agriculture

Hay/pasture

Herbaceous wetland

Woody wetland

Ice/snow

Ecoregion boundary

Level II

Level III
Atlantic Highlands

NAPU Northern Appalachian Plateau and Uplands

NCA North Central Appalachians

NEH Northeastern Highlands

Central USA Plains

CCBP Central Corn Belt Plains

ECBP Eastern Corn Belt Plains

HELP Huron/Erie Lake Plains

SEWTP Southeastern Wisconsin Till Plains

Mississippi Alluvial and Southeast

USA Coastal Plains

ACPB Atlantic Coastal Pine Barrens

MACP Middle Atlantic Coastal Plain

MAP Mississippi Alluvial Plain

SCOP Southern Coastal Plain

SFCP Southern Florida Coastal Plain [Everglades]

WGCP Western Gulf Coastal Plain [Texas-Louisiana Coastal PLain]

Mixed Wood Plains

DA Driftless Area

EGLHL Eastern Great Lakes and

EP Hudson Lowlands

LPH Laurentian Plains and Hills

NCHF North Central Hardwood Forests

NECZ Northeastern Coastal Zone

SMNIDP Southern Michigan/Northern Indiana Drift Plains
Mixed Wood Shield

NLF Northern Lakes and Forests

NMW Northern Minnesota Wetlands

Ozark, Quachita-Appalachian Forests

AV Arkansas Valley

BRM Blue Ridge Mountains

BM Boston Mountains

CA Central Appalachians

OH Ozark Highlands

OM Ouachita Mountains

RV Ridge and Valley

SWA Southwestern Appalachians

WAP Western Allegheny Plateau

Southeastern USA Plains

ECTP East Central Texas Plains

IP Interior Plateau

IRL Interior River Lowland

MVLP Mississippi Valley Loess Plains

NP Northern Piedmont

P Piedmont

SCP South Central Plains

SEP Southeastern Plains

Figure 1-1.-Continued 
Table 1-1. Land use and land cover in the Eastern United States.

[For the National Land Cover Dataset, see Vogelmann and others (2001). Vegetation Change Tracker is a product of Landscape Fire and Resource Management Planning Tools Project (LANDFIRE; Rollins, 2009); see Huang and others (2010)]

\begin{tabular}{|c|c|c|c|}
\hline LULC class & Ecosystem & $\begin{array}{c}\text { Area, } \\
\text { in percent } \\
\text { of total }\end{array}$ & Source \\
\hline \multicolumn{4}{|c|}{ National Land Cover Dataset } \\
\hline Barren & Other lands & 0.1 & Bare rock, sand, and clay \\
\hline Cultivated crop & Agricultural lands & 13.9 & Row crop; small grains; fallow \\
\hline Deciduous forest & Forests & 23.7 & Deciduous forest \\
\hline Hay/pasture & Agricultural lands & 17.9 & Pasture and hay \\
\hline Herbaceous wetland & Wetlands & 0.4 & Emergent herbaceous wetlands \\
\hline Ice/snow & Other lands & 0.0 & Perennial ice and snow \\
\hline Mining & Other lands & 0.1 & Quarries, strip mines, and gravel pits \\
\hline Mixed forest & Forests & 12.6 & Mixed forest \\
\hline Woody wetland & Wetlands & 5.6 & Woody wetlands \\
\hline \multicolumn{4}{|c|}{ Landscape Fire and Resource Management Planning Tools Project } \\
\hline Mechanically disturbed, national forest & Forests & 0.1 & Vegetation Change Tracker \\
\hline Mechanically disturbed, other public land & Forests & 0.0 & Vegetation Change Tracker \\
\hline Mechanically disturbed, private land & Forests & 2.6 & Vegetation Change Tracker \\
\hline
\end{tabular}

Within the LULC classes, land-management activities were defined as those actions that were aligned with the LULC classes and modified the way land was used, but did not change the LULC classes. Forest clearcuts were mapped as a LULC change class but were treated as a management activity when deriving and analyzing carbon estimates. Input data describing land-management or ecosystem disturbances were developed in addition to the classifications in the NLCD; these additional data are described in chapters 3 and 4 . As a result, forest clearcuts and thinning were land-management activities included in the assessment, as were several agricultural management activities described in chapter 7. Ecosystem disturbances are defined as those natural disturbances that altered the production of carbon or other functions in an ecosystem. For this assessment, wildland fire was the only natural disturbance that was considered; natural disturbances such as persistent drought and insect-driven forest defoliation (such as gypsy moth) or mortality (such as spruce budworm epidemics) were not included.

The assessment was conducted based on a methodology framework that (1) collected and used existing data, including various biophysical data derived from remote sensing, inventories of biological resources and soil properties, climate histories and future projections, and measurements made by a national network of streamgages; (2) linked land-use, land-management, and climate data with statistical and process-based methods and models to generate spatially and temporally explicit carbon storage and GHG flux estimates; and (3) applied a set of future LULC and climate change scenarios to the assessment to project a range of estimates for carbon stock and sequestration and GHG flux in ecosystems. The major components of the assessment methodology and their roles and relations are listed in table 1-2 and shown in figure 1-2, with corresponding chapters of this report indicated in the boxes along with the methodological details described in the chapters.

The methodology framework shown in figure $1-2$ is spatially and temporally explicit. The spatial and temporal framework is described in chapter 2. Based on this framework, the ecosystems were mapped or modeled, and all pixels from the mapping effort were partitioned into LULC and LULC-change classes, using the landscape LULC model described in chapter 3 . The resulting digital maps, described in chapters 3 through 7, have a nominal spatial resolution of 250 meters. Because the assessment was conducted at national and broad regional scales, the resulting information and data products should be applied only at the regional scale or broader.

In this report, the term "region" is often used in a general sense, depending on the context, whereas the term "ecoregion" refers to the U.S. Environmental Protection Agency (EPA) ecoregion mapping hierarchy (U.S. Environmental Protection Agency, 2013a). In total, seven level II EPA ecoregions 
Table 1-2. Main features of the assessment methodology of carbon storage and fluxes in the Eastern United States.

[EPA, U.S. Environmental Protection Agency; FIA, Forest Inventory and Analysis National Program (USDA); FORE-SCE, forecasting scenarios of future land cover; LANDFIRE, Landscape Fire and Resource Management Planning Tools Program (Rollins, 2009); LULC, land use and land cover; IPCC, Intergovernmental Panel on Climate Change; MTBS, Monitoring Trends in Burn Severity Project; NASA, National Aeronautics and Space Administration; NHD, National Hydrography Dataset; NLCD, National Land Cover Dataset (Vogelmann and others, 2001); NOAA, National Oceanic and Atmospheric Administration; NWIS, National Water Information System; RESSED, Reservoir Sedimentation Database; SRES, Special Report on Emissions Scenarios; USDA, U.S. Department of Agriculture; USGS, U.S. Geological Survey; VCT, vegetation change tracker (a product of LANDFIRE; Huang and others, 2010)]

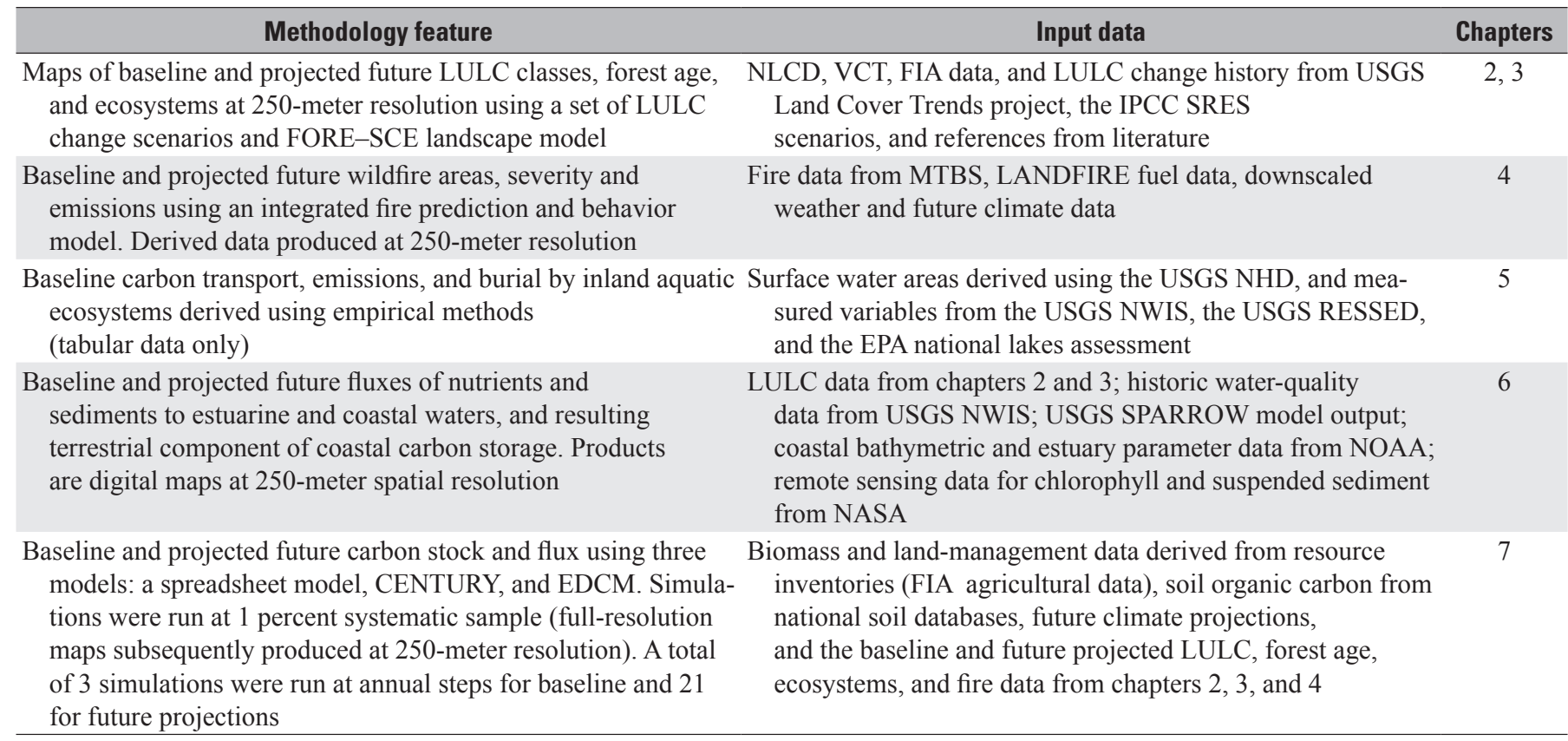

were used for the assessment: (1) Mixed Wood Shield, (2) Atlantic Shield, (3) Mixed Wood Plains, (4) Central USA Plains, (5) Southeastern USA Plains, (6) Ozark, OuachitaAppalachian Forests, and (7) Mississippi Alluvial and Southeast USA Coastal Plains (which includes the Everglades and the Texas-Louisiana Coastal Plain ecoregions for the purposes of this assessment; Zhu and others, 2010, fig. 3-1).

All the models used in this assessment were parameterized, and the results were calibrated and validated on the basis of these ecoregions. The major terrestrial and aquatic ecosystems are analyzed within these ecoregions. The use of the ecoregions and the NLCD LULC classes chosen for the ecosystems in this assessment suggest that the reported results are meaningful within the defined ecoregion and ecosystem definitions and may not be directly comparable with other national- or regional-level estimates because of the different boundary definitions. Further discussion of the ecoregions and ecosystems may be found in Zhu and others (2010).

The temporal foundation of the assessment was twofold and included a baseline and a range of future projections, as described in chapter 2. Baseline is defined as the average contemporary annual conditions to be assessed. Different components of the assessment have different ranges of baseline years stemming from considerations for data availabilities: LULC are assessed from 1992 through 2005; wildland fires, from 2001 through 2008; terrestrial carbon and GHG fluxes, from 2001 through 2005; and aquatic carbon fluxes, from the 1920s through 2011. A range of future LULC scenarios projecting from the time after the end of the baseline period through 2050 were developed by incorporating rationales and criteria of a set of GHG emission trajectories used in the Intergovernmental Panel on Climate Change (IPCC) Special Report on Emission Scenarios (SRES; Nakićenović and others, 2000), ensuring consistency of globally available climate and land-use data with the LULC scenarios developed for this assessment at the national and regional scales.

Based on the spatial and temporal frameworks, changes in LULC and forest age were mapped (and modeled) in annual steps using a spatially explicit landscape model (chap. 3). Fire areas, severity, and combustion emissions also were estimated and mapped, using a coupled statistical and landscape simulation model (chap. 4). The derived LULC, forest age, and fire data, along with other available data (including national soil databases, biomass growth curves, available land-management activity data (such as partial forest cutting in forests and the use of fertilization in agriculture), and future climate projections), were incorporated into a modeling task using three process-based ecosystem models (described in chap. 7) to estimate the current and projected future carbon stock, carbon flux, and GHG flux in four terrestrial ecosystems (forests, grasslands/shrublands, agricultural lands, and wetlands). Three general carbon pools were represented (live biomass, soil organic matter, and dead biomass (including litter and woody debris)). Ecosystem processes represented 


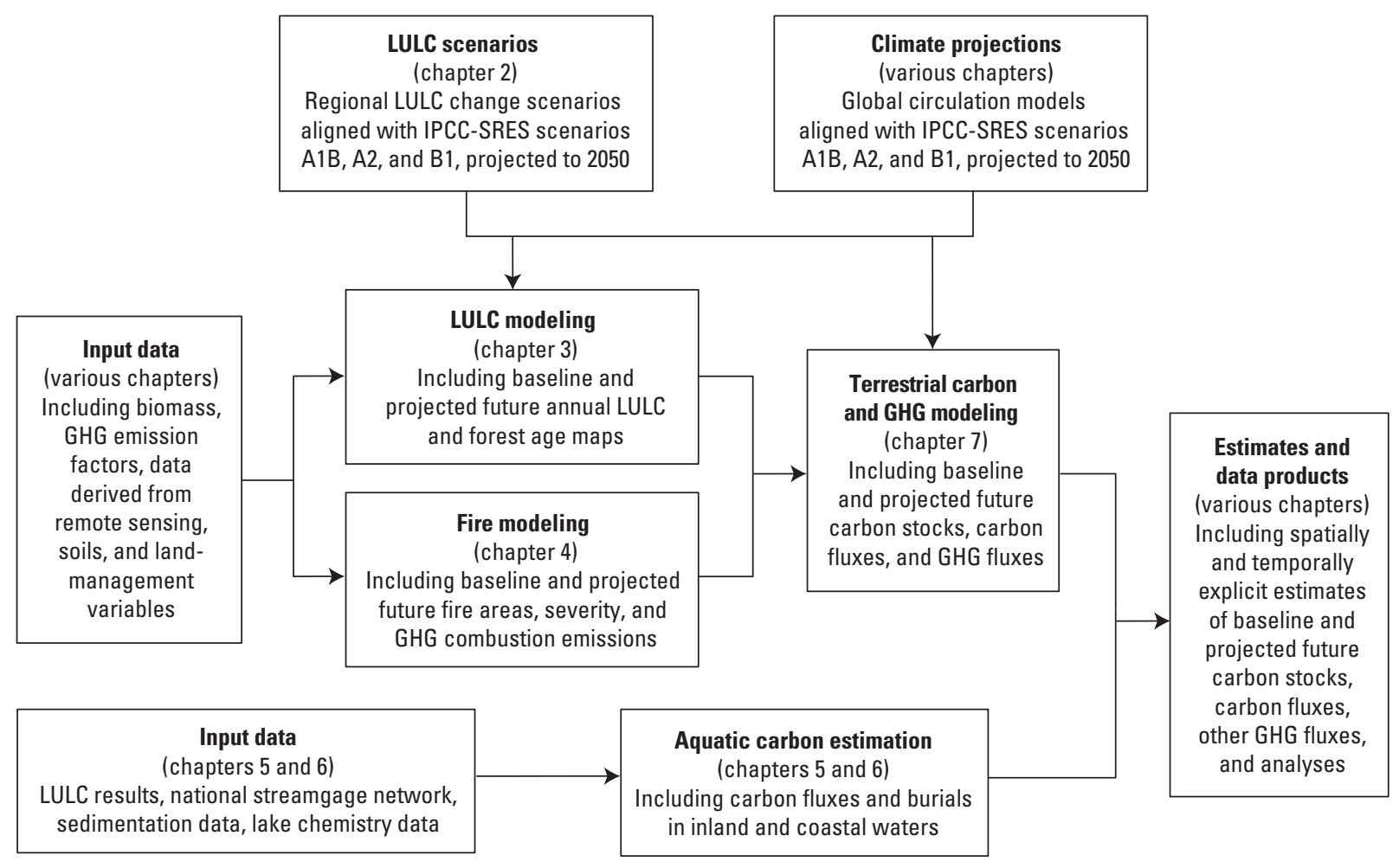

Figure 1-2. Flow diagram showing the general framework of the methodology used in the assessment of carbon storage and fluxes in the Eastern United States. The heading in each box represents a major component of the assessment. The chapter numbers indicate where in this report those components are discussed. Arrows show relations between components. GHG, greenhouse gas; IPCC-SRES, Intergovernmental Panel of Climate Change Special Report on Emissions Scenarios (Nakićenović and others, 2000); LULC, land use and land cover.

in the modeling task included transitions between the LULC and ecosystem classes, net primary production (NPP), heterotrophic respiration (HR), harvested wood (HWD; only accounting for carbon removed from landscapes from clearcuts and partial cuts), long-term effects of wildland fire, and available land-management activities (detailed in chap. 7). Estimates of carbon transport through riverine systems, emissions and burial by all inland water bodies, and flux and burial in estuaries and coastal waters were calculated separately and were based on a series of methods and models detailed in chapters 5 and 6 . The results represent a baseline and a range of potential carbon sequestration rates by the ecosystems under a range of projected climate and land-use conditions, which is a requirement of the EISA.

Flux refers to emissions of GHG (such as carbon) to the atmosphere and to uptake by ecosystems. In presenting the results of terrestrial carbon flux assessment, net flux and net ecosystem carbon balance (NECB) are used interchangeably in this report to refer to the net rate of the change in carbon storage in ecosystems. For a given ecosystem and GHG, net flux and NECB are the same as net ecosystem exchange (NEE). However, the use of net carbon flux or NECB is conventional in large-area, land-based studies, such as this assessment. The terms used in calculating NECB and (or) net flux include net ecosystem production (NEP, which is the difference between the NPP and the HR), combustion and long-term emissions from wildland fires, and biomass harvesting. When reporting losses or gains in carbon storage, a negative number indicates carbon uptake, carbon sequestration, or a carbon sink; a positive number indicates a carbon emission or a carbon source. These conventions are used throughout this report unless noted. The usages follow standard conventions found in the literature on this topic (for example, Chapin and others, 2006; U.S. Environmental Protection Agency, 2012) and are consistent with the terms used in the assessment reports for the Great Plains (Zhu and others, 2011) and Western (Zhu and Reed, 2012) regions of the United States. In addition to assessing carbon storage and fluxes in ecosystems, the fluxes or emissions of other GHGs (such as $\mathrm{CO}_{2}, \mathrm{CH}_{4}, \mathrm{CO}$, DIC, and $\mathrm{N}_{2} \mathrm{O}$ ) were also assessed. Fluxes or emissions of the other GHGs are reported as $\mathrm{CO}_{2}$-equivalent values and flux estimates were calculated based on their respective global warming potential factors. The units of measurement used in this report also follow previous usages. The total amount of carbon stored in the three major carbon pools (live biomass, soil organic matter, and dead biomass) for a given region is reported in teragrams of carbon. When reporting carbon stock per unit of area, the values are given in kilograms of carbon. When reporting the carbon flux per unit of area, the values are given in grams of carbon. 
Whenever possible, the estimates are provided as a range of values, in addition to mean values, in order to represent the spread of variability in assessment results. The ranges of values were presented depending on chapters or components of the report. For variables of wildland fires (chap. 4), estimates were presented for the 5th and 95th percentile values, as well as median, mean, minimum, and maximum values, using Monte Carlo simulations. For the inland water component (chap. 5), the range of values was derived from the 5th and 95th confidence intervals of Monte Carlo simulations. Range values from the coastal water chapter reflected 10th and 90th confidence intervals using Monte Carlo simulations. Range values of terrestrial carbon and GHG estimates (chap. 7) refer to the minimum and maximum of annual mean values by model runs in the baseline and by model runs in LULC scenarios and future climate projections.

The spread of variability in the assessment results, as represented by the range values, covers a major portion of uncertainties in the resulting estimates. Uncertainties in this assessment were related to two general sources: the use of various input data and methods and models (in the baseline and future projections) and the use of LULC scenarios (future projections only). Monte Carlo simulations were used to quantify uncertainties and produce a range of estimated results related to the input data and the methods in the fire and aquatic assessments. For terrestrial carbon and GHG modeling (chap. 7), the Monte Carlo method was not used to estimate the uncertainties in the final results due to constraints of computation intensity and time. However, because model structure and parameterization are often a major source of uncertainty, multiple ecosystem models (as described in chap. 5) were used to produce ranges of terrestrial carbon results. The LULC scenarios were a primary foundation of projecting future potential carbon estimates, including stock and fluxes. By design, multiple scenarios were used to allow analysis of the effects of a range of potential choices and to bound the overall uncertainties in the projected results (Zhu and others, 2010). As a result, the ranges of results presented in this assessment for terrestrial carbon and GHG estimates represent a major part of the overall uncertainties. The methodology, design rationales, and technical specifications are detailed in Zhu and others (2010).

\subsection{National and Regional Studies of Carbon Sequestration and Greenhouse- Gas Flux}

The Eastern United States has seen the most active LULC change swings in the country, including pressure to expand urban or suburban infrastructure (development pressure), cropland expansion and contraction, increased timber harvesting activities in recent decades, and a continued recovery from deforestation of the 19th century (chaps. 2 and 3; Claggett and others, 2004; Chen and others, 2006; Auch and others, 2012). LULC change, particularly the rate of land conversions to developed lands, and land-management activities, particularly forest harvesting (clearcutting) of plantation forestry, in the Eastern United States in recent decades have been rapid and more active than in any other region in the Nation (Sleeter and others, 2013). The rapid LULC changes have significant hydrological and biogeochemical consequences, including carbon fluxes and sequestration (Houghton and others, 1999; Milesi and others, 2003; Birdsey and others, 2006; Chen and others, 2006; Woodbury and others, 2006; Houghton, 2010; Michalak and others, 2011; Williams and others, 2012; Robinson and others, 2013).

Existing estimates of carbon storage and sequestration and GHG fluxes varied widely by ecosystem and region in the Eastern United States. Forests occupy a significant land base in the east, representing about one-half the total area in the region and are the most important carbon sink. The forest inventories that were conducted by the U.S. Department of Agriculture Forest Service indicated that, in 2010, forest lands in the Eastern United States had a combined 24.2 petagrams of carbon $(\mathrm{PgC})$ in forest ecosystems (table 1-3). The carbon inventory estimate of $24.2 \mathrm{PgC}$ stock for the forests in the Eastern United States (Brad Smith, U.S. Department of Agriculture, Forest Service, unpub. data, 2010) was higher than that of the forests in the Western United States by more than 50 percent, whereas the per unit of area carbon stock was also higher compared with that in the forests of the Western United States (15.7 kilograms of carbon per square meter $\left(\mathrm{kgC} / \mathrm{m}^{2}\right)$ in the east compared with $14.5 \mathrm{kgC} / \mathrm{m}^{2}$ in the west). Among the seven ecoregions in the Eastern United States, the Southeastern USA Plains contained more stored carbon than any other ecoregion. The most recent Resource Planning

Table 1-3. Total carbon stock from all major pools in the forest ecosystems in the seven ecoregions used in the assessment of carbon storage and fluxes in the Eastern United States.

[Data were derived from the Forest Inventory Database Online (FIDO; U.S. Department of Agriculture, Forest Service, 2012b) and were analyzed by Brad Smith (U.S. Department of Agriculture, Forest Service, unpub. data, 2010). Ecoregions are from Zhu and others (2010) as modified from U.S. Environmental Protection Agency (1999). $\mathrm{kg} / \mathrm{m}^{2}$, kilograms per square meter; $\mathrm{TgC}$, teragrams of carbon]

\begin{tabular}{|c|c|c|}
\hline Ecoregion & $\begin{array}{l}\text { Carbon, in } \\
\operatorname{TgC}\end{array}$ & $\begin{array}{c}\text { Carbon per } \\
\text { unit of area, } \\
\text { in } \mathrm{kg} / \mathrm{m}^{2}\end{array}$ \\
\hline Mixed Wood Shield & $3,556.2$ & 23.5 \\
\hline Atlantic Shield & $2,815.8$ & 18.6 \\
\hline Mixed Wood Plains & $2,845.6$ & 18.5 \\
\hline Central USA Plains & 426.2 & 16.9 \\
\hline Southeastern USA Plains & $7,230.5$ & 12.9 \\
\hline Ozark, Quachita-Appalachian Forests & $4,646.0$ & 14.0 \\
\hline $\begin{array}{l}\text { Mississippi Alluvial and Southeast Coastal } \\
\text { Plains }{ }^{1}\end{array}$ & $2,660.8$ & 15.5 \\
\hline Eastern United States, total & $24,181.2$ & 15.7 \\
\hline
\end{tabular}

${ }^{1}$ Includes the Everglades and Texas-Louisiana Coastal Plain level II ecoregions for the analysis of this assessment. 
Act (RPA) assessment produced by the Forest Service for the conterminous United States and coastal Alaska shows a steady increase of the total carbon stock from $44,643 \mathrm{TgC}$ in 1990 to $48,437 \mathrm{TgC}$ in 2010 , and the net annual change varied from 185.7 teragrams of carbon per year $(\mathrm{TgC} / \mathrm{yr})$ in 1990 to $248.6 \mathrm{TgC} / \mathrm{yr}$ in 2005 (U.S. Department of Agriculture, Forest Service, 2012).

Studies confirm that ecosystems in the United States are a carbon sink (Houghton and others, 1999; Pacala and others, 2001; Pan and others, 2011). There are differences in definitions, boundaries of reporting classes (ecosystems), components, and methods used in these studies. However, results from these studies were useful as references to this assessment. For example, the most recent national GHG inventory report by the EPA covering the conterminous United States suggested a net sink of -246.8 teragrams of carbon $(\mathrm{TgC})$ in 2011 by forests, grasslands/shrublands, agricultural lands, and settled areas, which represented an offset of about 15.4 percent of the total fossil fuel $\mathrm{CO}_{2}$ emissions in the United States (U.S. Environmental Protection Agency, 2012). Most of the $-226.7 \mathrm{TgC} / \mathrm{yr}$ ( -75.6 grams of carbon per square meter per year $\left.\left(\mathrm{gC} / \mathrm{m}^{2} / \mathrm{yr}\right)\right)$, as a mean value, of carbon sequestration between 2007 and 2011 came from forest lands. Data from the Forest Inventory and Analysis Program of the Forest Service were the common basis for the EPA report as well as other similar publications. In describing the methodology and analysis using the Forest Service data, Heath and others (2011a,b) estimated that the combined net carbon flux of forest ecosystems and urban trees in the conterminous United States, including pools of soil organic carbon and HWD products, was about $-223.5 \mathrm{TgC} / \mathrm{yr}\left(-89.8 \mathrm{gC} / \mathrm{m}^{2} / \mathrm{yr}\right)$ in 2002 , $-244.1 \mathrm{TgC} / \mathrm{yr}\left(-97.5 \mathrm{gC} / \mathrm{m}^{2} / \mathrm{yr}\right)$ in 2005 , and $-241.8 \mathrm{TgC} / \mathrm{yr}$ $\left(-95.4 \mathrm{gC} / \mathrm{m}^{2} / \mathrm{yr}\right)$ in 2008 .

A net forest carbon flux of $-180 \mathrm{TgC} / \mathrm{yr}$ in the conterminous United States between 1992 and 2001 was derived (Zheng and others, 2011) by relating forest cover change from the NLCD data with carbon density estimates from the Forest Inventory Analysis (FIA). Carbon removed from forests as a result of wildfire $(9.9 \mathrm{TgC} / \mathrm{yr})$ and HWD products (142 TgC/yr) was included in deriving the net forest carbon flux. However, it is not clear from Zheng and others (2011) whether including forest harvesting from the FIA inventory and NLCD forest cover change data resulted in double counting of carbon removed from the landscape. Using a relationship between forest age derived from forest inventory and carbon recovery derived from remote sensing, Williams and others (2012) arrived at a much lower total net forest carbon flux $(-47 \mathrm{TgC} / \mathrm{yr})$, together with carbon removed from forest harvest $(107 \mathrm{TgC} / \mathrm{yr})$ and wildland fire $(10 \mathrm{TgC} / \mathrm{yr})$ for the conterminous United States in 2005.

Three recent studies provided estimates for regional forest carbon flux and balances for areas that approximately correspond to the area of study for this assessment. For two Forest Service regions (the Southern and Eastern regions), Heath and others $(2011 \mathrm{a}, \mathrm{b})$ reported forests of all ownerships had a net sequestration rate (excluding soil organic carbon) ranging between -132.2 and $-42.1 \mathrm{TgC} / \mathrm{yr}$, with a mean value of $-88.2 \mathrm{TgC} / \mathrm{yr}$, or about two-thirds the total estimate in the conterminous United States. On a per-unit-area basis using areas of NLCD forest classes in the two regions, the mean carbon sink was about $-57.2 \mathrm{gC} / \mathrm{m}^{2} / \mathrm{yr}$ (excluding woody wetlands). Turner and others (1995) analyzed regional forest carbon change from the FIA forest survey data collected in the 1990s and estimated regional sink strengths to be $-190 \mathrm{gC} / \mathrm{m}^{2} / \mathrm{yr}$ for the Northeast region, $-290 \mathrm{gC} / \mathrm{m}^{2} / \mathrm{yr}$ for the Southeast region, and $-250 \mathrm{gC} / \mathrm{m}^{2} / \mathrm{yr}$ for the South-Central region. For comparison, Williams and others (2012) provided forest carbon flux estimates for four of several regions in the conterminous United States (Northeast, Southeast, SouthCentral, and northern States in the Great Lakes region). The total gross forest carbon flux for 2005 was $-114 \mathrm{TgC} / \mathrm{yr}$ for the four regions before subtracting carbon removal terms, including forest harvesting and wildland fire emission.

In addition to estimates of forest carbon fluxes in recent years, long-term trends and future projections have also been reported. Between 1600 and 1800, forests were in a state of carbon balance. The 19th century saw significant land-userelated carbon emissions due to land clearing, followed by regrowth of forests and resulting carbon sequestration in the 20th century (Birdsey and others, 2006). Projected to future years based on the IPCC emission scenarios (Nakićenović and others, 2000), forest lands in various regions in the conterminous United States could become a net carbon source (U.S. Department of Agriculture, Forest Service, 2012) or weakened carbon sink (Hurtt and others, 2002; Birdsey and others, 2006; Liu and others, 2012b). As a comparison, the projected future forest carbon sink in the Western United States ranged between -10.8 and $-100.2 \mathrm{gC} / \mathrm{m}^{2} / \mathrm{yr}$, depending on land-use scenarios, future climate projections, and biogeochemical models used (Liu and others, 2012b).

Carbon sequestration is a function of the biogeochemical exchange between the atmosphere and biosphere, including soils, and is strongly influenced by key controlling processes such as land use, land-management activities, ecosystem disturbances, and climate (Bachelet and others, 2003; Law and others, 2004; Running, 2008). In the Southeastern United States, where the LULC change is the most active in the recent decades, estimation of carbon stocks and fluxes and effects of primary driving processes are of particular importance. Tian and others $(2010,2012)$ estimated from several related studies covering 13 Southeastern States extending from Texas to Virginia that the total terrestrial ecosystem carbon stock was about $30.2 \mathrm{PgC}$, with 64 percent as soil organic carbon (SOC). Between 1951 and 2007, there has been a trend of increase in carbon stored in the ecosystems, totaling $-2.0 \mathrm{PgC}$ over the 57 years, or a mean uptake of $-35 \mathrm{TgC} / \mathrm{yr}$. Among different land and vegetation cover types, the net primary production was $679 \mathrm{gC} / \mathrm{m}^{2} / \mathrm{yr}$ by broadleaf deciduous forests, $715 \mathrm{gC} / \mathrm{m}^{2} / \mathrm{yr}$ by needleleaf evergreen forests, $676 \mathrm{gC} / \mathrm{m}^{2} / \mathrm{yr}$ by herbaceous and woody wetlands, and $520 \mathrm{gC} / \mathrm{m}^{2} / \mathrm{yr}$ by agricultural lands. Using LULC change data derived from a sample of Landsat imagery and a biogeochemical model, Liu 
and others (2004) estimated that, between 1973 and 2000, the Southern region averaged a carbon sink of $89 \mathrm{gC} / \mathrm{m}^{2} / \mathrm{yr}$. Albani and others (2006) analyzed the effects of LULC change and timber harvesting for all terrestrial ecosystems in the Eastern United States and estimated that the net carbon flux ranged from 0.21 petagram of carbon per year $(\mathrm{PgC} / \mathrm{yr})$ in the $1980 \mathrm{~s}$ to $0.25 \mathrm{PgC} / \mathrm{yr}$ in the $1990 \mathrm{~s}$ and $0.26 \mathrm{PgC} / \mathrm{yr}$ in 2008 ; they also projected that the net carbon flux in future years would be about $0.25 \mathrm{PgC} / \mathrm{yr}$.

The specific effects of various controlling processes are difficult to estimate. Land-use change in the Southern United States is often characterized by conversions from forests to agricultural and developed areas and by forestry practices of economically determined rotation ages and planting improved stock, which have led to dynamic cover loss and gain patterns. Woodbury and others (2006) attributed changes in carbon balance to land-use conversions, and estimated that, between 1990 and 2004, carbon gains as the result of afforestation outweighed carbon losses due to deforestation by 49 to $88 \mathrm{TgC}$. Over a 50 -year period, converting marginal pasture lands to southern pine plantations could result in improved sequestration from an average of 8.3 megagrams of carbon per hectare $(\mathrm{MgC} / \mathrm{ha}$; $\left.0.83 \mathrm{kgC} / \mathrm{m}^{2}\right)$ by marginal pastures to $58 \mathrm{MgC} / \mathrm{ha}\left(5.8 \mathrm{kgC} / \mathrm{m}^{2}\right)$ by southern pine plantations (Lee and Dodson, 1996). Tian and others (2012) noted that the strength of the carbon sink in the Southeastern States may be attributed to fertilization by increased $\mathrm{CO}_{2}$ in the atmosphere and nitrogen deposition in the past five to six decades, although such effects could be easily overestimated if relying on simulation modeling alone (Albani and others, 2006).

Climate is also a major controlling factor in the direction and size of carbon sources or sinks. For example, Chen and others (2012) estimated that the terrestrial ecosystems in the Southeast (the 13 Southeastern States from Texas to Virginia) could be a carbon source (emitting $72.5 \mathrm{TgC} / \mathrm{yr}$ ) during the driest 10 years in the recent record or a sink $(-81.45 \mathrm{TgC} / \mathrm{yr})$ during the wettest 10 years in the recent record. Keenan and others (2012) noted that changes in climate (including lengthening of the growing season) may be responsible for increases in forest growth rates and carbon uptake in eastern North America and specifically the observed increases in NEE in the Harvard Forest in Petersham, Massachusetts, from 1992 to 2009.

The effects of wildland fires on carbon sequestration in ecosystems include (1) the immediate release of GHGs from combustion emissions and (2) the long-term combined effects of decomposing biomass, which releases carbon into the atmosphere, and regenerating vegetation, which increases the uptake of carbon (Law and others, 2004; Hurteau and Brooks, 2011). Hawbaker and Zhu (2012) estimated that the immediate release of GHGs from wildland fires in the Western United States in recent years offset about 10 percent of the total ecosystem carbon sequestration. Although fires of ecosystems in the Eastern United States are less frequent and intense than those of the Western United States and are not expected to affect carbon balance on a comparable scale (chap. 4 of this report), fires in the Eastern United States have had unique and significant effect on individual ecosystems and in specific locations, such as the carbon-rich pocosin peatland soils along the Atlantic coastal regions. Emissions from a fire that burned Pocosin Lakes in North Carolina in 1985, for example, were estimated to range between 1.01 and $3.76 \mathrm{TgC}$, depending on depth of peat consumed (Poulter and others, 2006). To illustrate the importance of peat fires in the Atlantic coastal ecosystems, this one fire emitted as much as 30 percent of the average annual fire emissions of the ecosystems in the Western United States (Hawbaker and Zhu, 2012).

Development pressure in the Southeastern States has a significant effect on the overall carbon balances, but estimates of the effects of development pressure have been variable. Milesi and others (2003), using remote sensing data, estimated that development in the Southeastern States was responsible for a reduction of $3.04 \mathrm{TgC} / \mathrm{yr}$ in NPP by terrestrial ecosystems. However, Zhang and others (2012) estimated the loss of carbon from southeastern ecosystems to be $3.4 \mathrm{TgC} / \mathrm{yr}$ between 1945 and 2007 and suggested that whether developed areas were a carbon source or sink is dependent on whether the lands were converted to developed areas from forests or agricultural lands. Forests in established developed areas remain a sizeable carbon sink and are responsible for about 8 to 10 percent of the total forest carbon sequestration in the conterminous United States (Nowak and Crane, 2002; U.S. Environmental Protection Agency, 2012).

The Eastern United States is a major agricultural region. Agricultural lands account for about 32 percent of the total area in the region, mostly concentrated in the Corn Belt of the Ohio River Valley and the Mississippi Alluvia Plains as well as interspersed throughout the eastern plains. In a synthesis study for tillage practices in the conterminous United States, West and Marland (2002) estimated that the average rates of carbon sequestration in agricultural soils were about $0 \mathrm{gC} / \mathrm{m}^{2} / \mathrm{yr}$ in conventionally tilled lands and $-37 \mathrm{gC} / \mathrm{m}^{2} / \mathrm{yr}$ in no-till lands. West and Marland (2002) further noted that, when taking soil carbon sequestration and farm operation emissions into calculations, the average net carbon flux would be $16.8 \mathrm{gC} / \mathrm{m}^{2} / \mathrm{yr}$ for conventional tillage and $-20 \mathrm{gC} / \mathrm{m}^{2} / \mathrm{yr}$ for no-till practices. However, when considering only SOC balance in farmlands in the Midwest, Christopher and Mishra (2009) found that tillage effects in a whole profile were mixed and there was no significant difference in SOC between no-till and conventional till farming; the two practices yielded an average SOC stock of $4.8 \mathrm{kgC} / \mathrm{m}^{2}$.

A majority of the freshwater and saltwater wetlands with herbaceous and woody vegetation cover in the conterminous United States are located in the East. As mapped by the NLCD (Vogelmann and others, 2001; Homer and others, 2007), the wetlands in the conterminous United States cover about 312,571 square kilometers $\left(\mathrm{km}^{2}\right)$, or 4 percent of the land mass of the conterminous United States. In the Eastern United States, wetlands total $272,442 \mathrm{~km}^{2}$, representing 8.9 percent of the total area in the region and 87 percent of all wetland areas in the conterminous United States. These wetlands 
include peat and mineral soil types. Large wetland areas are distributed in the Great Lakes region, particularly in northern Minnesota and Wisconsin, and in the coastal plains of the Atlantic coast and the Gulf of Mexico.

Bridgham and others (2006) synthesized data from published sources to estimate the total rates of carbon stock and sequestration in the wetlands of the conterminous United States to be $19,600 \mathrm{TgC}$ and $-17.3 \mathrm{TgC} / \mathrm{yr}$, respectively. Using the total wetland area estimate of $431,000 \mathrm{~km}^{2}$, these estimates translate to $45.5 \mathrm{kgC} / \mathrm{m}^{2}$ for the per-unit-of-area of carbon stock and $-40.1 \mathrm{gC} / \mathrm{m}^{2} / \mathrm{yr}$ for the per-unit-of-area sequestration rate in the conterminous United States. Freshwater peatlands and mineral soil wetlands store most of wetland carbon in the conterminous United States; however, tidal marshes have the highest per-unit-of-area sequestration rate at $-220 \mathrm{gC} / \mathrm{m}^{2} / \mathrm{yr}$, followed by peatlands $\left(-71 \mathrm{gC} / \mathrm{m}^{2} / \mathrm{yr}\right)$ and mineral soil wetlands $\left(-17 \mathrm{gC} / \mathrm{m}^{2} / \mathrm{yr}\right)$. Sequestration in estuaries is mostly accomplished as the result of sedimentation (Bridgham and others, 2006). For comparison, Armentano and Menges (1986) estimated a range of soil carbon accumulation rates that ranged from $-48 \mathrm{gC} / \mathrm{m}^{2} / \mathrm{yr}$ in peatlands in the northern part of the region to $-2.25 \mathrm{gC} / \mathrm{m}^{2} / \mathrm{yr}$ in peatlands in Florida. Chmura and others (2003) reported carbon accumulation in the coastal tidal marshlands of $-136.5 \mathrm{gC} / \mathrm{m}^{2} / \mathrm{yr}$ and $-296.6 \mathrm{gC} / \mathrm{m}^{2} / \mathrm{yr}$ for the Atlantic and the gulf coast areas, respectively. Methane emissions from ecosystems in the conterminous United States were estimated to be about 50.4 teragrams of $\mathrm{CO}_{2}$-equivalent per year (Bridgham and others, 2006) and were mostly emitted from freshwater mineral-rich soil in wetlands because of the low salinity content of this soil type (Poffenbarger and others, 2011).

The emission, transport, and sequestration of carbon by aquatic ecosystems should be considered when estimating carbon balances in ecosystems (Chapin and others, 2006; Cole and others, 2007; Tranvik and others, 2009). National-scale studies suggest that lateral transport of carbon fixed within the conterminous United States and exported to coastal areas can represent about 10 percent of the total carbon sequestered in forests (trees and soils), croplands, and shrublands (Pacala and others, 2001; Butman and Raymond, 2011; Stackpoole and others, 2012). In addition to the role of aquatic ecosystems in transporting and sequestering carbon, recent global studies have indicated that inland waters can also be sources of carbon emitted into the atmosphere (Cole and others, 2007; Tranvik and others, 2009). In a carbon flux and sequestration assessment for the Western United States (Stackpoole and others, 2012), the mean values of emission of $\mathrm{CO}_{2}$ from lateral fluxes, water surfaces, and sequestration (burial) in lakes and reservoirs were estimated to be $7.2 \mathrm{TgC} / \mathrm{yr}, 28.2 \mathrm{TgC} / \mathrm{yr}$, and $-2.4 \mathrm{TgC} / \mathrm{yr}$, respectively.

The above-referenced studies produced estimates of net carbon flux that were spatially and temporally variable; however, these estimates also provide a set of reference points against which this assessment may be compared. Estimates for the agricultural lands, forests, and wetlands ecosystems in the Eastern United States from these recent studies are summarized in table $1-4$.

Table 1-4. Mean net carbon flux per unit of area from a selected sample of studies for the four major terrestrial ecosystems used in the assessment of carbon storage and fluxes in the Eastern United States.

[The four major terrestrial ecosystems are forests, agricultural lands, grasslands/shrublands, and wetlands. C, carbon; gC/ $/ \mathrm{m}^{2} / \mathrm{yr}$, grams of carbon per square meter per year; $\mathrm{kgC} / \mathrm{m}^{2} / \mathrm{yr}$, kilograms of carbon per square meter per year; $\mathrm{SOC}$, soil organic carbon]

\begin{tabular}{|c|c|c|c|c|}
\hline Ecosystem & Geography & $\begin{array}{l}\text { Estimates, units, and } \\
\text { type of estimate }\end{array}$ & Source & $\begin{array}{l}\text { Timeframe of the } \\
\text { sourced work }\end{array}$ \\
\hline \multirow[t]{3}{*}{$\begin{array}{l}\text { Agricultural } \\
\text { lands }\end{array}$} & Conterminous United States & $1.5 \mathrm{gC} / \mathrm{m}^{2} / \mathrm{yr}$, net $\mathrm{C}$ flux & $\begin{array}{l}\text { U.S. Environmental Protection } \\
\text { Agency }(2012 b)\end{array}$ & $2007-2011$ \\
\hline & Conterminous United States & $\begin{array}{l}0 \mathrm{gC} / \mathrm{m}^{2} / \mathrm{yr} \text {, net } \mathrm{C} \text { flux by } \\
\text { conventional tillage }\end{array}$ & West and Marland (2002) & $1990 \mathrm{~s}$ \\
\hline & Conterminous United States & $\begin{array}{l}-37 \mathrm{gC} / \mathrm{m}^{2} / \mathrm{yr} \text {, net } \mathrm{C} \text { flux by } \\
\text { no-till farming }\end{array}$ & West and Marland (2002) & $1990 \mathrm{~s}$ \\
\hline \multirow[t]{3}{*}{ Forests } & Conterminous United States & $-84.6 \mathrm{gC} / \mathrm{m}^{2} / \mathrm{yr}$, net $\mathrm{C}$ flux & Heath and others $(2011 a, b)$ & $2002,2005,2008$ \\
\hline & Major Eastern United States & $-82.8 \mathrm{gC} / \mathrm{m}^{2} / \mathrm{yr}$, net $\mathrm{C}$ flux & Williams and others (2012) & 2005 \\
\hline & Eastern United States & $-243 \mathrm{gC} / \mathrm{m}^{2} / \mathrm{yr}$, net $\mathrm{C}$ flux & Turner and others (1995) & Early 1990s \\
\hline Peat wetlands & Northern United States & $-37.8 \mathrm{gC} / \mathrm{m}^{2} / \mathrm{yr}$ & Yu (2012) & 1998-2009 \\
\hline Tidal marshlands & Atlantic and gulf coast areas & $\begin{array}{c}-136.5 \mathrm{gC} / \mathrm{m}^{2} / \mathrm{yr} \text { and } \\
-296.6 \mathrm{gC} / \mathrm{m}^{2} / \mathrm{yr}\end{array}$ & Chmura and others (2003) & $1990 \mathrm{~s}$ \\
\hline
\end{tabular}




\title{
Chapter 2. Ecoregion and Scenario Framework
}

\author{
By Benjamin M. Sleeter, ${ }^{1}$ Glenn E. Griffith, ${ }^{1}$ Tamara S. Wilson, ${ }^{1}$ Rachel R. Sleeter, ${ }^{1}$ Christopher E. Soulard, ${ }^{1}$ \\ Kristi L. Sayler, ${ }^{1}$ Ryan R. Reker, ${ }^{2}$ Michelle A. Bouchard, ${ }^{2}$ and Terry L. Sohl'
}

\subsection{Introduction}

The current and projected changes in LULC are key components for this assessment of carbon and GHG stocks and fluxes (Zhu and others, 2010). Mapping of the baseline (1992-2005) LULC conditions (chap. 3) provided a spatial foundation for the wall-to-wall assessment of carbon stocks and GHG fluxes in various ecosystems (chap. 1). The development of a range of potential future LULC projections together with corresponding climate-change projections allowed for an evaluation of potential future carbon sequestration capacities and vulnerabilities as influenced by these projected drivers. This chapter provides an overview of methods used to construct the alternative LULC scenarios and descriptions of the distinguishing characteristics of each of the ecoregions used for the assessment.

\subsection{Definition of Terms}

The framework for projected changes in LULC and land management for three future scenarios from 2005 through 2050 are presented in this chapter. LULC classes used for this assessment are described in detail in chapter 3 . To maintain consistency with the overall assessment, we present results of the land use scenario downscaling process consistent with the broad ecosystem types used to assess regional-scale carbon dynamics. These ecosystems include forests, grasslands/shrublands, agricultural lands, and wetlands. Urban development was modeled as a separate LULC class but was collapsed into the "other" category. Urban areas with significant tree cover were considered in carbon modeling, as noted in chapter 1.

Changes in land use (conversions) are associated with the conversion of lands from one use type to another. Typical conversions include changes between forest and agricultural lands (afforestation and deforestation) and conversions to development (for example, urbanization). Land management practices, such as timber harvesting, are captured as changes in land cover where it is assumed that logged areas no longer meet the definition of a forest cover classification. Areas of

\footnotetext{
${ }^{1}$ U.S. Geological Survey

${ }^{2}$ ASRC Federal InuTeq
}

forest logging are accounted for through the use of a temporary mechanical disturbance category, where the specific areas remain until the next temporal period ( 5 years for scenarios) before being reassigned to the forest class. As a result, forest land use is considered a land use class, consisting of areas ranging from mature forest to areas where logging has recently occurred and trees may not be present or have only recently been replanted. In the following sections, we present projections of changes in forest cover, forest use, and forest management (mechanical disturbance of forest land or logging). For some ecoregions and scenarios, we also present the gross conversions associated with deforestation and afforestation where those changes were important to regional-scale land use dynamics.

\subsection{Spatial Domain Used for the Assessment}

This assessment is organized by seven level II ecological regions (ecoregions) that cover the Eastern United States; the ecoregions were adapted from the ecoregion frameworks of the EPA (U.S. Environmental Protection Agency, 2013a) and for the purposes of this assessment are as follows: (1) Mixed Wood Shield, (2) Atlantic Highlands, (3) Mixed Wood Plains, (4) Central USA Plains (5) Southeastern USA Plains, (6) Ozark, Ouachita-Appalachian Forests, and (7) Mississippi Alluvial and Southeast USA Coastal Plains (includes the Everglades and the Texas-Louisiana Coastal Plain level II ecoregions for analysis of this assessment; fig. 1-1). All the assessment models were parameterized, and the results were calibrated and reported based on these ecoregions. In this report, the term region is often used in a general sense, depending on the context, whereas the term ecoregion refers to the EPA ecoregion hierarchy (U.S. Environmental Protection Agency, 2013a). The major terrestrial and aquatic ecosystems are analyzed within these ecoregions. The use of the ecoregions and the NLCD's LULC classes chosen for the ecosystems in this assessment suggest that the reported results are meaningful within the defined ecoregion and ecosystem boundaries and may not be directly comparable with other national- or regional-level estimates because of the different boundary definitions. Further discussion of the ecoregions and ecosystems may be found in Zhu and others (2010). 
The EPA ecoregion framework was used to capture regionally unique processes and landscape potential (Omernik, 1987; U.S. Environmental Protection Agency, 2013a). Ecoregions represent areas with similar patterns of biotic, abiotic, aquatic, and human land-use characteristics and have proven to be a useful framework for collecting and synthesizing information about LULC change (Gallant and others, 2004). Ecoregions as defined by the EPA are hierarchical at four spatial scales (levels I, II, III, and IV) for the conterminous United States. The 1999 version of level III ecoregions (U.S. Environmental Protection Agency, 1999) was used as the base map for the assessment. Based on this version of the EPA 1999 framework, a further modified version consisting of seven level II ecoregions was developed to serve as the framework for this assessment (fig. 1-1). Condensed versions of the ecoregion descriptions are included in the following sections.

\subsubsection{Mixed Wood Shield}

The Mixed Wood Shield ecoregion covers the northern parts of Minnesota, Wisconsin, and Michigan in the United States and contains the Northern Minnesota Wetlands and the Northern Lakes and Forests level III ecoregions (fig. 1-1). Although there are some minor areas of bedrock exposure, this is a glaciated region, and most areas are covered with glacial drift. The broad landforms are mostly smooth to irregular plains with a few areas of hills.

The ecoregion has a severe midlatitude humid continental climate, marked by warm summers and very cold winters, with no pronounced dry season. The mean annual temperature ranges from 2 to 6 degrees Celsius $\left({ }^{\circ} \mathrm{C}\right)$; the mean summer temperature is about $16^{\circ} \mathrm{C}$; and the mean winter temperature ranges from -10 to $-12{ }^{\circ} \mathrm{C}$. The frost-free period ranges from less than 100 days to near 160 days in lake-moderated areas. The mean annual precipitation ranges from about 500 to 960 millimeters $(\mathrm{mm}$ ) within the region (Wiken and others, 2011).

The subboreal vegetation includes northern coniferous forests, northern hardwood forests, boreal hardwood-conifer forests, swamp forests, and peatlands. Changes in stand densities and forest composition from hardwood and conifers to successional species that have occurred during the past 150 years have been affected by land use history and management (Albert, 1995; Zhang and others, 2000; Schulte and others, 2007). From the mid-1800s through the early 1900s, there was intense logging, repeated slash-and-burn fires, and a short period of attempted settlement or agricultural use of cutover lands and then abandonment. As forests recovered, mixed coniferous forests transformed into hardwood (especially aspen)-dominated forests; aspen has proven to be an early successional species with strong post-disturbance sprouting ability (Friedman and Reich, 2005). Fire suppression policies also represent a major change from the natural disturbance history in this region.

Land cover in the Mixed Wood Shield ecoregion is dominated by forest, wetlands, and water, which account for about 87 percent of the region's area. The region has a relatively low human population compared with other regions of the Eastern United States. The economy is based primarily on forestry, recreation and tourism, hunting and fishing, and iron ore mining. Land change is driven by demand for resources such as timber, minerals, and in the lower peninsula of Michigan, some energy resource extraction from oil and natural gas. Forestry activities are the main drive of land use and land cover change in the Mixed Wood Shield ecoregion. Land change during the past 40 years shows the continued dominance of forest land cover, although this land use has declined slightly. Wetlands have been relatively stable at about 20 percent of the region's land cover since 1973. With the cold climate and thin, nutrient-poor soils in the region, agriculture is very limited compared with the adjacent Mixed Wood Plains and Central USA Plains ecoregions to the south. Agricultural lands covered about 7 percent of the region in 2000, a relatively stable land use since the early 1970s. Where there is agriculture, it is generally in small areas; the most common products are hay and grain crops, beef and dairy cattle, and potatoes.

\subsubsection{Atlantic Highlands}

The Atlantic Highlands ecoregion covers forested upland areas in Pennsylvania, New Jersey, New York, Connecticut, Massachusetts, Vermont, New Hampshire, and Maine in the northeastern United States (fig. 1-1). This is a cool, humid, forested, and formerly glaciated region that is relatively sparsely populated compared with adjacent regions. It has higher elevations and more rugged topography than most adjacent ecoregions and contains iconic mountain ranges and elevated plateau areas of the Northeast, including the White, Green, Taconic, Berkshire, Adirondack, Catskill, and Pocono Mountains, the Hudson Highlands, and the Allegheny Plateau. Elevations reach more than 1,900 meters (m) at Mount Washington in New Hampshire. The Atlantic Highlands ecoregion contains the Northern Appalachian and Atlantic Maritime Highlands (includes the northern Appalachian Plateau and uplands) and North Central Appalachians level III ecoregions (U.S. Environmental Protection Agency, 2013a).

The Atlantic Highlands ecoregion has a severe midlatitude humid continental climate, marked by warm summers and cold, snowy winters. The mean annual temperature ranges from about 1 to $8{ }^{\circ} \mathrm{C}$, varying by elevation and latitude. The frost-free period ranges from less than 50 days at high elevations to near 180 days in low-elevation southeast areas. The mean annual precipitation ranges from about $840 \mathrm{~mm}$ to more than 2,000 $\mathrm{mm}$ on high peaks (Wiken and others, 2011).

As with climate, the vegetation of the region also varies by elevation and latitude. Forest types are transitional in a broad zone between the boreal forests to the north in Canada and the broadleaf deciduous forests to the south (Braun, 1950; Goldblum and Rigg, 2010). Forest types include northern hardwoods, northern hardwoods-spruce, and northeastern 
spruce-fir forests in the north and Appalachian oak forests in the south (Kuchler, 1964). To the south and at low elevations, northern hardwood forests give way to transition hardwood forests

with more oaks, hickories, and pines on dry sites and northern hardwoods and hemlock on mesic and north-facing slopes.

The economy of the Atlantic Highlands ecoregion today is based primarily on forestry, tourism and recreation, hunting and fishing, and some small-scale farming. Forestry activities for paper and pulp production, sawlogs, and biomass chipping are important, especially in the part of the region that is covered by Maine, and some high-quality hardwoods are harvested in the Pennsylvanian forests (Napton and others, 2003). Forest management is influenced by the varied land ownership patterns in the region. Private forest land dominates the region, from large corporate land holdings in Maine to small individual holdings in southern areas.

During the past few decades, the area of forest land cover in the region has started to decline, a trend seen in other parts of the Northeastern and Eastern United States (Drummond and Loveland, 2010; Jeon and others, 2012). Forest cover has decreased by nearly 3 percent since 1973 (Sleeter and others, 2013).

Agricultural lands are the second largest class of land cover in the Atlantic Highlands ecoregion, covering about 9 percent of the region. With its cold climate and stony soils, agriculture is limited in most parts of the Atlantic Highlands ecoregion compared with the adjacent Mixed Wood Plains ecoregion. The most common products are dairy cattle, hay and silage crops, apple orchards, and nursery stock. Similar to the Mixed Wood Shield ecoregion, the Atlantic Highlands ecoregion also has a relatively low human population compared with other regions in the Eastern United States. The area covered by developed land increased from 1.9 percent of the region in 1973 to 2.4 percent in 2000 (Sleeter and others, 2013).

\subsubsection{Mixed Wood Plains}

The Mixed Wood Plains ecoregion covers an area of glaciated, rolling to level terrain with mixed land cover that extends across parts of Minnesota, Wisconsin, Iowa, Illinois, Michigan, Indiana, Ohio, Pennsylvania, New York, New Jersey, Connecticut, Massachusetts, Vermont, New Hampshire, and Maine (fig. 1-1). The ecoregion is characterized by a land cover mosaic of agricultural lands, forest, wetlands, and glacial lakes. This is in contrast to the Mixed Wood Shield and Atlantic Highlands ecoregions to the north where soils are more nutrient-poor and mostly lacking in agricultural lands and in contrast to the nutrient-rich Central United States Plains and Temperate Prairies ecoregions to the south and west where landscapes are dominated by agricultural land use. The Mixed Wood Plains ecoregion contains the North Central Hardwood Forests, Driftless Area, Southern Michigan/Northern Indiana Drift Plains, Northeastern Coastal Zone, Erie Drift Plain, Maine/New Brunswick Plains and Hills, and Eastern
Great Lakes and Hudson Lowlands level III ecoregions

(U.S. Environmental Protection Agency, 2013a).

The Mixed Wood Plains ecoregion has been glaciated and includes a wide variety of deep glacial and marine deposits with a few areas of bedrock outcrops. The terrain includes flat lake plains, rolling till plains, outwash plains, hummocky stagnation moraines, a less-glaciated dissected plateau in the Driftless Area (that is, with only some patchy pre-Illinoian glacial drift), and some low to high hills, especially in New England.

The Mixed Wood Plains ecoregion has a severe midlatitude humid continental climate, marked by warm summers and cold, snowy winters. There is some maritime influence in coastal areas and lake-effect influence near the Great Lakes. The mean annual temperature ranges from 4 to $10{ }^{\circ} \mathrm{C}$. The frost-free period ranges from 110 to 170 days. Mean annual precipitation ranges from about $600 \mathrm{~mm}$ in the far west to more than $1,250 \mathrm{~mm}$ in wetter parts of the east (Wiken and others, 2011).

Although once mostly forested, because the region stretches from near the edge of the Great Plains grasslands in the west to coastal New England in the east, the historical vegetation of the Mixed Wood Plains ecoregion is varied. In Minnesota, Iowa, and Wisconsin, a forest and savanna transition zone includes small patches of prairie, oak savannas, and maple-basswood forests on mesic sites (Braun, 1950; Kuchler, 1964). In south-central Wisconsin, pine barrens with jack pine (Pinus banksiana) and scrub oaks were common in the sandy, droughty outwash and lake plains, along with areas of wet conifer swamps and peatlands (Curtis, 1959). In the central section of the Mixed Wood Plains from Lake Michigan to Lake Ontario, there are beech-maple forests with some oak-hickory forests on drier sites. Further east, in southern New England and the lower Hudson Valley of New York, Appalachian oak and northeastern oak-pine forests occur, with several forest species at the northern limits of their range.

The economy of the Mixed Wood Plains ecoregion continues to be diverse, based on manufacturing and technology, finance, health research and services, education, agriculture, forestry, fishing, and tourism. LULC reflects some of this diversity with its mixed uses. Land use is dominated slightly by agricultural lands, accounting for about 40 percent of the region in 2000, whereas forest cover was nearly as extensive at 37 percent of the region. Agricultural lands have decreased since 1973 and tend to be a more dominant part of the landscape in the western half of the ecoregion, in Minnesota, Iowa, Wisconsin, and Michigan. The most typical agricultural activities center around dairy and beef cattle, hay and silage crops, corn, oats, soybeans, fruit orchards and vineyards, and nursery stock. Forests, however, are similar to other parts of the Northeastern and Eastern United States, and have been declining in the past few decades (Drummond and Loveland, 2010; Jeon and others, 2012). Forest land is more dominant in the New England part of the region, especially in the Maine/New Brunswick Plains and Hills ecoregion of Maine, which was about 70 percent covered in forest in 2000. 


\subsubsection{Central USA Plains}

The Central USA Plains ecoregion is an area of glaciated, flat-to-gently-rolling plains that extends across parts of Wisconsin, Illinois, Indiana, Michigan, and Ohio (fig. 1-1). The ecoregion is characterized by LULC that is dominated by agricultural lands. It is one of the largest areas of the Eastern United States with suitable relief and soils for cropland (Hart, 1968). This is in contrast to the Mixed Wood Plains to the north that has a bimodal mix of agricultural lands and forests and to the nonglaciated Southeastern USA Plains and Ozark, Ouachita-Appalachian Forests ecoregions to the south and east that are more densely forested and have more irregular or hilly landforms. The Central USA Plains ecoregion includes the Southeastern Wisconsin Till Plains, Huron/Erie Lake Plains, Central Corn Belt Plains, and Eastern Corn Belt Plains level III ecoregions (U.S. Environmental Protection Agency, 2013a)

The Central USA Plains ecoregion has a severe midlatitude humid continental climate, marked by warm to hot summers and cold winters. The mean annual temperature ranges from approximately $7^{\circ} \mathrm{C}$ in the north to $13{ }^{\circ} \mathrm{C}$ in the south. Temperatures are moderated in areas near the Great Lakes. The frost-free period ranges from 150 to 200 days. Mean annual precipitation varies from about $700 \mathrm{~mm}$ to 1,140 mm (Wiken and others, 2011). Tornados are not uncommon in late spring and early fall.

The historical vegetation of the Central USA Plains ecoregion ranged from mostly prairies and savannas in the west to various forest types and some savanna mosaics to the east. A large part of the region consists of the eastern extent of the Prairie Peninsula region (Transeau, 1935; Geis and Boggess, 1968). In southeast Wisconsin, northern Illinois, and parts of Indiana and western Ohio, a forest and savanna transition zone included small patches of prairie, oak savannas, and beech-maple forests on mesic and eastern sites (Braun, 1950; Kuchler, 1964; Albert, 1995). The savannas contained a tallgrass prairie mosaic along with bur oak (Quercus macrocarpa) and other woody species.

Economic restructuring in the steel and other manufacturing sectors resulting from a decline in the heavy manufacturing industry in the area caused job losses and economic decay in parts of the Central USA Plains ecoregion in the late 20th century. The economy of the region today is still based primarily on manufacturing, agriculture, and financial and other services. The ecoregion is dominated by agriculture, although the extent of agricultural lands has decreased in response to increased demands for urban land uses (Sleeter and others, 2013). The most typical agricultural activities center on cash grain farming primarily of corn and soybeans, with some wheat and oats. Also important in the region are dairy and beef cattle, hogs, poultry, and hay and silage crops; these farms are on the small and truck farming scales. Dry beans and sugar beets are grown in the Saginaw Lake Plain of Michigan. Although forests only cover about 11 percent of the region, they cover only slightly more land than developed land, which covered slightly less than 11 percent of the region in 2000. Forest land has seen relatively small but consistent declines since 1973, a declining trend similar to other parts of Eastern United States (Drummond and Loveland, 2010). Most of the loss in forest land area is a result of conversion to developed land, with some conversion of forests to agricultural lands in certain areas.

\subsubsection{Southeastern USA Plains}

The Southeastern USA Plains ecoregion is the largest level II ecoregion in the Eastern United States, covering the inner coastal plains, Piedmont areas, and interior low plateaus in parts of 22 States. The ecoregion is characterized by a land cover mosaic of forest, pasture, cropland, and developed land. The region is generally not as arable as the more nutrient-rich Central USA Plains ecoregion to the north or the Great Plains region to the west. However, there are several parts of the Southeastern USA Plains that are better suited to agriculture than the bordering Ozark, Ouachita-Appalachian Forests ecoregion, which is typically hilly. The Southeastern USA Plains ecoregion contains the East Central Texas Plains, South Central Plains, Piedmont, Northern Piedmont, Southeastern Plains, Interior Plateau, Interior River Valleys and Hills, and Mississippi Valley Loess Plains level III ecoregions (U.S. Environmental Protection Agency, 2013a).

The Southeastern USA Plains ecoregion is mostly unglaciated except for a few areas in the northern fringes, in Iowa, Missouri, Illinois, Indiana, and New Jersey. The ecoregion has landforms consisting mostly of smooth to irregular plains with some areas of open hills. There are also areas of karst plains, dissected plateaus and tablelands, and some steep slopes and ravines. Elevations in the region range from sea level along Chesapeake Bay to more than $800 \mathrm{~m}$ on high hills of the inner Piedmont.

Most of the Southeastern USA Plains ecoregion has a mild midlatitude humid subtropical climate, marked by hot and humid summers and mild winters. The northernmost areas are somewhat cooler, located along the boundary of severe midlatitude humid continental climates with colder winters. The mean annual temperature ranges from $10{ }^{\circ} \mathrm{C}$ in the north in Illinois to $21^{\circ} \mathrm{C}$ in the far southwest in Texas. The frost-free period ranges from 160 days in the north to 300 days near the Gulf of Mexico in the south. Mean annual precipitation ranges from about $680 \mathrm{~mm}$ in the dry southwest to more than $1,650 \mathrm{~mm}$ in wet parts of the south (Wiken and others, 2011). Precipitation is fairly evenly distributed throughout the year, falling as rain from frontal storms in fall, winter, and early spring and from convective thunderstorms or tropical storms and hurricanes in the warm late spring and summer months. Droughts occasionally affect the region.

The historical vegetation of the Southeastern USA Plains ecoregion was varied because of its latitudinal extent and the diverse landscape elements and ecosystems contained within the ecoregion. A mixed oak and oakhickory-pine forest covered much of the Piedmont and parts of the upper coastal plains. Longleaf pine (Pinus palustris) was one of the most ecologically important tree species in 
the Southern United States, and covered an extensive area, although today only a small fraction of the longleaf pine ecosystem remains (Earley, 2004). In the interior plateaus and far western parts of the ecoregion, oak-hickory forests were sometimes intermixed with prairies. In the Interior Plateau ecoregion in Tennessee and Kentucky, oak-hickory forest with some areas of bluestem prairie, cedar glades, and some mixed mesophytic forest were predominant ecosystems (Kuchler, 1964; Griffith and others, 1997; Wood and others, 2002). In the East Central Texas Plains ecoregion, the landscape was originally covered by post oak (Quercus stellata) savanna vegetation, in contrast to the more open prairie to the west and to the pine forests to the east.

Although forest is the most extensive land cover class in the Southeastern USA Plains ecoregion, it accounts for less than half of the area of the region, which has some variation in forest resource lands and areas with different historical trends. Overall, forest land cover has been declining for at least the past four decades (Drummond and Loveland, 2010). However, the ecoregion is one of the most important timber production regions of the United States; pine plantation forestry is an important driver of land change in parts of the region, with tree cutting and regrowth cycles accounting for substantial amounts of land conversion. Private land ownership dominates the forests of the Southeastern USA Plains ecoregion, consisting primarily of small, nonindustrial properties of individual ownership, but there are also some larger corporate land holdings. Agricultural lands accounted for an estimated 31 percent of the region in 2000 (Sleeter and others, 2013), a decrease from 33 percent in 1973, part of a long-term regionwide decline affected by multiple driving forces and government policies (Drummond and Loveland, 2010; Sleeter and others, 2013).

Developed land is the third largest cover type in the Southeastern USA Plains ecoregion and the class with the largest net gain (Sleeter and others, 2013). Developed land covered approximately 10 percent of the region in 2000 , an increase from 7.5 percent in 1973. Although parts of the Southeastern USA Plains ecoregion were still relatively rural by the middle of the 20th century, other areas of the region were poised for expansive growth. In the northeast, as part of the megalopolis between New York City, New York, and Washington, D.C., the Northern Piedmont ecoregion experienced growth in urban, suburban, and exurban land covers at the expense of farms and forest from the New Jersey suburbs to Washington (Auch and others, 2012). Further south, Piedmont population growth exceeded the national average each decade after 1960, and developed land increased from less than 12 percent to more than 16 percent of the region by 2000 (Napton and others, 2010).

\subsubsection{Ozark, Ouachita-Appalachian Forests}

The Ozark, Ouachita-Appalachian Forests ecoregion consists of two separate areas that make up most of the unglaciated forested mountains and upland plateaus in the Central and Eastern United States (fig. 1-1). The ecoregion is characterized by high elevations, high-relief terrain, high-gradient streams, and vegetation and includes some of the most diverse temperate forests in the world (Stephenson and others, 1993). About twothirds of the ecoregion land cover of the ecoregion is forested, and one-quarter is agricultural lands. The Ozark, OuachitaAppalachian Forests ecoregion contains the Ouachita Mountains, Ozark Highlands, Arkansas Valley, Blue Ridge, Ridge and Valley, Southwestern Appalachians, Central Appalachians, Boston Mountains, Western Allegheny Plateau level III ecoregions (U.S. Environmental Protection Agency, 2013a)

The Ozark, Ouachita-Appalachian Forests ecoregion is almost entirely unglaciated except for a few small areas in the northeastern fringes, in New York, Pennsylvania, and New Jersey. The ecoregion includes landforms consisting mostly of high hills and low mountains, with some open high hills and plains with hills. The ecoregion has higher elevations and more relief than the adjacent Southeastern USA Plains ecoregion. Elevations in the region range from about $95 \mathrm{~m}$ in the south to more than 2,035 $\mathrm{m}$ at Mount Mitchell in North Carolina, the highest point in the United States east of the Mississippi River.

Most of the Ozark, Ouachita-Appalachian Forests ecoregion has a severe midlatitude humid continental climate, with warm summers and cold winters. High elevations record the coldest temperatures in the region. The south is characterized by a mild midlatitude climate, marked by hot and humid summers and mild winters. The mean annual temperature ranges from $7{ }^{\circ} \mathrm{C}$ at the high elevations in the north to $17^{\circ} \mathrm{C}$ at the low elevations in the southern and southwestern areas. The frost-free period ranges from 125 days to 245 days. Mean annual precipitation ranges from about $900 \mathrm{~mm}$ in the dry valleys to more than $2,500 \mathrm{~mm}$ on the high mountain peaks of the south (Wiken and others, 2011).

Vegetation in the Ozark, Ouachita-Appalachian Forests ecoregion historically varied because of the latitudinal extent of the ecoregion and the diversity of landscape elements and ecosystems. Appalachian oak, mixed mesophytic, oak-hickory, and oak-hickory-pine forests were the primary natural forest types (Kuchler, 1964). The region contains one of the richest temperate broadleaf forests in the world, with a high diversity of flora and fauna. Within the Appalachian oak forests, there is a wide variety of oak, hemlock, cove hardwood, and pine communities.

Forest is the most extensive land cover class in the ecoregion, accounting for nearly two-thirds of the area of the ecoregion in 2000. The ecoregion has some variation in forest resource lands and areas with different historical trends, but overall, forest land cover has been declining here for at least the past four decades (Drummond and Loveland, 2010). Forest cover in the Ozark, Ouachita-Appalachian ecoregion decreased from 67 percent of the ecoregion in 1973 to 65 percent in 2000, the largest change in any of the land cover categories of the ecoregion (Sleeter and others, 2013). Forestry is an important driver of land change in parts of the ecoregion, with tree cutting and regrowth cycles accounting for substantial amounts of land-cover change. Agricultural lands were the second most extensive cover at 25 percent of the area in 2000. Agricultural lands have maintained this approximate areal amount since 
1973 when 24 percent of the region was in agricultural lands. In general, this is one of the more unproductive ecoregions for agriculture in the Eastern United States, with some severe physical limitations of steepness or poor soils. Developed land was the third largest cover type in the Ozark, OuachitaAppalachian Forests ecoregion and was the class with the largest net gain. Developed land covered 5.2 percent of the region in 2000, an increase from 4.4 percent in 1973.

\subsubsection{Mississippi Alluvial and Southeast USA Coastal Plains}

The Mississippi Alluvial and Southern USA Coastal Plains ecoregion covers the outer Atlantic and Gulf of Mexico coastal plains and the low-lying, mostly Quaternary alluvial part of the Mississippi Embayment, including the floodplains of the lower Mississippi, White, Arkansas, Ouachita, and Red Rivers. The ecoregion's land cover is characterized by a mosaic of agricultural lands, wetlands, forests, water, and developed land. The region is generally lower, flatter, and warmer than the adjacent Southeastern USA Plains ecoregion. The Mississippi Alluvial and Southern Coastal Plains ecoregion contains the Middle Atlantic Coastal Plain, Mississippi Alluvial Plain, Southern Coastal Plain, and Atlantic Coastal Pine Barrens level III ecoregions (U.S. Environmental Protection Agency, 2013a). For the purposes of the analysis for this assessment, the Southern Florida Coastal Plain level III ecoregion of the Everglades level II ecoregion has been included in the Mississippi Alluvial and Southeast USA Coastal Plains ecoregion, as has the Western Gulf Coastal Plain level III ecoregion of the Texas-Louisiana Coastal Plain level II ecoregion because of the similarities of the ecoregions.

The Mississippi Alluvial and Southern Coastal Plains ecoregion is unglaciated except for the terminal moraine and glacial outwash materials that formed Long Island, N.Y., and Cape Cod, Massachusetts. The ecoregion has landforms consisting mostly of flat plains, smooth plains, and a few irregular plains. There are also karst plains, river deltas, floodplains and low terraces, oxbows, swamps, bogs, estuaries, barrier islands, coral islands and reefs, dunes, and beaches. Elevations in the region range from sea level to about $100 \mathrm{~m}$ in Illinois, and relief is typically only 1 to $10 \mathrm{~m}$. The region consists mostly of Quaternary sands, silts, and clays, with a few areas of Tertiary and Cretaceous-age marine terrace sediments.

Most of the Mississippi Alluvial and Southern Coastal Plains ecoregion has a mild midlatitude humid subtropical climate, marked by hot and humid summers and mild winters. The northeasternmost areas are somewhat cooler than the southern areas and are located along the boundary of severe midlatitude humid continental climates with colder winters, whereas southern Florida has a humid subtropical to tropical savanna climate with hot summers and warm winters. The mean annual temperature ranges from $11{ }^{\circ} \mathrm{C}$ in the northwest in Illinois to $25^{\circ} \mathrm{C}$ in southern Florida and southern Texas. Summer heat is tempered by sea breezes in coastal areas. The frost-free period ranges from 190 days in the northeast to 365 days at the southern tip of Florida.
Mean annual precipitation ranges from about $600 \mathrm{~mm}$ in the driest southwest part of the region in southern Texas to more than $1,760 \mathrm{~mm}$ along the wettest parts of the central gulf coast (Wiken and others, 2011). Precipitation is fairly evenly distributed throughout the year, falling as rain from frontal storms in fall, winter, and early spring and from convective thunderstorms or tropical storms and hurricanes in the warm late-spring and summer months. Southern areas typically have a drier winter season than the northern areas. Droughts occasionally affect parts of the region, mostly in the south.

The natural vegetation of the Mississippi Alluvial and Southern Coastal Plains ecoregion is varied due to the latitudinal extent, diverse soil textures, and the subtle but often dynamic landforms. Small differences in elevation, water-table levels, or exposure to maritime salts can greatly affect vegetation patterns. The longleaf pine forest types were diverse and have proven difficult to classify given the great variations in disturbance history, site conditions, and species composition in the gradients from xeric upland sandhill communities to more mesic and wet flatwoods and savannas (Christensen, 1988; Peet and Allard, 1993). With species-rich understories, the longleaf pine historically marked one of the country's most ecologically important forest regions, although today only a fraction of the historical extent of the forests of the ecoregion remains (Earley, 2004). Another important forest type in the Mississippi Alluvial and Southern Coastal Plains ecoregion consists of the bottomland hardwood forests of floodplains and river terraces that provide crucial habitat for a variety of fish and wildlife. The mostly oak-dominated floodplain forest covered the majority of the Mississippi Alluvial Plain ecoregion. These forests had a variable species mix that was dependent on the tolerances of the species to different periods of flooding (Sharitz and Mitsch, 1993).

The landscapes of the Mississippi Alluvial and Southern Coastal Plains ecoregion have been greatly altered from the early times of Euro-American settlement, especially with 20th century technology and energy sources. Although the large urban centers have typically diverse economies with manufacturing and technology, finance, medical, education, and service elements, many of the more rural areas of the region remain dependent on agricultural production, forestry, fish and shellfish catches, energy production, or tourism. Land cover data reflect some of the diversity and dynamism of the region's mixed uses, and there is a high overall footprint of change compared with most other ecoregions in the Eastern United States.

Agricultural lands were the most extensive cover class in the ecoregion, accounting for approximately one-quarter of the ecoregion in 2000. The most typical agricultural activities in the Mississippi Alluvial and Southern Coastal Plains ecoregion differ by area. Pasture land and hay land occur in several parts of the Mississippi Alluvial and Southern Coastal Plains ecoregion, but the traditional cash crop production is concentrated in those areas where the land is best suited to cultivation or where specialty crops, such as citrus, rice, and sugar cane, can best be grown (Hart, 1978). Most of the cropland is in those areas of rich and deep soils such as the Mississippi Alluvial Plain ecoregion, where crop production is dominated by soybeans, rice, 
cotton, corn, and wheat, with sugar cane in the south. Wetlands are the second most extensive land cover and are one of the distinguishing features of the ecoregion's land cover mosaic. Wetlands and surface water combined to account for nearly 36 percent of the region, with wetlands accounting for 22 percent of the area and surface water of the ecoregion, accounting for about 14 percent of the area. Forest is the third most extensive land cover class in the Mississippi Alluvial and Southern Coastal Plains ecoregion and was the largest decreasing land cover class in the ecoregion, following the consistent trend in other forests in the Eastern United States (Drummond and Loveland, 2010). Pine plantation forestry is an important driver of forest cover loss in parts of the ecoregion, such as the Carolinas, Georgia, and northern Florida, with tree cutting and regrowth cycles accounting for substantial amounts of logging. Developed land covered about 11 percent of the region in 2000, an increase from 8 percent in 1973. Although parts of the ecoregion remain relatively rural, other areas, especially in Florida and around Houston, Texas, have experienced expansive population and development growth.

\subsection{Temporal Domain}

This assessment was conducted to estimate carbon stock and balance and their relation to LULC change and other controlling processes for baseline and future projection periods. The baseline period covers 1992 through 2005. Projections of LULC and carbon stocks and fluxes were modeled for the baseline period using observational data from the USGS and other sources (Zhu and others, 2010). The projection period extended from the end of the baseline through 2050. Annual projections of LULC and carbon stocks and fluxes were produced for the projection period across a range of scenarios and input data (for example, emission scenarios, ecosystem models, general circulation model (GCM) outputs). Whenever possible, the estimates are provided as a range of values in order to represent the spread of variability in assessment results. The ranges of values for baseline estimates were derived from the minimum and maximum of averages of model runs for 2001 through 2005. For projected future values, the ranges of values were derived from the means of the unique LULC scenarios, climate-change projections, and biogeochemical models for 2006 through 2050.

\subsection{Scenario Framework}

In 2000, the IPCC published the SRES (Nakićenović and others, 2000), which documented the development of a global set of GHG-emission scenarios based on an underlying set of socioeconomic conditions that were consistent with the current (at the time) scenario literature. The SRES scenarios were designed to assess the effects of alternative GHG-emission pathways on coupled human and environmental systems and evaluate future vulnerabilities on those systems under various combinations of projected change. These scenarios have been used as the basis for the IPCC third and fourth assessment reports on future projected climate change. The SRES scenarios consist of four basic narrative storylines, each of which describe alternative developments in the major drivers of GHG emissions, such as population growth, economic growth, technological change, energy use, globalization, and environmental protection. The four scenarios are oriented along two axes with either economic growth (denoted as A) or environmental protection (denoted as B) aligned along one axis and either global development (denoted as 1) or regional development (denoted as 2) aligned along the other axis; for example, the B1 scenario assumes strong environmental protection and global cooperation.

In order to explore sensitivities in the energy sector, the A1 scenario was subdivided into three subscenarios that focused on fossil-fuel use (A1FI), renewable technologies (A1T), and a balanced energy sector that did not rely on any particular energy source (A1B). Six modeling teams characterized the various scenarios, ultimately producing 40 quantified scenarios. No probability of occurrence was assigned to any one of the SRES scenarios and all should be considered equally plausible with none considered more or less preferable. Furthermore, no integrated climate-change policies, such as the emissions targets of the Kyoto Protocol (United Nations Framework Convention on Climate Change, 1998), are incorporated into any of the scenarios; therefore, the scenarios serve as reference conditions to evaluate the effects of potential mitigation actions and strategies. Since the inception of the SRES scenarios, a suite of future climate-change projections (GCM data) have also become available and correspond to the major scenarios. At the early stage of this assessment, GCM data corresponding to the B2 scenario were not available. Because this assessment required the use of both the LULC scenarios and the climate-change projection scenarios, only scenarios A1B, A2, and B1 were used in the assessment. Furthermore, although the SRES scenarios extend through 2100 , this assessment only used projection data through 2050. Assumptions about the major driving forces associated with each scenario are listed in table $2-1$.

\subsection{Scenario Downscaling}

In order to use the global scenarios, a scenario downscaling process was needed to translate the coarse-scale scenario data to fine geographic scales while maintaining consistency with the original dataset and with local data (van Vuuren and others, 2007, 2010). Land-change scenarios were developed using a modular modeling approach. A global integrated assessment model (IAM) was used to supply future projections of land use at the national scale. An accounting model was developed to refine the national-scale IAM projections and to downscale to hierarchically nested ecoregions. The ecoregion-based projections were then converted into annual maps of LULC using a spatially explicit LULC change model. The approach used for this assessment 
Table 2-1. Assumptions about the primary driving forces affecting land-use and land-cover change.

[These assumptions were used to downscale scenarios A1B, A2, and B1 of the Intergovernmental Panel for Climate Change Special Report on Emission Scenarios (Nakićenović and others, 2000). Population and per-capita income projections are from Strengers and others (2004)]

\begin{tabular}{llcc}
\multicolumn{1}{c}{ Driving forces } & \multicolumn{1}{c}{ Scenario A1B } & Scenario A2 & Scenario B1 \\
\hline $\begin{array}{l}\text { Population growth (global and } \\
\text { United States) }\end{array}$ & $\begin{array}{c}\text { Medium; } 8.7 \text { billion by 2050, then } \\
\text { declining; in the United States, }\end{array}$ & $\begin{array}{c}\text { High; 15.1 billion by 2100; in the } \\
\text { United States 417 million by }\end{array}$ & $\begin{array}{c}\text { Medium; } 8.7 \text { billion by 2050, then } \\
\text { declining; in the United States, }\end{array}$ \\
& 385 million by 2050 & 2050 & 385 million by 2050 \\
Economic growth in the & Very high; per capita income & Medium; per capita income & High; per capita income \\
United States & $\$ 72,531$ by 2050 & $\$ 47,766$ by 2050 & $\$ 59,880$ by 2050 \\
Regional or global orientation & Global & Regional & Global \\
Technological innovation & Rapid & Slow & Rapid \\
Energy sector & Balanced use & Adaptation to local resources & Smooth transition to renewable \\
Environmental protection & Active management & Local and regional focus & Protection of biodiversity \\
\hline
\end{tabular}

follows the methods described in Zhu and others (2010) and more recently in Sohl and others (2012b) and Sleeter and others (2012a). The next sections review each of the major components of the scenario downscaling process.

\subsubsection{Global Integrated Assessment Model}

Initial quantities of projected LULC changes were formulated in a scenario named "demand" by implementing an accounting model for downscaling land-use scenarios (described in detail in Sleeter and others, 2012a). National-scale LULC projections were based on national-scale projections from the Integrated Model to Assess the Global Environment (IMAGE, version 2.2; Planbureau voor de Leefomgeving [Netherlands Environmental Assessment Agency], 2001), land-use histories, and expert knowledge. IMAGE was used to simulate future environmental change, including GHG emissions and landuse changes, for the three SRES marker scenarios (A1B, A2, B1; Strengers and others, 2004). IMAGE used a series of linked modules to project environmental consequences resulting from anthropogenic activity (Alcamo and others, 1998; Planbureau voor de Leefomgeving [Netherlands Environmental Assessment Agency], 2001). Environmental changes were projected for 17 world regions (the United States was treated as a single region) with LULC data available in a 30 -footby-30-foot grid. IMAGE produced projections of demand for agriculture and forest harvest, which were incorporated directly into the scenario downscaling model described in Sleeter and others (2012a). Future projections of development and mining were developed through the use of proxy data (population and coal usage, respectively) from IMAGE. Land-use histories were then used to expand the scenario projections of net change in major land-use classes into comprehensive projections of gross changes between all major LULC types.

\subsubsection{Land-Use Histories}

Land-use histories described the recent historical LULC changes in ecoregions of the United States. These data came primarily from the USGS Land Cover Trends Project, which provided ecoregion-based estimates on the rates, extent, and types of LULC change for multiple dates between 1973 and 2000 (Loveland and others, 2002; Sleeter and others, 2012b, 2013). Maps of land-cover change for the conterminous United States were generated through the interpretation and classification of satellite data for 2,866 sample sites, stratified by ecological region. A comparison of land-cover maps after classification was used to produce estimates of change across major classes (fig. 2-1).

USGS land cover trends data were incorporated into the construction and downscaling of the scenarios in two primary ways. First, the data were used to expand projections of net change in development, mining, and agricultural lands LULC classes into gross conversions between all primary LULC classes at the national scale. Second, the data were used to downscale proportionally these LULC conversions to ecoregions of the conterminous United States. Throughout the downscaling process, regional and sectoral experts were consulted in a series of workshops and ad-hoc consultations. The data served as a default parameter for downscaling, and experts were able to modify certain variables in order to produce regionally specific scenarios that retained consistency with the SRES scenarios. A complete description of the downscaling process can be found in Sleeter and others (2012a).

\subsubsection{Mapping Scenarios of Land-Cover Change}

Regional LULC scenarios, developed in the process as described above, were used as input to the Forecasting Scenarios of Land-Use Change (FORE-SCE) model (Sohl and Sayler, 2008; Sohl and others, 2012a). The FORE-SCE model produced annual, spatially explicit LULC maps from 2006 through 2050 that were consistent with the scenario assumptions and LULC proportions from the scenario downscaling process. The initial LULC map for the beginning of the simulation period was the 2005 LULC map produced from the baseline LULC modeling described in chapter 3 of this report. Suitability-of-occurrence surfaces were used to model baseline 


\section{A. Landsat MSS, TM, and ETM+ images (top row) and interpreted land cover (bottom row)}
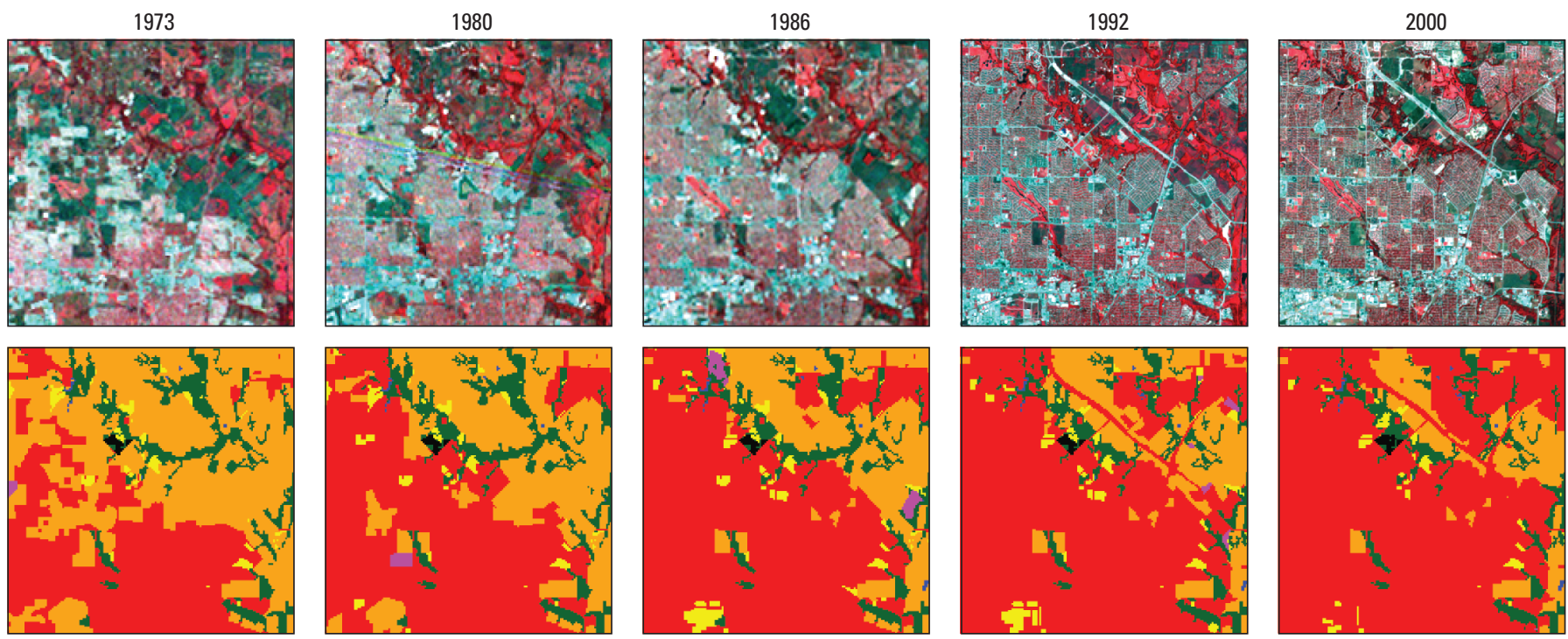

$B$. Change/no change images between successive image dates

$1973-1980$

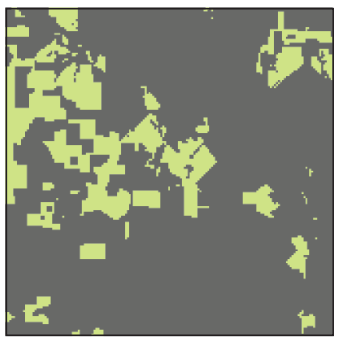

Landsat false-color composite (first row in part $A$ ) Wavelength range, in micrometers

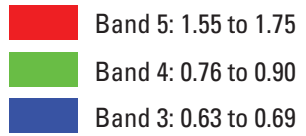

1980-1986

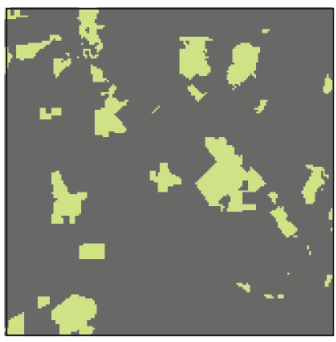

$1986-1992$

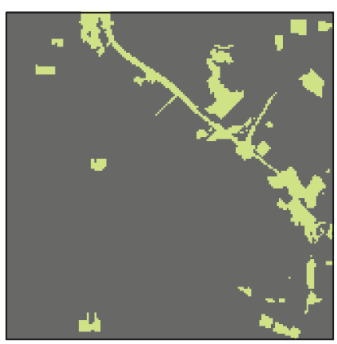

1992-2000

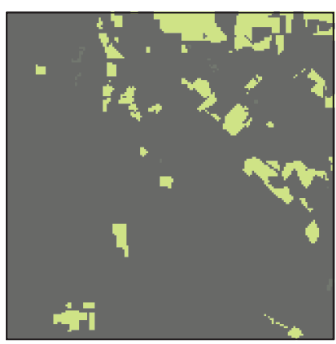

Change/no change

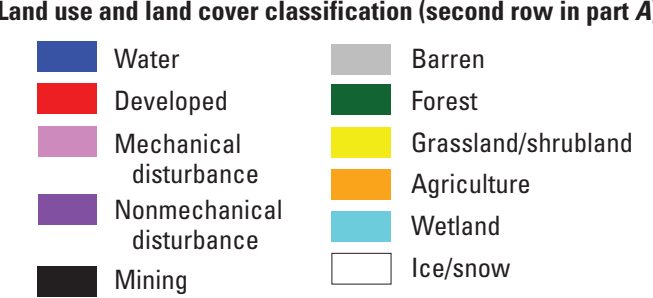

(part $\boldsymbol{B}$ )
No change

Change

Figure 2-1. Satellite images used in the assessment of carbon sequestration and fluxes in the Eastern United States. A, Land-cover change images and $B$, corresponding interpretation produced from manual interpretation of Landsat data. C, Level of change for four time intervals. The example images are from the Texas Blackland Prairies level III ecoregion, which is included in the analysis of the Mississippi Alluvial and Southeast USA Coastal Plains ecoregion. EMT+, Enhanced Thematic Mapper Plus; MSS, multispectral scanner; TM, Thematic Mapper.

LULC change. These surfaces were developed through a logistic regression process to guide the placement of patches of change for the 2006 through 2050 scenarios (see chap. 3). Each level III ecoregion was individually parameterized and modeled by applying the FORE-SCE model for each of the three SRES scenarios used in this assessment. The models of LULC from 2006 through 2050 provide downscaled spatial representations of plausible outcomes that are based on the SRES scenarios. When combined with the mapped and modeled baseline (1992 through 2005) LULC maps described in chapter 3, the baseline and modeled scenarios resulted in a continuous, consistent map database for LULC from 1992 through 2050. 


\subsection{Scenario Downscaling Results for the Eastern United States}

The seven level II ecoregions included in this assessment cover about $3.05 \mathrm{Mkm}^{2}$, or approximately 38 percent of the land area of the conterminous United States and account for 82 percent of the forest area, 87 percent of the wetlands, 70 percent of the developed area, and 47 percent of the agricultural lands in the conterminous United States. Combined, level II ecoregions in the Eastern United States comprise 47 percent forest cover, 32 percent agricultural lands,
9 percent wetlands, 5 percent development, and 2 percent grasslands/shrublands (fig. 2-2).

Total overall LULC change in the Eastern United States was projected to range between 3 and 5 percent (per 5-year time period), depending on scenario. Scenarios A1B and A2 had the highest rates of change and generally were projected to experience an accelerating rate of change through the projection period. Scenario B1 remained relatively consistent at 3 to 3.6 percent change (per 5-year period) throughout the projection period. Table 2-2 provides the range of 5-year overall change projections by level II ecoregion.

\section{A. Land use and land cover in the Eastern United States}

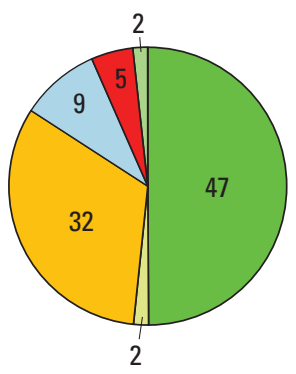

EXPLANATION

Land use and land cover, in percent

Forest

Grassland/shrubland

Agriculture

Wetland

Developed

Forest (harvested)

\section{B. Land use and land cover in level II ecoregions of the Eastern United States}
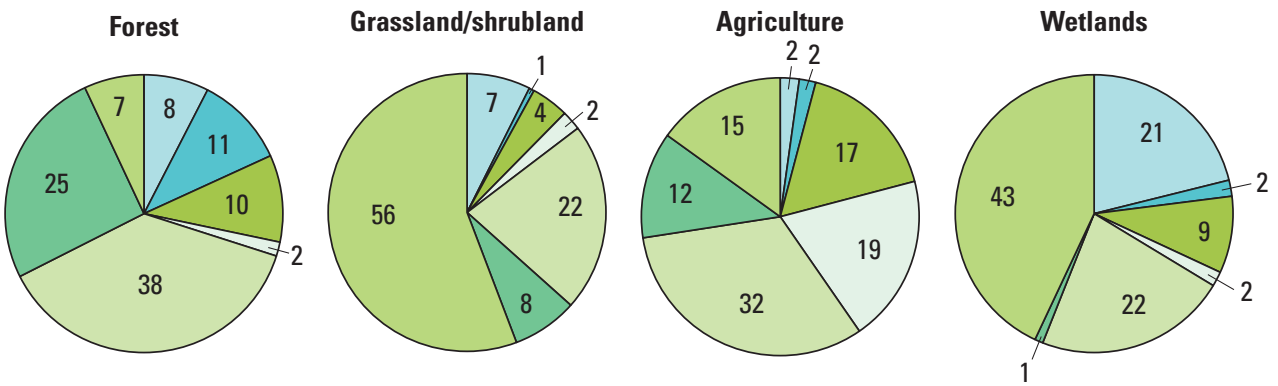

EXPLANATION

Level II ecoregion

Mixed Wood Shield

Atlantic Highlands

Mixed Wood Plains

Central USA Plains

Southeastern USA Plains

Ozark, Ouachita-Appalachian Forests

Mississippi Alluvial and Southeast USA Coastal Plains

Figure 2-2. Pie charts showing $A$, total composition by land use and land cover (LULC) type and, $B$, distribution of LULC in level II ecoregions of the Eastern United States.

Table 2-2. Projected land-use and land-cover change from 2005 through 2050 in the Eastern United States.

[Values listed in the Intergovernmental Panel for Climate Change Special Report on Emission Scenarios (SRES; Nakićenović and others, 2000) columns are the percentage of each level II ecoregion that experienced a change in land use or land cover at least once between 2005 and 2050. Level II ecoregions are from U.S. Environmental Protection Agency (1999, 2013). $\mathrm{km}^{2}$, square kilometers]

\begin{tabular}{|c|c|c|c|c|}
\hline Ecoregion & $\begin{array}{l}\text { Area, } \\
\text { in } \mathbf{k m}^{2}\end{array}$ & $\begin{array}{c}\text { Scenario A1B, } \\
\text { as percentage } \\
\text { change }\end{array}$ & $\begin{array}{c}\text { Scenario A2, } \\
\text { as percentage } \\
\text { change }\end{array}$ & $\begin{array}{c}\text { Scenario B1 } \\
\text { as percentage } \\
\text { change }\end{array}$ \\
\hline Mixed Wood Shield & 215,648 & $4.7-7.2$ & $4.6-6.6$ & $2.2-2.5$ \\
\hline Atlantic Highlands & 187,551 & $3.6-5.1$ & $3.6-5.1$ & $2.7-3.1$ \\
\hline Mixed Wood Plains & 388,858 & $1.7-2.6$ & $1.8-2.7$ & $0.9-1.3$ \\
\hline Central USA Plains & 239,027 & $0.7-1.0$ & $0.6-0.8$ & $0.2-0.5$ \\
\hline Ozark, Ouachita-Appalachian Forests & 520,486 & $2.8-4.8$ & $3.2-4.5$ & $1.8-2.3$ \\
\hline Mississippi Alluvial and Southeast USA Coastal Plain ${ }^{1}$ & 506,807 & $2.1-3.4$ & $1.9-2.5$ & $2.2-2.8$ \\
\hline Eastern United States (total) & $3,052,732$ & $3.2-5.0$ & $3.2-4.4$ & $3.0-3.6$ \\
\hline
\end{tabular}

${ }^{1}$ Includes the Everglades and Texas-Louisiana Coastal Plain level II ecoregions for the analysis of this assessment. 


\title{
Chapter 3. Mapping and Modeling of Land Use and Land Cover in the Eastern United States From 1992 Through 2050
}

\author{
By Ryan R. Reker, ${ }^{1}$ Kristi L. Sayler, ${ }^{2}$ Aaron M. Friesz, ${ }^{3}$ Terry L. Sohl, ${ }^{2}$ Michelle A. Bouchard, ${ }^{2}$ \\ Benjamin M. Sleeter, ${ }^{2}$ Rachel R. Sleeter, ${ }^{2}$ Tamara S. Wilson, ${ }^{2}$ Glenn E. Griffith, ${ }^{2}$ and Michelle L. Knuppe ${ }^{2}$
}

\subsection{Highlights}

- LULC maps at 250-m resolution were produced for each year of the baseline period of 1992 through 2005 and for three scenarios of future LULC change from 2006 through 2050. Modeling of terrestrial carbon stocks and fluxes, as detailed in chapter 7 of this report, used 2001 through 2005 as the baseline period.

- Forested ecosystems with large amounts of clearcutting generally had the highest rates of LULC change in all scenarios. Conversion to urban development was another significant change, particularly in ecoregions with large metropolitan areas. Conversion of forests to agricultural lands was significant in scenarios A1B and A2.

- The Southeastern USA Plains ecoregion had the greatest amount of change in the baseline period with 14.2 percent of the ecoregion changing LULC at least once and nearly 30 percent or greater changing LULC in all three scenarios of projected change.

- The Central USA Plains ecoregion had some of the lowest amounts of LULC change throughout the Eastern United States with less than 10 percent in each scenario and 2.6 percent during the baseline period.

\subsection{Introduction}

The spatial and temporal frameworks introduced in chapter 2 of this report serve as input to the spatial LULC modeling component described in this chapter. The mapping and modeling of LULC form the spatial foundations of this assessment and are used to define the composition of the assessed ecosystems. The LULC maps directly feed into other

${ }^{1}$ Arctic Slope Regional Corporation Research and Technology Solutions

${ }^{2}$ U.S. Geological Survey

${ }^{3}$ Information Dynamics components of the assessment, particularly the assessment of GHG fluxes of aquatic systems (chaps. 5 and 6) and carbon storage and GHG fluxes of terrestrial systems (chap. 7).

LULC in the Eastern United States is diverse. Historically dominated by natural forests, the region now consists of a fragmented mosaic of urban areas, agricultural lands, areas of surface mining, and heavily managed forest lands. LULC change is equally as varied, with some areas undergoing rapid LULC change and others remaining relatively static, historically and projected into the future. The ecoregions for this assessment are defined in chapter 2 of this report.

This assessment uses a thematic classification system that represents a mix of LULC classes. The mixed LULC scheme enables the mapping and modeling of natural and anthropogenic processes that affect the landscape and, ultimately, biogeochemical cycles of GHGs. The temporal foundation of this assessment includes baseline data (data available for the historical period described in this chapter) and projected future data (generated through spatially modeled future scenarios, as described in chapter 2 of this report). Baseline and projected LULC data were used to guide the assessment of baseline and future changes in carbon storage and GHG fluxes. Spatial LULC modeling used to produce projected LULC maps consistent with the IPCC SRES, as described in chapter 2 of this report.

\subsection{Methods and Data}

\subsubsection{Spatial Model Used for Mapping and Modeling}

The spatial modeling framework FORE-SCE was used to produce annual LULC maps from 1992 through 2050. FORE-SCE has been used successfully in the past to model annual LULC change for large geographic regions (Sohl and Sayler, 2008; Sohl and others, 2012a,b). The FORE-SCE model uses separate but linked demand and spatial allocation components to produce spatially explicit, annual LULC maps. The demand component provides aggregate-level quantities of LULC change for a region or a prescription for the overall 
regional LULC proportions. The spatial allocation component ingests demand and produces spatially explicit LULC maps using a patch-based allocation procedure.

In the spatial allocation component, FORE-SCE uses suitability surfaces, unique to each modeled LULC class, to guide placement of new patches of LULC change on the landscape (Sohl and Sayler, 2008). Suitability surfaces are created using logistic regression to quantify empirical relationships between LULC and spatially explicit biophysical and socioeconomic variables. Suitability surfaces are made for each unique LULC class in every individually parameterized region or subregion that is modeled. Individual patches of new LULC are placed on the landscape for a given annual model run until demand is met for that given year. The process is repeated for each successive year until the modeling period is completed. Information on land under protected status can be used during spatial allocation procedures to restrict the placement of specific forms of LULC change on certain types of protected lands (for example, restricting urban development in national park lands).

The age of forest stands is also tracked spatially and temporally and can be estimated in the modeling environment in concert with the modeling of forest clearcuts, afforestation, and deforestation. In the FORE-SCE model, data about foreststand ages are needed to ensure accurate modeling of clearcutting cycles (based on the typical age when a forest stand is ready for harvesting) for a given geographic area and provide information on forest structure. The FORE-SCE model tracks forest-stand age for each annual model iteration and resets the stand age to 0 whenever a new forest area was generated or a forest was clearcut. Minimum cutting age thresholds can also be established for forest LULC classes to ensure harvest does not occur in forested areas of insufficient age. Additional details on the FORE-SCE model framework may be found in Sohl and Sayler (2008) and Sohl and others (2012a,b)

\subsubsection{Starting LULC and Baseline Period}

The baseline period permits an examination of recent LULC change and the calibration of the LULC and biogeochemical modeling processes before the simulations of projected future conditions. A modified version of the 1992 NLCD (Vogelmann and others, 2001) served as the initial LULC data for this work. The start of the baseline period was set to 1992 because it marked the earliest year for which consistent, nationwide, satellite-derived LULC data were available. NLCD data were available for 1992, 2001, and 2006 (Vogelmann and others, 2001; Homer and others, 2007; Xian and others, 2009), but annual maps were not available, and different mapping methodologies between NLCD versions precluded the use of the NLCD alone for providing LULC data for the 1992 through 2005 baseline period. Annual LULC maps for the baseline period were required to adequately portray gross changes between LULC classes that could be missed by a temporal interval longer than 1 year and thus could affect carbon and GHG calculations. The endpoint of the baseline period was set to 2005. The latest NLCD data available at the time of the assessment was conducted were from the 2006 NLCD (Xian and others, 2009), but 2005 was chosen as the end date for the baseline period to facilitate the use of equal 5-year intervals for construction of the projected scenarios.

The NLCD thematic classification system could be directly generalized to the primary ecosystem types analyzed for this assessment (table 1-1). The original resolution of the 1992 NLCD was $30 \mathrm{~m}$, but the data were resampled to $250 \mathrm{~m}$ for this assessment to reduce the volume of data and hold the modeling requirements to a consistent level. Several adjustments were made to the thematic classes for practical considerations and to improve the ability of the modeling framework to address LULC impacts on carbon and GHG fluxes. The four urban classes from the 1992 NLCD were collapsed into one urban/developed class, because separate categories were not required to explicitly model detailed urban class changes for the conterminous United States. Similarly, three agricultural lands classes from the 1992 NLCD (row crop, small grains, and fallow) were collapsed into one agriculture lands class that represented cultivated crops.

The classification scheme was also altered to include classes representing forest clearcutting (mechanically disturbed), because forest management and clearcutting can affect significantly not only biogeochemical cycling, but other ecological processes as well. The thematic labeling of forest clearcuts allowed for tracking and modeling of clearcut locations and the resulting effect on forest structure, while recognizing that the underlying forest land use had not changed. The 1992 NLCD dataset was augmented (fig. 3-1) by incorporating information from the Vegetation Change Tracker (VCT; Huang and others, 2010) of the Landscape Fire and Resource Management Planning Tools Project. The VCT data mapped natural and anthropogenic disturbances, particularly forest clearcuts and wildland fires, by analyzing stacked images from the Landsat Thematic Mapper (TM) and Enhanced Thematic Mapper Plus (ETM+). Wildfires were extracted from the VCT data using fire locations from the Monitoring Trends in Burn Severity Project (MTBS; Eidenshink and others, 2007). Data on contemporary rates of forest clearcutting and spatial information on clearcut patch characteristics from the USGS Land Cover Trends Project were subsequently used to filter the VCT data to approximate locations of clearcut forest harvests. Clearcut forest locations derived from edited VCT data from the baseline period were used to populate mechanically disturbed classes 3,4 , and 5 (table 1-1) for the starting 1992 land cover. The LULC class mechanically disturbed derives from the USGS Land Cover Trends Project (Auch and others, 2012; Napton and others, 2010; Sleeter and others, 2012a,b) and is used in this report to refer to forest clearcutting for the harvest of timber resources exclusively.

The three mechanically disturbed classes are differentiated as national forest, other public land, and private land 


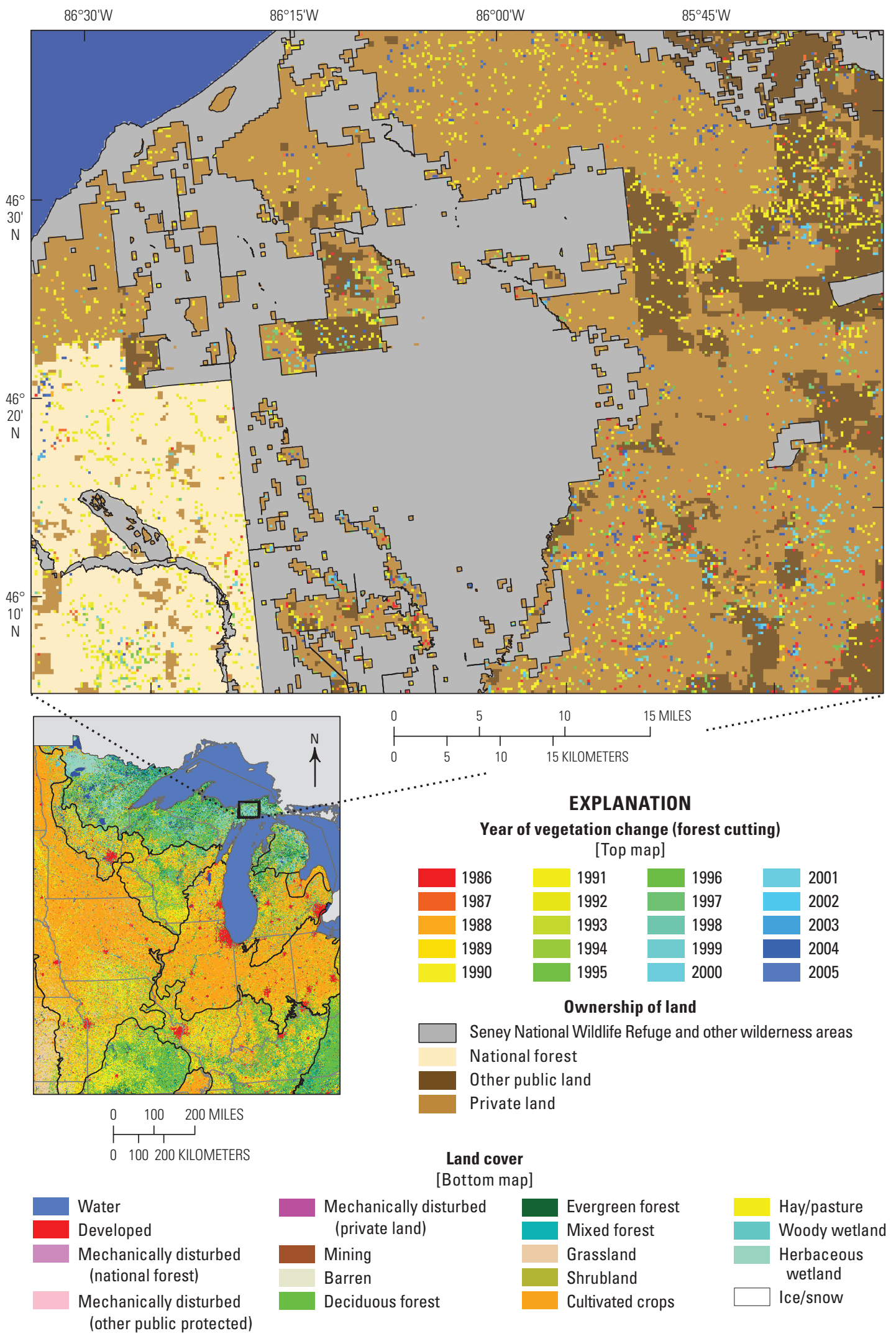

Figure 3-1. Map showing how data from the vegetation change tracker of Landscape Fire and Resource Management Planning Tools Project (LANDFIRE) provided information on ecosystem disturbances for the assessment of carbon fluxes and storage in the Eastern United States. 
based on ownership and protection status. The Protected Area Database of the United States (PAD-US; Protected Areas Database of the United States Partnership, 2009) was used to spatially distinguish ownership for the three disturbance classes. The PAD-US database includes Federal, State, and local protected lands, as well as information from national nonprofit organizations. The database does not cover all protected lands (for example, conservation easements), but it is the most comprehensive and accurate protected lands database available for the United States. In this framework, the mechanically disturbed classification is used strictly to represent a temporary land cover status within the overall land use class of forest. When a forest parcel is clearcut, the mechanically disturbed label is temporarily applied to the parcel. Timber on parcels labeled as mechanically disturbed can thus be assumed to have been recently harvested, and the parcel is still assumed to be managed as a forested land use. The framework of the assessment makes the assumption that the forest cover regenerates over time after the clearcut, and after an average of seven years, the thematic label returns to the original forest class. Although forest use does not change for areas that have been clearcut, the temporary use of the mechanically disturbed label allows tracking, quantifying, and modeling forest cutting and forest stand age.

The demand component of FORE-SCE for the LULC change in the baseline period was separated into two periods to take advantage of temporally specific historical data. Demand from 1992 through 2000 was provided by USGS land cover trends data (U.S. Geological Survey, 2012). The USGS Land Cover Trends Project used a sampling approach and the historical archive of Landsat data to produce estimates of LULC change for each of 84 level III ecoregions (modified from U.S. Environmental Protection Agency, 1999) in the conterminous United States (Loveland and others, 2002). Although the coarse-scale level II ecoregion framework was used for the overall assessment in the Eastern United States, the fine-scale level III ecoregion framework served as the primary framework for all FORE-SCE-based LULC modeling, which improved the representation of spatial LULC change patterns in a heterogeneous landscape.

Demand information from the USGS Land Cover Trends Project was provided separately for each level III ecoregion, and the spatial allocation component of FORE-SCE was parameterized individually for each level III ecoregion. From 1992 through 2000, USGS land cover trends data provided baseline regional proportions of LULC change; however, these data were thematically less detailed than the LULC classes used for this assessment as shown in table 1-1. For example, USGS land cover trends only estimated one aggregate forest class, whereas this assessment differentiated between deciduous, evergreen, and mixed forest types. To obtain the three forest types and their transitions from the USGS land cover trends data from 1992 through 2000, the proportions of the three forest types from the 1992 NLCD were used to disaggregate the USGS land cover trends single forest class for each level III ecoregion. A similar disaggregation of USGS land cover trends classes using the 1992 NLCD was performed to split the USGS land cover trends class grasslands/shrublands into the grassland and shrubland classes, split wetland into the herbaceous wetland and woody wetland classes, and split agricultural lands into hay/pasture and cultivated crop. Finally, the estimates for 1992 through 2000 by ecoregion were annualized to produce annual rates of change that served as annual demand for the FORE-SCE model.

A similar methodology was used to populate the demand component of the model for 2001 through 2005. The demand for this period was provided by the 2001 through 2006 NLCD change data (Xian and others, 2009). The 2001 and 2006 NLCD data provided a LULC change product that provided consistent, wall-to-wall LULC data for the conterminous United States. The level of thematic detail was mostly compatible with this assessment, and unlike the USGS land cover trends data for 1992 through 2000, no disaggregation to a finer thematic scale was necessary. The 2001 through 2006 NLCD change data were annualized to produce rates of change that served as annual demand for 2001 through 2005 for the FORE-SCE model.

\subsubsection{Projection Period}

The timeframe of 2006 through 2050 served as the projected LULC modeling period. The scenarios (chap. 2) served as input to the FORE-SCE spatial modeling framework, with FORE-SCE producing spatially explicit representations for each of the three SRES scenarios. Spatial resolution $(250 \mathrm{~m})$, temporal characteristics (annual LULC maps), and thematic resolution (table 1-1) were consistent with the baseline period, resulting in a consistent, continuous series of LULC maps between the baseline and projected periods (annual LULC maps from 1992 through 2050).

Regional LULC storylines were downscaled to formulate future alternative landscape scenarios (chap. 2). These scenarios provided quantitative prescriptions of future landscape composition that were used in conjunction with spatial modeling to create a suite of LULC maps from 2006 through 2050. The FORE-SCE model served as the primary modeling framework for ingesting scenario storylines and producing the spatially explicit LULC projections. As with the baseline LULC modeling, the demand component of the framework again supplied overall proportions of LULC change at a regional level, and the spatial allocation component ingested those proportions and produced spatially explicit LULC maps. Demand for the LULC projection period of 2006 through 2050 was supplied by the quantified scenarios described in chapter 2. For this assessment, a version of FORE-SCE was used that ingests and models specific LULC transitions; for example, each scenario provided a quantified matrix of LULC transitions for a given annual model run. FORE-SCE used the same suitability surfaces as in the baseline period to guide the placement of individual patches of landscape change.

The last year (2005) of the mapped and modeled baseline period served as the starting point for the LULC projections. 
The 2005 forest stand age layer from the baseline runs provided the starting stand age layer for the projected LULC model runs. The PAD-US data again were used to spatially partition portions of the landscape with a protected status, but for the projected period, the implementation of the PAD-US data was dependent upon scenario. More forms of protected lands in the PAD-US were protected from LULC change in the environmentally focused scenario B1 than in the economically focused scenarios A1B and A2, resulting in a potentially different spatial configuration of LULC change between scenarios even if the prescribed LULC proportions from the scenarios were the same. Parameterization of the FORE-SCE model was again conducted for each level III ecoregion, but for the projected period, parameterization differed across scenarios. For example, a dispersion variable was used to determine what proportion of the suitability surface histogram is open to LULC change. For a scenario such as A1B, urban development may be allowed to occur on a wider part of the suitability surface histogram, resulting in a more dispersed urban footprint that represents urban sprawl. Conversely, for an environmental scenario such as B1, assumptions of compact urban development led to a tightening of the dispersion variable, resulting in smaller, more compact urban footprints. Individual patch characteristics may also differ between scenarios, as dictated by the qualitative scenario storylines.

Modeling within the FORE-SCE framework was conducted with annual model iterations, by level III ecoregion, with patches of LULC change placed on the landscape until demand for a given annual run was met for that ecoregion. Processing then continued to each subsequent year until the 2006 through 2050 period was complete. The modeled LULC change for 2006 through 2050 thus provided plausible spatial representations for each of the three SRES scenarios. When combined with the mapped and modeled baseline LULC maps, the LULC mapping and modeling work described in this section resulted in a continuous, annual, consistent LULC map database from 1992 through 2050.

\subsection{Results and Discussion}

\subsubsection{Baseline LULC Mapping and Modeling}

To understand LULC change in the Eastern United States, it is often necessary to discuss changes in individual LULC classes nested within the ecosystems. The following discussion of results provides a summary of ecosystems defined for this assessment, as well as a discussion of nested LULC classes where appropriate. Ecosystem composition in the Eastern United States at the beginning of the baseline period was dominated by forests with 48.1 percent $\left(1,467,167 \mathrm{~km}^{2}\right)$ and agricultural lands with 31.9 percent $\left(972,486 \mathrm{~km}^{2}\right)$, combining for 80 percent $\left(2,439,652 \mathrm{~km}^{2}\right)$ of the region. Remaining ecosystems consisted of other lands with 9.5 percent $\left(290,470 \mathrm{~km}^{2}\right)$, wetlands with 8.9 percent $(272,486$ $\left.\mathrm{km}^{2}\right)$, and grasslands/shrublands with 1.6 percent $(50,168$ $\mathrm{km}^{2}$ ). Two LULC classes nested within the ecosystem categories warrant special attention for their effects on carbon and GHG dynamics and status as primary drivers of land change in the Eastern United States. The three mechanically disturbed classes are part of the forests ecosystem and represent 3.2 percent $\left(46,168 \mathrm{~km}^{2}\right)$ of the ecosystem and 1.5 percent of the total Eastern United States. Changes in forest ecosystem area affect all six nested LULC forest classes (deciduous, evergreen, and mixed forests and the three mechanically disturbed classes) to reflect total changes in forest area via conversions to other ecosystem classes (that is, developed or agricultural lands). LULC changes in the mechanically disturbed class reflect transitional changes within the forest lands ecosystem, indicating changing rates of forest harvest, but these changes do not affect overall ecosystem area. The developed class is nested within the other lands ecosystem, making up 41.1 percent $\left(119,413 \mathrm{~km}^{2}\right)$ of the class and 3.9 percent of the total region.

The LULC change footprint is defined as the percentage of the Eastern United States or an ecoregion that changed LULC type at least once during the time period (Sleeter and others, 2012a,b; Wilson and others, 2012). During the baseline period, approximately 8 percent $\left(244,331 \mathrm{~km}^{2}\right)$ of the Eastern United States changed at least once (fig. 3-2; table 3-1). The developed, other lands, and mechanically disturbed classes contributed the most to the footprint of LULC change of the Eastern United States through unidirectional conversions to urban lands and the cyclical nature of forest harvest and subsequent regeneration.

Developed land led all LULC classes in net change with an increase of 19.4 percent $\left(23,186 \mathrm{~km}^{2}\right)$ in urban area (fig. 3-3; table 3-2). LULC change in the other lands ecosystem class showed a change of 8.9 percent, with most of the categories within the class showing little change, aside from mining, which saw a net increase of 29.5 percent $\left(1,355 \mathrm{~km}^{2}\right)$. Water area increased by only 0.8 percent $\left(1,381 \mathrm{~km}^{2}\right)$, and changes in the barren and ice/snow categories were relatively minor.

LULC change in the forests ecosystem (including deciduous, evergreen, and mixed forest cover types and mechanically disturbed LULC classes) appeared relatively stable during the baseline period, decreasing by only 0.4 percent $\left(5,700 \mathrm{~km}^{2}\right)$. Within the forests ecosystem, LULC in the three mechanically disturbed classes experienced a total net increase of 8.3 percent $\left(9,525 \mathrm{~km}^{2}\right.$; table 3-2) with most of the gains occurring on private lands (11.4 percent, 4,760 $\mathrm{km}^{2}$ ). More than 90 percent of all forest cutting in the Eastern United States was on private lands with that trend continuing throughout the baseline period (fig. 3-4). Gains in area by the mechanical disturbance classes reflect decreases in area of the forested LULC classes, indicating an increase in the rate of forest clearcutting. A variety of factors contributed to more intensive forest clearcutting in the Eastern United States during the baseline period. In the southern half of the region, the shift towards increased private industrial forest management of 


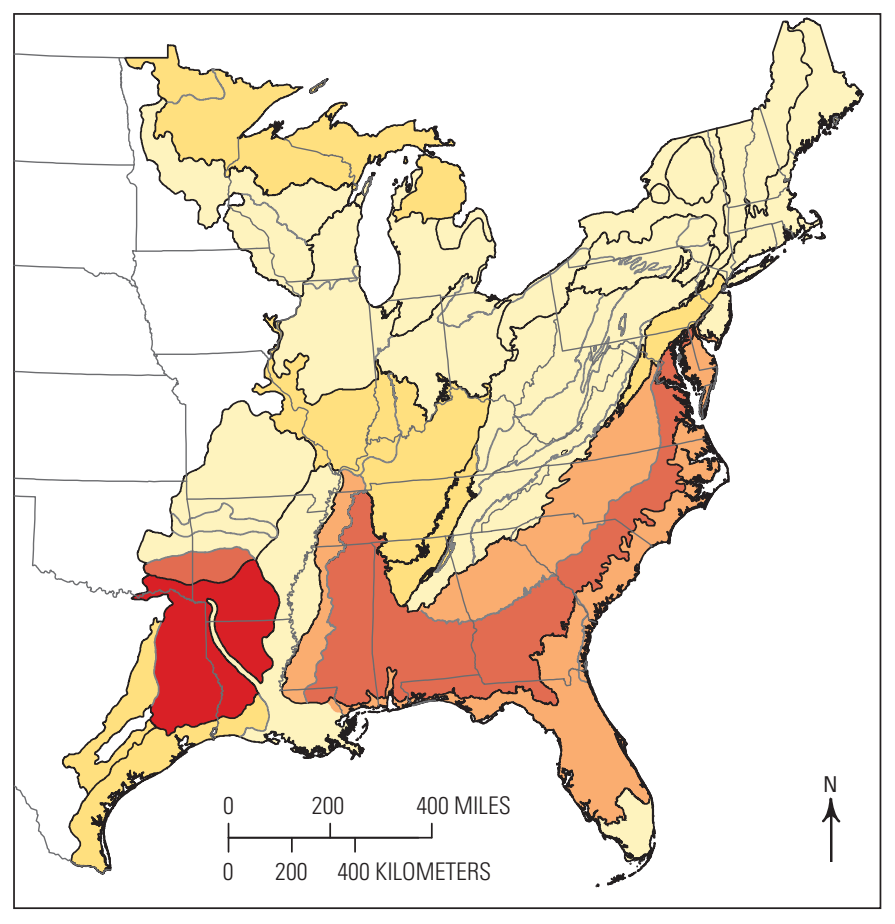

EXPLANATION

Spatial variability of land-use and land-cover change in the Eastern United States, by level III ecoregion, in percent

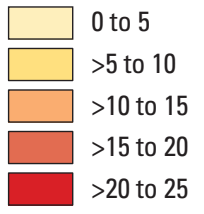

Ecoregion boundary

- Level II — Level III

Figure 3-2. Map showing spatial variability of land-use and land-cover change in the Eastern United States. intensely cultivated pine monocultures was already occurring, and the trend continued throughout the baseline period (Binford and others, 2006). On a managed pine plantation, harvest cycles for timber products can be as short as 20 to 25 years, enabling multiple harvests in the same amount of time it takes to make a single cutting in more temperate forests. Production in the Southeastern United States also increased due to timber harvest decreases in the Pacific Northwest (Haynes, 2003; Drummond and Loveland, 2010).

LULC change in the agricultural lands ecosystem class decreased by more than 2.1 percent $\left(20,471 \mathrm{~km}^{2}\right)$ during the baseline period. Modern losses in agricultural lands have been well documented by contemporary studies of LULC change in the Eastern United States (Brown and others, 2005; Drummond and Loveland, 2010). Decreasing profitability associated with farming marginal land led to losses of nearly 2 percent each in cropland $\left(10,773 \mathrm{~km}^{2}\right)$ and hay/pasture $\left(9,698 \mathrm{~km}^{2}\right)$ to forest lands through abandonment, conversion to managed timber production, or government conservation programs, such as the Conservation Reserve Program (CRP).

LULC change in the grasslands/shrublands ecosystem increased by 2.3 percent $\left(1,138 \mathrm{~km}^{2}\right)$ during the baseline period, mostly due to enrollment of agricultural lands into the CRP in western parts of the region, such as the East Central Texas Plains level III ecoregion, where agricultural lands conversion was more suited to native and managed grasses. The wetlands ecosystem class encompassed 8.9 percent $\left(272,422 \mathrm{~km}^{2}\right)$ of the Eastern United States and remained fairly static during the baseline period, with wetland losses of 0.4 percent $\left(959 \mathrm{~km}^{2}\right)$.

The LULC footprint closely reflected the spatial variability of the two major types of land change, developed and forest clearcutting, with each class displaying vastly different spatial patterns from the other. Several level III ecoregions

Table 3-1. Land-use and land-cover change footprint in the Eastern United States from 1992 through 2005.

$\left[\mathrm{km}^{2}\right.$, square kilometers]

\begin{tabular}{lcc}
\hline \multicolumn{1}{c}{ Ecoregion } & Area, in $\mathbf{~ k m}^{\mathbf{2}}$ & Percentage change \\
\hline Mixed Wood Shield & 215,648 & 7.6 \\
Atlantic Highlands & 187,551 & 2.3 \\
Mixed Wood Plains & 388,858 & 2.9 \\
Central USA Plains & 239,027 & 2.6 \\
Southeastern USA Plains & 994,355 & 14.2 \\
Ozark, Ouachita-Appalachian Forests & 520,486 & 4.2 \\
Mississippi Alluvial and Southeast USA Coastal $\quad$ Plains & & 8.4 \\
Eastern United States (total) & 506,807 & 8.0 \\
\hline
\end{tabular}

${ }^{1}$ Includes the Everglades and Texas-Louisiana Coastal Plain level II ecoregions for the analysis of this assessment. 
with large amounts of forest clearcutting and developed lands had LULC change footprints of 40 percent or more (fig. 3-5). A brief examination of the basic characteristics of the seven level II ecoregions and major driving forces of LULC change in the ecoregions is provided in chapter 2.

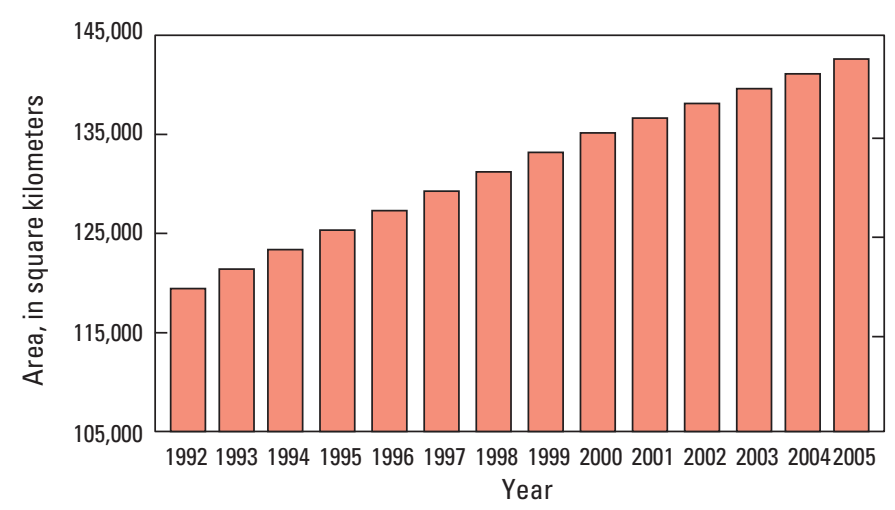

Figure 3-3. Chart showing the increasing trend in the areal extent of the developed land-use and land-cover class in the Eastern United States between 1992 and 2005.

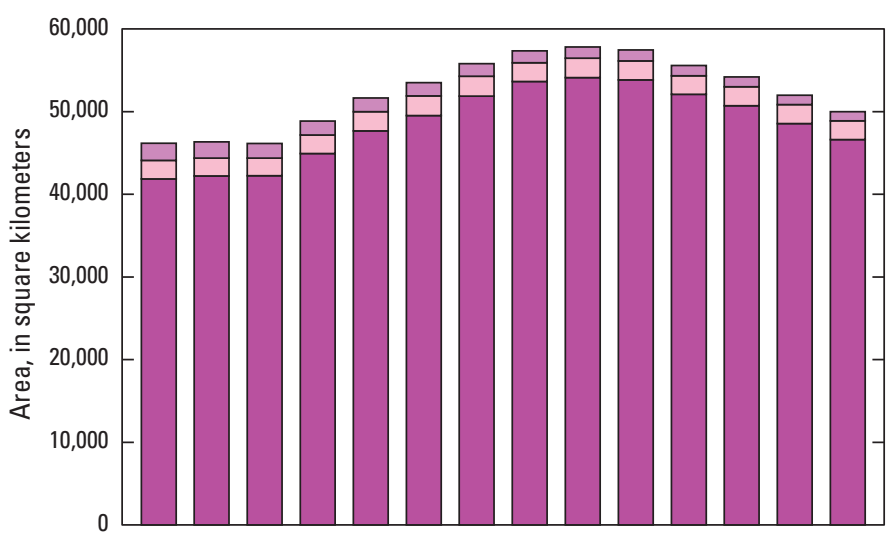

19921993199419951996199719981999200020012002200320042005 Year

EXPLANATION

Mechanically disturbed land

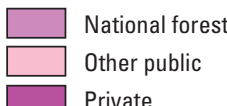

Private

Figure 3-4. Chart showing the increasing trend of forest clearcutting in the Eastern United States between 1992 and 2005. Private lands make up the largest share of timber harvest and also saw the greatest gains. The greatest declines were noted on national forest lands.

Table 3-2. Mapped and modeled land use and land cover in the Eastern United States from 1992 through 2005.

$\left[\mathrm{km}^{2}\right.$, square kilometers $]$

\begin{tabular}{lrrrr}
\hline \multirow{2}{*}{ Ecosystem class } & \multicolumn{2}{c}{ Area, in $\mathbf{~ k m}^{\mathbf{2}}$} & \multicolumn{2}{c}{ Change between $\mathbf{1 9 9 2}$ and 2005 } \\
\cline { 2 - 5 } & \multicolumn{1}{c}{$\mathbf{1 9 9 2}$} & $\mathbf{2 0 0 5}$ & Area, in km $\mathbf{~}^{2}$ & Percentage \\
\hline Forests & $1,467,167$ & $1,461,467$ & 5,700 & -0.4 \\
Agricultural lands & 972,486 & 952,014 & $-20,471$ & -2.1 \\
Other lands & 290,470 & 316,463 & 25,993 & 8.9 \\
Wetlands & 272,442 & 271,483 & -959 & -0.4 \\
Developed & 119,413 & 142,598 & 23,186 & 19.4 \\
Grasslands/shrublands & 50,168 & 51,306 & 1,138 & 2.3 \\
Mechanically disturbed & 46,168 & 49,993 & 3,825 & 8.3 \\
\hline
\end{tabular}



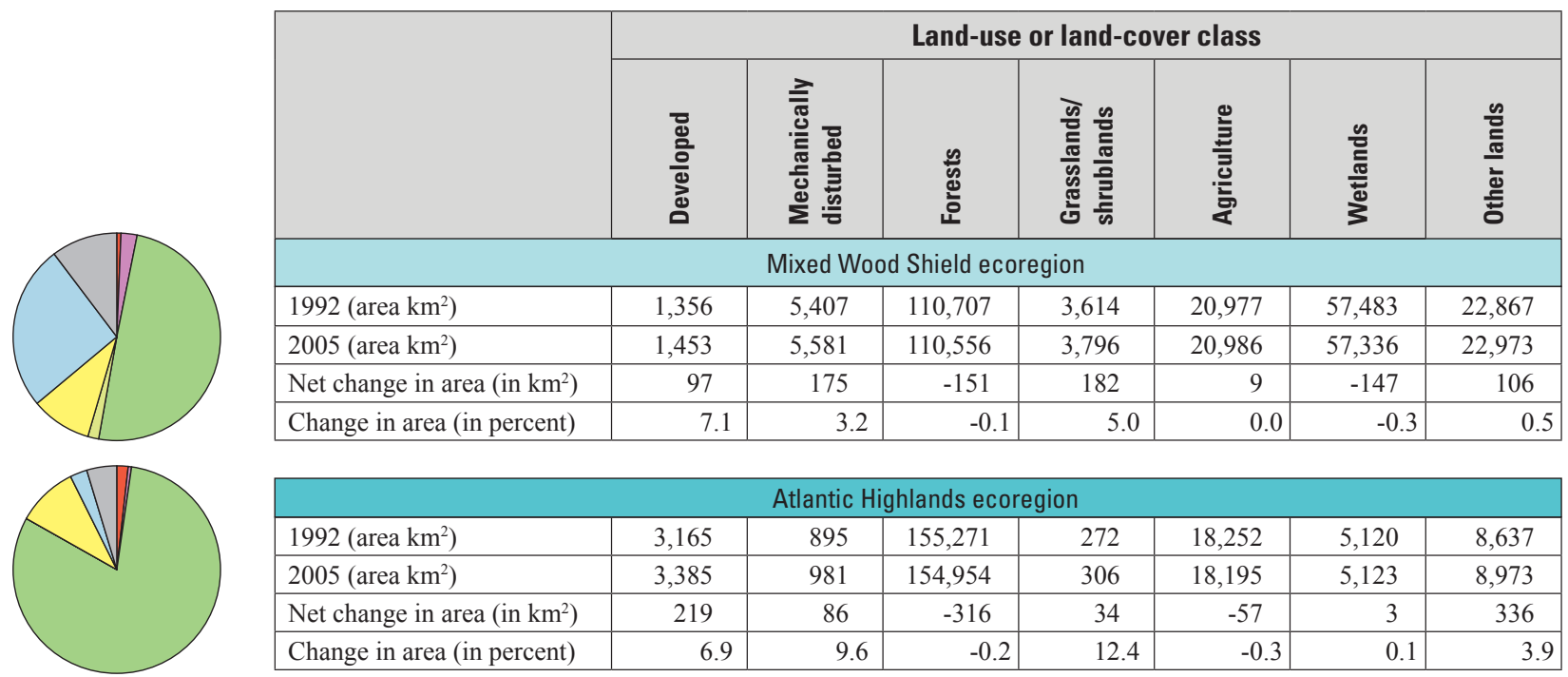

\begin{tabular}{|l|r|r|r|r|r|r|r|}
\hline \multicolumn{7}{|c|}{ Atlantic Highlands ecoregion } \\
\hline $1992\left(\right.$ area $\left.\mathrm{km}^{2}\right)$ & 3,165 & 895 & 155,271 & 272 & 18,252 & 5,120 & 8,637 \\
\hline $2005\left(\right.$ area $\left.\mathrm{km}^{2}\right)$ & 3,385 & 981 & 154,954 & 306 & 18,195 & 5,123 & 8,973 \\
\hline Net change in area (in km$\left.{ }^{2}\right)$ & 219 & 86 & -316 & 34 & -57 & 3 & 336 \\
\hline Change in area (in percent) & 6.9 & 9.6 & -0.2 & 12.4 & -0.3 & 0.1 & 3.9 \\
\hline
\end{tabular}

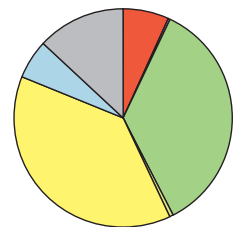

\begin{tabular}{|l|c|c|c|r|r|r|c|}
\hline \multicolumn{7}{|c|}{ Mixed Wood Plains ecoregion } \\
\hline $1992\left(\mathrm{area}_{\mathrm{km}}^{2}\right)$ & 24,380 & 1,380 & 149,476 & 2,023 & 162,651 & 24,257 & 50,452 \\
\hline $2005\left(\right.$ area $\left.\mathrm{km}^{2}\right)$ & 28,401 & 1,185 & 147,983 & 2,247 & 159,757 & 24,231 & 54,639 \\
\hline Net change in area (in $\left.\mathrm{km}^{2}\right)$ & 4,021 & -195 & $-1,493$ & 224 & $-2,893$ & -26 & 4,188 \\
\hline Change in area (in percent) & 16.5 & -14.1 & -1.0 & 11.1 & -1.8 & -0.1 & 8.3 \\
\hline
\end{tabular}

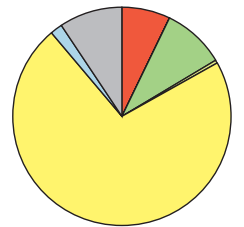

\begin{tabular}{|l|r|r|r|r|r|r|c|}
\hline \multicolumn{7}{|c|}{ Central USA Plains ecoregion } \\
\hline $1992\left(\right.$ area $\left.\mathrm{km}^{2}\right)$ & 14,296 & 62 & 24,219 & 1,001 & 189,424 & 4,678 & 19,706 \\
\hline $2005\left(\right.$ area $\left.\mathrm{km}^{2}\right)$ & 18,427 & 61 & 23,787 & 1,175 & 185,336 & 4,675 & 24,055 \\
\hline Net change in area (in km$\left.)^{2}\right)$ & 4,131 & -1 & -432 & 174 & $-4,089$ & -3 & 4,349 \\
\hline Change in area (in percent) & 28.9 & -1.4 & -1.8 & 17.4 & -2.2 & -0.1 & 22.1 \\
\hline
\end{tabular}

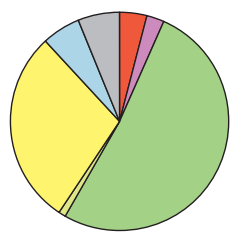

\begin{tabular}{|l|r|r|r|r|r|r|r|}
\hline \multicolumn{7}{|c|}{ Southeastern USA Plains ecoregion } \\
\hline $1992\left(\right.$ area $\left.\mathrm{km}^{2}\right)$ & 34,573 & 26,819 & 550,271 & 10,999 & 316,505 & 60,373 & 56,207 \\
\hline $2005\left(\right.$ area $\left.\mathrm{km}^{2}\right)$ & 42,990 & 27,757 & 550,030 & 11,262 & 306,678 & 60,763 & 65,623 \\
\hline Net change in area (in km $\left.{ }^{2}\right)$ & 8,418 & 939 & -241 & 263 & $-9,828$ & 390 & 9,416 \\
\hline Change in area (in percent) & 24.3 & 3.5 & -0.0 & 2.4 & -3.1 & 0.6 & 16.8 \\
\hline
\end{tabular}

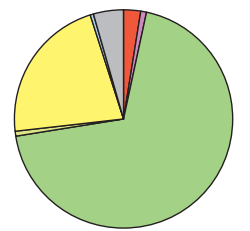

\begin{tabular}{|l|c|c|c|c|c|r|c|}
\hline \multicolumn{7}{|c|}{ Ozark, Ouachita-Appalachian Forests ecoregion } \\
\hline $1992\left(\right.$ area $\left.\mathrm{km}^{2}\right)$ & 11,605 & 3,352 & 374,361 & 3,550 & 118,434 & 2,571 & 21,570 \\
\hline $2005\left(\right.$ area $\left.\mathrm{km}^{2}\right)$ & 13,611 & 4,569 & 372,212 & 3,903 & 117,760 & 2,592 & 24,020 \\
\hline Net change in area (in km $\left.{ }^{2}\right)$ & 2,007 & 1,217 & $-2,149$ & 353 & -674 & 21 & 2,450 \\
\hline Change in area (in percent) & 17.3 & 36.3 & -0.6 & 9.9 & -0.6 & 0.8 & 11.4 \\
\hline
\end{tabular}

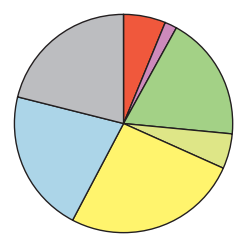

\begin{tabular}{|l|c|r|r|r|r|r|c|}
\hline \multicolumn{7}{|c|}{ Mississippi Alluvial and Southeast USA Coastal Plains ecoregion } \\
\hline $1992\left(\mathrm{area}_{\mathrm{km}}^{2}\right)$ & 30,037 & 8,253 & 102,863 & 28,709 & 146,244 & 117,960 & 111,032 \\
\hline $2005\left(\right.$ area $\left.\mathrm{km}^{2}\right)$ & 34,331 & 9,858 & 101,945 & 28,618 & 143,304 & 116,763 & 116,179 \\
\hline Net change in area $\left(\right.$ in $\left.\mathrm{km}^{2}\right)$ & 4,293 & 1,604 & -918 & -92 & $-2,940$ & $-1,198$ & 5,147 \\
\hline Change in area (in percent) & 14.3 & 19.4 & -0.9 & -0.3 & -2.0 & -1.0 & 4.6 \\
\hline
\end{tabular}

\section{EXPLANATION}

[Pie charts represent data for 2005]

\section{Land-use and land-cover class}

\begin{tabular}{|c|c|c|}
\hline \multicolumn{3}{|c|}{ Land-use and land-cover class } \\
\hline Developed & Forests & Agriculture \\
\hline $\begin{array}{l}\text { Mechanically } \\
\text { disturbed }\end{array}$ & $\begin{array}{c}\text { Grasslands/ } \\
\text { shrublands }\end{array}$ & $\begin{array}{l}\text { Wetlands } \\
\text { Other }\end{array}$ \\
\hline
\end{tabular}

Figure 3-5. Charts showing the proportions of land-use and land-cover (LULC) by level II ecoregion at the end of the baseline period (pie charts for 2005) and the net change in the mapped and modeled LULC classes between 1992 and 2005. 


\subsubsection{Projected LULC Mapping and Modeling}

The projected changes in LULC were variable across scenarios and ecoregions of the Eastern United States. Under the scenarios used for this assessment, the projected LULC change footprint ranged from a low of 17.2 percent in scenario B1 to the highs of 22.9 percent in scenario A1B and 20.8 percent in scenario A2 (fig. 3-6; table 3-3). The scenarios that indicated the greatest (A1B) and smallest (B1) amounts of projected LULC change shared the same population assumptions; however, the focus on economic growth in scenario A1B resulted in higher demand for forest products, urban growth, and agricultural intensification contributing to greater overall amounts of LULC change than in scenario B1. Scenario B1 was characterized by strengthening environmental protections and more resourcefriendly lifestyles, which limited anthropogenic conversion of natural land covers to urban or agricultural lands LULC. The demand for forest products and agricultural commodities was reduced in scenario $\mathrm{B} 1$ compared with scenario $\mathrm{A} 1 \mathrm{~B}$, and the environmental emphasis associated with scenario B1 resulted in a more compact pattern of urbanization than in scenario A1B. Similar to scenario A1B, scenario A2 focused on economic growth. However, with a regional focus on growth as opposed to globalization that characterized scenario A1B, economic growth was muted in comparison to scenario A1B, resulting in more moderate amounts of forest cutting, agricultural expansion, and urban growth by 2050 . The LULC change footprints for all scenarios in the Southeastern USA Plains ecoregion were near or greater than 30 percent, whereas the LULC change footprints for all scenarios in the Central USA Plains ecoregion were less than 10 percent (fig. 3-5).

Spatial patterns of developed growth varied within the Eastern United States as well. Generally, urban growth occurred where high-population cities already existed. High growth in the developed LULC class occurred in the Southeastern USA Plains ecoregion, which contained 30 percent $\left(42,990 \mathrm{~km}^{2}\right)$ of all developed lands in the Eastern United States, and increased by 66 percent in scenario B1 to 92.9 percent $\left(39,946 \mathrm{~km}^{2}\right)$ in scenario A1B. Urban growth in the ecoregion centered on the large metropolitan centers of Atlanta, Georgia; Washington, D.C.; and New York City, New York. In contrast, the Mixed Wood Shield ecoregion ranked near the bottom in developed growth with a 24.9 percent $\left(361 \mathrm{~km}^{2}\right)$ increase in scenario B1 to a high of 49.4 percent $\left(717 \mathrm{~km}^{2}\right)$ in scenario A1B. The Mixed Wood Shield ecoregion contained only 1 percent $\left(1,453 \mathrm{~km}^{2}\right)$ of all developed lands in the Eastern United States clustered in small cities, such as Duluth, Minnesota, and Marquette, Michigan.

Changes in the extent of agricultural lands occurred mostly in regions with a mixture of agricultural lands and forest ecosystems, such as the Southeastern USA Plains ecoregion, which was an area that had the highest LULC change footprint in the Eastern United States at nearly one-third of the ecoregion in all three scenarios and a fairly balanced distribution of agricultural lands (30.8 percent, $\left.306,678 \mathrm{~km}^{2}\right)$ and forests $\left(55.3\right.$ percent, $\left.550,030 \mathrm{~km}^{2}\right)$ at the start of the projection period. In scenario A1B, which had the highest LULC change footprint of all scenarios, 88.1 percent of the agricultural lands class in 2006 remained stable in 2050. In scenario A1B, the Southeastern USA Plains ecoregion had a relatively low degree of agricultural stability compared with ecoregions where forests or agricultural lands dominate the landscape.

The Central USA Plains ecoregion predominantly comprises agricultural lands (79.3 percent, $185,336 \mathrm{~km}^{2}$ ) with a small amount of lands as forests (10 percent, 23,787); the ecoregion had the lowest LULC change footprint (less than 10 percent) across all scenarios. The ecoregion is part of the highly fertile Corn Belt, a productive agricultural region with little new land available for conversion to agricultural lands. Other ecoregions with less fertile soils would be more likely to lose agricultural lands before this core area of the Corn Belt. As a result, the 98.7 percent of the agricultural lands class in 2006 remained unchanged in 2050 in scenario A1B. In heavily forested ecoregions, such as the Atlantic Highlands ecoregion, which had more forests ( 82.6 percent, $\left.154,954 \mathrm{~km}^{2}\right)$ than agricultural lands (9.7 percent, 18,195 km²) at the start of the projection period, increases in agricultural lands were restricted by poor soils, terrain, and climate. The relatively small amounts of agricultural lands LULC at the start of the projection period made large-scale decreases in the

Table 3-3. Projected land-use and land-cover change footprint in the Eastern United States.

[IPCC, Intergovernmental Panel on Climate Change; $\mathrm{km}^{2}$, square kilometers; SRES, Special Report on Emission Scenarios (Nakićenović and others, 2000). $\mathrm{km}^{2}$, square kilometers]

\begin{tabular}{|c|c|c|c|c|}
\hline \multirow[t]{2}{*}{ Ecoregion } & \multirow{2}{*}{$\begin{array}{l}\text { Area, } \\
\text { in } \mathbf{k m}^{2}\end{array}$} & \multicolumn{3}{|c|}{$\begin{array}{l}\text { IPCC SRES scenario, } \\
\text { percentage change }\end{array}$} \\
\hline & & A1B & A2 & B1 \\
\hline Mixed Wood Shield & 215,648 & 29.9 & 27.6 & 13.3 \\
\hline Atlantic Highlands & 187,551 & 22.9 & 22.1 & 14.2 \\
\hline Mixed Wood Plains & 388,858 & 13.1 & 13.9 & 7.3 \\
\hline Central USA Plains & 239,027 & 9.3 & 7.5 & 4.6 \\
\hline Southeastern USA Plains & 994,355 & 33.2 & 29.5 & 30.6 \\
\hline $\begin{array}{l}\text { Ozark, Ouachita-Appalachian } \\
\text { Forests }\end{array}$ & 520,486 & 20.5 & 19.7 & 10.6 \\
\hline $\begin{array}{l}\text { Mississippi Alluvial and Southeast } \\
\text { USA Coastal Plains }{ }^{1}\end{array}$ & 506,807 & 16.1 & 13.1 & 13.9 \\
\hline Eastern United States (total) & $3,052,732$ & 22.9 & 20.8 & 17.2 \\
\hline
\end{tabular}

${ }^{1}$ Includes the Everglades and Texas-Louisiana Coastal Plain level II ecoregions for the analysis of this assessment. 


\section{A. Scenario A1B}

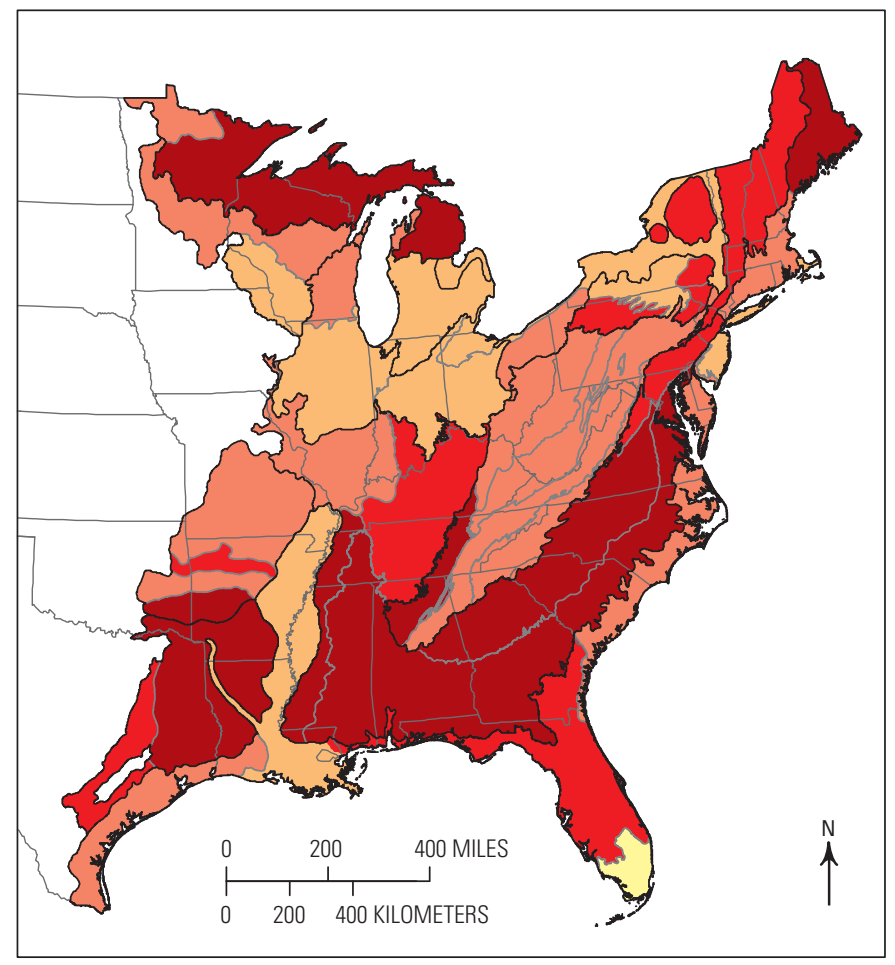

\section{B. Scenario A2}

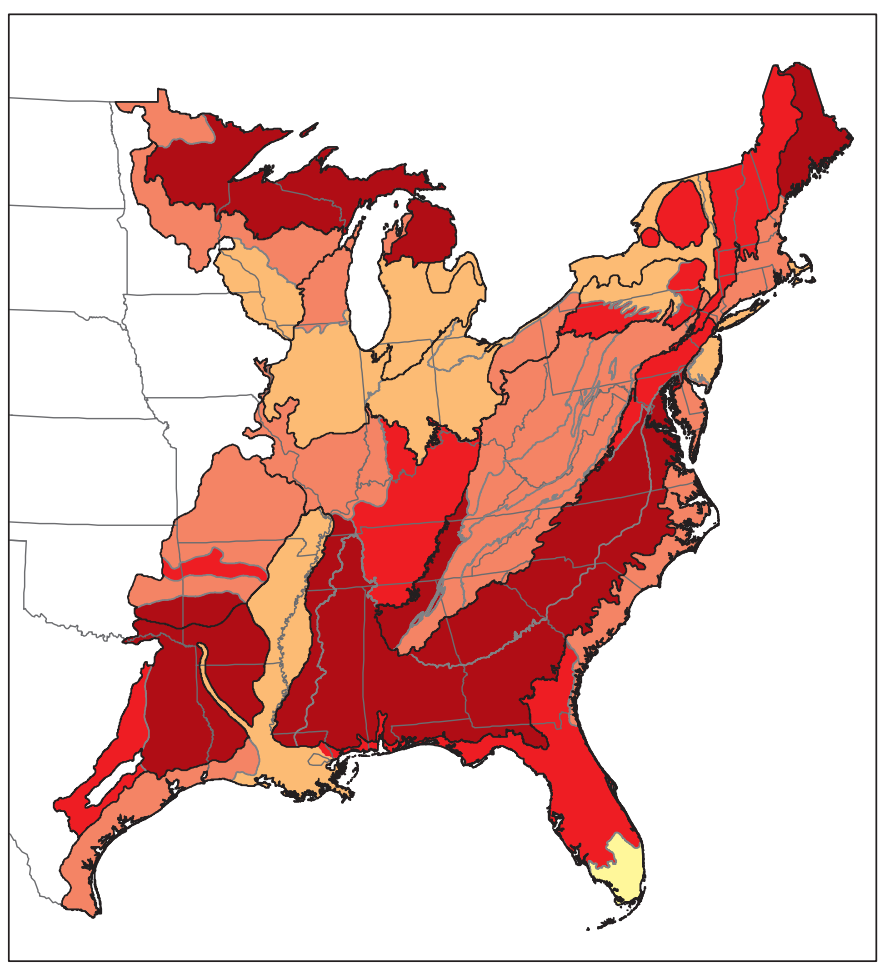

\section{Scenario B1}

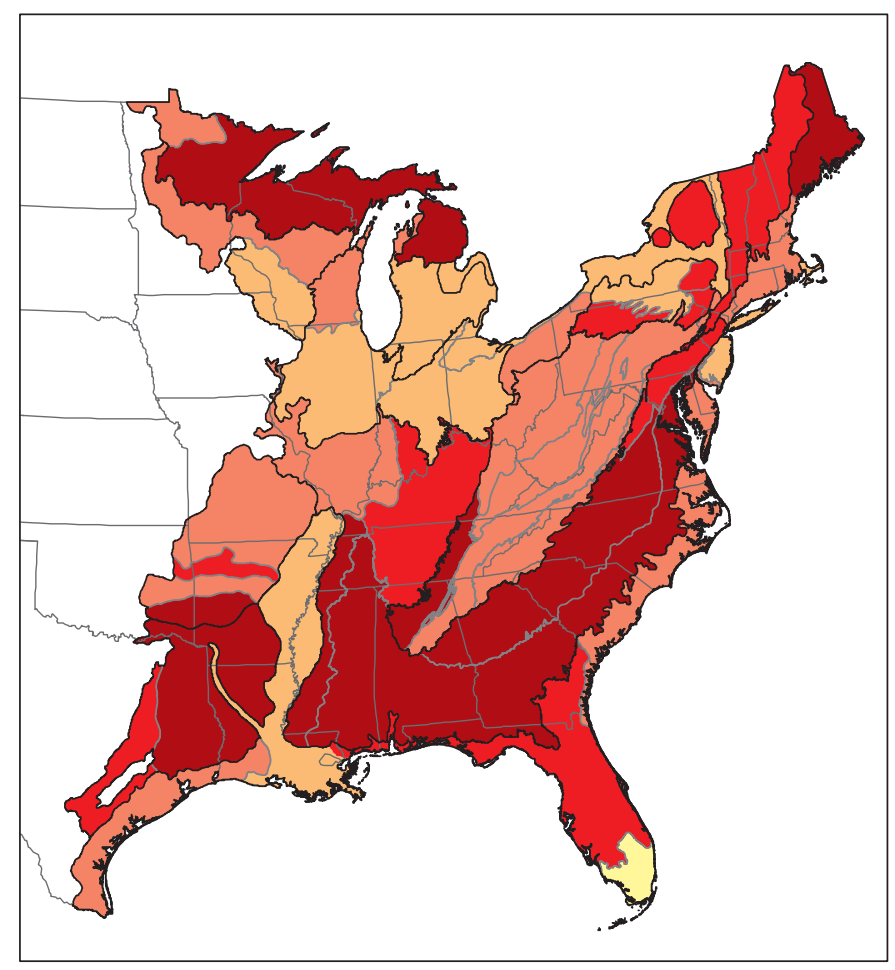

\section{EXPLANATION}

Percentage of ecoregion area projected to experience land-use or land-cover change at least once between 2005 and 2050

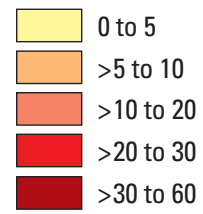

Ecoregion boundary

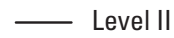

Level III

Figure 3-6. Maps showing the projected land-use and land-cover change footprint for the level II and III ecoregions of the Eastern United States. The footprint represents the percentage of the ecoregion that changed at least once between 2005 and 2050. $A$, Scenario A1B; $B$, scenario $\mathrm{A} 2 ; C$, scenario $B 1$. 
agricultural lands class unlikely as well. These factors contributed to the 91 percent of agricultural lands in 2006 remaining unchanged by 2050 in scenario A1B.

Aside from conversions to developed lands, change in the forests class was generally linked to change in agricultural lands, so that increases in agricultural lands LULC classes from forested LULC classes were more than 85 percent in scenario A1B and more than 90 percent in scenario A2, leading to net decreases of the forests ecosystem class in both scenarios. Forest LULC generally increased across the Eastern United States in the more environmentally oriented scenario $\mathrm{B} 1$ as demand for agricultural goods decreased and focus shifted to restoration of natural land cover types.

Forest clearcutting was the single largest LULC change in the Eastern United States during the projected period, contributing extensively to the region's overall LULC change. Projected forest harvest (the sum of the areas between 2006 and 2050 that experienced clearcut logging) exceeded net increases in developed lands by a wide margin across scenarios (fig. 3-7). Developed LULC change affected a smaller area of the Eastern United States and was concentrated near existing cities; however, this LULC class is unidirectional and more permanent than forest clearcutting. Forest harvest and regrowth is more cyclical developed change because the same forest parcel can be harvested multiple times during the projection period and harvest widely occurs throughout the region. Forest clearcutting rates and trajectories varied across scenarios during the projection period (fig. 3-8).

Forest use assumptions associated with scenario A1B led to a rapid increase in timber harvest early in the projection period and remained the highest cutting scenario overall, with forest harvest increasing by 541.9 percent $\left(5,315 \mathrm{~km}^{2}\right)$ in the Atlantic Highlands ecoregion and 162.2 percent $\left(7,410 \mathrm{~km}^{2}\right)$ in the Ozark, Ouachita-Appalachian Forests ecoregion. Forest cutting increased at a less steep rate in scenario A2 than in scenario A1B, but narrowed the gap in area of forest lands harvested toward the end of the projected period to end just slightly lower than scenario A1B. Overall forest cover decreased in scenarios A1B and A2, whereas forest clearcutting increased. Forest cutting increased slightly early in scenario B1, but the overall rate of harvesting decreased by 6.9 percent $\left(3,430 \mathrm{~km}^{2}\right)$ to end up lower than at the beginning of the projection period. Forest cutting continued a diverse regional pattern in scenario B1 with cutting rates increasing by 204.5 percent $\left(2,006 \mathrm{~km}^{2}\right)$ in the Atlantic Highlands ecoregion but decreasing in other ecoregions by as much as 53.8 percent $\left(5,305 \mathrm{~km}^{2}\right)$ in the Mississippi Alluvial and Southeast USA Coastal Plains ecoregion. Details of the projected results for the seven ecoregions are presented in the next section.

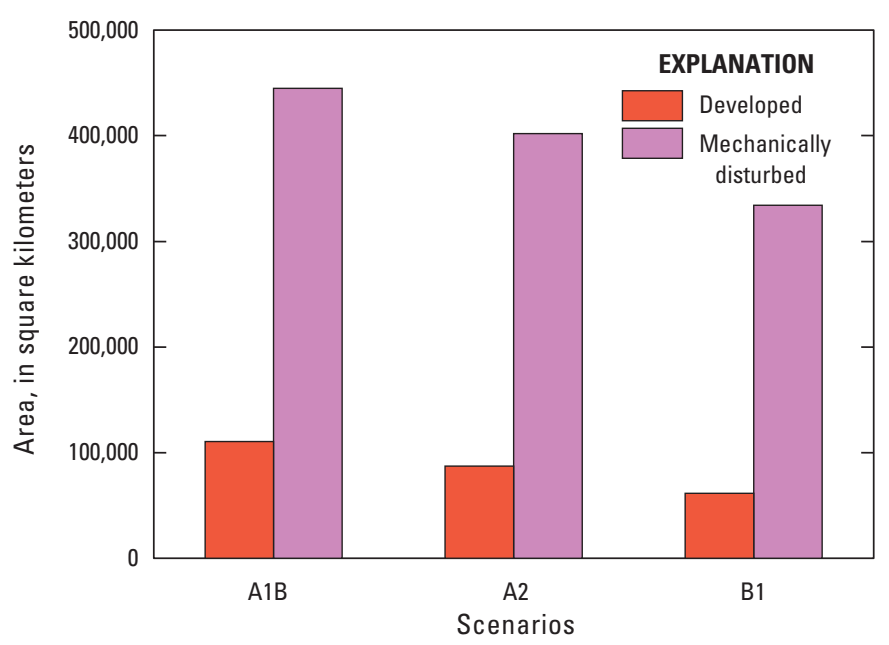

Figure 3-7. Graph showing comparison between mechanically disturbed and developed land use classes in the Eastern United States for three land-use and land-cover scenarios (Nakićenović and others, 2000).

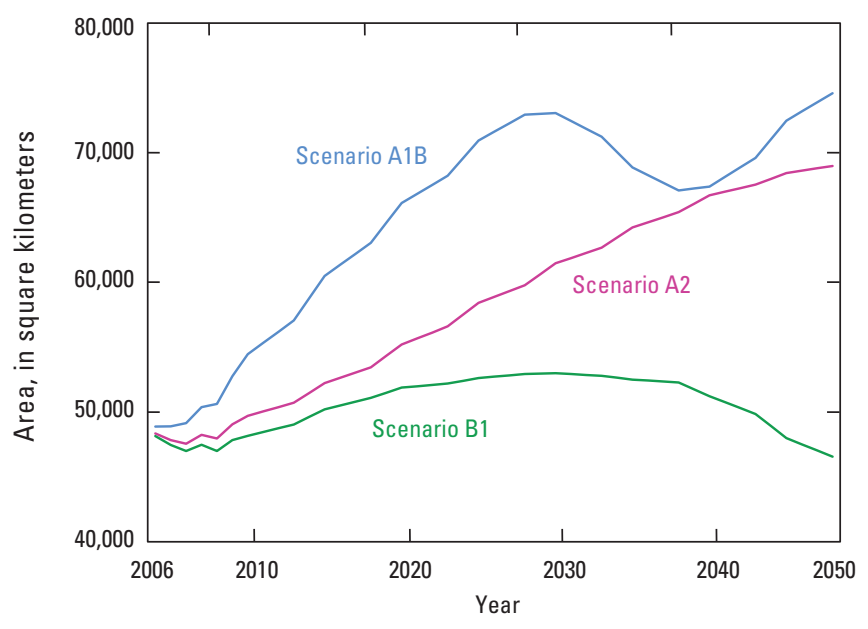

Figure 3-8. Graph showing trends for mechanically disturbed land use in the Eastern United States for the projected period (2006 through 2050). 


\subsubsection{Projections of Land Use and Land Cover Patterns in the Eastern United States From 2006 Through 2050}

\subsubsection{Mixed Wood Shield}

During the projected period (2006-2050) for the assessment of carbon fluxes and storage in the Eastern United States, the footprint of LULC change in the Mixed Wood Shield ecoregion for each scenario was relatively high compared with that in other ecoregions in the Eastern United States. Scenario A1B had the greatest amount change, with 29.9 percent of the land area changing at least once (table 3-3). Scenario A2 had the second highest amount of change (27.6 percent), whereas scenario B1 had the lowest amount (13.3 percent). There was little to no spatial variability in the amount of LULC change between level III ecoregions depending upon the presence and (or) amount of forest clearcutting.

The Northern Minnesota Wetlands level III ecoregion consists of a mix of LULC types with little forest harvest. In the highest changing scenario, $\mathrm{A} 1 \mathrm{~B}$, only 10.8 percent $\left(2,590 \mathrm{~km}^{2}\right)$ of LULC changed, whereas in scenarios A2 and B1, only 9.8 percent $\left(2,359 \mathrm{~km}^{2}\right)$ and 6.2 percent $\left(1,486 \mathrm{~km}^{2}\right)$, respectively, of LULC changed.

In the more forested Northern Lakes and Forest ecoregion, LULC change was much higher than in other level III ecoregions in the Eastern United States due to forest harvest, with change in scenarios A1B, A2, and B1 amounting to 32.4 percent $(61,984$ $\left.\mathrm{km}^{2}\right), 29.8$ percent $\left(57,145 \mathrm{~km}^{2}\right)$, and 14.2 percent $(27,100$ $\mathrm{km}^{2}$ ), respectively. In the economically focused scenarios A1B and $A 2$, change was driven primarily by the increase in forest use (represented by increased rates of clearcutting) and by the expansion of developed and agricultural lands within the ecoregion. The extent of forest clearcutting in scenario A1B increased by 78.3 percent $\left(4,371 \mathrm{~km}^{2}\right)$ between 2006 and 2050 even though the forests ecosystem (forest and mechanically disturbed LULC classes) was reduced by 5.8 percent $(6,371$ $\left.\mathrm{km}^{2}\right)$. Scenario A2 had an increase of 64.5 percent $\left(3,602 \mathrm{~km}^{2}\right)$ in the extent of forest clearcutting, while also losing 5.8 percent $\left(6,411 \mathrm{~km}^{2}\right)$ of the total forest ecosystem area.The economically focused scenarios saw increases in the extents of developed and agricultural lands. The extent of developed lands in scenario A1B increased by 49.4 percent $\left(717 \mathrm{~km}^{2}\right)$, whereas in scenario $\mathrm{A} 2$, the extent of developed lands increased by 44.4 percent $\left(646 \mathrm{~km}^{2}\right)$. The decrease in the extent of the forests ecosystem contributed the most to increases in the extent of developed lands. In scenario A1B, 85.6 percent $\left(597 \mathrm{~km}^{2}\right)$ of the gains in the extent of developed lands came from forests, whereas in scenario A2, 79.4 percent $\left(553 \mathrm{~km}^{2}\right)$ of the gains came from forests. The story was the same for agricultural lands as well. The economic scenarios $\mathrm{A} 1 \mathrm{~B}$ and $\mathrm{A} 2$ experienced increases in the extent of agricultural lands, undergoing increases of 21.5 percent $\left(4,508 \mathrm{~km}^{2}\right)$ and 21.1 percent $\left(4,435 \mathrm{~km}^{2}\right)$, respectively, in extent. Gains in the extent of agricultural lands from forests totaled 89 percent $\left(4,011 \mathrm{~km}^{2}\right)$ in scenario A1B and 91.7 percent in scenario A2.

LULC change in scenario B1 varied from the changes experienced in the economic scenarios, with the extent of the forested ecosystem decreasing slightly (1.9 percent; $\left.2,106 \mathrm{~km}^{2}\right)$ and the extent of forest clearcutting reduced by 48.1 percent $\left(2,682 \mathrm{~km}^{2}\right)$. In this environmentally conscious scenario, the extent of developed lands increased by 24.9 percent $\left(361 \mathrm{~km}^{2}\right)$, a much lower extent than in the economically focused scenarios, and the extent of agricultural lands saw a minor decrease of about 1 percent. Increases in the extent of developed lands in this scenario came primarily from forests (79.4 percent, $287 \mathrm{~km}^{2}$ ) and, to a lesser extent, from agricultural lands.

An example of typical LULC change in the Mixed Wood Shield ecoregion is the area around Duluth, Minnesota, and Superior, Wisconsin (fig. 3-9). Encroachment into forested areas by developed lands around these cities can be seen in all scenarios. Agricultural expansion, due to the growing population and the market demand for agricultural commodities around Duluth and Superior can be seen in all scenarios, although to a lesser extent in scenario B1. Differences in the forest characteristics of the economically driven scenarios versus the environmentally oriented scenario are stark and driven by scenario assumptions. In scenarios A1B and A2, where high pressure is placed on forest resources, clearcutting can be seen throughout the entire area. In contrast, the extent of forest clearcutting in scenario B1 is much less dramatic. Although clearcutting in scenario B1 possesses a similar geographic distribution as in the economic scenarios, the large concentrations of clearcut areas are absent, and the extent of forest gains are higher, albeit scattered. 

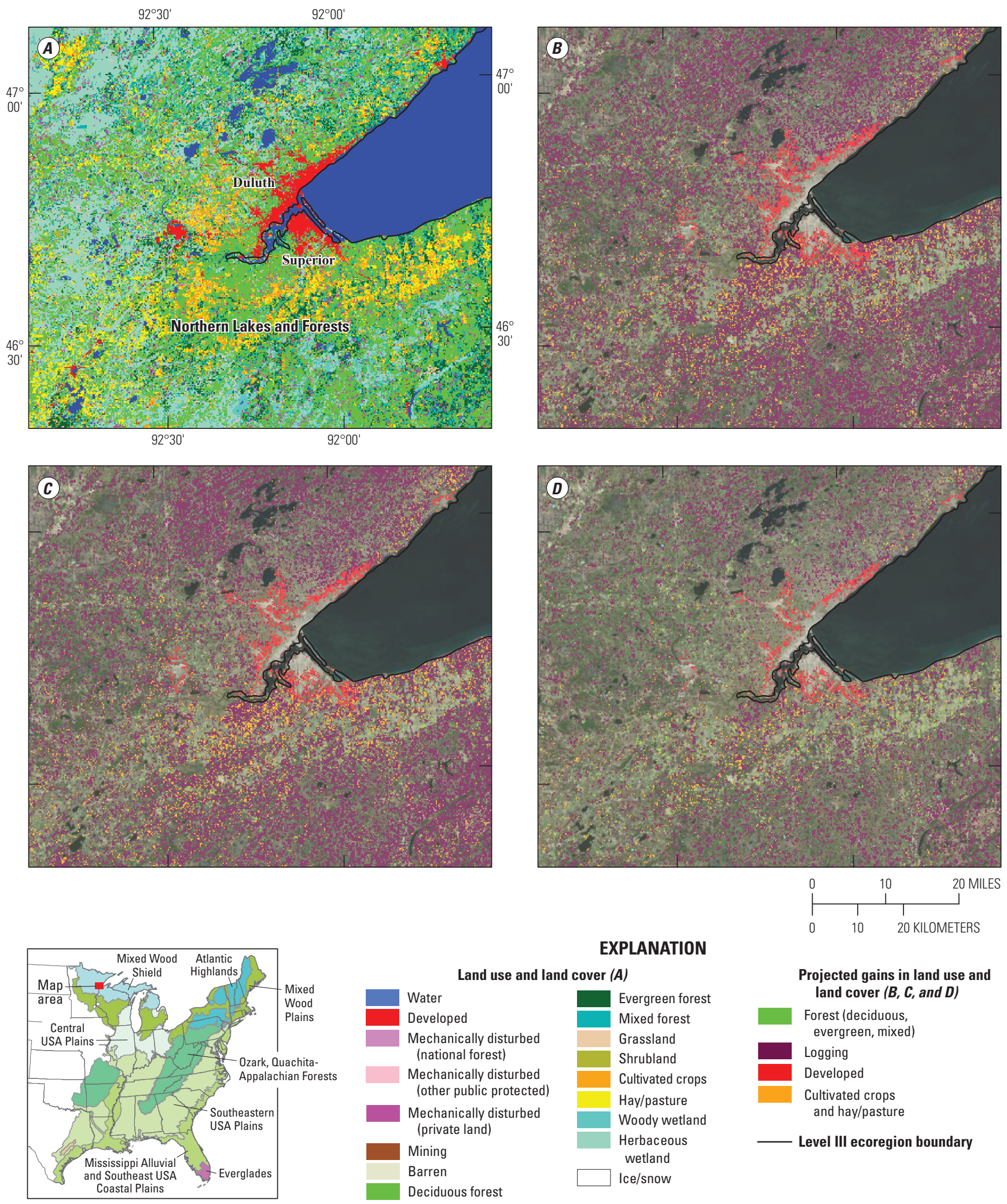

Figure 3-9. Maps showing $A$, land use and land cover (LULC) and a comparison of the projected LULC change in scenarios $B, A 1 B$, $C, \mathrm{~A} 2$, and $D, \mathrm{~B} 1$ in 2050 for the area around Duluth, Minnesota, in the Mixed Wood Shield ecoregion. Changes were projected to be the result of land-use change (agricultural lands, forests, developed lands) or forest clearcutting. 


\subsubsection{Atlantic Highlands}

The LULC change footprint for each scenario in the Atlantic Highlands ecoregion was among the most extensive of the ecoregions in the Eastern United States during the projected time period. The two economically focused scenarios A1B and A2 had similar amounts of change with 22.9 percent of the ecoregion area changing at least once in scenario A1B and 22.1 percent changing in scenario A2 (table 3-3). In the environmentally oriented scenario B1, 14.2 percent of the ecoregion changed.

There was significant variation in the amount of LULC change projected between the three level III ecoregions that make up the Atlantic Highlands ecoregion. During the projected period, high amounts of change occurred in the Northern Appalachian and Atlantic Maritime Highlands and the North Central Appalachians level III ecoregions where large amounts of forest cutting and conversion to developed was common. Conversely, the Northern Appalachian Plateau and Uplands level III ecoregion experienced slight changes in LULC, largely because of the area's lack of clearcutting.

A majority of the change in the economically focused scenarios A1B and A2 was due to clearcutting activities in forests and increases in other anthropogenic land uses. Between 2006 and 2050, increases in forest harvest activities were dramatic. In scenario A1B, the extent of clearcutting increased by 541.9 percent $\left(5,315 \mathrm{~km}^{2}\right)$, whereas in scenario A2, the extent of clearcutting increased by 492 percent $\left(4,825 \mathrm{~km}^{2}\right)$. The increase in the extent of developed lands was substantial as well. In the A1B scenario, the extent of developed lands increased by 107.1 percent $\left(3,625 \mathrm{~km}^{2}\right)$, whereas in scenario A2, the extent of developed lands increased by 42.5 percent $\left(1,438 \mathrm{~km}^{2}\right)$. The extent of agricultural lands also expanded in scenario A2 (28.5 percent, $\left.5,193 \mathrm{~km}^{2}\right)$ and to a lesser extent in scenario A1B. The extent of mining expanded in the two scenarios as well, increasing by 66.5 percent $\left(158 \mathrm{~km}^{2}\right)$ in scenario A1B and by 91.1 percent $\left(217 \mathrm{~km}^{2}\right)$ in scenario A2. In both scenarios, conversion from forests contributed to more than 90 percent of the gains seen by each of these anthropogenic LULC types.

In scenario B1, clearcutting activities and expansion of developed lands contributed the most to land changes that were observed for the projected period. The extents of clearcutting and developed lands were lower compared with those in the economic scenarios but still high overall. The extent of clearcutting of forested lands expanded by 204.5 percent $\left(2,006 \mathrm{~km}^{2}\right)$, whereas the extent of developed lands increased by 25.1 percent $\left(848 \mathrm{~km}^{2}\right)$. Most of the gains in developed were at the expense of forests (79.9 percent, $678 \mathrm{~km}^{2}$ ); however, this did not result in an overall loss in forest cover. Scenario B1 was the only scenario to have an increase in the extent of the forests ecosystem, albeit a minor gain (1.2 percent, $\left.1,895 \mathrm{~km}^{2}\right)$. This was mostly due to the large declines in the extent of agricultural lands (15.2 percent, $2,771 \mathrm{~km}^{2}$ ) during the projected time period.

Figure 3-10 represents typical LULC patterns between scenarios. The expansion in all directions near and around the cities of Pittsfield and Springfield, Massachusetts, can clearly be discerned in all scenarios as the area's population increases. In this example, gains in the extent of developed lands are considerably less in scenario B1 where growth is more compact compared with the more sprawling scenarios A1B and A2. Agricultural lands expand considerably in scenarios A1B and A2, particularly in lowland valleys and adjacent to existing cultivated areas. In an attempt to accommodate the increased demand for agricultural products, agriculture stretches into the west and northeast to increasingly marginal lands. In scenario B1, agriculture LULC does expand slightly into new areas; however, agricultural lands are also being converted to other ecosystem classes, leading to an overall decrease in the extent of agricultural lands in this scenario. Between scenarios, the spatial distributions of clearcut forest are the same for this area. The density of clearcutting, however, varies between economic and environmental scenarios. In the economic scenarios, forest resources are in high demand with less of a focus on preservation and responsible forest use. Conversely, the environmental scenarios put a value on forest preservation and restoration, leading to lower amounts of clearcutting as well as increases in total forested area, particularly as the lower demand for agricultural commodities result in conversions of agricultural lands to forests ecosystems. 

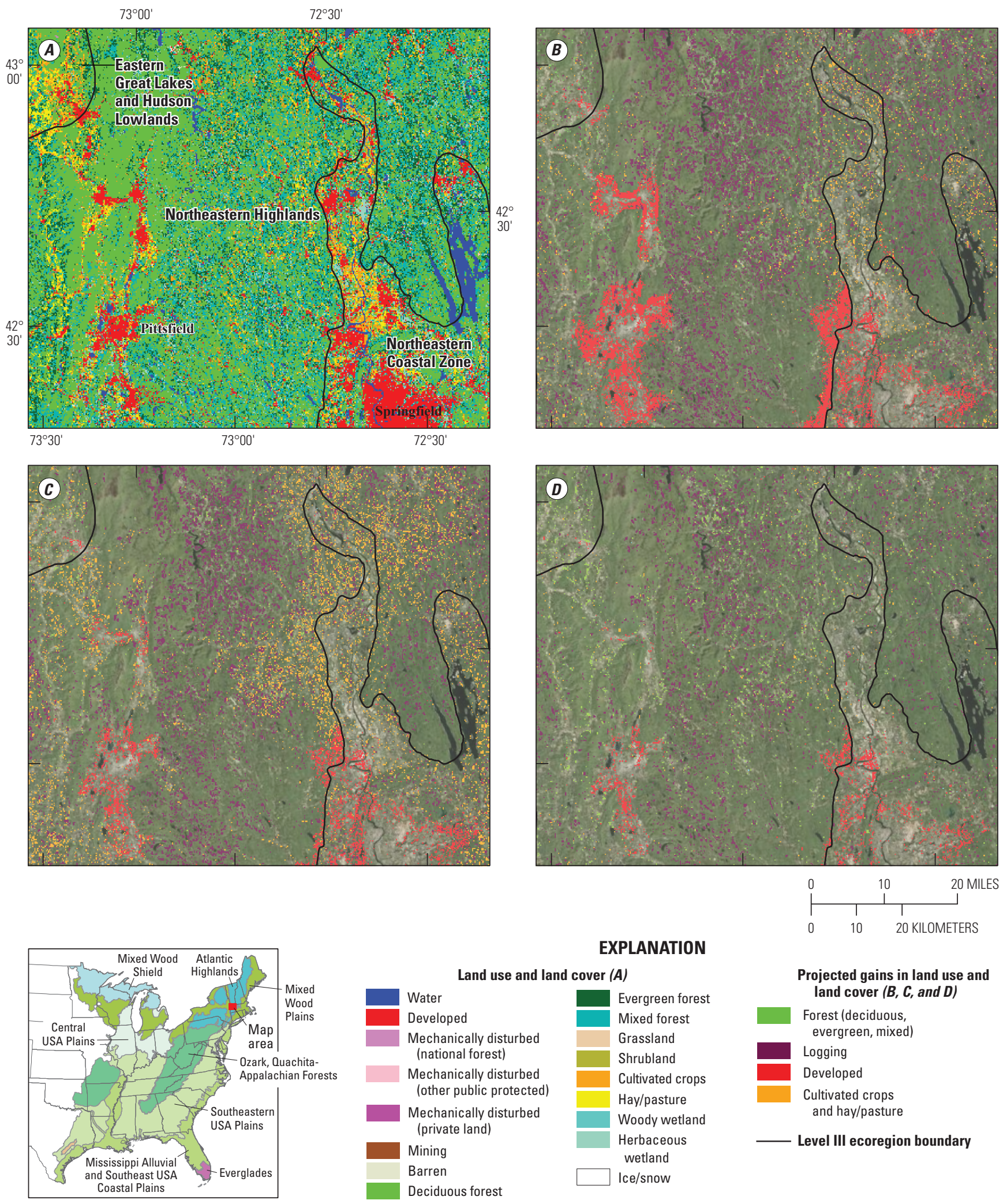

EXPLANATION

Level II ecoregions

Figure 3-10. Maps showing $A$, land use and land cover (LULC) and a comparison of the projected LULC change in scenarios $B, A 1 B, C, A 2$, and $D, B 1$ in 2050 for the area near Springfield, Massachusetts, in the Atlantic Highlands ecoregion. Changes were projected to be the result of land-use change (agricultural lands, forests, developed lands) or forest clearcutting. 


\subsubsection{Mixed Wood Plains}

Each of the scenarios for the Mixed Wood Plains ecoregion exhibited some of the lowest amounts of LULC change in the Eastern United States. By contrast to many other eastern ecoregions, the LULC change footprint in the Mixed Wood Plains ecoregion was greatest in the in scenario $\mathrm{A} 2$ rather than scenario A1B. In scenario A2, 13.9 percent of the ecoregion's LULC changed at least one time between 2006 and 2050, with scenario A1B similar at 13.1 percent (table 3-3). Scenario B1 had the least amount of LULC change, with only 7.3 percent.

There is spatial variability in the amount and types of LULC change across the ecoregion. For example, the Maine/New Brunswick Plains and Hills level III ecoregion continued the historical trend of having the highest amount of spatial change across all scenarios due to high amounts of forest cutting. The Driftless Area ecoregion in Wisconsin and Minnesota had the lowest amount of change in scenarios A1B and A2, but in the environmental scenario $\mathrm{B} 1$, this area had the second highest amount of change due to afforestation.

In both the economically focused scenarios, the extents of developed lands and forest clearcutting increased dramatically during the projected time period. In scenarios A1B and A2, the extents of developed lands increased by 47.1 percent $\left(13,366 \mathrm{~km}^{2}\right)$ and 37.9 percent $\left(10,764 \mathrm{~km}^{2}\right)$, respectively. Forests and agricultural lands combined to contribute more than 90 percent of the land converted to developed lands; however, the contributions of forest and agricultural lands to developed lands varied by scenario. In scenario A1B, 39.6 percent $\left(5,293 \mathrm{~km}^{2}\right)$ of the land converted to developed lands came from forests, and 55.9 percent $\left(7,472 \mathrm{~km}^{2}\right)$ came from agricultural lands, whereas in scenario A2, the trend was reversed. The variation in conversions reflects where new developed occurred. In scenario A1B, there was more development in agricultural areas in the western part of the ecoregion, whereas in scenario A2, the extent of developed lands grew more in the more forested eastern regions.
The economically focused scenarios saw increases in forest clearcutting of 279.1 percent $\left(3,308 \mathrm{~km}^{2}\right)$ in scenario A1B and 249.3 percent $\left(2,955 \mathrm{~km}^{2}\right)$ in scenario A2. Although forest harvest increased, the areal extent of the overall forest ecosystem decreased by 7.9 percent $\left(11,747 \mathrm{~km}^{2}\right)$ in scenario A1B and 13.8 percent $\left(20,430 \mathrm{~km}^{2}\right)$ in scenario A2 due to conversion to other LULC types. From 2006 through 2050, the extent of agricultural lands in scenario A1B experienced a small net loss of less than $200 \mathrm{~km}^{2}$, with losses occurring to developed lands but gains coming from forests. Scenario A2 saw a 6.6 percent $\left(10,533 \mathrm{~km}^{2}\right)$ increase in the extent of agricultural lands, predominantly from forests.

The environmental scenario B1 had the smallest increase in the extent of developed lands at 29 percent $\left(8,239 \mathrm{~km}^{2}\right)$. Conversions to developed lands were similar to scenario A1B where more agricultural lands (60 percent, $4,943 \mathrm{~km}^{2}$ ) were converted than forests ( 36.4 percent, $2,999 \mathrm{~km}^{2}$ ). The extent of the forests ecosystem in scenario B1 changed little, but forest clearcutting did increase by nearly 20 percent. Finally, agricultural lands saw a decrease of 5.3 percent $\left(8,463 \mathrm{~km}^{2}\right)$ during the projected time period due to conversions to developed lands and forests

Figure 3-11 illustrates typical projected LULC change in the Bangor, Maine, area between 2006 and 2050. In all scenarios, developed lands expanded into the agricultural lands and forested areas around the city, but to a lesser degree in scenario B1 than in scenarios A1B and A2. A drastic increase in the amount of forest clearcutting can be seen throughout the surrounding area in the economically focused scenarios. Conversely, the expansion of forest cutting in scenario B1 was more moderate than in scenarios A1B and A2, and small patches of new forested land can be observed. The economic scenarios also showed a large gain in the amount of agricultural lands, which helped offset losses to developed areas. However, in scenario B1, gains in the extent of agricultural LULC are much smaller, and losses to developed lands result in an overall decrease in the extent of agricultural lands in the area between 2006 and 2050. 

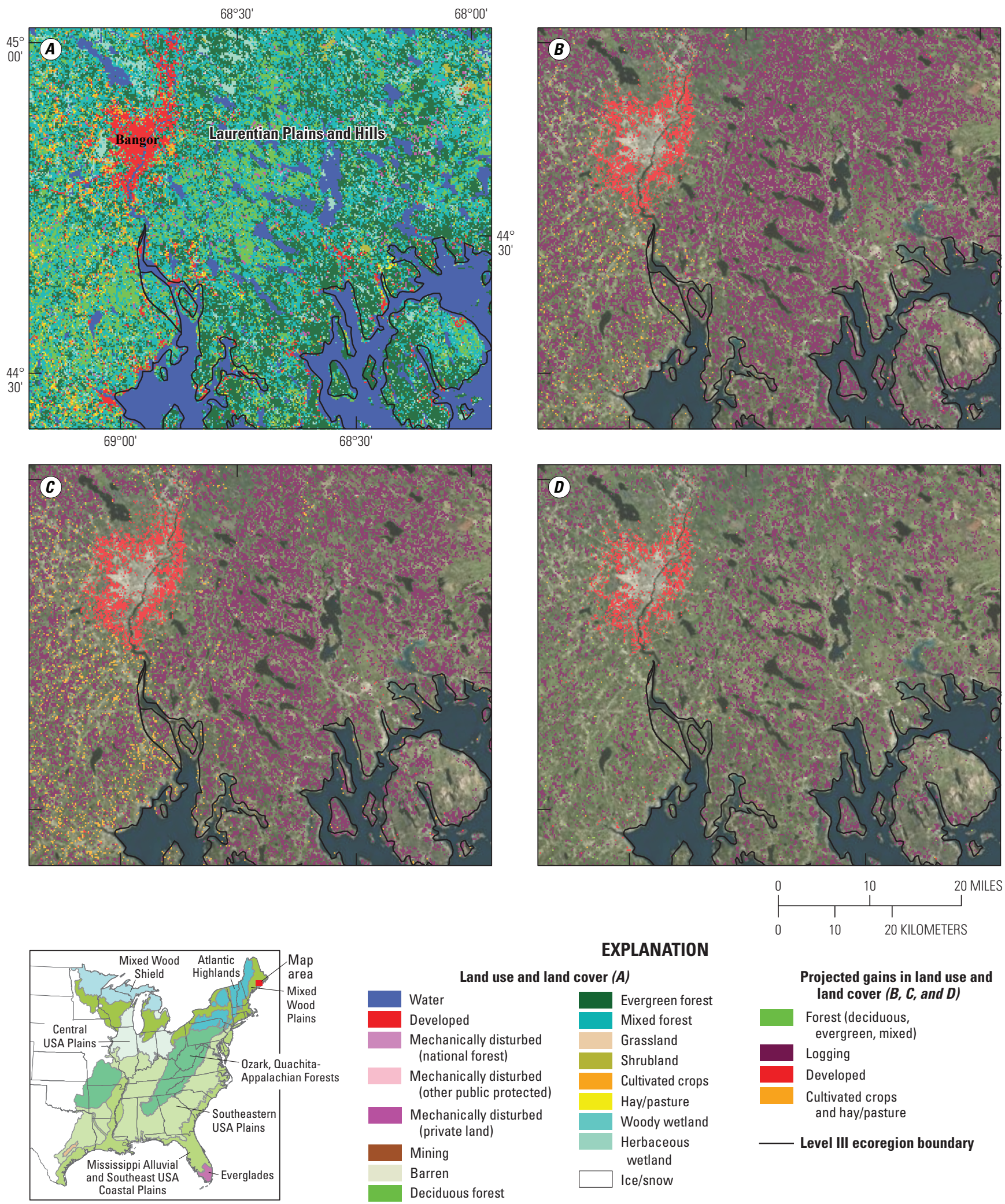

Figure 3-11. Maps showing $A$, land use and land cover (LULC) and a comparison of the projected LULC change in scenarios $B, A 1 B, C, A 2$, and $D, B 1$ in 2050 for the area around Bangor, Maine, in the Mixed Wood Plains ecoregion. Changes were projected to be the result of land-use change (agricultural lands, forests, developed lands) or forest clearcutting. 


\subsubsection{Central USA Plains}

The Central USA Plains ecoregion was the least active ecoregion in the Eastern United States in terms of LULC change, with LULC change footprints in each scenario the lowest of the entire Eastern United States. With little existing forest, there are only small amounts of clearcutting to contribute to LULC change, and much of the area has stabilized as a highly productive agricultural region. Scenario B1 had the least amount of LULC change in the Central USA Plains ecoregion with only 4.6 percent of the ecoregion changing at least once between 2006 and 2050 (table 3-3). Scenario A2 saw 7.5 percent of the ecoregion change at least once, and scenario A1B saw 9.3 percent of the ecoregion change at least once. The spatial variability of LULC change across the ecoregion was low. Between level III ecoregions in the Central USA Plains, variability in footprint change did not exceed 4 percent.

The economically focused scenarios saw considerable increases in the extents of developed lands and decreases in the extents of agricultural lands and forests. In scenario A1B, the extent of developed lands increased by 80.1 percent $\left(14,757 \mathrm{~km}^{2}\right)$, whereas scenario A2 saw an increase of 55.8 percent $\left(10,275 \mathrm{~km}^{2}\right)$. In both economic scenarios, gains in the extent of developed lands came primarily from the conversion of agricultural lands. Despite these conversions, agricultural lands retained almost 90 percent of the extent in 2005 during the projected time period, experiencing only small net decreases of 6.1 percent $\left(11,214 \mathrm{~km}^{2}\right)$ in scenario A1B and 3.6 percent $\left(6,759 \mathrm{~km}^{2}\right)$ in scenario A2. Natural ecosystems saw reductions in their extent as well, with forests declining by similar amounts (13.9 percent, $3,316 \mathrm{~km}$ in scenario A1B and 13.9 percent, $3,311 \mathrm{~km}^{2}$ in scenario A2).

In scenario $\mathrm{B} 1$, increases in the extent of developed lands were modest compared with those in scenarios A1B and A2. The extent of developed lands increased by 24.2 percent $\left(4,458 \mathrm{~km}^{2}\right)$ between 2006 and 2050, with most of the increase coming from agricultural lands ( 86 percent, $3,834 \mathrm{~km}^{2}$ ). Similar to the economically focused scenarios, the extent of agricultural lands experienced a net decrease ( 2.5 percent, $4,712 \mathrm{~km}^{2}$ ) in scenario B1, but this decrease was smaller than that in the other two scenarios due to scenario assumptions limiting expansion of developed lands. The extent of the forests ecosystem saw a slight increase of less than 1 percent. Types of LULC change in the Chicago, Illinois, area are typical of the changes in the Central USA Plains from 2006 through 2050. In all scenarios, developed lands expanded into agricultural lands along the fringes of the metropolitan areas (fig. 3-12). In scenarios A1B and A2, development was more apt to occur in the remaining forested areas within the city. However, in scenario B1, development was more compact and, coupled with an increased focus on preserving natural cover types, kept developed lands from encroaching as much into the city's forested areas. 

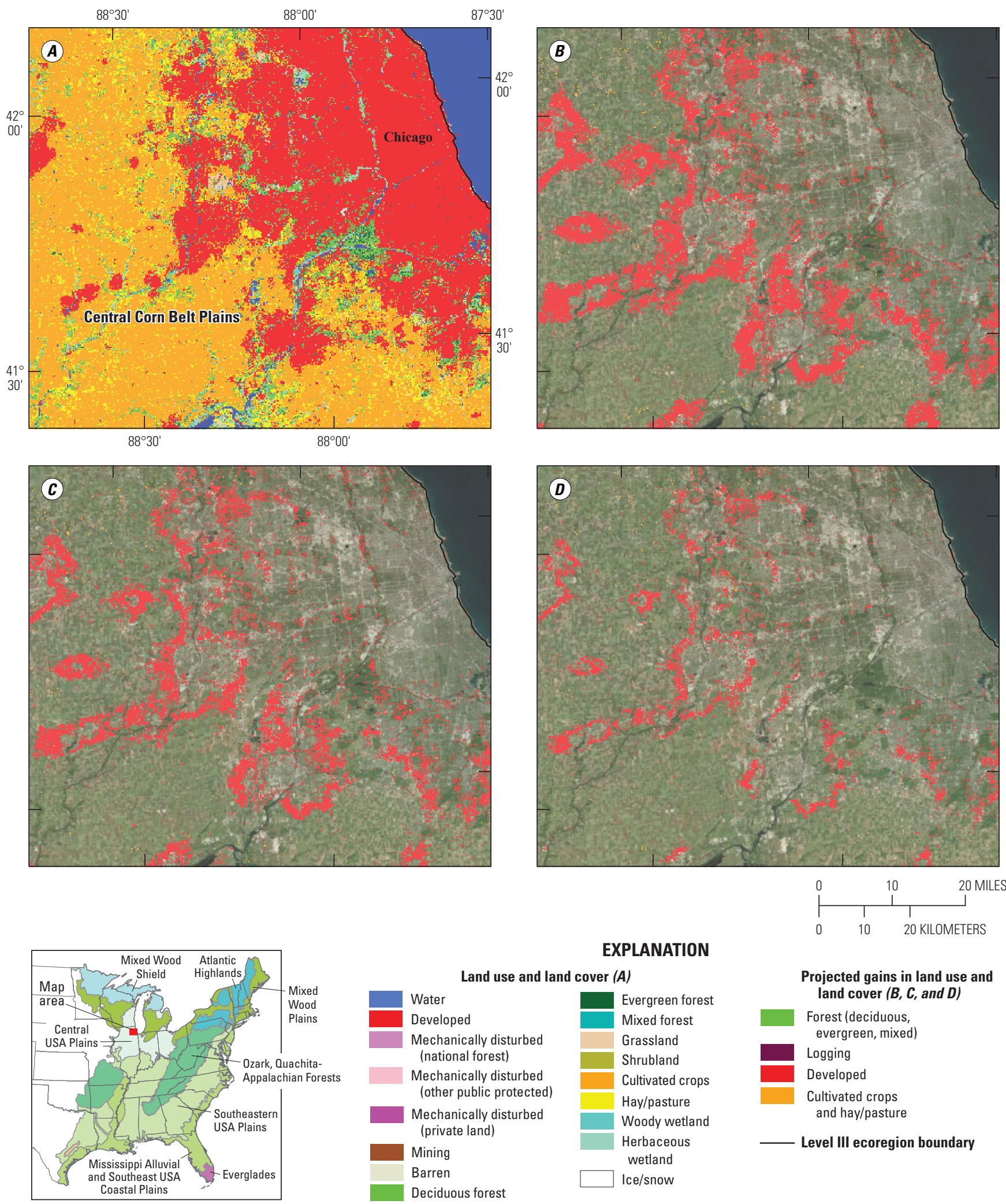

Figure 3-12. Maps showing $A$, land use and land cover (LULC) and a comparison of the projected LULC change in scenarios $B, A 1 B, C, A 2$, and $D, B 1$ in 2050 for the area around Chicago, Illinois, in the Central USA Plains ecoregion. Changes were projected to be the result of land-use change (agricultural lands, forests, developed lands) or forest clearcutting. 


\subsubsection{Southeastern USA Plains}

The Southeastern USA Plains ecoregion continued the recent historical trend of being the highest changing level II ecoregion in the Eastern United States in every scenario due to high rates of clearcutting and LULC conversions. The ecoregion is very dynamic and had the largest LULC change footprints in the Eastern United States, with 33.2 percent in scenario A1B, 30.6 percent in scenario B1, and 29.5 percent in scenario A2 (table 3-3). Within the heart of the Southeastern USA Plains, the LULC change footprint exceeded 40 percent in the South Central Plains, Piedmont, Southeastern Plains, and Mississippi Valley Loess Plains level III ecoregions.

In both the economically focused scenarios, change was driven by high amounts of anthropogenic land uses in the form of forest clearcutting, developed lands, and agriculture. The ecoregion accounted for more than half (55.5 percent) of all forest clearcutting in the Eastern United States at the start of the projection period, and in both scenarios, clearcutting maintained an approximately 50 percent share in 2050 . The extent of forest cutting increased by 34.6 percent $\left(9,614 \mathrm{~km}^{2}\right)$ over the projection period in scenario A1B, which was a modest rate increase with the ecoregion being heavily harvested already. In addition to the increases in forest cutting, the extent of the forest ecosystem decreased by 13.8 percent $\left(75,816 \mathrm{~km}^{2}\right)$, putting further conversion pressure on the region's forests. In scenario A2, forest clearcutting increased by 24.2 percent $\left(6,724 \mathrm{~km}^{2}\right)$, and the extent of the overall forests ecosystem decreased by 12.4 percent $\left(68,367 \mathrm{~km}^{2}\right)$.

In scenario A1B, the developed LULC class had the highest rate of increase across all ecoregions and scenarios with a 92.9 percent $\left(39,946 \mathrm{~km}^{2}\right)$ gain. Conversions to developed lands in scenario A1B primarily came from forests (59.6 percent, 23,808 $\mathrm{km}^{2}$ ) and agricultural lands (35 percent, $\left.13,981 \mathrm{~km}^{2}\right)$. Scenario A2 experienced a 76.4 percent $\left(32,848 \mathrm{~km}^{2}\right)$ increase in the extent of developed lands, with a greater percentage of new developed lands coming from forests $\left(67.3\right.$ percent, $\left.22,107 \mathrm{~km}^{2}\right)$ than in scenario A1B and a smaller share ( 26.1 percent, $8,573 \mathrm{~km}^{2}$ ) from agricultural lands. Increases in the extent of developed lands were primarily concentrated in level III ecoregions with high LULC change footprints and in existing large urban corridors, with the Piedmont and Southeastern Plains level III ecoregions accounting for approximately 65 percent of all urban growth in both economic scenarios. In the Piedmont, the urban corridor stretching from Atlanta, Georgia; Washington, D.C.; Charlotte, Winston-Salem, and Raleigh-Durham, North Carolina, saw the greatest increases with 119.7 percent $\left(14,480 \mathrm{~km}^{2}\right)$ in scenario A1B and 103.2 percent $\left(12,484 \mathrm{~km}^{2}\right)$ in scenario A2. Developed lands in the Southeastern Plains level III ecoregion focused in cities along the edge of the Piedmont from Montgomery, Alabama; Macon, Ga.; Colombia, South Carolina; and Richmond, Virginia; to the southeastern fringes of Baltimore, Maryland, with increases of 92.7 percent $\left(8,969 \mathrm{~km}^{2}\right)$ in scenario A1B and 80.8 percent $\left(7,821 \mathrm{~km}^{2}\right)$ in scenario A2.
Gains in the extent of the agricultural lands ecosystem were also the largest by area in scenarios A1B and A2 compared with changes in the other level II ecoregions in the Eastern United States. The extent of agricultural lands increased by 11.7 percent $\left(35,828 \mathrm{~km}^{2}\right)$ in scenario A1B and 11 percent $\left(33,810 \mathrm{~km}^{2}\right)$ in scenario $\mathrm{A} 2$, with gains in both scenarios predominantly coming from forests and to a lesser degree from grasslands/shrublands.

Scenario B1 had the second highest LULC change footprint in this ecoregion due to continued high amounts of forest cutting, growth in developed lands, and restoration of forests and wetlands ecosystems. Forest cutting continued to increase ( 7.9 percent, $2,200 \mathrm{~km}^{2}$ ), although at a rate much lower than scenarios A1B and A2. This increase is a deviation from much of the Eastern United States in scenario B1 where timber harvest generally decreased in the Eastern United States under this scenario. As a result of conversion of agricultural lands to forest, the overall extent of the forests ecosystem increased by 2.9 percent $\left(15,829 \mathrm{~km}^{2}\right)$ during the projection period. The increases in the extent of developed lands ( 66 percent, $28,387 \mathrm{~km}^{2}$ ) remained the highest of any ecoregion in the Eastern United States, but was still lower than either of the economic scenarios. New developed lands came more from agricultural lands ( 53.1 percent, $15,074 \mathrm{~km}^{2}$ ) than from forests (42.4 percent $12,036 \mathrm{~km}^{2}$ ) in scenario B1, with similar patterns of new urban growth as the economic scenarios except for a greater share of increases in the extent of developed lands in cities of the Interior Plateau and Interior River Valleys and Hills level III ecoregions, such as St. Louis, Missouri; Nashville, Tennessee; and Louisville, Kentucky. The extent of the wetlands ecosystem experienced a 7.8 percent $\left(4,722 \mathrm{~km}^{2}\right)$ increase in scenario B1, with conversions to wetlands types predominantly from agricultural lands ( 67.7 percent, $\left.3,197 \mathrm{~km}^{2}\right)$ and forests (30.6 percent, $1,445 \mathrm{~km}^{2}$ ).

LULC change in the Augusta, Ga., region that borders the Piedmont and Southeastern Plains level III ecoregions is typical of the Southeastern USA Plains (fig. 3-13). Increases in the extent of developed lands from forested areas around Augusta were similar in the A1B and A2 scenarios; however, increases in the extent of developed lands were much lower in scenario B1, which has assumptions that focus more on compact urban growth. Higher rates of forest clearcutting and conversion to new agricultural lands are apparent in scenario A1B, with the higher densities of new agriculture visible in the areas northwest and southwest of Augusta. In scenario B1, forest restoration is noticeable in the cropped areas south of Augusta and in isolated patches in the western portion of the image. Use of the Protected Area Database of the United States in the LULC modeling is also apparent as seen near Fort Gordon, Ga., on the outskirts of Augusta. Anthropogenic LULC change is restricted on military lands in all scenarios as illustrated by the lack of new agricultural lands, forest clearcutting, and developed lands on base. However, conversions to natural LULC types such as forest and wetland are allowed in scenario B1 as seen by the new patches of forest in the center of the base. 

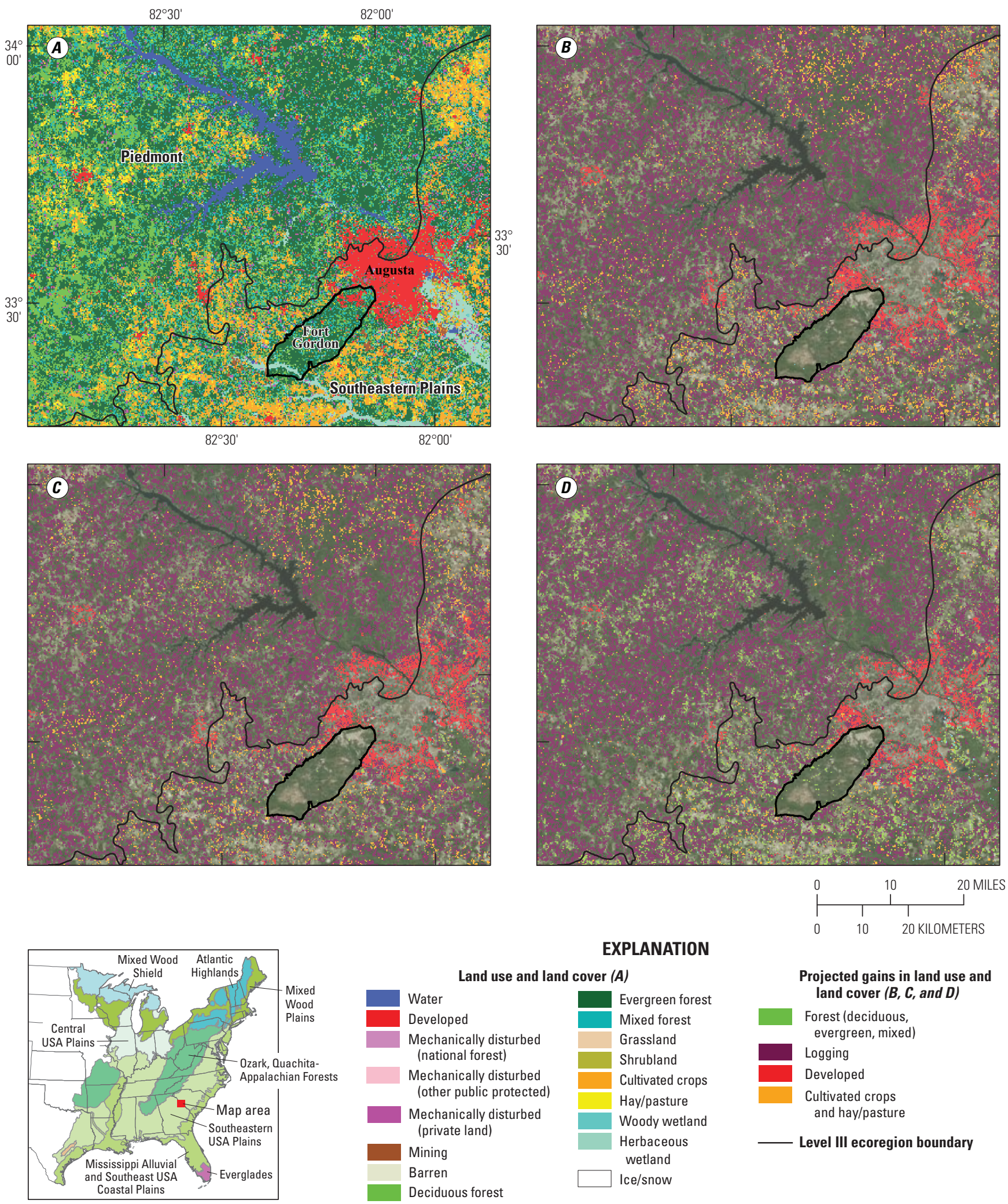

Figure 3-13. Maps showing $A$, land use and land cover (LULC) and a comparison of the projected LULC change in scenarios $B, \mathrm{~A} 1 \mathrm{~B}, C, \mathrm{~A} 2$, and $D, \mathrm{~B} 1$ in 2050 for the area around Augusta, Georgia, in the Southeastern USA Plains ecoregion. Changes were projected to be the result of land-use change (agricultural lands, forests, developed lands) or forest clearcutting. 


\subsubsection{Ozark, Ouachita-Appalachian Forests}

The LULC change footprint in the Ozark, OuachitaAppalachian Forests ecoregion closely resembles the average pattern for the Eastern United States during the projection period, especially in the economic scenarios. The A1B and A2 scenarios had change rates of 20.5 percent and 19.7 percent, respectively, compared with the Eastern United States with 22.9 percent in scenario A1B and 20.8 percent in scenario A2 (table 3-3). However, the rate of LULC change in scenario B1 was considerably lower (10.6 percent) than the Eastern United States average (17.2 percent). However, several level III ecoregions were noticeable exceptions to the trend in the ecoregion, with the Southwestern Appalachians and Ouachita Mountains level III ecoregions showing a rate of LULC change of about 40 percent or more due to the high amounts of forest clearcutting in these areas. The Ouachita Mountains ecoregion in particular had the highest rate of any level III ecoregion in the entire Eastern United States, with nearly half of the area changing at least once during the projection period in every scenario (48.1 percent in scenario A1, 55.4 percent in scenario A2, and 44.7 percent in scenario B1; fig. 3-5).

In both the economically focused scenarios, LULC change was driven primarily by forest clearcutting, moderate growth in major urban centers, and agricultural expansion in the Ozark Highlands ecoregion and the lowland valleys of the Appalachian Mountains. Forest clearcutting in scenario A1B increased by 162.2 percent $\left(9,129 \mathrm{~km}^{2}\right)$ and 145.5 percent $\left(7,426 \mathrm{~km}^{2}\right)$ in scenario A2 during the projected period, an increase three times that of the Eastern United States averages of 49.2 percent $\left(24,593 \mathrm{~km}^{2}\right)$ in scenario A1B and 38 percent $\left(18,978 \mathrm{~km}^{2}\right)$ in scenario A2. The extent of the forests ecosystem decreased by 7.2 percent $\left(26,898 \mathrm{~km}^{2}\right)$ in scenario A1B and 8.2 percent $\left(30,599 \mathrm{~km}^{2}\right)$ in scenario A2 due to conversions to agricultural and developed lands. Both scenarios saw increases in the extent of the developed agricultural lands, with the extent of developed lands increasing by 67.1 percent $\left(9,129 \mathrm{~km}^{2}\right)$ primarily from forests $(67.6$ percent, $\left.6,171 \mathrm{~km}^{2}\right)$ compared with agricultural lands (29.9 percent,
$2,730 \mathrm{~km}^{2}$ ) in scenario A1B. In scenario A2, the extent of developed lands increased by 54.6 percent $\left(7,426 \mathrm{~km}^{2}\right)$, with a greater proportion of new urban lands coming from forests (77.7 percent, $\left.5,770 \mathrm{~km}^{2}\right)$ than agricultural lands (19.9 percent, $1,478 \mathrm{~km}^{2}$ ). Compared with developed lands, increases in agricultural lands were higher in scenario A2 (19.1 percent, $\left.22,520 \mathrm{~km}^{2}\right)$ than in scenario A1B (14.8 percent, $\left.17,425 \mathrm{~km}^{2}\right)$, with almost all new agricultural lands converted from forests.

Scenario B1 saw few net changes in the ecoregion with the extents of forest, agriculture, and forest clearcutting LULC all remaining relatively stable throughout the projection period. The extent of developed lands saw a moderate increase of 31.1 percent $\left(4,229 \mathrm{~km}^{2}\right)$ for the largest scenario change. Gains in developed lands were balanced between forests (56.2 percent, 2,377 $\mathrm{km}^{2}$ ) and agricultural lands (40.2 percent, $1,700 \mathrm{~km}^{2}$ ). Forest clearcutting was considerably lower in scenario B1 compared with the economically oriented scenarios but did increase slightly by a little more than 3 percent during the projection period, in contrast with the Eastern United States as a whole, which saw clearcutting decrease by 6.9 percent $\left(3,430 \mathrm{~km}^{2}\right)$. The extent of the forests ecosystem decreased overall by 0.8 percent $\left(2,991 \mathrm{~km}^{2}\right)$ due primarily to conversions to new urban growth. Decreases in agricultural lands were minimal.

LULC change in the Birmingham, Alabama, area is indicative of changes in the region (fig. 3-14), with high amounts of forest clearcutting seen in scenarios A1B and A2 and less so in scenario B1. Growth of large cities such as Birmingham is similar between scenarios A1B and A2, with slightly higher increases in scenario A1B. Smaller cities such as Jasper, Ala., follow similar growth patterns as the larger towns, whereas increases in the extent of developed lands are much lower in metropolitan and rural areas in scenario B1. Conversions of forests to agricultural lands are highest in scenario $\mathrm{A} 2$, with greater concentrations of new agricultural lands northwest and southwest of Birmingham. Increases in agricultural lands are slightly lower in scenario A1B, following similar patterns as scenario A2. Widespread forest restoration is visible throughout scenario B1, as isolated patches of agricultural lands are converted to forests. 

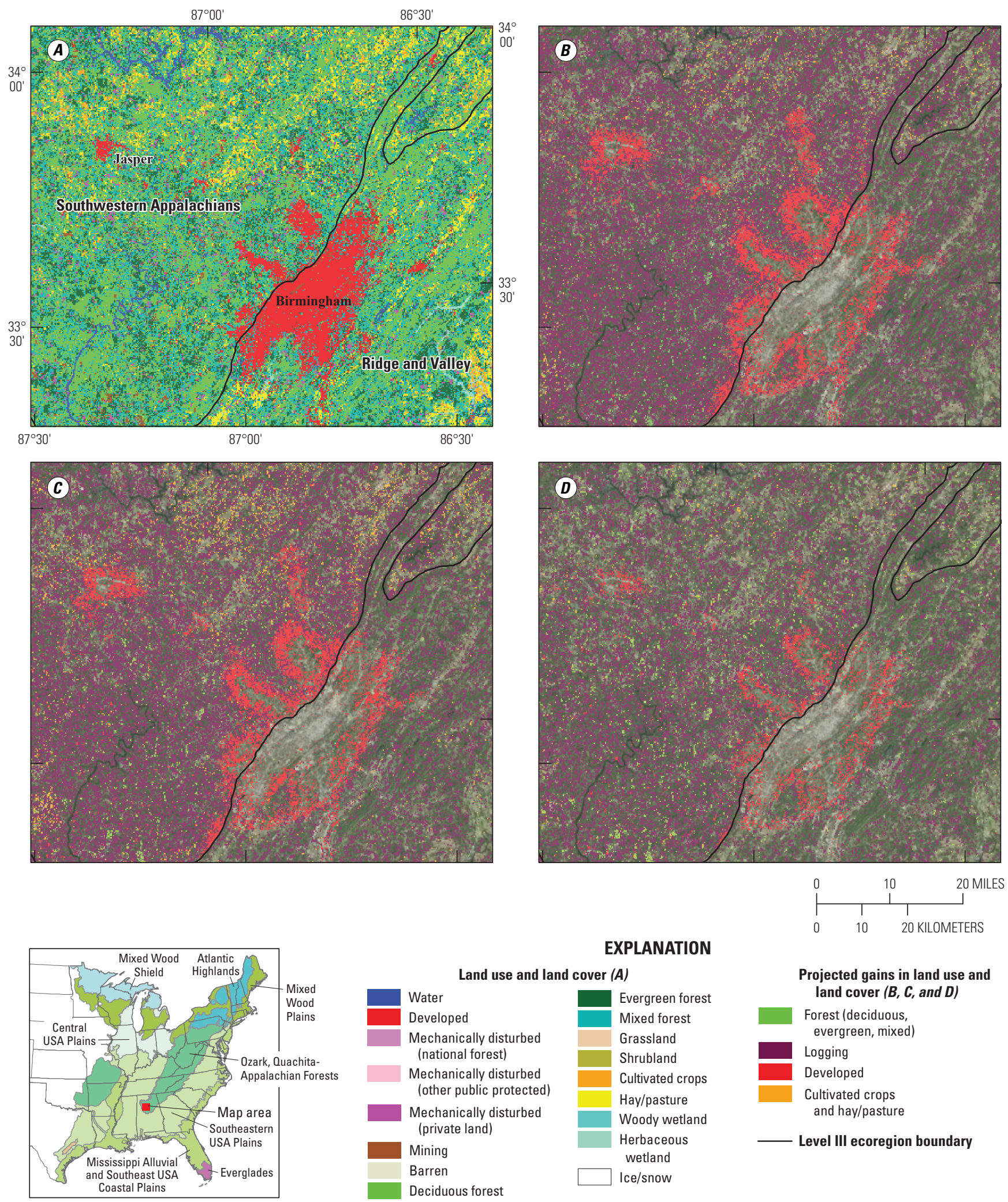

Figure 3-14. Maps showing $A$, land use and land cover (LULC) and a comparison of the projected LULC change in scenarios $B, A 1 B, C, A 2$, and $D, B 1$ in 2050 for the area Birmingham, Alabama, in the Ozark, Ouachita-Appalachian Forests ecoregion. Changes were projected to be the result of land-use change (agricultural lands, forests, developed lands) or forest clearcutting. 


\subsubsection{Mississippi Alluvial and Southeast USA Coastal Plains}

From 2006 through 2050, the Mississippi Alluvial and Southeast USA Coastal Plains ecoregion experienced modest amounts LULC change in each scenario. Scenario A1B had the greatest amount of LULC change with 16.1 percent of the ecoregion changing at least once during the projected period (table 3-3). Scenario B1 experienced the second largest LULC change with 13.9 percent and scenario A2 was a close third with 13.1 percent. The amount of LULC change varied spatially by level III ecoregions within the Mississippi Alluvial and Southeast USA Coastal Plains ecoregion. As in the baseline results, the Southern Coastal Plain ecoregion in the southeastern part of the ecoregion saw large amounts of LULC change in all scenarios. The Middle Atlantic Coastal Plain and the Western Gulf Coastal Plain (of the TexasLouisiana Coastal Plains level III ecoregion) ecoregions saw comparatively modest amounts of change, whereas the Atlantic Coastal Pine Barrens and the Mississippi Alluvial Plain ecoregions saw relatively little change (fig. 3-5).

The economically focused scenarios experienced drastic increases in the extent of developed lands and substantial decreases in the extents of natural ecosystems (forests, wetlands, and grasslands/shrublands) during the projected time period. In scenario A1B, the extent of developed lands increased by 84.1 percent $\left(28,872 \mathrm{~km}^{2}\right)$, most of which came from agricultural lands ( 38.3 percent, $\left.11,058 \mathrm{~km}^{2}\right)$, forests $(35.1$ percent, $\left.10,134 \mathrm{~km}^{2}\right)$, and wetlands (16.6 percent, $\left.4,793 \mathrm{~km}^{2}\right)$. The extent of developed lands in scenario A2 saw a 69.6 percent $\left(23,891 \mathrm{~km}^{2}\right)$ increase, with a greater share of conversions from forests in this scenario $\left(40.4\right.$ percent, $\left.4,793 \mathrm{~km}^{2}\right)$ and relatively equal amounts from agricultural lands ( 23.7 percent, $5,662 \mathrm{~km}^{2}$ ) and wetlands ( 22.8 percent, $\left.5,447 \mathrm{~km}^{2}\right)$.

In scenarios A1B and A2, the extent of the forests ecosystem saw decreases of 21.5 percent $\left(21,919 \mathrm{~km}^{2}\right)$ and 15.9 percent $\left(16,258 \mathrm{~km}^{2}\right)$ respectively. However, forest clearcuts increased by 54.9 percent $\left(5,412 \mathrm{~km}^{2}\right)$ in scenario A1B and by 58.4 percent $\left(5,758 \mathrm{~km}^{2}\right)$ in scenario A2 in a decreasing forested land base. The extent of the wetlands ecosystem also decreased, by 7.2 percent $\left(8,403 \mathrm{~km}^{2}\right)$ in scenario A1B and by 6 percent $\left(7,018 \mathrm{~km}^{2}\right)$ in scenario A2. The Mississippi Alluvial and Southeast USA Coastal Plains ecoregion was one of the few areas of the Eastern United States that had substantial amounts of the grasslands/shrublands ecosystem, which decreased by 7.5 percent $\left(2,142 \mathrm{~km}^{2}\right)$ in scenario A1B and 8.7 percent $\left(2,490 \mathrm{~km}^{2}\right)$ in scenario A2. Conversions from these natural ecosystems were primarily to developed and agricultural lands, which also saw slight increases of 2.2 percent $\left(3,106 \mathrm{~km}^{2}\right)$ in scenario A1B and 0.9 percent $\left(1,327 \mathrm{~km}^{2}\right)$ in scenario $\mathrm{A} 2$.

In scenario B1, the extent of developed lands continued to grow, with a 43.6 percent $\left(14,959 \mathrm{~km}^{2}\right)$ increase being the second highest in the Eastern United States (scenario B1), which came primarily from agricultural lands (43.6 percent, $\left.6,522 \mathrm{~km}^{2}\right)$, forests $\left(37.5\right.$ percent, $\left.5,610 \mathrm{~km}^{2}\right)$, and grasslands/shrublands (9.1 percent, $\left.1,361 \mathrm{~km}^{2}\right)$. Forests and grassland/shrublands ecosystems continued to experience net declines in scenario B1, with the extents of forests decreasing by 5.1 percent $\left(5,173 \mathrm{~km}^{2}\right)$ and grasslands/shrublands by almost 3 percent. Forest clearcutting decreases were the greatest across the entire Eastern United States, with a decrease of 53.8 percent $\left(5,305 \mathrm{~km}^{2}\right)$ during the projection period. The wetlands ecosystem, contrary to the economic scenarios, experienced a net increase of 5.1 percent $\left(5,985 \mathrm{~km}^{2}\right)$, with conversions to wetlands almost exclusively from agricultural lands. Agricultural lands experienced a net loss of 11.2 percent $\left(16,067 \mathrm{~km}^{2}\right)$ to developed lands and wetlands.

LULC changes in the Jacksonville, Florida, area are representative of the variety of changes that took place in the Mississippi Alluvial and Southeast USA Coastal Plains ecoregion. The extent of developed lands in scenarios A1B and A2 showed similar patterns of expansion into the forests and wetlands surrounding Jacksonville, whereas increases in developed lands in scenario B1 were much lower (fig. 3-15). Other developed lands expanded to the south of Camp Blanding, Fla., and came from forests, agricultural lands, and wetlands. Gains in agriculture are greatest in scenario A1B and can be seen expanding into the forest lands north of Camp Blanding. In scenario B1, agricultural losses to forested lands can be seen in several areas. Both Camp Blanding and Okefenokee Swamp were protected under all scenarios and thus growth was restricted in those places. 

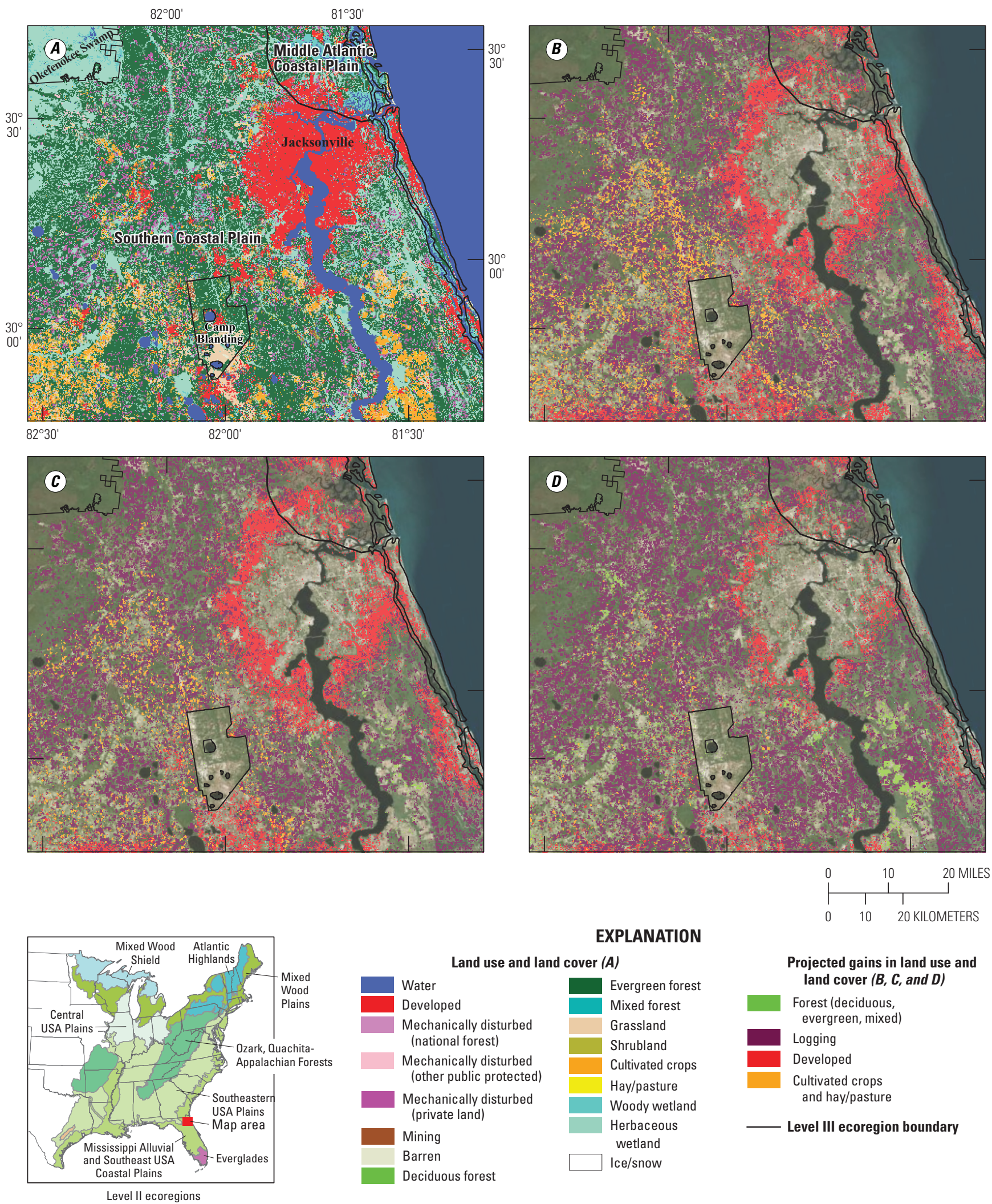

Figure 3-15. Maps showing $A$, land use and land cover (LULC) and a comparison of the projected LULC change in scenarios $B$, A1B, C, A2, and D, B1 in 2050 for the area around Jacksonville, Florida, in the Mississippi Alluvial and Southeast USA Coastal Plains ecoregion. Changes were projected to be the result of land-use change (agricultural lands, forests, developed lands) or forest clearcutting. 


\subsection{Validation and Uncertainty}

\subsubsection{Baseline Validation and Uncertainty}

For a historical period, a formal, quantitative validation of the 1992 through 2005 LULC maps is theoretically possible. Quantitative validation of LULC model output typically examines measurements of quantitative disagreement to ensure that the model produced the correct LULC quantities over a study area and allocation disagreement to ensure that the model place LULC change in the correct locations (Pontius and Millones, 2012). The quantity of mapped LULC change for the baseline period was informed and calibrated by data derived from the USGS Land Cover Trends Project for 1992 through 2000 and by the NLCD2006 land cover change product for LULC change from 2001 through 2005. The FORE-SCE model has the ability to precisely match prescribed proportions of LULC change and thus replicate the historical amounts of LULC change provided by the two datasets. Quantitative disagreement was therefore not an issue, because model runs were rejected if FORE-SCE could not accurately replicate the prescribed quantities of LULC change for any reason.

Conversely, allocation disagreement is potentially subject to validation. Given that all level III ecoregions were parameterized and modeled independently, allocation disagreement was partially mitigated because the proportions of LULC change were spatially distributed to the appropriate ecoregion. Allocation disagreement was thus only an issue within a level III ecoregion. Forest clearcuts were not modeled, but were mapped using the LANDFIRE VCT data. All other types of LULC change were modeled by FORE-SCE and were subject to allocation disagreement assessment. However, there were difficulties in assessing allocation disagreement using USGS trends and NLCD data. The USGS trends data are sample based, limiting our ability to make spatial comparisons with the wall-to-wall maps. The starting 1992 NLCD used a different classification scheme and mapping methodology than the 2001 NLCD, and the two datasets cannot be directly compared to determine change between 1992 and 2001. A retrofit product of LULC change between 1992 and 2001 was produced for NLCD, remapping the 1992 NLCD using 2001 methodologies; the retrofitted 1992 data represent a different product than the 1992 NLCD used for this work. The 2001 and 2006 NLCD data were produced using a consistent methodology and theoretically could be used to evaluate the allocation disagreement of the modeled LULC change for that period. However, the 2001 and 2006 NLCD products are not directly comparable to the starting 1992 NLCD, again making direct comparison with the modeled 2001 through 2006 maps of little use.

There is no single standardized methodology for judging all LULC models (Rykiel, 1996), and quantitative validation cannot serve as the sole basis for judging a model to be valid or invalid (Verburg and others, 2006). Given the lack of quantitative disagreement (with FORE-SCE matching prescribed LULC proportions), model assessment boils down to the question of whether LULC change is being placed in suitable locations. With quantitative validation difficult due to characteristics of the available historical LULC data, model assessment thus focused on qualitative assessment of model input parameters controlling suitability of the land to support a given LULC type and of model results. Suitability surfaces were constructed for each LULC class in every level III ecoregion of the Eastern United States, each serving to control the location of LULC change. For each and every suitability surface, the quality of the surface and the fidelity of the regressions used to create those surfaces were reviewed. Suitability surfaces with perceived statistical or representational issues were recreated and subject to further review. A similar qualitative assessment was used to judge final model performance. During the modeling process, the performance of the model from 1992 through 2005 was evaluated independently for each level III ecoregion using a visual assessment of the LULC change distribution. The assessment was based on historical and current patterns of change, LULC patch size characteristics, spatial arrangement and context, and dispersion patterns. An unacceptable distribution of LULC change resulted in a reparameterization of the FORE-SCE model, and a subsequent new model run was initiated, with the process repeating until model performance was deemed acceptable.

\subsubsection{Projected Validation and Uncertainty}

A formal validation of the projected LULC changes was not possible because there were no reference data for a future timeframe. Although a validation cannot be performed for the projected period, sources of uncertainty may be examined in the projections for the future. There are many sources of uncertainty for LULC projections into the future and may include data sources, modeling assumptions regarding future driving forces, misrepresentation of processes within the model, incomplete knowledge and unknowns, and uncertainty propagation between model components (Dendocker and others, 2008; Verburg and others, 2012). Sensitivity analyses on the effects of individual contributors to overall uncertainty have been performed by land cover modelers, but accounting for all sources of uncertainty and how they propagate through a LULC modeling framework remains a daunting challenge.

For this assessment, the proportions of the projected LULC change in the scenarios themselves were used to bound overall uncertainties regarding future LULC proportions. Although not all sources of uncertainty that contribute to the final maps of projected LULC could be quantitatively assessed, the same quantity and allocation disagreement measurements discussed previously may be used to examine sources of uncertainty between the modeled scenarios. In this context, a quantitative disagreement measurement can be used to examine the differences in projected LULC proportions between scenarios. The spatial modeling component of FORE-SCE introduced allocation disagreement between scenarios in that the spatial pattern of change at a pixel level 
may differ between two scenarios even if the prescribed scenario LULC proportions were similar. Applications of quantitative and allocation disagreement measurements to each pair of the three scenarios allowed for a determination of whether the per-pixel differences between scenarios maps were because of the scenario LULC prescriptions themselves or were a result of the spatial modeling and the placement of LULC change (Sohl and others, 2012a).

Total disagreement, the per-pixel measurement of differences between paired scenario images, was relatively similar between each scenario pair, topping out at around 14 percent by 2050 (fig. 3-16). However, the contributions of quantitative disagreement and allocation disagreement differ between scenario pairs. Even by 2050, the prescribed proportions of LULC change, as provided by scenarios $\mathrm{A} 1 \mathrm{~B}$ and $\mathrm{A} 2$, are quite similar, because quantitative disagreement is quite low. Most of the per-pixel differences between scenarios A1B and A2 are due to exact placement of change from the spatial allocation model, and not from prescribed scenario differences. Given the similarity between scenarios A1B and A2, results of comparisons of those scenarios to scenario $\mathrm{B} 1$ are quite similar. The comparisons between scenarios A1B and B1 and between scenarios A2 and $\mathrm{B} 1$ show significant levels of quantitative disagreement, with quantitative disagreement reaching similar levels as allocation disagreement by 2050 . This is a similar pattern to past FORE-SCE model runs with per-pixel differences in the placement of LULC change outweighing differences early in simulations due to the scenarios themselves, but with scenario differences becoming increasingly important as the model iterates forward in time (Sohl and others, 2012a). Although this assessment only analyzed change through 2050, LULC model runs were completed through 2100. In all scenario pairs, quantitative disagreement significantly increases after 2050, including in the A1B and A2 scenario pair, suggesting that in this modeling framework, long simulation periods are most effective for evaluating prescribed scenario differences. It should be noted, however, that allocation disagreement measures are calculated at the pixel level, and allocation disagreement will be measured even if LULC change is placed in very close proximity between two scenarios. Given the emphasis that FORE-SCE places on LULC change in suitable locations for a given LULC type, it is not expected that per-pixel differences between exact placement of LULC change patches would result in significant differences in reported carbon and GHG fluxes in this assessment, although future sensitivity analyses may be needed to confirm this.

Differences between scenarios can also be examined spatially to identify areas where future LULC is more certain (for example, same LULC type regardless of future modeled scenario) or more uncertain (for example, different LULC type due to either scenario or spatial allocation of LULC change). The spatial diversity image (fig. 3-17) indicates where the three scenarios are the same in 2050 and where they are different, at the pixel level. When examining differences between the three scenarios for 2050, 19.7 percent of all pixels for the Eastern United States are different between two or more scenarios, whereas 80.3 percent are the same between all scenarios. The scenarios are clearly the most different in forested ecoregions of the Southeast. Levels of forest clearcutting differ between the scenarios, and scenario differences clearly show up in the forested ecoregions of the Southeastern United States with high levels of timber activity. Quantitative disagreement (scenario differences) undoubtedly contributes to much of the per-pixel diversity, but allocation disagreement (pixel-level differences of where LULC change patches are placed) is also an important factor in differences between modeled scenarios (fig. 3-17). Forested regions with low amounts of cutting, such as those in the Northeast and upper Midwest, show lower diversity between scenarios than do the ecoregions in the Southeast. Scenarios are the most similar in heavily agricultural ecoregions, such as in the Corn Belt of the Midwest and the Mississippi Alluvial Valley.
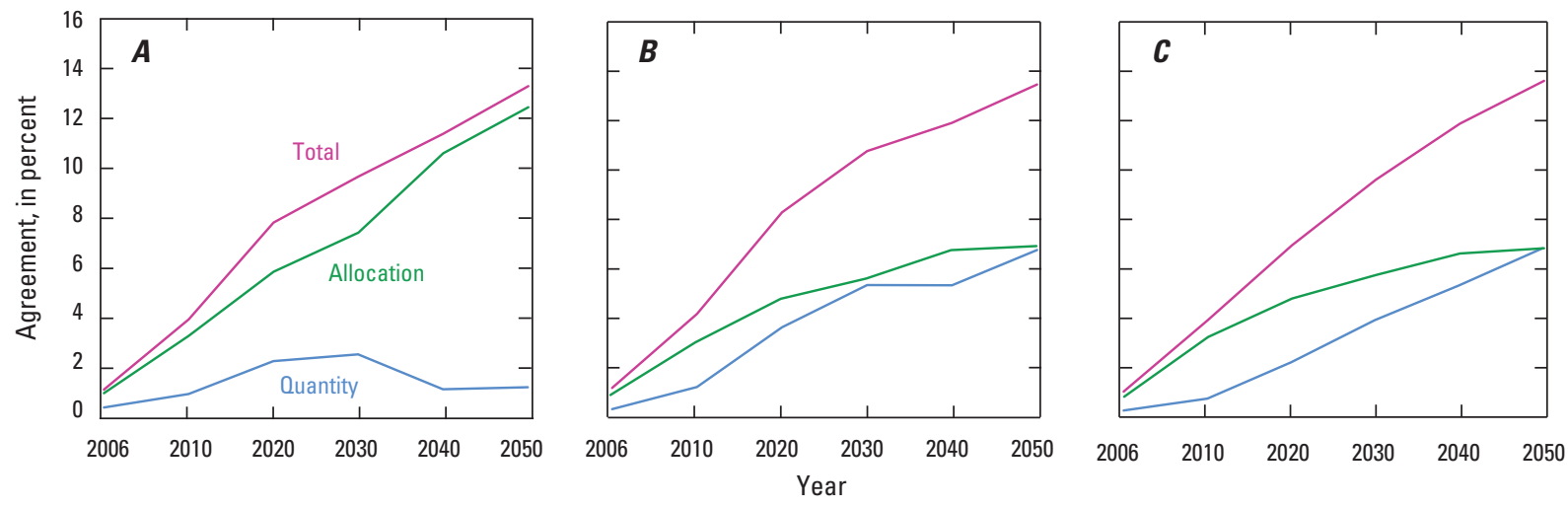

Figure 3-16. Graphs showing comparisons of quantity and allocation disagreement for land-use and land-cover scenarios (Nakićenović and others, 2000) A, A1B and A2, B, A2 and B1, and $C, \mathrm{~A} 1 \mathrm{~B}$ and $\mathrm{B} 1$ for the Eastern United States from 2006 through 2050. The total disagreement between scenario pairs is relatively similar for the three scenario pairs. However, scenarios A1B and A2 are clearly similar through 2050, with allocation disagreement making up most of the disagreement between scenarios A1B and A2 even by 2050. 


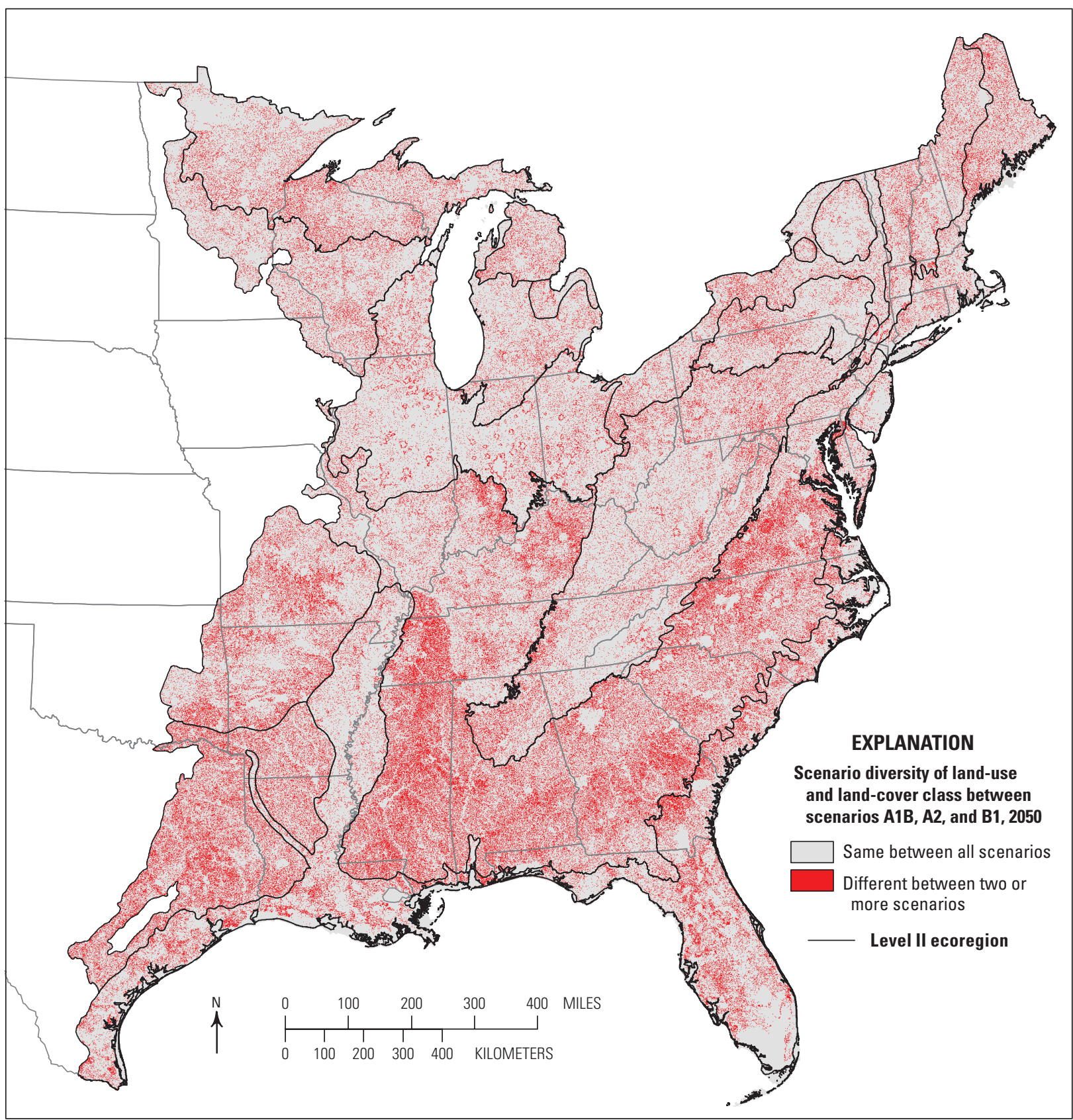

Figure 3-17. Map showing the spatial diversity between three land-use and land-cover scenarios (Nakićenović and others, 2000) in the Eastern United States in 2050. 


\title{
Chapter 4. Wildland Fire Occurrence and Emissions in the Eastern United States From 2001 Through 2050
}

\author{
By Todd Hawbaker and Zhiliang Zhu
}

\subsection{Highlights}

- During the baseline period of the wildland fire part of the assessment (2001 through 2008), the median of area burned by wildland fires was 1,355 square kilometers per year $\left(\mathrm{km}^{2} / \mathrm{yr}\right)$, and the 95 th percentile was $4,092 \mathrm{~km}^{2} / \mathrm{yr}$.

- During the baseline period of the wildland fire part of the assessment, the median of emissions from wildland fires was 5.2 teragrams of carbon dioxide equivalent per year $\left(\mathrm{TgCO}_{2}\right.$-eq/yr; $\left.1.4 \mathrm{TgC} / \mathrm{yr}\right)$, and the 95th percentile was $17.3 \mathrm{TgCO}_{2}$-eq/yr (4.7 TgC/yr).

- During the baseline period of the wildland fire part of the assessment, the median of wildfire emissions in the Eastern United States was equivalent to 0.51 percent of the average NEP $(279 \mathrm{TgC} / \mathrm{yr}$; chap. 7), and the 95 th percentile was 1.59 percent of the average NEP.

- During the baseline period of the wildland fire assessment, the median of wildfire emissions in the Eastern United States was equivalent to 0.09 percent of fossil fuel emissions for the United States, and the 95 th percentile was 0.31 percent of fossil fuel emissions for the United States.

- For the projected period (2009 through 2050), wildland fire occurrence and greenhouse-gas emissions increased in the Eastern United States under all of the climate-change scenarios considered in this assessment.

- For the projected period, there was substantial variability in the direction and magnitude of change among ecoregions, and not all ecoregions experienced increases in wildland fire occurrence and emissions under all climate-change scenarios.

- The projected median amount of area burned annually from 2041 through 2050 was as much as 51 percent greater than the median amount of area burned annually during the baseline years. The median annual emissions were projected to increase by as much as 41 percent from the baseline median annual emissions.
- Extreme fire years (years in which the amount of area burned are ranked the 95th percentile) are projected to become more extreme. The annual area burned in extreme fire years was projected to increase by 43 to 122 percent from the early conditions, and the 95th percentile of annual wildland fire emissions was projected to increase by 41 to 111 percent from the baseline 95th percentile estimate.

- Prescribed fire is an important land management tool in the Eastern United States; however, the lack of accurate and consistent data about prescribed fires limits understanding of their contributions to GHG emissions.

\subsection{Introduction}

The methodology for this assessment (Zhu and others, 2010) explicitly addressed ecosystem disturbances, including human- and natural-caused wildland fires, as required by the EISA (U.S. Congress, 2007). Estimates for the baseline and projected biomass combustion emissions from wildland fires and effects in long-term carbon balance were components of the assessment (fig. 1-2). Biomass combustion emission results are presented in this chapter. The baseline burned areas and the projected future potential burned areas for wildland fires and their severity, described in this chapter, were used as input into the assessment of the long-term effects of ecosystem carbon balances (chap. 5).

Wildland fires are a critical component of the global carbon cycle because they produce an immediate release of GHGs - $\mathrm{CO}, \mathrm{CO}_{2}$, and $\mathrm{CH}_{4}$ - when biomass is consumed through combustion (Seiler and Crutzen, 1980). However, previous estimates of emissions from wildland fires in the United States were highly variable, and after converting the reported emissions to carbon-dioxide equivalents, they were as follows:

- from $15 \mathrm{TgCO}_{2}$-eq/yr in 2001 to $73 \mathrm{TgCO}_{2}$-eq/yr in 2008 (Giglio and others, 2010; van der Werf and others, 2010; Oak Ridge National Laboratory, 2012),

- from $29 \mathrm{TgCO}_{2}$-eq/yr in 2001 to $199 \mathrm{TgCO}_{2}$-eq/yr in 2008 (French and others, 2011; Michigan Tech Research Institute, 2012), and 
- from $157 \mathrm{TgCO}_{2}$-eq/yr in 2002 to $283 \mathrm{TgCO}_{2}$-eq/yr in 2006 (Wiedinmeyer and Neff, 2007).

When compared with the 2010 estimate of $1,075 \mathrm{TgCO}_{2}$-eq/yr of net carbon flux from ecosystems in the continental United States reported by the EPA (U.S. Environmental Protection Agency, 2012), the annual emissions from wildland fires were equivalent to 1 to 26 percent of the ecosystem's total annual net carbon flux. In contrast, the combustion of fossil fuels produced 5,642 $\mathrm{TgCO}_{2} / \mathrm{yr}$ from 2001 to 2008 (U.S. Environmental Protection Agency, 2012), and emissions increased at a rate of 1 percent per year (Pacala and others, 2007). Based on these rates, the annual emissions from wildland fires were equivalent to 0.3 to 5.1 percent of the emissions from fossil-fuel consumption.

The differences among the variability and quality of these results, the spatial and temporal resolution of the data, and assumptions about variations in combustion efficiency were the primary sources of uncertainties in wildland fire emissions estimates (Larkin and others, 2009; French and others, 2011). The assumptions about the proportion of aboveground biomass consumed by wildland fire, especially aboveground woody biomass in forests, can have a substantial influence on emission estimates (Campbell and others, 2007; Meigs and others, 2009). The methods used to calculate emissions relied on estimates of the area that was burned, fuel loads (volume of live and dead biomass available for burning), combustion efficiency, and emission factors (Seiler and Crutzen, 1980; Albini and others, 1995; Wiedinmeyer and Neff, 2007; Ottmar and others, 2008). For example, the Global Fire Emissions Database (GFED; Giglio and others, 2010; van der Werf and others, 2010) estimates biomass consumption and emission at fire locations (including agricultural fires) detected by the National Aerospace and Space Administration's (NASA) moderate resolution imaging spectroradiometer (MODIS; Roy and others, 2002; Giglio and others, 2003) based on land-cover types, combustion completeness, soil moisture, and land-cover-specific emission factors. The GFED also incorporates changes in fuel loads using the Carnegie Ames Stanford approach to characterize biomass production (Potter and others, 1993, 2012). Wiedinmyer and Neff (2007) also used active wildland fire observations from MODIS satellite sensors (Giglio and others, 2003), but calculated the emissions based on static land-cover types, percentage of land cover, and biomass at 1-kilometer $(\mathrm{km})$ resolution. French and others (2011) used the Forest Service Consume model (Ottmar and others, 2008), which calculated fuel consumption and emission using fuel loads derived from the Forest Service Fuel Characteristic Classification System (FCCS; Ottmar and others, 2007) and fuel moistures derived from weather-station data.

Wildland fires also have long-term effects on ecosystem carbon balance by influencing the rate of carbon sequestration after combustion, through the decomposition of dead vegetation (which can provide nutrients to help establish new vegetation), and by reducing the rate of photosynthesis per unit area. Because of those effects, years to decades can pass before carbon stocks return to conditions before the fire (Turner and others, 1998; Cleary and others, 2010; Hurteau and Brooks, 2011; Kashian and others, 2012). If fire regimes are stable and assuming no other land management, the longterm effects of wildland fires on ecosystem carbon balance are typically negligible because carbon sequestration through growth of new vegetation and carbon loss through wildland fire emissions cancel out each other over long periods (Balshi and others, 2009a,b; Flannigan and others, 2009). However, if a fire regime changes, then the vulnerability for carbon storage is high because the amount of carbon stored in the ecosystem can be altered or lost through emissions.

Substantial evidence is available to document that fire regimes have not been static in modern times. For example, the frequency of wildland fires has been greatly reduced since settlement of the United States began mainly due to land-use changes and the success of fire suppression in the past century (Cleland and others, 2004). In the Western United States, the frequency of wildland fires has been increasing since the 1990s because of climate changes leading to an increasingly earlier snowmelt (Westerling and others, 2006). Wildland fires and emissions to carbon cycling are likely to be less important in the Eastern United States than in the Western United States, but limited research has been conducted quantifying relationships between wildfire occurrence and climate change in the Eastern United States. If the climate shifts to warmer and drier conditions, then increases in fire frequency and emissions are likely. Therefore, any comprehensive assessment of carbon storage and fluxes in ecosystems through time must account for the potential changes in wildland fire occurrence and emissions.

Wildland fire regimes are a function of the interactions between vegetation, land use, and ultimately, the climate (Swetnam and Betancourt, 1990; Gedalof and others, 2005; Westerling and others, 2006; Falk and others, 2007). A changing climate may result in changes in wildland fire regimes, including their occurrence and severity. Hessl (2011) outlined the primary pathways through which climate change may alter wildland fire regimes, including (1) altered fuel conditions, such as a change in fuel moisture; (2) altered fuel loads; and (3) changes in ignition patterns. The effects of climate change on wildland fires in the Eastern United States are expected to be significant and result in changes in weather patterns that would alter (1) ignition patterns, (2) wildland fire behavior, and (3) to a lesser extent, the distribution of vegetation. No single study, however, has addressed all three types of changes simultaneously at the scale required by this assessment (Flannigan and others, 2009).

Previous studies provided an estimate of the effects of wildland fires on carbon balance at a national scale but lacked the regional detail required by this assessment. Furthermore, there were few projections of future potential wildland fire emissions that were consistent with the existing baseline emission estimates. Therefore, a set of baseline emissions and projected future potential emissions was developed to ensure consistency throughout this and other regional assessments. 
The primary questions addressed in this chapter include: (1) what were the patterns of wildland fire occurrence and emissions in the Eastern United States? (2) what may be the potential changes in wildland fire occurrence and emissions for the Eastern United States under climate change? (3) how did recent wildland fire occurrence and emissions vary temporally and spatially among the ecoregions of the Eastern United States? and (4) which ecoregions of the Eastern United States have the greatest potential for changes in fire-occurrence and emissions?

\subsection{Methods and Data}

The wildfire modeling and estimation study for the carbon sequestration assessment of ecosystems of the Eastern United States had two tasks: (1) calculating the baseline quantities for wildland fire occurrence and emissions and (2) simulating future (2009-2050) projections of wildland fire occurrence and emissions under climate-change scenarios. The methods used for this study are the same methods (Hawbaker and Zhu, 2012) used in the USGS western ecosystem carbon sequestration assessment (Zhu and Reed, 2012). Some specific technical processes are common to both parts of the study; other methods are specific for a single task. The baseline estimates for the number of wildland fires, the area burned, and emissions were derived from the Wildland Fire Leadership Council's Monitoring Trends in Burn Severity (MTBS) database (Eidenshink and others, 2007) and the Forest Service's First Order Fire Effects Model (FOFEM; Reinhardt and others, 1997) for the major GHGs $\mathrm{CO}_{2}, \mathrm{CO}$, and $\mathrm{CH}_{4}$. This method was applied to each wildland fire in the region that was in the MTBS database to produce estimates of $\mathrm{CO}_{2}$, $\mathrm{CO}$, and $\mathrm{CH}_{4}$ emissions (converted to $\mathrm{CO}_{2}$ equivalents).

The wildland fire modeling approach used for the future projections in this assessment incorporated three primary components: wildfire ignitions, spread, and effects. The parameters for the ignition and spread components were selected through a calibration process using the baseline observed data, which were used to simulate future potential wildfires and burned areas and then FOFEM was used to estimate emissions for the simulated burned areas. Results of the baseline and future projections of wildland fires were aggregated to produce estimates of emissions for the Eastern United States as a whole and for each level II ecoregion within it (fig. 1-1; as described in detail in chapter 2 of this report). The datasets and methods used by the various wildland fire modeling components are described briefly in Hawbaker and Zhu (2012) and in more detail in the following sections.

\subsubsection{MTBS Wildland Fire Data}

The locations of wildland fires were taken from MTBS data (Eidenshink and others, 2007) and were used for baseline observations and to calibrate the ignition and spread components of the wildland fire modeling system. The MTBS data described fires that occurred from 1984 to 2008 and covered areas that were larger than 404 hectares (ha; 1,000 acres) in the Western United States and 202 ha (500 acres) in the Eastern United States. The MTBS data did not include small fires but captured the majority of the area burned because they included the largest fires, which contributed most to total area burned (Strauss and others, 1989; Stocks and others, 2002). Some prescribed fires are included in the MTBS database; however, they were excluded from this assessment because the completeness of prescribed fire coverage in the MTBS database was uncertain and likely underestimated actual prescribed fire use in the Eastern United States. Each wildland fire detailed in the MTBS database was identified in State or Federal fire records, and its burn scar and severity were manually mapped using Landsat imagery from before and after the fire. Because of the MTBS methodology, there was a high degree of confidence in the spatial and temporal accuracy of the wildland fire data, whereas other wildland fire databases had known problems, including duplicate records and erroneous locations (Brown and others, 2002), which would require laborious error checking before use.

\subsubsection{Fuels and Topography}

The methodology for the baseline and projected wildfires relied on vegetation, fuels, and topography data from the Landscape Fire and Resource Management Planning Tools (LANDFIRE) Program (Rollins, 2009) of the U.S. Department of the Interior (DOI) and the U.S. Department of Agriculture (USDA). These data included information about existing vegetation, fire-behavior fuel models, and tree canopy fuels (cover, height, base height, and bulk density), as well as the elevation, slope, and aspect of the terrain. To calculate emissions from wildland fires, the Fuel-Loading Model (FLM; Lutes and others, 2009) data layer of the LANDFIRE program was used. Vegetation and fuels were held static throughout the simulations for future wildfires and were not altered by simulated disturbances and other types of LULC change. All raster data were aggregated to 250-meter $(\mathrm{m})$ resolution in order to improve the processing efficiency using a nearest-neighbor rule (Lillesand and others, 2007). The nearest-neighbor aggregation was desirable because it preserved the proportion of vegetative-cover types within the study area, whereas other aggregation methods were more likely to result in common vegetative-cover types being overrepresented and uncommon vegetative-cover types being underrepresented.

\subsubsection{Weather and Climate Data}

The assessment methodology required daily weather data, including temperature, precipitation, relative humidity, and wind speeds, for the baseline and future periods. For the baseline period, gridded daily weather data for the conterminous United States with 0.125-degree $\left(^{\circ}\right)$ spatial resolution (approximately $12 \mathrm{~km}$ ) were used (Maurer and others, 2002). 
These data were interpolated from weather stations and included the minimum and maximum daily temperature and daily precipitation from 1950 to 2010 . The data on afternoon wind speed and direction from the $0.333^{\circ}$ (approximately $32 \mathrm{~km}$ ) North American regional reanalysis (Mesinger and others, 2006) were joined to the $0.125^{\circ}$ daily temperature and precipitation data.

In order to simulate the effects of the climate-change scenarios on wildland fire occurrence and emissions, downscaled monthly climate data provided by the World Climate Research Programme (WCRP) Coupled Model Intercomparison Project phase 3 (CMIP3) multimodel dataset were used. The CMIP3 data were corrected for bias and spatially downscaled to match the $0.125^{\circ}$-resolution baseline weather data (Maurer and others, 2007). For this analysis, the downscaled data from the Climate Research Branch of Environment Canada's Canadian Centre for Climate Modelling and Analysis (CCCma) third generation coupled global climate model (CGCM 3.1; Flato and Boer, 2001), the Australian Bureau of Meteorology's Commonwealth Scientific and Industrial Research Organisation Mark 3.0 (CSIRO Mk3.0; Gordon and others, 2000) climate model, and the Model for Interdisciplinary Research on Climate version 3.2 medium resolution (MIROC 3.2-medres; Hasumi and Emori, 2004) for each of climate-change scenarios A1B, A2, and B1 (chap. 2) were downloaded from the bias corrected and downscaled WCRP CMIP3 climate projections archive (Maurer and others, 2007; Meehl and others, 2007). The GCMs and scenarios were selected on the basis of their ability to capture past climate patterns (Balshi and others, 2009a,b). Additionally, the range of variability among the projections generally bracketed the extremes of temperature and precipitation projections for the conterminous United States (Gonzalez and others, 2010). Seasonal summaries of the climate projections were generated for the 1991 through 2020 and 2031 through 2060 periods. These 30 -year periods are after the baseline period (2001-2008) and the last decade of the projections (2041-2050) used in this assessment. Differences in temperature and precipitation among the 1991 through 2020 and 2031 through 2060 periods for the different climate-change scenario and GCMs used in this assessment are shown in figure 4-1.

The downscaled climate data only provided monthly temperature and precipitation values, so a temporal disaggregation algorithm (Wood and others, 2002) was implemented to produce the daily values necessary for wildland fire simulations. This algorithm randomly rearranged year-long sequences of the baseline weather data for each future year and then adjusted the disaggregated daily values of temperature and precipitation so that the monthly means matched the values provided by the monthly climate forecasts. Using this methodology, three replicate weather sequences were generated for each GCM and climate-change scenario combination for a total of 27 simulation runs. The number of GCMs used and replicate runs was ultimately limited by computing power and processing times.

For the baseline and future climate change scenarios, additional processing steps were taken to produce the live and dead fuel moisture variables required for simulating wildland fire spread and behavior. First, the University of Montana mountain climate simulator (MT-CLIM) algorithms (Glassy and Running, 1994) were used to calculate relative humidity based on minimum and afternoon daily temperatures (Kimball and others, 1997). Once humidity was estimated, the National Fire Danger Rating System (NFDRS) algorithms were used to estimate daily values for live and dead fuel moistures, as well as wildland fire behavior indices, such as an energy release component (ERC; Deeming and others, 1977; Bradshaw and others, 1983; Burgan, 1988). The NFDRS algorithms required information about the beginning of spring (green, up) and fall (brown, down) to estimate live fuel moistures. To account for potential shifts in phenology, a technique was implemented that determined the dates of seasonal
Number of wildland fires per year

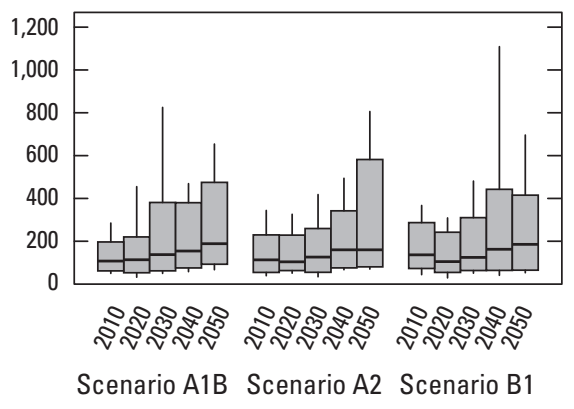

Area burned, in square kilometers per year

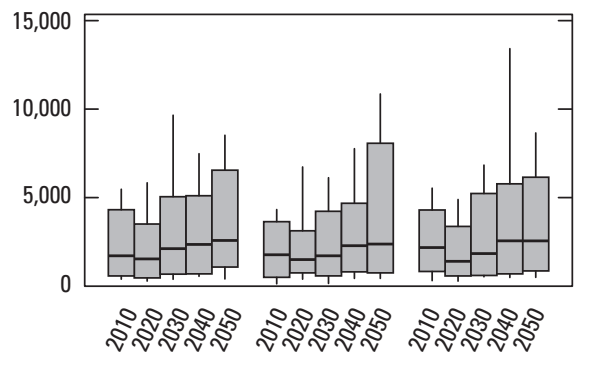

Scenario A1B Scenario A2 Scenario B1
Emissions, in carbon dioxide equivalent per year

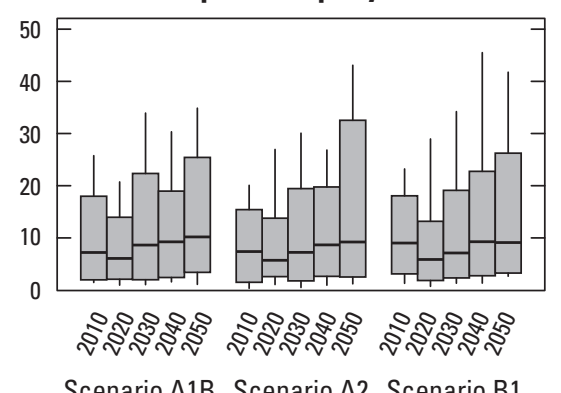

Figure 4-1. Graphs showing summaries of projected wildland fire ignitions, burned area, and emissions for the Eastern United States by decade from 2001 through 2050. The x-axis labels indicate the last year in the decade; for example, 2010 on the graph corresponds to the decade from 2001 through 2010. Scenarios A1B, A2, and B1 are from Nakićenović and others (2000).

EXPLANATION

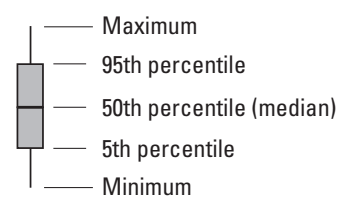


changes based on green-up and brown-down dates using an index that incorporated the daily photoperiod, minimum temperature, and the vapor-pressure deficit (Jolly and others, 2005).

\subsubsection{Baseline Wildland Fire Occurrence and Emissions}

Baseline wildland fire emissions were calculated for each burned pixel in the MTBS database using FOFEM, which used fuel loads along with fuel moistures to estimate the amount of forest litter and downed deadwood that was consumed (Albini and Reinhardt, 1995, 1997; Albini and others, 1995). The consumption of duff (decaying forest litter), trees, plants, and shrubs was estimated as a function of the region, season, fuel moistures, and fuel loads. Canopy fuel consumption was estimated as a function of the burn severity provided by the MTBS data. The emissions of $\mathrm{CO}, \mathrm{CO}_{2}$, and $\mathrm{CH}_{4}$ were then calculated based on the amount of fuel consumed, the organicmatter content of the fuel, and how efficiently it burned. The required input data for FOFEM included fuel loads, burn severity, and dead and live fuel moistures. To simplify the reporting of results, the emission estimates were summarized for all carbon-containing constituents to $\mathrm{CO}_{2}$ equivalents using the following equation:

$$
\mathrm{CO}_{2} \text {-eq }=\mathrm{CO}_{2}+(2.33 \times \mathrm{CO})+\left(21 \times \mathrm{CH}_{4}\right) \text {. }
$$

Fuel-load data provided an estimate of the amount of biomass that was available for consumption and were derived from the LANDFIRE Project's FLM data layer (Lutes and others, 2009). These fuel-load data were categorized by $1-, 10-, 100-$, and 1,000-hour fuel classes for dead, decaying (duff and forest litter), and live (grass, shrubs, and tree canopy) biomass. In the FOFEM, the amount of tree canopy that was consumed was a direct function of burn-severity values from the MTBS data. The amounts of canopy foliage consumed in the high, moderate, and low burn-severity categories were assumed to be 100 percent, 60 percent, and 20 percent, respectively. Similarly, the consumption of the canopy's branch wood in the high, moderate, and low burn-severity categories was set at 50 percent, 30 percent, and 10 percent, respectively. These values were based on previously published estimates (Spracklen and others, 2009; Zhu and others, 2010) and on a comparison of FOFEM emissions with previously published results for selected wildland fires. The emissions were calculated for wildland fires between 2001 and 2008. Wildland fires before 2001 were excluded because the LANDFIRE fuels data were derived from Landsat imagery from about 2001.

After calculating emissions, summaries of the wildland fire data for each level II ecoregion and for the entirety of the Eastern United States were generated for the baseline period. These summaries include the minimum, mean, median, 95th percentile, and maximum values for number of fires per year, area burned per year, and emissions per year. The median and 95th percentile summary statistics were assumed to represent typical and extreme fire years, respectively.

\subsubsection{Projected Future Wildland Fire Occurrence and Emissions}

Past studies generally suggest that the area affected by large wildland fires and emissions from the fires was a function of ignition patterns and fire behavior, primarily spread; ignition patterns and fire behavior were largely influenced by weather conditions, fuels, and topography (Cary and others, 2009) and in some regions, ignitions were influenced by human activity (Cardille and others, 2001; Syphard and others, 2007). Projecting the potential changes in wildfire patterns, therefore, required an understanding and accurate characterization of the drivers that created the observed patterns of ignitions, spread, and emissions (Keane and others, 2003; Flannigan and others, 2009; Hessl, 2011). Accordingly, the wildland fire modeling approach used for this assessment incorporated three primary components: wildfire ignitions, spread, and effects. The parameters for the ignition and spread components were selected through a calibration process using the baseline observed data, which were used to simulate future potential wildfires.

\subsubsection{Ignitions}

General linear models (GLMs) with a binary response were constructed to predict daily ignition probabilities within each $0.125^{\circ}$ weather grid cell. From the data described above, a suite of potential predictor variables was compiled that included daily weather statistics (minimum and maximum temperature and ERC), monthly weather summaries (temperature and precipitation), seasonal weather summaries (temperature and precipitation), and monthly and seasonal regional summaries of temperature and precipitation. Also included within the $0.125^{\circ}$ weather grid cells as potential predictors in the GLM modeling were the proportions of land area classified as public or urban and existing vegetation type groups from the LANDFIRE database.

Most observations (grid cells with daily weather data) had no data on ignitions; therefore, a subsample was selected using a case-control sampling design. Any observation with precipitation greater than 0.25 centimeters $(\mathrm{cm})$ was removed; this was done to ensure that ignition probabilities were zero on days with substantial precipitation that would limit fire spread. All observations with ignition data were retained along with a randomly selected set of observations without ignition data. The number of observations without ignition data was 10 times the number of observations with ignition data. The choice of design was somewhat arbitrary, but justified because the predictive performance of models using case-control sampling designs has been shown to increase with the ratio of cases to controls (Hastie and others, 2009). The intercept of the GLM was adjusted using equation 4-2 to account for unequal proportions of cases (ignitions) and controls 
(non-ignitions) in the sample compared with the population (Preisler and others, 2004; Hastie and others, 2009).

$$
\log \left(\frac{{\text { non }- \text { ignitions }_{\text {sample }}}_{\text {non }- \text { ignitions }_{\text {population }}}}{\text { igno }}\right)-\log \left(\frac{\text { ignitions }_{\text {sample }}}{\text { ignitions }_{\text {population }}}\right)
$$

To build the GLMs, an initial set of predictor variables was selected using forward stepwise regression, including only variables with $p$-values less than or equal to 0.05 and limiting the number of predictors to one-tenth the number of wildland fire observations. Each GLM was then evaluated and modified as needed to ensure that the selected predictor variables accurately described weather and climate conditions known to affect wildland fire occurrence in a given ecoregion. The overall performance of the final GLM was judged using the area under the curve (AUC) of a receiver-operator characteristic plot (Hanley and McNeil, 1982). The AUC measured the probability of correctly classifying a random pair of fire and nonfire observations; an AUC value of 0.5 indicated that the model predictions were equivalent to a random guess, and an AUC value of 1.0 indicated perfect predictions. AUC values greater than 0.8 were generally considered to be good.

\subsubsection{Spread}

During the simulations, the minimum travel time (MTT) algorithm (Finney, 2002) was used to simulate the spread of wildland fires after ignition. The MTT algorithm has been used extensively for local- and national-scale simulations of burn probability (Calkin and others, 2011; Finney and others, 2011). In addition to an ignition location, the MTT algorithm relied on fuels (surface and canopy), topography (elevation, slope, and aspect), weather (wind speed and direction), and live and dead fuel moisture data. The MTT algorithm also required a specified number of days and minutes per day that a wildland fire can spread. The outputs produced by the MTT algorithm included the arrival time (duration of the wildland fire since ignition) of every pixel representing burned area, as well as wildland fire-behavior metrics, such as fire line intensity and crown-fire activity.

\subsubsection{Emissions}

To calculate emissions, the FOFEM (Reinhardt and others, 1997; Reinhardt and Keane, 2009) was applied to each pixel burned by the simulated wildland fires using the same processing steps that were used for the baseline emissions.

\subsubsection{Calibration}

A number of calibration simulations were required to determine the appropriate number of days and minutes per day to allow wildland fires to spread using the MTT algorithm. The initial values for the minimum and maximum number of days to allow the spread and minutes of spread per day were selected based on values derived from Federal fire records. Nine replicate simulations were run using the available weather data (1984-2008). After the simulations were complete, a two-sided t-test was used to determine if the annual average area burned during the simulations differed significantly from the annual average area burned based on observations from the MTBS database. If the differences were significant, the number of days of fire spread and the minutes of spread per day were altered and the calibration process was repeated until the $p$-value of the t-test was less than 0.05 , indicating that the calibration simulations reproduced the baseline fire patterns.

\subsubsection{Simulations of Future Fires}

After calibration, future potential wildland fire ignitions, spread, and emissions were generated for three replicate simulations for each of the climate-change scenarios and GCMs, starting in 2001 and ending in 2050. The replicate simulations were run to help quantify uncertainty because of the stochastic nature of the models; more replicate simulations would have been ideal, but processing times limited the number of replicates to three. The simulated annual number of wildland fires, area burned, and emissions were summarized across the GCMs and replicates and were shown as the median and 95th percentile for each climate-change scenario for each decade, which represented typical and extreme fire years, respectively. The relative change between 2001-2010 and 2041-2050 were reported. Significance of each change was assessed at a 0.05 -alpha $(\alpha)$ level using Monte Carlo permutation test with 1,000 permutations (Hesterberg and others, 2012).

\subsubsection{Limitations and Uncertainties}

The results generated for this assessment for baseline wildfire emissions differed and were generally lower than estimates of emissions from the peer-reviewed literature for the Eastern United States. The highest estimates of emissions from peer-reviewed literature were from Wiedinmyer and Neff (2007), who used the active fire product from the MODIS sensors from 2002 to 2006 and estimated the mean of annual emissions to be $71 \mathrm{TgCO}_{2}$-eq for Alabama, Connecticut, Delaware, Florida, Georgia, Illinois, Indiana, Kentucky, Louisiana, Maine, Maryland, Massachusetts, Michigan, Mississippi, New Hampshire, New Jersey, New York, North Carolina, Ohio, Pennsylvania, Rhode Island, South Carolina, Tennessee, Vermont, Virginia, West Virginia, and Wisconsin. The area used in Wiedinmyer and Neff (2007) is not the same as the area used for this analysis of the Eastern United States.

French and others (2011) calculated emissions using the MTBS data and Consume model (Ottmar and others, 2008) for wildland fires occurring from 2001 to 2008; the results are available as ecoregion-level summaries (Michigan Tech Research Institute, 2012). When the results from French and 
others (2011) were summarized across the Eastern United States, the average and standard deviation of annual emissions were $20.5 \mathrm{TgCO}_{2}$-eq and $12 \mathrm{TgCO}_{2}$-eq, respectively. The emission estimates from these analyses were substantially greater than the estimates produced for this assessment. The differences among results are likely due to differences in methods, data, and the resolution of the data used. Wiedinmyer and Neff (2007) relied on 1-km-resolution active wildland fire data from MODIS and fuel data from the FCCS (U.S. Department of Agriculture, Forest Service, 2012a), which typically have higher fuel loads then the FLM data used for this assessment. They also assumed that all the available biomass could potentially burn, and that is often not the case, especially for woody fuels (Campbell and others, 2007; Meigs and others, 2009). French and others (2011) also used the 1-km-resolution FCCS fuels data and aggregated 1-km-resolution MTBS data. The fuel data in their report differed from the data layer used in this assessment in terms of information and resolution. The methods used in this assessment made use of fuel moistures, which are based on gridded daily weather data. The methods used by French and others (2011) also made use of fuel moistures, but recommended 10 percent levels for 1,000-hour availability and duff moistures, which are very favorable conditions for combustion. The full effects of the differences in fuel maps and moisture levels on the accuracy of fire modeling were difficult to assess, but these comparisons suggest that the results in this assessment are more conservative than previously published estimates of wildland fire emissions.

The MTBS data used in this assessment did not include small wildland fires, but they still captured the majority of the area burned because they included the largest wildland fires that contributed most to the amount of area burned (Strauss and others, 1989; Stocks and others, 2002). A comparison of the MTBS data with the Federal wildland fire-occurrence database (U.S. Department of Interior, 2012) showed that the MTBS listed only 3 percent of all wildland fires but accounted for 88 percent of the area burned in the Eastern United States. Therefore, the results of this assessment captured the general patterns and trends of wildland fires in the Eastern United States, but in all likelihood, underestimated wildland fire emissions.

In this assessment, the baseline and projected estimates of area burned and emissions also did not include the influence of prescribed and agricultural fires (for example, burning crop residues); however, the emissions produced by those types of fires were suspected to be low relative to the wildland fire emissions (Liu, 2004; van der Werf and others, 2010). The influence of prescribed fires on emissions was difficult to assess because the data characterizing prescribed fires were generally poor based on inconsistent reporting about them across the country. The existing estimates of emissions from prescribed fires suggested that they produced only 10 percent of the emissions from wildland fires (Liu, 2004), in part because prescribed fires usually burn under less extreme meteorological conditions than wildland fires. The influence of agricultural fires was also estimated to be about 10 percent of the wildland fire emissions in the GFED database.
In the Eastern United States, the relative amount of emissions produced by prescribed and agricultural fires is likely to be more substantial than in other parts of the United States, because agricultural fires are common in the region (Korontzi and others, 2006; Tulbure and others, 2011). Prescribed fires in the Eastern United States, especially those in the Southeast, accounted for 70 percent of the area burned by prescribed fires nationwide, and area burned by prescribed fires in the study area was more than 2.5 times the area burned by wildfires (based on 2002 to 2008 data from the National Interagency Fire Center, 2012). Unfortunately, records for many prescribed fires are not entered into national-level databases, so accurate data characterizing the individual locations of each prescribed fire are not available. In the MTBS database, the area burned by prescribed fires was only 18 percent of the total area burned in the Eastern United States. Because prescribed fires burn under less extreme meteorological conditions, severity and emissions are expected to be lower than wildfires (Liu, 2004; Outcalt and Wade, 2004; van der Werf and others, 2010). However, speculating about the locations of prescribed fires, the fuels they burn though, and the conditions under which they burn would likely introduce a greater amount of uncertainty into the emission estimates provided in this assessment. These uncertainties will remain difficult to resolve until better information is available on the timing and location of prescribed fires.

In spite of the uncertainties about the timing and location of prescribed fires in the Eastern United States, emission estimates have been included in the EPA's National Greenhouse Gas Emissions Inventory (U.S. Environmental Protection Agency, 2012) and can provide some indication of the impact of prescribed fires on emissions. The EPA methods for wildland and prescribed fire emissions focus on forests and apply emission factors to carbon stock-changes. The EPA estimates for 2005, 2007, and 2008 for wildfire emissions averaged $144.3 \mathrm{TgCO}_{2}$-eq/yr and for prescribed emissions averaged $20.3 \mathrm{TgCO}_{2}$-eq/yr for the conterminous United States. Assuming that 70 percent of prescribed fires occur in the Eastern United States (National Interagency Fire Center, 2012), then average annual emissions from prescribed fires would be $14.2 \mathrm{TgCO}_{2}$-eq/yr, a value substantially larger than the median wildfire emissions from the baseline period of this assessment $\left(5.2 \mathrm{TgCO}_{2}\right.$-eq/yr). However, the EPA's wildfire estimates for the continental United States (144.3 $\mathrm{TgCO}_{2}$-eq/yr) are also substantially larger than those produced for this assessment, the Great Plains assessment (Zhu and others, 2011), and the Western assessment (Hawbaker and Zhu, 2012), which collectively had a median value of $56.0 \mathrm{TgCO}_{2}$-eq/yr and a maximum value of $101.4 \mathrm{TgCO}_{2}$-eq/yr.

Throughout the wildland fire simulations, vegetation and fuels remained static, which introduced some limitations into the assessment. Because of succession and disturbances (especially anthropogenic, such as LULC change), the composition and structure of vegetation may change substantially during the 50-year span used in this assessment (Foster and others, 1998; Gallant and others, 2004; Rhemtulla and others, 2009). 
These changes could result in altered surface and canopy fuels that influence wildland fire behavior and emissions. By holding land use, vegetation, and fuels static, the interactions among wildland fire and LULC change were oversimplified, which are limitations that are shared by many broad-scale studies of projected climate change and wildland fires.

Vegetation dynamics have often been ignored in climate-change projections in part because of the difficulty of parameterizing the successional trajectories of each individual ecosystem type and the lack of information about how ecosystems may shift across the landscape under climate change. The influence that vegetation dynamics might have had on the results of this assessment is uncertain. In spite of the projected increases in wildland fire ignitions and area burned simulated for this assessment, the extent of the area burned each year was projected to be quite small relative to the extent of area that could potentially burn in an ecoregion. Thus, in the ecoregions included in this portion of the assessment, it is unlikely that the amount and arrangement of burnable vegetation on the landscape will limit wildland fires. Shifts in vegetation, however, might affect the type of vegetation and the amount of fuel available to burn; thus, past wildland fires and LULC change might alter the fuels, behavior, and emissions of future wildland fires (Bachelet and others, 2001, 2003).

Specifically, in the Eastern United States these processes could include the mesophication of forests in the mid-Atlantic throughout southern Appalachia that is reducing understory vegetation density and the flammability of litter fuels (Nowacki and Abrams, 2008). In the Southeastern USA Plains and the Mississippi Alluvial and Southeast USA Coastal Plains ecoregions, crown fire occurrence and wildland fire emissions could potentially increase with shifts in the acreage of short-rotation pine forests, with little fire management. Defoliation and mortality following insect outbreaks can affect substantial areas in the Eastern United States. The effects of insect outbreaks on carbon cycling in the Eastern United States could include short-term decreases in primary productivity and increases in respiration through altered decomposition rates (Hicke and others, 2012). However, the effects of insect disturbances on carbon cycling at ecoregional scales are not well understood, and models to predict where future outbreaks are likely are not currently available, thus the effects of insect disturbances were not incorporated into this assessment. These processes and vegetation dynamics into the ecosystem-disturbance model component should be considered for incorporation into future carbon assessments (Running, 2008; Goetz and others, 2012).

\subsection{Results}

Results for the baseline and future potential projections of wildland fire occurrence and emissions are presented using summary statistics of the median and 95th percentile values. These were assumed to represent typical and extreme fire years respectively.

\subsubsection{Baseline Wildland Fires and Emissions}

During the baseline period (2001-2008) in the Eastern United States, the number of wildland fires per year in a typical fire year was 112 , but year-to-year variability was high, and as many as 186 wildfires occurred during extreme fire years (fig. 4-2; table 4-1). The area burned by wildfires in a typical fire year was $1,355 \mathrm{~km}^{2}$, but was more than twice that in extreme fire years $\left(4,092 \mathrm{~km}^{2}\right)$. Annual emissions from wildfires were 5.2 teragrams of carbon dioxide equivalent $\left(\mathrm{TgCO}_{2}\right.$-eq) during typical fire years, but more than four times that amount in extreme fire years $\left(17.3 \mathrm{TgCO}_{2}\right.$-eq).

Combined, the Mixed Wood Shield and Mixed Wood Plains ecoregions had the least amount of fire activity among
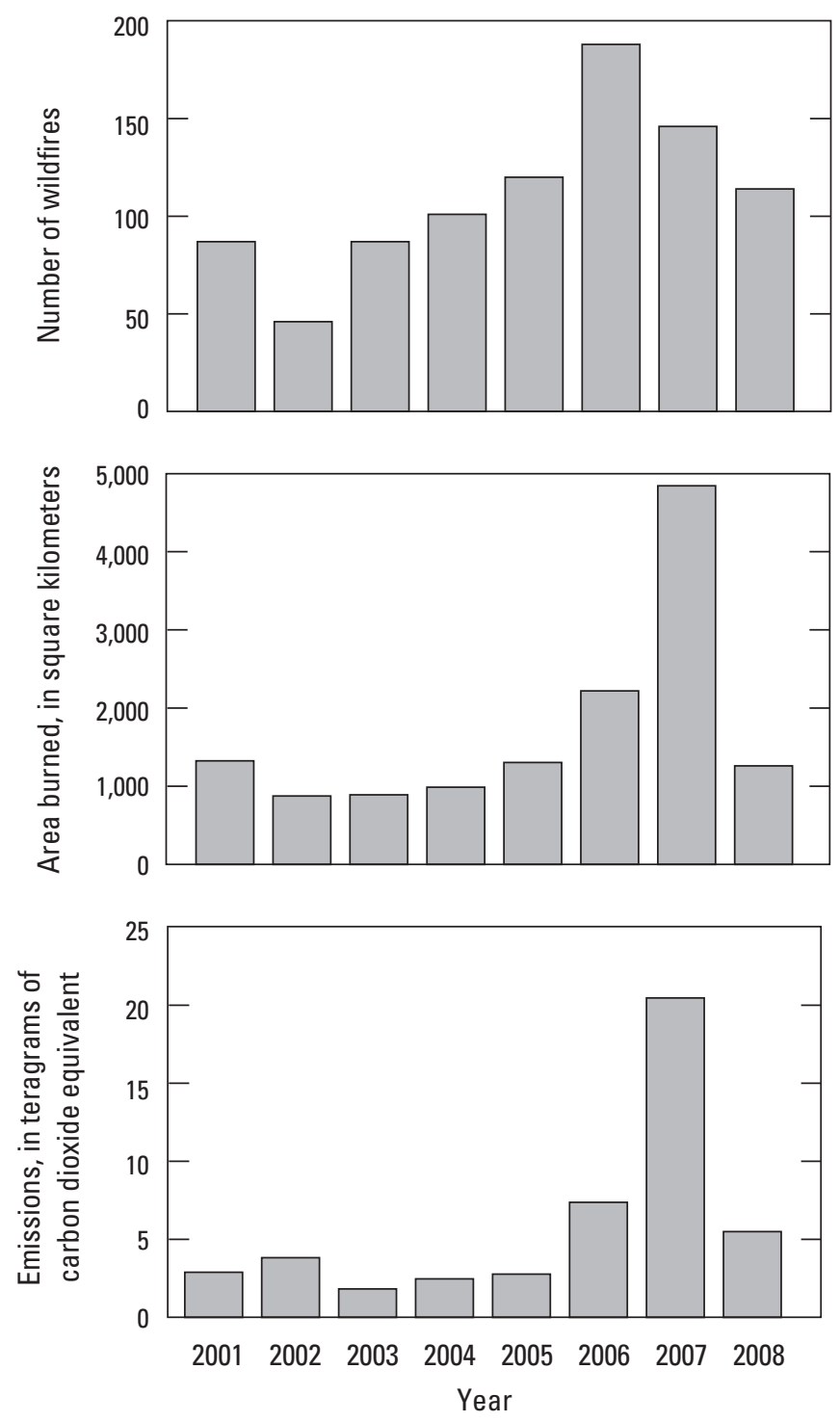

Figure 4-2. Graphs showing the annual number of wildland fires, area burned, and emissions for the baseline (2001-2008) period of the carbon flux and storage assessment of the Eastern United States. 
Table 4-1. Summary statistics for the number of wildland fires, area burned, and emissions.

\begin{tabular}{|c|c|c|c|c|c|}
\hline Metric & $\begin{array}{l}\text { Mixed Wood Shield } \\
\text { and } \\
\text { Mixed Wood Plains }\end{array}$ & $\begin{array}{l}\text { Southeastern } \\
\text { USA Plains }\end{array}$ & $\begin{array}{l}\text { Ozark, Ouachita- } \\
\text { Appalachian Forests }\end{array}$ & $\begin{array}{l}\text { Mississippi Alluvial } \\
\text { and Southeast USA } \\
\text { Coastal Plains }{ }^{1}\end{array}$ & $\begin{array}{c}\text { Eastern } \\
\text { United States }\end{array}$ \\
\hline \multicolumn{6}{|c|}{ Number of wildfires per year } \\
\hline Minimum & 1 & 2 & 13 & 24 & 60 \\
\hline Median & 9 & 10 & 41 & 49 & 112 \\
\hline 95th percentile & 17 & 49 & 54 & 97 & 186 \\
\hline \multicolumn{6}{|c|}{ Area burned, in square kilometers per year } \\
\hline Mean & 173 & 137 & 311 & 1,225 & 1,851 \\
\hline Minimum & 3 & 21 & 60 & 499 & 974 \\
\hline Median & 81 & 52 & 382 & 746 & 1,355 \\
\hline 95th percentile & 497 & 417 & 462 & 3,164 & 4,092 \\
\hline Maximum & 523 & 526 & 470 & 4,035 & 5,048 \\
\hline 95th percentile & 5.8 & 1.0 & 1.3 & 11.9 & 17.3 \\
\hline Maximum & 6.0 & 1.3 & 1.3 & 15.6 & 22.3 \\
\hline
\end{tabular}

${ }^{1}$ Includes the Everglades and Texas-Louisiana Coastal Plain level II ecoregions for the analysis of this assessment.

the four ecoregions analyzed in the Eastern United States (fig. 4-3A; table 4-1). The median number of wildfires per year was 9 , and the 95th percentile of wildfires per year was 17. Area burned during typical fire years was $81 \mathrm{~km}^{2}$ and was as high as $497 \mathrm{~km}^{2}$ in extreme fire years. Emissions were very low at $1.2 \mathrm{TgCO}_{2}$-eq/yr in a typical fire year. However, in spite of having the least amount of wildfires and area burned, emissions during extreme fire years were relatively high in this ecoregion at $5.8 \mathrm{TgCO}_{2}$-eq/yr.

In the Southeastern USA Plains ecoregion, the median values for wildfire occurrence, area burned, and emissions were 10 wildfires per year, $52 \mathrm{~km}^{2} / \mathrm{yr}$, and $0.1 \mathrm{TgCO}_{2}$-eq/yr, respectively (fig. 4-3B; table 4-1). The number of wildfires, area burned, and emissions were much greater during extreme fire years at 49 wildfires per year, $417 \mathrm{~km}^{2} / \mathrm{yr}$, and $1 \mathrm{TgCO}_{2}$-eq/yr, respectively.

Fire occurrence in the Ozark, Ouachita-Appalachian Forests ecoregion during typical fire years was greater than in the Southeastern USA Plains, Mixed Wood Shield, and Mixed Wood Plains ecoregions (fig. 4-3C; table 4-1). The number of wildfires, area burned, and emissions were 41 per year, $382 \mathrm{~km}^{2} / \mathrm{yr}$, and $0.9 \mathrm{TgCO}_{2}$-eq/yr, respectively. Rates of wildfire occurrence and emissions were not substantially different during extreme fire years when the number of wildfires, area burned, and emissions were 54 per year, $462 \mathrm{~km}^{2} / \mathrm{yr}$, and $1.3 \mathrm{TgCO}_{2}$-eq/yr, respectively.

Among the four ecoregions of the Eastern United States, the Mississippi Alluvial and Southeast USA Coastal Plains ecoregion had the greatest number of wildfires, area burned, and emissions (fig. 4-3D; table 4-1). During typical fire years, the number of wildfires, area burned, and emissions were 49 per year, $746 \mathrm{~km}^{2} / \mathrm{yr}$, and $2.8 \mathrm{TgCO}_{2}$-eq/yr, respectively. During extreme fire years, there were nearly twice as many wildfires (97 per year), with more than four times as much area burned $\left(3,164 \mathrm{~km}^{2} / \mathrm{yr}\right)$ and emissions $\left(11.9 \mathrm{TgCO}_{2}\right.$-eq/yr).

\subsubsection{Climate-Change Trends in the Eastern United States}

In the Eastern United States, general warming trends were projected across all seasons and almost all GCMs between the 1991 through 2020 and 2031 through 2060 periods (fig. 4-4). As noted before, to compare results of baseline and future projection years, these intervals were used because they were centered over the adjusted baseline period (2001 through 2010, \pm 10 years) and the last decade of the projections (2041 through $2050, \pm 10$ years). Temperatures were projected to increase by 1 to 2 degrees Celsius $\left({ }^{\circ} \mathrm{C}\right)$ for all ecoregions and all seasons across the Eastern United States. Precipitation changes were more variable, but appeared to have a decreasing trend (drier) in the summer and fall. Patterns of winter and spring precipitation varied depending on the ecoregion and scenario, but tended toward increased moisture in the Northeast, Upper Great Lakes, and the Ozark and Appalachian Mountains and decreased in the Southeastern USA Plains and Mississippi Alluvial and Southeast USA Coastal Plain ecoregions (fig. 4-4). For temperature and precipitation, the spatial patterns of change were generally similar for a given GCM across scenarios, but appeared to be more variable across the GCMs than the scenarios.

In the Mixed Wood Shield ecoregion, average seasonal temperature change was projected to be $1.9^{\circ} \mathrm{C}, 1.4^{\circ} \mathrm{C}, 1.4^{\circ} \mathrm{C}$, and $1.2^{\circ} \mathrm{C}$ for the winter, spring, summer, and fall seasons, respectively. Precipitation changes were more variable and depended on the specific scenario and GCM. In general, 
Number of wildfires

A. Mixed Wood Shield and Mixed Wood Plains

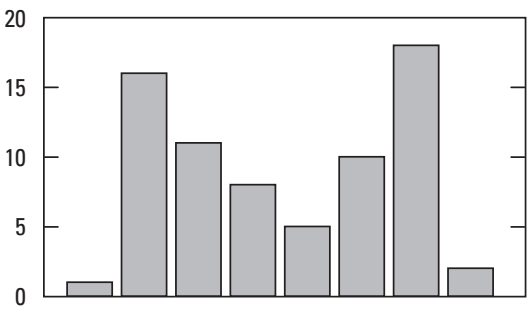

Area burned, in square kilometers

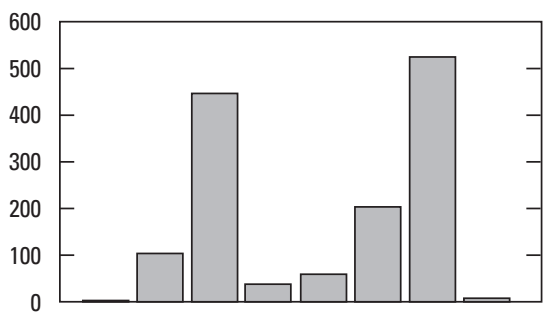

Emissions, in teragrams of carbon dioxide equivalent

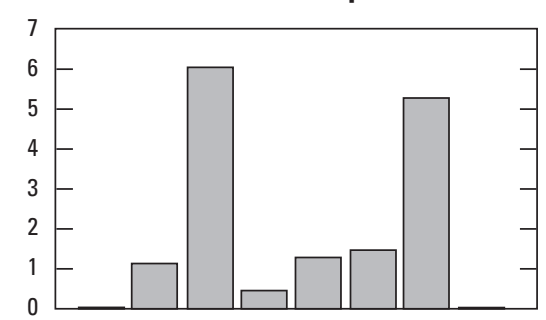

\section{B. Southeastern USA Plains}

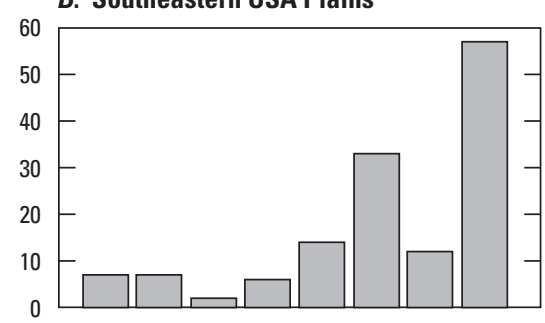

C. Ozark, Ouachita-Appalachian Forests

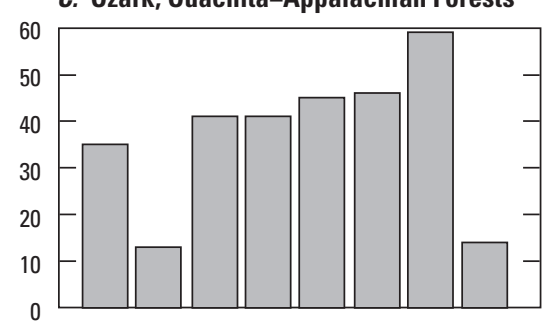

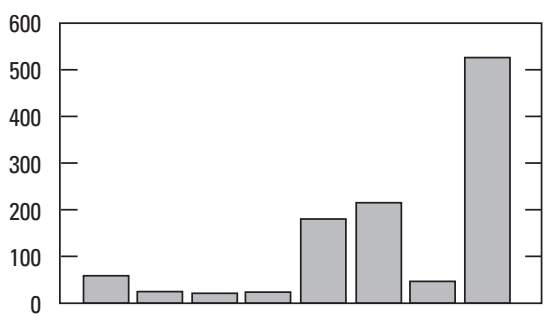

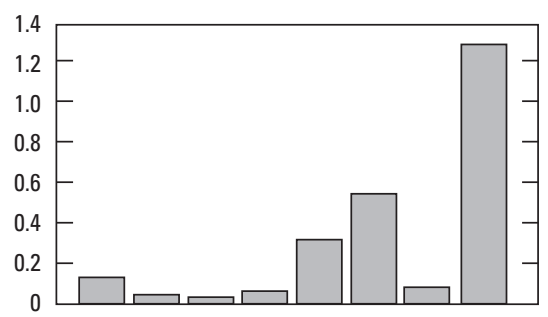

D. Mississippi Alluvial and Southeast USA Coastal Plains
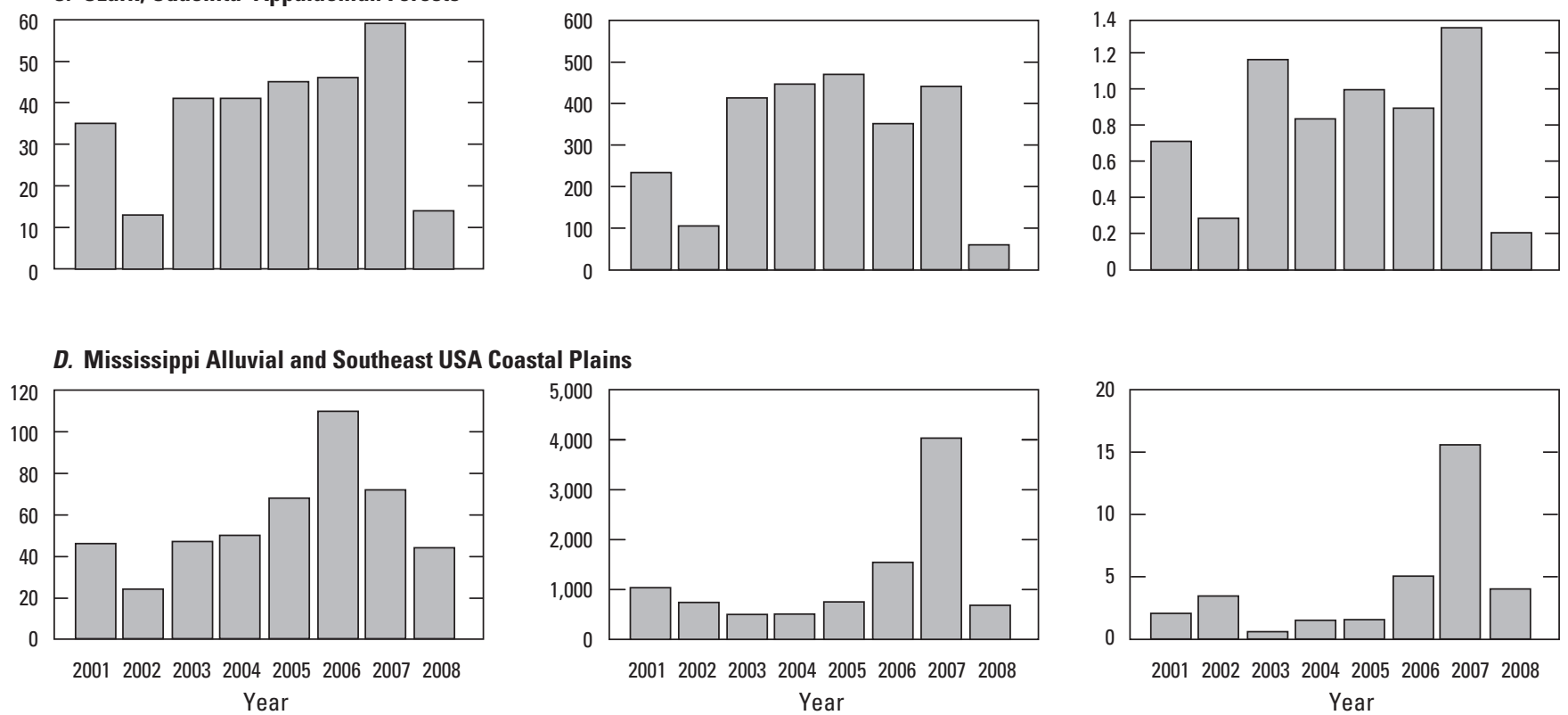

Figure 4-3. Graphs showing the annual number of wildland fires, area burned, and emissions for the baseline (2001-2008) period for the $A$, Mixed Wood Shield and Mixed Wood Plains, B, Southeastern USA Plains, $C$, Ozark, Ouachita-Appalachian Forests, and $D$, Mississippi Alluvial and Southeast USA Coastal Plains ecoregions (U.S. Environmental Protection Agency, 2013a) in the Eastern United States. 
Temperature change
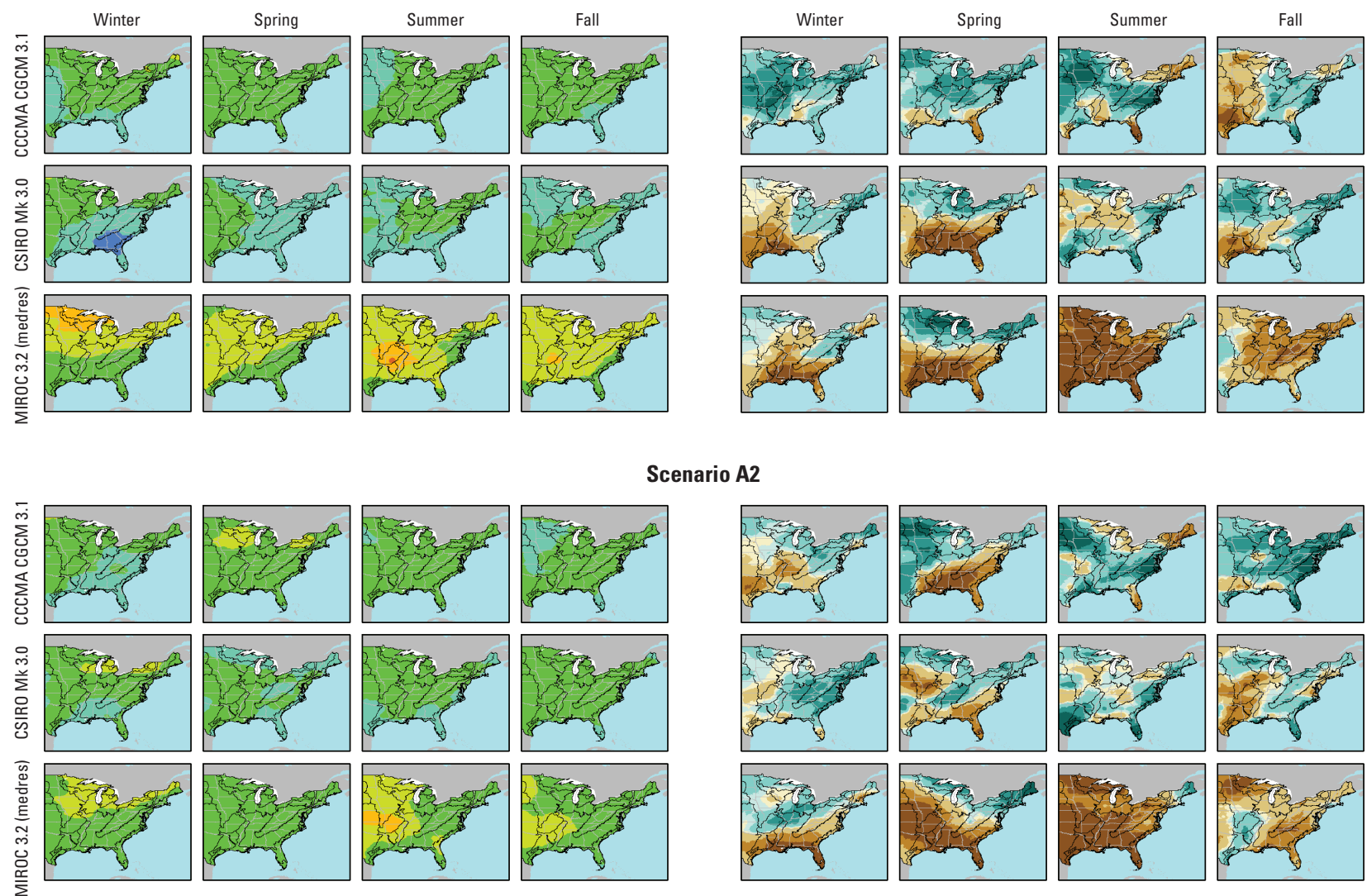

Scenario B1
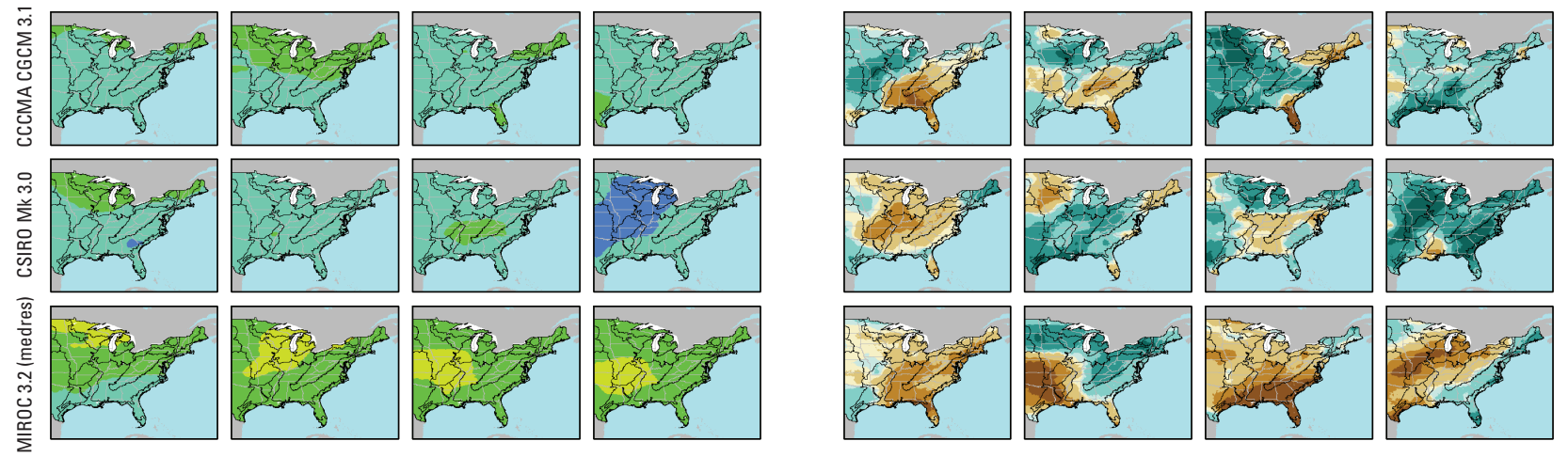

EXPLANATION

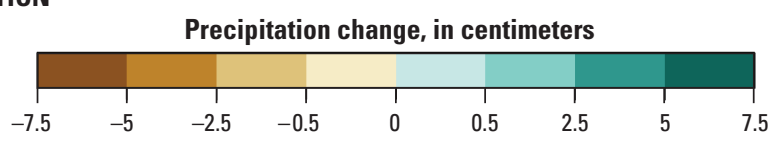

Figure 4-4. Maps showing the projected changes in mean daily temperature and total precipitation by season, calculated using the difference in mean values from 2031 through 2060 and from 1991 through 2021. Climate data are from Maurer and others (2007). Scenarios A1B, A2, and B1 are from Nakićenović and others (2000). CCCMA CGCM 3.1, Canadian Centre for Climate Modelling and Analysis third generation coupled global climate model; CSIRO Mk 3.0, Commonwealth Scientific and Industrial Research Organisation Mark 3.0; MIROC 3.2 (medres), Model for Interdisciplinary Research on Climate version 3.2 medium resolution. 
winter and spring seasons were projected to have increases in precipitation of $0.5 \mathrm{~cm}$ and $2.4 \mathrm{~cm}$, respectively. Precipitation decreased in the summer season by $0.5 \mathrm{~cm}$, and fall precipitation changed little.

Warming trends were also projected by most scenarios and GCMs in the Southeastern USA Plains ecoregion. Average winter, spring, summer, and fall temperatures were $1{ }^{\circ} \mathrm{C}$, $1.3^{\circ} \mathrm{C}, 1.4^{\circ} \mathrm{C}$, and $1.3^{\circ} \mathrm{C}$, respectively, greater in the 2031 through 2050 period than they were in the 1991 through 2020 period. Winter and spring precipitation decreased by $1.1 \mathrm{~cm}$ and $1.9 \mathrm{~cm}$, respectively. Summer and fall projections were more mixed depending on the GCM and scenario. Average summer precipitation decreased by $0.9 \mathrm{~cm}$, but average fall precipitation increased slightly by $0.3 \mathrm{~cm}$.

Similar to the Southeastern USA Plains ecoregion, temperature changes in the Ozark, Ouachita-Appalachian Forests ecoregion increased the least in winter $\left(1.2^{\circ} \mathrm{C}\right)$ and the most in spring $\left(1.4^{\circ} \mathrm{C}\right)$, summer $\left(1.5^{\circ} \mathrm{C}\right)$, and fall $\left(1.3^{\circ} \mathrm{C}\right)$. In all seasons, the GCMs and scenarios were evenly split with about how precipitation would change: about half of the simulations projected drier conditions, and half projected wetter conditions. When the precipitation change projections were averaged across GCMs and scenarios, winter precipitation decreased minimally by $0.04 \mathrm{~cm}$, spring precipitation decreased by $0.5 \mathrm{~cm}$, summer precipitation decreased by $0.9 \mathrm{~cm}$, and fall precipitation increased slightly by $0.3 \mathrm{~cm}$.

Projected changes in temperature for the Mississippi Alluvial and Southeast USA Coastal Plains ecoregion were the smallest among all ecoregions in the Eastern United States. Winter, spring, summer, and fall temperatures were projected to increase by $0.9^{\circ} \mathrm{C}, 1.2^{\circ} \mathrm{C}, 1.3{ }^{\circ} \mathrm{C}$, and $1.2^{\circ} \mathrm{C}$, respectively, between the 1991 through 2020 and 2031 through 2050 periods. Precipitation changes were consistently drier in the winter and spring seasons (decreases of $1.4 \mathrm{~cm}$ and $2.5 \mathrm{~cm}$, respectively) and to some extent in the summer season (decrease of $1.6 \mathrm{~cm}$ ), but precipitation increased slightly in the fall season $(0.6 \mathrm{~cm})$.

\subsubsection{Projected Future Wildland Fires and Emissions}

GLMs were fit to each level III ecoregion and used to generate daily ignition probabilities in the simulations. In general, the model fits were good with the AUC values averaging 0.87 and ranging from 0.72 to 0.93 . The best model fits were in the level III ecoregions within the Ozark, Ouachita-Appalachian Forests and the worst model fit was for the Southern Florida Coastal Plain level III ecoregion (reported with the Mississippi Alluvial and Southeast USA Coastal Plains ecoregion in this report). Most models included the energy release component (ERC) or 10- or 100-hour dead fuel moistures as a predictor as well as monthly and seasonal weather summaries (which captured seasonal and year-toyear variability). Most ecoregions also included at least one vegetation predictor. Developed land (which included high- and low-density urban areas, golf courses, urban parks, and highways), public lands, and (or) area of wildland vegetation and agriculture were often included as predictors too. When included, developed land and agriculture had negative relationships with wildfire ignition probability, and public lands and wildland vegetation area had positive relationships with ignition probability.

Calibration simulations were run for each level III ecoregion to ensure that the patterns of wildland fire occurrence from 1984 through 2008 could be reproduced. For all the ecoregions, there was no significant difference in the average annual burned area between the calibration simulation and the observed values from the MTBS database, assuming that differences were not significant when a $p$-value of 0.05 or greater was calculated using a two-sided t-test that assumed unequal variance. After the calibration process, the simulated wildland fires were allowed to spread between 4 to 24 hours per day, and the burn durations ranged from 1 to 6 days, depending on the ecoregion.

For the entire Eastern United States and across all the climate-change scenarios, the projection simulations resulted in an increase in wildland fire ignitions, area burned, and emissions between the first (2001-2010) and last (2041-2050) decades (fig. 4-1; table 4-2). In typical fire years, the median number of ignitions was projected to increase, ranging from 36 percent under scenario $\mathrm{B} 1$ to 42 percent under scenario A2 and 75 percent under scenario A1B. The area burned was projected to increase, ranging from a 17 percent increase in scenario $\mathrm{B} 1$ to a 51 percent increase in scenario A1B. Wildland fire emissions followed similar patterns, with projected increases of 41 percent under scenario A1B, 25 percent under scenario A2, and 1 percent under scenario B1. However, the changes in median area burned and emissions were not statistically significant at a $0.05 \alpha$ level under scenario B1. Characteristics of scenarios $\mathrm{A} 1 \mathrm{~B}, \mathrm{~A} 2$, and $\mathrm{B} 1$ are provided in chapter 2 .

The simulated changes in ignitions, area burned, and emissions were significantly greater in extreme fire years (95th percentile); across the Eastern United States, ignitions were projected to increase by 45 to 153 percent, the area burned was projected to increase by 43 to 122 percent, and emissions were projected to increase by 41 to 111 percent (fig. 4-1; table 4-2). The rate of change was generally nonlinear, and the greatest increases in ignitions, area burned, and emissions were projected in 2021 to 2030 for scenario A1B, 2041 to 2050 in scenario A2, and 2031 to 2040 in scenario B1.

There was a large amount of variability in the projections of future potential wildfires, area burned, and emissions in the Mixed Wood Shield and Mixed Wood Plains ecoregions (fig. 4-5A; table 4-2) and not all the changes were statistically significantly different from zero. Ignitions increased by as much as 71 percent during typical fire years and as much as 43 percent during extreme fire years. Area burned and emissions did not necessarily increase even though ignitions did under all scenarios. During typical fire years, the change 
Number of wildland fires per year

A. Mixed Wood Shield and Mixed Wood Plains

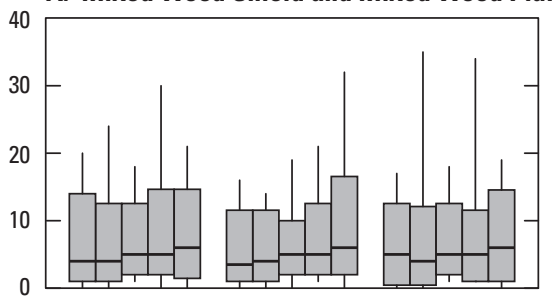

B. Southeastern USA Plains

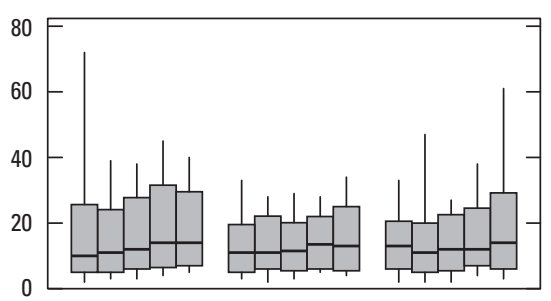

Area burned, in square kilometers per year

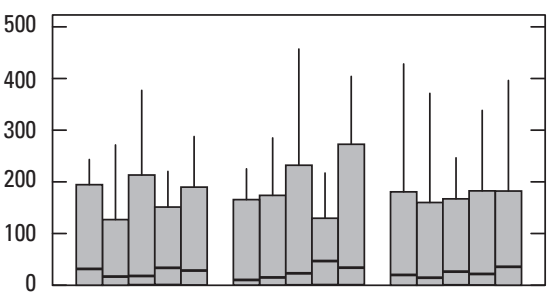

Emissions, in carbon dioxide equivalent per year

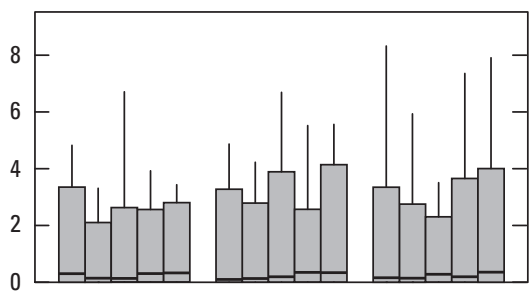

\section{Ozark, Ouachita-Appalachian Forests}
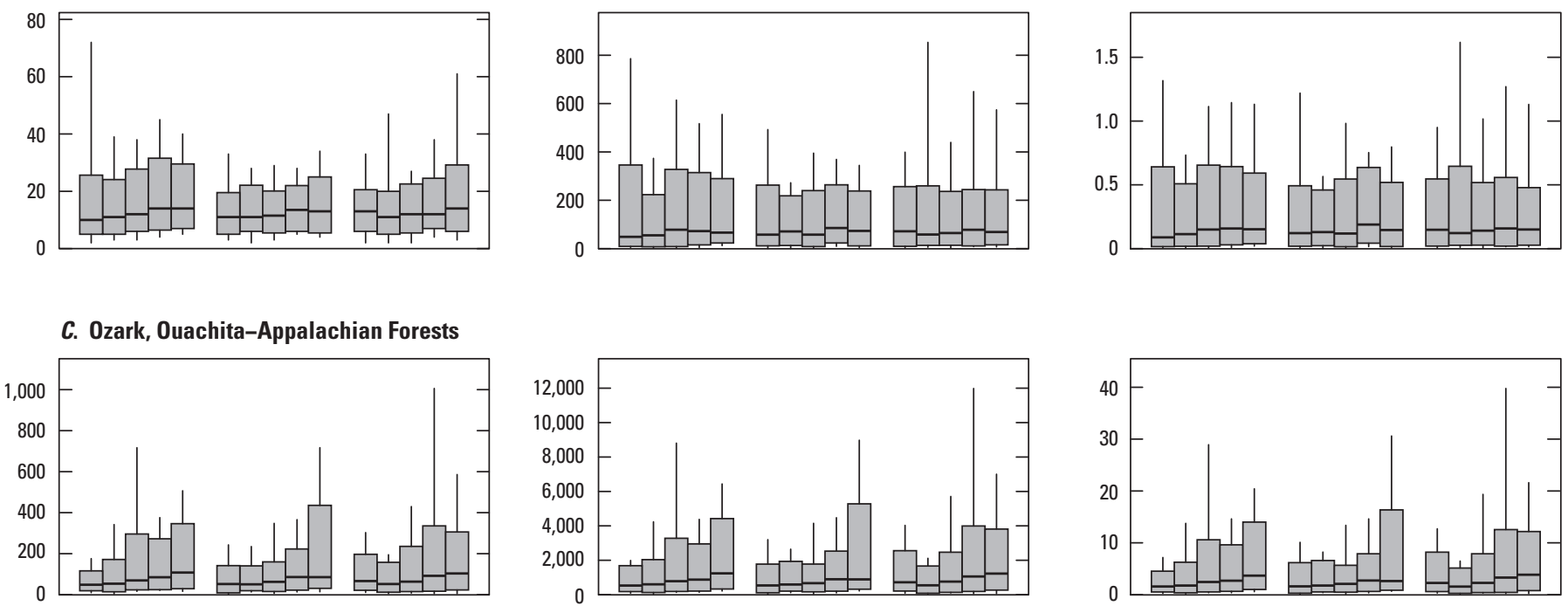

D. Mississippi Alluvial and Southeast USA Coastal Plains

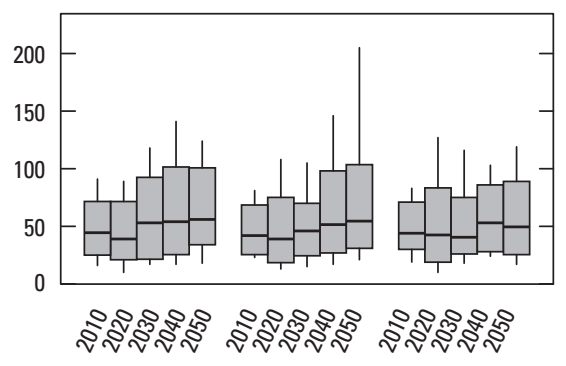

Scenario A1B Scenario A2 Scenario B1

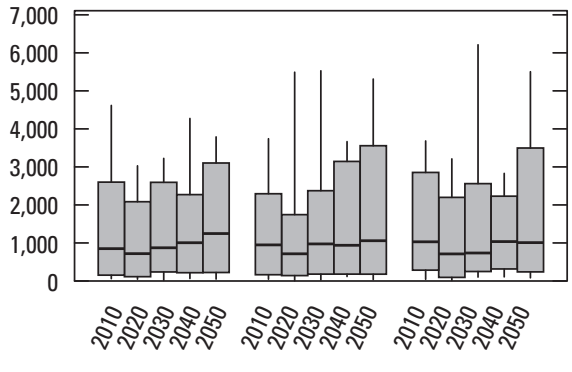

Scenario A1B Scenario A2 Scenario B1

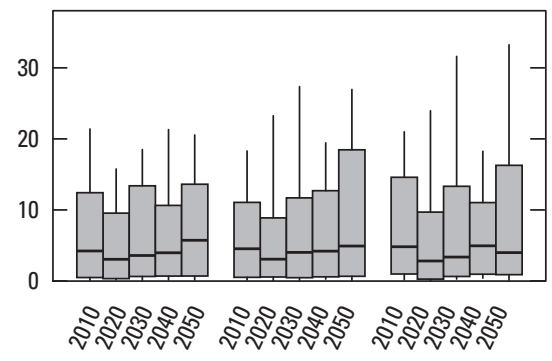

Scenario A1B Scenario A2 Scenario B1

Figure 4-5. Graphs showing summaries of projected wildland fire ignitions, burned area, and emissions for the $A$, Mixed Wood Shield and Mixed Wood Plains, $B$, Southeastern USA Plains, $C$, Ozark, Ouachita-Appalachian Forests, and D, Mississippi Alluvial and Southeast USA Coastal Plains ecoregions (U.S. Environmental Protection Agency, 2013a) by decade from 2001 through 2050. The $x$-axis labels indicate the last year in the decade; for example, 2010 on the graph corresponds to 2001 through 2010. Scenarios A1B, A2, and B1 are from Nakićenović and others (2000).

\section{EXPLANATION}

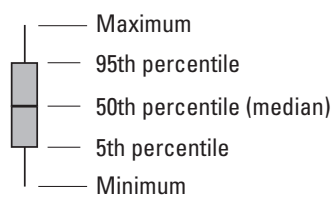


in the amount of area burned ranged as much as 234 percent in scenario A2, and in emissions, as much as 246 percent in scenario A2. The large amount of change is likely an artifact of the small amount of area burned and emissions during the baseline period ( $5 \mathrm{~km}^{2}$ and $0.04 \mathrm{TgCO}_{2}$-eq, respectively), so that even small increases resulted in large relative change. The projected changes for ignitions, area burned, and emissions were less in extreme fire years than in typical fire years and were mostly not statistically significant. Ignitions increased by as much as 43 percent, area burned changed by as much as 65 percent, and emissions changed by as much as 26 percent, but only changes in ignitions under scenario A2 were statistically significant.

In the Southeastern USA Plains ecoregion, projected changes were only statistically significant for typical fire years under scenario A1B (fig. 4-5B; table 4-2), during which ignitions increased by as much as 40 percent, burned area increased by as much as 36 percent, and emissions increased by as much as 72 percent. Projected changes for the number of wildfires, area burned, and emissions were not statistically significant for scenario A1B for extreme fire years and for scenarios A2 and B1 for typical and extreme fire years.

The Ozark, Ouachita-Appalachian Forests ecoregion experienced the greatest amount of change in the Eastern United States in fire occurrence and emissions in typical and extreme fire years, and the all the projected changes were substantial (fig. 4-5C; table 4-2). The number of ignitions was projected to change by 56 to 123 percent in typical fire years and 55 to 207 percent in extreme fire years. Projected changes in burned area were similar and increased by 66 to 133 percent in typical fire years and 49 to 197 percent in extreme fire years. Changes in emissions largely followed changes in burned area and increased by 64 to 132 percent in typical fire years and 48 to 209 percent in extreme fire years.

Projected changes in fire occurrence and emissions in the Mississippi Alluvial and Southeast USA Coastal Plains ecoregion generally increased (fig. 4-5D; table 4-2). Decreases were projected under some climate-change scenarios, but were not statistically significant. In typical fire years, the amounts of change ranged by as much as 30 percent for ignitions, 47 percent for area burned, and 36 percent for emissions. The decreases occurred under scenario B1, and increases were projected for scenarios A1B and A2. In extreme fire years, fire occurrence and emissions increased under all scenarios. Changes ranged by as much as 51 percent for ignitions, 55 percent for area burned, and 67 percent for emissions.

\subsubsection{Summary of Wildland Fire Occurrence and Emissions of Carbon Fluxes}

From 2001 through 2008, wildland fire activity in the Eastern United States was less substantial than other regions of the United States. Large wildland fires numbered between 60 and 200 per year and burned 974 to $5,048 \mathrm{~km}^{2}$ each year. These wildland fires in the Eastern United States

Table 4-2. Relative projected changes in the 50th and 95th percentiles for wildfire ignitions, area burned, and emissions between 2001-2010 and 2041-2050.

\begin{tabular}{|c|c|c|c|c|c|c|}
\hline Scenario & Metric & $\begin{array}{c}\text { Mixed Wood Shield } \\
\text { and } \\
\text { Mixed Wood Plains }\end{array}$ & $\begin{array}{l}\text { Southeastern } \\
\text { USA Plains }\end{array}$ & $\begin{array}{c}\text { Ozark, Ouachita- } \\
\text { Appalachian Forests }\end{array}$ & $\begin{array}{c}\text { Mississippi Alluvial } \\
\text { and Southeast USA } \\
\text { Coastal Plains }{ }^{1}\end{array}$ & $\begin{array}{c}\text { Eastern } \\
\text { United States }\end{array}$ \\
\hline \multicolumn{7}{|c|}{ Percentage of number of wildfires per year } \\
\hline $\mathrm{A} 1 \mathrm{~B}$ & Median & $50 *$ & $40 *$ & $123^{*}$ & $26^{*}$ & $75 *$ \\
\hline A2 & Median & $71 *$ & 18 & $64 *$ & $30 *$ & $42 *$ \\
\hline B1 & Median & 20 & 8 & $56^{*}$ & 12 & $36 *$ \\
\hline $\mathrm{A} 1 \mathrm{~B}$ & 95 th percentile & 5 & 15 & $198 *$ & $41 *$ & $141 *$ \\
\hline A2 & 95 th percentile & $43 *$ & 28 & $207 *$ & $51 *$ & $153 *$ \\
\hline $\mathrm{B} 1$ & 95 th percentile & 16 & 42 & $55^{*}$ & $25 *$ & $45^{*}$ \\
\hline \multicolumn{7}{|c|}{ Percentage of area burned per year } \\
\hline A1B & Median & -10 & $36^{*}$ & $133^{*}$ & $47 *$ & $51 *$ \\
\hline A2 & Median & $234 *$ & 27 & $66^{*}$ & 12 & $34 *$ \\
\hline B1 & Median & 79 & -4 & $70 *$ & -2 & 17 \\
\hline $\mathrm{A} 1 \mathrm{~B}$ & 95 th percentile & -2 & -16 & $162 *$ & 19 & $52 *$ \\
\hline A2 & 95 th percentile & $65 *$ & -9 & $197 *$ & $55^{*}$ & $122 *$ \\
\hline $\mathrm{B} 1$ & 95 th percentile & 1 & -5 & $49 *$ & 22 & $43 *$ \\
\hline \multicolumn{7}{|c|}{ Percentage of emissions per year } \\
\hline A1B & Median & 9 & $72 *$ & $132 *$ & $36^{*}$ & $41 *$ \\
\hline $\mathrm{A} 2$ & Median & $246^{*}$ & 20 & $64 *$ & 9 & $25^{*}$ \\
\hline B1 & Median & 127 & 2 & $70 *$ & -17 & 1 \\
\hline A1B & 95 th percentile & -16 & -8 & $209 *$ & 10 & $41 *$ \\
\hline $\mathrm{A} 2$ & 95 th percentile & 26 & 5 & $164 *$ & $67 *$ & $111 *$ \\
\hline $\mathrm{B} 1$ & 95 th percentile & 20 & -12 & $48 *$ & 12 & $45^{*}$ \\
\hline
\end{tabular}

${ }^{1}$ Includes the Everglades and Texas-Louisiana Coastal Plain level II ecoregions for the analysis of this assessment. 
represented 23 percent of all wildland fires that occurred in the conterminous United States from 2001 through 2008 and are mapped in the MTBS database and accounted for 10 percent of all the area burned. The median of annual emissions was $5.2 \mathrm{TgCO}_{2}$-eq/yr, which was equivalent to 0.48 percent of NEP (chap. 5). The interannual variability in emissions was high and ranged from 2.9 to $22.3 \mathrm{TgCO}_{2}$-eq in the Eastern United States, which was equivalent to 0.27 to 2.05 percent of NEP. In 2010, the median of annual wildfire emissions was $5,594 \mathrm{TgCO}_{2}$-eq/yr, equivalent to 0.09 percent of nationwide fossil-fuel emissions (U.S. Environmental Protection Agency, 2012); minimum wildfire emissions were 0.13 percent and maximum wildfire emissions were 0.40 percent of the nationwide fossil-fuel emissions. The relative contribution of wildland fires of the Eastern United States to nationwide greenhouse-gas emissions was small when compared that of other regions of the United States (Zhu and others, 2010; Hawbaker and Zhu, 2012) and to the contribution of fossil-fuel emissions.

Wildland fire ignitions and area burned were projected to increase across all the climate-change scenarios for the Eastern United States as a whole, and the changes were larger for extreme fire years than for typical fire years. The annual amount of area burned by wildfires in the Eastern United States was projected to increase by as much as 51 percent from $1,355 \mathrm{~km}^{2}$ in typical fire years and as much as 122 percent from $4,092 \mathrm{~km}^{2}$ in extreme fire years. The projected changes in burned area resulted in similar changes in emissions, which increased by as much as 41 percent from $5.2 \mathrm{TgCO}_{2}$-eq in typical fire years and between 41 and 111 percent from 17.3 $\mathrm{TgCO}_{2}$-eq in extreme fire years. These changes were driven by the influence of climate change on live and dead fuel moisture levels, which in turn had a large influence on ignition probabilities, fire spread, fuel consumption, and emissions.

The magnitude and direction of change of the wildfire projections varied among ecoregions and climate-change scenarios. The only ecoregion that had consistent increases in the number of wildfires, area burned, and emissions across all climate-change scenarios was the Ozark, OuachitaAppalachian Forests ecoregion. The Mixed Wood Shield and Mixed Wood Plains ecoregions projected increases in ignitions under all scenarios and increases in area burned and emissions under scenarios A2 and B1, but not for scenario A1B where precipitation projections suggested a wetter climate. The Southeastern USA Plains ecoregion had mixed results, with typical fire years experiencing mostly increases in ignitions, area burned, and emissions, but with extreme fire years experiencing decreases in area burned and emissions. The Mississippi Alluvial and Southeast USA Coastal Plains ecoregion experienced increases in fire occurrence and emissions under scenarios A1B and A2, but not under scenario B1.

In this study area, wildfire emissions were relatively low compared with carbon sequestered in terrestrial ecosystems (chap. 5), but this does not necessarily mean that wildfires do not have important effects on carbon balance in the Eastern United States. Instead, the largest effects of wildfires on carbon balance in the Eastern United States might be localized to specific ecosystems that currently have high carbon storage, but are at risk of losing carbon because of increased fire activities or altered fire behavior. These ecosystems may include pocosin wetlands with deep peat deposits along the Atlantic coast (Messina and Conner, 1998), southern boreal forests also with deep peat deposits and high fuel loads in the Upper Great Lakes (Heinselman, 1973), pine barrens in the Upper Great Lakes and New Jersey (Forman, 1998; Radeloff and others, 2000), and pine forests in the Southeastern USA Coastal Plains (Christensen, 1999). Management efforts designed to maintain or increase carbon storage in these ecosystems may be challenged by the potential carbon losses due to the projected climate-driven increases in wildland fire activities. In other ecosystems in the Eastern United States, wildfire plays a smaller role in carbon cycling, and other natural disturbances may be more important, for example, wind throw (Canham and Loucks, 1984; Frelich and Lorimer, 1991) and anthropogenic LULC change (chap. 3). 



\title{
Chapter 5. Carbon Sequestration, Transport, and Emission From Inland Aquatic Ecosystems in the Eastern United States
}

\author{
By Sarah Stackpoole, ${ }^{1}$ David Butman, ${ }^{1}$ David Clow, ${ }^{1}$ Cory McDonald, ${ }^{2}$ Edward Stets, ${ }^{1}$ and Robert Striegl ${ }^{1}$
}

\subsection{Highlights}

- The total surface area of inland waters in the Eastern United States was 93,000 km², which represented about 3.1 percent of the total land surface area of the region.

- Riverine ecosystems of the Eastern United States were carbon sources, exporting dissolved inorganic carbon and total organic carbon to coastal areas at a rate of $6.4 \mathrm{gC} / \mathrm{m}^{2} /$ $\mathrm{yr}$ and emitting $14 \mathrm{gC} / \mathrm{m}^{2} / \mathrm{yr}$ as $\mathrm{CO}_{2}$ to the atmosphere.

- Lacustrine systems of the Eastern United States were sources and sinks of carbon with $3.3 \mathrm{gC} / \mathrm{m}^{2} / \mathrm{yr}$ emitted as $\mathrm{CO}_{2}$ to the atmosphere and $3.1 \mathrm{gC} / \mathrm{m}^{2} / \mathrm{yr}$ of carbon sequestered in sediments.

- There was considerable variability in the estimated carbon fluxes of inland waters among the seven ecoregions in the Eastern United States. This was likely due to the differences in the size and abundance of water bodies, topography, climate, and land cover associated with each ecoregion.

\subsection{Introduction}

Section 712 of the EISA specifically required an assessment of carbon fluxes related to freshwater aquatic ecosystems. This chapter focuses on freshwater ecosystems, including streams, rivers, perennial ponds, lakes, and impoundments, which collectively are categorized as inland waters. Carbon sequestration rates in coastal estuaries, which are transition zones between rivers and oceans, are presented in chapter 6 , and carbon fluxes from wetland systems are addressed in chapter 7. Carbon fluxes associated with aquatic ecosystems (this chapter) were assessed separately from those of terrestrial ecosystems (chap. 7) in this report because of limited empirical aquatic data and a lack of a large-scale, spatially explicit carbon model that integrates terrestrial and aquatic fluxes.

Inland waters are active sites for transport, transformation, and storage of carbon between terrestrial landscapes and oceans

\footnotetext{
${ }^{1}$ U.S. Geological Survey
}

${ }^{2}$ Wisconsin Department of Natural Resources
(Cole and others, 2007; Striegl and others, 2007; Tranvik and others, 2009). On a global scale, inland waters cover only about 1 percent of the land surface (Battin and others, 2009), but carbon emissions from inland waters to the atmosphere are comparable in magnitude with terrestrial NEP values (Tranvik and others, 2009). So although inland aquatic systems represent less than 3 percent of the total land surface of the United States (Zhu and others, 2010), they may play a significant role in the regional carbon budget in the Eastern United States.

The objective of this chapter is to provide baseline estimates of carbon sequestration, carbon transport, and gaseous carbon emissions from inland waters for the seven ecoregions of the Eastern United States. In addition to national maps depicting the spatial extent of water bodies, datasets of water chemistry, flow, and sedimentation rates, spanning from 1920 through 2011, were used to calculate the following fluxes: (1) lateral transport of DIC and total organic carbon (TOC) in riverine systems, (2) gaseous carbon emissions in the form of $\mathrm{CO}_{2}$ from riverine systems, (3) gaseous carbon emissions in the form of $\mathrm{CO}_{2}$ from lacustrine systems, and (4) carbon burial rates in sediments of lacustrine systems. All ecoregion boundaries used in this chapter are consistent with those presented in chapter 1 (U.S. Environmental Protection Agency, 2013a).

Differences in physiography, land cover, and climate associated with each ecoregion are expected to have an effect on carbon storage, transport, and loss to the atmosphere. Flux values presented in this chapter were normalized to total land surface area to produce yield estimates. These baseline estimates of carbon yields were then used in two integrated analyses to compare (1) relative magnitudes of yield values of inland waters among ecoregions and (2) yields of inland waters to terrestrial carbon storage.

\subsection{Methods and Data}

\subsubsection{Lateral Carbon Transport in Riverine Systems}

Lateral carbon fluxes in riverine systems account for carbon derived from terrestrial ecosystems, groundwater, and in-stream production (photosynthesis) minus the losses from sedimentation and $\mathrm{CO}_{2}$ flux to the atmosphere. Water-quality 
data for estimating lateral fluxes were obtained from the National Water Information Service (NWIS; U.S. Geological Survey, undated). In this chapter, lateral fluxes are represented by calculations derived from two different datasets, the Coastal Export Dataset and the Ecoregion Dataset.

Flux values calculated using the Coastal Export Dataset were categorized by the receiving body of water. For the Eastern United States, this included the Atlantic Ocean, Great Lakes, Gulf of Mexico, and Rainy River. The dataset represents the most downstream streamgages on rivers draining to the coast that had continuous stream discharge data. Therefore, areas heavily influenced by tides were not included, nor were the small coastal watersheds outside of the coastal boundary. Some of the watersheds that drain to coastal areas crossed political boundaries into Canada, but in most instances the area outside the United States border was small and no correction was made. However, since 56 percent of the Great Lakes total drainage area was in Canada, only watersheds

A. Riverine within-ecoregion carbon fluxes

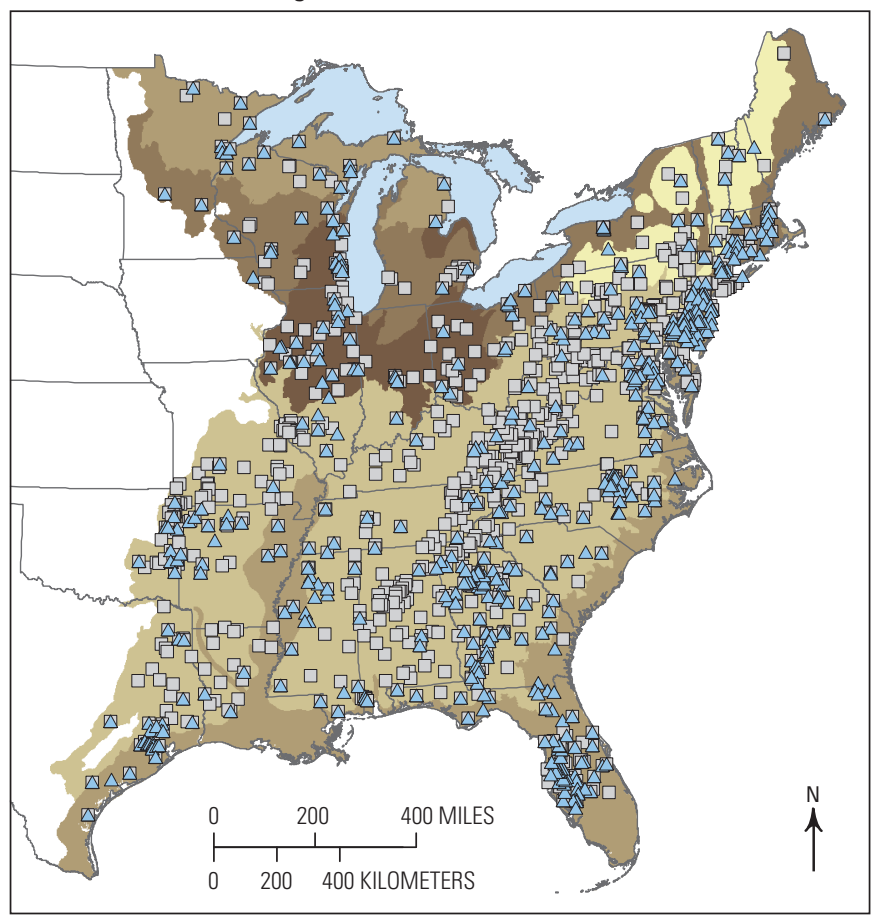

\section{EXPLANATION}

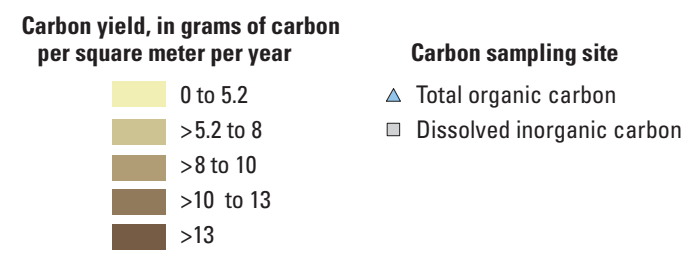

inside the United States border were used to calculate carbon flux to the Great Lakes. Ultimately, the Coastal Export Dataset included DIC estimates from 122 NWIS sites and TOC estimates from 109 NWIS sites (fig. 5-1). These sites covered approximately $2.5 \mathrm{Mkm}^{2}$ or 75 percent of the total drainage area for the regions of these receiving waters.

The Ecoregion Dataset included only drainage basins contained entirely within a single ecoregion of the Eastern United States. These estimates were useful to illustrate ecoregional variability in carbon fluxes across the entire Eastern United States. There was some overlap with the Coastal Export Dataset for streamgages located upstream from coastal areas that had watersheds entirely within ecoregional boundaries. The Ecoregion Dataset included DIC estimates from 1,001 NWIS sites and TOC estimates from 511 NWIS sites (fig. 5-1A). The flux estimates associated with this dataset were derived from small drainage basins, ranging in size from 3.4 to $59,000 \mathrm{~km}^{2}$. About 33 percent of the total

\section{B. Riverine carbon dioxide emissions}
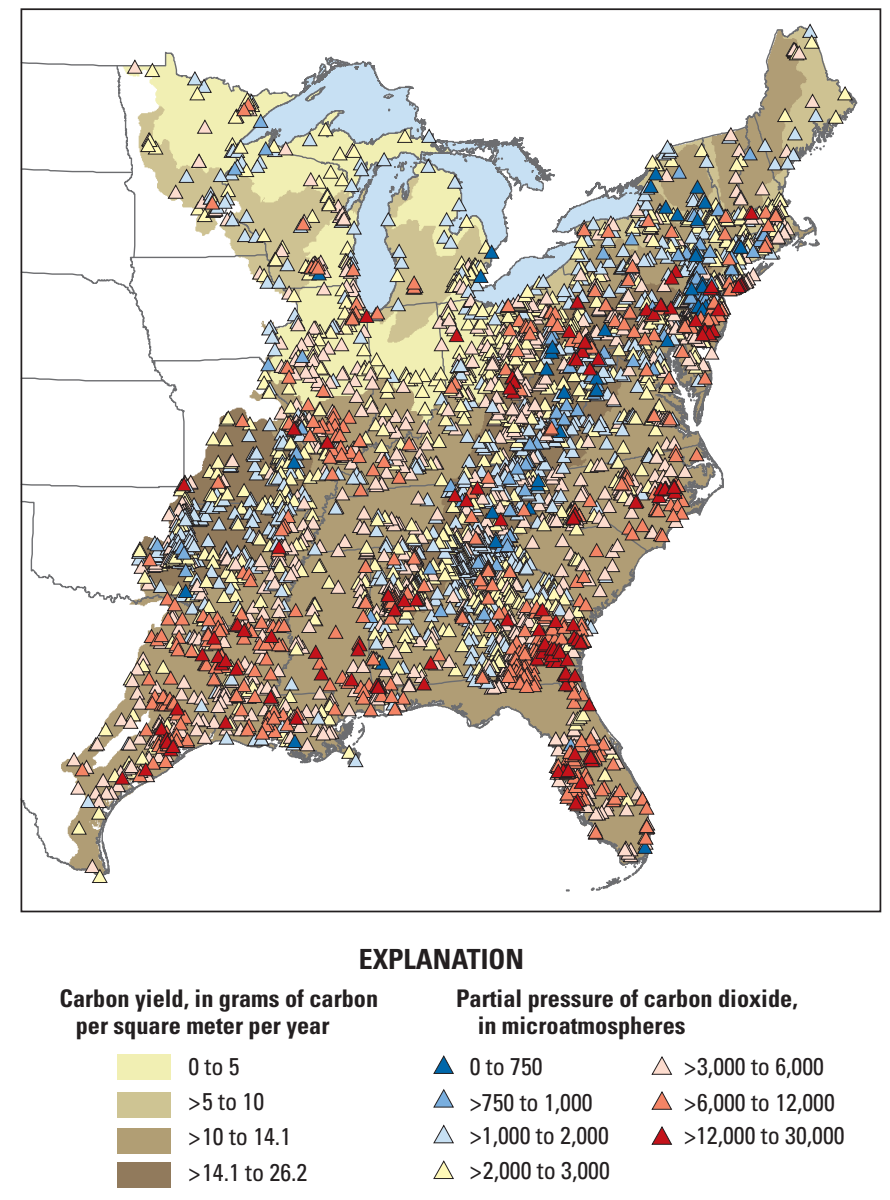

Figure 5-1. Maps showing the estimated relative magnitude of carbon yields. $A$, Within-ecoregion lateral carbon transport by riverine systems. $B$, Carbon dioxide $\left(\mathrm{CO}_{2}\right)$ emissions from riverine systems. $C$, Lateral carbon export to coasts by riverine systems. $D, \mathrm{CO}_{2}$ emissions from lacustrine systems. $E$, Carbon burial rates in lacustrine systems. The maps show locations of calibrated sample data. Panels $B$ and $D$ also indicate the estimated relative magnitude of the partial pressure of $\mathrm{CO}_{2}\left(p \mathrm{CO}_{2}\right)$ concentrations at the sampling locations. 


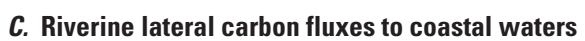

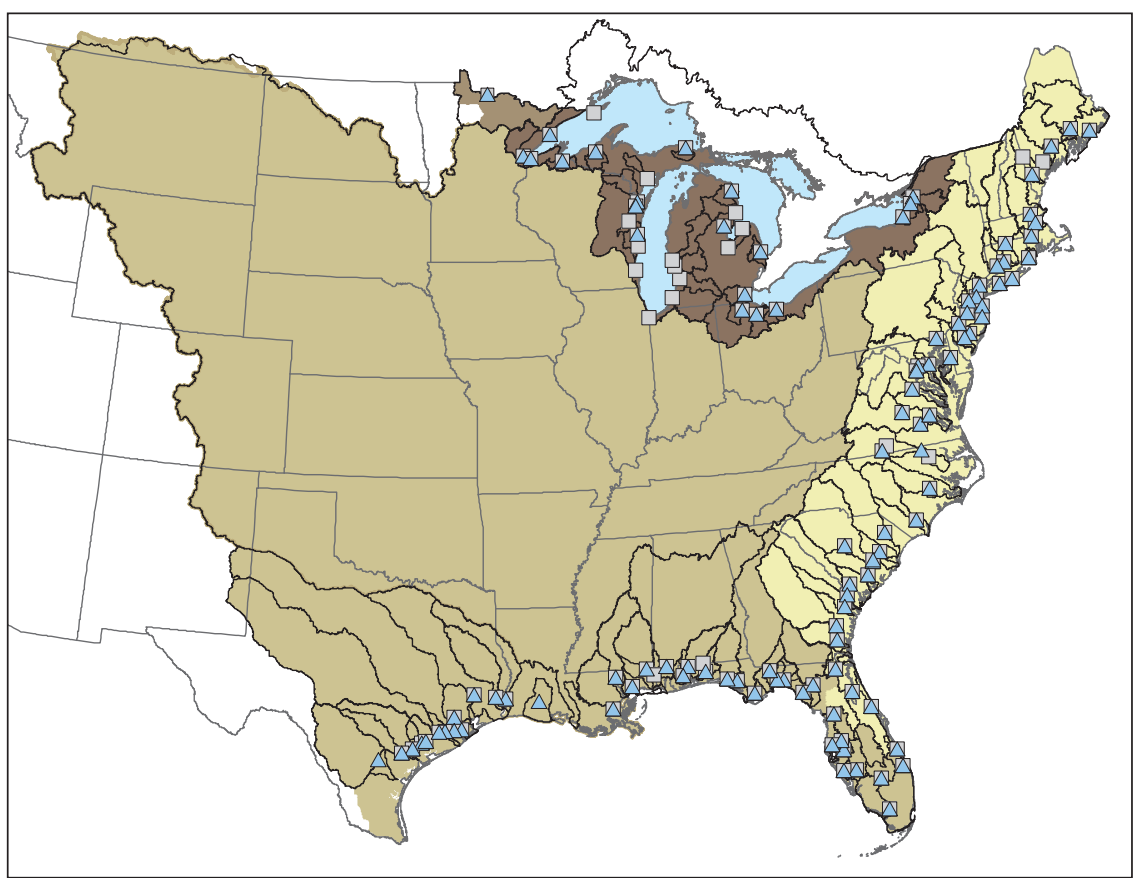

\section{EXPLANATION}

Carbon yield, in grams of carbon per square meter per year

5.3

9.5

11.6

13.5

_ Watershed boundary

Carbon sampling site

$\triangle \quad$ Total organic carbon

$\square \quad$ Dissolved inorganic carbon

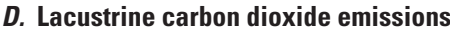

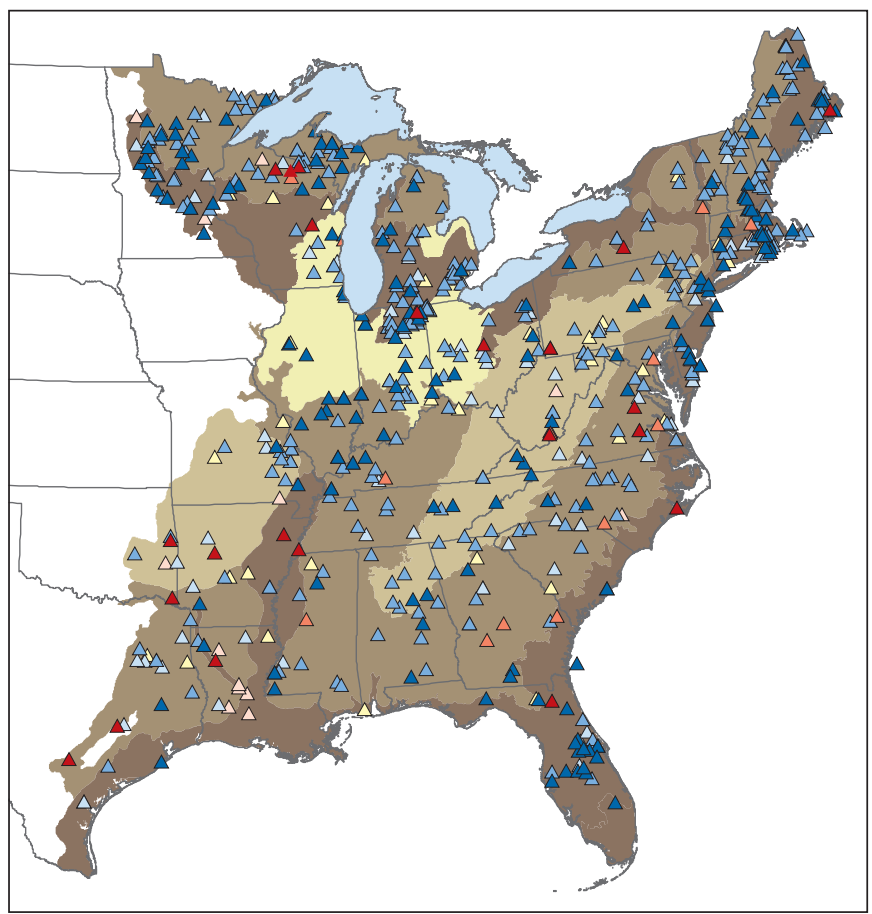

EXPLANATION

Carbon yield, in grams of carbon per square meter per year

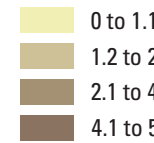

0 to 1.1

2.1 to 4

4.1 to 5
Partial pressure of carbon dioxide in microatmospheres

$\Delta<400$

$\triangle>400$ to 750

$\triangle>750$ to 1,000

$\triangle>1,000$ to 1,500 $\triangle>2,000$ to 2,500

$\Delta>2,500$

\section{E. Lacustrine carbon burial}

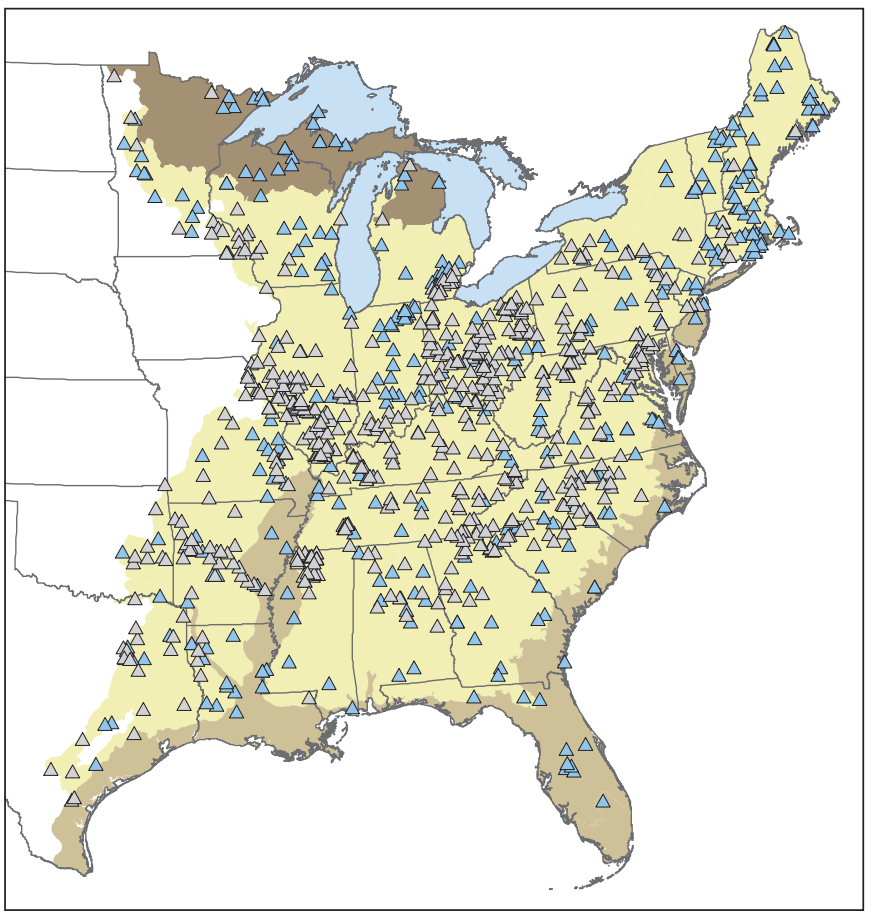

\section{EXPLANATION}

Carbon yield, in grams of carbon per square meter per year

Dataset and modeling method for sedimentation estimate

$\triangle$ Sedimentation rate location

$\triangle$ Sediment carbon location 
ecoregional area of the Eastern United States was accounted for by the drainage areas associated with these sites.

For all lateral carbon flux estimates, the DIC concentration was estimated from $\mathrm{pH}$, temperature, and either filtered or unfiltered alkalinity. The estimated TOC concentration was taken directly from water-quality data or was calculated as the sum of dissolved and particulate organic carbon (Stets and Striegl, 2012). Carbon fluxes were estimated from water-quality and daily streamflow data using the USGS Load Estimator Model (LOADEST; Runkel and others, 2004). LOADEST is a multiple-regression adjusted maximum likelihood estimation model that uses measured DIC or TOC concentration values to calibrate a regression between constituent load, streamflow, seasonality, and time. The

LOADEST model uses Akaike Information Criterion to select the best combination of coefficients at each streamgage station from the full model, which is based on the following equation:

$$
\begin{gathered}
\ln L O A D=a_{0}+a_{1} \ln Q+a_{2} \ln Q^{2}+a_{3} \sin (2 \pi d t i m e) \\
+a_{4} \cos (2 \pi \text { dtime })+a_{5} d \text { time }+a_{6} \text { dtime } e^{2}+\varepsilon
\end{gathered}
$$

where

$$
\begin{aligned}
\ln L O A D & \text { is the natural log of the constituent load, } \\
Q & \text { is the discharge, } \\
\text { dtime } & \text { is time in decimal years, } \\
a_{0}, a_{1}, \ldots a_{6} & \text { are regression coefficients, and } \\
\varepsilon & \text { is an independent and normally } \\
& \text { distributed error. }
\end{aligned}
$$

The model calibration required at least 12 paired water-quality and daily streamflow values. The input data were log-transformed to avoid bias and centered to avoid multicollinearity.

For the Coastal Export Dataset, daily carbon fluxes were converted to annual fluxes and then summed across the contributing area. Carbon export (Total $E_{\mathrm{C}}$ ) was estimated by extrapolating to the drainage area not captured by sites included in the dataset (Stets and Striegl, 2012) by using the following equation:

$$
\text { Total } E_{C}=E_{C(I N)} \times\left(A_{T O T} / A_{I N}\right),
$$

where

$$
\begin{gathered}
E_{\mathrm{C}(\mathrm{IN})} \quad \begin{array}{c}
\text { is the carbon export estimated from sites } \\
\text { included in the database, }
\end{array} \\
A_{\text {TOт }} \quad \begin{array}{c}
\text { is the total exorheic drainage area (draining } \\
\text { to coastal areas), and }
\end{array} \\
A_{\mathrm{IN}} \quad \begin{array}{l}
\text { is the total drainage for which lateral flux } \\
\text { estimates could be made. }
\end{array}
\end{gathered}
$$

This extrapolation assumed an equivalent areal carbon flux from the remaining (unmeasured) drainage area. The 5th and 95th confidence intervals were calculated from associated standard errors. Coastal carbon yields were calculated by dividing total carbon fluxes by associated drainage area. Ungaged area from the Coastal Export Dataset ranged from 0 percent at the Rainy River to 35 percent at the Atlantic Ocean, with an average of 15 percent ungaged area for the entire Eastern United States.
Large river basins in the Coastal Export Dataset included source areas that lay within ecoregions that were considered in the Central (Zhu and others, 2011) or Western (Zhu and Reed, 2012) United States assessment reports, which complicated flux estimates based on ecoregional boundaries due to potential double counting. For the assessment of the Eastern United States, total coastal export to the receiving waters was considered a part of the assessment if the coastal outlet was within the assessment boundaries of the Eastern United States; some additional explanation was provided to establish the significance of carbon and water entering the Eastern United States from ecoregions outside of this assessment area. For example, the Mississippi-Atchafalaya River Basin was the largest in the United States (total basin area of $3.18 \mathrm{Mkm}^{2}$ ) and had its coastal outlet in the Eastern United States. However, only 40 percent of the total drainage area of the MississippiAtchafalaya River Basin is within the assessment area of the Eastern United States; 54 percent of the basin is in ecoregions that were considered in the report for the Central United States (Temperate Prairies, West-Central Semiarid Prairies, and South-Central Semiarid Prairies ecoregions), and 6 percent is within ecoregions considered in the report for the Western United States (Western Cordillera, Cold Deserts, and Warm Deserts ecosystems). The majority of the area outside the study area was encompassed by the Missouri River, Arkansas River, and Red River Basins. Total carbon yields from these rivers were $1.3 \mathrm{gC} / \mathrm{m}^{2} / \mathrm{yr}$ and $2.4 \mathrm{gC} / \mathrm{m}^{2} / \mathrm{yr}$ for the Arkansas and Missouri Rivers, respectively (Stackpoole and Stets, unpub. data, June 25, 2013). Ecoregions in the Eastern United States had much higher runoff and terrestrial primary production than ecoregions in the Central and Western United Sates and therefore had higher carbon yields as well. For example, total carbon yields for the Ohio River, which was entirely within the Eastern United States assessment area, had a total carbon yield of $10.2 \mathrm{gC} / \mathrm{m}^{2} / \mathrm{yr}$ (Sarah M. Stackpoole and Edward G. Stets, U.S. Geological Survey, unpub. data, June 25, 2013).

Rivers draining to the Gulf of Mexico west of the Mississippi River Basin also crossed regional boundaries. The headwaters of many of these rivers were in the SouthCentral Prairies and Southern Texas Plain ecoregions, but the outlets to the Gulf of Mexico were in the Mississippi Alluvial and Southeast USA Coastal Plains ecoregion. Carbon yields in the South-Central Prairies and Southern Texas Plain ecoregions were smaller than those in the Mississippi Alluvial and Southeast USA Coastal Plains ecoregion, suggesting that the absolute magnitude of carbon flux from the Southeast USA Coastal Plain ecoregion was small and had a minor effect on the total carbon export estimates for the Eastern United States.

Individual site fluxes from the Ecoregion Dataset were summed by ecoregion $\left(\mathrm{E}_{\mathrm{CIN})}\right)$, and the ecoregional carbon flux estimate (Total $\mathrm{E}_{\mathrm{C}}$ ) was calculated using equation 5-2, where $\mathrm{A}_{\text {Tот }}$ represented the total ecoregional area and $\mathrm{A}_{\mathrm{IN}}$ represented the sum of the drainage areas associated with sites included in the dataset. This correction also assumed an equivalent areal carbon flux from the remaining (unmeasured) drainage area. 
To calculate 5th and 95th confidence intervals for the mean ecoregional fluxes, a bootstrap with replacement method was run for 1,000 iterations. Total carbon fluxes represent the sum of DIC and TOC fluxes. The total carbon yields for an ecoregion were calculated by dividing annual fluxes by area of the ecoregion.

\subsection{2. $\mathrm{CO}_{2}$ Flux From Riverine Systems}

Three values were required to measure the gas fluxes from aquatic systems: (1) the concentration of dissolved $\mathrm{CO}_{2}$, (2) the gas transfer velocity, and (3) the surface area of the water body. The vertical flux of $\mathrm{CO}_{2}$ from riverine systems in the Eastern United States was modeled according to established methods (Butman and Raymond, 2011) and as outlined in the following equation:

$$
\mathrm{CO}_{2} \text { flux }=\left(\mathrm{CO}_{2} \text {-water }-\mathrm{CO}_{2} \text {-air }\right) \times \mathrm{kCO}_{2} \times \mathrm{SA},
$$

$$
\begin{aligned}
& \text { where } \\
& \mathrm{CO}_{2} \text { flux is the total net emission of } \mathrm{CO}_{2} \text { from riverine } \\
& \text { systems of the Eastern United States, } \\
& \mathrm{CO}_{2} \text {-water is the riverine } \mathrm{CO}_{2} \text { concentration, } \\
& \mathrm{CO}_{2} \text {-air is the } \mathrm{CO}_{2} \text { concentration in the atmosphere, } \\
& \mathrm{kCO}_{2} \text { is the gas transfer velocity of } \mathrm{CO}_{2} \text { across } \\
& \text { the air-water interface, and } \\
& S A \quad \text { is the riverine surface area. }
\end{aligned}
$$

The total flux was estimated by summing all of the mean annual fluxes for a stream order (Strahler, 1952) within an ecoregion.

The dissolved $\mathrm{CO}_{2}$ concentrations $\left[\mathrm{CO}_{2}\right.$-water $]$ were estimated from stream and river alkalinity data available through NWIS using the Mathworks, Inc. CO2SYS program (van Heuven and others, 2009). CO2SYS used temperature, $\mathrm{pH}$, and alkalinity to estimate the dissolved $\mathrm{CO}_{2}$ concentrations by incorporating disassociation constants for carbonic acid $\left(\mathrm{H}_{2} \mathrm{CO}_{3}\right)$ into its calculations. Disassociation constants are mathematical constants that describe the tendency of a large molecule, such as $\mathrm{H}_{2} \mathrm{CO}_{3}$, to disassociate into smaller molecules, such as bicarbonate $\left(\mathrm{HCO}_{3}^{-}\right)$, carbonate $\left(\mathrm{CO}_{3}{ }^{2-}\right)$, and $\mathrm{CO}_{2}$ in an aqueous environment. The disassociation constants used in the CO2SYS equations for this assessment were from Millero (1979).

Water-chemistry data were compiled from the late $1920 \mathrm{~s}$ through 2011, and only daily measurements of $\mathrm{pH}$ paired with temperature and alkalinity measurements were used to estimate dissolved $\mathrm{CO}_{2}$. For the seven ecoregions in the Eastern United States, 4,040 USGS streamgages had an adequate chemistry record, and their data were used for the $\mathrm{CO}_{2}$ flux estimate (fig. 5-1). At least 12 sampling dates were required for inclusion in this analysis. A total of 232,751 daily chemical measurements were identified. The concentration of $\mathrm{CO}_{2}$ in the atmosphere $\left(\mathrm{CO}_{2}\right.$-air $)$ was assumed to be constant at 390 parts per million (ppm) in equation 5-3 for all the ecoregions in the Eastern United States.

The gas transfer velocity $\left(\mathrm{kCO}_{2}\right)$ was modeled based on a meta-analysis of measurements of gas exchange and the gas transfer velocity made by direct tracer injections across small to midsized river systems in the United States (Melching and Flores, 1999; Raymond and others, 2012). The variation in gas transfer velocities within riverine systems was a function of turbulence at the air-water interface (Zappa and others, 2007). Physical parameters of stream slope and water velocity were used to predict gas transfer velocity, according to the following equation:

$$
k_{600}=S \times V \times 2,841.6+2.03,
$$

$$
\begin{aligned}
& \text { where } \\
& k_{600} \quad \text { is the gas transfer velocity of } \mathrm{CO}_{2} \text { normalized to }
\end{aligned}
$$

A total of 563 independent gas tracer injection measurements were included in the development of this model.

Average slope was derived from the NHDPlus (Horizon Systems Corporation, 2005) dataset for each stream order within each ecoregion of the Eastern United States. Velocity estimates were calculated from hydraulic geometry coefficients derived for each of the ecoregions in the Eastern United States using the NWIS database of measured slope and velocity at 4,900 streamgages from 1940 through 2011. A total of 630,182 discharge measurements were used to derive hydraulic geometry coefficients specific to each ecoregion. Hydraulic geometry of stream reaches showed remarkable consistency within and across watersheds to approximate channel width, velocity, and depth from measured discharge (Leopold and Maddock, 1953; Park, 1977). All scaling relationships derived by the calculation of hydraulic geometry exponents were statistically significant ( $p$-value less than 0.001). However, velocity measurements had coefficient of determination $\left(\mathrm{R}^{2}\right)$ values ranging from 0.23 to 0.56 , whereas width measurements had $\mathrm{R}^{2}$ values ranging from 0.86 to 0.95 . Modeled average annual discharge from the NHDPlus data was used to estimate average channel width and velocity by utilizing the ecoregion specific hydraulic geometry coefficients. Average slope and velocity were then calculated by stream order to estimate the gas transfer velocity of $\mathrm{CO}_{2}$ based on equation 5-4.

Stream surface area was calculated based on the same hydraulic geometry coefficients discussed in the previous paragraph. Average discharge was utilized to then calculate an average width for each stream order within an ecoregion. The total stream length was then calculated for each stream order within an ecoregion. Stream and river surface area was than calculated as the product of the average width and total length of streams by stream order.

Error propagation and uncertainty analyses were performed for each component of equation 5-3. To estimate 
error, a bootstrapping technique as outlined in Efron and Tibshirani (1993) and Butman and Raymond (2011) was utilized. Bootstrap with replacement $(\alpha=0.05)$ was run for 1,000 iterations to calculate 5 th and 95 th confidence intervals for the concentrations of the partial pressure of $\mathrm{CO}_{2}\left(p \mathrm{CO}_{2}\right)$ for each stream order within an ecoregion. Similarly, bootstrap with replacement was utilized to estimate confidence intervals associated with the hydraulic geometry coefficients derived from the measurements of stream width and velocity, which were subsequently used to estimate the stream surface area and gas transfer velocity. Overall bias associated with estimates of $p \mathrm{CO}_{2}$ remained low and had a negligible effect on the error associated with the use of the mean value for each stream order. Similarly, the effect of bootstrapping the hydraulic geometry parameters produced minimal bias.

A Monte-Carlo simulation was performed for each stream order estimate of the total carbon flux from riverine surfaces (equation 5-3). The 5th and 95th confidence intervals derived from the bootstrapping discussed above were used to set the boundary conditions of the Monte Carlo simulation for each parameter of equation 5-3. One thousand replications of the total flux calculation were performed. This approach is considered conservative because it allowed for the same probability of all combinations of each parameter in the total flux equation to be selected for each stream order and may have overestimated the error associated with the riverine evasion flux.

All estimates for the total carbon flux within an ecoregion were presented with the 5th and 95th confidence intervals derived from the Monte Carlo simulation. In general, this conservative approach biased the range of estimate high due to a slight skew in the distribution of $p \mathrm{CO}_{2}$ concentration within a stream order and ecoregion. It should be noted that the mean concentration by stream order was chosen rather than the median values because incorporating mean values approximated a broader spatial representation of $p \mathrm{CO}_{2}$ concentrations in the Eastern United States. All estimates derived from the Monte Carlo simulation were adjusted to account for monthly temperatures below freezing under the assumption that stream and river flux did not occur when monthly temperatures averaged less than $0^{\circ} \mathrm{C}$. This adjustment reduced the flux for the Mixed Wood Shield ecoregion by 40 percent, the Atlantic Highlands ecoregion by 32 percent, the Mixed Wood Plains ecoregion by 30 percent, the Central USA Plains ecoregion by 24 percent, the Ozark, Ouachita-Appalachian Forests ecoregion by 6 percent, and the Southeastern USA Plains ecoregion by 1 percent; the adjustment had no effect on the Mississippi Alluvial and Southeast USA Coastal Plains ecoregion.

\subsection{3. $\mathrm{CO}_{2}$ Flux From Lacustrine Systems}

Water-chemistry data used to estimate lacustrine $\mathrm{CO}_{2}$ emissions were obtained from the 2007 national lakes assessment (NLA) of the EPA (U.S. Environmental Protection Agency, 2009). The NLA used a probability-based survey design to select lakes and reservoirs that met the following criteria: (1) greater than 4 hectares (ha) in area, with a minimum of 0.1 ha of open water; (2) at least $1 \mathrm{~m}$ deep; and (3) not classified or described as treatment or disposal ponds or as brackish-water or ephemeral bodies (U.S. Environmental Protection Agency, 2009). Following outlier removal (McDonald and others, 2013), data from 549 lakes were used in the following calculations (fig. 5-1D); 45 of these lakes were sampled twice.

Sampling took place during summer 2007; 50 percent of the samples were obtained between July 12 and August 23, and nearly all (99 percent) were obtained between June 1 and September 30. The data were classified according to the seven ecoregions in the Eastern United States. The number of lakes ranged from 37 to 143 per ecoregion. Various biological, physical, and chemical indicators were measured during the NLA (U.S. Environmental Protection Agency, 2009), and only a subset of water-chemistry and physical data was used in this assessment and included acid-neutralizing capacity (ANC, assumed to be equal to alkalinity), $\mathrm{pH}$, temperature, and dissolved organic carbon (DOC).

The estimated $\mathrm{CO}_{2}$ flux from lacustrine systems was calculated using the general equation 5-3. The estimated dissolved $\mathrm{CO}_{2}\left(\mathrm{CO}_{2}\right.$-water) was computed using the equilibrium geochemical model PHREEQC version 2 (Parkhurst and Appelo, 1999). This model is similar to CO2SYS in that parameters such as water temperature, $\mathrm{pH}$, and alkalinity were used to estimate $\mathrm{CO}_{2}$ concentrations.

The gas transfer velocity for lacustrine systems is largely a function of wind speed (Cole and Caraco, 1998). The estimated mean wind speeds in summer (June to September) were determined for each ecoregion from surface meteorology and solar energy data of the National Aeronautics and Space Administration (NASA; 2012). The surface area of lakes and reservoirs was tabulated for each ecoregion, as in McDonald and others (2012).

Many of the parameters involved in these calculations violated normality assumptions; therefore, nonparametric 5 th and 95th confidence intervals were determined on 1 million ordinary bootstrap replicates. The confidence intervals for the estimated fluxes were determined by propagation of uncertainty, except for the total values (for example, the sum of the regional estimates). In those cases, the confidence intervals were assumed to be additive (uncertainty was not propagated) because potential errors in the regional estimates are likely to be systematic.

\subsubsection{Carbon Burial in Lacustrine Systems}

Carbon burial in lacustrine systems includes carbon buried in the sediments of lakes and reservoirs; it is a function of sedimentation rates, sediment carbon concentrations, and the areal extent of lacustrine systems. Carbon burial in lacustrine systems of the Eastern United States was modeled according to the following equation:

$$
\mathrm{C}_{\text {burial }}=\operatorname{SedRt} \times \mathrm{C}_{\text {conc }} \times \mathrm{SA}_{\mathrm{WB}}
$$


where

$$
\begin{array}{cl}
\mathrm{C}_{\text {burial }} & \text { is the carbon burial rate, } \\
\text { SedRt } & \text { is the sedimentation rate, } \\
\mathrm{C}_{\text {conc }} & \text { is the concentration of carbon in sediments, } \\
\text { and } & \text { is the surface area of the water body. }
\end{array}
$$

Data on sedimentation rates and carbon concentrations in sediments were sparse, necessitating an empirical approach that relied on existing data to build geostatistical models, which were then used to estimate carbon burial rates in unsampled lakes and reservoirs. The input data included (1) sedimentation rates derived from a national database (for reservoirs) and peer-reviewed literature (for lakes) and (2) carbon concentrations obtained from measurements on sediment samples collected as part of the 2007 NLA (U.S. Environmental Protection Agency, 2009, §10.3.3).

The areal extents of lacustrine systems were derived from the high-resolution (1:24,000) USGS National Hydrography Dataset (NHD; U.S. Geological Survey, 2012c). Sedimentation rates in lakes and carbon concentrations in lake sediments usually are different from those in reservoirs (Mulholland and Elwood, 1982; Dean and Gorham, 1998); thus, the water bodies were separated into lake and reservoir classes. Water bodies were classified as reservoirs if they met any of the following criteria: (1) the water body was tagged as a reservoir in the NHD, (2) the water-body name included the word "reservoir" in it, or (3) the water body was included in the National Inventory of Dams database (U.S. Army Corps of Engineers, 2012). Water bodies that were not classified as reservoirs were assumed to be lakes. A comparison with ground-based observations on the 697 lakes that were sampled for carbon in sediments during the 2007 NLA indicated that this classification scheme was correct 80 percent of the time; however, misclassification rates might have been higher for small water bodies (area less than or equal to $4 \mathrm{ha}$ ), such as farm ponds, which were not sampled during the NLA.

The best available national dataset of reservoir sedimentation rates was the Reservoir Sedimentation Database (RESSED), which included sedimentation-rate data on more than 1,800 georeferenced reservoirs in the United States (fig. 5-1E; Mixon and others, 2008; Ackerman and others, 2009). The sedimentation rates in the RESSED database were derived from repeat bathymetric surveys with the purpose of estimating losses in reservoir storage. On the basis of the hypothesis that sedimentation rates were related to land use, topography, soils, and vegetation characteristics in the area surrounding the reservoirs, a geographic information system (GIS) analysis was performed to quantify these characteristics for each hydrologic unit (represented by a 12-digit hydrologic unit code (HUC); U.S. Department of Agriculture, Natural Resources Conservation Service, 2012) adjacent to each reservoir. The sedimentation rates in the RESSED database strongly correlated with the net contributing area ( $\mathrm{R}^{2}$ equal to 0.94$)$. However, the values for the net contributing area were not available for most reservoirs in the United States; therefore, a reservoir's surface area, which should scale with the net contributing area, was used as a surrogate for the net contributing area.

The RESSED dataset was split evenly into calibration and validation datasets, and a stepwise multiple-linearregression (MLR) analysis was performed on the calibration data, where the sedimentation rate was the dependent variable, and the land use and basin characteristics were independent, explanatory variables. The independent variable that explained the most variance in the sedimentation rate entered the model first. The variances explained by the remaining explanatory variables were recalculated, and the variable that explained the next greatest amount of variance entered the model next. This iterative process was repeated until no additional variables showed statistically significant correlations to sedimentation rates, using a $p$-value less than or equal to 0.1 . The multicollinearity among explanatory variables was evaluated using the variance inflation factor (calculated as $1 /\left(1-\mathrm{R}^{2}\right)$; Hair and others, 2005), which had a threshold for exclusion of 0.2 . The resulting MLR equation was used to estimate the sedimentation rates for all the reservoirs in the NHD. The standard error of the equation was used to calculate uncertainty at 95-percent confidence for the predicted sedimentation rates for sites in the validation dataset.

A national dataset of lake sedimentation rates does not exist; therefore, sedimentation rates in lakes were estimated from data in peer-reviewed literature. Lake sedimentation rates have been calculated for more than 80 lakes around the world using lead-210 and cesium-137 isotope dating techniques on sediment cores; in most studies, multiple cores were collected from each lake. A review of peer-reviewed literature identified data for sites in Africa, Antarctica, Asia, Europe, New Zealand, and North America. The data were compiled and a statistical analysis was performed to characterize a probability density function of lake sedimentation rates. A sedimentation rate was assigned to each lake from the probability density function using random sampling with replacement. This procedure was repeated 100 times, drawing a new value from the statistical distribution each time in order to obtain 100 possible sedimentation rate values for each lake. Each of these values was used to calculate a carbon burial rate using equation 5-5, providing a range of carbon burial estimates for each lake. Uncertainty at the 95-percent confidence level was calculated as $2 \times$ F-pseudosigma, where F-pseudosigma is a nonparametric equivalent to the standard deviation.

Carbon concentrations were measured on sediment samples collected from 697 bodies of water during the 2007 NLA (fig. 5-1E; U.S. Environmental Protection Agency, 2009). The data were split into calibration and validation datasets, and a stepwise MLR analysis was performed using the same methods and explanatory variables as in the reservoir sedimentation-rate analysis. The resulting equation was used to estimate carbon concentrations in lake and reservoir sediments in unsampled water bodies across the Eastern United States. Uncertainty and model performance were evaluated in the same way as the reservoir sedimentation-rate analysis. 


\subsubsection{Exclusion of the Great Lakes From the Analysis}

In this study, the surface area, $\mathrm{CO}_{2}$ emissions, and carbon burial in sediments were not considered for the Laurentian Great Lakes, although their combined surface area is about equal to 160 percent of all other inland lakes in the contiguous United States combined (McDonald and others, 2012). Even using the most current modeling techniques, large uncertainty is still associated with carbon fluxes on these large water bodies (Bennington and others, 2012). $\mathrm{CO}_{2}$ emission estimates for the entire system remain very poorly constrained, currently ranging from less than 1 to more than $30 \mathrm{TgC} / \mathrm{yr}$ (McKinley and others, 2011). There is also the additional difficulty of dividing gas emissions and carbon burial for four of the Great Lakes between the borders of Canada and the United States.

\subsubsection{Limitations and Uncertainties}

The within-ecoregion lateral flux results presented in this chapter were based on empirical data, but there were two main limitations of the associated methods used to calculate these fluxes. The lateral flux values determined from the Ecoregion Dataset (table 5-1) represented only small watersheds with drainage areas between 3 and $59,000 \mathrm{~km}^{2}$, because watershed boundaries had to be entirely within ecoregional boundaries to be included in this analysis. Lateral fluxes represent carbon concentrations multiplied by flow, and because flow from smaller watersheds is generally lower than flow from large ones, the fluxes from this dataset may be biased toward the low end of the range of lateral fluxes. Additionally, watersheds included in the Ecoregion Dataset ranged from 18 to 40 percent of the total ecoregional area, and an equivalent areal carbon flux from the remaining (unmeasured) drainage area was a major assumption in the calculated flux. Additionally, large river basins included in the Coastal Export Dataset included source areas that lay within ecoregions that were considered in the Central (Zhu and others, 2011) or Western (Zhu and Reed, 2012) United States assessment reports, which complicated flux estimates based on ecoregional boundaries.

In this assessment, the estimated $\mathrm{CO}_{2}$ flux rates from riverine systems dominated the estimated aquatic carbon fluxes. Validation data to support fluxes of this magnitude do not currently exist; however, recent research measuring oxygen transfer rates suggests that gas transfer velocities in the upper reaches of the Colorado River can range from 9 meters per day $(\mathrm{m} / \mathrm{d})$ in the large main channels up to $338 \mathrm{~m} / \mathrm{d}$ in rapids (Hall and others, 2012). It is important to note that the model to estimate gas transfer velocity of $\mathrm{CO}_{2}$ outlined in Raymond and others (2012) and used for this assessment was developed from a dataset that did not include any measurements from steep-slope or high-altitude locations, and as such, the application of this model in highly diverse riverine landscapes must be done with appropriate caution.

The contribution of organic acids to the calculation of total alkalinity potentially could have caused an overestimation of the dissolved $p \mathrm{CO}_{2}$ concentrations (Tishchenko and others, 2006; Hunt and others, 2011). In typical naturally occurring fresh water, the only major contributors to noncarbonate alkalinity are organic acids, primarily humic and fulvic acids (Lozovik, 2005). The concentration of free organic ions was estimated for the lakes included in the 2007 NLA (U.S. Environmental Protection Agency, 2009) using the empirical relations of Oliver and others (1983). The estimated organic anion concentration for each lake or reservoir was subtracted from the measured alkalinity before performing an analysis of $p \mathrm{CO}_{2}$; however, an appropriate correction algorithm has not been developed for the dataset that was used for the flux calculation in riverine systems because of the limited locations of paired DOC and alkalinity

Table 5-1. Estimated within-ecoregion carbon fluxes and yields from riverine systems in the Eastern United States.

[Sites represent U.S. Geological Survey streamgages in endorheic and exorheic basins for which data were available to calculate estimated dissolved inorganic carbon (DIC) and total organic carbon (TOC) fluxes, respectively. Values presented in parentheses represent errors associated with total flux and total yield (fluxes normalized to watershed areas) at the bootstrapped 5th and 95th confidence intervals. Total carbon fluxes and mean yields were calculated by summing the estimated DIC and TOC. $\mathrm{gC} / \mathrm{m}^{2} / \mathrm{yr}$, grams of carbon per square meter per year; $\mathrm{TgC} / \mathrm{yr}$, teragrams of carbon per year]

\begin{tabular}{|c|c|c|c|c|c|}
\hline \multirow{2}{*}{ Ecoregion } & \multicolumn{2}{|c|}{ Number of sites } & \multirow{2}{*}{$\begin{array}{l}\text { Estimated total flux, } \\
\text { in } \mathrm{TgC} / \mathrm{yr}\end{array}$} & \multirow{2}{*}{$\begin{array}{l}\text { Estimated total yield, } \\
\text { in } \mathrm{gC} / \mathrm{m}^{2} / \mathrm{yr}\end{array}$} & \multirow{2}{*}{$\begin{array}{l}\text { Estimated flux as DIC, } \\
\text { in percent of total flux }\end{array}$} \\
\hline & DIC yields & TOC yields & & & \\
\hline Mixed Wood Shield & 25 & 18 & $1.3(0.6,2.1)$ & $6.4(2.9,10.0)$ & 55.7 \\
\hline Mixed Wood Plains & 73 & 50 & $2.1(1.0,3.1)$ & $5.5(2.5,8.3)$ & 80.3 \\
\hline Central USA Plains & 77 & 38 & $2.3(1.6,3.1)$ & $9.8(6.6,12.9)$ & 82.9 \\
\hline Southeastern USA Plains & 321 & 203 & $5.6(3.7,7.4)$ & $5.6(3.8,7.4)$ & 48.9 \\
\hline $\begin{array}{l}\text { Mississippi Alluvial and Southeast } \\
\text { USA Coastal Plains }{ }^{1}\end{array}$ & 106 & 103 & $3.0(1.5,4.4)$ & $6.6(3.3,9.9)$ & 43.2 \\
\hline Eastern United States (total) & 1,001 & 511 & $19.4(15.2,23.6)$ & $6.5(5.1,8.0)$ & 57.1 \\
\hline
\end{tabular}

${ }^{1}$ Includes the Everglades and Texas-Louisiana Coastal Plain level II ecoregions for the analysis of this assessment. 
measurements within the NWIS database. Because the current methodology for estimating alkalinity in riverine systems does not account for organic acids, some of the existing estimates of riverine fluxes may be high. Uncertainties in the estimates may be reduced by accounting for noncarbonate alkalinity (organic acids) when deriving $p \mathrm{CO}_{2}$ concentration from total alkalinity measurements.

The stream and river surface-area estimates for each ecoregion ranged from 0.3 to 0.9 percent of the total area and are consistent with other published values (Aufdenkampe and others, 2011; Downing and others, 2012); however, the accuracy of stream and river surface area estimates may improve by using remote-sensing techniques to further constrain the hydraulic geometry parameters that are appropriate at the ecoregion scale (Striegl and others, 2012). Specifically, there is a need to constrain the surface areas of first-order stream systems (headwaters areas) that may be poorly characterized within the NHDPlus dataset and that may exhibit strong seasonal variation in water flow. Regional efforts to physically map first-order stream surface areas in combination with scaling laws would reduce uncertainties.

The locations of USGS streamgages, which were used to calculate the hydraulic geometry coefficients, introduced a bias because the streamgages were placed in a location that was best suited for accurate discharge measurements (Leopold and Maddock, 1953; Park, 1977). Therefore these streamgage locations most likely do not represent the entire range of variability in the relationships among stream depth, width, and velocity that exists along the flow paths of rivers in the Eastern United States. The results from the Monte Carlo simulation suggested levels of uncertainty approaching 52 percent for the Mixed Wood Shield ecoregion and between 32 and 40 percent for each of the six other ecoregions. In addition, the current application of bootstrapping and simulation was considered very conservative; however, as suggested above, without extensive efforts in field validation for both the gas transfer velocity and dissolved $\mathrm{CO}_{2}$ concentration in small stream environments, the model estimates reported in this assessment represent the most comprehensive to date.

Using the available data, it was not possible to accurately model the impact of seasonality on estimated mean $\mathrm{CO}_{2}$ flux from lacustrine systems. In dimictic lakes (lakes that experience ice cover and mix completely in the spring and fall), $\mathrm{CO}_{2}$ concentrations build up under ice cover and in the hypolimnion (bottom waters) during stratification as a result of heterotrophic respiration and are degassed rapidly during mixing (Michmerhuizen and others, 1996; Riera and others, 1999). Because the available data for the assessment were collected from surface waters only during the summer, this aspect of the seasonal $p \mathrm{CO}_{2}$ dynamics was not included in the estimates.

There were numerous sources of uncertainty in the carbon burial estimates. The datasets used to calibrate the regression models of sedimentation rates in reservoirs and carbon concentrations in sediments were derived from national databases; however, they represented less than 0.2 percent of the total number of water bodies in the conterminous United States. A national database of sedimentation rates in lakes does not exist, necessitating a statistical probability approach to estimating lake sedimentation rates, which probably misses substantial regional variability. Carbon concentrations in water body sediments were derived from surface sediment samples collected at single points within each water body and may not represent average carbon concentrations in the surface sediments. Important constants used in the carbon burial calculations include sediment bulk density and porosity; these parameters were assigned values based on information in the literature (Dean and Gorham, 1998), but the values may vary widely among lacustrine systems. Combining all these sources of uncertainty yields a conservative error estimate of approximately \pm 50 percent in carbon burial rates. It may be possible to reduce the uncertainty in these estimates in the future, as additional data on sedimentation rates and sediment carbon concentrations become available.

\subsection{Results}

\subsubsection{Lateral Carbon Transport in Riverine Systems}

The total carbon export from exorheic basins, calculated using the Coastal Export Dataset, was estimated to be $36.5 \mathrm{TgC} / \mathrm{yr}$ (with lower and upper confidence intervals of $28.1 \mathrm{TgC} / \mathrm{yr}$ and $44.8 \mathrm{TgC} / \mathrm{yr}$, respectively; table 5-2), with 74 percent of the export occurring as DIC. The Mississippi

Table 5-2. Estimated coastal carbon exports and yields from riverine systems in the Eastern United States.

[Sites represent U.S. Geological Survey streamgages for which data were available to calculate estimated carbon fluxes from exorheic basins. Values presented in parentheses represent the 5 th and 95 th confidence intervals. Total exports and total yields were calculated by summing dissolved inorganic carbon (DIC) and total organic carbon (TOC). $\mathrm{gC} / \mathrm{m}^{2} / \mathrm{yr}$, grams of carbon per square meter per year; $\mathrm{TgC} / \mathrm{yr}$, teragrams of carbon per year]

\begin{tabular}{|c|c|c|c|c|c|}
\hline \multirow{2}{*}{ Waterway } & \multicolumn{2}{|c|}{ Number of sites } & \multirow{2}{*}{$\begin{array}{l}\text { Estimated total export, } \\
\text { in } \mathrm{TgC} / \mathrm{yr}\end{array}$} & \multirow{2}{*}{$\begin{array}{l}\text { Estimated total yield, } \\
\text { in } \mathrm{gC} / \mathrm{m}^{2} / \mathrm{yr}\end{array}$} & \multirow{2}{*}{$\begin{array}{l}\text { Estimated flux as DIC, } \\
\text { as percentage of total expor }\end{array}$} \\
\hline & DIC yields & TOC yields & & & \\
\hline Atlantic Ocean & 55 & 52 & $4.1(3.7,4.6)$ & $5.3(4.8,5.9)$ & 50 \\
\hline Great Lakes & 30 & 20 & $5.4(5.3,5.6)$ & $18.7(18.3,19.1)$ & 85 \\
\hline Rainy River & 1 & 1 & $0.2(0.1,0.3)$ & $11.6(6.3,16.8)$ & 38 \\
\hline All regions & 122 & 109 & $36.5(28.1,44.8)$ & $6.4(5.0,7.9)$ & 74 \\
\hline
\end{tabular}


River was the single largest source of carbon to the coastal ocean $(22.1 \mathrm{TgC} / \mathrm{yr})$, and therefore, the majority of carbon export from the Eastern United States was to the Gulf of Mexico, which received 26.3 TgC/yr. The Great Lakes received $5.4 \mathrm{TgC} / \mathrm{yr}$, whereas the Atlantic Ocean received 4.1 TgC/yr. The Rainy River in the Mixed Wood Shield ecoregion exported $0.2 \mathrm{TgC} / \mathrm{yr}$.

The estimated total fluxes (table 5-1), calculated using the Ecoregion Dataset, were highest in the Southeastern USA Plains ecoregion (5.6 TgC/yr) and lowest in the Atlantic Highlands ecoregion $(0.2 \mathrm{TgC} / \mathrm{yr})$. The estimated mean yields were highest in the Ozark, Ouachita-Appalachian Forests ecoregion $\left(10.7 \mathrm{gC} / \mathrm{m}^{2} / \mathrm{yr}\right)$ and lowest in the Atlantic Highlands ecoregion $\left(1.2 \mathrm{gC} / \mathrm{m}^{2} / \mathrm{yr}\right.$; fig. 5-1; table 5-1). The mean DIC concentration in the Central USA Plains ecoregion (51 milligrams per liter $(\mathrm{mg} / \mathrm{L})$ ) was eight times higher than the estimated mean DIC concentration in the Atlantic Highlands ecoregion $(6 \mathrm{mg} / \mathrm{L})$. The range of TOC concentrations were narrower, with the highest estimated mean concentration in the Mississippi Alluvial and Southeast USA Coastal Plains ecoregion $(16 \mathrm{mg} / \mathrm{L})$ and the lowest in the Atlantic Highlands ecoregion $(4 \mathrm{mg} / \mathrm{L})$. There was substantial variability in the mean runoff among the ecoregions, with the greatest mean runoff in the Atlantic Highlands ecoregion (627 millimeters per year $(\mathrm{mm} / \mathrm{yr})$ ) and the smallest mean runoff was in the Mixed Wood Shield ecoregion (297 mm/yr).

\subsection{2. $\mathrm{CO}_{2}$ Flux From Riverine Systems}

The mean concentration of dissolved $\mathrm{CO}_{2}$ in streams and rivers across the Eastern United States exceeded atmospheric concentrations, indicating that these ecosystems represent sources of carbon to the atmosphere. Mean $p \mathrm{CO}_{2}$ concentration was greatest in the Southeastern USA Plains ecoregion at 4,902 microatmospheres ( $\mu \mathrm{atm})$, which is 12.5 times greater than atmospheric $p \mathrm{CO}_{2}$ concentration, and smallest in the Atlantic Highlands ecoregion at 2,088 $\mu \mathrm{atm}$, which is 5.3 times greater than atmospheric $p \mathrm{CO}_{2}$ concentration. The mean $p \mathrm{CO}_{2}$ concentration for all regions was 3,265 $\mu \mathrm{atm}$, which was 8.3 times greater than atmospheric $p \mathrm{CO}_{2}$ concentration (fig. 5-1).

Stream surface area ranged from $630 \mathrm{~km}^{2}$ in the Mixed Wood Shield ecoregion (representing 0.3 percent of the total land surface area of the Eastern United States) to $5,617 \mathrm{~km}^{2}$ in the Southeastern USA Plains ecoregion ( 0.56 percent; table 5-3). The total stream surface area for the Eastern United States was $16,467 \mathrm{~km}^{2}$ representing 0.56 percent of the land surface. Stream and river surface area was greatest in the Mississippi Alluvial and Southeast Coastal Plain ecoregion at $23,465 \mathrm{~km}^{2}$, or 0.9 percent.

The total riverine vertical flux of carbon for the Eastern United States was $152.1 \mathrm{TgCO}_{2}$-eq/yr with 5th and 95th percentiles of 101 and 211, respectively. Ecoregion specific fluxes ranged from a high of $49.4 \mathrm{TgCO}_{2}$-eq/yr (5th and 95th percentiles of 33.7 to $70.3 \mathrm{TgCO}_{2}$-eq/yr) in the Ozark, Ouachita-Appalachian Forests ecoregion to $2.2 \mathrm{TgCO}_{2}$-eq/yr (5th and 95th percentiles of 1.1 to $3.7 \mathrm{TgCO}_{2}$-eq/yr) in the Mixed Wood Shield ecoregion. Riverine flux on an area basis for ecoregions in the Eastern United States was $14 \mathrm{gC} / \mathrm{m}^{2} / \mathrm{yr}$ (5th and 95th percentiles of 7.9 and $17 \mathrm{gC} / \mathrm{m}^{2} / \mathrm{yr}$, respectively), ranging from $2.93 \mathrm{gC} / \mathrm{m}^{2} / \mathrm{yr}$ (5th and 95th percentiles of 1.6 and $4.9 \mathrm{gC} / \mathrm{m}^{2} / \mathrm{yr}$, respectively) in the Mixed Wood Shield ecoregion to $26.2 \mathrm{gC} / \mathrm{m}^{2} / \mathrm{yr}$ (with 5th and 95th percentiles of 17.9 and $37.3 \mathrm{gC} / \mathrm{m}^{2} / \mathrm{yr}$, respectively) in the Ozark, Ouachita-Appalachian Forests ecoregion (fig. 5-1).

\subsection{3. $\mathrm{CO}_{2}$ Flux From Lacustrine Systems}

The estimated mean concentration of $p \mathrm{CO}_{2}$ in lacustrine systems of the Eastern United States was 1,184 $\mu$ atm with a median of $740 \mu \mathrm{atm}$, which was greater than atmospheric concentrations for all eastern ecoregions. Thus, all ecoregions were net sources of carbon to the atmosphere. The mean $p \mathrm{CO}_{2}$ was greatest in the Southeastern USA Plains ecoregion at $1,866 \mu \mathrm{atm}$, which was 4.8 times greater than the atmospheric concentration of $\mathrm{CO}_{2}$, and smallest in the Mixed Wood Shield ecoregion at $714 \mu \mathrm{atm}$, which was 1.8 times greater than the atmospheric concentration of $\mathrm{CO}_{2}$ (fig. 5-1).

Table 5-3. Estimated vertical fluxes and yields of $\mathrm{CO}_{2}$ from riverine systems in the Eastern United States.

[Sites are U.S. Geological Survey streamgages for which data were available to calculate the estimated partial pressure of carbon dioxide $\left(p \mathrm{CO}_{2}\right)$. Values presented in parentheses represent errors associated with total flux and total yield (fluxes normalized to watershed areas) at the 5th and 95th percentiles derived from a Monte Carlo simulation. Total yields were calculated by dividing the estimated total flux by the ecoregion area. $\mathrm{gC} / \mathrm{m}^{2} / \mathrm{yr}$, grams of carbon per square meter per year; $\mathrm{km}^{2}$, square kilometers; $\mathrm{TgC} / \mathrm{yr}$, teragrams of carbon per year]

\begin{tabular}{|c|c|c|c|c|}
\hline Ecoregion & $\begin{array}{l}\text { Number } \\
\text { of sites }\end{array}$ & $\begin{array}{c}\text { Stream area, } \\
\text { in } \mathbf{~ k m}^{2}\end{array}$ & $\begin{array}{l}\text { Estimated total flux, } \\
\text { in } \mathrm{TgC} / \mathrm{yr}\end{array}$ & $\begin{array}{l}\text { Estimated total yield, } \\
\text { in } \mathrm{gC} / \mathrm{m}^{2} / \mathrm{yr}\end{array}$ \\
\hline Mixed Wood Shield & 59 & 630 & $0.6(0.3,1.0)$ & $2.9(1.6,4.9)$ \\
\hline Atlantic Highlands & 194 & 861 & $2.6(1.6,3.8)$ & $13.1(8.6,20.2)$ \\
\hline Mixed Wood Plains & 367 & 1,598 & $2.8(1.9,3.8)$ & $7.1(5.0,10.2)$ \\
\hline Central USA Plains & 223 & 807 & $1.1(0.7,1.6)$ & $4.6(3.1,6.6)$ \\
\hline Southeastern USA Plains & 1,444 & 5,617 & $14.5(9.9,19.4)$ & $14.0(10.0,19.4)$ \\
\hline Eastern United States (total) & 4,040 & 16,467 & $41.6(27.5,57.7)$ & $14.0(7.9,17.0)$ \\
\hline
\end{tabular}

\footnotetext{
${ }^{1}$ Includes the Everglades and Texas-Louisiana Coastal Plain level II ecoregions for the analysis of this assessment.
} 
The estimated mean flux of $\mathrm{CO}_{2}$ across the air-water interface was primarily determined by the gradient between the dissolved and atmospheric concentrations of carbon. The estimated gas transfer velocity was less variable than the estimated $p \mathrm{CO}_{2}$ among all of the ecoregions - smallest in the Atlantic Highlands ecoregion $(0.99 \mathrm{~m} / \mathrm{d})$ and greatest in the Central USA Plains ecoregion $(1.21 \mathrm{~m} / \mathrm{d})$. The ecoregional estimates of total annual $\mathrm{CO}_{2}$ flux from lacustrine systems (table 5-4) ranged from $0.3 \mathrm{TgC} / \mathrm{yr}$ $\left(1.2 \mathrm{TgCO}_{2}-\mathrm{eq} / \mathrm{yr}\right)$ in the Central USA Plains ecoregion to $3.9 \mathrm{TgC} / \mathrm{yr}\left(14.3 \mathrm{TgCO}_{2}\right.$-eq/yr) in the Southeastern USA Plains ecoregion. The total $\mathrm{CO}_{2}$ flux from the Eastern United States was estimated to be $9.7 \mathrm{TgC} / \mathrm{yr}\left(35.6 \mathrm{TgCO}_{2}\right.$-eq/yr). The estimated ecoregional flux values were directly related to the surface area of the lacustrine systems (table 5-4), which varied among the ecoregions, partially because of differences in regional morphology and climate but mainly due to differences in the size of the ecoregions.

In order to facilitate a direct comparison between lake and reservoir gas fluxes, lateral carbon transport, carbon burial, and terrestrial processes, the estimated $\mathrm{CO}_{2}$ flux values were normalized to the total land surface area in each ecoregion to provide the carbon yield (fig. 5-1; table 5-4). The estimated carbon yields ranged from $1.1 \mathrm{gC} / \mathrm{m}^{2} / \mathrm{yr}$ in the Central USA Plains ecoregion to $4.6 \mathrm{gC} / \mathrm{m}^{2} / \mathrm{yr}$ in the Mixed Wood Plains and the Mississippi Alluvial and Southeast USA Coastal Plains ecoregions. The estimated mean carbon yield (expressed as $\mathrm{CO}_{2}$ flux per unit of total land and water area) from lacustrine systems in the Eastern United States was $3.3 \mathrm{gC} / \mathrm{m}^{2} / \mathrm{yr}$.

\subsubsection{Carbon Burial in Lacustrine Systems}

The estimated net flux of carbon due to burial in lacustrine sediments of the Eastern United States was $-9.2 \mathrm{TgC} / \mathrm{yr}$ (negative values represent a carbon sink; table 5-5). The Mixed Wood Shield and the Mississippi Alluvial and Southeast USA Coastal Plain ecoregions had the highest estimated carbon burial rates, accounting for net fluxes of $-2.5 \mathrm{TgC} / \mathrm{yr}$ and $-2.7 \mathrm{TgC} / \mathrm{yr}$, respectively. The Central USA Plains and the Ozark, Ouachita-Appalachian Forest ecoregions had the lowest estimated carbon burial rates, with net flux of $-0.4 \mathrm{TgC} / \mathrm{yr}$ each (table 5-5).

When normalized to the area of each ecoregion (yield), the estimated net flux due to carbon burial in lacustrine systems was $-3.1 \mathrm{gC} / \mathrm{m}^{2} / \mathrm{yr}$ (fig. 5-1; table 5-5). The ecoregion-normalized fluxes ranged from $-0.8 \mathrm{gC} / \mathrm{m}^{2} / \mathrm{yr}$ in the Ozark, Ouachita-Appalachian Forest ecoregion to $-11.9 \mathrm{gC} / \mathrm{m}^{2} / \mathrm{yr}$ in the Mixed Wood Shield ecoregion.

\subsection{Discussion}

\subsubsection{Coastal Export, Lateral Transport, and $\mathrm{CO}_{2}$ Flux From Riverine Systems}

The highest riverine within-ecoregion lateral carbon fluxes and $\mathrm{CO}_{2}$ emissions occurred in the Ozark, OuachitaAppalachian Forests ecoregion. Moderate DIC and TOC concentrations (15.3 mg/L and $4 \mathrm{mg} / \mathrm{L}$, respectively) coupled with high annual precipitation $(1,218 \mathrm{~mm} / \mathrm{yr})$ and average annual runoff (average streamflow divided by drainage area, $533.8 \mathrm{~mm} / \mathrm{yr}$ ) produced within-ecoregion riverine lateral carbon fluxes of $10.7 \mathrm{gC} / \mathrm{m}^{2} / \mathrm{yr}$. Elevated $p \mathrm{CO}_{2}$ concentrations $(4,950 \mu \mathrm{atm})$ were also estimated for this ecoregion, where terrestrial soil processes may have a significant impact on stream water chemistry. Direct input of terrestrial soil and root respiration is often facilitated by increased levels of precipitation and water throughput as groundwater enters a stream environment (Jones and Mulholland, 1998). In fact, Jones and Mulholland (1998) measured $p \mathrm{CO}_{2}$ concentration in excess of $6,000 \mu \mathrm{atm}$ within forested headwater catchments of the Ozark, Ouachita-Appalachian Forests ecoregion, 20 percent greater than the $p \mathrm{CO}_{2}$ concentrations estimated across similar headwaters systems presented in this report. The high riverine

Table 5-4. Estimated vertical flux of carbon dioxide from lacustrine systems in the Eastern United States.

[Sites are from the 2007 National Lakes Assessment (U.S. Environmental Protection Agency, 2009). The data from the 2007 NLA were used in the calculation of the partial pressure of carbon dioxide $\left(\mathrm{pCO}_{2}\right)$. Values presented in parentheses represent errors associated with total flux and total yield (fluxes normalized to watershed areas) at the bootstrapped 5th and 95th confidence intervals. Carbon yields were calculated by dividing the estimated total flux by the ecoregion area. $\mathrm{gC} / \mathrm{m}^{2} / \mathrm{yr}$, grams of carbon per square meter per year; $\mathrm{km}^{2}$, square kilometers; $\mathrm{TgC} / \mathrm{yr}$, teragrams of carbon per year]

\begin{tabular}{|c|c|c|c|c|}
\hline Ecoregion & $\begin{array}{l}\text { Number } \\
\text { of sites }\end{array}$ & $\begin{array}{l}\text { Lake and } \\
\text { reservoir area, } \\
\text { in } \mathbf{k m}^{2}\end{array}$ & $\begin{array}{l}\text { Estimated total flux, } \\
\text { in } \mathrm{TgC} / \mathrm{yr}\end{array}$ & $\begin{array}{l}\text { Estimated total yield, } \\
\text { in } \mathrm{gC} / \mathrm{m}^{2} / \mathrm{yr}\end{array}$ \\
\hline Mixed Wood Shield & 58 & 12,300 & $0.7(0.4,1.2)$ & $3.5(1.8,6.0)$ \\
\hline Mixed Wood Plain & 143 & 11,700 & $1.7(1.4,2.2)$ & $4.6(3.6,5.8)$ \\
\hline Central USA Plains & 37 & 3,170 & $0.3(0.1,0.4)$ & $1.1(0.6,1.8)$ \\
\hline Southeastern USA Plains & 124 & 17,400 & $3.9(2.9,5.1)$ & $3.9(2.9,5.1)$ \\
\hline Eastern United States (total) & 549 & 76,620 & $9.7(6.8,13.9)$ & $3.3(2.9,4.0)$ \\
\hline
\end{tabular}

${ }^{1}$ Includes the Everglades and Texas-Louisiana Coastal Plain level II ecoregions for the analysis of this assessment. 
Table 5-5. Estimated carbon burial in lacustrine sediments in the Eastern United States.

[Sites were those in the 2007 National Lakes Assessment (U.S. Environmental Protection Agency, 2009) that were used to develop a regression equation to estimate carbon concentrations in sediment. Values presented in parentheses represent errors associated with total flux and total yield (fluxes normalized to watershed areas) at the bootstrapped 5 th and 95 th confidence intervals. Carbon yields were calculated by dividing the estimated total flux divided by the ecoregion area. $\mathrm{gC} / \mathrm{m}^{2} / \mathrm{yr}$, grams of carbon per square meter per year; $\mathrm{TgC} / \mathrm{yr}$, teragrams of carbon per year]

\begin{tabular}{|c|c|c|c|}
\hline Ecoregion & $\begin{array}{l}\text { Number } \\
\text { of sites }\end{array}$ & $\begin{array}{l}\text { Estimated total flux, } \\
\text { in } \mathrm{TgC} / \mathrm{yr}\end{array}$ & $\begin{array}{l}\text { Estimated total yield, } \\
\text { in } \mathrm{gC} / \mathrm{m}^{2} / \mathrm{yr}\end{array}$ \\
\hline Mixed Wood Shield & 21 & $-2.5(-1.2,-3.7)$ & $-11.9(-6.0,-17.9)$ \\
\hline Atlantic Highlands & 47 & $-0.6(-0.3,-1.0)$ & $-3.4(-1.7,-5.1)$ \\
\hline Central USA Plains & 30 & $-0.4(-0.2,-0.5)$ & $-1.5(-0.8,-2.3)$ \\
\hline Southeastern USA Plains & 95 & $-1.3(-0.6,-1.9)$ & $-1.3(-0.6,-2.0)$ \\
\hline Ozark, Ouachita-Appalachian Forests & 53 & $-0.4(-0.2,-0.7)$ & $-0.8(-0.4,-1.3)$ \\
\hline
\end{tabular}

${ }^{1}$ Includes the Everglades and Texas-Louisiana Coastal Plain level II ecoregions for the analysis of this assessment.

$\mathrm{CO}_{2}$ emissions in the Ozark, Ouachita-Appalachian Forests ecoregion were also likely related to physical parameters of the riverine systems in this ecoregion. The slopes of streambeds in the headwaters were high, averaging 3 percent, which when coupled with high stream velocities, resulted in gas transfer velocities upwards of $22 \mathrm{~m} / \mathrm{d}$. The combination of elevated $\mathrm{CO}_{2}$ concentrations and gas transfer rates resulted in large areal riverine $\mathrm{CO}_{2}$ flux estimates of $26.2 \mathrm{gC} / \mathrm{m}^{2} / \mathrm{yr}$ in this ecoregion.

Similarly, the riverine $\mathrm{CO}_{2}$ yield of $13.1 \mathrm{gC} / \mathrm{m}^{2} / \mathrm{yr}$ calculated for the Atlantic Highlands ecoregion, which includes much of the White Mountains throughout New England, was a result of the physical characteristics of the landscape. Estimated headwater slope averaged 3.5 percent, and calculated gas transfer rates were $25.6 \mathrm{~m} / \mathrm{d}$. The differences in climate, with a mean annual temperature of $6.1^{\circ} \mathrm{C}$ in the Atlantic Highlands ecoregion compared with $12.6^{\circ} \mathrm{C}$ for the Ozark, Ouachita-Appalachian Forests ecoregion, could explain the change in flux from $2.6 \mathrm{TgC} / \mathrm{yr}$ to $13.8 \mathrm{TgC} / \mathrm{yr}$ between the two ecoregions, respectively. At the lower temperatures that are characteristic of the Atlantic Highlands ecoregion, the mineralization and soil weathering rates are comparatively low, which would also lower the carbon yields (Post and others, 1982; Lauerwald and others, 2012). Additionally, the dilute water chemistry of this ecoregion also likely played a role in low riverine $\mathrm{CO}_{2}$ emissions, as there were relatively low $p \mathrm{CO}_{2}$ concentrations (2,088 microatmospheres) in the Atlantic Highlands ecoregion.

The headwaters of the Susquehanna River, one of the larger rivers in the Northeastern United States, are in the Atlantic Highlands and the Ozark, Ouachita-Appalachian Forests ecoregions. Coastal exports from this river are ultimately delivered to the Chesapeake Bay. This river accounted for about 1 percent of the total coastal carbon exports in the Eastern United States, with a total carbon yield of $5.8 \mathrm{gC} / \mathrm{m}^{2} / \mathrm{yr}$. This value represents an average of the carbon yields of the three ecoregions that this river encounters along its flow path: the Atlantic Highlands ecoregion (main branch of the Susquehanna River), the Ozark, Ouachita-Appalachian Forests ecoregion (west branch of the Susquehanna River), and the Southeastern USA Plains ecoregion (coastal outlet), which have ecoregional yields of $1.2 \mathrm{~g} / \mathrm{m}^{2} / \mathrm{yr}, 10.7 \mathrm{~g} / \mathrm{m}^{2} / \mathrm{yr}$, and $5.6 \mathrm{~g} / \mathrm{m}^{2} / \mathrm{yr}$, respectively. These coastal export values for the Eastern United States are similar to previously reported (Mulholland and Watts, 1982; Shih and others, 2010) estimated TOC export values for the North Atlantic $\left(3.4 \mathrm{gC} / \mathrm{m}^{2} / \mathrm{yr}\right)$ and southern Atlantic gulf $\left(5.9 \mathrm{gC} / \mathrm{m}^{2} / \mathrm{yr}\right)$.

The Mississippi Alluvial and Southeast USA Coastal Plains ecoregion had the highest riverine $p \mathrm{CO}_{2}$ concentrations at 4,902 $\mu \mathrm{atm}$. The riverine DIC $(15.2 \mathrm{mg} / \mathrm{L})$ and TOC $(16 \mathrm{mg} / \mathrm{L})$ concentrations for the ecoregion were also high, indicating that both inorganic and organic carbon could have contributed to the high $p \mathrm{CO}_{2}$ values. Additionally, the coastal outlet of the Mississippi River is in the Mississippi Alluvial and Southeast USA Coastal Plains ecoregion, and the combination of the Mississippi River and Atchafalaya River Basins represented more than 60 percent of the total carbon export from the Eastern United States. The flux of $20.6 \mathrm{TgC} / \mathrm{yr}$ estimated for the Mississippi River Basin is similar to reported flux values (Raymond and Cole, 2003; Turner and Rabalais, 2004). The high average concentrations and fluxes in this southern ecoregion may be supported by direct inputs from highly productive wetland and riparian vegetation that cover more than 30 percent of the total land area and average annual precipitation exceeds $1.3 \mathrm{~m}$. Additionally, the areal extent of streams and rivers within the Mississippi Alluvial and Southeast USA Coastal Plains ecoregion was the greatest across the Eastern United States at about 1 percent of the total ecoregion area. The connectivity of wetland and riparian sources of dissolved carbon gasses to stream and river ecosystems has not been well established along spatial and temporal gradients; however, a study in other wetland-dominated systems suggests very high concentrations of $\mathrm{CO}_{2}$ at these riparian interfaces (Clilverd and others, 2008). Although research does suggest that, in regions with high groundwater recharge rates, the penetration of root respiration derived $\mathrm{CO}_{2}$ from wetlands can be enhanced (Hunt and others, 1999), the analysis presented in this chapter is unable to quantify this effects across ecoregions. 
The Mixed Wood Shield $\left(6.4 \mathrm{gC} / \mathrm{m}^{2} / \mathrm{yr}\right)$, Mixed Wood Plains $\left(5.5 \mathrm{gC} / \mathrm{m}^{2} / \mathrm{yr}\right)$, and Central USA Plains $\left(9.8 \mathrm{gC} / \mathrm{m}^{2} / \mathrm{yr}\right)$ ecoregions had substantial within-ecoregion lateral carbon fluxes. The Mixed Wood Shield ecoregion, which is dominated by wetlands and forests, represented an ecoregion where total carbon was divided relatively equally between DIC and TOC. Both these major land cover classes (forests and wetlands) deliver substantial amounts of organic matter to riverine systems (Mulholland, 2003; Creed and others, 2008). In contrast, the Mixed Wood Plains and Central USA Plains ecoregions had more than 80 percent total carbon export as DIC. Fluvial export of terrestrial alkalinity is a major component of riverine DIC concentrations (Raymond and Cole, 2003; Stets and Striegl, 2012), but sedimentary rock coverage in either ecoregion was not substantial (less than 10 percent). However, agricultural lands and urban development did dominate the land cover in this ecoregion; these two landscape types have been linked with elevated DIC concentrations (Barnes and Raymond, 2009). Interestingly, the magnitude of riverine $\mathrm{CO}_{2}$ emissions was not as high in these two ecoregions, most likely because of the flat topography of these glacially impacted ecoregions.

\subsection{2. $\mathrm{CO}_{2}$ Flux From and Carbon Burial in Lacustrine Systems}

Similar to the riverine flux results, the average lacustrine $\mathrm{CO}_{2}$ emissions $\left(4.6 \mathrm{gC} / \mathrm{m}^{2} / \mathrm{yr}\right)$ and carbon burial fluxes $\left(-6.2 \mathrm{gC} / \mathrm{m}^{2} / \mathrm{yr}\right)$ were high in the Mississippi Alluvial and Southeast USA Coastal Plains ecoregion. However, unlike the riverine $\mathrm{CO}_{2}$ emissions, the northern ecoregions of the Eastern United States (Mixed Wood Shield and Mixed Wood Plains ecoregions) also had relatively high lacustrine $\mathrm{CO}_{2}$ emissions $\left(4.6 \mathrm{gC} / \mathrm{m}^{2} / \mathrm{yr}\right.$ and $3.5 \mathrm{gC} / \mathrm{m}^{2} / \mathrm{yr}$, respectively) and carbon burial fluxes $\left(-11.9 \mathrm{gC} / \mathrm{m}^{2} / \mathrm{yr}\right.$ and $-3.7 \mathrm{~g} \mathrm{C} / \mathrm{m}^{2} / \mathrm{yr}$, respectively). The high fluxes in these ecoregions reflected the size and density of lakes in those areas. The southern part of the Eastern United States contains a higher density of smaller water bodies, many of which are artificial, compared with the northern part of the Eastern United States where there is a relatively low density of lakes, but the lakes that are present have large surface areas, particularly in the Mixed Wood Shield ecoregion. Water body area alone explained 60 percent of the variation in carbon burial rates among ecoregions.

In general, the ecoregions with higher $\mathrm{CO}_{2}$ emissions were also ecoregions with high carbon burial rates, indicating that excess carbon entering lacustrine systems that is not processed and emitted as $\mathrm{CO}_{2}$ may otherwise be buried. Lacustrine systems with higher carbon burial rates also had a strong positive correlation between ecoregional average soil organic carbon and sediment carbon concentration. Higher lacustrine burial rates were related to the prevalence of wetlands particularly in the Mixed Wood Shield and the Mississippi Alluvial and Southeast USA Coastal Plains ecoregions. As with the riverine fluxes, this reflects the importance of allochthonous (terrestrially derived) inputs of carbon to lakes and reservoirs in freshwater carbon budgets (Stets and others, 2009).

Variations in total annual carbon burial among ecoregions reflected differences in the sedimentation rates and sediment carbon concentrations of lacustrine systems as well as the prevalence and size of water bodies within each ecoregion. In the Eastern United States, sedimentation rates in reservoirs were highest in the Central USA Plains ecoregion, where the dominant land use was cultivated crops, a land cover that is associated with high erosion rates (Crowder, 1987; McIntyre, 1993). These results further emphasize the important influence that land cover can have on inland water carbon fluxes, as the relationship between high within-ecoregion lateral fluxes for the Central USA Plains ecoregion was also linked to the combined effects of agricultural lands and urban development in the previous section.

Regions with higher total lacustrine $\mathrm{CO}_{2}$ emissions (table 5-4) tended to also exhibit higher total riverine $\mathrm{CO}_{2}$ emissions (table 5-3). A notable exception is the Ozark, Ouachita-Appalachian Forests ecoregion, which had relatively low lacustrine emissions. This was likely due to the greater abundance of streams relative to lakes and reservoirs in this mountainous region. Lacustrine $\mathrm{CO}_{2}$ emissions (table 5-4) normalized to ecoregion area (yields) produced values that range from 6 to 52 percent of lateral inorganic carbon flux and from 28 to 126 percent of lateral organic carbon flux (table 5-1). Although there was not a strong relationship between the magnitude of lateral fluxes and lake emissions, there was a positive relationship between the fraction of the lateral flux present as inorganic carbon (table 5-1) and ecoregional $\mathrm{CO}_{2}$ yield from lakes and reservoirs, so that ecoregions with high proportions of total carbon as DIC had low $\mathrm{CO}_{2}$ emissions. This suggests that the carbon composition, as indicated by the ratio of DIC to TOC, rather than the overall amount of allochthonous-derived carbon, controlled lacustrine $\mathrm{CO}_{2}$ flux.

\subsubsection{Summary and Conclusions of Carbon Storage From Inland Aquatic Systems}

The considerable variability in the estimated inland waters' carbon fluxes among the seven ecoregions in the Eastern United States was likely due to the differences in the size and abundance of water bodies, topography, climate, and land cover associated with each ecoregion. In general, those ecoregions across the Eastern United States that had the highest annual temperature, natural vegetation cover, and precipitation had the highest total carbon fluxes, suggesting strong linkages across the terrestrial to aquatic interface. Overall, these results highlight the impact that climate and land cover can have on annual carbon transfer, storage, and flux from inland waters.

Riverine systems and lacustrine systems covered 0.55 and 2.6 percent of the total ecoregional area of the 
Eastern United States, respectively, excluding the Laurentian Great Lakes. Despite the small surface area that these inland waters cover, they accounted for considerable carbon losses. Riverine $\mathrm{CO}_{2}$ emissions were the largest carbon sources to the atmosphere $\left(14 \mathrm{gC} / \mathrm{m}^{2} / \mathrm{yr}\right)$. Additionally, a total of $6.3 \mathrm{gC} / \mathrm{m}^{2} / \mathrm{yr}$ as DIC and TOC was exported to coastal areas. The lacustrine $\mathrm{CO}_{2}$ losses $\left(3.3 \mathrm{gC} / \mathrm{m}^{2} / \mathrm{yr}\right)$ were balanced by nearly equivalent fluxes of carbon buried in lacustrine sediments $\left(-3.1 \mathrm{gC} / \mathrm{m}^{2} / \mathrm{yr}\right)$. Accounting for the three carbon loss terms (riverine and lacustrine $\mathrm{CO}_{2}$ loss, and lateral carbon coastal export) and one sequestration term (lacustrine carbon burial) resulted in a net inland waters' carbon yield of $23.5 \mathrm{gC} / \mathrm{m}^{2} / \mathrm{yr}$.

The results presented in this study indicate that the magnitude of aquatic fluxes in inland waters is significant, and that integration of these fluxes into the traditional terrestrial carbon cycle is needed. In this study, the terrestrial NEP value defined as carbon stored in terrestrial biomass, soil organic carbon, or harvested wood is equivalent to $99.9 \mathrm{gC} / \mathrm{m}^{2} / \mathrm{yr}$ (chap. 7). The sum of carbon transported, emitted, or buried in aquatic ecosystems $\left(29.7 \mathrm{~g} \mathrm{C} / \mathrm{m}^{2} / \mathrm{yr}\right)$ was equivalent to about 30 percent of this terrestrial NEP estimate. This percentage value must be interpreted with caution, as it is possible that some of the carbon considered as a part of the terrestrial soil organic carbon pool, may in fact have been lost to lacustrine and riverine systems via erosion or leaching processes, which would already be accounted for in the inland aquatic ecosystems' yield values. However, this comparison indicates that the linkage between terrestrial and aquatic ecosystems is critically important to understand fully the role natural ecosystems play in greenhouse-gas storage and cycling.

This chapter focused on current carbon fluxes from inland aquatic systems, but projected climate and land-use changes are likely to influence aquatic fluxes in future decades. Predicted changes to the hydrologic cycle include increased precipitation and streamflow (Mearns and others, 2003; Hayhoe and others, 2007; Huntington and others, 2009), reduction in the number of ice cover days on lakes and rivers (Magnuson and others, 2000; Jensen and others, 2007), and decreases in snow depth (Hayhoe and others, 2007; Burakowski and others, 2008). Delivery of carbon to aquatic ecosystems will also be changed by expected alterations to both terrestrial and aquatic biogeochemical cycling of carbon. Increases in net primary productivity (Freeman and others, 2004; Wrona and others, 2006) and organic matter decomposition rates (Davidson and Janssens 2006; Craine and others, 2010), as well as land-use changes such as urbanization and changes in agricultural management practices (Raymond and Cole, 2003; Barnes and Raymond, 2009; Aufdenkampe and others, 2011) are all likely to affect the amount and composition of carbon delivered to aquatic systems. Coupling both hydrologic and biogeochemical reactions in a systematic fashion over space and time will be key to accurately predicting changes in the magnitude of aquatic carbon fluxes in the future. 


\title{
Chapter 6. Terrestrial Fluxes of Nutrients and Sediment to Coastal Waters and Their Effects on Coastal Carbon Storage in the Eastern United States
}

\author{
By Brian A. Bergamaschi, ${ }^{11}$ Richard A. Smith, ${ }^{1}$ Michael J. Sauer, ${ }^{1}$ Jhih-Shyang Shih, ${ }^{2}$ and Lei Ji'
}

\subsection{Highlights}

- Model estimates indicate that nutrient and sediment fluxes from terrestrial environments of the Eastern United States contribute significantly to the uptake and storage of carbon in coastal waters.

- Changes in population and land use are projected to result in significantly greater fluxes of nutrients and sediments to coastal waters by 2050 relative to the baseline years (2001-2005). However, total organic carbon flux to coastal areas is projected to increase only slightly. For example, projected nitrate fluxes for 2050 are 16 to 52 percent higher than the baseline year, depending on the region and LULC scenario modeled. As a consequence, an associated increase in the frequency and duration of coastal and estuarine hypoxia events and harmful algal blooms could be expected.

- The estimated annual coastal carbon storage flux related to continental inputs was $7.9 \mathrm{TgC} / \mathrm{yr}$, or 3 percent of the estimated average annual terrestrial flux based on LULC in 2005.

- Although variable by region, about 60 percent of coastal carbon storage related to terrestrial inputs is buried in sediments and 40 percent is stored in deep ocean waters, below the surface ocean mixed layer.

- Annual rates of coastal carbon storage are projected to increase by 18 to 56 percent between 2005 and 2050, based on several modeled LULC scenarios. This is in contrast to terrestrial rates of carbon storage, which are projected to decrease by 20 percent. The differing trends in coastal and terrestrial storage result from projected increases in nutrient and sediment runoff from urban and agricultural lands and from decreases in forest cover.

- Fluxes of nutrients and sediments from the Eastern United States in 2005 could account for about

${ }^{1}$ U.S. Geological Survey

${ }^{2}$ Resources for the Future
9,100 TgC of burial in the active coastal sediment carbon pool (the upper $1 \mathrm{~m}$ ) and about $6,000 \mathrm{TgC}$ in deep ocean waters. This represents about two thirds of the mass of carbon stored in the major terrestrial carbon pools and is in addition to coastal carbon storage related to oceanic fluxes of nutrients and sediments.

\subsection{Introduction}

The current and projected LULC maps of the United States that form the centerpiece of the USGS land carbon national assessment (chap. 3) provide a unique opportunity to examine the extent to which LULC affects carbon storage in coastal oceans, given the influence of riverborne fluxes of nutrients and sediments to the coastal oceans, and the role of nutrients and sediments in carbon storage processes. Coastal oceans remove a greater amount of carbon from the atmosphere globally than terrestrial biomass, largely through photosynthetic uptake of atmospheric carbon by phytoplankton and sequestration of this organic material from the surface ocean through either burial in sediments or removal to the deep ocean (Walsh and others, 1985; Hedges and Keil, 1995; Sarmiento and Gruber, 2002; Dunne and others, 2007). More than 90 percent of global phytoplankton productivity occurs in coastal areas of the oceans, in part because of the elevated nutrient supply from terrestrial sources (Smith and Hollibaugh, 1993; Behrenfeld and Falkowski, 1997). These fluxes of sediment from the continents act to sink and bury this phytoplankton production (Milliman and Syvitski, 1992; Armstrong and others, 2001; Dunne and others, 2005; Syvitski and others, 2005). Coastal carbon preservation in sediments is strongly coupled to the availability of nutrients and the sediment supply (Boudreau and Ruddick, 1991; Dagg and others, 2004; Meybeck and others, 2006). Thus, changes in the continental fluxes of nutrients and sediments will affect the coastal storage of carbon.

It is well established that LULC distributions are a primary determinant of terrestrial fluxes of sediments and nutrients to coastal oceans (Seitzinger and others, 2005; Howarth, 2008; Mayorga and others, 2010). It is also well known that both sediment and nutrient delivery to coastal waters has 
been significantly altered by changes in population and land use (Syvitski and others, 2005; da Cunha and others, 2007; Glibert, 2010), resulting in modified patterns of coastal production and carbon burial (Walsh and others, 1985; Rabalais and others, 1996; Leithold and others, 2005; Middelburg and Levin, 2009). This increasing nutrient supply has raised coastal productivity enough to increase commercial fish harvests and to expand the areas where hypoxic conditions occur (Howarth and others, 1996; Nixon and others, 1996; Rabalais and others, 1996; Boyer and others, 2006; Swaney and others, 2012). Continued population growth and increased areal extent and intensity of agricultural lands are expected to accelerate these changes (Syvitski and others, 2005; Mayorga and others, 2010; Seitzinger and others, 2010; Vörösmarty and others, 2010).

The goals of this coastal carbon storage analysis were to evaluate how terrestrial fluxes of sediment and nutrients contribute to carbon storage in the coastal oceans of the Eastern United States and how changing sediment and fluxes associated with different prospective future LULC conditions may alter rates of carbon storage. Terrestrial fluxes of sediment, nutrients, and carbon were quantified for baseline conditions and a range of projected LULC distributions associated with different SRES storylines (chaps. 2 and 3), and the resulting coastal carbon storage for each LULC distribution was inferred using a simple biogeochemical model. These projected changes in terrestrial flux are also useful for assessing potential future coastal water quality conditions (Whitehead and others, 2009), forecasting fish harvests (Oczkowski and Nixon, 2008; Breitburg and others, 2009), gaging the potential for coastal and estuarine hypoxia (Rabalais and others, 2010; Zhang and others, 2010), and evaluating the vulnerability of coastal ecosystems to harmful algal blooms (Glibert and others, 2005; Litchman and others, 2006). The spatially explicit nature of the assessment permits the use of economic models for evaluating and comparing among different policy and land management decisions made to prevent further degradation of aquatic habitats (Paerl, 2006; Shepherd and others, 2007). The coastal carbon storage and burial portion of the assessment will likely help guide scientific studies and monitoring programs in the coastal ocean as well as provide the basis for economic analysis of this important carbon resource (Burdige, 2007; Williams and others, 2009).

Continental flux and coastal carbon storage models were prepared for baseline LULC and projected future LULC under SRES scenarios A1B, A2, and B1 (chaps. 2 and 3) to explore a range of potential effects of LULC on carbon flux and storage. The geographic extent of the coastal assessment was from the northern border to the southern border of the Eastern United States and was divided into the Great Lakes, Gulf of Maine, Mid-Atlantic Bight, South Atlantic Bight, and Gulf of Mexico regions (fig. 6-1). The model includes all the watersheds that drain from these regions into the adjacent coastal waters, composing the majority of the continental United States. The coastal carbon storage model considers only coastal processes affected by the terrestrial nutrients and sediments delivered to coastal waters within a particular region, with an arbitrary offshore oceanic boundary at the 2,000-m isobath.
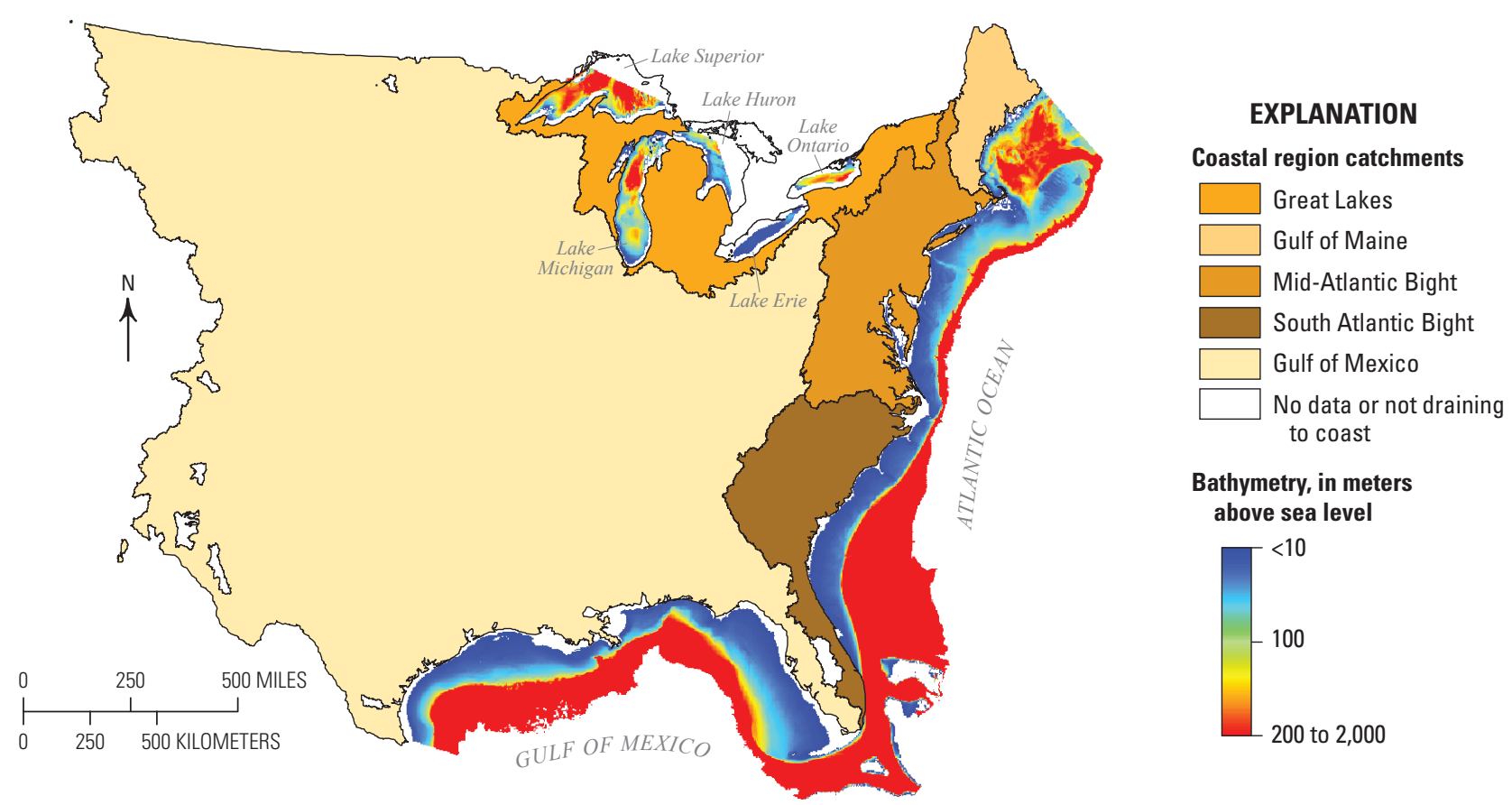

Figure 6-1. Map showing the geographic extent of the five regions used in the assessment of coastal carbon storage in the Eastern United States. The geographic extent of the regions includes all catchments in the Eastern United States draining to waters of the Atlantic Ocean, the Gulf of Mexico, and the Great Lakes and extends in coastal waters to a water depth of 2,000 meters (m). Catchment areas within the model domain that do not drain to the coast or have insufficient data to accurately model are indicated. 


\subsection{Coastal Carbon Storage Model}

\subsubsection{Background and Overview}

The analysis described in this chapter comprises two distinct modeling efforts. One assesses the riverine fluxes of nutrients and sediments to coastal waters and changes caused by changing LULC, and a separate one assesses the effect those fluxes may have on carbon storage in coastal waters, as well as how carbon storage may change under scenarios of altered terrestrial fluxes.

The first model relies on the databases described in chapter 3 of this report that document present and future projected LULC under different SRES scenarios (A1B, A2, and B1). For the baseline LULC and for the projected LULC for each scenario in 2050, riverine fluxes of TOC, total nitrogen (TN), total phosphorus (TP), and total suspended sediment (TSS) to coastal waters were estimated using the hybrid statisticalmechanical Spatially Referenced Regression on Watershed Attributes (SPARROW) model (Smith and others, 1997; Schwarz and others, 2006). The SPARROW model consists of regressions of large water quality datasets to LULC, processbased mass-transport components for water flow paths and in-stream processing, and mass-balance constraints (Schwarz and others, 2006). Relations between land use and flux are statistically robust, provided water quality records used for model development cover a sufficient length of time and include accurate streamflow measurements (Cohn and others, 1992). The SPARROW model is routinely used for regional assessments of contaminant sources and fluxes and is now a routine part of the USGS water-quality assessment activities (Preston and others, 2011). The advantage of using the SPARROW model is that it permits assessment using projected future LULC and population conditions. Results from the SPARROW model based on SRES storylines and spatially detailed modeling represent an important product of this analysis because they project changes in loads of nutrients and sediment to estuaries and coastal areas and may be useful in separate assessments of water quality for a range of potential future conditions.

The second part of this analysis uses a simple heuristic biogeochemical model to assess the potential magnitude of coastal carbon storage directly associated with the riverine fluxes of sediments, carbon, and nutrients. The model structure follows that of Dunne and others (2007), who demonstrated that the rate of carbon burial in shallow ocean waters may be much higher than previously recognized. The goal of the coastal model is to provide the basis for comparing coastal carbon storage estimates associated with baseline and projections of individual SRES scenarios. To permit such a comparison, the model was developed to provide estimates of millennial carbon storage associated with a single year of riverine inputs under different scenarios. This approach necessarily involves evaluation of the flux of a single year through processes occurring over timescales of days to weeks (for example, primary production), months to decades (for example, sediment transport), and decades to centuries (for example, carbon burial). Given this construct, the coastal model is intended to be representational rather than realistic and focuses specifically on how LULC may be related to coastal carbon storage. The model makes no attempt to reproduce or project coastal ocean carbon cycling and does not account for carbon cycling and carbon storage associated with upwelling, downwelling, advective transport of carbon, and other oceanic processes. It should be noted that the carbon storage estimates provided by the model represent only a fraction of the total carbon stored in coastal sediments.

For the purpose of this analysis, carbon storage is defined as burial in coastal sediments below the zone of pore-water oxygen penetration or removal of carbon from the surface ocean across the maximum depth of the upper mixed layer and away from contact with the atmosphere. Separate components of the model estimate retention of nutrients and sediment in estuaries, "new production" of phytoplankton biomass, transit and degradation of biomass through the water column, and burial of biomass in sediments or loss below the deep mixed layer into the deep ocean, depending on the location of the original biomass production. It also estimates the amount of terrestrial TOC stored. Because the amount of surface productivity that is eventually stored depends largely on the depth of the water column and the sediment burial rate, carbon storage in coastal areas is sensitive to the spatial distribution of nutrients and sediments in the surface waters. The model presented here uses a spatial distribution developed from averaged remote sensing data to represent the physical processes leading to spatial variability in coastal waters.

Climate-related changes, such as those to river discharge and vegetation, were not estimated in the LULC coverages and thus were not part of this analysis. The potential effects of climate change on nutrients or biological processes in the coastal ocean also were not included. Although changing climate would be expected to have some influence on future fluxes of nutrients and suspended sediment to coastal waters, LULC is expected to be the main driver of the variability in these parameters between 2005 and 2050 (Allan, 2004). Potential effects of temperature rise on $\mathrm{TN}$ flux can be estimated from the characteristics of the temperature term in the SPARROW TN model (Alexander and others, 2008). For example, the TN flux from a typical watershed in the Eastern United States was projected to decrease by 13 percent because of increased denitrification associated with the higher temperature for an air temperature increase of $2{ }^{\circ} \mathrm{C}$ between 2005 and 2050. The effects of temperature on TP, TSS, and TOC flux would be expected to be smaller. Effects of changing streamflow on nutrients and sediment are more difficult to anticipate given the large current uncertainty about the direction and magnitude of changes in the hydrologic cycle in the Eastern United States (Najjar and others, 2000, 2010)

\subsubsection{Methods and Data}

\subsubsection{Terrestrial Flux Model}

Estimates of TN, TP, TSS, and TOC fluxes were prepared for the baseline year and for SRES scenarios A1B, A2, and B1 
for 2050 using SPARROW models calibrated to 1992 LULC conditions (see chap. 3 for description of modeling of LULC changes from 2005 through 2050). SPARROW models describe the steady-state balance between contaminant supply rates and average streamflow and water quality conditions (Schwarz and others, 2006; Shih and others, 2010; Smith and others, 1997). Use of the TN, TP, TSS, and TOC models to project fluxes through 2050 assumes that contaminant sources change in accordance with projected LULC scenarios and that water quality conditions reach a new steady state based on current streamflow rates.

Modeled estimates of TSS, TN, TP, and TOC fluxes were produced for 2,174 tributary drainages to the Great Lakes and the east and gulf coasts of the United States. Estimates of TOC that were produced using a different modeling approach (chap. 5) agree with those presented here.

For surface-water monitoring stations that had sufficient data on discharge and water quality, water-quality parameters were estimated by spatially correlating the stream data with georeferenced data on the constituent sources (for example, atmospheric deposition, fertilizers, human and animal wastes) and delivery factors (for example, precipitation, topography, vegetation, soils, and water routing). Parameter estimation ensured that the calibrated model would not be more complex than can be supported by the data.

SPARROW models describe mass transport in watersheds as three sequential processes - (1) source supply, (2) land-to-water transport, and (3) channel-network transport (Smith and others, 1997). Data describing these processes are developed on a stream reach and associated catchment basis. There are about 63,000 reaches or catchments in the national-scale dataset used to calibrate the models. Table $6-1$ provides information on the TN, TP, TSS, and TOC models used in this assessment to quantify the flux of material to coastal waters.

The source variables (table 6-1) were of particular importance because they served as the basis for translating the baseline and projected LULC into coastal delivery of TOC, TN, TP, and TSS from 2005 through 2050. Table 6-2 summarizes the correspondence between the LULC classes and the source categories from the SPARROW model. An underlying assumption made in modeling projected changes in coastal flux was that the rate of the source supply will change in proportion to the LULC changes in each modeled catchment. The change in the value of the population variable in the TN model within each catchment was approximated by the projected change in the developed land area (chap. 3). The modeled SRES scenarios are thus reflected in the LULC and SPARROW modeling (chaps. 2 and 3; Sohl and others, 2012b).

The 90-percent confidence intervals for the coastal flux estimates in table 6-3 were developed through a bootstrap procedure in which 200 equally likely estimates for each entry in the table were randomly generated based on the error characteristics of the model determined during calibration. The width of the confidence intervals surrounding the 1992 and 2050 flux estimates includes coefficient and residual (that is, model specification) errors (Schwarz and others, 2006). The residual errors of the flux estimates for individual coastal rivers within each region were assumed to reflect idiosyncrasies of the river watersheds. However, the estimated errors surrounding the "percent-change" estimates for each coastal river were assumed to arise only from coefficient error, based on the further assumption that the idiosyncrasies of a given river can be assumed to be the same in 2005 and 2050. Thus, the confidence intervals for the percent-change estimates are smaller than those for the separate 2005 and 2050 flux estimates.

\subsubsection{Coastal Carbon Storage Model}

The approach used for modeling coastal processes for storing carbon was based largely on the model approach of Dunne and others (2007) that captured the fate of surface productivity as it moves through the water column and into the deep ocean and sediments. This model approach was adapted to analyze only the sensitivity of carbon storage associated with the potential new production that results from terrestrial inputs from the Eastern United States.

Table 6-1. Variables used in the SPARROW models of total nitrogen, total phosphorous, total suspended sediment, and total organic carbon fluxes in the assessment of coastal carbon storage and fluxes in the Eastern United States.

$\left[\mathrm{R}^{2}\right.$, coefficient of determination; SPARROW, spatially referenced regressions of watershed attributes water-quality model; TN, total nitrogen; TP, total phosphorus; TSS, total suspended solids; TOC, total organic carbon]

\begin{tabular}{ccccccc}
\hline Model & $\begin{array}{c}\text { Number } \\
\text { of sites }\end{array}$ & $\mathbf{R}^{2}$ & Source variables & Reference \\
\hline TN & 425 & 0.933 & $\begin{array}{c}\text { Population, atmospheric nitrate deposition, corn or soybean fertilizer, } \\
\text { alfalfa fertilizer, wheat fertilizer, other crop fertilizer, farm animal } \\
\text { waste, forest, barren land, shrubland }\end{array}$ & Alexander and others (2008) \\
TP & 425 & 0.871 & $\begin{array}{c}\text { Population, corn or soybean fertilizer, alfalfa fertilizer, other crop fertil- } \\
\text { izer, farm animal waste, forest, barren land (transitional), shrubland }\end{array}$ & Alexander and others (2008) \\
TSS & 1,828 & 0.711 & $\begin{array}{c}\text { Urban area, forest, crop and pasture land, federal land, other marginal } \\
\text { land, channel storage and erosion }\end{array}$ & Schwarz (2008) \\
TOC & 1,125 & 0.928 & $\begin{array}{c}\text { Cultivated land, pasture, deciduous forest, evergreen forest, mixed } \\
\text { forest, rangeland, urban land, wetlands, in-stream photosynthesis }\end{array}$ & Shih and others (2010) \\
\hline
\end{tabular}


Table 6-2. Assumed correspondences between the source categories of the SPARROW model and the LULC classes used in the assessment of coastal carbon storage and fluxes in the Eastern United States.

[See chapter 3 of this report for definitions of the land use and land cover (LULC) classes. NA, not available;

SPARROW, spatially referenced regressions of watershed attributes water-quality model]

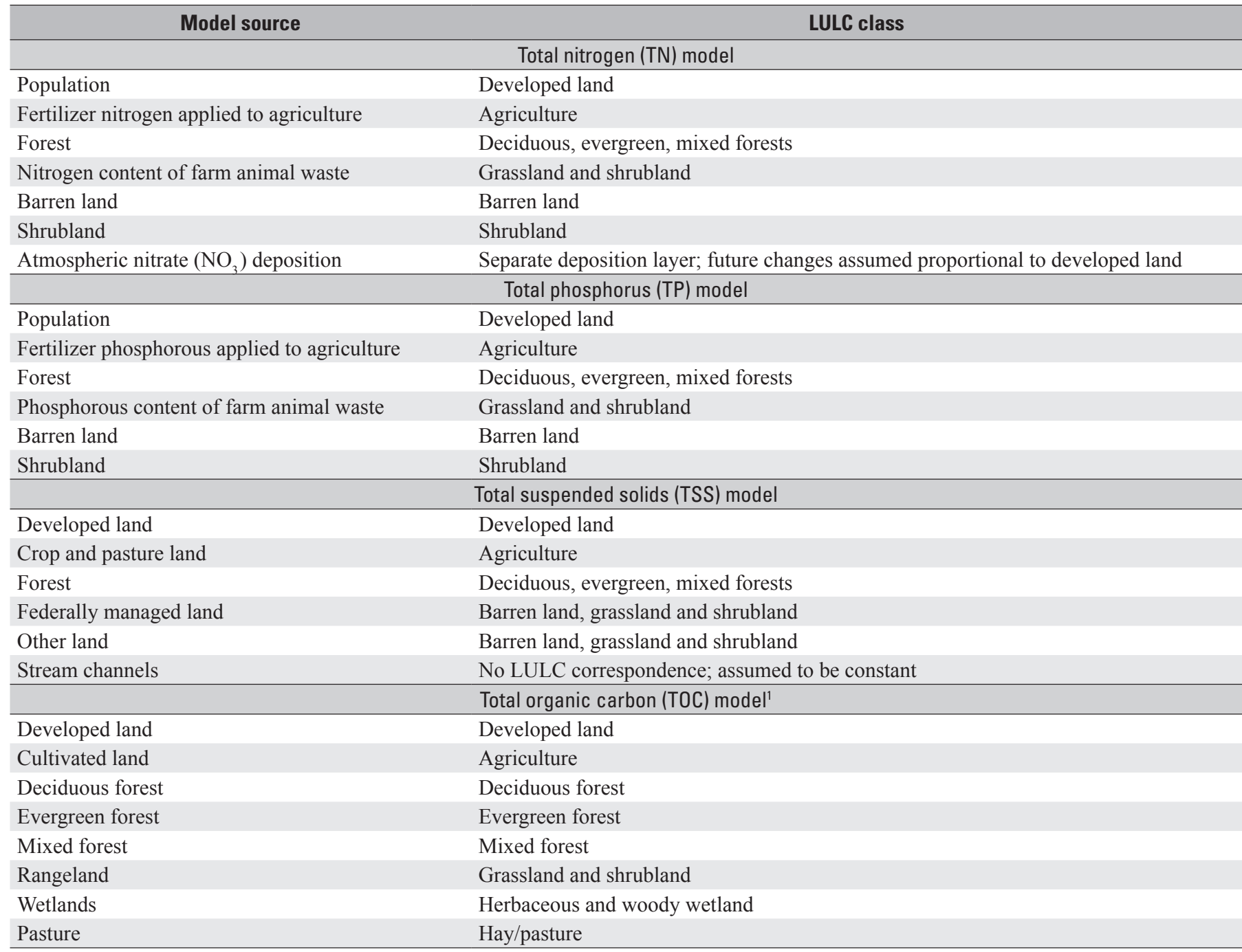

${ }^{1}$ The TOC model includes in-stream photosynthesis as a TOC source which does not correspond directly to a LULC class. However, the in-stream photosynthesis estimates depend, in part, on predictions from the TP model, which does incorporate the LULC classes, as indicated in this table.

The model is a simple heuristic one-dimensional model of productivity, carbon burial in sediments, and deep water remineralization implemented with a 4-km resolution over the 10 - to 2,000-m bathymetry of the coastal oceans and Great Lakes of the Eastern United States. A 4-km model resolution was used to correspond with the spatial resolution of the remote sensing imagery and used to establish a realistic spatial distribution of nutrients and sediments in the coastal ocean.

A representative spatial field for production and for sediment dispersion in the coastal ocean was developed from a composite image of chlorophyll a ( $\mathrm{Chl} a$ ) and of total suspended sediment (TSS) derived from European Space Agency medium resolution imaging spectrometer (MERIS) data at nominal $4-\mathrm{km}$ resolution for the entire coastal waters of the United States in 2011. The Chl2 algorithm from MERIS was specifically used to avoid overestimation of $\mathrm{Chl} a$ due to colored dissolved organic matter present in nearshore coastal zones where typical empirical ocean color algorithms fail (for example, algorithms OC4 and OC3 from the SeaWiFS Data Analysis System (SeaDAS); Szeto and others, 2011; Sauer and others, 2012; Siegel and others, 2013). The resulting ocean color imagery was divided into study regions and aligned with NOAA ETOPO1 bathymetry. Loading to each pixel in the model domain was estimated by unit-normalizing the integrated value across the region and multiplying by the input mass to that region.

The purpose of the remote sensing imagery is to conceptualize coastal physical dynamics in the model while 
Table 6-3. Modeled baseline (2005) and projected (2050) estimates of total nitrogen, total phosphorus, total suspended sediment, total organic carbon fluxes to coastal waters, and estimated inventory of carbon in the upper 1 meter of sediment directly attributable to terrestrial inputs in the Eastern United States.

[Data in parentheses are 90-percent confidence intervals. Projected (2050) conditions are based on Intergovernmental Panel on Climate Change Special Report on Emissions Scenarios (SRES; Nakićenović and others, 2000) scenarios A1B, A2, and B1. Values may not add to totals shown due to independent rounding. $\mathrm{CI}$, confidence intercval; $\mathrm{Tg} / \mathrm{yr}$, teragrams per year; $\mathrm{kg} / \mathrm{km}^{2} / \mathrm{yr}$, kilograms per square kilometer per year; $\mathrm{km}^{2}$, square kilometers; -, no data]

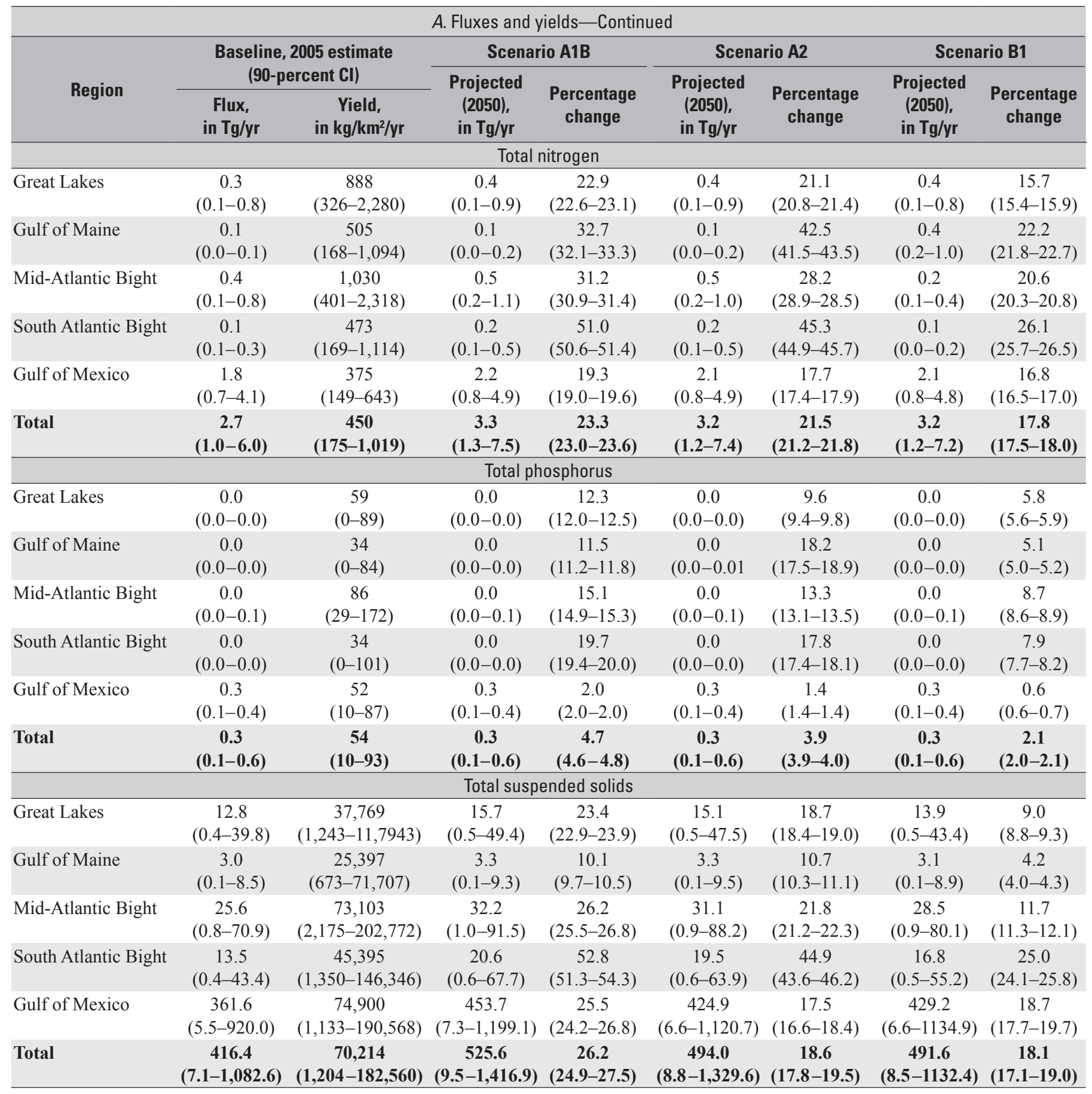


Table 6-3. Modeled baseline (2005) and projected (2050) estimates of total nitrogen, total phosphorus, total suspended sediment, total organic carbon fluxes to coastal waters, and estimated inventory of carbon in the upper 1 meter of sediment directly attributable to terrestrial inputs in the Eastern United States.-Continued

[Data in parentheses are 90-percent confidence intervals. Projected (2050) conditions are based on Intergovernmental Panel on Climate Change Special Report on Emissions Scenarios (SRES; Nakićenović and others, 2000) scenarios A1B, A2, and B1. Values may not add to totals shown due to independent rounding. $\mathrm{CI}$, confidence intercval; $\mathrm{Tg} / \mathrm{yr}$, teragrams per year; $\mathrm{kg} / \mathrm{km}^{2} / \mathrm{yr}$, kilograms per square kilometer per year; $\mathrm{km}^{2}$, square kilometers; —, no data]

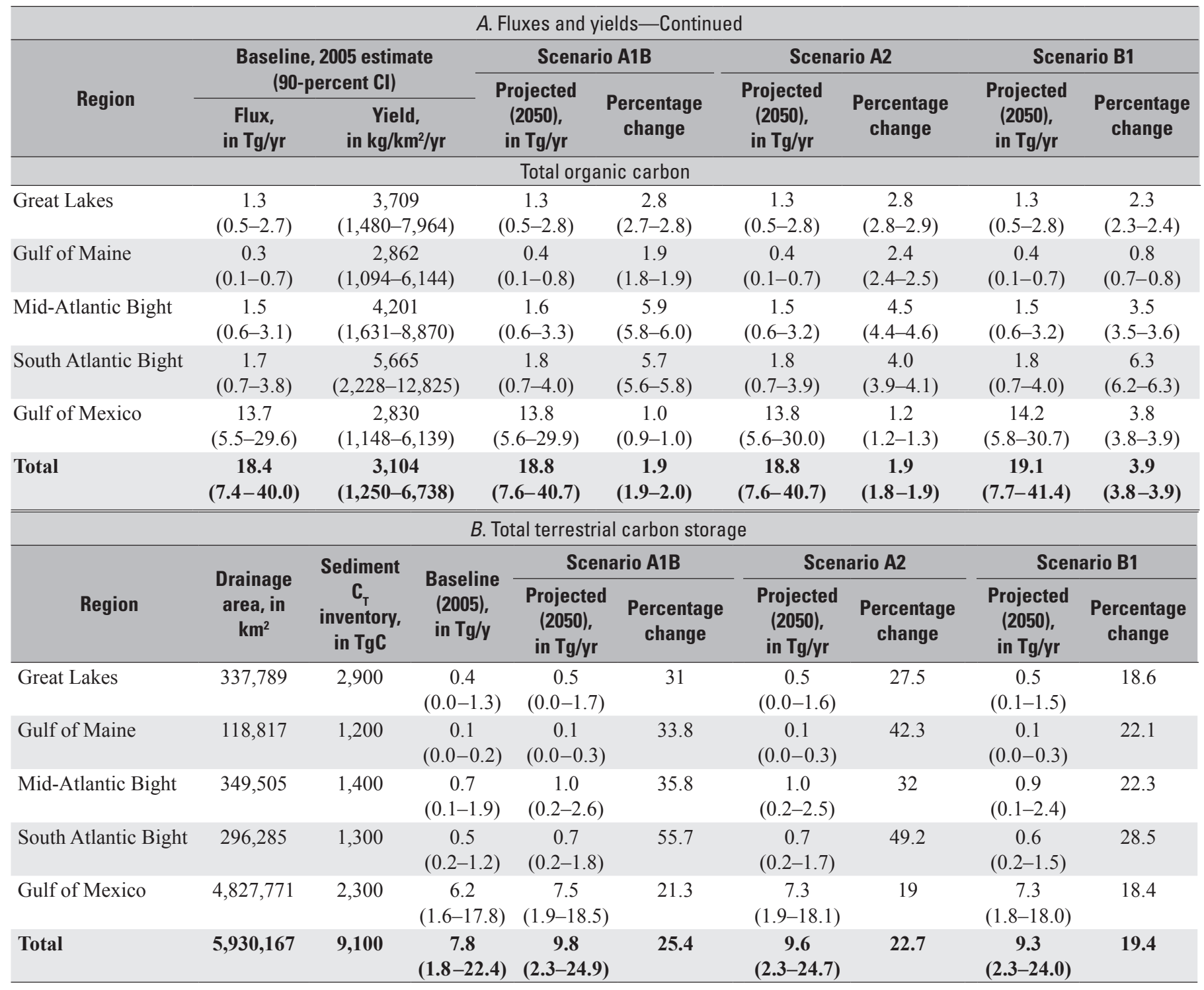

still permitting use of the one-dimensional carbon storage modeling framework across the model domain. There is no horizontal transport in the model. This is an oversimplification that neglects to account in any way for processes not present in the composite images, such as near-bottom cross shelf transport of sediment and carbon (Hales and others, 2008). However, explicitly modeling the effects of physical dynamics is beyond the scope of this analysis.

The model input for the coastal portion of the analysis was the output from the SPARROW fluxes to estuaries and 
coastal areas, modified to account for nutrient and sediment retention in estuaries and for direct diffusive denitrification of nitrate from coastal waters in coastal sediments. Direct coastal erosion is not included in the analysis, but nutrient and sediment fluxes from the land surface adjacent to coasts and estuaries are included in the SPARROW model output from the modeling scenarios that were run for this assessment even if the coasts and estuaries are not part of a watershed included in the database. Nutrient retention in estuaries was estimated separately for nitrogen and phosphorus according to the global relations presented by Nixon and others (1996) and the residence time estimates in the NOAA National Estuarine Eutrophication Assessment (NEEA) estuaries database (http://ian.umces.edu/neea/siteinformation.php). Sediment retention was assumed to be similar to phosphorus retention. No retention was assumed for the Mississippi River because of the discharge geometry and the time scale of the analysis. This assumption was necessary because no models exist for long-term carbon burial in estuaries, and estuaries are subject to substantial reworking of sedimentary carbon on decadal time scales (Keil and others, 1997).

Denitrification is a strong sink for nitrogen in the coastal oceans, resulting in a loss of nitrogen potentially available to support photosynthetic production (Nixon and others, 1996; Seitzinger and Giblin, 1996), with the bulk of removal occurring through either denitrification during remineralization of organic matter or direct denitrification of nitrate in the overlying water. Separate approaches were used to account for each of these processes in the model. Before calculating primary production, the demand from shallow water column and direct denitrification was removed from the totalized TN mass as an inverse geometric function of water depth and $\mathrm{TN}$ concentration. The shallow water TN demand used in the model ranged from 1,200 millimoles per square meter per year $\left(\mathrm{mmol} / \mathrm{m}^{2} / \mathrm{yr}\right)$ in shallow waters to $6 \mathrm{mmol} / \mathrm{m}^{2} / \mathrm{yr}$ at $200 \mathrm{~m}$. Denitrification during remineralization within the sediments was accounted for by assuming that organic nitrogen from new production arriving at the sediment surface is either buried or denitrified and thus was not available to support additional primary production in the surface waters (Murray and Parslow, 1999; Piña-Ochoa and Alvarez-Cobelas, 2006). Phosphate was assumed to be liberated by remineralization and consequently was not found to be limiting to modeled production.

Following reduction of TSS mass estimated by the SPARROW model for estuary retention, the resulting lower TSS mass was converted to pixel loadings across each region by multiplying the total input mass by each normalized pixel value of the TSS MERIS images across the 30- to 2,000-m bathymetry (fig. 6-2). For the purpose of this assessment, it was assumed that no net sediment deposition (or carbon burial) occurred at mean water depths less than $30 \mathrm{~m}$ over time scales of decades, owing to sediment resuspension and transport due to wind waves, internal waves, storms, and flood events (Blair and others, 2004).

Nutrient loading to each pixel was established using the unit normalized satellite $\mathrm{Chl} a$ imagery (fig 6-2) multiplied by the adjusted input mass of TN. Due to the denitrification demand, TN distribution was performed in two iterations. In the first iteration, the TN mass adjusted for retention by estuaries was distributed across the 10 - to 2,000 -m bathymetry for the purpose of calculating the diffusive and shallow water denitrification demand (see below). After the calculation and removal of TN lost through these processes, a second iteration redistributed the remainder of the TN mass across the 30 - to 2,000-m bathymetry.

Nutrient inputs to the surface ocean were assumed to be converted by photosynthetic activity into "new production" according to the stoichiometric balance described by Anderson and Sarmiento (1994), where the ratio of carbon to nitrogen is $7: 1$ and the ratio of carbon to phosphorus is $117: 1$. Nutrients released into the surface waters during water-column remineralization were assumed to be available to support additional new production.

The fate of this modeled new production depended on the depth of the water column and the deep mixed layer. The deep mixed layer was assigned a uniform thickness of $200 \mathrm{~m}$, based on the statistical analysis of global ocean annual maximum mixed layer depths (Kara and others, 2000; de Boyer Montégut and others, 2004). New production in areas with water column depths shallower than $200 \mathrm{~m}$ was presumed to undergo the process of sediment burial, with remineralized $\mathrm{CO}_{2}$ equilibrated with the atmosphere. Where water depths exceeded $200 \mathrm{~m}$, new production sank out of the deep mixed layer, and the carbon and associated nutrients were considered removed from the surface ocean and stored in the deep ocean. Remineralization of new production below the mixed layer was modeled using the relationship derived by the Martin curve (Martin and others, 1987) as employed in Dunne and others (2007), yielding a fraction of new production that is subject to burial in sediments and a fraction that is stored as dissolved inorganic carbon in the deep ocean. However, because there is no millennial deep-water reservoir of carbon in the Great Lakes, all carbon storage in the Eastern United States is presumed to be through sediment burial and all $\mathrm{CO}_{2}$ resulting from remineralization presumed equilibrated with the atmosphere.

Nutrients supporting new organic production were presumed to regenerate until fully consumed and removed from the mixed layer by sinking or to the sediments. Once new production was removed to the sediments, it was not considered buried until it was buried below the zone of oxygen penetration and resistant to remineralization over millennial timescales (Hedges and Keil, 1995; Dunne and others, 2007). Burial of the fraction of material arriving at the sediment surface was estimated using the empirical formulation of Dunne and others (2007, equation 2), using data from Alperin and others (2002), Thomas and others (2002), and Hofmann and others (2011). Organic carbon of terrestrial origin was assumed to be 5 percent of the total carbon buried (Blair and others, 2003; Burdige, 2005). Terrestrial carbon buried in sediments represents about 0.4 percent of the SPARROWestimated terrestrial TOC flux under baseline conditions. All 


\section{A. Sediment dispersion}

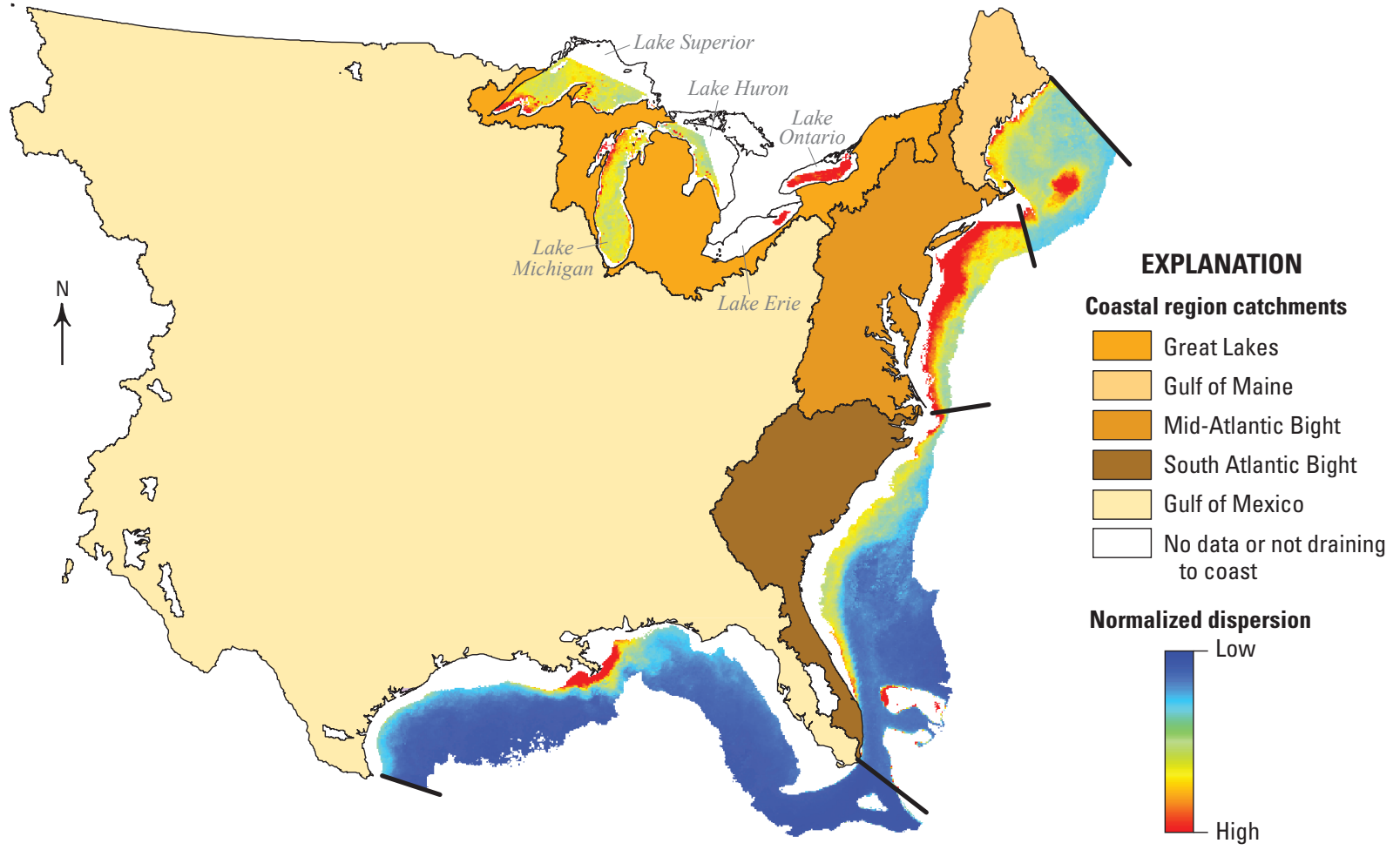

B. Nutrient dispersion

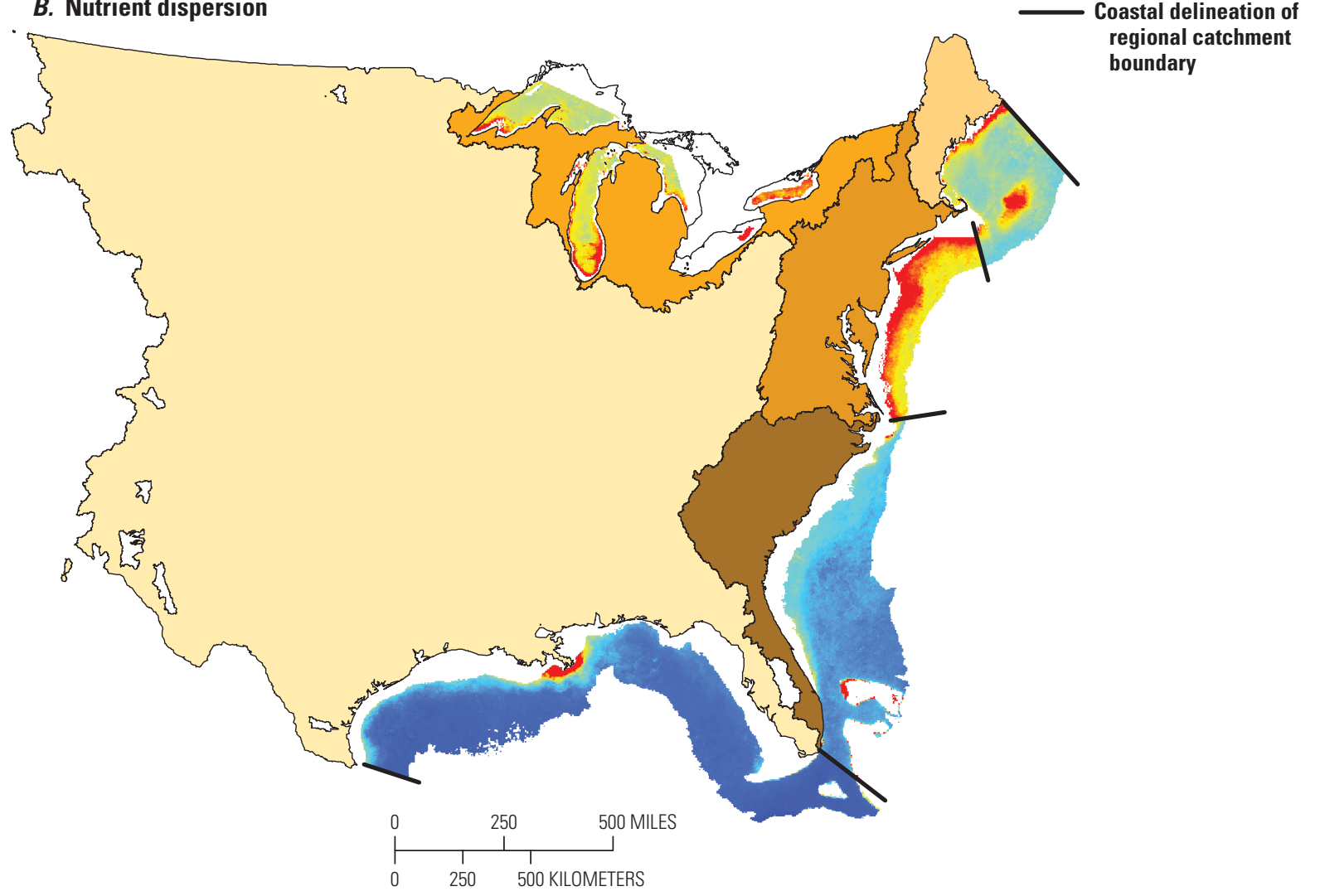

Figure 6-2. Maps showing dispersion fields for $A$, nutrients and $B$, sediments in the coastal carbon sequestration model for the Eastern United States. Heavy black lines indicate the boundaries between the Great Lakes, east coast, and Gulf of Mexico. 
remaining TOC mass that originates from terrestrial flux is presumed remineralized in the surface ocean and the resulting $\mathrm{CO}_{2}$ equilibrated with the atmosphere (Hedges and Keil, 1995; Hedges and others, 1997).

The effects of increased hypoxia on carbon burial were not considered; generally, increased hypoxia results in higher rates of organic carbon preservation (Bergamaschi and others, 1997; Green and others, 2006). Thus, carbon storage in this model is defined as the rate at which carbon fixed by new production is either buried to the extent that it escapes remineralization over millennial timescales or is exported to the deep ocean where it is buried or prevented from equilibration with the atmosphere over timescales of ocean circulation. Burial was calculated over the entire model domain, whereas carbon was stored in deep ocean waters only where water depths exceed the depth of the permanent mixed layer.

To permit comparison to terrestrial carbon stocks and to assess the process of long-term sediment carbon accumulation, the amount of carbon that would accumulate in the upper $1 \mathrm{~m}$ of sediments due to the modeled storage rates was estimated by applying the organic content derived from the model to the upper meter of sediment, assuming a porosity of 0.7 and a density of 2.5 grams per cubic meter $\left(\mathrm{g} / \mathrm{cm}^{3}\right.$; Dunne and others, 2007). The organic content was given by dividing the carbon burial rate by the sediment mass accumulation rate. It should be noted that this heuristic calculation yields a result for the conditions of the modeled year (2005) although the timescale of accumulation of the upper $1 \mathrm{~m}$ of sediment can span thousands of years.

\subsection{Results and Discussion}

The primary active pools of carbon storage in the oceans are organic carbon buried in surficial sediment and dissolved inorganic carbon in seawater (Hedges and Keil, 1995; Sarmiento and Gruber, 2002). This study focuses exclusively on how nutrient and sediment fluxes from terrestrial environments affect carbon storage within both these pools. To understand the model results, the carbon derived from terrestrial process must be clearly distinguished from carbon derived from other processes that store carbon in the coastal ocean, such as primary production supported by nutrients from the deep ocean (Sarmiento and Gruber, 2002). The model presented here tracks the fraction of carbon associated with primary production that is specifically supported by nutrients from the continents (terrestrial carbon; $\mathrm{C}_{\mathrm{T}}$ ) and ultimately estimate the fraction of this carbon eventually stored in the coastal ocean through either the transport and burial of that primary production by riverborne sediments or through the transport to the deep ocean, with both processes isolating carbon from the atmosphere for millennial timescales. The symbol $\mathrm{C}_{\mathrm{T}}$ is introduced here to distinguish this subset of terrestrially supported carbon from the much larger carbon pool in the ocean.

\subsubsection{Flux of Nutrients, Suspended Sediment, and TOC to Coastal Waters}

Sources in common for TN and TP include treated municipal sewage, industrial wastewater, urban runoff, and crop and animal agricultural activity. Although the atmosphere contributes significant amounts of TN, it is a negligible source of TP in most watersheds. Principal sources for TSS are erosion and channel scour as well as urban, crop, and pasture lands. The principal source for TOC is in-stream photosynthesis, followed by wetlands and cultivated lands.

\subsubsection{Total Nitrogen}

The SPARROW model estimated a baseline TN flux of 2.7 Tg/yr (fig. 6-3; table 6-3) for the Eastern United States. About two thirds of the total flux originated in the Gulf of Mexico drainage, nearly one quarter originated in the east coast drainages, and about one tenth originated in the Great Lakes drainage. However, after adjusting for drainage area, the flux per unit area (yield) of TN in the Gulf of Mexico drainage was lowest among the five regions (table 6-3). This reflects the much longer distances nitrogen must travel to the Gulf of Mexico from sources in the large Mississippi Basin, which leads to elevated losses of TN to denitrification in stream and river channels. By contrast, the highest yields of TN came from the Mid-Atlantic Bight part of the east coast drainages (Gulf of Maine, Mid-Atlantic Bight, and South Atlantic Bight) where urban, agricultural, and atmospheric sources are high and travel distances to the east coast are relatively short.

The estimated TN flux from all five coastal regions was projected to increase significantly by 2050 under all three SRES scenarios (fig. 6-4; table 6-3), primarily because of increasing population and resulting increases in atmospheric sources of $\mathrm{CO}_{2}$ in those areas (table 6-4). Under scenarios A1B and A2, U.S. and global population and per-capita income were projected to increase substantially by 2050. Although U.S. agricultural production was expected to increase substantially to meet elevated worldwide demand, the increase was assumed to occur largely through increases in yield rather than in agricultural land area. The estimated $\mathrm{TN}$ flux from all five regions was projected to increase by more than 20 percent in scenarios A1B and A2, with increases in the South Atlantic Bight region alone projected to increase by 45 percent and 51 percent, respectively (figs. 6-3 and 6-4; table 6-3). By contrast, under scenario $\mathrm{B} 1$, a greater focus on biodiversity protection than under scenarios $\mathrm{A} 1 \mathrm{~B}$ and $\mathrm{A} 2$ results in a smaller rise in the land area devoted to urban development, despite increases in population and wealth. Hence, TN flux to the five coastal regions of the Eastern United States is projected to increase by smaller percentages under scenario B1 than under scenario A1B or A2. 


\section{A. Estimated delivered total nitrogen yield}

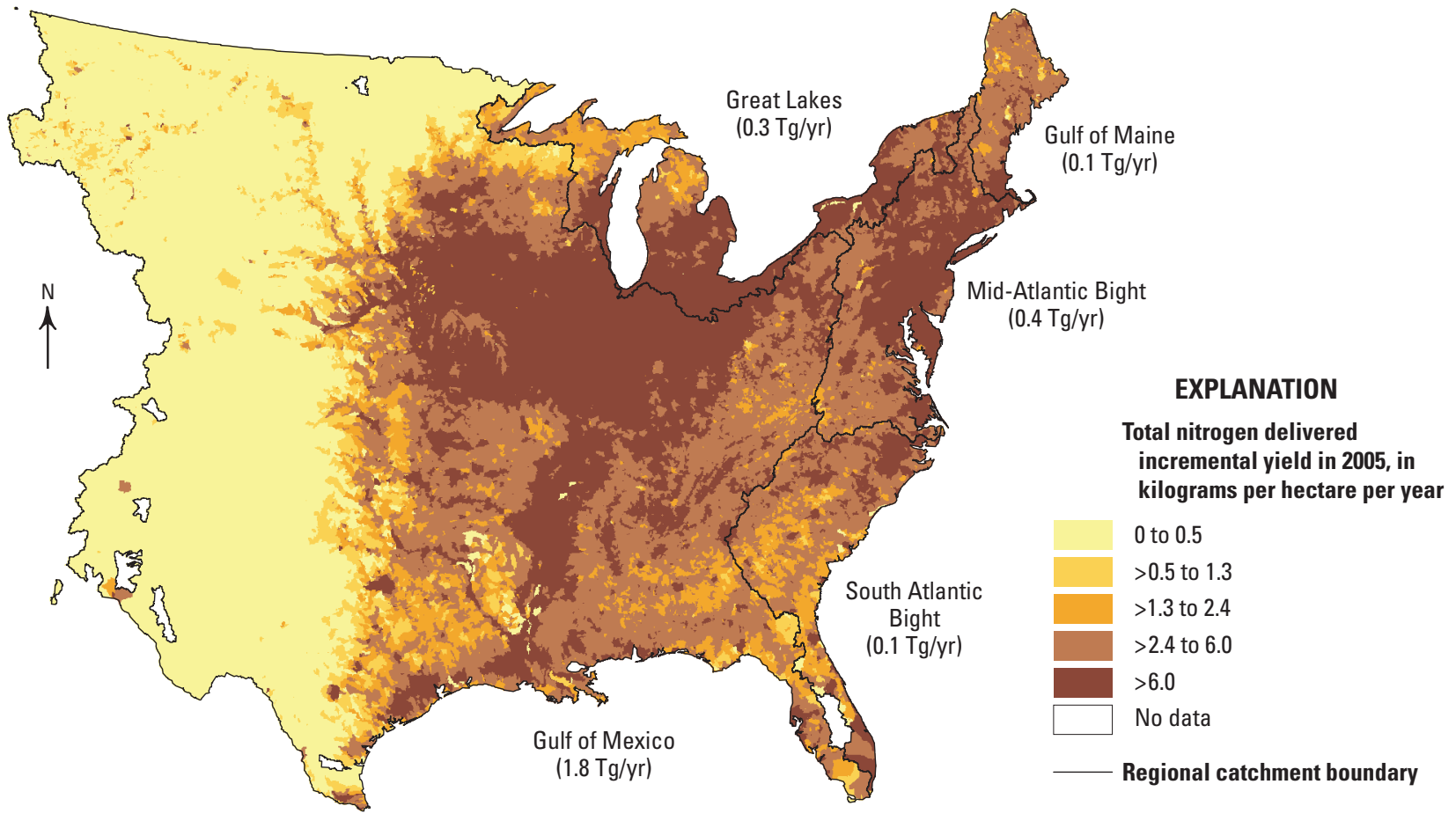

\section{B. Major sources of total nitrogen in model catchments}

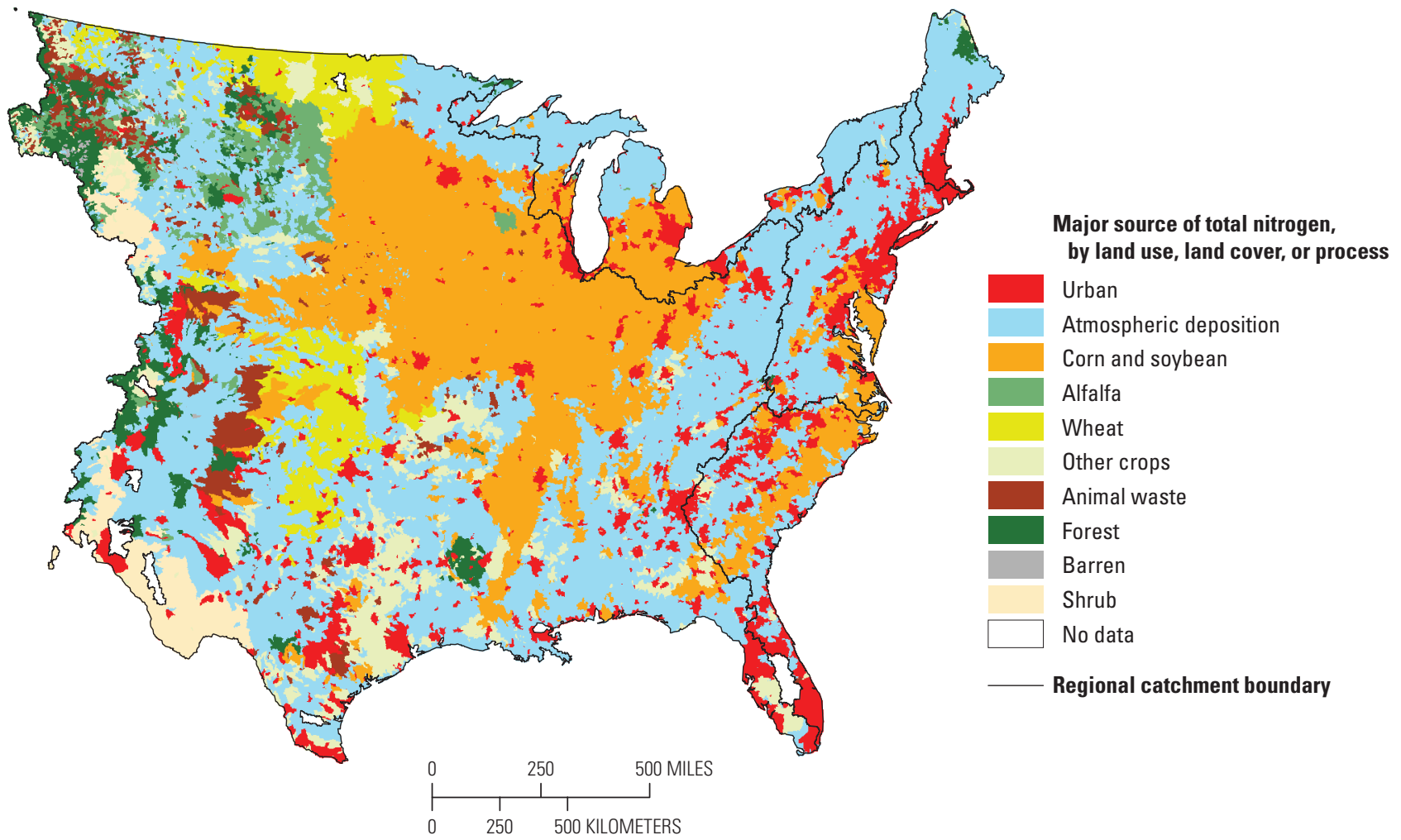

Figure 6-3. Maps showing $A$, estimated delivered total nitrogen (TN) yield to coastal waters and $B$, major sources of TN in model catchments under baseline (2005) conditions in the Eastern United States. Delivered yield reflects the effects of in-stream losses that occur during transport from the outlet of a catchment through the stream and river system to coastal waters. Values shown in parentheses indicate net flux of TN for each region. LULC, land cover and land use; Tg/yr, teragrams per year; $>$, more than. 


\section{A. Difference in total nitrogen yield between baseline and scenario A1B}

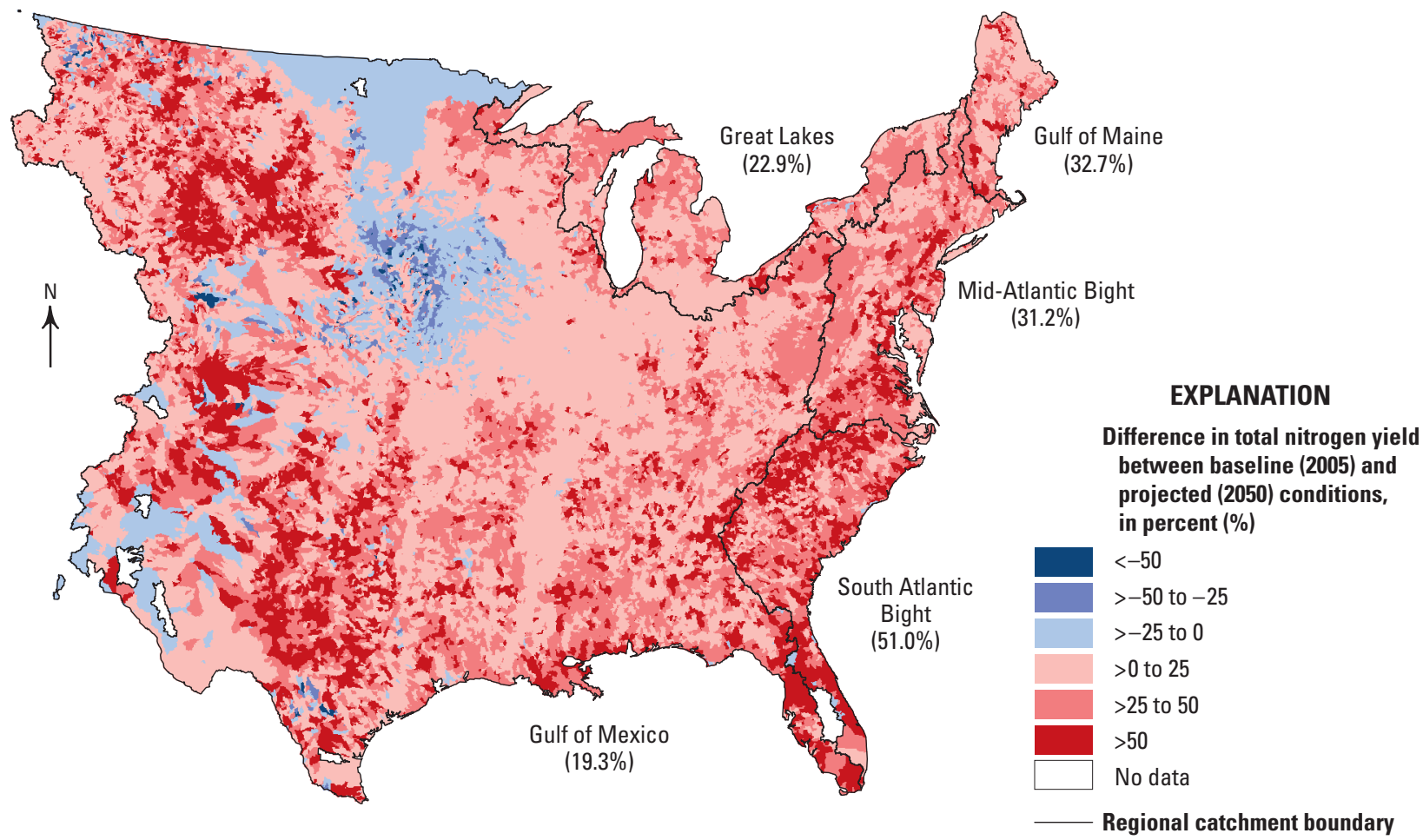

\section{B. Difference in total nitrogen yield between baseline and scenario B1}

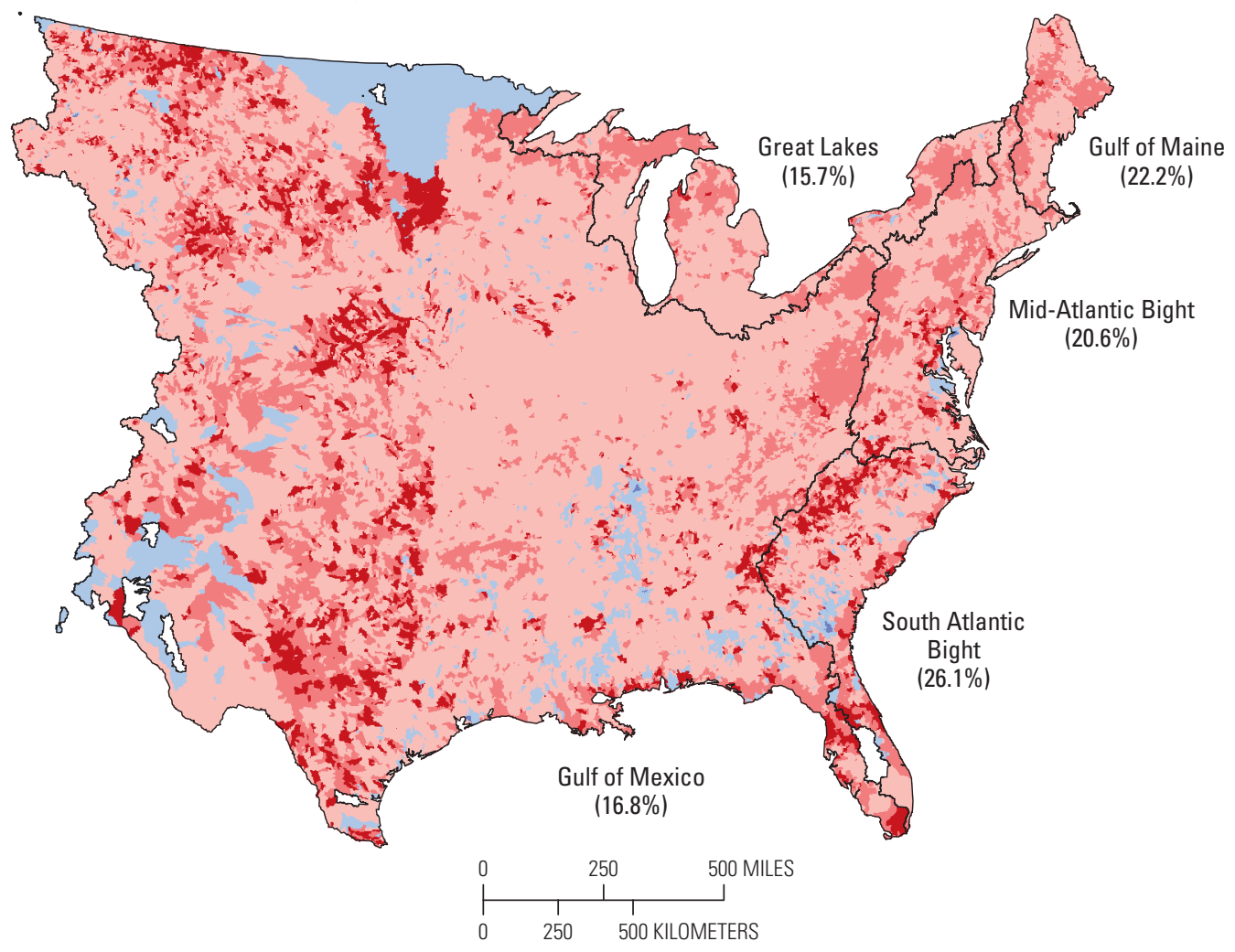

Figure 6-4. Maps showing difference between estimated delivered total nitrogen (TN) yield to coastal waters under baseline (2005) and projected (2050) conditions for Intergovernmental Panel on Climate Change Special Report on Emissions Scenarios (SRES; Nakićenović and others, 2000) scenarios $A, \mathrm{~A} 1 \mathrm{~B}$ and $B, \mathrm{~B} 1$ in the Eastern United States. Values shown in parentheses indicate regional difference from baseline. $<$, less than; $>$, more than. 
Table 6-4. Estimates of total nitrogen, total phosphorous, total suspended sediment, and total organic carbon fluxes to the coastal waters of the Eastern United States by source of the fluxes, under baseline and projected conditions.

[Projected (2050) conditions are based on Intergovernmental Panel on Climate Change Special Report on Emissions Scenarios (SRES; Nakićenović and others, 2000) scenarios A1B, A2, and B1. Data may not add to totals shown due to independent rounding. Gg/yr, billion grams per year]

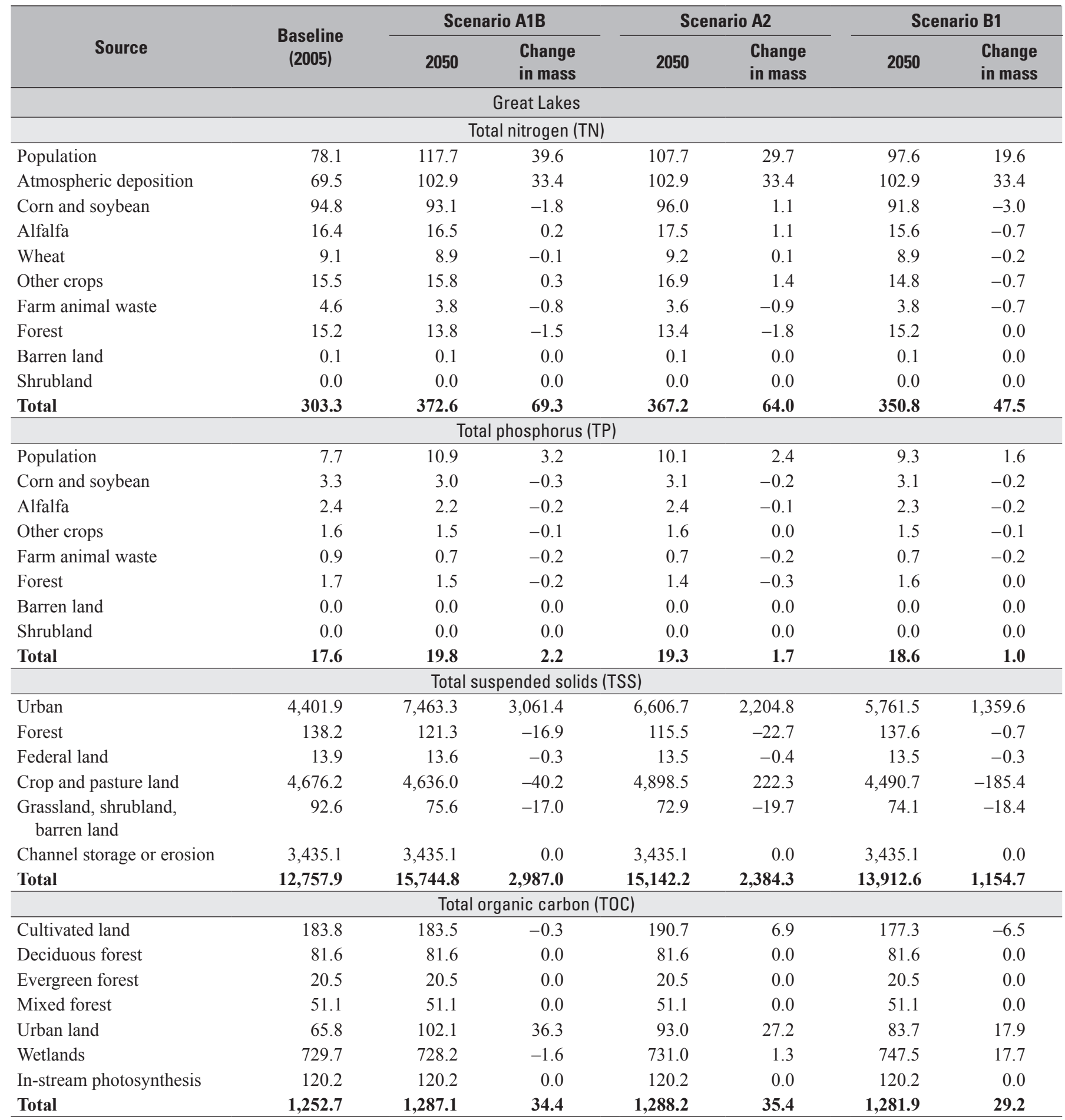


Table 6-4. Estimates of total nitrogen, total phosphorous, total suspended sediment, and total organic carbon fluxes to the coastal waters of the Eastern United States by source of the fluxes, under baseline and projected conditions. - Continued

[Projected (2050) conditions are based on Intergovernmental Panel on Climate Change Special Report on Emissions Scenarios (SRES; Nakićenović and others, 2000) scenarios A1B, A2, and B1. Data may not add to totals shown due to independent rounding. Gg/yr, billion grams per year]

\begin{tabular}{|c|c|c|c|c|c|c|c|}
\hline \multirow[b]{2}{*}{ Source } & \multirow{2}{*}{$\begin{array}{c}\text { Baseline } \\
(2005)\end{array}$} & \multicolumn{2}{|c|}{ Scenario A1B } & \multicolumn{2}{|c|}{ Scenario A2 } & \multicolumn{2}{|c|}{ Scenario B1 } \\
\hline & & 2050 & $\begin{array}{l}\text { Change } \\
\text { in mass }\end{array}$ & 2050 & $\begin{array}{l}\text { Change } \\
\text { in mass }\end{array}$ & 2050 & $\begin{array}{l}\text { Change } \\
\text { n mass }\end{array}$ \\
\hline \multicolumn{8}{|c|}{ Total nitrogen (TN) } \\
\hline Population & 18.6 & 24.7 & 6.2 & 23.8 & 5.3 & 21.6 & 3.1 \\
\hline Atmospheric deposition & 21.0 & 31.1 & 10.1 & 31.1 & 10.1 & 31.1 & 10.1 \\
\hline Alfalfa & 0.6 & 0.7 & 0.1 & 1.0 & 0.4 & 0.6 & -0.1 \\
\hline Wheat & 0.0 & 0.0 & 0.0 & 0.0 & 0.0 & 0.0 & 0.0 \\
\hline Other crops & 3.3 & 7.3 & 4.0 & 13.5 & 10.2 & 3.7 & 0.4 \\
\hline Farm animal waste & 0.3 & 0.3 & 0.0 & 0.3 & 0.0 & 0.3 & 0.0 \\
\hline Forest & 13.6 & 12.3 & -1.3 & 12.1 & -1.5 & 13.3 & -0.3 \\
\hline Population & 2.5 & 3.2 & 0.6 & 3.1 & 0.6 & 2.9 & 0.4 \\
\hline Corn and soybean & 0.0 & 0.0 & 0.0 & 0.0 & 0.0 & 0.0 & 0.0 \\
\hline Alfalfa & 0.1 & 0.1 & 0.0 & 0.1 & 0.0 & 0.1 & 0.0 \\
\hline Other crops & 0.2 & 0.5 & 0.2 & 0.9 & 0.7 & 0.2 & 0.0 \\
\hline Farm animal waste & 0.1 & 0.1 & 0.0 & 0.1 & 0.0 & 0.1 & 0.0 \\
\hline Forest & 1.7 & 1.4 & -0.3 & 1.3 & -0.4 & 1.6 & -0.1 \\
\hline Barren land & 0.2 & 0.1 & 0.0 & 0.1 & 0.0 & 0.2 & 0.0 \\
\hline Shrubland & 0.0 & 0.0 & 0.0 & 0.0 & 0.0 & 0.0 & 0.0 \\
\hline Total & 4.8 & 5.3 & 0.5 & 5.7 & 0.9 & 5.0 & 0.2 \\
\hline \multicolumn{8}{|c|}{ Total suspended solids (TSS) } \\
\hline Total & $3,017.6$ & $3,322.8$ & 305.2 & $3,341.0$ & 323.4 & $3,143.3$ & 125.7 \\
\hline \multicolumn{8}{|c|}{ Total organic carbon (TOC) } \\
\hline Cultivated land & 6.9 & 8.4 & 1.5 & 11.4 & 4.5 & 6.4 & -0.6 \\
\hline Deciduous forest & 26.6 & 26.6 & 0.0 & 26.6 & 0.0 & 26.6 & 0.0 \\
\hline Evergreen forest & 35.7 & 35.7 & 0.0 & 35.7 & 0.0 & 35.7 & 0.0 \\
\hline Mixed forest & 83.3 & 83.3 & 0.0 & 83.3 & 0.0 & 83.3 & 0.0 \\
\hline Urban land & 21.6 & 29.2 & 7.5 & 28.0 & 6.4 & 25.5 & 3.8 \\
\hline Wetlands & 135.0 & 132.4 & -2.6 & 132.4 & -2.6 & 134.4 & -0.7 \\
\hline In-stream photosynthesis & 34.3 & 34.3 & 0.0 & 34.3 & 0.0 & 34.3 & 0.0 \\
\hline Total & 343.6 & 350.0 & 6.4 & 351.9 & 8.3 & 346.2 & 2.6 \\
\hline
\end{tabular}


Table 6-4. Estimates of total nitrogen, total phosphorous, total suspended sediment, and total organic carbon fluxes to the coastal waters of the Eastern United States by source of the fluxes, under baseline and projected conditions.-Continued

[Projected (2050) conditions are based on Intergovernmental Panel on Climate Change Special Report on Emissions Scenarios (SRES; Nakićenović and others, 2000) scenarios A1B, A2, and B1. Data may not add to totals shown due to independent rounding. Gg/yr, billion grams per year]

\begin{tabular}{|c|c|c|c|c|c|c|c|}
\hline \multirow[b]{2}{*}{ Source } & \multirow{2}{*}{$\begin{array}{c}\text { Baseline } \\
(2005)\end{array}$} & \multicolumn{2}{|c|}{ Scenario A1B } & \multicolumn{2}{|c|}{ Scenario A2 } & \multicolumn{2}{|c|}{ Scenario B1 } \\
\hline & & 2050 & $\begin{array}{l}\text { Change } \\
\text { in mass }\end{array}$ & 2050 & $\begin{array}{l}\text { Change } \\
\text { in mass }\end{array}$ & 2050 & $\begin{array}{l}\text { Change } \\
n \text { mass }\end{array}$ \\
\hline \multicolumn{8}{|c|}{ Total nitrogen (TN) } \\
\hline Population & 170.1 & 242.2 & 72.2 & 226.4 & 56.3 & 214.2 & 44.1 \\
\hline Atmospheric deposition & 84.3 & 124.7 & 40.5 & 124.7 & 40.5 & 124.7 & 40.5 \\
\hline Alfalfa & 11.4 & 11.5 & 0.2 & 13.3 & 1.9 & 10.1 & -1.2 \\
\hline Wheat & 5.1 & 5.5 & 0.4 & 5.4 & 0.3 & 4.5 & -0.6 \\
\hline Other crops & 16.1 & 17.4 & 1.3 & 19.7 & 3.6 & 14.2 & -1.9 \\
\hline Farm animal waste & 0.5 & 0.6 & 0.0 & 0.4 & -0.1 & 0.5 & -0.1 \\
\hline Forest & 25.5 & 22.6 & -2.9 & 22.2 & -3.3 & 25.3 & -0.2 \\
\hline Population & 19.7 & 26.1 & 6.4 & 24.9 & 5.2 & 23.8 & 4.1 \\
\hline Corn and soybean & 2.0 & 1.8 & -0.1 & 1.9 & 0.0 & 1.7 & -0.3 \\
\hline Alfalfa & 2.3 & 2.0 & -0.3 & 2.3 & 0.0 & 1.9 & -0.5 \\
\hline Other crops & 1.4 & 1.3 & -0.1 & 1.5 & 0.1 & 1.2 & -0.2 \\
\hline Farm animal waste & 0.1 & 0.1 & 0.0 & 0.1 & 0.0 & 0.1 & 0.0 \\
\hline Forest & 4.5 & 3.2 & -1.3 & 3.3 & -1.2 & 4.0 & -0.5 \\
\hline Barren land & 0.1 & 0.1 & 0.0 & 0.1 & 0.0 & 0.1 & 0.0 \\
\hline Shrubland & 0.0 & 0.0 & 0.0 & 0.0 & 0.0 & 0.0 & 0.0 \\
\hline Total & 30.1 & 34.7 & 4.6 & 34.1 & 4.0 & 32.7 & 2.6 \\
\hline \multicolumn{8}{|c|}{ Total suspended solids (TSS) } \\
\hline Total & $25,550.3$ & $32,234.9$ & $6,684.7$ & $31,113.5$ & $5,563.3$ & $28,528.9$ & $2,978.6$ \\
\hline \multicolumn{8}{|c|}{ Total organic carbon (TOC) } \\
\hline Cultivated land & 117.0 & 124.6 & 7.7 & 133.1 & 16.1 & 103.5 & -13.4 \\
\hline Deciduous forest & 134.4 & 134.4 & 0.0 & 134.4 & 0.0 & 134.4 & 0.0 \\
\hline Evergreen forest & 39.6 & 39.6 & 0.0 & 39.6 & 0.0 & 39.6 & 0.0 \\
\hline Mixed forest & 132.7 & 132.7 & 0.0 & 132.7 & 0.0 & 132.7 & 0.0 \\
\hline Urban land & 155.1 & 236.9 & 81.8 & 219.5 & 64.4 & 202.8 & 47.8 \\
\hline Wetlands & 557.8 & 555.0 & -2.8 & 543.8 & -14.0 & 575.5 & 17.7 \\
\hline In-stream photosynthesis & 331.6 & 331.6 & 0.0 & 331.6 & 0.0 & 331.6 & 0.0 \\
\hline Total & $1,468.3$ & $1,554.9$ & 86.6 & $1,534.7$ & 66.4 & $1,520.3$ & 52.0 \\
\hline
\end{tabular}


Table 6-4. Estimates of total nitrogen, total phosphorous, total suspended sediment, and total organic carbon fluxes to the coastal waters of the Eastern United States by source of the fluxes, under baseline and projected conditions.-Continued

[Projected (2050) conditions are based on Intergovernmental Panel on Climate Change Special Report on Emissions Scenarios (SRES; Nakićenović and others, 2000) scenarios A1B, A2, and B1. Data may not add to totals shown due to independent rounding. Gg/yr, billion grams per year]

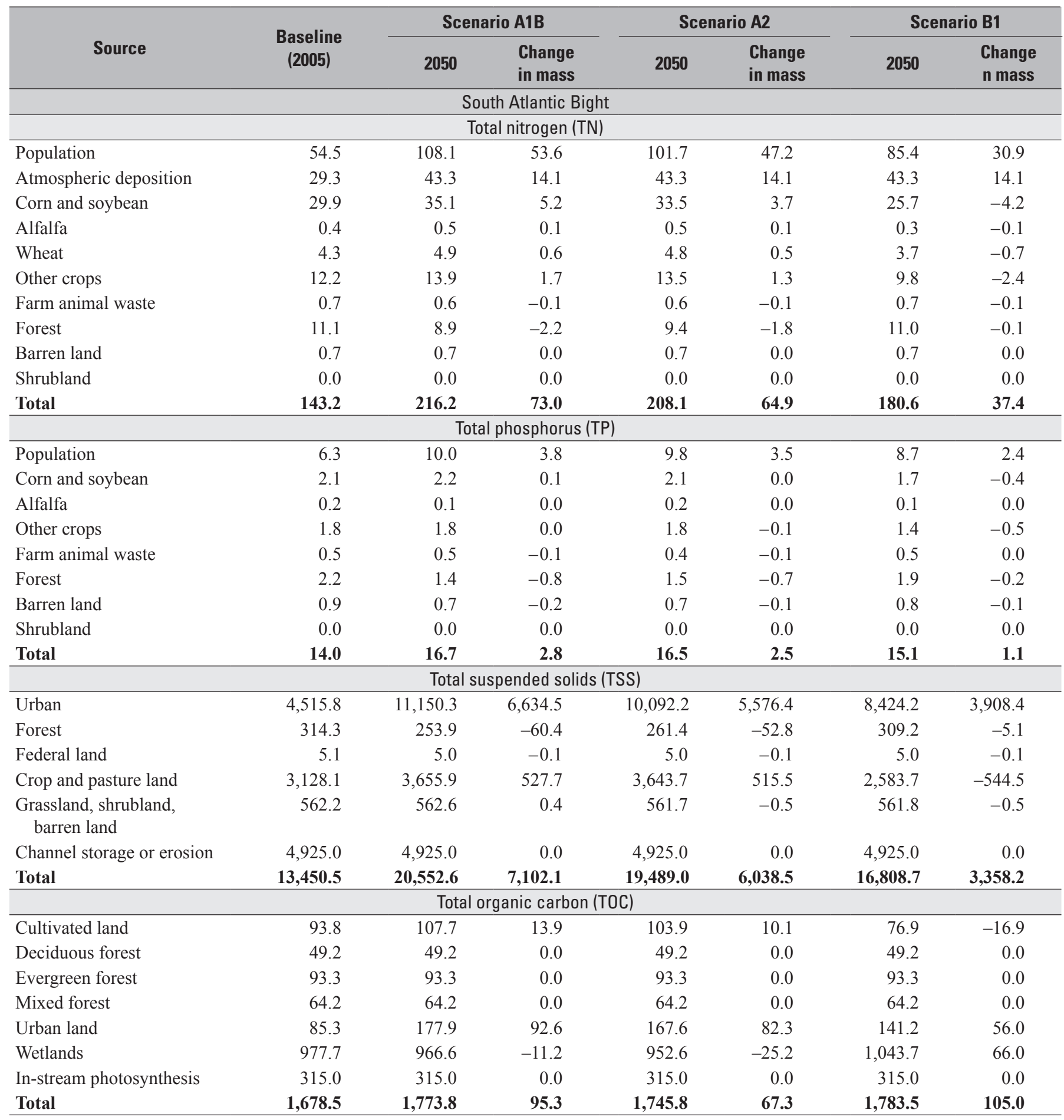


Table 6-4. Estimates of total nitrogen, total phosphorous, total suspended sediment, and total organic carbon fluxes to the coastal waters of the Eastern United States by source of the fluxes, under baseline and projected conditions.-Continued

[Projected (2050) conditions are based on Intergovernmental Panel on Climate Change Special Report on Emissions Scenarios (SRES; Nakićenović and others, 2000) scenarios A1B, A2, and B1. Data may not add to totals shown due to independent rounding. Gg/yr, billion grams per year]

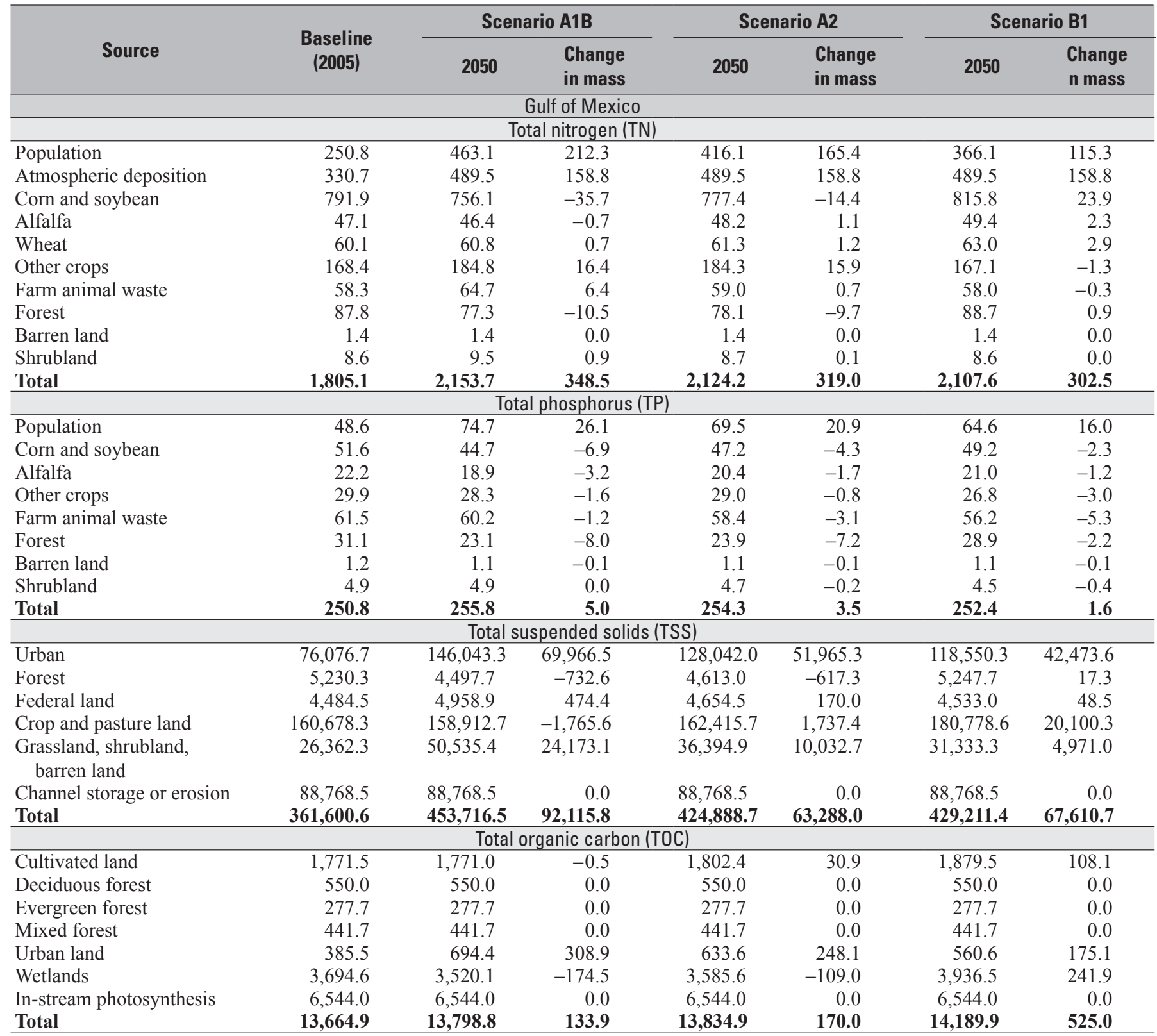




\subsubsection{Total Phosphorus}

The results for TP flux to coastal waters followed a generally similar pattern to those for $\mathrm{TN}$, reflecting similar environmental sources. The total baseline (2005) flux of TP from the five regions was $0.3 \mathrm{Tg} / \mathrm{yr}$ (figs. $6-5$ and $6-6$; table 6-3), with 79 percent originating in the Gulf of Mexico drainage, 15 percent originating in the combined east coast drainages, and 6 percent originating in the Great Lakes drainage. Again, the mid-Atlantic Bight part of the east coast drainage had the highest yield of the three regions of the east coast due to large sources from urban and agricultural lands and relatively short travel distances to the east coast. In contrast to the pattern for TN yield, however, the Mid-Atlantic Bight TP yield was not dramatically larger than that from the gulf coast drainage. This is because, whereas atmospheric sources of $\mathrm{TN}$ were especially high in the Mid-Atlantic Bight, atmospheric sources of TP were negligible in both regions.

The estimated TP flux from all five coastal regions was projected to increase between 2005 and 2050 under all three future projection scenarios (fig. 6-6; table 6-3), but only minimally so for some regions and scenarios. Most notably, TP flux from the Gulf of Mexico drainage was projected to increase by only 2.0 percent, 1.4 percent, and 0.6 percent under scenarios $\mathrm{A} 1 \mathrm{~B}, \mathrm{~A} 2$, and $\mathrm{B} 1$, respectively, during the 45 years of study (fig. 6-6; table 6-3). By contrast, TP flux from the South Atlantic Bight drainage was projected to increase by 19.7 percent, 17.9 percent, and 7.9 percent under scenarios A1B, A2, and B1, respectively, during the same period. Projected increases in TP flux under all scenarios are consistently smaller than those for TN flux because of the lack of an atmospheric source of phosphorus. The effects of population and developed land growth on TN are compounded by associated increases in the atmospheric sources, which are an important source in many basins in the Eastern United States. Moreover, rising population and urban development under all scenarios tended to have the greatest influence on the coastal flux of both nutrients and is most pronounced outside of the Gulf of Mexico drainage.

\subsubsection{Total Suspended Sediment}

The baseline TSS flux to the five coastal regions averaged $416.5 \mathrm{Tg} / \mathrm{yr}$ (fig. 6-7; table 6-3). Similar to TN and TP, the Gulf of Mexico drainage produced 87 percent of TSS, the three east coast regions together contributed 10 percent, and the Great Lakes region contributed about 3 percent. In contrast to the patterns for TN and TP, however, the large TSS yield from the Gulf of Mexico drainage (74,900 kilograms per square kilometer per year $\left.\left(\mathrm{kg} / \mathrm{km}^{2} / \mathrm{yr}\right)\right)$ was highest among the five regions due to large areas of erodible cropland in the basin (table 6-4). Lowest in yield terms were the Gulf of Maine and Great Lakes regions $\left(25,397 \mathrm{~kg} / \mathrm{km}^{2} / \mathrm{yr}\right.$ and $37,769 \mathrm{~kg} / \mathrm{km}^{2} / \mathrm{yr}$, respectively) due to large areas of less erodible forest and pasture in those regions.

The estimated TSS flux from all five regions was projected to increase between 4 percent and 53 percent by 2050 under scenarios A1B and A2, with the largest increases in the South Atlantic Bight region (fig. 6-8; table 6-3). In all regions, urban development contributed most to increases in TSS. By contrast, under scenario B1, greater environmental and biodiversity protection than in scenario A1B or A2 results in a smaller increase in the land area devoted to urban development; consequently, an increase in sources from agricultural lands explained a greater fraction of the increase (nearly one third) than under other scenarios. Hence, TSS flux to the five coastal regions is projected to increase by smaller percentages under scenario $\mathrm{B} 1$ than under either scenario A1B or scenario A2.

\subsubsection{Total Organic Carbon}

The baseline (2005) coastal flux of TOC from the five regions was $18.5 \mathrm{Tg} / \mathrm{yr}$ (table $6-3$ ). Seventy-four percent originated in the Gulf of Mexico drainage, 18 percent originated in the combined east coast drainages, and 8 percent originated in the Great Lakes drainage (fig. 6-9). The South Atlantic Bight part of the east coast drainage had the highest yield $\left(5,665 \mathrm{~kg} / \mathrm{km}^{2} / \mathrm{yr}\right)$ due to large wetland and forest sources (table 6-4), and relatively short travel distances to the east coast. Other regions with high delivered TOC yield were the Mid-Atlantic Bight $\left(4,201 \mathrm{~kg} / \mathrm{km}^{2} / \mathrm{yr}\right)$ and Great Lakes $\left(3,709 \mathrm{~kg} / \mathrm{km}^{2} / \mathrm{yr}\right)$ drainages and stem from the extensive forest cover and relatively short travel distances in the basin. The Gulf of Mexico drainage had the lowest yield $\left(2,830 \mathrm{~kg} / \mathrm{km}^{2} / \mathrm{yr}\right)$ due to longer travel times and larger in-stream losses than in any other region of the Eastern United States.

Predicted increases in TOC flux by 2050 for the five regions were small, ranging from 0.8 to 6.3 percent among the three scenarios (fig.6-10). These changes are significantly smaller than those projected for TN, TP, and TSS and reflect the fact that changes in forest and wetland cover were predicted to be generally small under all scenarios. The largest changes in TOC in the five regions were predicted under scenario B1 (3.9 percent overall increase) because efforts to reverse urban development and nurture natural areas led to more modest predicted increases in wetland areas (chap. 2). For example, coastal TOC flux from wetlands in the Gulf of Mexico drainage was projected to increase by about 6 percent under scenario B1, whereas, coastal TOC flux was predicted to decrease by 5 percent under scenario A1B. 


\section{A. Estimated delivered total phosphorous yield}

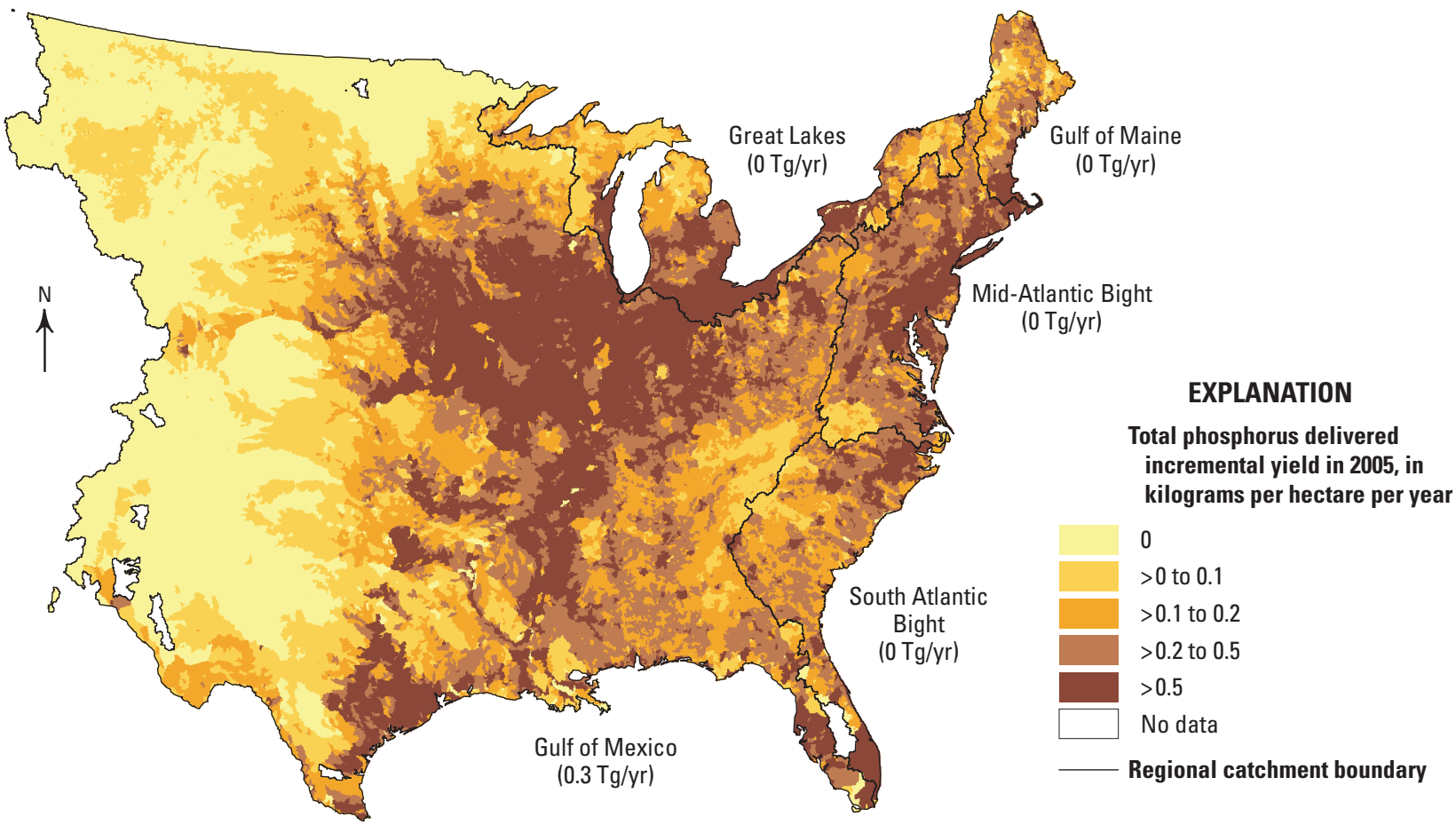

B. Major sources of total phosphorous in model catchments

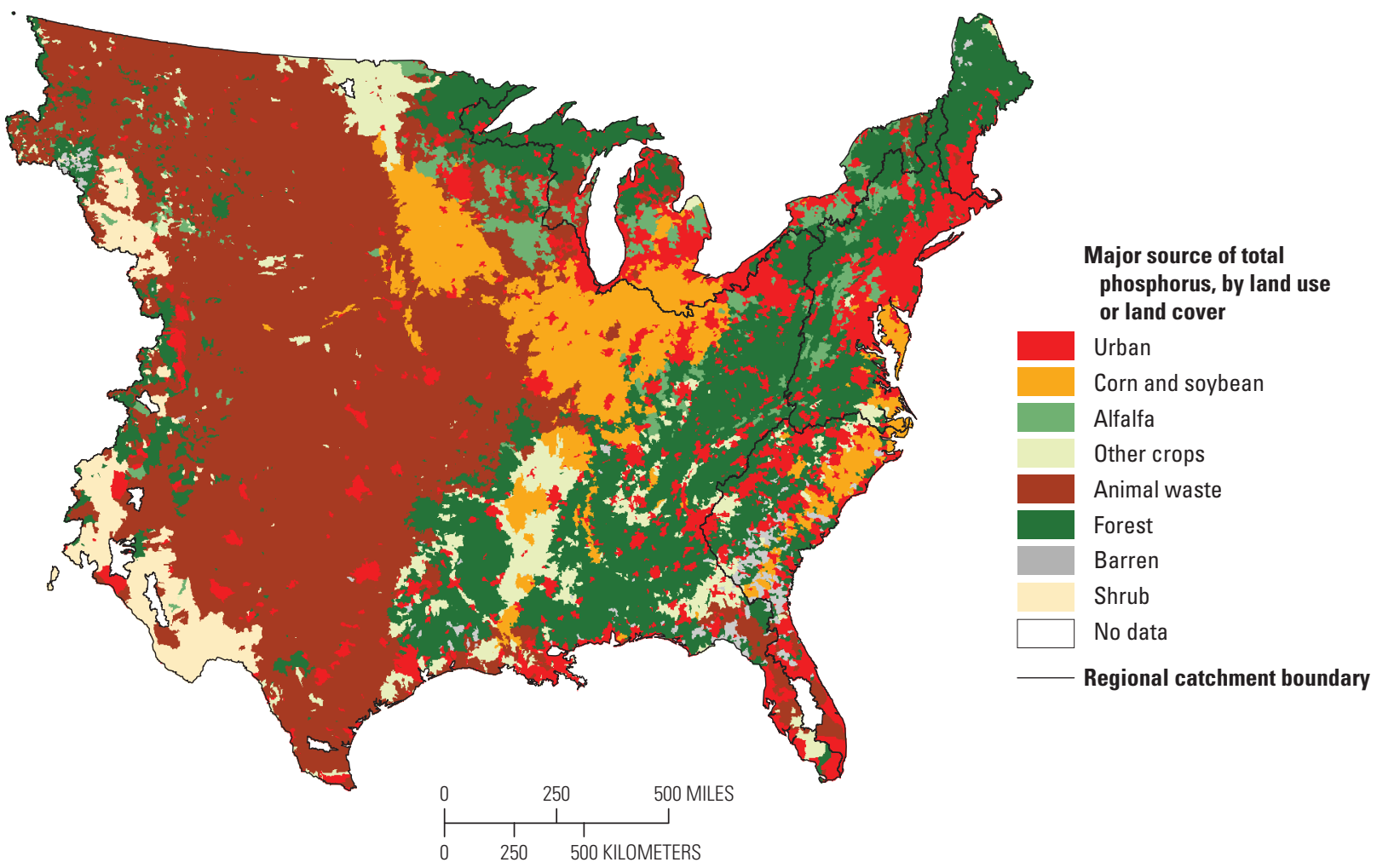

Figure 6-5. Maps showing $A$, estimated delivered total phosphorus (TP) yield to coastal waters and $B$, major sources of TP in model catchments under baseline (2005) conditions in the Eastern United States. Delivered yield reflects the effects of in-stream losses that occur during transport from the outlet of a catchment through the stream and river system to coastal waters. Values shown in parentheses indicate net flux of TP for each region. Tg/yr, teragrams per year; >, more than. 


\section{A. Difference in total phosphorus yield between baseline and scenario A1B}

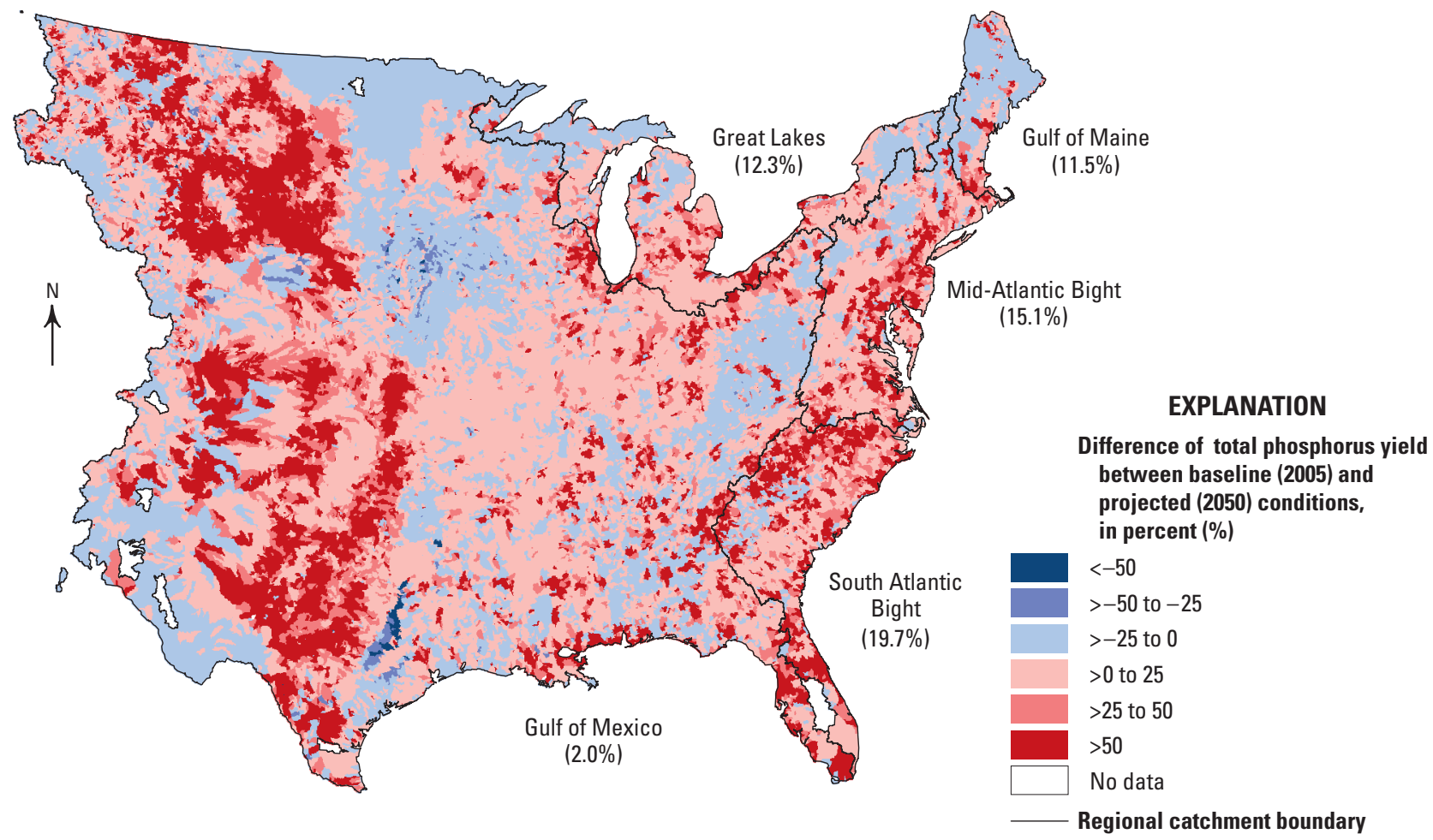

\section{B. Difference in total phosphorus yield between baseline and scenario B1}

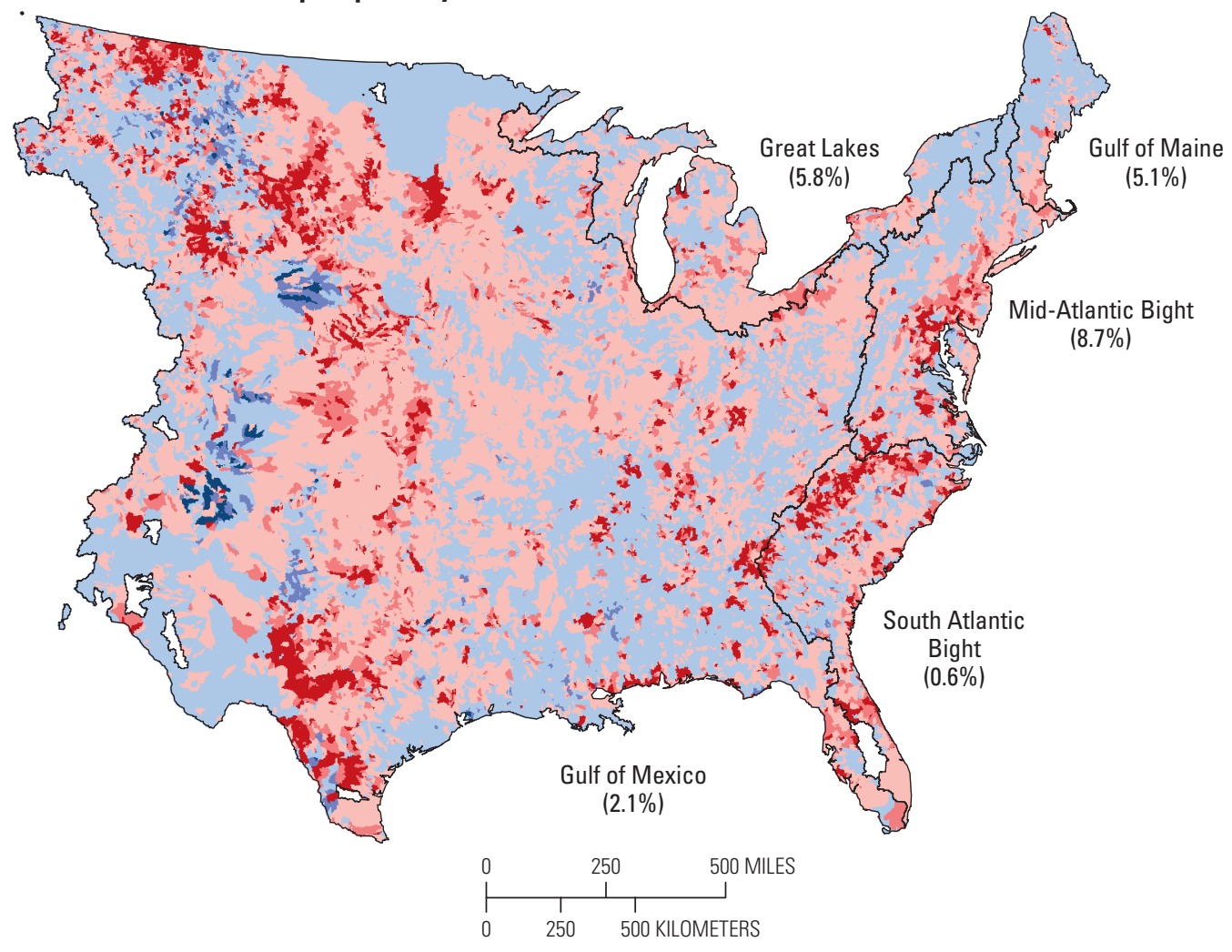

Figure 6-6. Maps showing difference between estimated delivered total phosphorus (TP) yield to coastal waters under baseline (2005) conditions and projected (2050) conditions for Intergovernmental Panel on Climate Change Special Report on Emissions Scenarios (SRES; Nakićenović and others, 2000) scenarios A, A1B and B, B1 in the Eastern United States. Values shown in parentheses indicate regional difference from baseline. $<$, less than; $>$, more than. 


\section{A. Estimated delivered total suspended sediment yield}

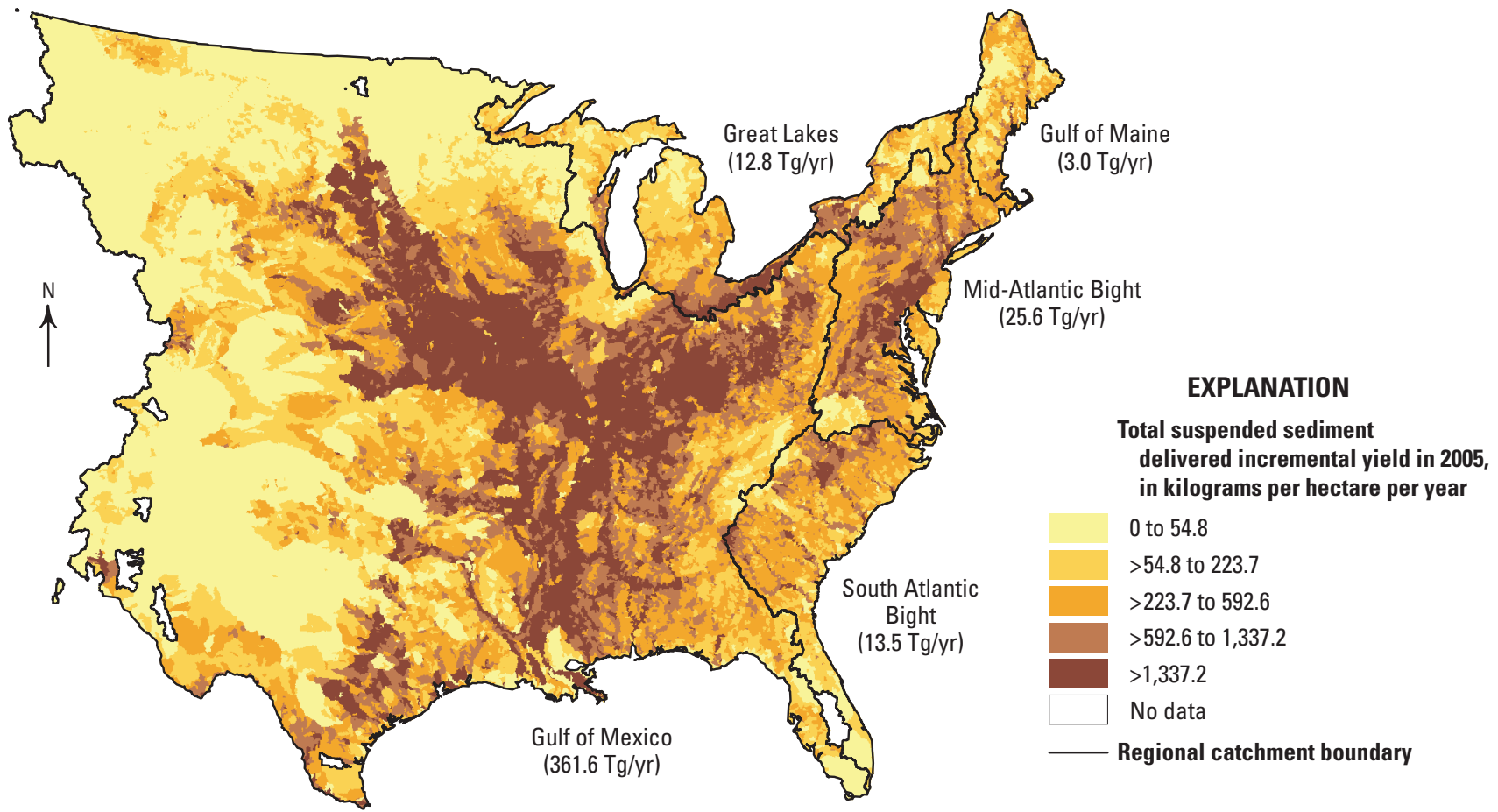

B. Major sources of total suspended sediment in model catchments

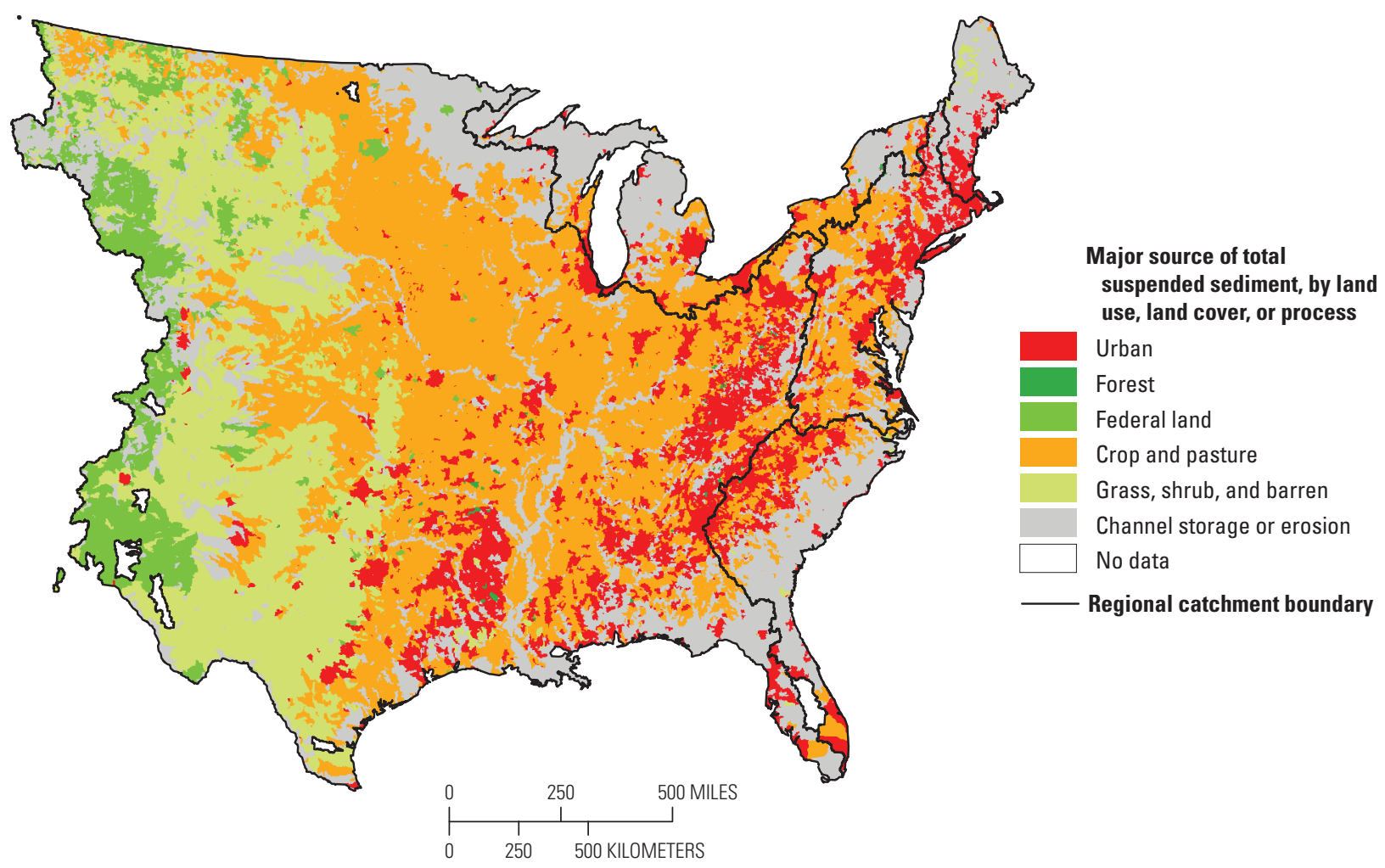

Figure 6-7. Maps showing A, estimated delivered total suspended sediment (TSS) yield to coastal waters and $B$, major sources of TSS in model catchments under baseline (2005) conditions in the Eastern United States. Delivered yield reflects the effects of in-stream losses that occur during transport from the outlet of a catchment through the stream and river system to coastal waters. Values shown in parentheses indicate net flux of TSS for each region. Tg/yr, teragrams per year; >, more than. 


\section{A. Difference in total suspended sediment yield between baseline and scenario A1B}

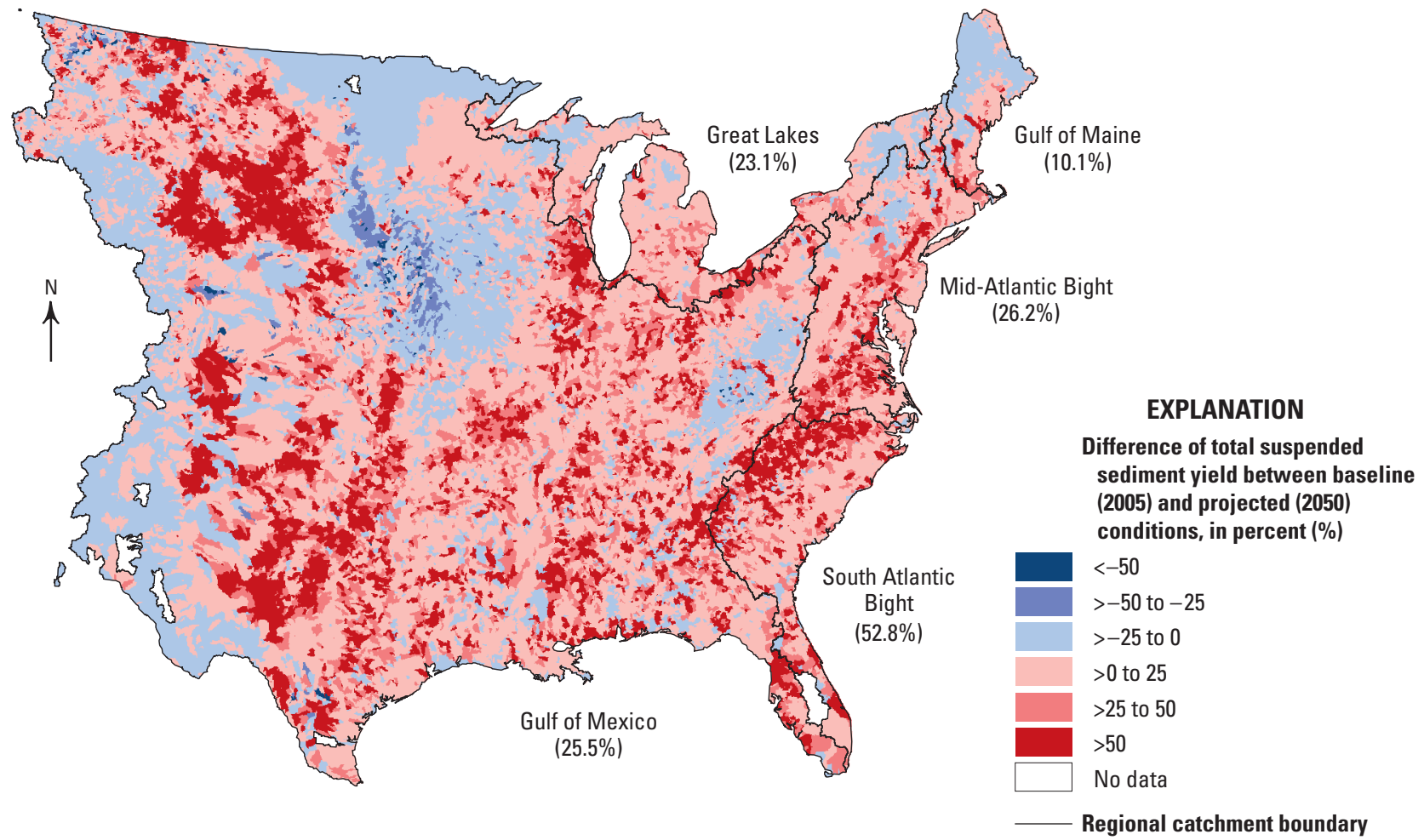

\section{B. Difference in total suspended sediment yield between baseline and scenario B1}

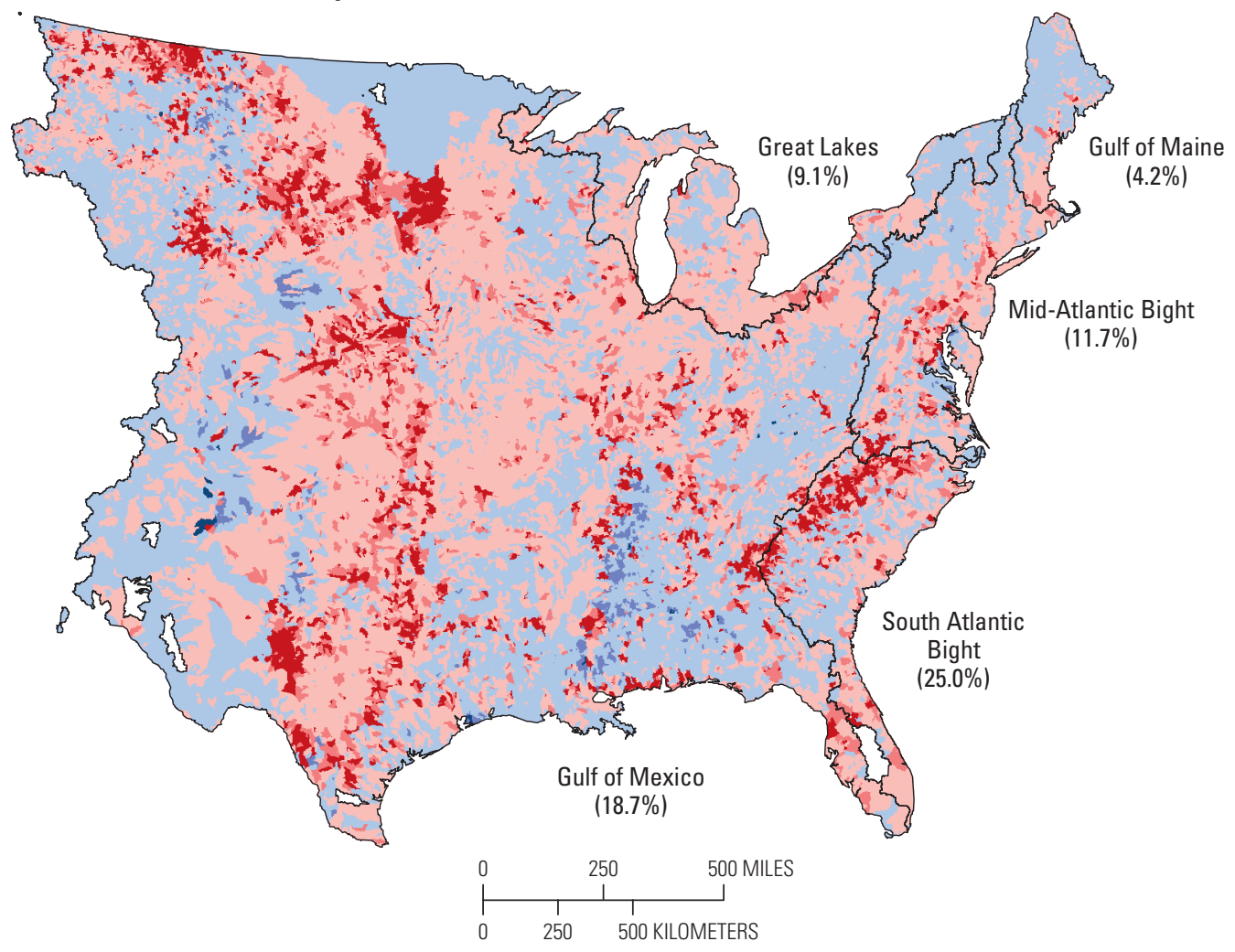

Figure 6-8. Maps showing difference between estimated delivered total suspended sediment (TSS) yield to coastal waters under baseline (2005) conditions and projected (2050) conditions for Intergovernmental Panel on Climate Change Special Report on Emissions Scenarios (SRES; Nakićenović and others, 2000) scenarios $A, \mathrm{~A} 1 \mathrm{~B}$ and $B, \mathrm{~B} 1$ in the Eastern United States. Values shown in parentheses indicate regional difference from baseline. $<$, less than; $>$, more than. 


\section{A. Estimated delivered total organic carbon yield}

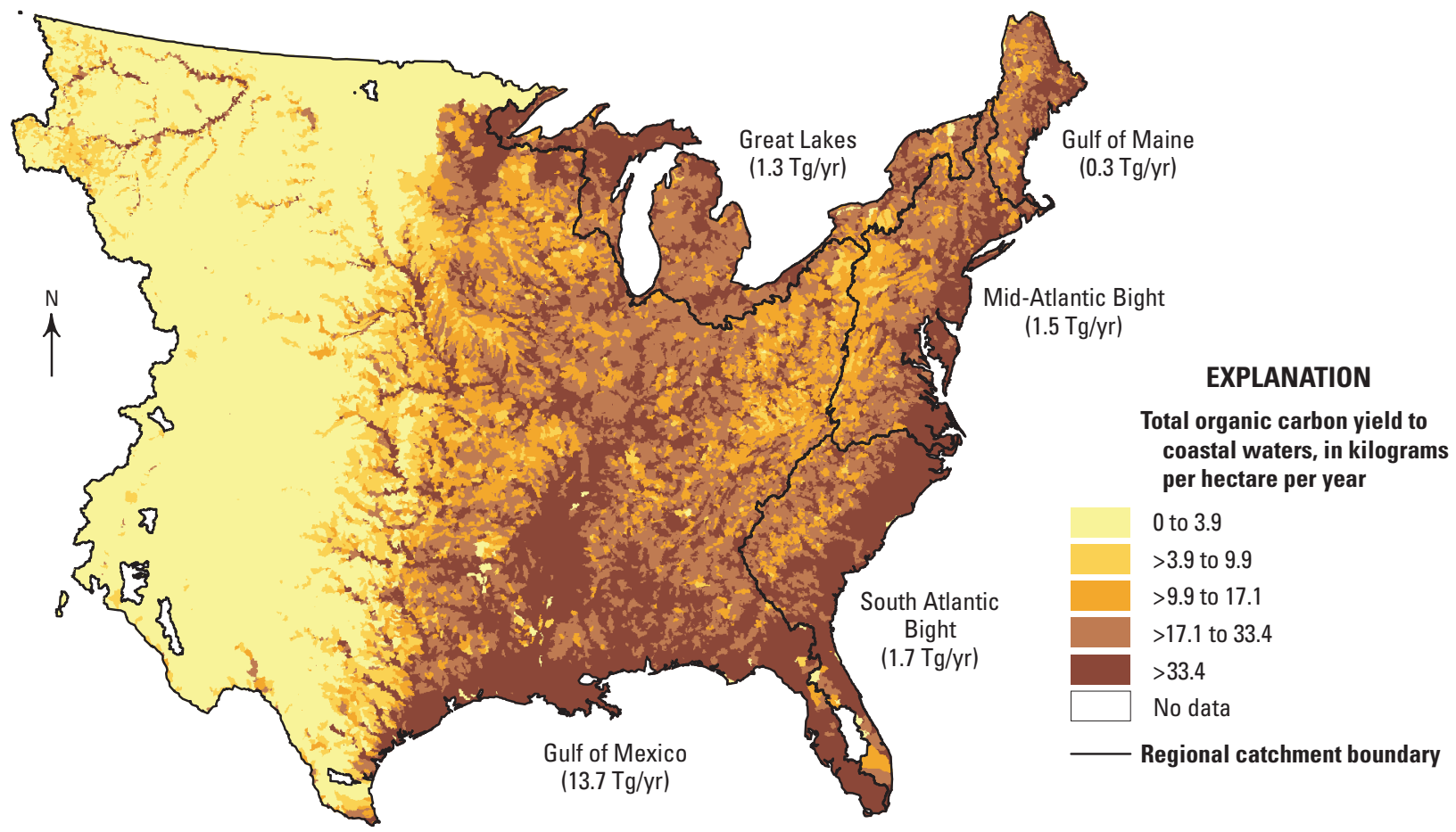

\section{B. Major sources of total organic carbon in model catchments}

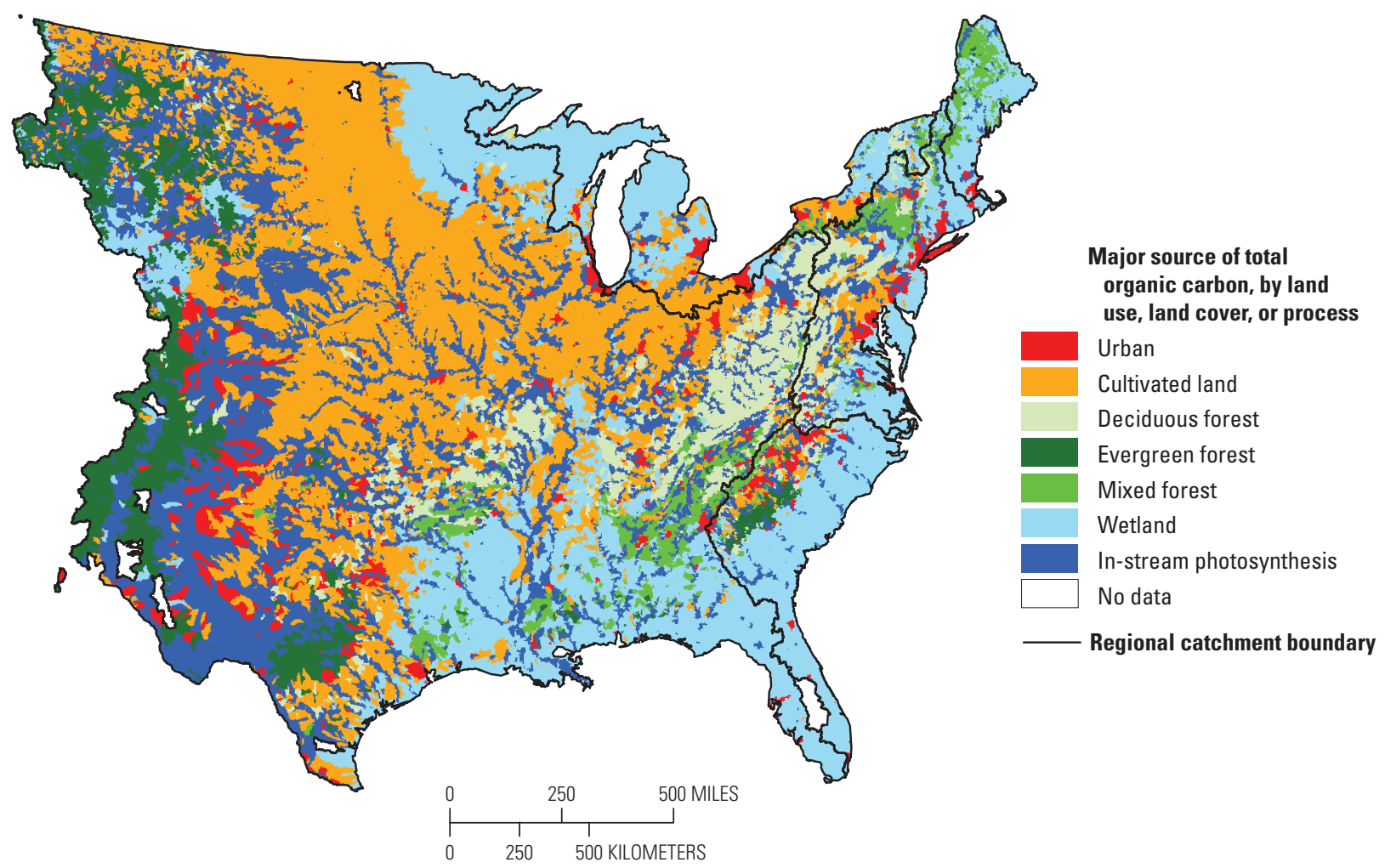

Figure 6-9. Maps showing $A$, estimated delivered total organic carbon (TOC) yield to coastal waters and $B$, major sources of TOC in model catchments under baseline (2005) conditions in the Eastern United States. Delivered yield reflects the effects of in-stream losses that occur during transport from the outlet of a catchment through the stream and river system to coastal waters. Values shown in parentheses indicate net flux of TOC for each region. Tg/yr, teragrams per year; >, more than. 


\section{A. Difference in total organic carbon yield between baseline and scenario A1B}

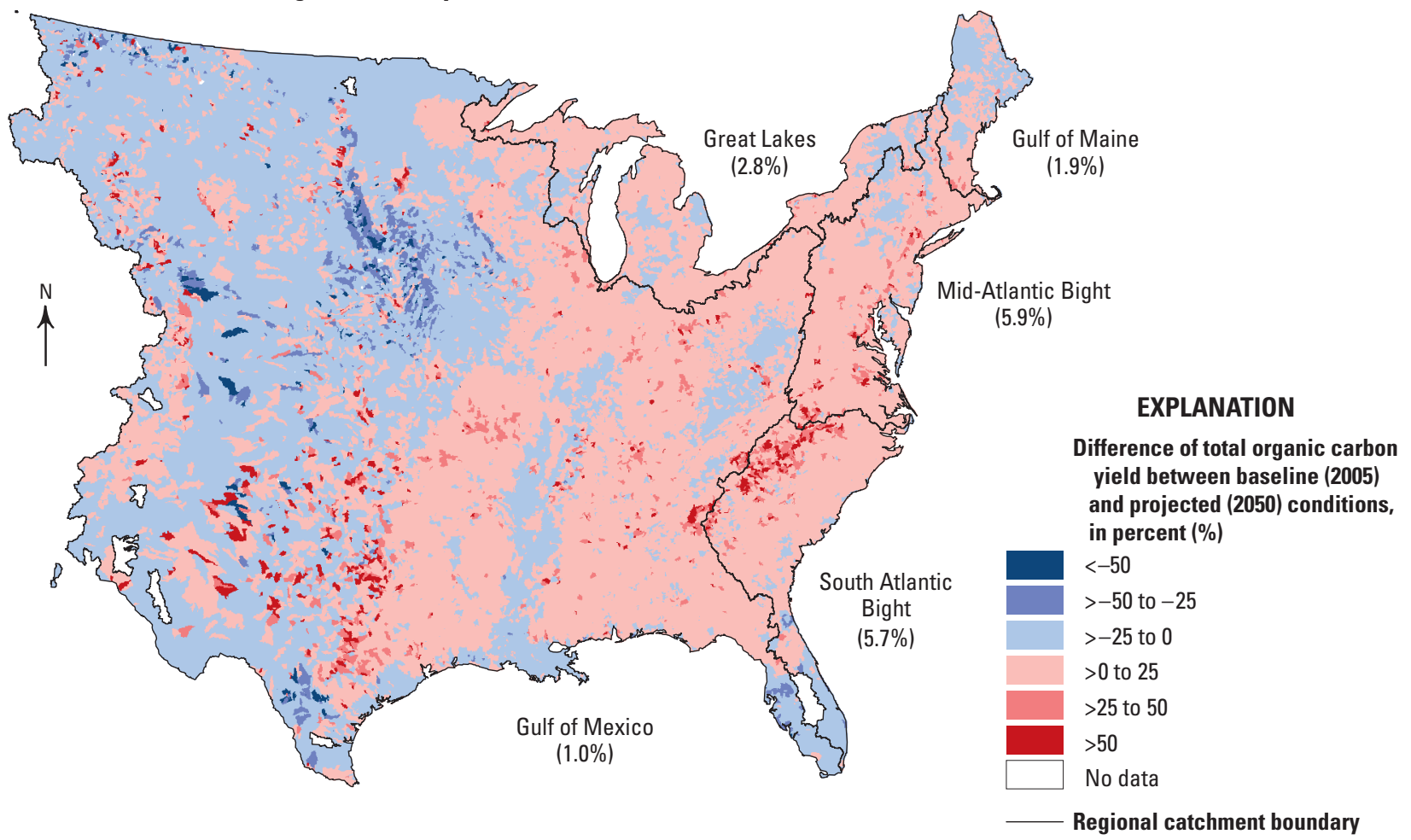

\section{B. Difference in total organic carbon yield between baseline and scenario B1}

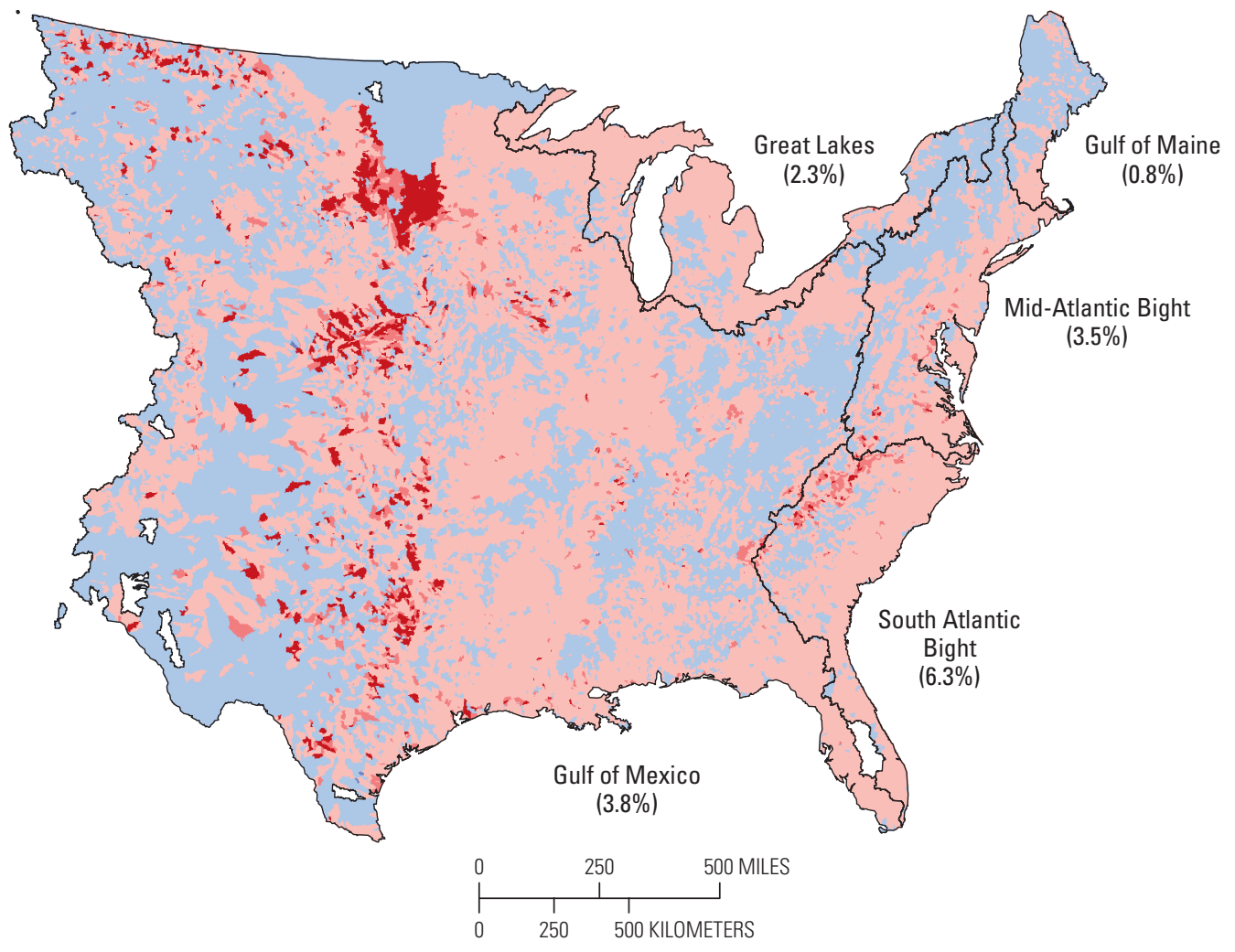

Figure 6-10. Maps showing difference between estimated delivered total organic carbon (TOC) yield to coastal waters under baseline (2005) conditions and projected (2050) conditions for Intergovernmental Panel on Climate Change Special Report on Emissions Scenarios (SRES; Nakićenović and others, 2000) scenarios $A, A 1 B$ and $B, B 1$ in the Eastern United States. Values shown in parentheses indicate regional difference from baseline. $<$, less than; $>$, more than. 


\subsubsection{Carbon Storage in Coastal Waters}

The coastal model used the adjusted nutrient and sediment inputs to estimate the millennial $\mathrm{C}_{\mathrm{T}}$ storage rates in coastal waters-burial in sediments and storage in deep ocean waters. This provides an estimate of the amount of $\mathrm{CO}_{2}$ removed from the atmosphere into coastal oceans that is specifically attributable to the terrestrial fluxes of nutrients and sediments. The model also estimated burial rates across the entire domain to facilitate comparisons to regional sediment carbon budgets. Finally, the "active" sedimentary inventory of $\mathrm{C}_{\mathrm{T}}$ was also estimated as the mass of $\mathrm{C}_{\mathrm{T}}$ in the upper $1 \mathrm{~m}$ of sediment (Hedges and Keil, 1995) using burial conditions based on the fluxes in the baseline year. This was done to permit comparisons to terrestrial soil carbon and biomass carbon pool size estimates (chap. 7).

\subsubsection{Estuary Retention and Denitrification}

The SPARROW-modeled fluxes of nutrients and sediments were converted to annual rates of carbon storage in sediments and in the deep ocean by separately estimating primary production, sediment burial, and remineralization in the deep ocean using the model framework described above. However, the SPARROW fluxes were adjusted for retention within estuaries before being used in the coastal $\mathrm{C}_{\mathrm{T}}$ storage model because the SPARROW model typically ends at the last nontidal reach. Sediment and phosphate retention in estuaries rates ranged up to 63 percent in the Chesapeake Bay, with an average of 11 percent among major estuaries (those in the NEEA database). TN retention rates in estuaries ranged up to 50 percent in Chesapeake Bay and averaged 22 percent among major estuaries. The information available to calculate retention in the Great Lakes region was insufficient, so median values for retention in coastal estuaries were used.

Similarly, an adjustment for nitrogen loss due to diffusive denitrification was also made to the SPARROW fluxes before use in the model. Modeled nitrogen loss ranged from 4.3 percent in the Gulf of Maine to 11 percent in the South Atlantic Bight. The effective estimated rates of diffusive denitrification in shallow waters ranged up to more than $1,000 \mathrm{mmol} / \mathrm{m}^{2} / \mathrm{yr}$, which was consistent (on an areal basis) with literature estimates (Seitzinger and Giblin, 1996; PiñaOchoa and Alvarez-Cobelas, 2006). It should be noted that, as a sink for nitrogen, diffusive denitrification represents the lesser of the two ways denitrification was accounted for in the model.

\subsubsection{Coastal $\mathrm{C}_{\mathrm{T}}$ Storage}

Storage of $\mathrm{C}_{\mathrm{T}}$ in coastal waters of the Eastern United States was estimated to be $7.8 \mathrm{Tg} / \mathrm{yr}$ for the baseline year. This is roughly four times the $\mathrm{C}_{\mathrm{T}}$ storage estimate for coastal waters Pacific United States, calculated using similar methods (Zhu and others, 2010). The Gulf of Mexico alone accounted for 79 percent of the total $C_{T}$ for the Eastern United States, or about three times the $\mathrm{C}_{\mathrm{T}}$ storage of the Pacific United States, owing to the large flux of nutrients and sediments from the Mississippi River. High nutrient and suspended sediment fluxes originating from the Mississippi River resulted in high model estimates of primary production and high burial efficiencies, magnifying the $\mathrm{C}_{\mathrm{T}}$ storage in shallow gulf coast waters.

Much of the modeled $\mathrm{C}_{\mathrm{T}}$ storage in the Gulf of Mexico was due to burial near the mouth of the Mississippi River, with the highest modeled burial rates near the Mississippi River Delta (fig. 6-11). This is consistent with global assessments showing that the majority of carbon stored in coastal sediments is found in large river deltas (Hedges and Keil, 1995). The model also showed that burial along the coastline to the west of the Mississippi and along the coast of western Florida were important (fig. 6-11). The influence of fluxes from the Mississippi River on modeled $\mathrm{C}_{\mathrm{T}}$ storage extended to the western model boundary and offshore all the way to the 2,000-m boundary (figs. 6-2 and 6-11). High burial rates along the coast west of the Mississippi River are consistent with high carbon accumulation rates and high modern content of carbon observed in this region (Gordon and others, 2001; Turner and others, 2007; Sampere and others, 2008). Along the coastline of western Florida, modeled $\mathrm{C}_{\mathrm{T}}$ storage rates decreased as the shelf becomes wider and as TN, TP, and TSS concentrations decreased. As a result, 58 percent of $\mathrm{C}_{\mathrm{T}}$ stored in the gulf coast region was buried in the sediments; 84 percent of this burial was at water depths less than $200 \mathrm{~m}$.

Nevertheless, it should be noted that, despite the high burial in shallow zones near the mouth of the Mississippi River, modeled $\mathrm{C}_{\mathrm{T}}$ storage in the deep ocean for the Gulf of Mexico represented 42 percent of the total storage, largely in the deeper areas of the northeastern gulf coast (fig. 6-11). This highlights the importance of bathymetry in determining $\mathrm{C}_{\mathrm{T}}$ storage. Deep waters have a disproportionately large influence on carbon storage rates because transport of primary production below the deep mixed layer and into deep ocean waters is the most efficient form of $\mathrm{C}_{\mathrm{T}}$ storage in the model. Remineralization within sediments during burial reduces the amount of carbon stored considerably compared areas of similar productivity over deep water. In areas of low sediment flux, calculated burial efficiencies were near zero.

For the eastern seaboard, total modeled $\mathrm{C}_{\mathrm{T}}$ storage was $1.3 \mathrm{Tg} / \mathrm{yr}$ (table 6-4), accounting for about 17 percent of the total for the Eastern United States. $\mathrm{C}_{\mathrm{T}}$ storage along the east coast was about 36 percent lower than that of the Pacific coast, corresponding to lower nutrient and sediment fluxes on the east coast. The sediment, terrestrial carbon and nutrient fluxes on the east coast were also much lower than for the Gulf of Mexico, but the contrast in modeled $\mathrm{C}_{\mathrm{T}}$ storage was even greater; although the nutrient flux along the eastern seaboard comprised one third of the gulf coast nutrient flux, $\mathrm{C}_{\mathrm{T}}$ storage in the eastern seaboard was only one fifth as large as that of the gulf coast. This lower relative $\mathrm{C}_{\mathrm{T}}$ storage was due largely to lower relative suspended sediment flux in the region (about 5 percent), which resulted in lower modeled burial efficiencies. Similar to the Gulf of Mexico, regional bathymetry played 


\section{A. Baseline (2005) carbon storage rate from terrestrial input}
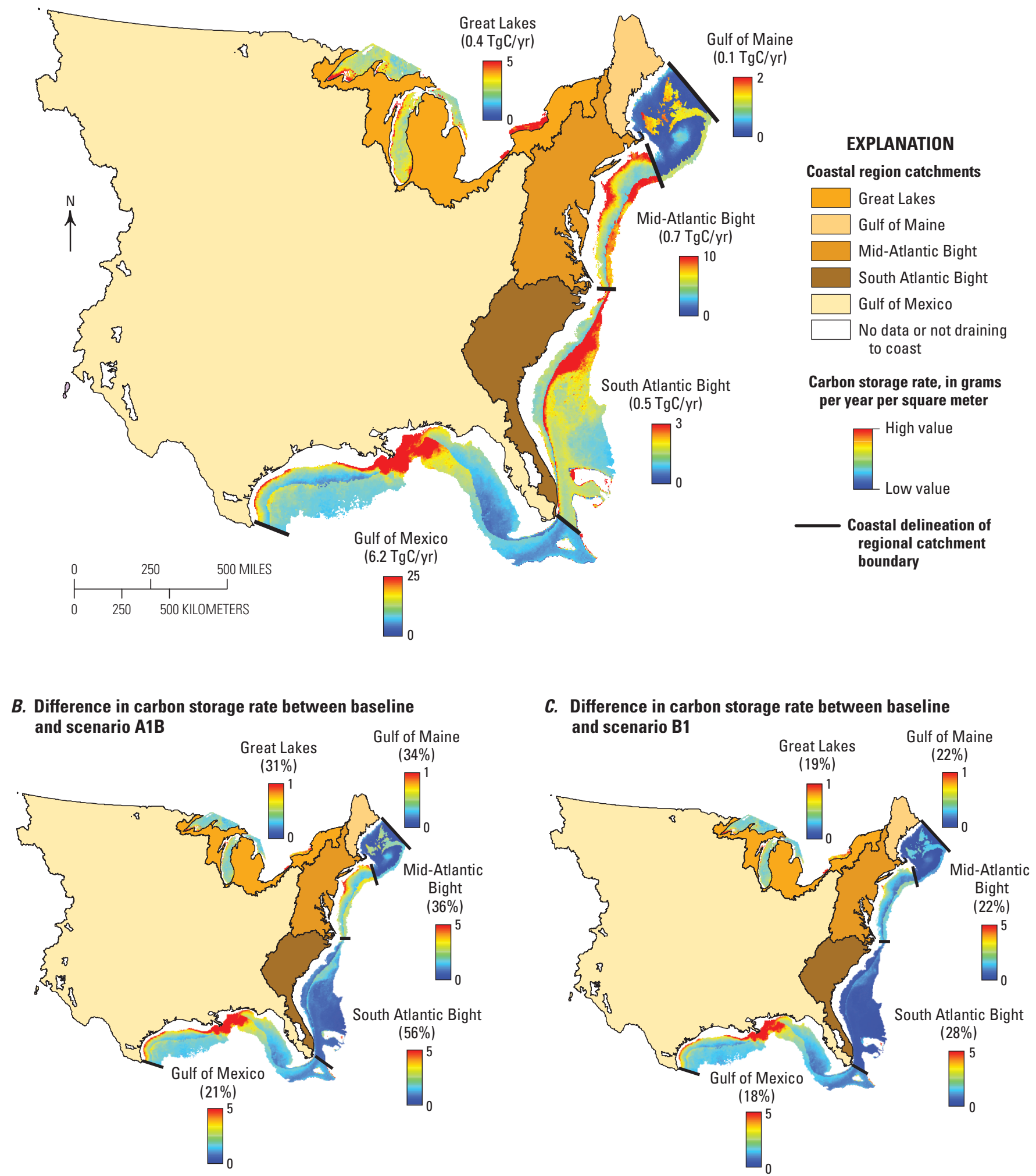

Figure 6-11. Maps showing model-derived millennial carbon storage rates for carbon storage directly attributable to terrestrial inputs $\left(C_{T}\right)$ in coastal waters $A$, under baseline (2005) conditions and as differences for projected (2050) conditions based on Intergovernmental Panel on Climate Change Special Report on Emissions Scenarios (SRES; Naki enovi and others, 2000) scenarios $B, A 1 B$ and $C, B 1$ in the Eastern United States. Values shown in parentheses indicate total carbon storage rate $A$, for each region or $B$ and $C$, as a difference for each region. Color scales are unique to each region. $\mathrm{TgC} / \mathrm{yr}$, teragrams of carbon per year; \%, percent. 
an important role; a shallower average bathymetry along the eastern seaboard resulted in a greater proportion of $\mathrm{C}_{\mathrm{T}}$ storage as burial rather than deep ocean storage.

There is considerable bathymetric diversity among the eastern seaboard regions; whereas the South Atlantic Bight has relatively steep bathymetric gradients, the Mid-Atlantic Bight has relatively broad shallow bathymetry, and the Gulf of Maine and Great Lakes have irregular bathymetric gradients. Modeled storage of $\mathrm{C}_{\mathrm{T}}$ in the deep (more than $200 \mathrm{~m}$ ) offshore waters was dominant in the South Atlantic Bight, accounting for 75 percent of $\mathrm{C}_{\mathrm{T}}$ storage as DIC in deep waters (remineralized remains of the phytoplankton production from the surface ocean) in the South Atlantic Bight. By contrast, sediment $\mathrm{C}_{\mathrm{T}}$ burial in the relatively shallow bathymetry of the Mid-Atlantic Bight accounted for 73 percent of total $\mathrm{C}_{\mathrm{T}}$; much of the $\mathrm{C}_{\mathrm{T}}$ stored in the Mid-Atlantic Bight was buried in shallow shelf sediments rather than stored in deep ocean waters.

There was considerable diversity in modeled $\mathrm{C}_{\mathrm{T}}$ storage among the physiographic regions on the eastern seaboard due to bathymetric differences as well as differences in sediment and nutrient inputs. The highest rates of coastal $\mathrm{C}_{\mathrm{T}}$ storage were in the Mid-Atlantic Bight, which accounted for 57 percent of the total, followed by the South Atlantic Bight (37 percent) and the Gulf of Maine (6 percent). The higher rates of $\mathrm{C}_{\mathrm{T}}$ storage in the Mid-Atlantic Bight were attributable primarily to elevated modeled primary production resulting from high nutrient inputs (fig. 6-11; table 6-3). The Mid-Atlantic Bight had the highest modeled terrestrial organic carbon and nutrient inputs, largely due to the higher population and urban land use in the Hudson River Basin and the Chesapeake Bay (figs. 6-3 and 6-5; table 6-4; Malone and others, 1996; Gibson, 1998). These inputs were elevated in the coastal ocean despite the comparatively high modeled estuarine $\mathrm{C}_{\mathrm{T}}$ retention in the Mid-Atlantic Bight.

The lowest modeled $\mathrm{C}_{\mathrm{T}}$ storage rates in the Eastern United States were in the Gulf of Maine (6 percent; fig. 6-11). Terrestrial organic carbon and nutrient flux was nearly five times lower in the Gulf of Maine compared with the Mid-Atlantic Bight and only half as much in the South Atlantic Bight, resulting in lower modeled primary production and $\mathrm{C}_{\mathrm{T}}$ storage. Reduced riverine suspended sediments entering the Gulf of Maine compounded the effect of lower nutrient flux by contributing to reduced burial efficiencies and $\mathrm{C}_{\mathrm{T}}$ burial rates in shallow waters (table 6-3). Further, the variable bathymetry of the Gulf of Maine resulted in a higher proportion of $\mathrm{C}_{\mathrm{T}}$ storage (43 percent) through burial rather than through transport to the deep ocean relative to other regions (fig. 6-11).

The Great Lakes accounted for about 5 percent of the total modeled $\mathrm{C}_{\mathrm{T}}$ storage in the Eastern United States (table 6-3), driven by nutrient and sediment dispersion among the lakes. In contrast to the other regions, there was no permanent deep mixed layer under which $\mathrm{CO}_{2}$ is presumed to accumulate and thus contribute to total $\mathrm{C}_{\mathrm{T}}$ storage; all storage is through sediment burial. Consequently, the effects of bathymetry in model results were less important than for the other regions, and burial efficiency was the primary determinant of $\mathrm{C}_{\mathrm{T}}$ storage. Maximum modeled rates of burial were in Lake Ontario, followed by the small deep basin of eastern Lake Erie and the shorelines of eastern Lake Michigan and southern Lake Superior (fig. 6-11), although the assessment extends only to the border of the United States. All these areas are characterized by dense population and high levels of urban and agricultural lands use, characteristics that lead to elevated riverine export of nutrients and total suspended sediment (table 6-4). Relatively little $\mathrm{C}_{\mathrm{T}}$ storage was found to occur in the deep waters of northern Lake Huron where low watershed population densities and agricultural lands use correspond with relatively low riverine terrestrial organic carbon, nutrient, and sediment inputs.

\subsubsection{Sediment $\mathrm{C}_{\mathrm{T}}$ Inventory}

Organic carbon in the upper meter of sediment is considered one of the primary "active" pools of carbon storage in the marine system and can be considered a rough analog of the terrestrial soil organic carbon pool that is commonly used in comparisons and aggregations of active carbon pools (Hedges and Keil, 1995). Based on the results of the model, the integrated total mass of $\mathrm{C}_{\mathrm{T}}$ that would accumulate as a pool of carbon in the upper meter of sediment under baseline flux conditions from the Eastern United States is 9,100 teragrams (Tg; fig. 6-12; table 6-3), which represents one third of terrestrial carbon pools (chap. 7). However, the distribution of this sediment $\mathrm{C}_{\mathrm{T}}$ "inventory" among the coastal regions was different from the distribution of storage rates (fig. 6-3), highlighting the importance of burial rates in determining the long-term sediment repository for carbon. For example, the majority of $\mathrm{C}_{\mathrm{T}}$ inventory of coastal sediments in the Eastern United States was in the sediments of the eastern seaboard, whereas the highest rates of $\mathrm{C}_{\mathrm{T}}$ storage were in the Gulf of Mexico. The modeled $\mathrm{C}_{\mathrm{T}}$ inventory of the eastern seaboard was about 4,000 Tg (fig. 6-12) compared with about 2,300 Tg for the Gulf of Mexico and 2,900 Tg for the Great Lakes.

There are two main reasons why the distribution of sediment $\mathrm{C}_{\mathrm{T}}$ inventory does not correspond to the rates of storage. First, the sediment $\mathrm{C}_{\mathrm{T}}$ inventory is dependent on the percentage of organic carbon in buried sediments, which is determined by the local sediment flux, the ratio of productivity to sediment flux, and the bathymetry. Very high inorganic sediment fluxes can result in dilution of the organic carbon buried (Tyson, 2001). Second, the modeled $\mathrm{C}_{\mathrm{T}}$ storage rate is not simply a function of the burial rate. Rather, it is the sum of the burial rate and the accumulation rate of remineralized $\mathrm{C}_{\mathrm{T}}$ in the deep ocean water, which can be substantial. For example, despite the high rates of sediment burial, a significant amount of carbon is also stored as DIC in the deep ocean waters (more than $200 \mathrm{~m}$ ) of the Gulf of Mexico, the result of remineralization combined with the steep bathymetry of the northeastern Gulf of Mexico (fig. 6-1).

The allocation of total $C_{T}$ storage rates between sediment burial and storage in deep ocean water as DIC provides a 


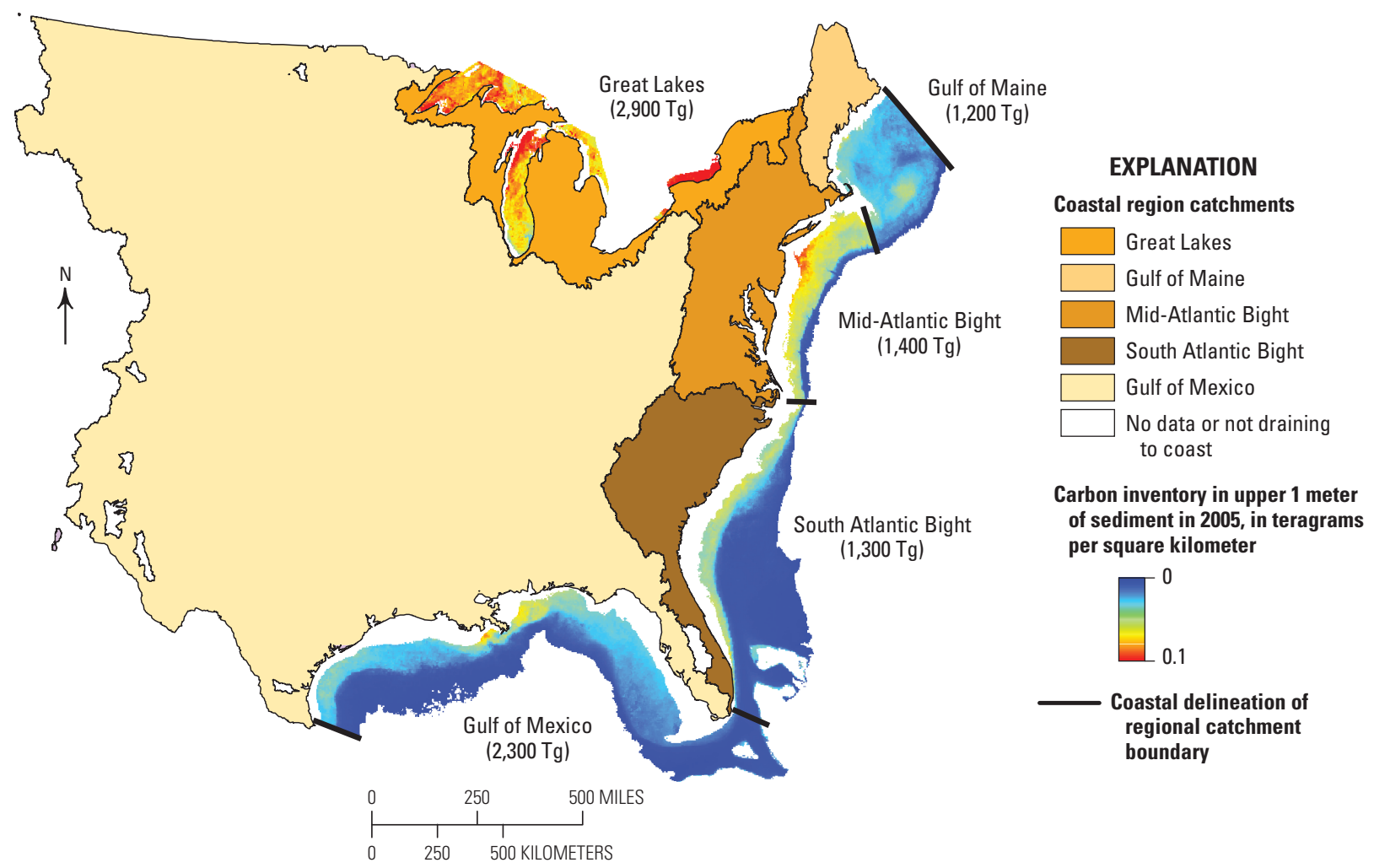

Figure 6-12. Map showing estimated inventory of carbon directly attributable to terrestrial inputs $\left(C_{T}\right)$ that would be stored in the upper 1 meter of sediment under baseline (2005) flux conditions in the Eastern United States. Values shown in parentheses indicate total carbon storage for each region. Tg, teragrams.

means to crudely assess the carbon inventory accumulated in both pools together for the time during which the upper $1 \mathrm{~m}$ of sediment accreted. Assuming that this ratio, which is largely determined by bathymetry, is consistent for the period of deposition, an amount of carbon equivalent to two thirds of buried carbon is stored as DIC in the deep ocean. This suggests that, under baseline flux conditions, a total $\mathrm{C}_{\mathrm{T}}$ inventory of nearly $15,000 \mathrm{Tg}$ would result. This represents a pool size more than half the estimated size of the terrestrial carbon pool $(26,962 \mathrm{TgC})$ and about equal to the size of the terrestrial soil carbon pool (chap. 7).

However, the time scales of carbon accumulation in these two pools are very different. The rate of carbon accumulation as well as the rate of response to change are much lower in coastal systems than in terrestrial systems (Sarmiento and Gruber, 2002). The $C_{T}$ burial rate in marine sediments $(4.7 \mathrm{Tg} / \mathrm{yr})$ is far less than that in terrestrial soils $(65.4 \mathrm{Tg} / \mathrm{yr}$; chap. 7$)$. The $\mathrm{C}_{\mathrm{T}}$ storage rate in coastal waters of the Eastern United States total is only 3 percent of the estimated terrestrial flux (chap. 7).

\subsubsection{Projected Changes in $\mathrm{C}_{T}$ Storage in Coastal Waters}

$\mathrm{C}_{\mathrm{T}}$ storage and burial rates in coastal systems increased under all three modeled SRES scenario LULC projections. The projected future rise in $\mathrm{C}_{\mathrm{T}}$ storage rate was driven by substantially elevated nutrient and sediment fluxes, which interact synergistically to increase modeled carbon storage rate. The relative changes in these fluxes and in carbon storage rate was highest for SRES scenario A1B, with rates of carbon storage in the Eastern United States projected to increase by an average of 25 percent by 2050 . The South Atlantic Bight showed the highest increase (56 percent), followed by the Mid-Atlantic Bight (36 percent), the Gulf of Maine (34 percent), the Great Lakes (31 percent), and the Gulf of Mexico (21 percent). Scenario B1 had the lowest projected rise in $\mathrm{C}_{\mathrm{T}}$ storage rate of the three scenarios tested, with the average storage rate in 2050 estimated to be 19 percent higher than the baseline; this was still only about 76 percent of the increase projected for scenario A1B (with a similar proportional change between regions).

The amount of change in $\mathrm{C}_{\mathrm{T}}$ storage rates (fig. 6-11) reflects the spatial variability and relative change in urban, agricultural, and atmospheric sources (figs. 6-3, 6-5, 6-7, and 6-11; table 6-4). The projected changes in $\mathrm{C}_{\mathrm{T}}$ storage rates under all SRES scenarios were greatest in the eastern seaboard, particularly in the South Atlantic Bight. This was largely the result of large projected increases in nutrient and total suspended sediment flux to coastal waters, but these increases were exacerbated by relatively low watershed and estuarine retention and steep increases in the depth of coastal waters. Although the Gulf of Mexico dominated 
total $\mathrm{C}_{\mathrm{T}}$ storage rates in the Eastern United States due to the large fluxes of nutrients and suspended sediments from the Mississippi River, the increase in these fluxes compared with the baseline flux was low for all scenarios tested. Because the Mississippi River sediment and nutrient fluxes account for about 80 percent of the input to coastal waters for the Eastern United States, the aggregate average increase for the Eastern United States as a whole is biased toward the low projected change in the Gulf of Mexico.

The projected changes in $\mathrm{C}_{\mathrm{T}}$ storage rates under scenario B1 were smaller than those estimated for scenarios A1B and A2 (fig. 6-11; table 6-3) because less land area is devoted to urban development under scenario B1 (fig. 6-5). This resulted in a lower nutrient and suspended sediment flux for scenario B1 than for scenario A1B, particularly along the eastern seaboard where there are many major population centers. Although relative differences in $\mathrm{C}_{\mathrm{T}}$ storage projections for scenario B1 were greatest on the eastern seaboard, the differences between regions were less than for the other scenarios (fig. 6-11), indicating that the differences in patterns of development and land use embodied in the different scenarios can substantially affect coastal $\mathrm{C}_{\mathrm{T}}$ storage rates, thereby altering the carbon cycle of the ocean significantly.

\subsubsection{Summary of Carbon Storage Related to Coastal Processes}

The majority of the portion of coastal carbon storage directly related to terrestrial processes in the Eastern United States resulted from the burial of organic carbon in sediments rather from than transport and storage in the deep ocean. However, transport to the deep ocean was also significant and was more sensitive to projected changing inputs. Of the total carbon stored, the model results suggested that about 60 percent of the coastal $\mathrm{C}_{\mathrm{T}}$ was buried in coastal sediments, whereas about 40 percent was stored as carbonate in deep ocean waters. The rate of $\mathrm{C}_{\mathrm{T}}$ storage was about 3 percent of the rate of terrestrial carbon storage, but the amount of $\mathrm{C}_{\mathrm{T}}$ that would be stored in the active coastal carbon pools under baseline flux conditions was on the same order as that stored in terrestrial carbon pools because of the longer timescales of carbon accumulation in the ocean compared with carbon accumulation by terrestrial processes.

Coastal bathymetry plays an important role in coastal carbon storage. Deep areas export primary production beneath the deep mixed layer, keeping dissolved inorganic carbon produced as a consequence of remineralization isolated from exchange with the atmosphere and resulting in relatively reduced remineralization rates upon organic carbon burial. By contrast, shallow regions, even those with high incident sediment loads, tend to bury more of their production, which is less efficient because the continued slow degradation in shallow (less than $200 \mathrm{~m}$ ) sediments results in return of the remineralized carbon to the atmosphere.

According to the model, the amount of $\mathrm{C}_{\mathrm{T}}$ buried in sediments was partitioned by water depth as follows: 38 percent was buried in waters less than $50 \mathrm{~m}$ deep, 32 percent was buried between $50 \mathrm{~m}$ and $100 \mathrm{~m}$ deep, 15 percent was buried between 100 and $200 \mathrm{~m}$ deep, and the remainder (about 15 percent) was stored in sediments more than $200 \mathrm{~m}$ deep. The decreased burial in the deep zones was because of the low sediment flux in this region and the remineralization that occurs during settling through a deep-water column. These results agree with Dunne and others (2007), who suggested that previous ocean models of carbon storage rates did not account for the appreciable carbon storage that occurs in shallow coastal sediments.

$\mathrm{C}_{\mathrm{T}}$ storage in coastal waters was found to be sensitive to projected changes in fluxes of sediment and nutrients to coastal waters. Under all scenarios modeled, carbon storage in coastal systems was projected to increase. The projected increase in carbon storage is driven by substantially elevated projected nutrient fluxes and elevated sediment fluxes. These two fluxes interact synergistically to increase modeled carbon storage. Projections for scenario A1B exhibited the greatest proportional change in coastal $\mathrm{C}_{\mathrm{T}}$ storage. Rates of total carbon storage for the Eastern United States were projected to increase by 25 percent for this scenario; the South Atlantic Bight showed the highest increase ( 56 percent), followed by the Mid-Atlantic Bight, the Great Lakes, the Gulf of Maine, and the Gulf of Mexico. Changes in $\mathrm{C}_{\mathrm{T}}$ storage in the Gulf of Mexico were primarily driven by changes in sedimentation, whereas the changes in the east coast and the Great Lakes were driven primarily by changes in population density and corresponding increases in nutrient and total suspended sediment transport via rivers to coastal waters.

\subsection{Conclusions and Implications}

Coastal ocean primary productivity has been changing in response to increased nutrient loading. Increased primary production (Herbert, 1999) and fisheries landings (Breitburg and others, 2009) and a greater areal extent of hypoxia resulting from terrestrial inputs (Bianchi and others, 2010) are well documented. The model results presented in this report project a continued increase in nutrient fluxes associated with increasing population and agricultural intensity (Howarth, 2008). This continued increase has important implications for management of coastal resources because of the increased incidence of coastal and estuarine hypoxia (Bianchi and others, 2010) and harmful algal blooms (Anderson and others, 2002; Glibert and others, 2005). Increased areas of hypoxic sediments will likely increase the rates of carbon storage (Bergamaschi and others, 1997; Middelburg and Levin, 2009).

This assessment highlights the notion that processes controlling carbon storage in coastal oceans are not in steady state; rates of nutrient and sediment input are continuously changing in response to land use modification and population increase, among the many other drivers of change. A debate exists in the published literature regarding whether a change in coastal carbon burial rates has been or will be observed 
in coastal sediments. Walsh and others (1985) believe that population and land use change have already led to increased coastal carbon burial rates. The Arabian Sea Carbon Flux Group and others (Lee and others, 1998) found evidence of changes to sediment burial due to anthropogenic activity in waters off the Pacific coast. Middelburg and Levin (2009) summarized the geochemical evidence for the levels of increased carbon preservation in coastal sediments that may be expected. Alternatively, some studies have found that modern carbon burial rates are similar to long-term rates, and thus no change has occurred; no evidence of recent changes in carbon burial rates was found in east coast sediments (Alperin and others, 2002; Thomas and others, 2004) or in the Gulf of Mexico (Allison and others, 2007). The results of the current study suggest that changes in $\mathrm{C}_{\mathrm{T}}$ burial - the part of the burial rate subject to change - are spatially variable and potentially obscured by competing processes. Changes in sediment carbon burial rates may be due to changes in phytoplankton production as well as sediment delivery, with elevated sediment delivery potentially leading to a reduced organic content rather than enrichment because of dilution (Tyson, 2001). The location of studies intended to document changes resulting from altered terrestrial fluxes must be carefully chosen to focus on the nutrient or sediment supply only.

This assessment underscores the need for progress in our understanding of carbon storage in coastal systems. Although there have been significant strides in understanding the role of denitrification and other nitrogen cycling processes in the coastal ocean, there is a high degree of uncertainty about the relative importance of different processes (Seitzinger and others, 2006; Burgin and Hamilton, 2007; Trimmer and Engström, 2011). Large-scale datasets that permit simple model synthetic reproduction are not available. Additional research in coastal nutrient cycling is necessary to accurately evaluate the effects of changing continental fluxes.

Finally, this assessment also highlights the need for a greater understanding of carbon storage and cycling in estuarine sediments. $\mathrm{C}_{\mathrm{T}}$ and the total inventory of carbon in estuaries was assumed to be constant in this assessment because no models were available to relate carbon burial efficiency in estuaries to sediment accumulation rates and because remote sensing data still cannot be interpreted reliably in these areas. Furthermore, based on a simple empirical model formulation, the results of this assessment indicate that sediment carbon burial rates in estuaries represent 1 to 6 percent of total coastal carbon storage rates. However, this is likely an underestimate because it presumes no long-term carbon sequestration. A clearer picture of carbon accumulation in estuaries is important for understanding the effects and mechanisms of estuarine processing that influence terrestrial efflux and coastal carbon storage. 


\title{
Chapter 7. Baseline and Projected Future Carbon Storage, Carbon Sequestration, and Greenhouse-Gas Fluxes in Terrestrial Ecosystems of the Eastern United States
}

\author{
By Shuguang Liu, ${ }^{1}$ Jinxun Liu, ${ }^{2}$ Yiping Wu, ${ }^{3}$ Claudia J. Young, ${ }^{2}$ Jeremy M. Werner, ${ }^{1}$ Devendra Dahal, ${ }^{2}$ \\ Jennifer Oeding, ${ }^{2}$ and Gail L. Schmidt ${ }^{2}$
}

\subsection{Highlights}

- From 2001 through 2005, the average total carbon stored in major pools (live biomass, soils (up to $20 \mathrm{~cm}$ in depth) and dead biomass) in the Eastern United States was estimated to be $26,962 \mathrm{TgC}$, ranging from 25,069 to $28,497 \mathrm{TgC}$. SOC in the top $20-\mathrm{cm}$ soil, live biomass, and dead biomass (such as litter and woody debris) accounted for 43 percent, 42 percent, and 15 percent, respectively, of the total carbon stored in the Eastern United States.

- From 2001 through 2005, the average annual net carbon flux (which is equivalent to the NECB) in the terrestrial ecosystems of the Eastern United States was estimated to be $-279.4 \mathrm{TgC} / \mathrm{yr}$, ranging from -405.5 to $-112.5 \mathrm{TgC} / \mathrm{yr}$ (negative values denote a carbon sink). Of the total NECB, live biomass accumulation accounted for $-188.7 \mathrm{TgC} / \mathrm{yr}$, followed by $\mathrm{SOC}$ at $-65.4 \mathrm{TgC} / \mathrm{yr}$ and dead biomass pool at $-25.2 \mathrm{TgC} / \mathrm{yr}$.

- The average annual net fluxes of GHGs were estimated to be $-1,024.6 \mathrm{TgCO}_{2}$-eq/yr for $\mathrm{CO}_{2}, 174.7$ $\mathrm{TgCO}_{2}$-eq/yr for $\mathrm{N}_{2} \mathrm{O}$, and $193 \mathrm{TgCO}_{2}$-eq/yr for $\mathrm{CH}_{4}$ in the Eastern United States, with a sum of -656.9 $\mathrm{TgCO}_{2}$-eq/yr for the baseline period, which was equivalent to 11.7 percent of the $5,594 \mathrm{TgCO}_{2}$-eq/ $\mathrm{yr}$ of nationwide fossil-fuel emissions in 2010 (U.S. Environmental Protection Agency, 2012).

- Based on the LULC scenarios, climate-change projections, and biogeochemical models used in the terrestrial assessment, the total carbon stored in the Eastern United States in 2050 was projected to be $37,082 \mathrm{TgC}$, ranging from 25,512 to $46,002 \mathrm{TgC}$, an increase of 37.5 percent from the average baseline carbon storage.

${ }^{1}$ U.S. Geological Survey

${ }^{2}$ Stinger Ghaffarian Technologies, Inc.

${ }^{3}$ ASRC Federal InuTeq
- Between 2006 and 2050, the NECB in the terrestrial ecosystems of the Eastern United States was projected to be $-224.9 \mathrm{TgC} / \mathrm{yr}$, ranging from -403.7 to 1.4 $\mathrm{TgC} / \mathrm{yr}$, a potential decrease of $54.5 \mathrm{TgC} / \mathrm{yr}$ (or 19.5 percent reduction in the magnitude of the carbon sink). On average, about 64.3 percent of the total carbon was projected to accumulate in live biomass, 20.3 percent in SOC, and the remaining 15.4 percent in dead biomass.Forests were projected to be the primary carbon sinkwith an average value of -157.6 $\mathrm{TgC} / \mathrm{yr}$. The projected future GHG fluxes averaged $-824.6 \mathrm{TgCO}_{2}$-eq/yr for $\mathrm{CO}_{2}, 174.7 \mathrm{TgCO}_{2}$-eq/yr for $\mathrm{N}_{2} \mathrm{O}$, and $198.7 \mathrm{TgCO}_{2}$-eq/yr for $\mathrm{CH}_{4}$.

- Only a partial attribution analysis was produced on effects of controlling processes (for example, effects of wildland fire [chap. 4], effects of timber production [this chapter], general attribution of LULC change [chap. 3 and this chapter], and uncertainty contribution from the three biogeochemical models, LULC scenarios, and GCMs [this chapter]).

- Results of this assessment suggested a wide range of uncertainty in the estimated carbon sequestration rates across models, LULC scenarios, and GCM projections in ecoregions and in the Eastern United States. In addition, the results showed that the uncertainty from models were far greater than the uncertainties from LULC and GCMs. These results are important but they are high-level observations without a detailed cause-and-effect analysis, which require a further effort to explain the differences among models, LULC scenarios, and GCM projections.

\subsection{Introduction}

Many inventory- and modeling-based studies that use atmospheric (top-down) and ground-based (bottom-up) methods have been conducted to quantify carbon stock and changes in the United States in the past decade. These studies agree on the presence of a carbon sink in the ecosystems of 
the conterminous United States (Houghton and others, 1999; Pacala and others, 2001; Pan and others, 2011). For example, Turner and others (1995) estimated that the total carbon stock in forests of the conterminous United States (at the beginning of 1990s) was about $36,700 \mathrm{TgC}$, with half of that amount in the soils. In 2011, the annual net carbon flux from ecosystems amounted to $-227.3 \mathrm{TgC} / \mathrm{yr}$ from forested lands and

$-246.9 \mathrm{TgC} / \mathrm{yr}$ from all lands in conterminous United States (U.S. Environmental Protection Agency, 2012). Woodbury and others (2007) estimated that the forest sector (including forests and wood products) sequestered an average $-162 \mathrm{TgC} / \mathrm{yr}$ in the United States from 1990 through 2005, providing an offset equal to 10 percent of the national total $\mathrm{CO}_{2}$ emissions in 2005. Climate change and land-use change have profound effects on the ability of ecosystems to sequester carbon and maintain a stable carbon stock (Goward and others, 2008; Houghton, 2010; Liu and others, 2011; Pan and others, 2011). Several recent studies suggested that a lower rate of carbon sequestration by ecosystems than these contemporary rates is possible in future years as the result of climate change and land-use change (Hurtt and others, 2002; Birdsey and others, 2006; Liu and others, 2012b), whereas other studies (such as Woodbury and others, 2007) estimated that forests in the United States would continue to sequester carbon in the near future at a rate similar to those of recent years.

As described in chapter 1 of this report, the scope of the assessment required a methodology that integrated several technical components, including LULC change, wildland fire disturbances, and modeling of terrestrial and aquatic carbon fluxes (fig. 1-2). The objective of this chapter is to describe methods used to estimate carbon stock, carbon fluxes, and the rate of sequestration in terrestrial ecosystems in the Eastern United States and present the results of the terrestrial assessment.

\subsection{Methods and Data}

\subsubsection{Ecosystem Biogeochemical Models}

Consistent with the approach used for the regional assessments conducted for the Great Plains (Zhu and others, 2011) and the Western United States (Zhu and Reed, 2012), the Century version 4.0 (Parton and others, 1987, 1994; Metherell and others, 1993), Erosion Deposition Carbon Model (EDCM; appendix 1; Liu and others, 2003), and Land Greenhouse-Gas Accounting Tool (LGAT; appendix 2) biogeochemical models were used for simulating ecosystem biogeochemical cycles and estimating carbon stock and flux values.

Major model-data intercomparison studies have shown diverse results of different models on estimating carbon stocks and fluxes (Schwalm and others, 2010; Huntzinger and others, 2012). These studies suggested that a collective use of multiple models would yield more useful information than any single model. Perhaps a major advantage of using several models together is the consideration that the range of results obtained from the models could serve to illustrate uncertainties stemming from inherent biases of the individual models. Based on the above considerations, an ensemble modeling strategy was adopted and implemented in the General Ensemble Biogeochemical Modeling System (GEMS; Liu, 2009; Liu and others, 2012c). For this assessment, the three biogeochemical models were run in an ensemble fashion on the GEMS platform to share input data and produce the range of results to quantify uncertainties of model outputs (appendix 3).

Running GEMS or any biogeochemical models over a large area is challenging because of the high computation load. To speed model simulations, a sampling approach can be implemented in GEMS in addition to the conventional approach that supports only wall-to-wall or per-pixel simulations. Using this sampling approach, users can choose different sampling densities to run GEMS to meet their needs. For example, EDCM and Century models can be both run with a $10 \times 10$ subsample factor to allow for adequate time of processing, generating statistics, and assessing the results. With this sampling scheme, only one pixel is simulated and processed for every 100 pixels (that is, 1 out of 10 pixels in each the $\mathrm{x}$ and $\mathrm{y}$ directions). The adequacy of sample intensity should be evaluated before full deployment over large areas.

The concept of a joint frequency distribution (JFD) table was originally used and implemented in GEMS to speed up model simulations and address input data uncertainty (see Liu and others, 2004; Liu, 2009). Containing one or multiple pixels, each JFD record in the table represents a unique combination of environmental conditions derived from overlay operations of multiple geospatial data layers, such as LULC, soil, and climate. The JFD approach is most efficient when the number of strata is relatively small and the spatial resolutions of the geospatial data layers are coarse. However, this efficiency decreases as the study area, resolution of the spatial data layers, and number of spatial data layers increase. The extreme of the JFD approach is the case that each JFD record contains only one pixel (that is, each pixel is uniquely defined by the spatial data layers), which then becomes the per-pixel model simulation. In this case, there is no need for explicit JFD tables in per-pixel GEMS simulations because operating on the geospatial data layers directly can gain efficiency by eliminating some searching and computing algorithms.

The major biogeochemical processes of the carbon cycle simulated by the two process-based models (that is, Century and EDCM) include NPP, photosynthetic allocation, litter fall, mortality, decomposition of plant tissues, and SOC. There is no need to predetermine endpoints of maximum carboncarrying capacity or predefine paths to describe how the endpoints are approached because the dynamics of vegetative and soil carbon pools are controlled by the fluxes of inputs and outputs. The endpoints and paths, varying in space with specific site conditions, are tightly coupled with and regulated by the nitrogen and water cycles, disturbances, and management activities. 


\subsubsection{Input Data}

Major input datasets included climate, LULC, soils, elevations, biomass, land management activities, and natural disturbances such as wildland fires. These datasets were obtained from different sources (table 7-1) and converted to standard spatial and temporal resolutions, projections, and data formats. Examples of input data layers (maps) are provided for the baseline (fig. 7-1) and projected future (fig. 7-2) periods of this assessment.

As with the previous assessments (Zhu and others, 2011; Liu and others, 2012a), this assessment relied on nationwide geospatial data layers to characterize the spatial and temporal distributions of land-management activities and natural disturbances. Examples of processing and formatting techniques for the data layers are given in Schmidt and others (2011). Major land-management activities and natural disturbances included in model runs for this assessment are listed in table 7-2, with examples for 2005 given in figure 7-3.

The spatial resolution of some data layers listed in table 7-2, especially those derived from censuses and inventories, was at the county, State, or FIA-unit level. These data layers were further downscaled to pixels to generate spatially explicit map layers using a Monte Carlo approach and some other additional information (techniques described in Schmidt and others (2011)). The most common pixel resolution among all the map layers was $250 \mathrm{~m}$. The map series had individual maps for each year from 1992 through 2050. Annual maps showing areas of forest clearcuts were produced as part of the LULC change modeling detailed in chapter 3 of this report. Annual maps of wildland fire disturbances were modeled as described in chapter 4 of this report.

The county-level crop management information used in this assessment included crop type, crop rotation, fertilization, manure addition, tillage practices, irrigation, and harvesting practices. Crop management activities were downscaled to pixel level on the LULC maps using a probability-based Monte Carlo approach and the crop composition information derived from the USDA agricultural census data (U.S. Department of Agriculture, National Agricultural Statistics Service, 2011). All the crop management data layers (except irrigation) were subsequently generated from these land-cover data layers, and more than 20 major crops were presented consistently for the United States (Schmidt and others, 2011). The tabular data about manure application were derived from the USDA census (U.S. Department of Agriculture, National Agricultural Statistics Service, 2011), which included, for each crop type in each State, the Federal Information Processing Standard (FIPS) code for each State, the year the crop was planted, the total planted area, the percentage of the planted area that was treated with manure, the amount of manure that was applied, the rate at which the manure was applied, the rate at which the nitrogen in the manure was applied, and the rate at which the carbon in the manure was applied. A gridded manure dataset for all agricultural lands in the region was generated from this tabular data along with the land-cover maps using a Monte Carlo approach.
The information about tillage practices was acquired from the Conservation Technology Information Center (CTIC) in tabular format. The tabular data included the FIPS code for each State, the year the area was tilled, the total planted area that was tilled, the total percentage of residue on all tilled areas, the planted area for each tillage type, and the percentage of residue for each tillage type by crop type within the State. The tillage practices included in the database included conventional, mulch, no-till, reduced, and ridge tillage. A gridded dataset showing the spatial and temporal changes of tillage practices for all agricultural lands was generated from these tabular data along with the land-cover maps using a Monte Carlo approach. An irrigation map derived from the MODIS (U.S. Geological Survey, 2010) for the United States was used to characterize the locations of irrigated land. Because of the lack of data showing the temporal changes in irrigation across the Eastern United States, this assessment assumed that the locations of irrigated land did not change over time during the assessment period.

Only nitrogen fertilization on agricultural lands was considered in this assessment. Forest fertilization was not included in the assessment due to the lack of spatially explicit information. A nationally consistent procedure was put in place to generate crop- and location-specific nitrogen-fertilization data for all agricultural lands (Schmidt and others, 2011). The tabular dataset included the FIPS code for each State, the year the planted area was fertilized, the total planted area where nitrogen fertilizer was applied, the percentage of total area that was fertilized with nitrogen, the rate of application for nitrogen fertilizer, and the total amount of nitrogen fertilizer applied for each crop type within each State. Because several States in the Eastern United States did not report this information, this assessment assumed that agricultural lands were automatically fertilized every year in order to satisfy growth requirements.

The selective or partial forest clearcutting (thinning) information used in this assessment included thinning ratio, thinning age, and thinning intensity, which were calculated from the FIA database (U.S. Department of Agriculture, 2012a) at the FIA-unit level (see appendix 4). Mortality caused by disturbances (insects, disease, fire, animals, weather, vegetation, or other) was also included in the assessment of the Eastern United States. A mortality ratio was calculated for each FIA unit by forest type from the FIA database. Because of the lack of data showing the temporal changes in partial cutting and mortality across the Eastern United States, this assessment assumed that the ratios did not change over time during the assessment period.

\subsubsection{Model Run Setup}

\subsubsection{Model Initialization}

The soil properties that were initialized based on data from the SSURGO database (U.S. Department of Agriculture, Natural Resources Conservation Service, 2009) included soil thickness, organic carbon storage, texture (fractions of sand, silt, and clay), bulk density, and drainage. The total SOC pool was partitioned into active ( 5 percent), slow ( 45 percent), and passive ( 55 percent) 
Table 7-1. Input data used in the model runs for the assessment of carbon fluxes and storage in the Eastern United States.

[Most of the input data have a 250-meter spatial resolution and variable temporal characteristics, although most data cover the first decade of the 21 st century. LGAT, Land Greenhouse Gas Accounting Tool; EDCM, erosion deposition carbon model; LULC, land use and land cover; MIROC 3.2-medres, Model for Interdisciplinary Research on Climate version 3.2 medium resolution; CGCM3.1, The Third Generation Coupled Global Climate Model; CSIRO Mk3.5, Commonwealth Scientific and Industrial Research Organisation Mark 3.5; $\mathrm{Db} 0.33$ bar $\mathrm{H}_{2} \mathrm{O}$, the oven-dry weight of the less than 2 millimeters of soil material per unit volume of soil at a water tension of 0.33 bar (as used in the Soil Survey Geographic database); FIA, Forest Inventory and Analysis; USDA, U.S. Department of Agriculture; GCM, general circulation model; K factor, an erodibility factor that quantifies the susceptibility of soil particles to detachment by water; $\mathrm{mm}$, millimeter; MODIS, moderate resolution imaging spectrometer; NASA, National Aeronautics and Space Administration; PRISM, parameter-elevation regressions on independent slopes model]

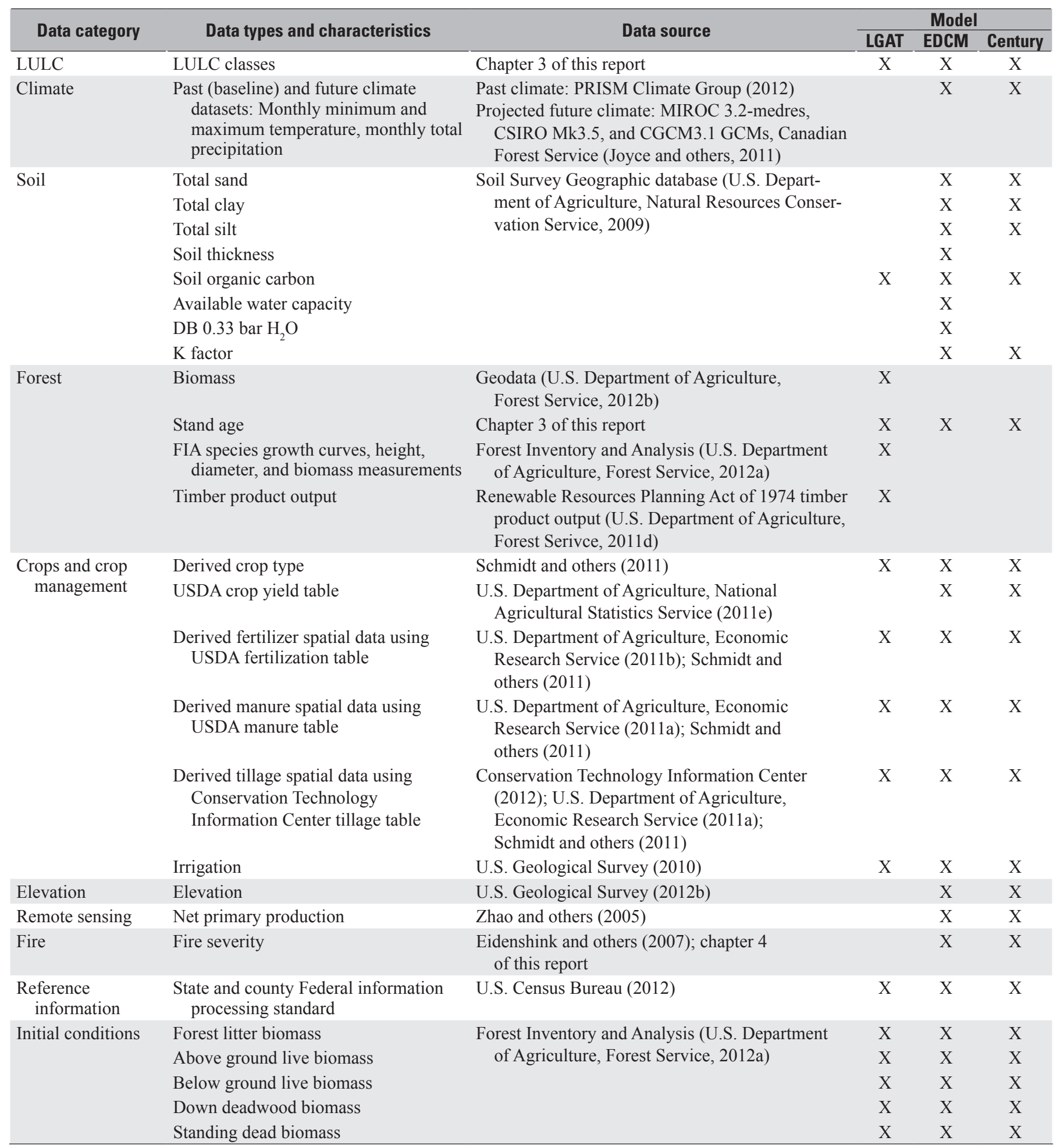


A. Soil organic carbon-Top layer

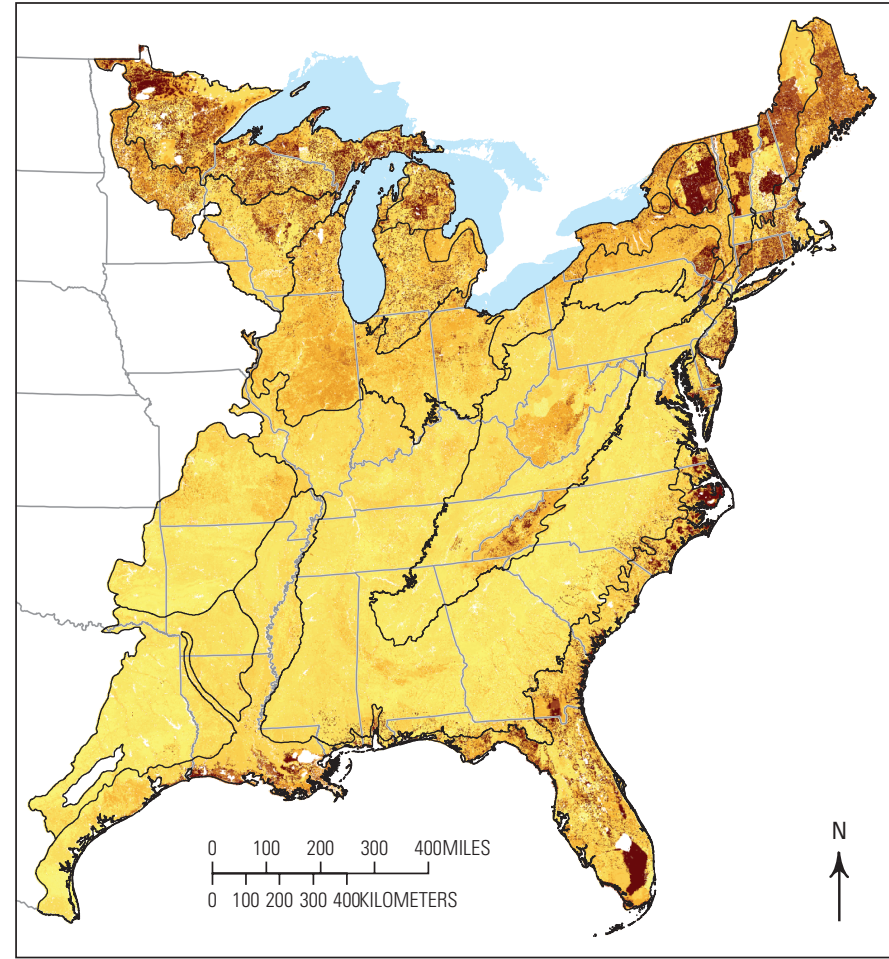

C. Land use and land cover in 2005

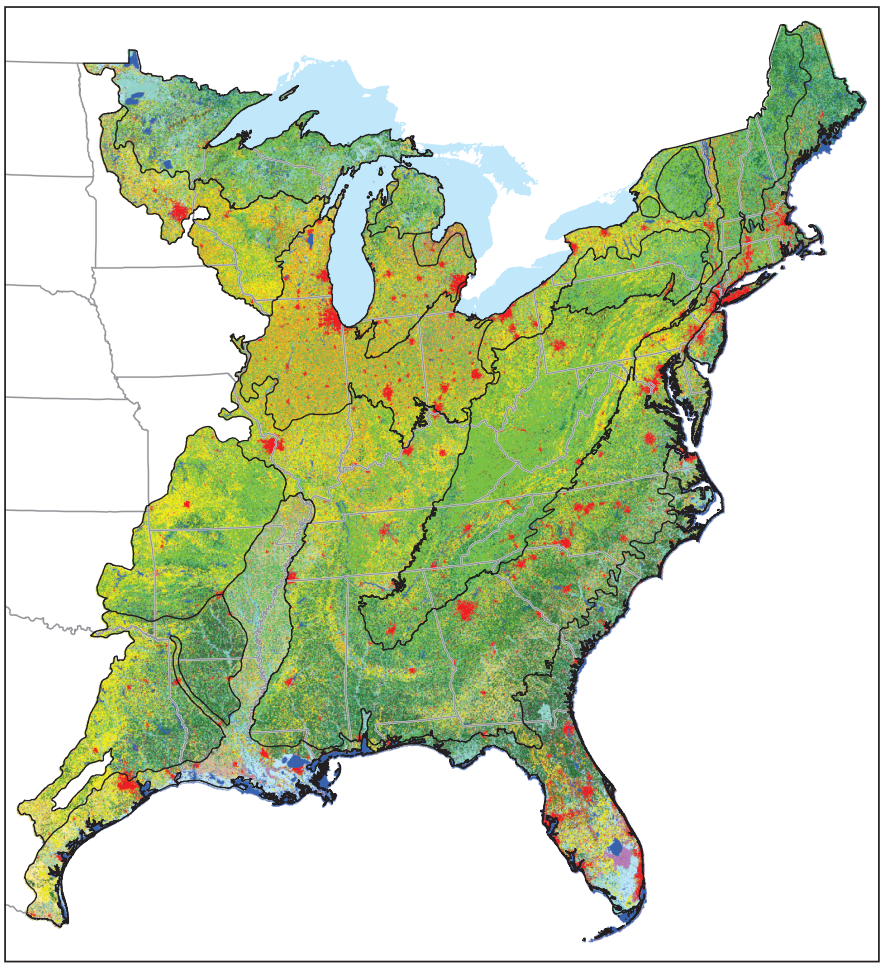

B. Total annual precipitation in 2005

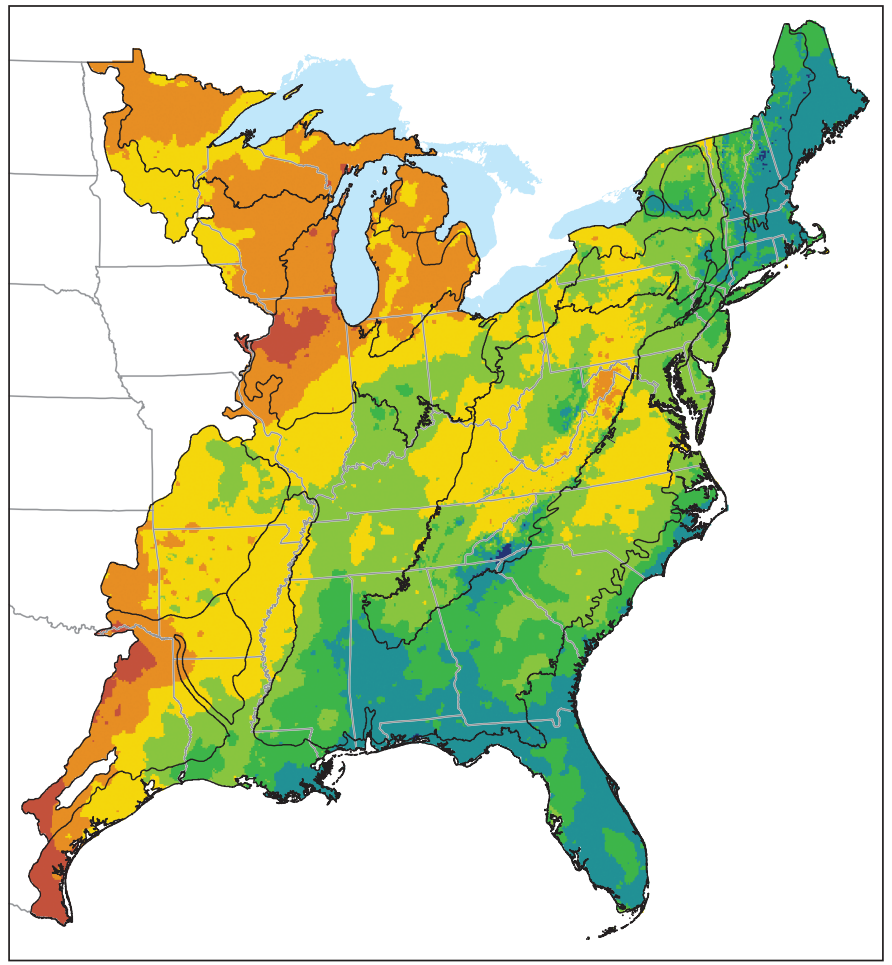

EXPLANATION

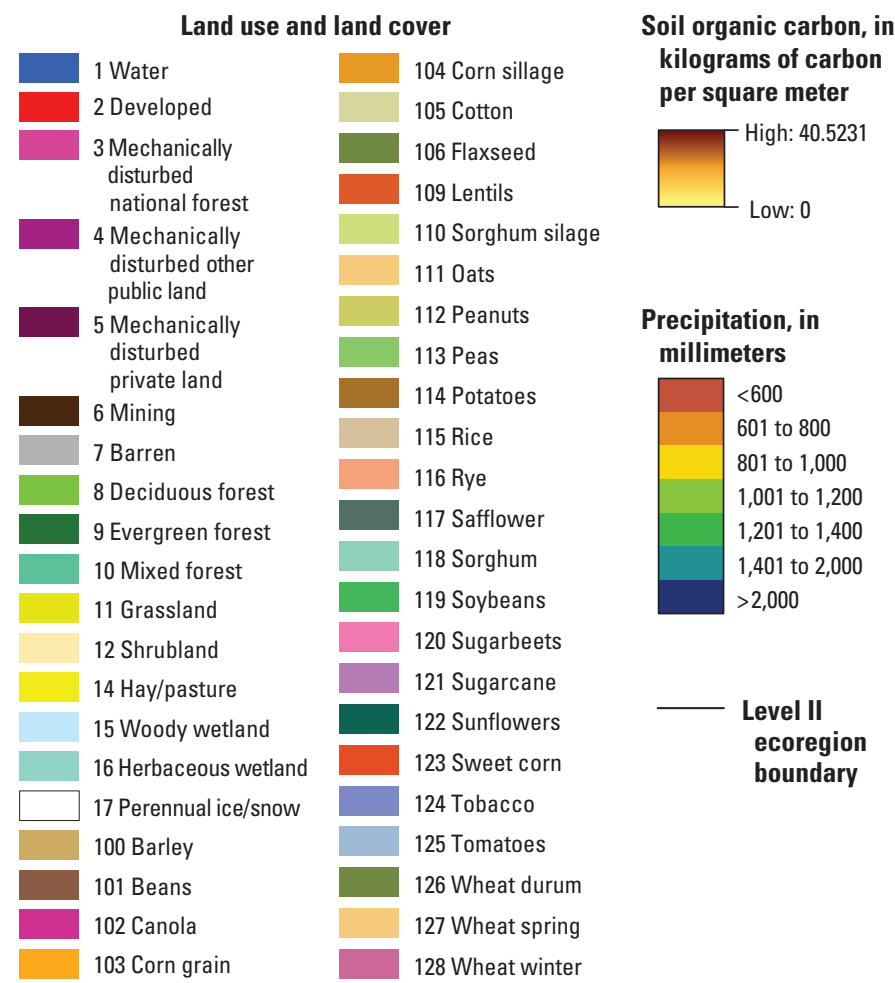

Figure 7-1. Examples of maps showing input data for the Eastern United States. A, Soil organic carbon (SOC) for the top 0 to 5 centimeters of the soil layer; data were derived from the Soil Survey Geographic (SSURGO) database (U.S. Department of Agriculture, Natural Resources Conservation Service, 2009). B, Total precipitation in 2005 (PRISM Climate Group, 2012). C, Land use and land cover (LULC) in 2005, from chapter 3 of this report with the agricultural lands class downscaled to the crop types. Level Il ecoregions are shown in figure 1-1. 
A. Precipitation, 2050-MIROC scenario A1B

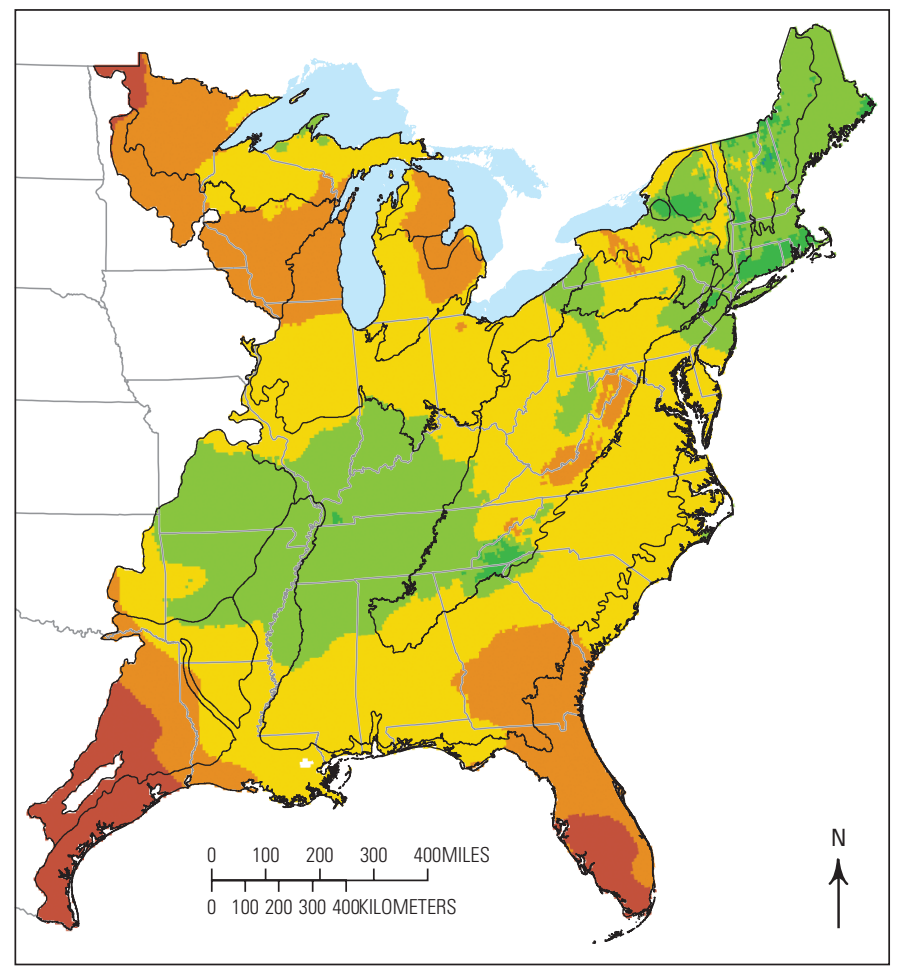

C. Precipitation, 2050-MIROC Scenario B1

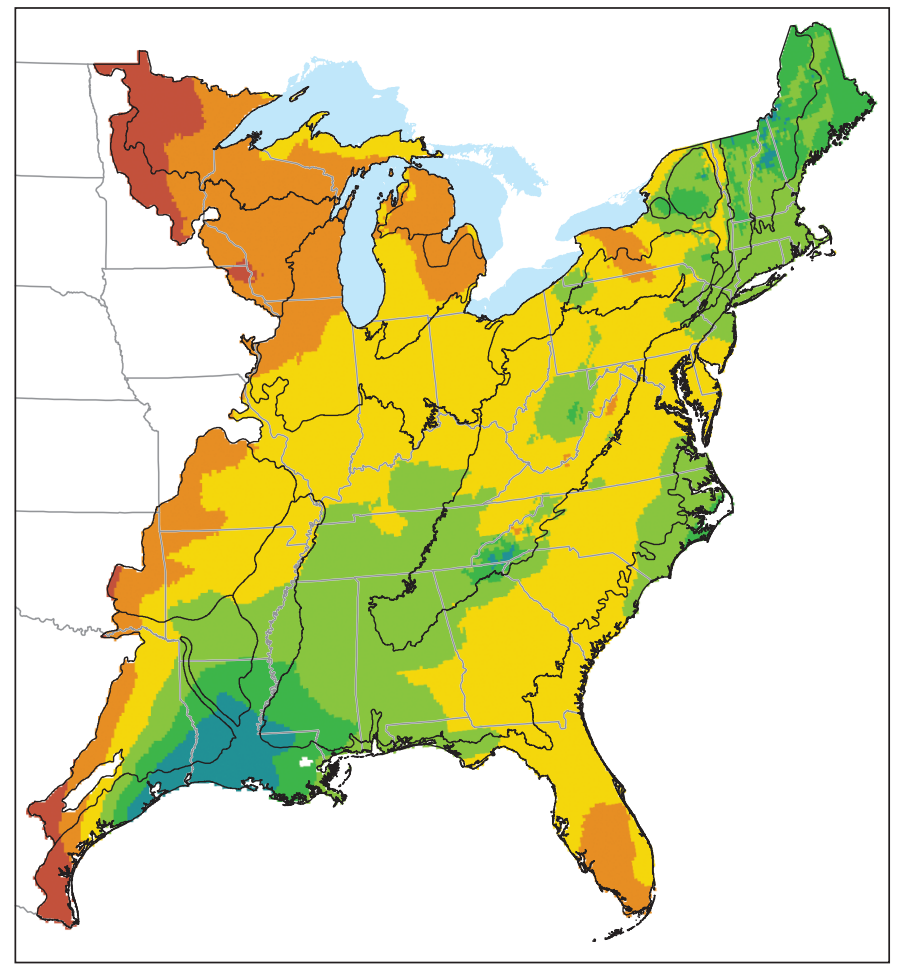

B. Precipitation, 2050-MIROC scenario A2

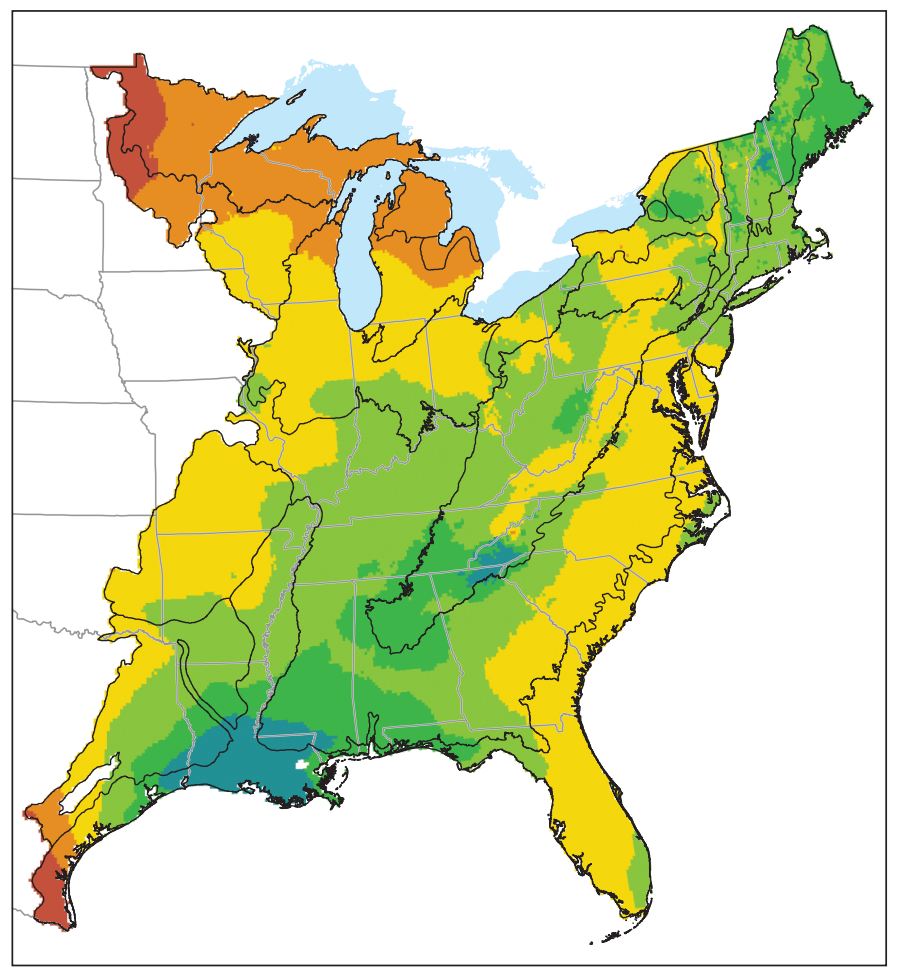

D. Land use and land cover, 2050 - Scenario A1B

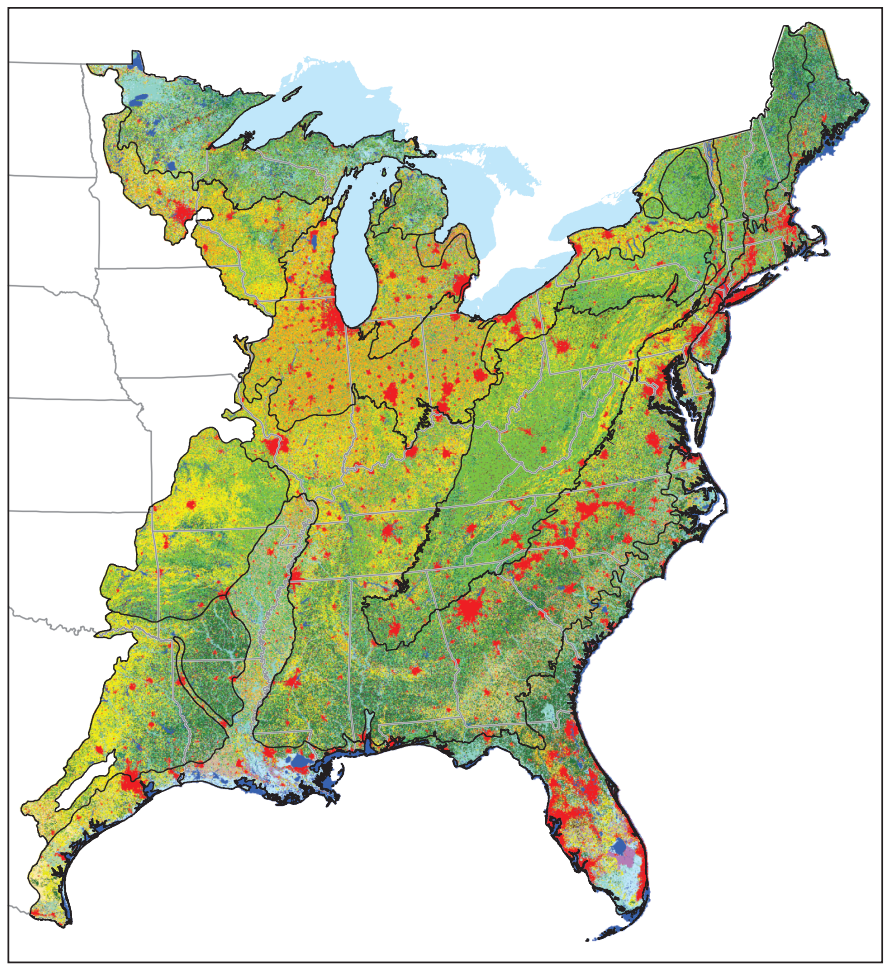

Figure 7-2. Maps showing projected total annual precipitation under Intergovernmental Panel on Climate Change Special Report on Emission Scenarios (SRES; Nakićenović and others, 2000) scenarios $A, A 1 B, B, A 2$, and $C$, B1 in 2050 and $D$, projected land use and land cover (LULC) under SRES scenario A1B in the Eastern United States in 2050. Precipitation data were projected by the Model for Interdisciplinary Research on Climate version 3.2 medium resolution (MIROC 3.2-medres) general circulation model (Joyce and others, 2011). Projected LULC change was from chapter 6 of this report with downscaling of agriculture to crop types by Schmidt and others (2011). Level II ecoregions are shown in figure 1-1. 
Table 7-2. Major land-management activities and natural disturbances included in model runs for the assessment of carbon fluxes and storage in the Eastern United States.

[m, meters; NA, not applicable; PRISM, parameter-elevation regressions on independent slopes model; FIA, Forest Inventory Analysis]

\begin{tabular}{|c|c|c|c|c|}
\hline $\begin{array}{l}\text { Management ac- } \\
\text { tivities or natural } \\
\text { disturbances }\end{array}$ & Data source & $\begin{array}{l}\text { Spatial } \\
\text { resolution }\end{array}$ & Time period & References \\
\hline $\begin{array}{l}\text { Forest harvesting } \\
\text { or clearcuts }\end{array}$ & Stand age, chapter 3 of this report & $250 \mathrm{~m}$ & $1992-2050$ & U.S. Geological Survey (2012a) \\
\hline Forest mortality & Mortality ratio from forest inventory data & FIA unit & $\begin{array}{l}\text { Average for } \\
1997-2010\end{array}$ & $\begin{array}{l}\text { U.S. Department of Agriculture, } \\
\text { Forest Service (2012a) }\end{array}$ \\
\hline $\begin{array}{l}\text { Wildland fire: } \\
\text { extent, severity, } \\
\text { frequency }\end{array}$ & Chapter 4 of this report & $250 \mathrm{~m}$ & 1992-2050 & Chapter 4 of this report \\
\hline Fertilization & $\begin{array}{l}\text { U.S. Department of Agriculture Economic Re- } \\
\text { search Service fertilization table }\end{array}$ & County & $1992-2050$ & $\begin{array}{l}\text { U.S. Department of Agriculture Eco- } \\
\text { nomic Research Service (2011b) }\end{array}$ \\
\hline Manure & U.S. Department of Agriculture manure table & County & $1992-2050$ & $\begin{array}{l}\text { U.S. Department of Agriculture } \\
\text { Economic Research Service (2011a) }\end{array}$ \\
\hline Tillage & $\begin{array}{l}\text { Conservation Technology Information Center } \\
\text { tillage table }\end{array}$ & County & $1992-2050$ & $\begin{array}{l}\text { Conservation Technology Information } \\
\text { Center (2012); U.S. Department of } \\
\text { Agriculture Economic Research } \\
\text { Service (2011a) }\end{array}$ \\
\hline Irrigation & U.S. Geological Survey & $250 \mathrm{~m}$ & Static & U.S. Geological Survey (2010) \\
\hline
\end{tabular}

\section{EXPLANATION}

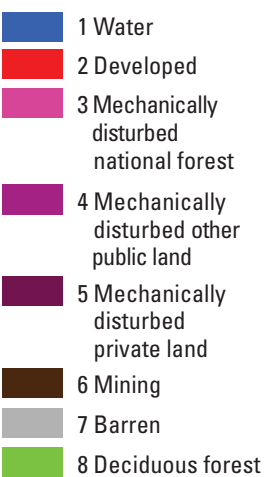

Figure 7-2.-Continued

Precipitation, in millimeters

9 Evergreen forest 10 Mixed forest

11 Grassland

12 Shrubland

14 Hay/pasture

15 Woody wetland

16 Herbaceous wetland

17 Perennial ice/snow

100 Barley

101 Beans

102 Canola

103 Corn grain
104 Corn sillage

105 Cotton

106 Flaxseed

109 Lentils

110 Sorghum silage

1110 ats

112 Peanuts

113 Peas

114 Potatoes

115 Rice

116 Rye

117 Safflower
118 Sorghum

119 Soybeans

120 Sugarbeets

121 Sugarcane

122 Sunflowers

123 Sweet corn

124 Tobacco

125 Tomatoes

126 Wheat durum

127 Wheat spring

128 Wheat winter

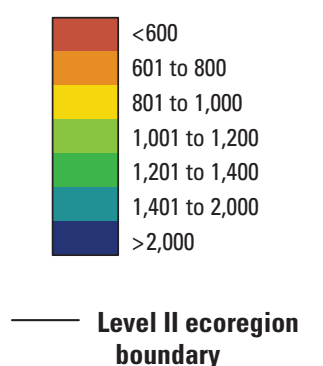

boundary 


\section{A. Land use and land cover, 2005}

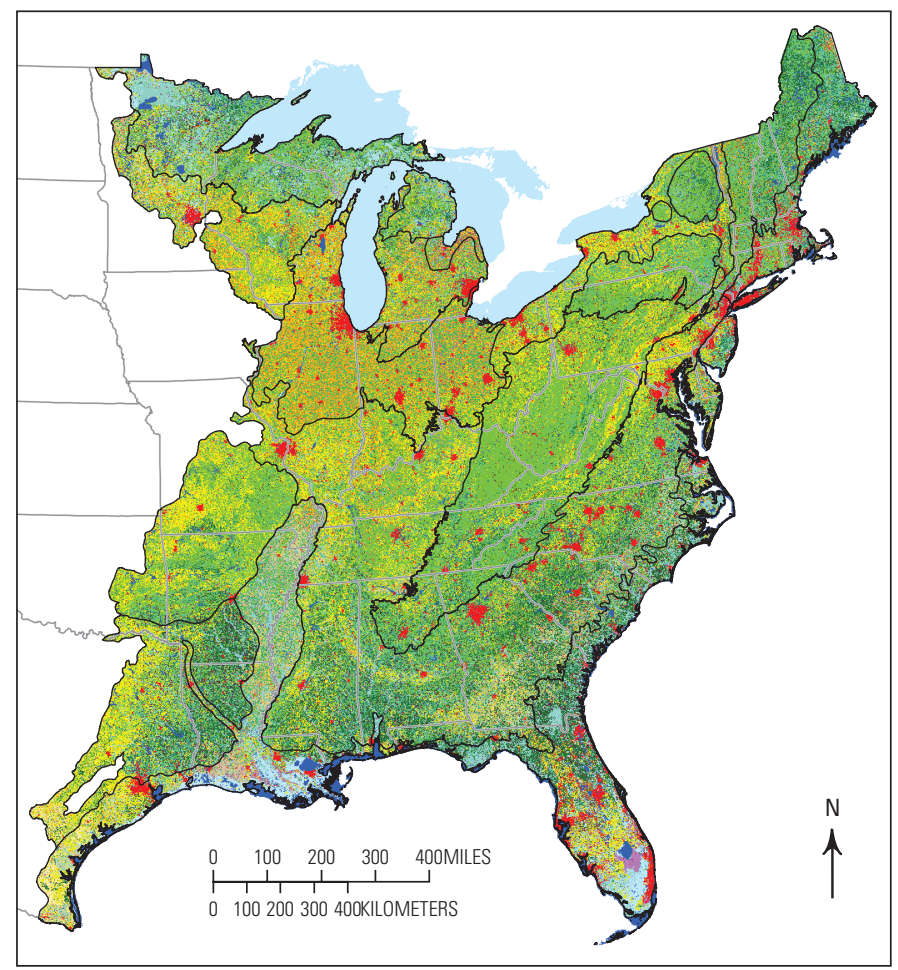

\section{B. Manure, 2005}

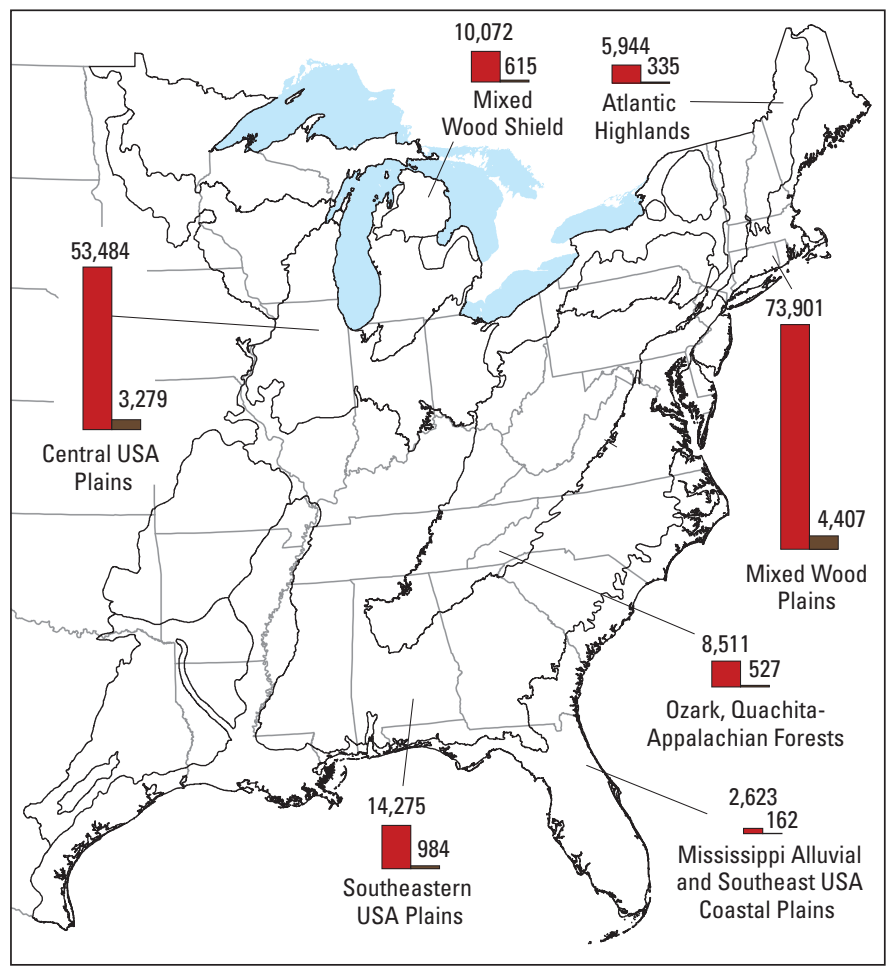

\begin{tabular}{|l}
\hline 1 Water \\
2 Developed \\
3 Mechanically \\
disturbed \\
national forest \\
4 Mechanically \\
disturbed other \\
public land \\
\hline 5 Mechanically \\
disturbed \\
private land \\
6 Mining \\
7 Barren \\
8 Deciduous forest \\
9 Evergreen forest \\
10 Mixed forest \\
11 Grassland \\
12 Shrubland \\
14 Hay/pasture \\
\hline
\end{tabular}

\section{Land use and land cover}

\begin{tabular}{|l|l|}
\hline \multicolumn{1}{|c|}{15 Woody wetland } \\
\hline 16 Herbaceous wetland \\
\hline 17 Perennial ice/snow \\
100 Barley \\
101 Beans \\
102 Canola \\
103 Corn grain \\
104 Corn sillage \\
105 Cotton \\
106 Flaxseed \\
109 Lentils \\
110 Sorghum silage \\
111 Oats \\
112 Peanuts \\
113 Peas
\end{tabular}

\section{EXPLANATION}

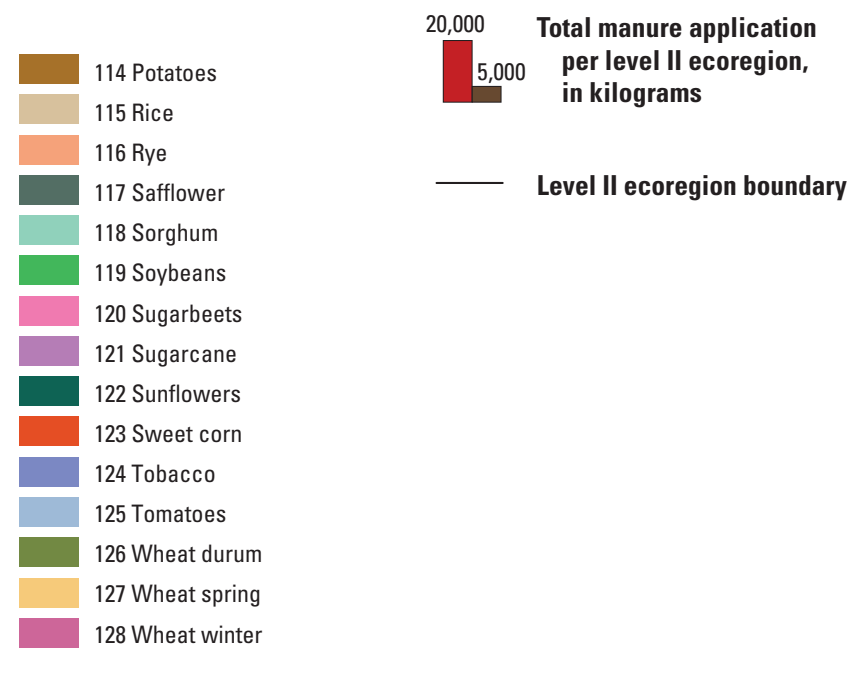

Figure 7-3. Maps showing examples of $A$, land use and land cover; $B$, manure; $C$, tillage; $D$, irrigation; and $E$, stand age data layers for land-management activities and natural disturbances in the Eastern United States for 2005. Level II ecoregions are shown in figure 1-1. 
C. Tillage, 2005

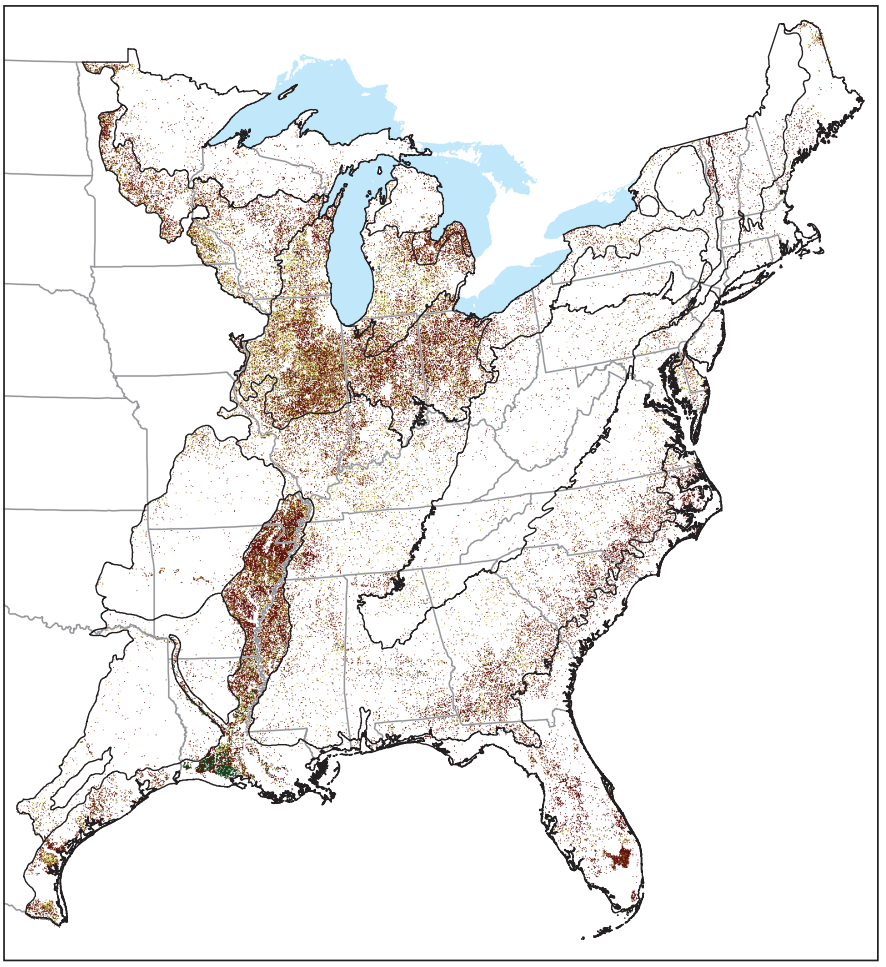

\section{E. Stand age, 2005}

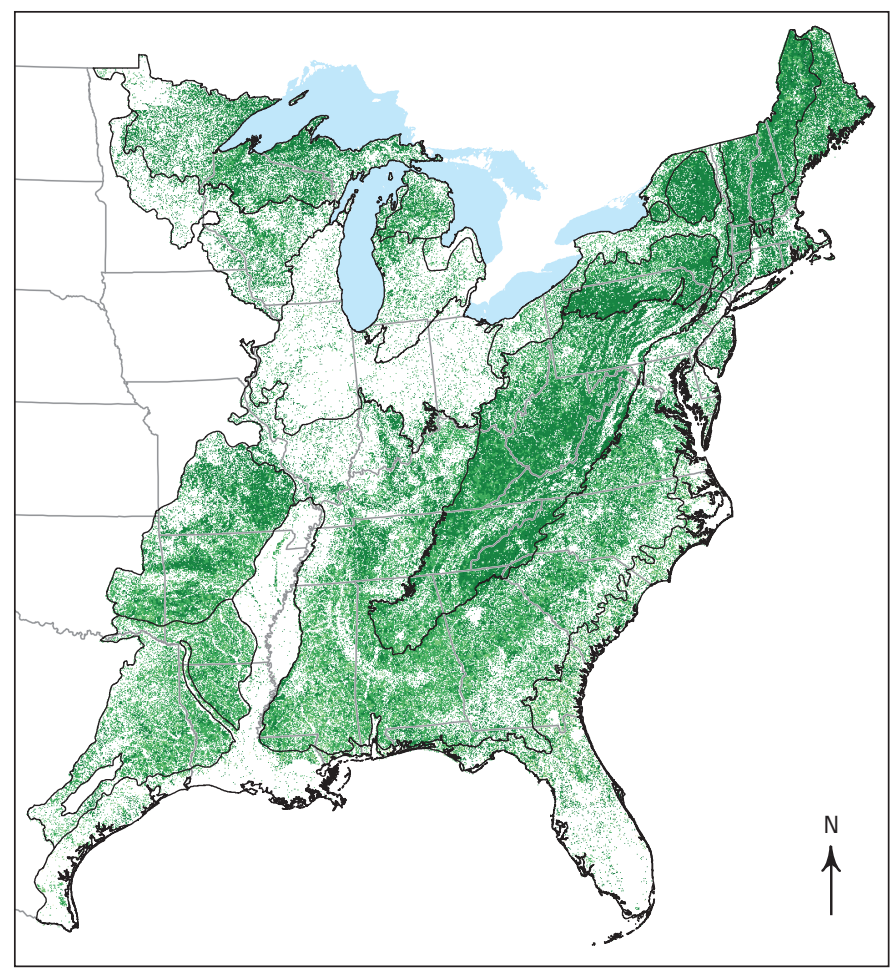

D. Irrigation, 2005

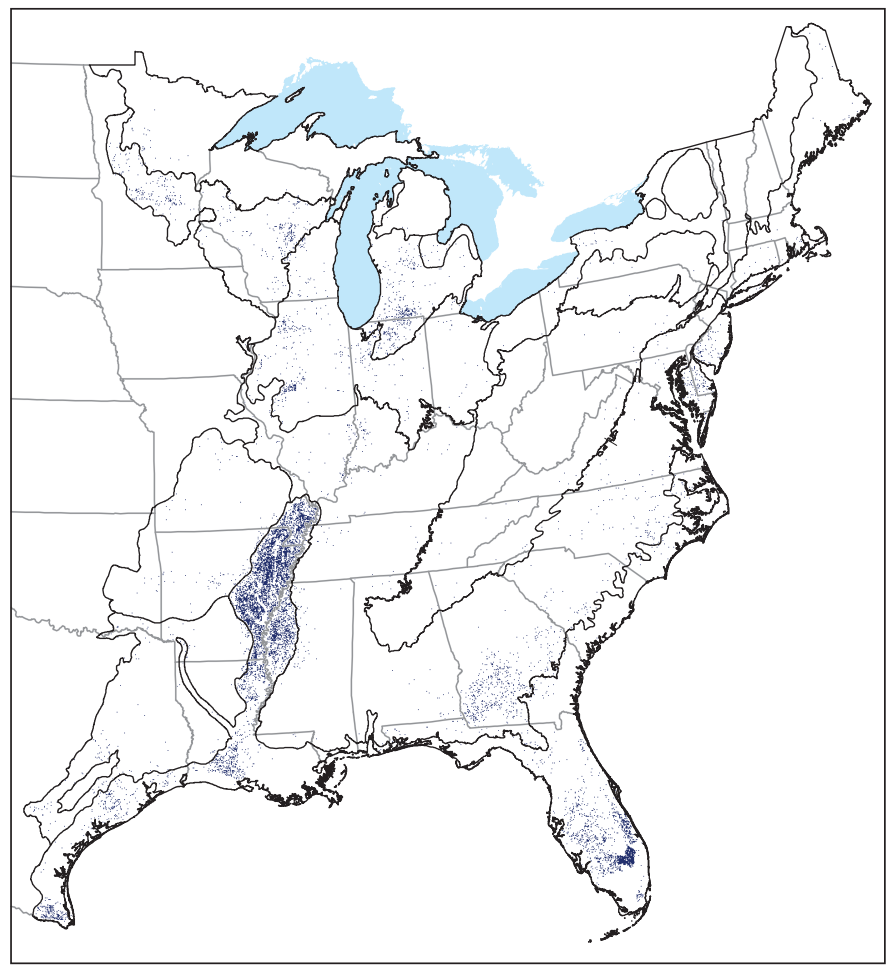

\section{EXPLANATION}

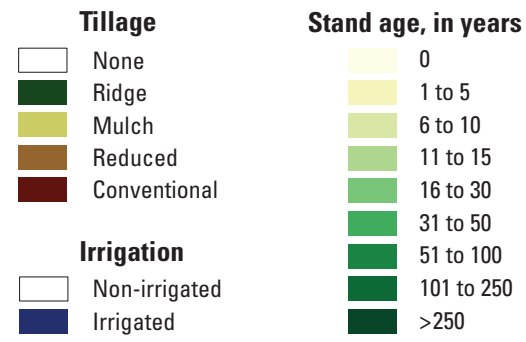

Level II ecoregion boundary

Figure 7-3.-Conitnued 
classifications for Century and EDCM initialization (Liu and others, 2003). Forest biomass carbon pools (aboveground and belowground live biomass or dead biomass consisting of forest litter and dead, woody debris) were initialized using the initial forest-age map (derived from FIA data; U.S. Department of Agriculture, Forest Service, 2012b), forest type (evergreen, broadleaf, and mixed), and the relation between forest age and carbon stock. For consistency and to avoid potential errors, the initialization of the SOC and biomass was done using the LGAT, and the outputs from the LGAT for 1992 (the first year of the model simulations) were then read directly by the Century model and the EDCM as initial conditions.

\subsubsection{Model Calibration and Validation}

Model calibration, the process of adjusting model parameters to minimize the difference between simulations and observations, was only applied to Century and the EDCM as all coefficients of the LGAT could be derived directly from field measurements. The observed data for calibration (from 2001 through 2005) included county-based grain yield survey data by crop type (U.S. Department of Agriculture, National Agricultural Statistics Service, 2011) and 250-m-resolution NPP data from the MODIS for other LULC types, such as forests and grasslands (Zhao and others, 2005). The MODIS NPP was found to lack consistent performance for calibrating crop production. As the result, crop yield data from the USDA were used. An automated calibration was implemented for EDCM using the Shuffled Complex Evolution (SCE-UA) method (Duan and others, 1992) and the R-language Flexible Modeling Environment (R-FME) software package (Soetaert and Petzoldt, 2010; Wu and Liu, 2012). On the other hand, manual calibration was used for Century model. The potential maximum production parameter (PRDX) was adjusted by comparing the modeled grain yield with the USDA county-level statistics of grain yield and the forest NPP with the county-level MODIS-derived NPP from 2001 through 2005. Appendix 5 summarizes the derived PRDX values of 13 main ecosystem types by county across all ecoregions in the Eastern United States.
Observational data used for validation included USDA forest biomass values (U.S. Department of Agriculture, Forest Service, 2012a), aboveground biomass from the Woods Hole Research Center National Biomass and Carbon Dataset for the Year 2000 (Kellndorfer and others, 2004), the MODISderived NPP (Zhao and others, 2005), and the USDA grain yield (U.S. Department of Agriculture, National Agricultural Statistics Service, 2011) for 2006, 2008, and 2010. Maps, binned scatterplots, and correlation plots were generated for different ecosystems in each ecoregion of the Eastern United States in order to compare the simulated results of the process-based models with observational data. Simple linear-regression modeling, the $\mathrm{R}^{2}$, and the root mean square error (RMSE) between the observed and modeled data were calculated to evaluate the performance of the models. Some of the results of the validation are shown in figure 7-4 and table 7-3. Figure 7-4 shows the comparison between NPP estimated by MODIS and NPP simulated by Century and EDCM in all seven ecoregions of the Eastern United States in 2006. Table 7-3 summarizes validation metrics from different models in the Mixed Wood Shield ecoregion in 2006 and serves as an example of statistics used in the models; other ecoregions, not shown in this report, show similar results.

\subsubsection{Ensemble Modeling}

Multiple GEMS simulations were run continuously for 1992 through 2050 with the following setup:

- Three models were run on the GEMS platform. EDCM and Century were run at monthly time steps with a sampling intensity of 1 percent (or 1 pixel for each 10 pixels in the $\mathrm{x}$ direction and 10 pixels in the $y$ direction) for this report. The validity of the sampling rate was confirmed by comparing results with those produced with per-pixel simulations (see appendix 6). The LGAT was run at annual time steps on a per-pixel basis because the time for each run was much shorter than the other two process-based models.

- Three LULC scenarios were incorporated. Each of the scenarios was developed (chapters 2 and 3 of this

Table 7-3. Biogeochemical models in the General Ensemble Modeling System in the Eastern United States for 2006.

[Based on aggregated results at the county level. RMSE, root mean squared error; $\mathrm{gC} / \mathrm{m}^{2} / \mathrm{yr}$, grams of carbon per square meter per year; $\mathrm{R}^{2}$, coefficient of determination; EDCM, Erosion Deposition Carbon Model; LGAT, Land Greenhouse Gas Accounting Tool]

\begin{tabular}{|c|c|c|c|c|}
\hline Observation & Model & System & $\begin{array}{c}\text { RMSE, } \\
\text { in } \mathrm{gC} / \mathrm{m}^{2} / \mathrm{yr}\end{array}$ & $\mathbf{R}^{2}$ \\
\hline National Biomass and Carbon Dataset (Kellndorfer and others, 2012) live biomass & LGAT & Forest & 0.819 & 0.95 \\
\hline \multirow[t]{3}{*}{ Moderate resolution imaging spectroradiometer-derived net primary production } & Century & Forest & 0.139 & 0.90 \\
\hline & EDCM & Forest & 0.172 & 0.86 \\
\hline & Century & Grassland/shrubland & 0.005 & 0.96 \\
\hline \multirow[t]{2}{*}{ U.S. Department of Agriculture grain yield } & Century & Winter wheat & 0.001 & 0.90 \\
\hline & EDCM & Winter wheat & 0.001 & 0.72 \\
\hline
\end{tabular}




\section{A. MODIS NPP}

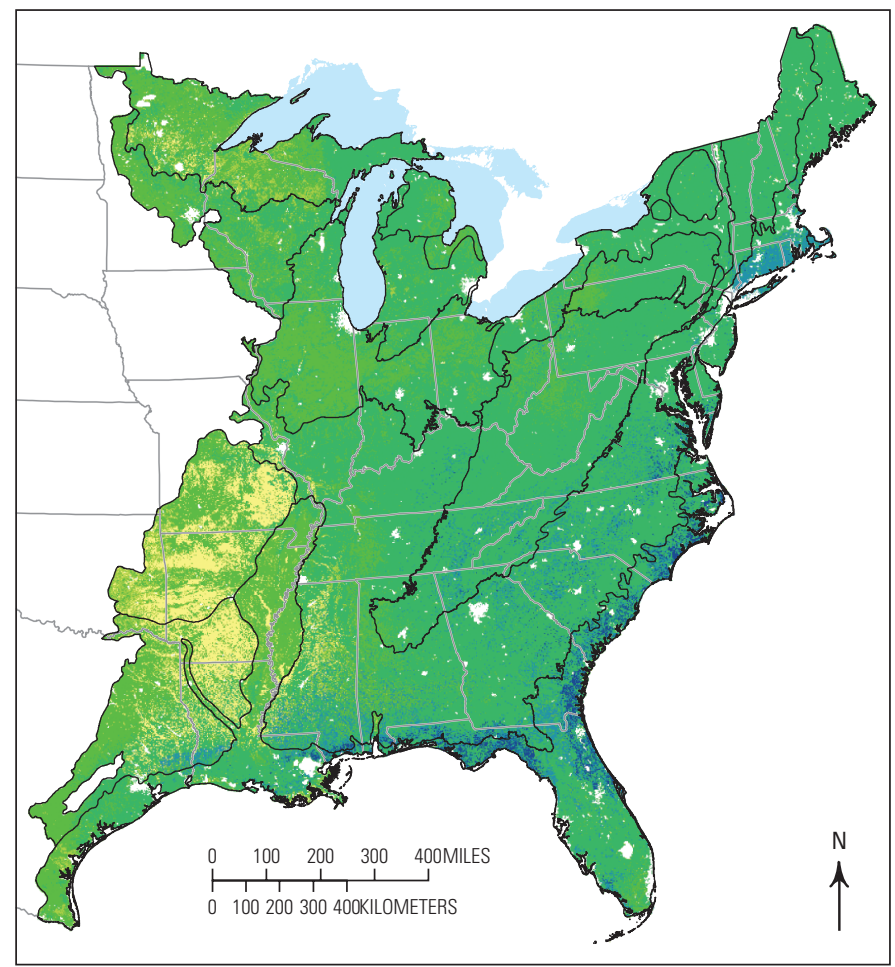

\section{B. GEMS-CENTURY MIROC A1B NPP}

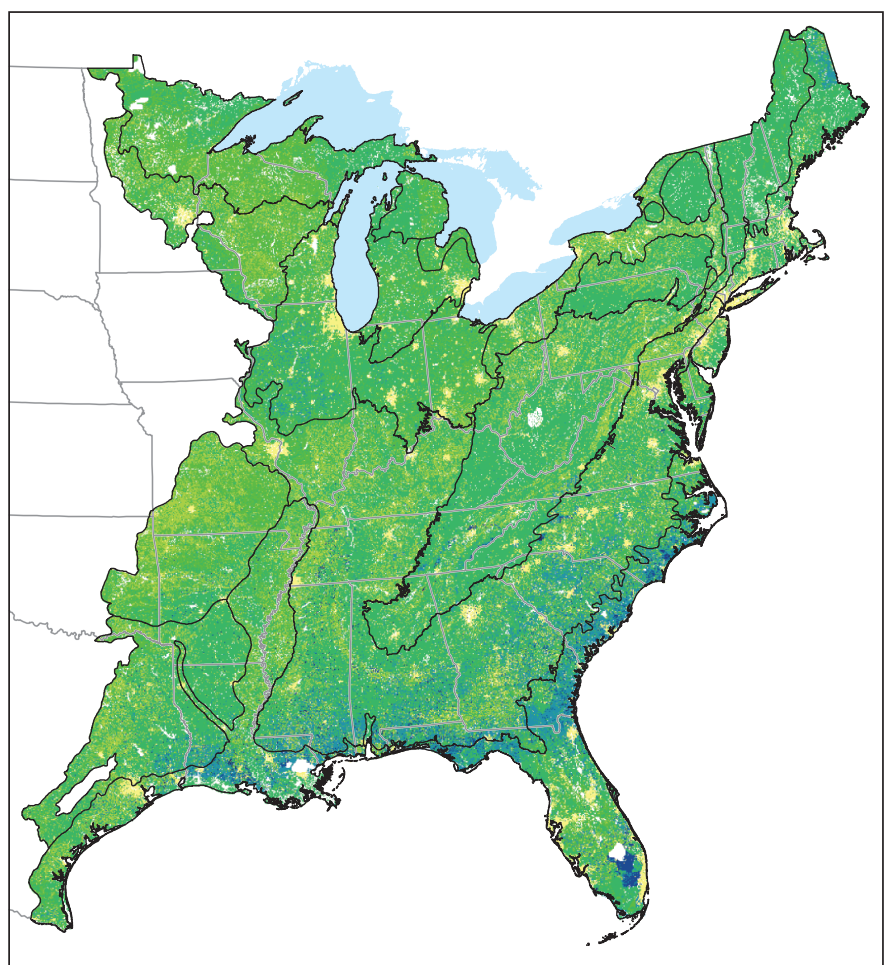

\section{GEMS-EDCM MIROC A1B NPP}

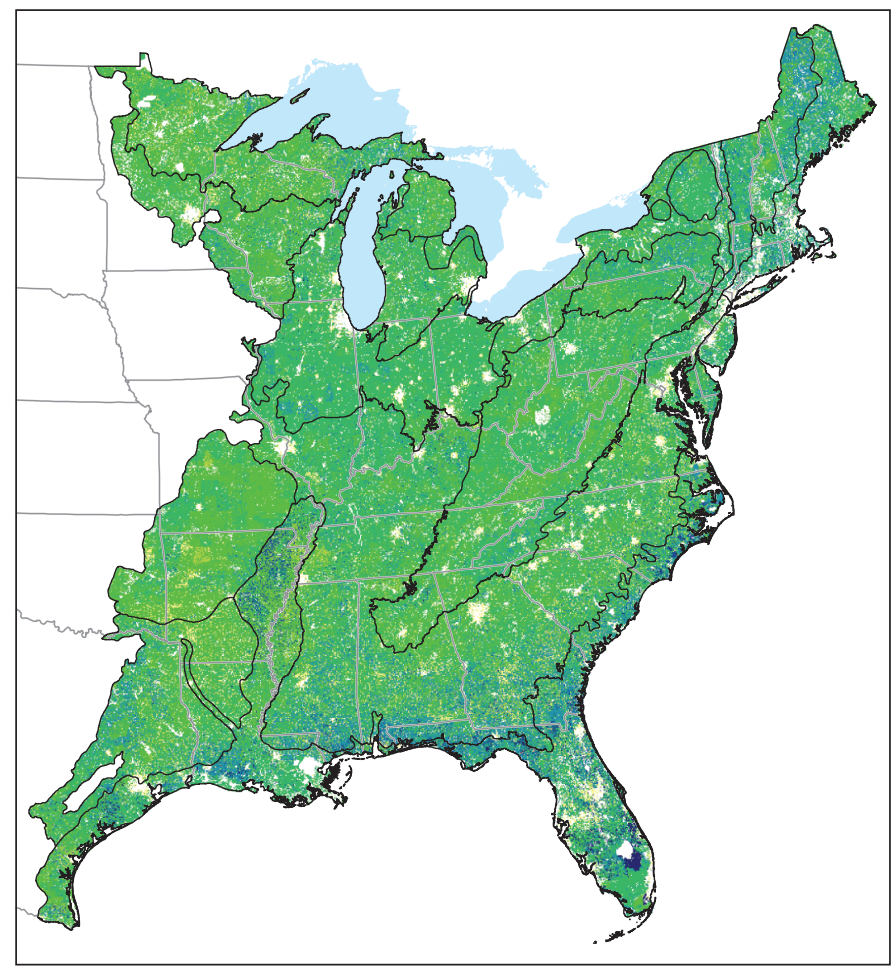

\section{EXPLANATION}

Net primary production, in kilograms of carbon per square meter

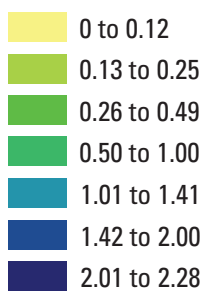

Level II ecoregion boundary

Figure 7-4. Maps showing a comparison of net primary production (NPP) in the Eastern United States for 2006 estimated by $A$, the moderate resolution imaging spectroradiometer (MODIS), $B$, the Century model run in conjunction with a General Ensemble Biogeochemical Modeling System (GEMS) model under Intergovernmental Panel on Climate Change Special Report on Emissions Scenarios (SRES; Nakićenović and others, 2000) scenario A1B using the Model for Interdisciplinary Research on Climate version 3.2 medium resolution (MIROC 3.2-medres) general circulation model (GCM), and C, the Erosion Deposition Carbon Model (EDCM) in conjunction with GEMS run under SRES scenario A1B using the MIROC 3.2-medres GCM. Level II ecoregions are shown in figure 1-1. 
report) in accordance with scenario A1B, A2, or B1 from the SRES (Nakićenović and others, 2000).

- Three GCM (MIROC 3.2-medres, CSIRO Mk3.0, and CCCma CGCM3.1; table 7-1) climate change projections associated with each LULC scenario were processed. Each of the GCMs corresponded to one of the SRES scenarios.

The models were run for the same land base from 1992 through 2050, with 1992 through 2000 used as model spin-up, 2001 through 2005 as the baseline period, and 2006 through 2050 as the scenario or projection period. Although a longer spin-up time window would be desirable (for example, thousands of years could be used to reach a quasisteady state of SOC under natural conditions (Liu and others, 2003)), the process would also require corresponding historical LULC data, which were not available for this analysis.

A total of 21 model runs were performed based on the combinations of models, LULC scenarios, and GCM projections. It was not 27 model runs (that is, three models for each of the three LULC scenarios for each of the three GCMs) because the LGAT is not designed to simulate the effects of climate change and therefore only had three runs (one for each of the three LULC scenarios). It should be noted that only three unique model simulations, generated by the three models with no variation in LULC and climate, existed from 1992 through 2006 because there were no alternative scenarios for climate and LULC data during the historical period. All three models produce all the individual carbon pools. For this assessment, $\mathrm{CH}_{4}$ and $\mathrm{N}_{2} \mathrm{O}$ were simulated only by the LGAT due to extreme challenges in simulating hydrological conditions, a critical controlling factor for $\mathrm{N}_{2} \mathrm{O}$ and $\mathrm{CH}_{4}$, in many wetlands over large areas using the process-based models Century and EDCM. The emission factors of $\mathrm{N}_{2} \mathrm{O}$ and $\mathrm{CH}_{4}$ compiled from literature are provided in appendix 7 .

\subsubsection{Definitions, Output, and Analysis}

\subsubsection{Definitions of Carbon Stocks and Fluxes and Uncertainty}

The key concepts and terminology of carbon stocks and fluxes used in this chapter, including net carbon flux, NPP, NEP, and NECB, consistent with previous reports for the Great Plains (Zhu and others, 2011) and Western (Zhu and Reed, 2012) regions of the United States, are defined in chapter 1 of this report and follow conventions used in the published literature (Chapin and others, 2006).

Three measures of uncertainty, where appropriate, were used in this chapter - standard deviation, range, and relative uncertainty. Uncertainty, meaning "doubt about the validity of a measurement", can be measured by a "parameter, associated with the result of a measurement, that characterizes the dispersion of the values that could reasonably be attributed to the measurand" (International Organization for Standardization, 1995). An example of the parameter is the standard deviation, which is referred as the "standard uncertainty." Ranges of values can be used as a measure of the dispersion or variation.

A "variability index" (V), a measure of relative uncertainty, was defined for this report and calculated to represent the relative dispersion of responses of carbon stock or flux to different models, LULC, or GCMs:

$$
\mathrm{V}=\left(\mathrm{C}_{\max }-\mathrm{C}_{\min }\right) / \mathrm{C}_{\text {mean }},
$$

where

$$
\begin{aligned}
& \mathrm{C}_{\max } \quad \text { is the maximum carbon stock or flux among } \\
& \text { all models, LULC scenarios, or GNMs; } \\
& \mathrm{C}_{\min } \quad \text { is the minimum carbon stock or flux among } \\
& \text { all models, LULC scenarios, or GNMs; } \\
& \text { and } \\
& \mathrm{C}_{\text {mean }} \quad \text { is the average carbon stock or flux among } \\
& \text { all models, LULC scenarios, or GNMs. }
\end{aligned}
$$

The variability index is similar to the relative sensitivity as both quantify the response of model result to the changing conditions. The larger the variability index, the more sensitive the GEMS to that variable and the greater the contribution of that variable to the overall uncertainty of GEMS results.

\subsubsection{Output and Further Processing}

For this assessment, all the carbon stocks reported were the carbon storage at the end of each year, and $\mathrm{CH}_{4}$ and $\mathrm{N}_{2} \mathrm{O}$ fluxes were the annual total fluxes. Annual maps of the following variables were generated from each model run:

- the total live biomass carbon (forest total carbon, FRSTC), including both aboveground and belowground

- SOC in the top 20-cm layer

- other components, including those that were not counted in the live biomass and SOC, such as coarse woody debris, litter, and understory

- $\mathrm{CH}_{4}$ and $\mathrm{N}_{2} \mathrm{O}$ only from the LGAT

- carbon removal from fields by timber and grain harvest or land cover conversion

The amounts of carbon removed from ecosystems by timber and grain production were tracked in GEMS. However, the fate of the offsite carbon in timber and grain products was not tracked. Therefore, the offsite contribution of the harvests was not included in this assessment. Fire emissions were tracked by GEMS according to the extent and severity data layers generated in chapter 4 . When a land was converted from type A to type $\mathrm{B}$, for example, the emissions of carbon were added to cover type B, consistent to IPCC good practice guidance (Watson and others, 2000). The following variables were calculated, when appropriate, based on the model output variables listed above:

- The minimum, maximum, standard deviation, and average of carbon stocks and fluxes in FRSTC, SOC, other pools, and all system carbon pools (the sum of the first three carbon stocks), as simulated by the 3 (baseline period) and 21 (projection period) model 
simulations, were summarized by ecoregion and ecosystem type.

- The annual carbon stock change in a given year $(t$; in other words, the net carbon flux and the NECB at ecosystem level) was calculated as the stock difference between year $t$ and the previous year $(t-1)$ as $\mathrm{C}_{t-1}-\mathrm{C}_{\mathrm{t}}$.

- The average NECB during the baseline period was calculated as the difference of total system carbon stock between 2001 and 2005 divided by the duration, which is 5 years $)$, as follows: $\mathrm{NECB}=\left(\mathrm{C}_{2001}-\mathrm{C}_{2005}\right) / 5$, where $\mathrm{C}_{2001}$ and $\mathrm{C}_{2005}$ represent the carbon storage at the beginning of 2001 and the end of 2005, respectively.

- Similarly, the average NECB during the projection period was calculated as the difference of total system carbon stock between 2006 and 2050 divided by the duration, which is 45 years, as follows: $\mathrm{NECB}=\left(\mathrm{C}_{2006}-\mathrm{C}_{2050}\right) / 45$, where $\mathrm{C}_{2006}$ and $\mathrm{C}_{2050}$ represent the carbon storage at the beginning of 2006 and the end of 2050, respectively.

Based on these calculations, negative NECB would indicate carbon sequestration in terrestrial ecosystems, and this notion is consistent with previous reports of the national assessment (Zhu and others, 2011; Zhu and Reed, 2012).

Global warming potentials (GWP) of $\mathrm{CH}_{4}$ and $\mathrm{N}_{2} \mathrm{O}$ fluxes in $\mathrm{CO}_{2}$-eq were calculated using 21 as a factor for $\mathrm{CH}_{4}$ and 310 as a factor for $\mathrm{N}_{2} \mathrm{O}$ (U.S. Environmental Protection Agency, 2012). $\mathrm{CO}_{2}$ flux was calculated from the NECB using a molecular factor of 3.667 to convert carbon to $\mathrm{CO}_{2}$. The total annual GWP of GHG fluxes was calculated as the sum of the GWP of $\mathrm{CO}_{2}, \mathrm{CH}_{4}$, and $\mathrm{N}_{2} \mathrm{O}$.

\subsubsection{Analysis}

The outcome of assessing carbon sequestration and GHG emissions is often influenced by diverse factors, including models, land use, disturbances, and climate. Many aspects of the carbon dynamics and GHG fluxes quantified in this assessment can be analyzed at a range of spatial and temporal scales. In this report, the focuses of our analysis are the following:

- Present and analyze the minimum, maximum, and average of the carbon stocks and GHG fluxes, estimated by ensemble modeling, during the baseline and projection periods for all ecosystems in each ecoregion of the Eastern United States. This helps answer the following questions:

- What are the spatial patterns of carbon storage and GHG fluxes in the Eastern United States?

- How much carbon could be sequestered in vegetation and soils by ecosystem and ecoregion?

- How will carbon sequestration strengths of different ecosystems change over time (that is, between the baseline and the projection period)?

- What are the uncertainties of the estimates?
- Examine and compare the projected average carbon stocks in 2050, projected average annual NECB from 2006 through 2050, and the variability index by model, LULC scenario, and GCM for each ecoregion and for the entire Eastern United States. This helps answer the following questions:

- What are the differences in the estimated carbon sequestration potentials across ecoregions and within the Eastern United States?

- What are the results of using different models, LULC scenarios, and GCMs on the estimated carbon sequestration?

-What is the major contributor among models, LULC, and GCMs to the uncertainty in the estimated carbon sequestration in various ecoregions and the entire Eastern United States?

- Examine the effects of major land use activities and disturbances (fire (chap. 4 of this report) and forest harvesting activities, including clearcutting and partial cutting) on carbon dynamics.

- Perform an integrated analysis of carbon stocks and fluxes for the baseline period by synthesizing results from fire emissions and aquatic systems. Similar integration could not be done for the projection period owing to the lack of data for aquatic systems.

- Identify major limitations of this assessment and future directions for carbon cycle research, assessment, and monitoring in the region.

\subsection{Results}

\subsubsection{Baseline Ecosystem Carbon Stocks}

Maps of estimated annual carbon stocks by the terrestrial ecosystems and ecoregions from 2001 through 2005 were produced using the three models. The magnitude and spatial pattern of the carbon stock estimated from 2001 through 2005 remained relatively stable; for this reason, the estimates for 2005 (the last year of the baseline period) are presented in this report. The map in figure 7-5 shows the spatial distribution and uncertainty estimates of total ecosystem carbon stock (carbon in live and dead biomass plus SOC in the top $20-\mathrm{cm}$ soil layer) in the Eastern United States in 2005. The high carbon storage locations are shown mostly in the northern States where soil carbon content was high (carbon in $20-\mathrm{cm}$ soil layer more than $5 \mathrm{kgC} / \mathrm{m}^{2}$ ) and along the Atlantic Ocean and Gulf of Mexico coastal regions where wetlands were dominant. The Blue Ridge hydrographic province also had high carbon storage because of high forest biomass. The uncertainty map, which shows the standard deviation, shows that high carbon storage regions usually had higher model uncertainty. 
Table 7-4 lists the range (minimum to maximum) and the average of the estimated amounts of carbon stored as estimated by the three models (LGAT, Century, and EDCM) for 2005, the last year of the baseline conditions. The total estimated carbon storage averaged 26,961.8 $\mathrm{TgC}$ (ranged from 25,068.8 to 28,497 $\mathrm{TgC}$ across the three models) for the Eastern United States. Among all the ecoregions within the Eastern United States, the Southeastern USA Plains ecoregion stored the most carbon with more than 7,794.2 $\mathrm{TgC}$ (29 percent), followed by the Ozark, Ouachita-Appalachian Forests (18 percent), Mississippi Alluvial and Southeast USA Coastal Plains (15 percent), Mixed Wood Plains (13 percent), Atlantic Highlands (10 percent), Mixed Wood Shield (10 percent), and Central USA Plains (6 percent) ecoregions. SOC in the top 20-cm soil, live biomass, and other carbon pool (such as litter and woody debris) accounted for 43 percent, 42 percent, and 15 percent of the total carbon storage in the Eastern United States, respectively. Breaking down different ecosystems, forests, agricultural lands, wetland, grassland/

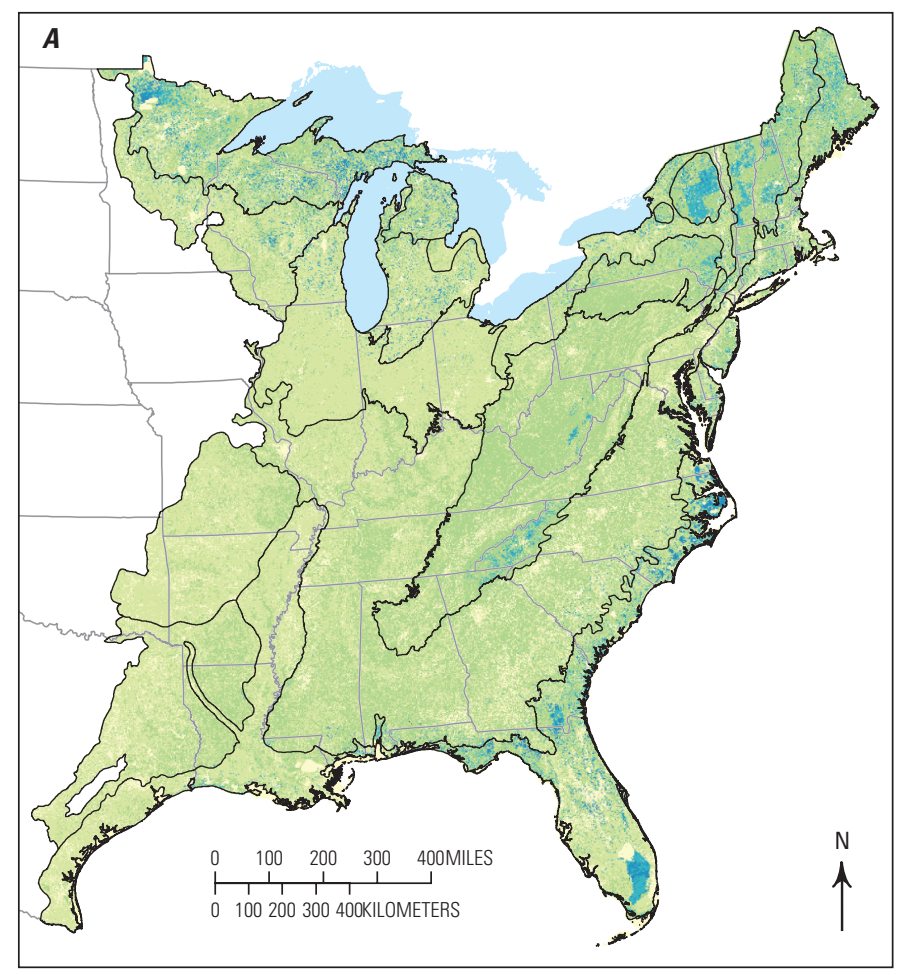

EXPLANATION

Average carbon storage in 2005, in kilograms of carbon per square meter

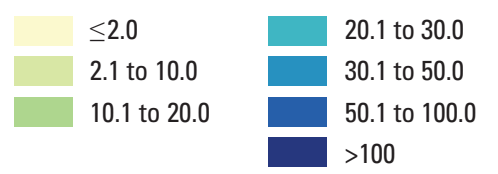

— Level II ecoregion boundary shrubland, and other lands stored 68 percent, 15 percent, 15 percent, 1 percent, and 1 percent of the total carbon, respectively. Among different ecosystems, forest was the dominant carbon storage location for the Mixed Wood Shield, Atlantic Highlands, Mixed Wood Plains, Southeastern USA Plains, and Ozark, Ouachita-Appalachian Forests ecoregions. Carbon storage in the Central USA Plains ecoregion was predominantly in agricultural lands, whereas carbon storage in the Mississippi Alluvial and Southeast USA Coastal Plains ecoregion was predominantly in wetlands.

Carbon density (that is, carbon storage per unit area) for a specific ecosystem varied substantially between ecoregions. The Atlantic Highlands ecoregion had the highest carbon storage density $\left(15 \mathrm{kgC} / \mathrm{m}^{2}\right)$, followed by the Mixed Wood Shield (12 $\left.\mathrm{kgC} / \mathrm{m}^{2}\right)$, Ozark, Ouachita-Appalachian Forests $\left(9.2 \mathrm{kgC} / \mathrm{m}^{2}\right)$, Mixed Wood Plains $\left(9.1 \mathrm{kgC} / \mathrm{m}^{2}\right)$, Southeastern USA Plains (7.8 $\left.\mathrm{kgC} / \mathrm{m}^{2}\right)$, Mississippi Alluvial and Southeast USA Coastal Plains $\left(7.7 \mathrm{kgC} / \mathrm{m}^{2}\right)$, and Central USA Plains $\left(6.3 \mathrm{kgC} / \mathrm{m}^{2}\right)$ ecoregions.

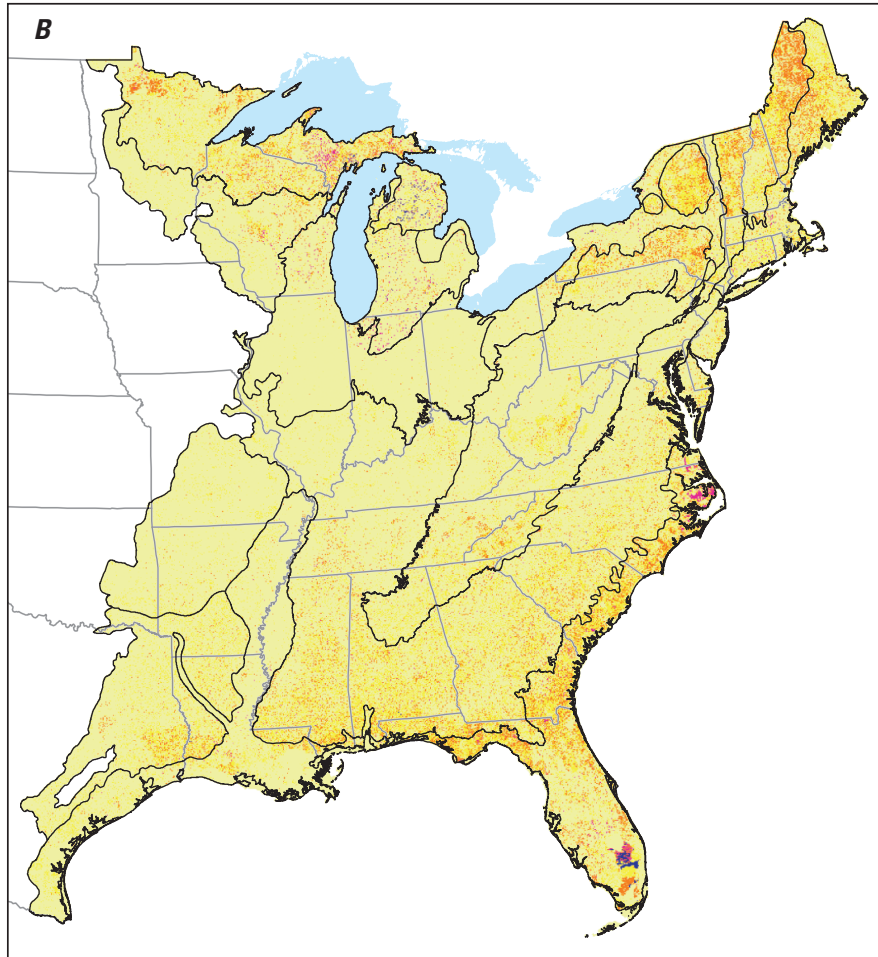

EXPLANATION

Standard deviation of the mean carbon storage for 2005, in kilograms of carbon per square meter

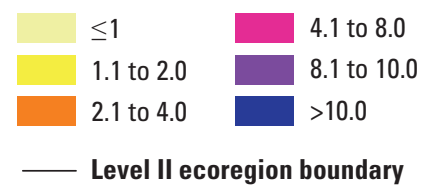

Figure 7-5. Maps showing the $A$, average amount and $B$, standard deviation from the average amount of carbon stored in the Eastern United States in 2005. The estimated average amount of carbon stored in 2005 was derived by averaging the results from three General Ensemble Modeling System (GEMS) models (Land GHG Accounting Tool, Century, and Erosion Deposition Carbon Model). Level II ecoregions are shown in figure 1-1. 
For forest, the highest carbon density was in the Atlantic Highlands ecoregion $\left(16.8 \mathrm{kgC} / \mathrm{m}^{2}\right)$ and the lowest carbon density was in the Southeast USA Coastal Plains ecoregion $(11 \mathrm{kgC} /$ $\mathrm{m}^{2}$ ). For grassland/shrubland, the highest carbon density was in the Atlantic Highlands ecoregion $\left(8.2 \mathrm{kgC} / \mathrm{m}^{2}\right)$ and the lowest carbon density was in the Ozark, Ouachita-Appalachian Forests ecoregion $\left(3.9 \mathrm{kgC} / \mathrm{m}^{2}\right)$. For agricultural lands, the Central USA Plains ecoregion had the highest carbon density $\left(5.7 \mathrm{kgC} / \mathrm{m}^{2}\right)$, whereas the Ozark, Ouachita-Appalachian Forests ecoregion had the lowest carbon density $\left(3 \mathrm{kgC} / \mathrm{m}^{2}\right)$. For wetlands, the Atlantic Highlands ecoregion had the highest carbon density $\left(19.2 \mathrm{kgC} / \mathrm{m}^{2}\right)$, whereas the Ozark, Ouachita-Appalachian Forests ecoregion had the lowest carbon density $\left(9.4 \mathrm{kgC} / \mathrm{m}^{2}\right)$.

\subsubsection{Mixed Wood Shield}

In this northern ecoregion of the Eastern United States, the total carbon storage in 2005 was $2,596 \mathrm{TgC}$, ranging between 2,470 and 2,745 $\mathrm{TgC}$ across the three models, of which 32 percent was in live biomass, 53 percent was in soil, and 15 percent was in ground litter and dead woody biomass. Among the different ecosystems, forest occupied 51 percent of the total land area and held 52 percent of the total carbon stock $(1,360 \mathrm{TgC})$. Grassland/shrubland occupied 2 percent of the land area and took 1 percent of the carbon storage $(26 \mathrm{TgC})$. Agricultural land area occupied 10 percent of land area with 4 percent of the total carbon storage $(105 \mathrm{TgC})$. The wetland system occupied 27 percent of land area, but accounted for 42 percent of the total carbon storage $(1,100 \mathrm{TgC})$. Carbon densities were $19.2 \mathrm{kgC} / \mathrm{m}^{2}, 12.3 \mathrm{kgC} / \mathrm{m}^{2}, 6.7 \mathrm{kgC} / \mathrm{m}^{2}$, $5 \mathrm{kgC} / \mathrm{m}^{2}$, and for wetland, forest, grassland/shrubland, and agricultural land, respectively.

\subsubsection{Atlantic Highlands}

The total carbon storage of this ecoregion in 2005 was $2,808 \mathrm{TgC}$, ranging between 2,619 and 3,008 $\mathrm{TgC}$ across models, of which 45 percent was in live biomass, 37 percent was in soil, and 17 percent was in ground litter and dead woody biomass. Forest had the major portion of carbon stock (2,608 TgC, 93 percent of the total), followed by agricultural land $(95 \mathrm{TgC}, 3$ percent of the total) and wetland ( $92 \mathrm{TgC}, 3$ percent of the total). The grassland/shrubland only had $2.5 \mathrm{TgC}(0.1$ percent of the total). This ecoregion had the highest forestland area percentage ( 83 percent) in the eastern ecoregions. The forest carbon density was also the highest $\left(16.9 \mathrm{kgC} / \mathrm{m}^{2}\right)$. The carbon densities of wetland, grassland/shrubland, and agricultural land were $17.9 \mathrm{kgC} / \mathrm{m}^{2}$, $8.2 \mathrm{kgC} / \mathrm{m}^{2}$, and $5.2 \mathrm{kgC} / \mathrm{m}^{2}$, respectively.

\subsubsection{Mixed Wood Plains}

This northern ecoregion was dominated by wetland and forest ecosystems, which accounted for 41 and 38 percent, respectively, of total land area. The total carbon storage in this ecoregion in 2005 was $3,550 \mathrm{TgC}$, ranging from 3,369 and $3,786 \mathrm{TgC}$ across all models, of which 55 percent was in soil, 32 percent was in live biomass, and 13 percent was in ground litter and dead woody biomass. Forest had the major portion of carbon storage $(2,234 \mathrm{TgC}, 63$ percent of the total), followed by agricultural land $(883 \mathrm{TgC}$, 25 percent of the total) and wetland $(345 \mathrm{TgC}, 10$ percent of the total). Grassland/shrubland occupied 0.6 percent of the total land area and accounted for only 0.4 percent $(14 \mathrm{TgC})$ of total carbon storage. Carbon densities were $15.1 \mathrm{kgC} / \mathrm{m}^{2}$, $14.3 \mathrm{kgC} / \mathrm{m}^{2}, 6.1 \mathrm{kgC} / \mathrm{m}^{2}$, and $5.5 \mathrm{kgC} / \mathrm{m}^{2}$ for forest, wetland, grassland/shrubland, and agricultural land, respectively.

\subsubsection{Central USA Plains}

As a primarily agricultural region, the Central USA Plains mainly consisted of agricultural and pasture lands. Together, they accounted for 78 percent of the total land area. Forest, wetland, and grassland/shrubland covered 10 percent, 2 percent, and 0.5 percent, respectively, of total land area. The total carbon storage of this ecoregion in 2005 was $1,500 \mathrm{TgC}$, ranging from 1,442 to $1,565 \mathrm{TgC}$ across models, of which 74 percent was in soil, 17 percent was in live biomass, and 9 percent was in ground litter and dead woody biomass. Crop land had the greatest portion of carbon stock $(1,057 \mathrm{TgC}$, 70 percent of the total), followed by forest $(320 \mathrm{TgC}$, 21 percent of the total), wetland $(68 \mathrm{TgC}, 5$ percent of the total) and grassland/shrubland ( $8 \mathrm{TgC}, 1$ percent of the total). Carbon densities were $14.6 \mathrm{kgC} / \mathrm{m}^{2}, 13.5 \mathrm{kgC} / \mathrm{m}^{2}, 6.6 \mathrm{kgC} / \mathrm{m}^{2}$, and $5.7 \mathrm{kgC} / \mathrm{m}^{2}$ for wetland, forest, grassland/shrubland, and agricultural land, respectively.

\subsubsection{Southeastern USA Plains}

This is the largest ecoregion in the Eastern United States with significant forest and agricultural lands, covering 55 and 31 percent, respectively, of total land area. Wetland covered 6 percent of the total land area, and grassland/ shrubland covered only 1 percent of the total land area. The total carbon storage of this ecoregion in 2005 was $7,794 \mathrm{TgC}$, ranging from 7,065 to $8,266 \mathrm{TgC}$ across the three models, of which 51 percent was in live biomass, 33 percent was in soil, and 16 percent was in ground litter and dead woody biomass. Forest land had the greatest portion of carbon stock $(6,052 \mathrm{TgC}, 78$ percent of the total), followed by cropland (895 TgC, 11 percent of the total), wetland $(732 \mathrm{TgC}$, 9 percent of the total), and grassland/shrubland $(48 \mathrm{TgC}$, 1 percent of the total). Carbon densities were $12.1 \mathrm{kgC} / \mathrm{m}^{2}$, $11 \mathrm{kgC} / \mathrm{m}^{2}, 4.3 \mathrm{kgC} / \mathrm{m}^{2}, 3 \mathrm{kgC} / \mathrm{m}^{2}$ for wetland, forest, grassland/shrubland, and agricultural land, respectively.

\subsubsection{Ozark, Ouachita-Appalachian Forests}

Approximately 72 percent of this ecoregion is forest. The total carbon storage of this ecoregion in 2005 was 
Table 7-4. Carbon stored in the Eastern United States in 2005.

[Carbon storage is by carbon pool for each ecoregion and ecosystem. Only soil organic carbon (SOC) in the top 20 centimeters of the soil layer was calculated. $\mathrm{km}^{2}$, square kilometers; max, maximum; min, minimum; $\mathrm{TgC}$, teragrams (or $10^{12}$ grams) of carbon]

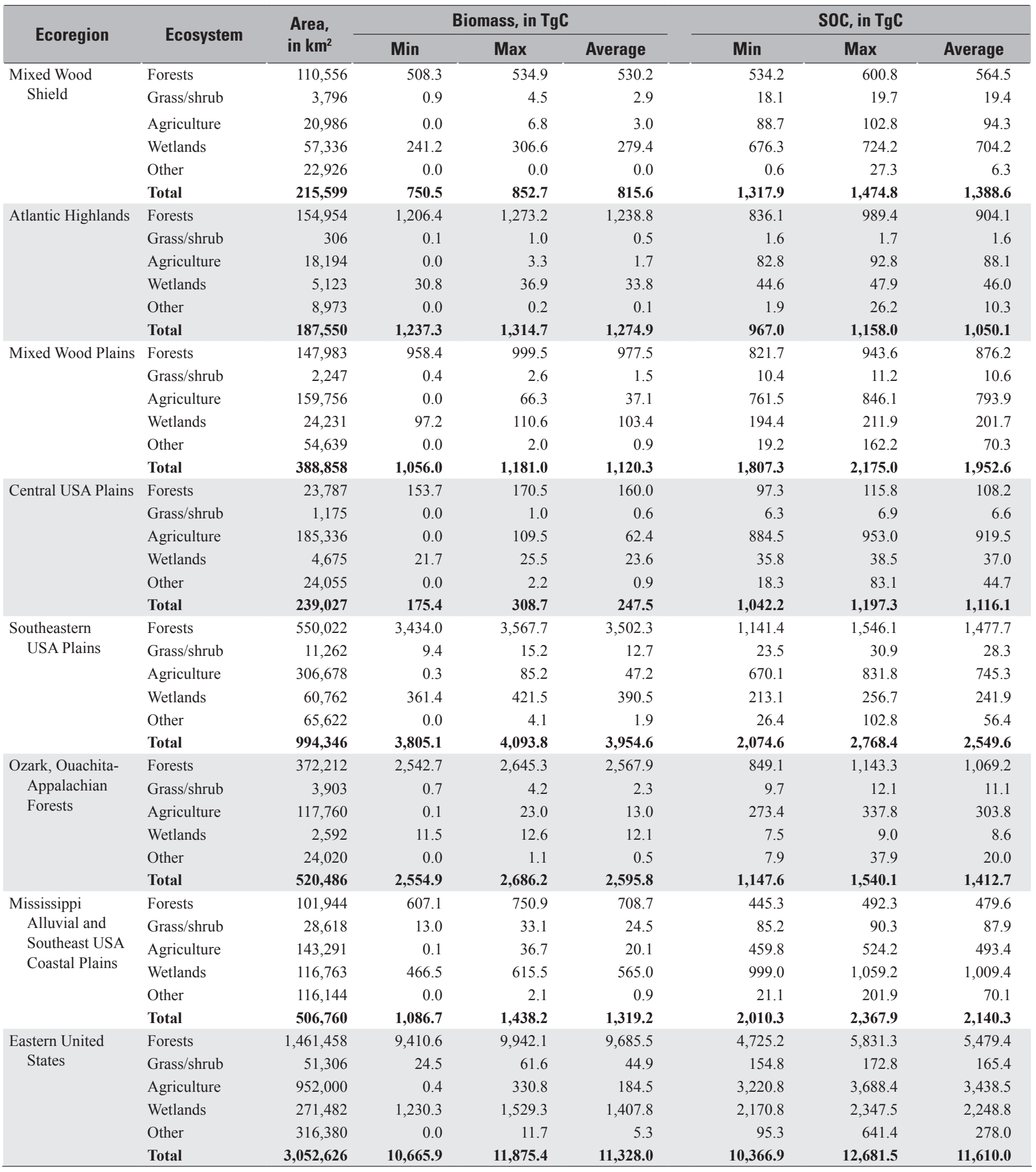


Table 7-4. Carbon stored in the Eastern United States in 2005.-Continued

[Carbon storage is by carbon pool for each ecoregion and ecosystem. Only soil organic carbon (SOC) in the top 20 centimeters of the soil layer was calculated. $\mathrm{km}^{2}$, square kilometers; max, maximum; min, minimum; $\mathrm{TgC}$, teragrams (or $10^{12}$ grams) of carbon]

\begin{tabular}{|c|c|c|c|c|c|c|c|c|}
\hline \multirow{2}{*}{ Ecoregion } & \multirow{2}{*}{ Ecosystem } & \multirow{2}{*}{$\begin{array}{l}\text { Area, } \\
\text { in } \mathrm{km}^{2}\end{array}$} & \multicolumn{3}{|c|}{ Others, in $\mathrm{TgC}$} & \multicolumn{3}{|c|}{ Total, in $\mathrm{TgC}$} \\
\hline & & & Min & Max & Average & Min & Max & Average \\
\hline \multirow{6}{*}{ Mixed Wood Shield } & Forests & 110,556 & 232.1 & 295.2 & 265.6 & $1,299.7$ & $1,424.3$ & $1,360.3$ \\
\hline & Grass/shrub & 3,796 & 0.0 & 4.9 & 3.2 & 22.5 & 28.9 & 25.5 \\
\hline & Agriculture & 20,986 & 0.0 & 12.4 & 7.3 & 98.4 & 109.6 & 104.7 \\
\hline & Wetlands & 57,336 & 107.4 & 123.9 & 116.0 & $1,048.9$ & $1,154.6$ & $1,099.6$ \\
\hline & Other & 22,926 & 0.0 & 0.2 & 0.1 & 0.8 & 27.3 & 6.4 \\
\hline & Total & 215,599 & 339.5 & 436.6 & 392.2 & $2,470.3$ & $2,744.5$ & $2,596.4$ \\
\hline \multirow[t]{6}{*}{ Atlantic Highlands } & Forests & 154,954 & 390.9 & 531.4 & 464.8 & $2,437.5$ & $2,779.3$ & $2,607.7$ \\
\hline & Grass/shrub & 306 & 0.0 & 0.7 & 0.4 & 1.8 & 3.0 & 2.5 \\
\hline & Agriculture & 18,194 & 0.0 & 9.3 & 5.1 & 89.0 & 102.1 & 94.9 \\
\hline & Wetlands & 5,123 & 11.1 & 13.2 & 12.2 & 87.4 & 97.7 & 91.9 \\
\hline & Other & 8,973 & 0.0 & 1.3 & 0.8 & 3.2 & 26.2 & 11.2 \\
\hline & Total & 187,550 & 402.0 & 555.9 & 483.2 & $2,619.0$ & $3,008.2$ & $2,808.2$ \\
\hline \multirow[t]{6}{*}{ Mixed Wood Plains } & Forests & 147,983 & 347.4 & 416.7 & 380.6 & $2,127.8$ & $2,344.7$ & $2,234.3$ \\
\hline & Grass/shrub & 2,247 & 0.0 & 2.4 & 1.5 & 12.0 & 15.1 & 13.6 \\
\hline & Agriculture & 159,756 & 0.0 & 75.2 & 51.6 & 873.6 & 907.7 & 882.6 \\
\hline & Wetlands & 24,231 & 39.1 & 40.3 & 40.1 & 332.0 & 356.2 & 345.2 \\
\hline & Other & 54,639 & 0.0 & 4.5 & 2.8 & 23.8 & 162.2 & 74.0 \\
\hline & Total & 388,858 & 386.6 & 539.1 & 476.6 & $3,369.1$ & $3,785.9$ & $3,549.6$ \\
\hline \multirow[t]{6}{*}{ Central USA Plains } & Forests & 23,787 & 50.1 & 52.7 & 51.8 & 310.3 & 330.2 & 319.9 \\
\hline & Grass/shrub & 1,175 & 0.0 & 0.9 & 0.6 & 6.9 & 8.8 & 7.8 \\
\hline & Agriculture & 185,336 & 0.0 & 97.6 & 75.1 & $1,039.7$ & $1,072.4$ & $1,057.0$ \\
\hline & Wetlands & 4,675 & 7.4 & 8.2 & 7.7 & 65.7 & 70.8 & 68.4 \\
\hline & Other & 24,055 & 0.0 & 1.0 & 0.7 & 19.3 & 83.1 & 46.4 \\
\hline & Total & 239,027 & 57.5 & 160.5 & 135.9 & $1,441.9$ & $1,565.3$ & $1,499.5$ \\
\hline \multirow{6}{*}{$\begin{array}{l}\text { Southeastern } \\
\text { USA Plains }\end{array}$} & Forests & 550,022 & 880.3 & $1,228.9$ & $1,072.0$ & $5,525.4$ & $6,338.1$ & $6,052.0$ \\
\hline & Grass/shrub & 11,262 & 0.0 & 12.7 & 7.3 & 38.4 & 58.9 & 48.2 \\
\hline & Agriculture & 306,678 & 0.0 & 180.2 & 102.7 & 805.8 & $1,012.3$ & 895.3 \\
\hline & Wetlands & 60,762 & 80.9 & 124.8 & 99.9 & 655.4 & 753.7 & 732.4 \\
\hline & Other & 65,622 & 0.0 & 13.0 & 8.1 & 39.7 & 102.8 & 66.3 \\
\hline & Total & 994,346 & 961.2 & $1,559.7$ & $1,290.0$ & $7,064.7$ & $8,265.8$ & $7,794.2$ \\
\hline \multirow{6}{*}{$\begin{array}{l}\text { Ozark, Ouachita- } \\
\text { Appalachian } \\
\text { Forests }\end{array}$} & Forests & 372,212 & 720.8 & 769.2 & 744.3 & $4,215.2$ & $4,417.0$ & $4,381.4$ \\
\hline & Grass/shrub & 3,903 & 0.0 & 2.7 & 1.7 & 12.5 & 18.1 & 15.1 \\
\hline & Agriculture & 117,760 & 0.0 & 56.8 & 30.6 & 311.3 & 394.6 & 347.4 \\
\hline & Wetlands & 2,592 & 3.3 & 4.1 & 3.6 & 23.2 & 24.6 & 24.3 \\
\hline & Other & 24,020 & 0.0 & 3.8 & 2.3 & 11.8 & 37.9 & 22.8 \\
\hline & Total & 520,486 & 724.1 & 836.7 & 782.5 & $4,574.0$ & $4,892.2$ & 4,791.0 \\
\hline \multirow{6}{*}{$\begin{array}{l}\text { Mississippi Alluvial } \\
\text { and Southeast } \\
\text { USA Coastal } \\
\text { Plains }\end{array}$} & Forests & 101,944 & 172.6 & 269.0 & 230.2 & $1,225.1$ & $1,497.6$ & $1,418.6$ \\
\hline & Grass/shrub & 28,618 & 0.0 & 24.0 & 14.1 & 108.0 & 147.4 & 126.4 \\
\hline & Agriculture & 143,291 & 0.0 & 120.5 & 70.4 & 537.6 & 644.6 & 583.8 \\
\hline & Wetlands & 116,763 & 107.2 & 179.0 & 145.6 & $1,633.0$ & $1,743.6$ & $1,720.0$ \\
\hline & Other & 116,144 & 0.0 & 4.9 & 3.0 & 26.1 & 201.9 & 74.0 \\
\hline & Total & 506,760 & 279.9 & 597.4 & 463.3 & $3,529.8$ & $4,235.1$ & $3,922.8$ \\
\hline \multirow{6}{*}{$\begin{array}{l}\text { Eastern United } \\
\quad \text { States }\end{array}$} & Forests & $1,461,458$ & $2,794.2$ & $3,563.1$ & $3,209.4$ & $17,141.1$ & $19,131.1$ & $18,374.2$ \\
\hline & Grass/shrub & 51,306 & 0.0 & 48.4 & 28.7 & 202.1 & 280.2 & 239.0 \\
\hline & Agriculture & 952,000 & 0.0 & 552.1 & 342.8 & $3,755.3$ & $4,243.2$ & $3,965.7$ \\
\hline & Wetlands & 271,482 & 356.4 & 493.4 & 425.2 & $3,845.5$ & $4,201.0$ & $4,081.8$ \\
\hline & Other & 316,380 & 0.0 & 28.8 & 17.8 & 124.8 & 641.4 & 301.1 \\
\hline & Total & $3,052,626$ & $3,150.7$ & $4,685.8$ & $4,023.8$ & $25,068.8$ & $28,497.0$ & $26,961.8$ \\
\hline
\end{tabular}


$4,791 \mathrm{TgC}$, ranging from 4,574 to $4,892 \mathrm{TgC}$ across models, of which 54 percent was in live biomass, 29 percent was in soil, and 16 percent was in ground litter and dead woody biomass. Forest land had the greatest portion of carbon stock $(4,381 \mathrm{TgC}, 91$ percent of the total), followed by cropland ( $347 \mathrm{TgC}, 7$ percent of the total), wetland $(24 \mathrm{TgC}, 1$ percent of the total) and grassland/shrubland $(15 \mathrm{TgC}, 0.3$ percent of the total). Carbon densities were $11.8 \mathrm{kgC} / \mathrm{m}^{2}, 9.4 \mathrm{kgC} / \mathrm{m}^{2}$, $3.9 \mathrm{kgC} / \mathrm{m}^{2}$, and $3 \mathrm{kgC} / \mathrm{m}^{2}$ for forest, wetland, grassland/ shrubland, and agricultural land, respectively.

\subsubsection{Mississippi Alluvial and Southeast USA Coastal Plains}

In this largest coastal ecoregion in the United States, cropland, wetland, forest, and grassland/shrubland occupied 28 percent, 23 percent, 20 percent, and 6 percent, respectively, of total land area. Other lands mostly have no natural vegetation cover (such as, barren and urban) and encompassed 23 percent of the total land area. The total carbon storage of this ecoregion in 2005 was $3,923 \mathrm{TgC}$, ranging from 3,530 to $4,235 \mathrm{TgC}$ across models, of which 54 percent was in soil, 34 percent was in live biomass, and 12 percent was in ground litter and dead woody biomass. Wetland had the greatest portion of carbon stock $(1,720 \mathrm{TgC}, 44$ percent of the total), followed by forest land $(1,419 \mathrm{TgC}, 36$ percent of the total), cropland (584 $\mathrm{TgC}, 15$ percent of the total) and grassland/shrubland (126 TgC, 3 percent of the total). Carbon densities were $14.7 \mathrm{kgC} / \mathrm{m}^{2}, 13.9 \mathrm{kgC} / \mathrm{m}^{2}, 4.4 \mathrm{kgC} / \mathrm{m}^{2}$, and $4.1 \mathrm{kgC} / \mathrm{m}^{2}$ for forest, wetland, grassland/shrubland, and agricultural land, respectively.

\subsubsection{Baseline Net Ecosystem Carbon Fluxes}

The magnitude and spatial distribution of the average net carbon fluxes across the Eastern United States are shown in figure 7-6, which indicates a strong carbon sink associated with forest areas in the region. The standard deviations were generally positively correlated with carbon gains, as was expected.

Table 7-5 lists the minimum, maximum, and average of the carbon stock change (that is, the NECB) by carbon pool (live biomass, dead biomass, and soil), ecosystem type, and ecoregion in the Eastern United States averaged from 2001 through 2005. The overall NECB ranged from -405.5 to $-112.5 \mathrm{TgC} / \mathrm{yr}$ among the three models, with an average of $-279.4 \mathrm{TgC} / \mathrm{yr}$, of which $-188.7 \mathrm{TgC}$ was attributed to live biomass accumulation, $-65.4 \mathrm{TgC}$ to soil carbon pool, and $-25.2 \mathrm{TgC}$ to dead biomass carbon pool. The forest ecosystem was the largest carbon sink ( 81 percent of the total), followed by wetland (13 percent), agricultural lands (4 percent), and grassland/shrubland (1 percent). On a per-unit area basis, the magnitude of the carbon sink in forests, wetlands, grassland/shrubland, and agricultural lands was $-155 \mathrm{gC} / \mathrm{m}^{2} / \mathrm{yr}$, $-132 \mathrm{gC} / \mathrm{m}^{2} / \mathrm{yr},-41 \mathrm{gC} / \mathrm{m}^{2} / \mathrm{yr}$, and $-12 \mathrm{gC} / \mathrm{m}^{2} / \mathrm{yr}$, respectively. Although all the ecoregions were carbon sinks from 2001 through 2005, certain individual ecosystems in specific ecoregions were not. For example, agricultural lands in the Mixed Wood Shield ecoregion and grassland/shrubland in the Central USA Plains ecoregion were estimated to be carbon neutral, and agricultural lands in the Atlantic Highlands and Mixed Wood Plains ecoregions were estimated to lose carbon at a rate of $0.2 \mathrm{TgC} / \mathrm{yr}$ and $1.5 \mathrm{TgC} / \mathrm{yr}$, respectively.

\subsubsection{Mixed Wood Shield}

The average estimate for net ecosystem carbon flux in this ecoregion was approximately -14.5 teragrams of carbon per year $(\mathrm{TgC} / \mathrm{yr})$, ranging from -18.6 to $-6.3 \mathrm{TgC} / \mathrm{yr}$ across models, of which 76 percent was allocated to live biomass, 13 percent to soil, and 11 percent to ground litter and dead woody biomass. Among the different ecosystems, the forest ecosystem sequestered $-9.7 \mathrm{TgC} / \mathrm{yr}$ (67 percent of the total), wetland $-4.5 \mathrm{TgC} / \mathrm{yr}$ (31 percent), grassland/shrubland $-0.3 \mathrm{TgC} / \mathrm{yr}$ (2 percent of the total), and agricultural land (carbon neutral).

\subsubsection{Atlantic Highlands}

The average estimate for net carbon flux in this overwhelmingly forested ecoregion was $-24.7 \mathrm{TgC} / \mathrm{yr}$, ranging from -28.6 to $-15.0 \mathrm{TgC} / \mathrm{yr}$ across models, of which 81 percent was allocated to live biomass, 18 percent to soil, and 1 percent to ground litter and dead woody biomass. The forest ecosystem sequestered $-24.2 \mathrm{TgC} / \mathrm{yr}$ ( 98 percent of the total), followed by wetland with $-0.6 \mathrm{TgC} / \mathrm{yr}$ ( 2 percent of the total). Agricultural land lost carbon at a small rate of $0.2 \mathrm{Tg} / \mathrm{yr}$.

\subsubsection{Mixed Wood Plains}

The average estimate for net carbon flux in this ecoregion was $-22.4 \mathrm{TgC} / \mathrm{yr}$, ranging from -26.2 to $-12.4 \mathrm{TgC} / \mathrm{yr}$ across the three models, of which 84 percent was allocated to live biomass, 9 percent to ground litter and dead woody biomass, and 7 percent to soil. Forest sequestered $-20.9 \mathrm{TgC} / \mathrm{yr}$ (93 percent of the total), followed by wetland with $-2.1 \mathrm{TgC} / \mathrm{yr}$ (9 percent of the total) and grassland/ shrubland with $-0.1 \mathrm{TgC} / \mathrm{yr}$ ( 0.5 percent of the total). Agricultural land was a carbon source at a rate of $1.5 \mathrm{TgC} / \mathrm{yr}$.

\subsubsection{Central USA Plains}

The ecoregion was dominated by agricultural lands (78 percent of the total land area). The average estimate for net carbon flux was $-5.2 \mathrm{TgC} / \mathrm{yr}$, ranging from -7.4 to $-2.9 \mathrm{TgC} / \mathrm{yr}$ across models, of which 46 percent was allocated to ground litter and dead woody biomass, 44 percent to live biomass, and 10 percent to soil. Forest sequestered $-2.7 \mathrm{TgC} / \mathrm{yr}$ (52 percent of the total), followed by agricultural land $(-1.6 \mathrm{TgC} / \mathrm{yr}$, 31 percent of the total), wetland $(-0.4 \mathrm{TgC} / \mathrm{yr}, 8$ percent of the total), and grassland/shrubland (carbon neutral). 


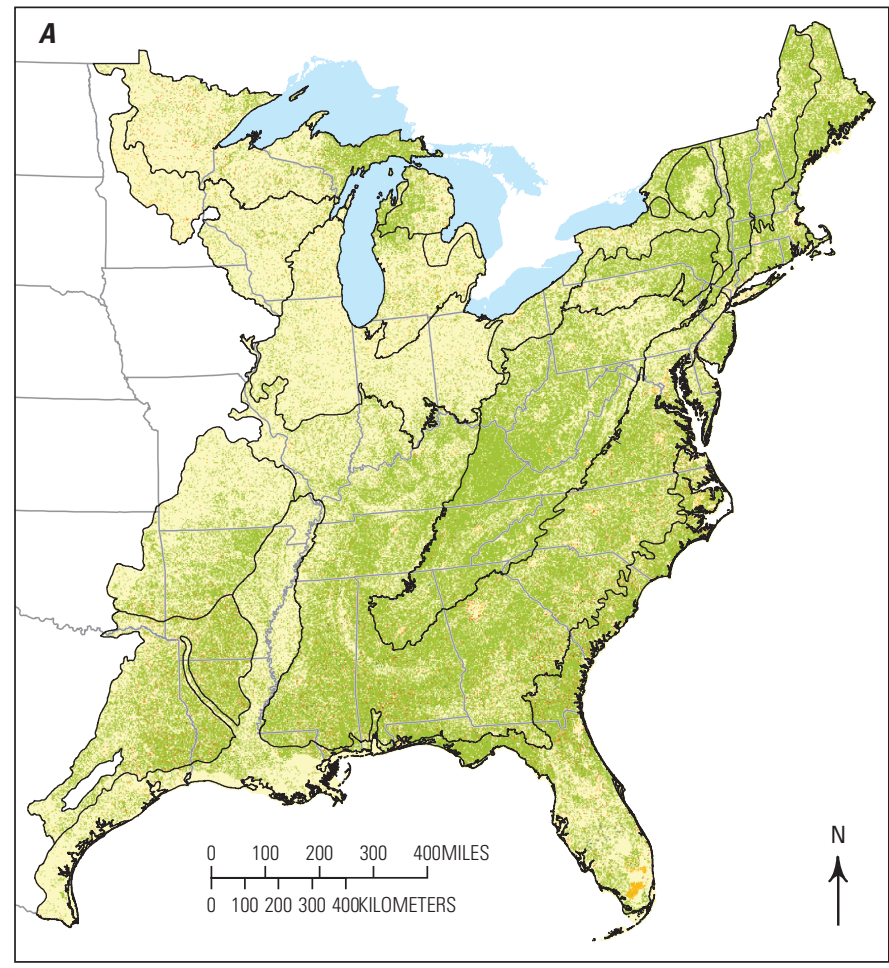

EXPLANATION

Total mean net carbon flux from 2001 to 2005, in kilograms of carbon per square meter per year

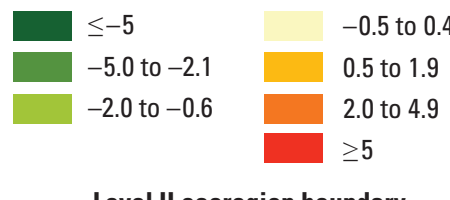

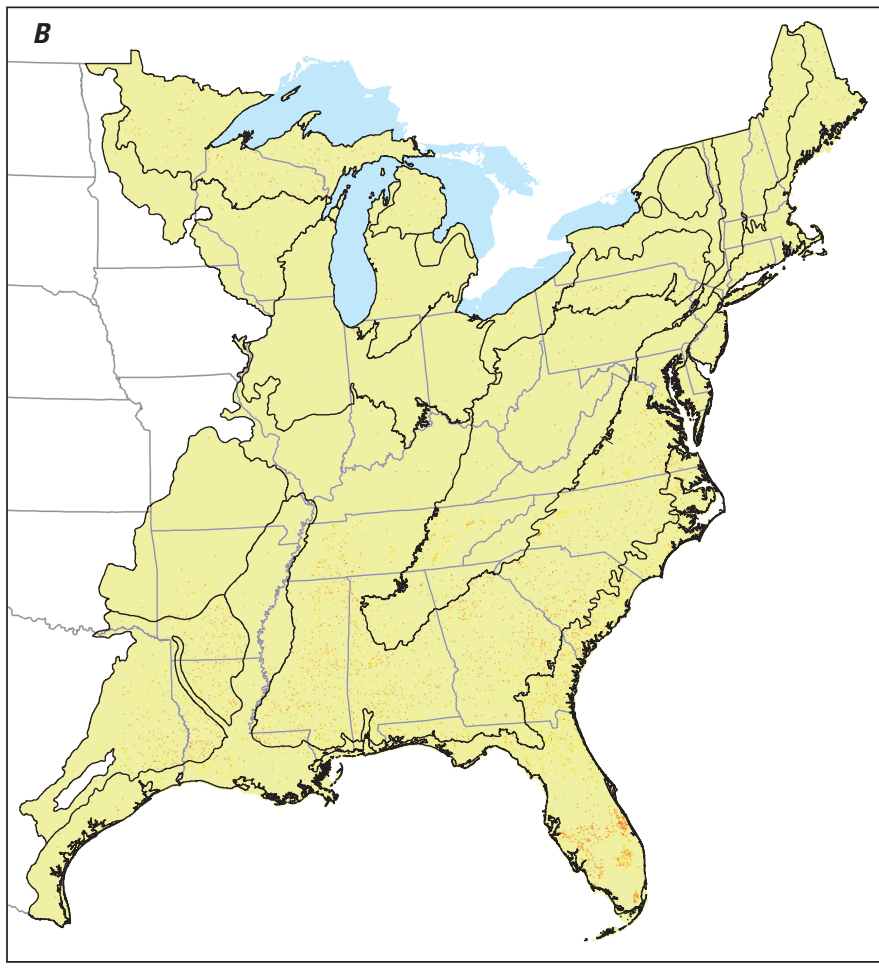

EXPLANATION

Standard deviation of the mean carbon storage for 2005, in kilograms of carbon per square meter

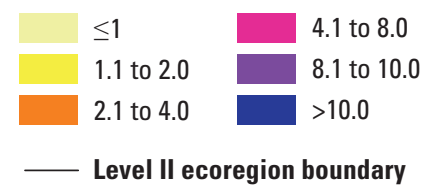

Figure 7-6. Maps showing carbon flux in ecosystems of the Eastern United States. A, The average net carbon flux derived from each of the three General Ensemble Modeling System (GEMS) models (Land GHG Accounting Tool, Century, and Erosion Deposition Carbon Model) and averaged for the baseline years (2001 through 2005). $B$, The standard deviation of the three models for the baseline years. Negative values indicate net carbon gains and positive values indicate net carbon losses. Level II ecoregions are shown in figure 1-1.

\subsubsection{Southeastern USA Plains}

This largest ecoregion in this assessment was dominated by forests and agricultural lands (55 percent and 31 percent, respectively, of total land area). The average estimate for net carbon flux was $-112.2 \mathrm{TgC} / \mathrm{yr}$, ranging from -176.7 to $-39.4 \mathrm{TgC} / \mathrm{yr}$ across the three models, of which $62 x p e r c e n t$ was allocated to live biomass, 29 percent to soil, and 9 percent to ground litter and dead woody biomass. Forest sequestered $-93.4 \mathrm{TgC} / \mathrm{yr}$ ( 83 percent of the total), followed by wetland $(-12.6 \mathrm{TgC} / \mathrm{yr}, 11$ percent of the total), cropland $(-4.7 \mathrm{TgC} / \mathrm{yr}, 4$ percent of the total), and grassland/shrubland $(-0.6 \mathrm{TgC} / \mathrm{yr}, 0.5$ percent of the total).

\subsubsection{Ozark, Ouachita-Appalachian Forests}

In this heavily forested ecoregion (72 percent of the total area), the average estimate for net carbon flux was
$-60.7 \mathrm{TgC} / \mathrm{yr}$, ranging from -84.6 to $-30.4 \mathrm{TgC} / \mathrm{yr}$ across models, of which 65 percent was allocated to live biomass, 29 percent to soil, and 6 percent to ground litter and dead woody biomass. Forest sequestered $-58 \mathrm{TgC} / \mathrm{yr}$ (96 percent of the total), followed by agricultural land $(-1.8 \mathrm{TgC} / \mathrm{yr}, 3$ percent of the total), wetland $(-0.4 \mathrm{TgC} / \mathrm{yr}, 1$ percent of the total), and grassland/shrubland $(-0.2 \mathrm{TgC} / \mathrm{yr}$, less than 0.5 percent of the total).

\subsubsection{Mississippi Alluvial and Southeast USA Coastal Plains}

The costal ecoregion consisted of agricultural lands (28 percent), wetlands ( 23 percent), other lands ( 23 percent), forests ( 20 percent), and grassland/shrubland (6 percent). The mean estimate for net carbon flux was $-39.7 \mathrm{TgC} / \mathrm{yr}$, ranging from -63.4 to $-6.2 \mathrm{TgC} / \mathrm{yr}$ across models, of which 70 percent was allocated to live biomass, 18 percent to soil, and 
Table 7-5. Net ecosystem carbon balance in the Eastern United States from 2001 through 2005.

[Data are by carbon pool for each ecoregion and ecosystem Negative numbers indicate carbon sequestration; positive numbers indicate a loss of carbon to the atmosphere. Only soil organic carbon (SOC) in the top 20 centimeters of the soil layer was calculated. $\mathrm{km}^{2}$, square kilometers; max, maximum; min, minimum; $\mathrm{TgC} / \mathrm{yr}$, teragrams (or $10^{12}$ grams) of carbon per year]

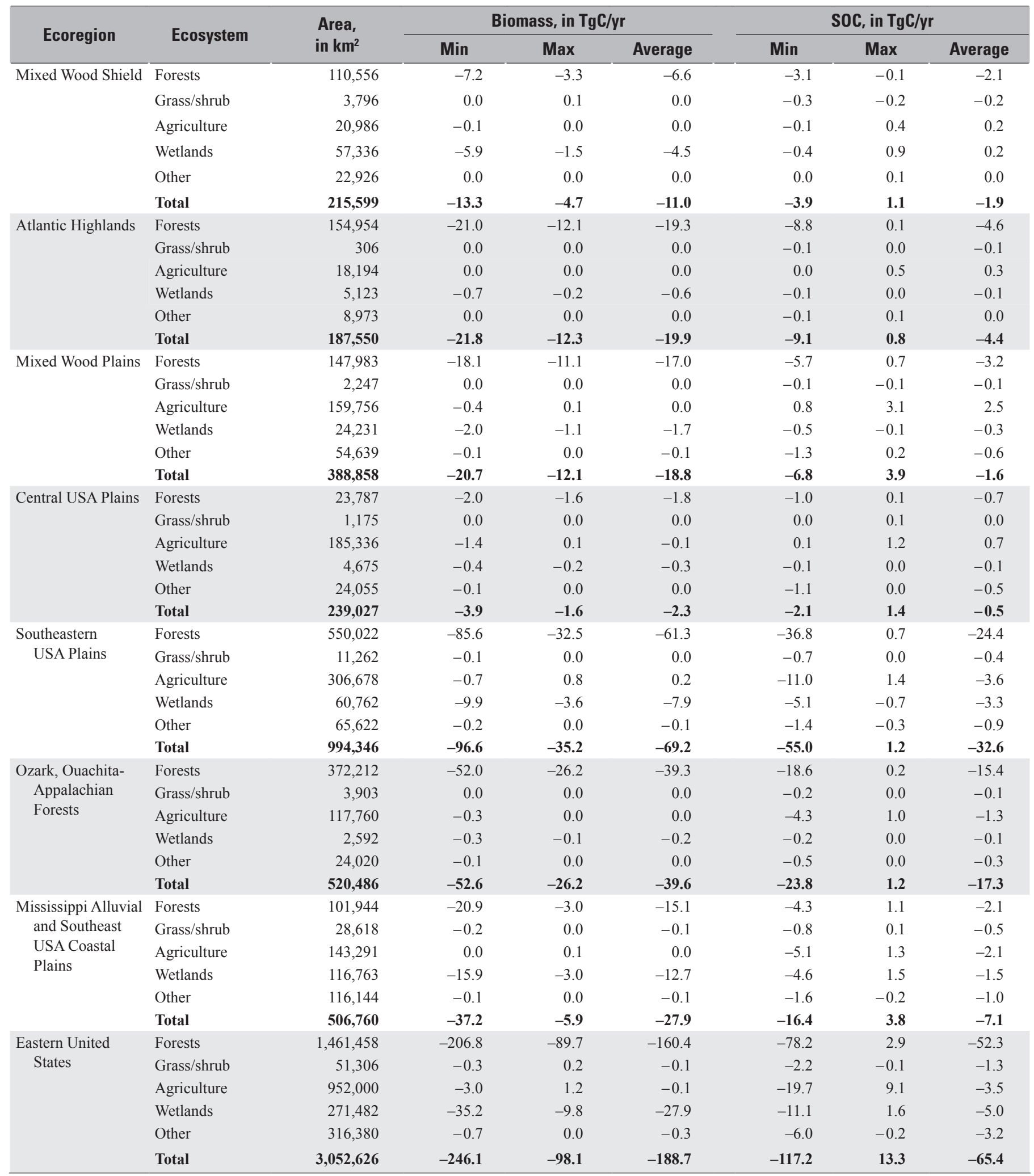


Table 7-5. Net ecosystem carbon balance in the Eastern United States from 2001 through 2005.—Continued

[Data are by carbon pool for each ecoregion and ecosystem Negative numbers indicate carbon sequestration; positive numbers indicate a loss of carbon to the atmosphere. Only soil organic carbon (SOC) in the top 20 centimeters of the soil layer was calculated. $\mathrm{km}^{2}$, square kilometers; max, maximum; min, minimum; $\mathrm{TgC} / \mathrm{yr}$, teragrams (or $10^{12}$ grams) of carbon per year]

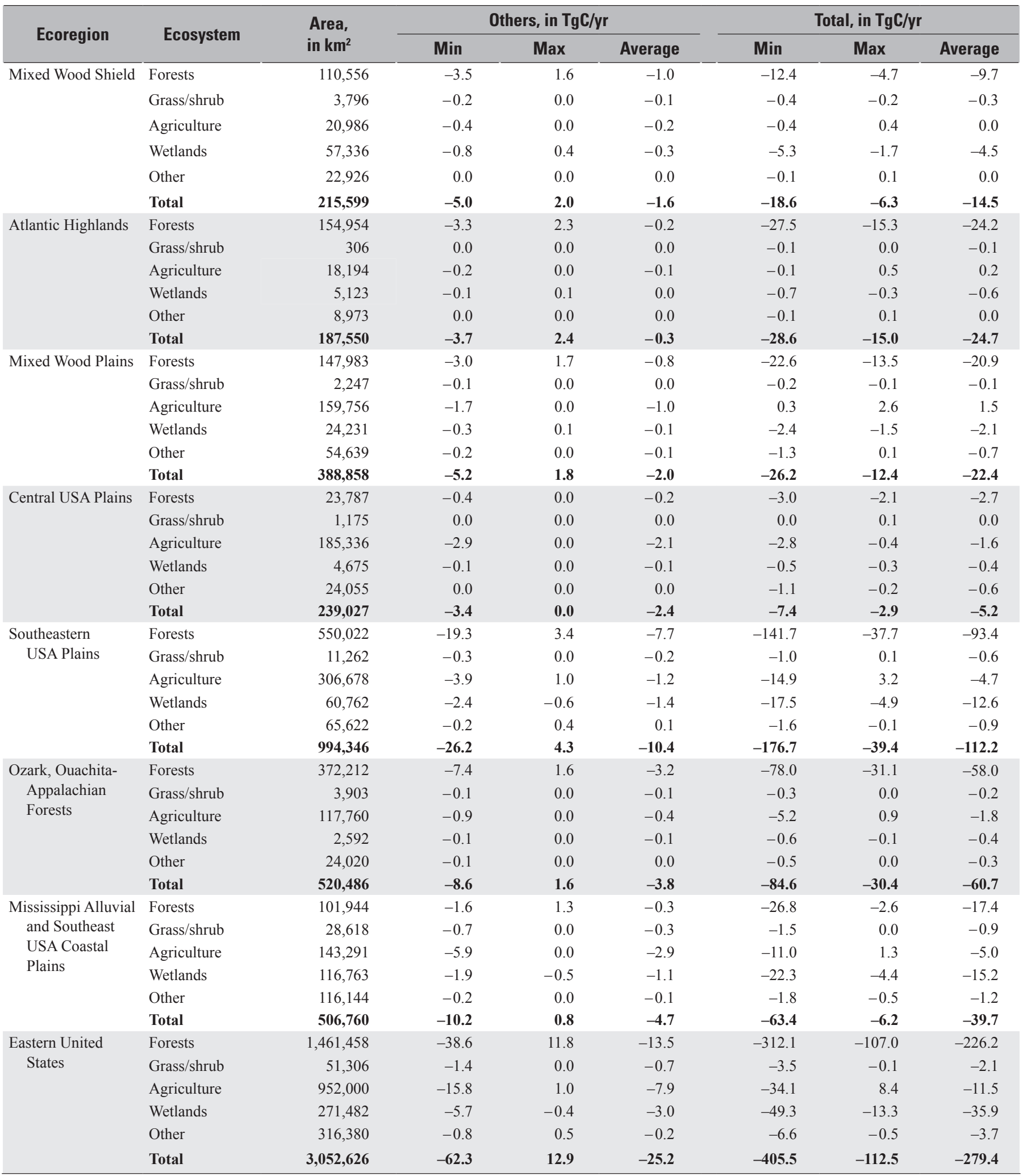


12 percent to ground litter and dead woody biomass. Forest sequestered $-17.4 \mathrm{TgC} / \mathrm{yr}$ (44 percent of the total), followed by wetland $(-15.2 \mathrm{TgC} / \mathrm{yr}, 38$ percent of the total), agricultural land $(-5 \mathrm{TgC} / \mathrm{yr}, 13$ percent of the total) and grassland/ shrubland $(-0.9 \mathrm{TgC} / \mathrm{yr}, 2$ percent of the total).
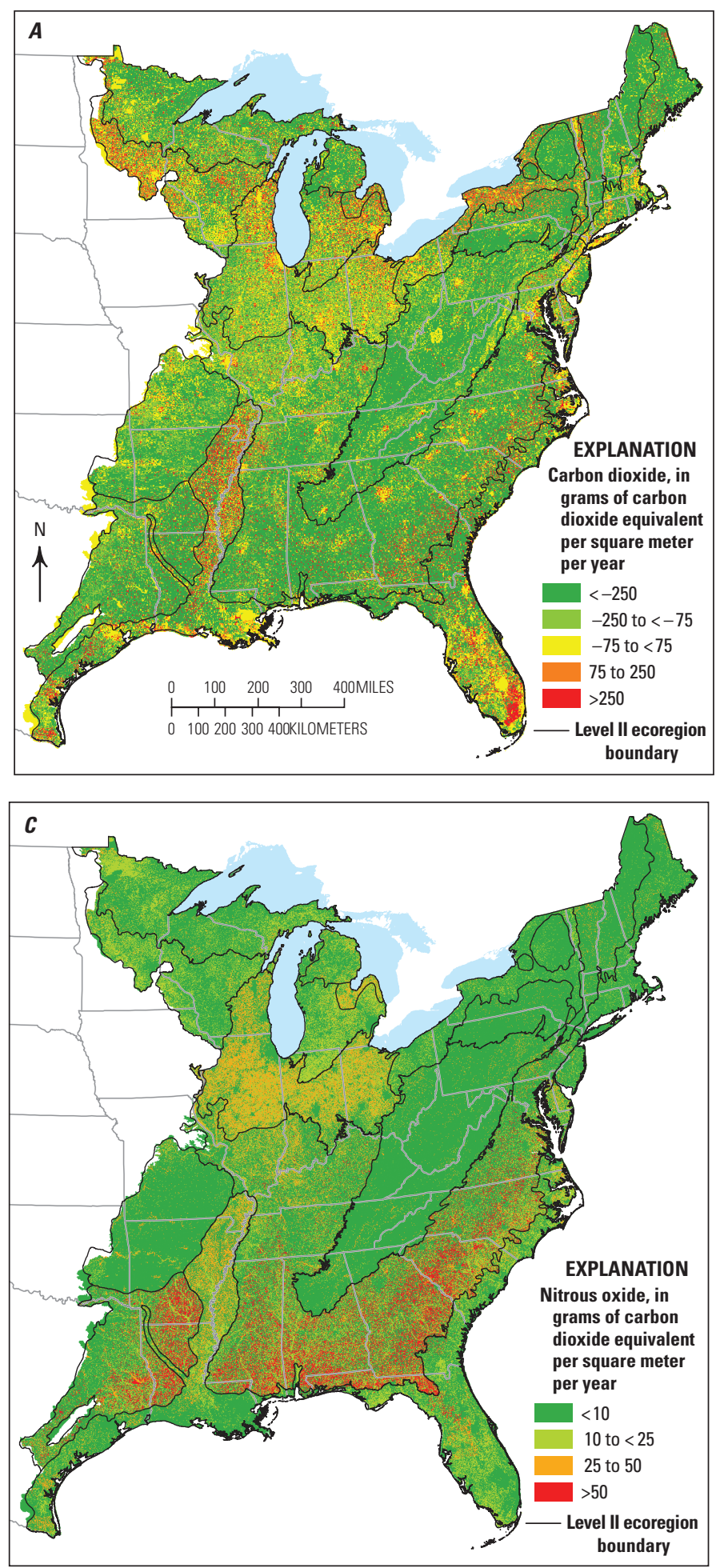

\subsubsection{Baseline GHG Fluxes}

The minimum, maximum, and average estimates of GHG fluxes for the baseline years are listed in table 7-6. To illustrate the spatial distribution, example maps of the GHG fluxes in 2005 are presented in figure 7-7.
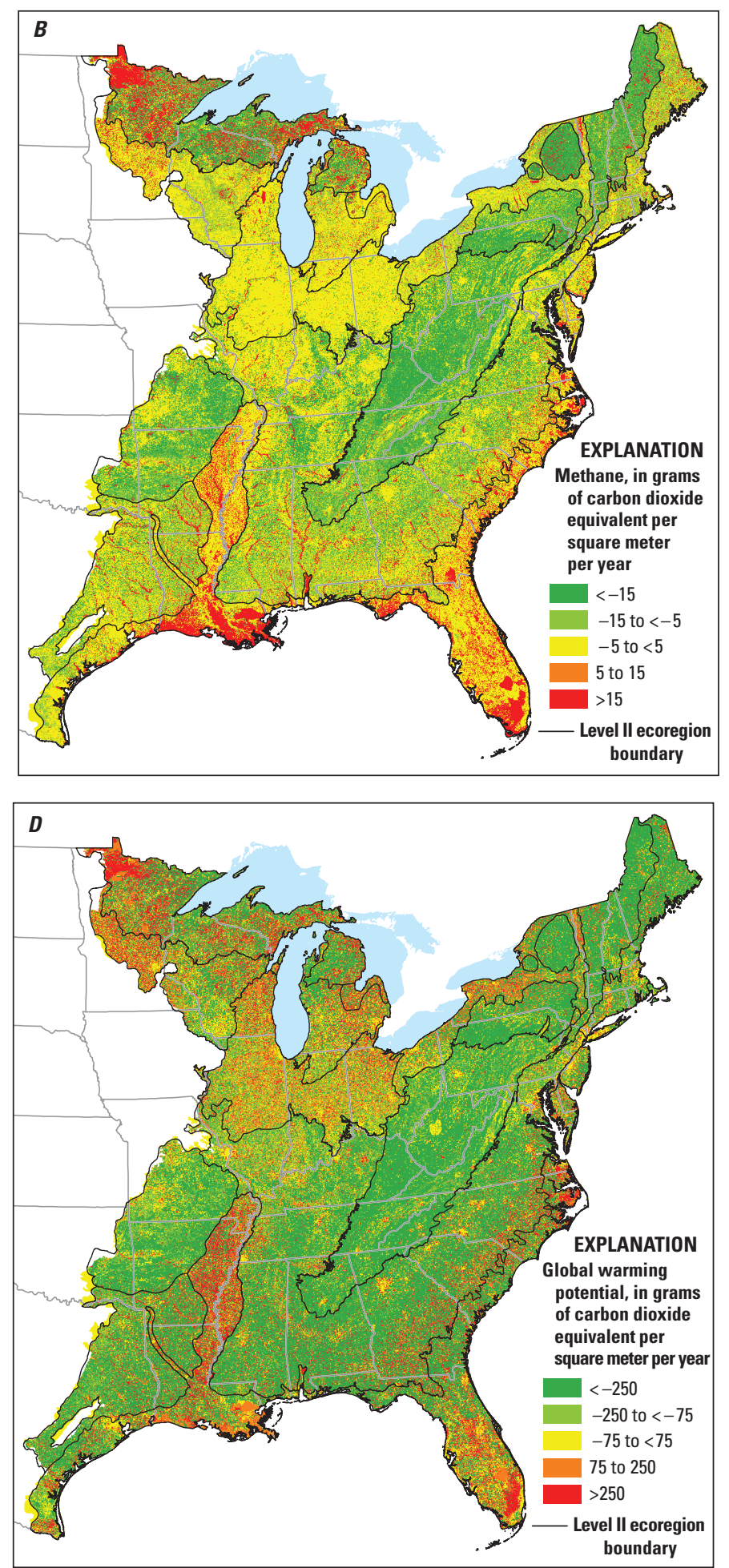

Figure 7-7. Maps showing the spatial distribution of the average annual carbon dioxide, methane, and nitrous oxide fluxes and the total global warming potential from 2001 through 2005 in the Eastern United States. Level II ecoregions are shown in figure 1-1. 
Overall, the Eastern United States served as a GHG sink at an average rate of $-656.9 \mathrm{TgCO}_{2}$-eq/yr (ranging from $-1,122.3$ to $-41.3 \mathrm{TgCO}_{2}$-eq/yr across the three models). On average, the net $\mathrm{CO}_{2}$ sink strength was $-1,024.6 \mathrm{TgCO}_{2}$-eq/yr. However, the $\mathrm{CO}_{2}$ sink was partially offset by $\mathrm{N}_{2} \mathrm{O}$ and $\mathrm{CH}_{4}$ emissions with averages of $174.7 \mathrm{TgCO}_{2}$-eq/yr and $193 \mathrm{TgCO}_{2}$-eq/yr, respectively. Among all ecosystems, forest was the largest sink of GHG (-776.6 $\mathrm{TgCO}_{2}$-eq/yr), whereas wetlands and cropland were net GHG sources emitting $69.6 \mathrm{TgCO}_{2}$-eq/yr and 45.9 $\mathrm{TgCO}_{2}-\mathrm{eq} / \mathrm{yr}$, respectively. Forest and cropland were major sources of $\mathrm{N}_{2} \mathrm{O}$ with average annual contributions of 76.4 $\mathrm{TgCO}_{2}$-eq/yr and $74.7 \mathrm{TgCO}_{2}$-eq/yr, respectively. Wetlands contributed the highest amount of $\mathrm{CH}_{4}$ with $186.2 \mathrm{TgCO}_{2}$-eq/yr on emission, followed by cropland with $12.9 \mathrm{TgCO}_{2}$-eq/yr, but forests took up $\mathrm{CH}_{4}$ with an average rate of $-23.2 \mathrm{TgCO}_{2}$-eq/yr.

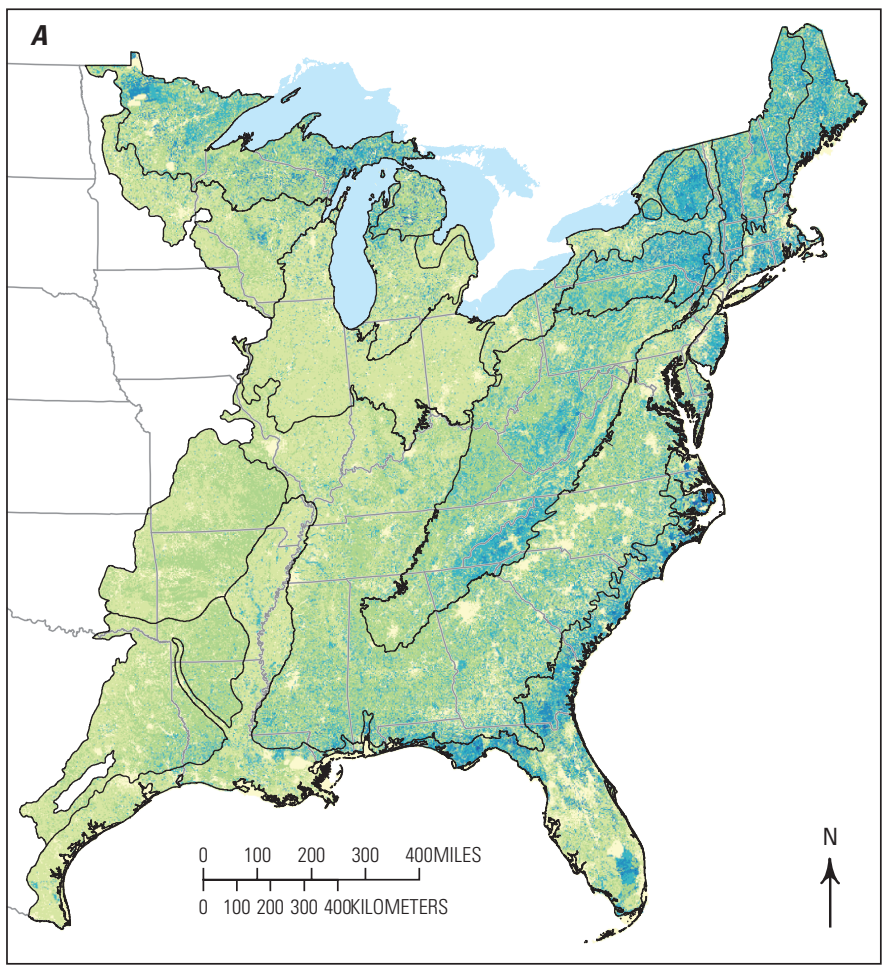

EXPLANATION

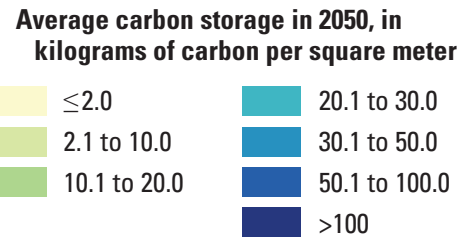

_ Level II ecoregion boundary

\subsubsection{Projected Future Carbon Stock Distributions}

A total of 21 maps resulted from the 21 simulation model runs described in the "Ensemble Modeling" and "Output and Further Processing" sections, which depict the spatial patterns of carbon storage in 2050 (the end year of the scenario period), were produced for the Eastern United States. The maps showing the average and standard deviation of the 21 simulation model runs are shown in figure 7-8. Similar to the baseline carbon stock maps (fig. 7-5), the projected future carbon stock maps show that forest ecosystems have the highest carbon density (that is, carbon storage per unit area), and grass/shrublands and agricultural lands have the lowest carbon densities. The spatial pattern of carbon storage in 2050 is in general agreement with that in 2005 .

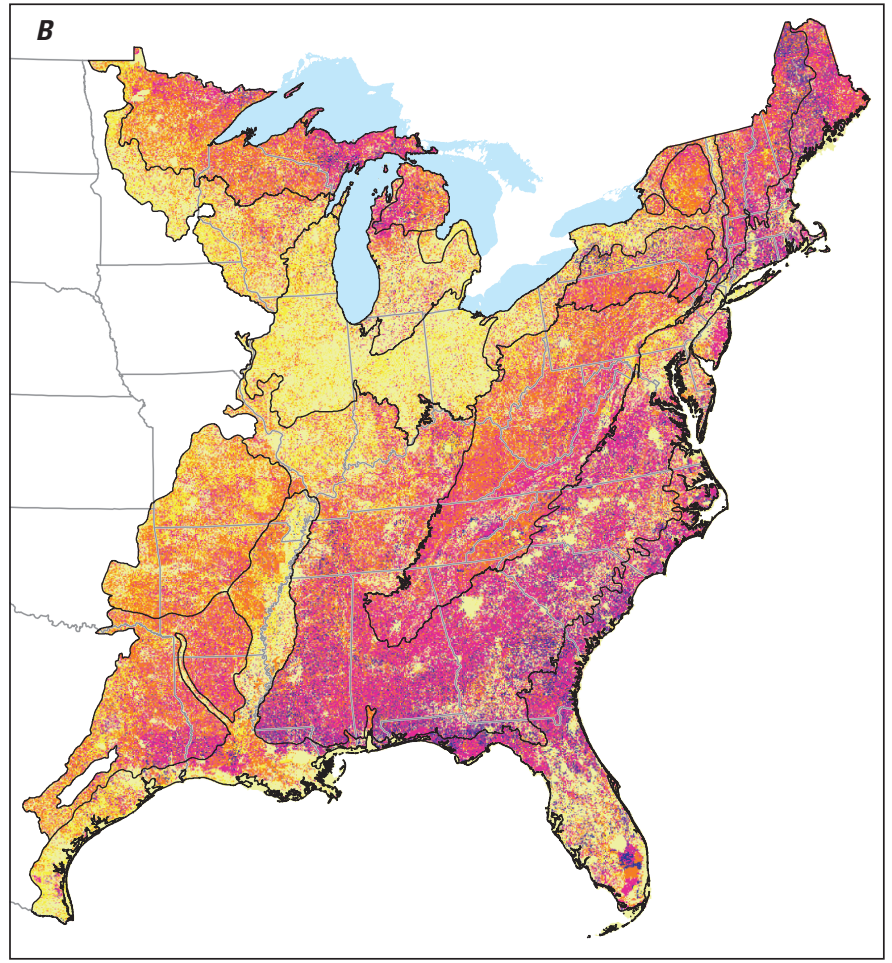

EXPLANATION

Standard deviation of the mean carbon storage for 2050, in kilograms of carbon per square meter

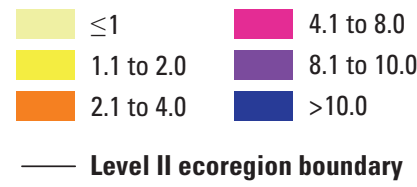

Figure 7-8. Maps showing the projected $A$, average amount and $B$, standard deviation of carbon stored in the Eastern United States in 2050. Projected average carbon stored in 2050 was derived from 21 simulation model runs using biogeochemical models Land GHG Accounting Tool, Century, and Erosion Deposition Carbon Model under Intergovernmental Panel on Climate Change Special Report on Emissions Scenarios (Nakićenović and others, 2000) scenarios A1B, A2, and B1 and general circulation models Third Generation Coupled Global Climate Model of the Canadian Centre for Climate Modelling and Analysis, Australia's Commonwealth Scientific and Industrial Research Organisation Mark 3.0, and Model for Interdisciplinary Research on Climate 3.2, medium resolution. Level II ecoregions are shown in figure 1-1. 
Table 7-6. Annual fluxes and total global warming potential from 2001 through 2005 in the Eastern United States.

[Data are by greenhouse-gas type for each ecosystem in each ecoregion. Estimates of methane $\left(\mathrm{CH}_{4}\right)$ and nitrous oxide $\left(\mathrm{N}_{2} \mathrm{O}\right)$ were generated by the land $\mathrm{GHG}$ accounting tool. Carbon dioxide $\left(\mathrm{CO}_{2}\right)$ was calculated using net ecosystem carbon balance values from table 7-5. Global warming potential is the sum of $\mathrm{CO}_{2}$, $\mathrm{CH}_{4}$, and $\mathrm{N}_{2} \mathrm{O} . \mathrm{TgCO}_{2}$-eq/yr, teragrams (or $10^{12}$ grams) of carbon dioxide equivalent per year]

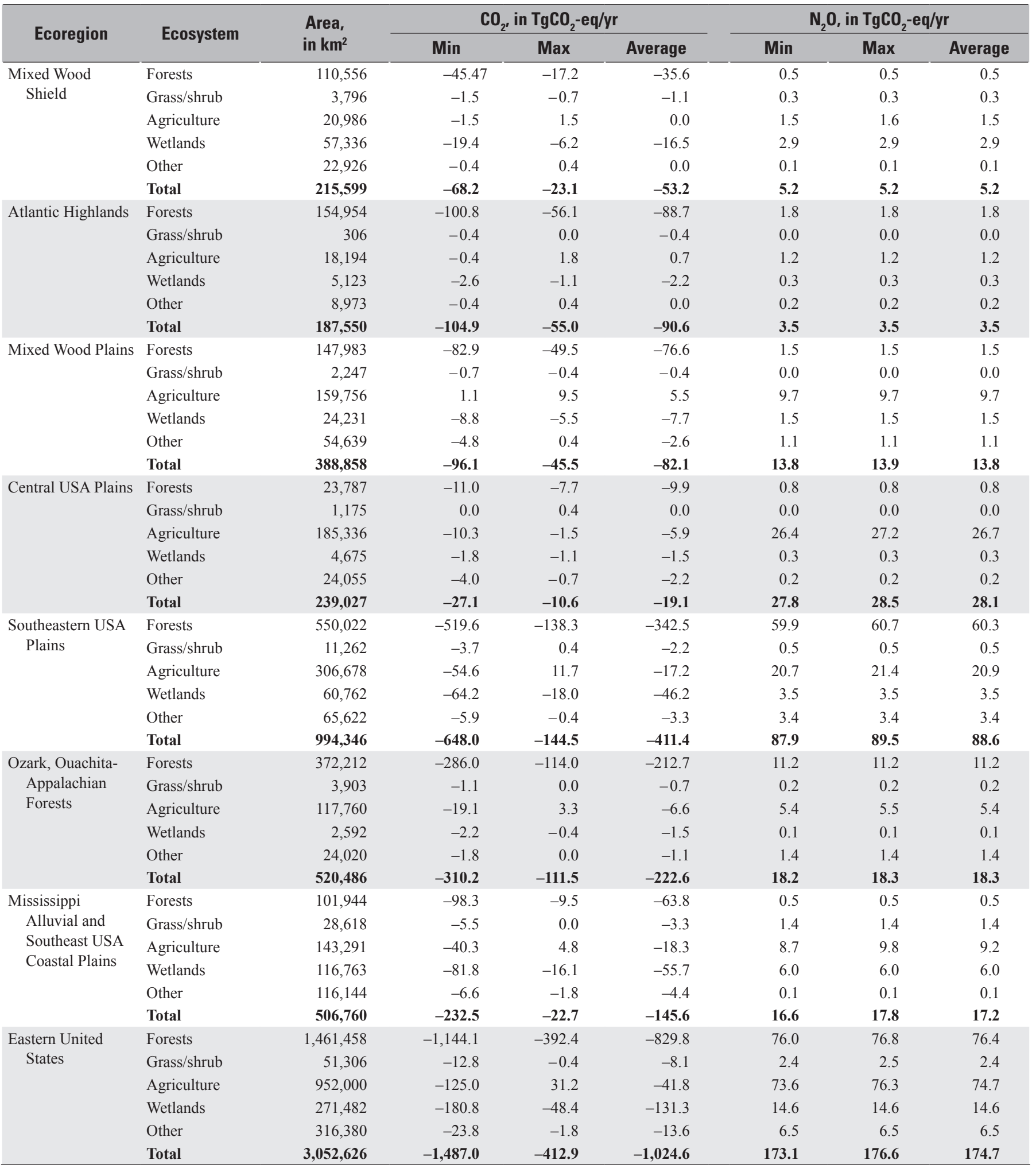


Table 7-6. Annual fluxes and total global warming potential from 2001 through 2005 in the Eastern United States.-Continued

[Data are by greenhouse-gas type for each ecosystem in each ecoregion. Estimates of methane $\left(\mathrm{CH}_{4}\right)$ and nitrous oxide $\left(\mathrm{N}_{2} \mathrm{O}\right)$ were generated by the land GHG accounting tool. Carbon dioxide $\left(\mathrm{CO}_{2}\right)$ was calculated using net ecosystem carbon balance values from table 7-5. Global warming potential is the sum of $\mathrm{CO}_{2}$, $\mathrm{CH}_{4}$, and $\mathrm{N}_{2} \mathrm{O} . \mathrm{TgCO}_{2}$-eq/yr, teragrams (or $10^{12}$ grams) of carbon dioxide equivalent per year]

\begin{tabular}{|c|c|c|c|c|c|c|c|c|}
\hline \multirow{2}{*}{ Ecoregion } & \multirow{2}{*}{ Ecosystem } & \multirow{2}{*}{$\begin{array}{l}\text { Area, } \\
\text { in } \mathrm{km}^{2}\end{array}$} & \multicolumn{3}{|c|}{$\mathrm{CH}_{4^{\prime}}$ in $\mathrm{TgCO}_{2}-\mathrm{eq} / \mathrm{yr}$} & \multicolumn{3}{|c|}{ GWP, in $\mathrm{TgCO}_{2}-\mathrm{eq} / \mathrm{yr}$} \\
\hline & & & Min & Max & Average & Min & Max & Average \\
\hline \multirow[t]{5}{*}{ Mixed Wood Shield } & Forests & 110,556 & -1.7 & -1.6 & -1.6 & -46.7 & -18.4 & -36.8 \\
\hline & Grass/shrub & 3,796 & 0.0 & 0.0 & 0.0 & -1.2 & -0.5 & -0.9 \\
\hline & Agriculture & 20,986 & 0.0 & 0.0 & 0.0 & 0.0 & 3.0 & 1.5 \\
\hline & Wetlands & 57,336 & 47.1 & 47.2 & 47.1 & 30.5 & 43.8 & 33.5 \\
\hline & Other & 22,926 & 2.2 & 2.2 & 2.2 & 1.9 & 2.6 & 2.3 \\
\hline & Grass/shrub & 306 & 0.0 & 0.0 & 0.0 & -0.4 & 0.0 & -0.4 \\
\hline & Agriculture & 18,194 & 0.0 & 0.0 & 0.0 & 0.8 & 3.0 & 1.9 \\
\hline & Wetlands & 5,123 & 3.6 & 3.6 & 3.6 & 1.3 & 2.8 & 1.7 \\
\hline & Other & 8,973 & 0.6 & 0.6 & 0.6 & 0.4 & 1.1 & 0.8 \\
\hline & Total & 187,550 & 1.0 & 1.0 & 1.0 & -100.4 & -50.5 & -86.0 \\
\hline \multirow{2}{*}{ Mixed Wood Plains } & Other & 54,639 & 2.7 & 2.7 & 2.7 & -1.0 & 4.2 & 1.2 \\
\hline & Total & 388,858 & 20.9 & 20.9 & 20.9 & -61.4 & -10.7 & -47.4 \\
\hline \multirow[t]{6}{*}{ Central USA Plains } & Forests & 23,787 & -0.5 & -0.5 & -0.5 & -10.6 & -7.3 & -9.5 \\
\hline & Grass/shrub & 1,175 & 0.0 & 0.0 & 0.0 & 0.0 & 0.4 & 0.0 \\
\hline & Agriculture & 185,336 & -0.1 & -0.1 & -0.1 & 16.1 & 25.6 & 20.8 \\
\hline & Wetlands & 4,675 & 3.3 & 3.3 & 3.3 & 1.7 & 2.5 & 2.1 \\
\hline & Other & 24,055 & 0.6 & 0.6 & 0.6 & -3.2 & 0.1 & -1.4 \\
\hline & Total & 239,027 & 3.3 & 3.3 & 3.3 & 4.0 & 21.2 & 12.3 \\
\hline \multirow{3}{*}{$\begin{array}{l}\text { Southeastern } \\
\text { USA Plains }\end{array}$} & Forests & 550,022 & -6.6 & -6.5 & -6.5 & -466.3 & -84.1 & -288.7 \\
\hline & Grass/shrub & 11,262 & -0.1 & -0.1 & -0.1 & -3.2 & 0.8 & -1.7 \\
\hline & Agriculture & 306,678 & -0.1 & 0.1 & 0.0 & -34.1 & 33.2 & 3.7 \\
\hline & Other & 24,020 & 0.9 & 0.9 & 0.9 & 0.4 & 2.2 & 1.1 \\
\hline & Total & 520,486 & -7.4 & -7.1 & -7.3 & -299.4 & -100.2 & -211.6 \\
\hline \multirow{6}{*}{$\begin{array}{l}\text { Mississippi Alluvial } \\
\text { and Southeast } \\
\text { USA Coastal } \\
\text { Plains }\end{array}$} & Forests & 101,944 & -0.7 & -0.7 & -0.7 & -98.5 & -9.8 & -64.1 \\
\hline & Grass/shrub & 28,618 & -0.2 & -0.2 & -0.2 & -4.3 & 1.2 & -2.1 \\
\hline & Agriculture & 143,291 & 12.5 & 14.6 & 13.3 & -19.2 & 29.2 & 4.2 \\
\hline & Wetlands & 116,763 & 67.3 & 67.5 & 67.4 & -8.5 & 57.4 & 17.7 \\
\hline & Other & 116,144 & 8.4 & 8.4 & 8.4 & 1.9 & 6.7 & 4.1 \\
\hline & Total & 506,760 & 87.3 & 89.7 & 88.2 & -128.5 & 84.7 & -40.2 \\
\hline \multirow{6}{*}{$\begin{array}{l}\text { Eastern United } \\
\quad \text { States }\end{array}$} & Forests & $1,461,458$ & -23.3 & -23.2 & -23.2 & $-1,091.4$ & -338.7 & -776.6 \\
\hline & Grass/shrub & 51,306 & -0.3 & -0.3 & -0.3 & -10.7 & 1.8 & -5.9 \\
\hline & Agriculture & 952,000 & 11.8 & 14.5 & 12.9 & -39.6 & 121.9 & 45.9 \\
\hline & Wetlands & 271,482 & 185.8 & 186.7 & 186.2 & 19.6 & 152.9 & 69.6 \\
\hline & Other & 316,380 & 17.3 & 17.4 & 17.4 & 0.0 & 22.0 & 10.3 \\
\hline & Total & $3,052,626$ & 191.7 & 195.0 & 193.0 & $-1,122.3$ & -41.3 & -656.9 \\
\hline
\end{tabular}


The projected minimum, maximum, and average amounts of stored carbon from the 21 simulation model runs are listed in table 7-7 and are by carbon pool, ecosystem, and ecoregion in the Eastern United States for 2050. The overall carbon stored in all seven ecoregions was projected to be $37,083 \mathrm{TgC}$, averaged across all scenarios, GCMs, and models used. The variability ranged from 25,513 to $46,002 \mathrm{TgC}$ across all 21 model simulations, which was considerably wider than the range of 25,069 to $28,497 \mathrm{TgC}$ for the baseline period. Among the ecoregions, the Southeastern USA Plains ecoregion was projected to have the most carbon stored by 2050, accounting for about 31 percent of the total carbon stored in the Eastern United States in terms of the average estimates, followed by the Ozark, Ouachita-Appalachian Forests (18 percent of the total), Mississippi Alluvial and Southeast USA Coastal Plains (14 percent), Mixed Wood Plains (13 percent), Atlantic Highlands (10 percent), Mixed Wood Shield ( 9 percent), and Central USA Plains (5 percent) ecoregions. Among the different ecosystems, forests were projected to store the most carbon (69 percent) in terms of total amount in the Eastern United States, followed by wetlands (16 percent) and agricultural lands (13 percent). About 48 percent and 37 percent of the total carbon stock were projected to be allocated to the live biomass and SOC pools, respectively, and the remaining 15 percent was projected to be stored in dead biomass (such as forest litter and dead, woody debris). Compared with the baseline period, the projected allocation indicates that the carbon stock in the live biomass pools grew a little faster than the SOC pools.

The average carbon density of the Eastern United States was projected to be about $12.2 \mathrm{kgC} / \mathrm{m}^{2}$. However, by ecosystems, the projected average future carbon densities varied substantially (fig. 7-8; table 7-7), as follows: wetlands $\left(21.8 \mathrm{kgC} / \mathrm{m}^{2}\right)$, forests $\left(18.7 \mathrm{kgC} / \mathrm{m}^{2}\right)$, grasslands/shrublands $\left(5.7 \mathrm{kgC} / \mathrm{m}^{2}\right)$, agricultural lands $\left(5.1 \mathrm{kgC} / \mathrm{m}^{2}\right)$, and other lands $\left(1.2 \mathrm{kgC} / \mathrm{m}^{2}\right)$. Geographically, the projected average future carbon density in forests varied among the Atlantic Highlands $\left(23.7 \mathrm{kgC} / \mathrm{m}^{2}\right)$, Mississippi Alluvial and Southeast USA Coastal Plains $\left(22.5 \mathrm{kgC} / \mathrm{m}^{2}\right)$, Mixed Wood Plains $\left(22.2 \mathrm{kgC} / \mathrm{m}^{2}\right)$, Central USA Plains $\left(18.6 \mathrm{kgC} / \mathrm{m}^{2}\right)$, Ozark, Ouachita-Appalachian Forests $\left(17.6 \mathrm{gC} / \mathrm{m}^{2}\right)$, Southeast USA Coastal Plains $\left(16.9 \mathrm{kgC} / \mathrm{m}^{2}\right)$, and Mixed Wood Shield $\left(16 \mathrm{kgC} / \mathrm{m}^{2}\right)$ ecoregions. For grasslands/shrublands, the highest carbon density was projected to be found in the Central USA Plains ecoregion $\left(9.1 \mathrm{kgC} / \mathrm{m}^{2}\right)$ and the lowest carbon density was projected to be found in the Atlantic Highlands ecoregion $\left(4.9 \mathrm{kgC} / \mathrm{m}^{2}\right)$.

\subsubsection{Mixed Wood Shield}

The total carbon stored in the Mixed Wood Shield was projected to range between 2,512 and $3,783 \mathrm{TgC}$ in 2050 across 21 model simulations used in this assessment (table 7-7). Live biomass, soil organic carbon (SOC), and dead biomass were projected to store an average of 40 percent, 43.5 percent, and 16.5 percent, respectively, of the total carbon. Among the different ecosystems, forests were projected to store the most carbon (average of 50.7 percent of the total) followed by wetlands (44 percent) and agricultural lands ( 4.2 percent). The projected allocation of carbon varied substantially between the three carbon pools (live biomass, SOC, and dead biomass) across ecosystems. Live biomass was projected to account for 44.4 percent of the total carbon stored in forests, whereas SOC was projected to be the dominant storage pool for other lands ( 92.1 percent), agricultural lands (82.9 percent), and grassland/shrubland (78.9 percent) in 2050 .

\subsubsection{Atlantic Highlands}

The estimated carbon stored in the Atlantic Highlands in 2050 was projected to range from 2,875 to $4,401 \mathrm{TgC}$ across 21 model simulations used in this assessment (table 7-7). Live biomass and SOC were projected to contain 51.5 percent and 31.1 percent, respectively, of this total amount. This being a predominantly forested region, forests were projected to store the most carbon ( 93.2 percent of the projected total carbon), followed by wetlands (3.4 percent) and agricultural lands ( 2.8 percent). The live biomass carbon pool was projected to contain the most carbon in wetlands, accounting for 49 percent, whereas the SOC pool was projected to be the largest for agricultural lands, other lands ecosystems, and grasslands/shrublands, accounting for 85.1 percent, 80.9 percent, and 73.3 percent, respectively, in 2050 .

\subsubsection{Mixed Wood Plains}

The estimated carbon stored in the Mixed Wood Plains ecoregion was projected to range from 3,401 to $5,426 \mathrm{TgC}$ in 2050 across 21 model simulations used in this assessment (table 7-7). Live biomass and SOC were projected to contain 40.1 percent and 45 percent, respectively, of this total amount. Forests were projected to serve as the primary carbon storage pool (66.2 percent), followed by agricultural lands (21 percent) and wetlands (10.2 percent). The total percentage of carbon stored in grasslands/shrublands and other lands was projected to be less than 3 percent. Live biomass was projected to serve as the major carbon pool in forests (52.6 percent of the total forests), but for the other ecosystems, most carbon was projected to be stored in the SOC pool, ranging from 45 percent (for wetlands) to 90.7 percent (for other lands).

\subsubsection{Central USA Plains}

For the Central USA Plains ecoregion, the projected total carbon ranged from 1,464 to $2,055 \mathrm{TgC}$ from the 21 model simulations used in this assessment (table 7-7). Unlike in the Mixed Wood Shield, Atlantic Highlands, and Mixed Wood Plains ecoregions, SOC was projected to be the primary carbon pool in the Central USA Plains ecoregion, by storing 69.9 percent of the total carbon, and live biomass was projected to store only 19.1 percent in this agricultural ecoregion. Croplands were projected to store the most carbon (67.4 percent of the total), followed by forests ( 22.8 percent) and other lands ( 5.3 percent). 
Live biomass was projected to account for 56.3 percent of the total carbon stock in forests, and SOC was projected to be the primary pool in grasslands/shrublands (85.3 percent), agricultural lands ( 84.7 percent), and others lands (93.4 percent).

\subsubsection{Southeastern USA Plains}

For the Southeastern USA Plains ecoregion, the total carbon stored in 2050 was projected to range from 6,863 to $15,311 \mathrm{TgC}$ by the 21 model simulations used in this assessment (table 7-7). Live biomass was projected to be the primary carbon pool (storing 53.5 percent of the total carbon) and SOC was projected to store 30.7 percent. The majority of the stored carbon was projected to be in forests (75.4 percent of the total), followed by wetlands (11.8 percent) and agricultural lands (11.1 percent). Live biomass was projected to be the primary carbon pools for forests and wetlands, accounting for 60.1 percent and 62.9 percent of their totals, whereas in other ecosystems, most carbon was projected to be stored in the SOC pool, ranging from 60.9 percent in grasslands/shrublands to 80.8 percent in other lands.

\subsubsection{Ozark, Ouachita-Appalachian Forests}

The estimated carbon stored in the Ozark, OuachitaAppalachian Forests ecoregion was projected to range from 4,847 to $8,328 \mathrm{TgC}$ in 2050 according to the 21 model simulations used in this assessment (table 7-7). Live biomass carbon was projected to be the primary carbon pool (accounting for 56.8 percent of the projected total amount of carbon), followed by SOC (27.6 percent). Forests were projected to serve as the primary carbon storage pool (91.2 percent), followed by agricultural lands (7.3 percent). The total percentage of carbon stored in grasslands/ shrublands, wetlands, and other lands was projected to be less than 2 percent. Live biomass was projected to serve as the major carbon pool in forests (61.5 percent of the total carbon in forests) and wetlands ( 56.5 percent of the total carbon in wetlands), but for the other ecosystems, most carbon was projected to be stored in the SOC pool, ranging from 79 percent (for grasslands/shrublands) to 82.4 percent (for agricultural lands).

\subsubsection{Mississippi Alluvial and Southeast USA Coastal Plains}

The total carbon stored in the Mixed Wood Shield was projected to range between 3,549 and 6,698 $\mathrm{TgC}$ in 2050 according to the 21 model simulations used in this assessment (table 7-7). Live biomass, SOC, and dead biomass were projected to store an average of 44.4 percent, 43.6 percent, and 12 percent, respectively, of the total carbon. Among the different ecosystems, wetlands were projected to store the most carbon (average of 44.2 percent of the total), followed by forests (36.6 percent) and agricultural lands (14.2 percent).
The carbon stored in grasslands/shrublands and other lands (combined) was projected to be the remaining 5 percent of the total carbon. The projected allocation of carbon varied substantially between the three pools (live biomass, SOC, and dead biomass) across ecosystems. Live biomass was projected to account for 60.2 percent of the total carbon stored in forests, whereas SOC was projected to be the dominant storage pool for other lands (87.9 percent), agricultural lands (82.1 percent), and grasslands/shrublands (68.5 percent) in 2050 .

\subsubsection{Projected Future Carbon Flux Estimates}

The projected average annual NECB and the standard uncertainty between 2006 and 2050 are shown in figure 7-9. The average annual NECB and standard deviation were calculated from all 21 simulation model runs. The projected high carbon sequestration rates (fig. 7-9, negative NECB, shown by green hues on the map) were strongly associated with the presence of forest ecosystems; the simulated disturbances, such as clearcutting, were projected to be responsible for a large number of carbon-release hot spots (fig. 7-9, positive NECB, indicated by red hues on the map). Carbon sequestration was also projected to occur in the agricultural lands. The standard deviation map, as shown in figure 7-9, was spatially similar to the pattern of the average annual NECB, suggesting the spread of NECB estimates was projected to be generally greater in areas experiencing large changes in carbon storage.

The projected minimum, maximum, and average of average annual net carbon fluxes-from the 21 simulations and averaged annually between 2006 and 2050 - are listed in table $7-8$ by carbon pool, ecosystem, and ecoregion in the Eastern United States. The annual NECB estimates were projected to vary between -403.7 and $1.4 \mathrm{TgC} / \mathrm{yr}$ across 21 simulations in the Eastern United States with an average value of $-224.9 \mathrm{TgC} / \mathrm{yr}$.

As shown in table 7-8, the average annual NECB in the ecoregions of the Eastern United States was projected to be highly variable, although all ecoregions within the Eastern United States were projected to be carbon sinks on average. Among the seven ecoregions, the Southeast USA Coastal Plains ecoregion was projected to be the greatest carbon sink with an average of $-79.4 \mathrm{TgC} / \mathrm{yr}$, followed by the Ozark, Ouachita-Appalachian Forests ( $-44.2 \mathrm{TgC} / \mathrm{yr})$, Mississippi Alluvial and Southeast USA Coastal Plains ( $-32.2 \mathrm{TgC} / \mathrm{yr})$, Atlantic Highlands ( $-23.5 \mathrm{TgC} / \mathrm{yr})$, Mixed Wood Plains $(-23.4 \mathrm{TgC} / \mathrm{yr})$, Mixed Wood Shield $(-16.3 \mathrm{TgC} / \mathrm{yr})$, and Central USA Plains ( $-5.8 \mathrm{TgC} / \mathrm{yr})$ ecoregions. Among all ecosystems, forests were projected to remain strong terrestrial carbon sinks, accounting for approximately 70 percent of the projected total average NECB. The other ecosystems were also projected to have the potential to sequester carbon, but the interannual variability was high. Wetlands were projected to have the highest average annual NECB per unit of area $\left(-150.5 \mathrm{gC} / \mathrm{m}^{2} / \mathrm{yr}\right)$, compared with forests $\left(-115.6 \mathrm{gC} / \mathrm{m}^{2} / \mathrm{yr}\right)$, 
Table 7-7. Projections of carbon stored in the Eastern United States in 2050.

[Results are based on 21 simulation model runs and are listed by ecosystem and ecoregion. Only soil organic carbon (SOC) in the top 20 centimeters of the soil layer was calculated. Data may not add to totals shown due to independent rounding. $\mathrm{km}^{2}$, square kilometers; max, maximum; min, minimum; $\mathrm{TgC}$, teragrams (or $10^{12}$ grams) of carbon]

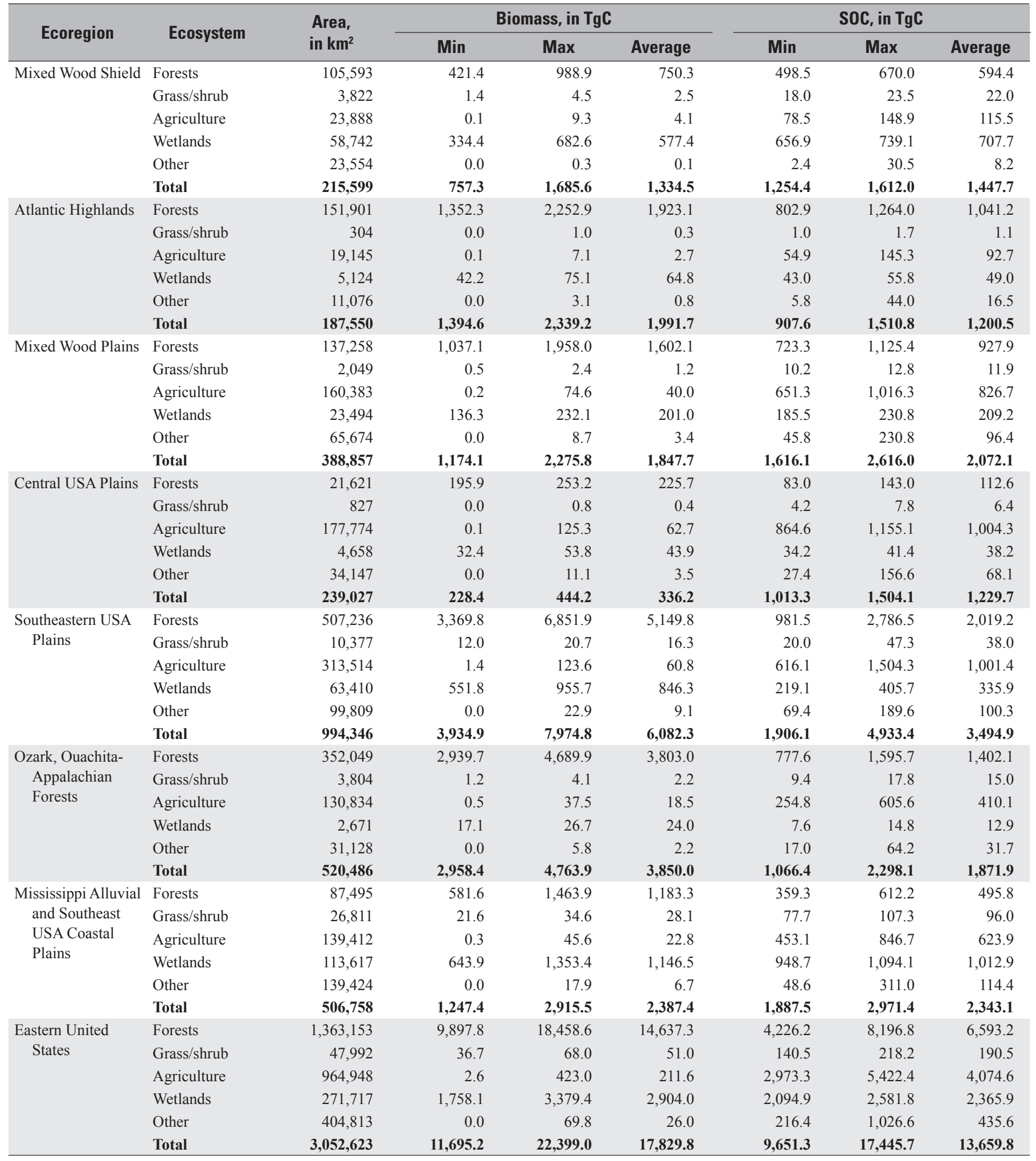


Table 7-7. Projections of carbon stored in the Eastern United States in 2050.-Continued

[Results are based on 21 simulation model runs and are listed by ecosystem and ecoregion. Only soil organic carbon (SOC) in the top 20 centimeters of the soil layer was calculated. Data may not add to totals shown due to independent rounding. $\mathrm{km}^{2}$, square kilometers; max, maximum; min, minimum; $\mathrm{TgC}$, teragrams (or $10^{12}$ grams) of carbon]

\begin{tabular}{|c|c|c|c|c|c|c|c|c|}
\hline \multirow{2}{*}{ Ecoregion } & \multirow{2}{*}{ Ecosystem } & \multirow{2}{*}{$\begin{array}{l}\text { Area, } \\
\text { in } \mathrm{km}^{2}\end{array}$} & \multicolumn{3}{|c|}{ Others, in $\mathrm{TgC}$} & \multicolumn{3}{|c|}{ Total, in $\mathrm{TgC}$} \\
\hline & & & Min & Max & Average & Min & Max & Average \\
\hline \multirow[t]{5}{*}{ Mixed Wood Shield } & Forests & 105,593 & 254.1 & 390.5 & 345.8 & $1,174.1$ & $1,929.0$ & $1,690.5$ \\
\hline & Grass/shrub & 3,822 & 0.0 & 5.1 & 3.4 & 22.5 & 30.4 & 27.9 \\
\hline & Agriculture & 23,888 & 0.0 & 37.0 & 19.8 & 93.3 & 184.6 & 139.4 \\
\hline & Wetlands & 58,742 & 154.5 & 197.9 & 179.5 & $1,218.7$ & $1,608.3$ & $1,464.7$ \\
\hline & Other & 23,554 & 0.0 & 1.5 & 0.6 & 3.1 & 30.5 & 8.9 \\
\hline \multirow{5}{*}{ Atlantic Highlands } & Grass/shrub & 304 & 0.0 & 0.2 & 0.1 & 1.1 & 2.7 & 1.5 \\
\hline & Agriculture & 19,145 & 0.0 & 36.7 & 13.6 & 61.9 & 182.5 & 108.9 \\
\hline & Wetlands & 5,124 & 16.9 & 21.0 & 18.3 & 103.7 & 148.1 & 132.1 \\
\hline & Other & 11,076 & 0.0 & 9.2 & 3.1 & 8.3 & 44.0 & 20.4 \\
\hline & Total & 187,550 & 560.4 & 757.2 & 674.0 & $2,874.8$ & $4,401.0$ & $3,866.1$ \\
\hline \multirow{2}{*}{ Mixed Wood Plains } & Other & 65,674 & 0.0 & 14.9 & 6.5 & 53.3 & 230.8 & 106.3 \\
\hline & Total & 388,857 & 459.1 & 853.0 & 683.6 & $3,401.0$ & $5,426.4$ & $4,603.4$ \\
\hline \multirow[t]{6}{*}{ Central USA Plains } & Forests & 21,621 & 53.5 & 74.3 & 62.8 & 332.6 & 460.3 & 401.0 \\
\hline & Grass/shrub & 827 & 0.0 & 1.1 & 0.6 & 4.8 & 9.6 & 7.5 \\
\hline & Agriculture & 177,774 & 0.0 & 168.9 & 119.1 & $1,019.0$ & $1,324.2$ & $1,186.2$ \\
\hline & Wetlands & 4,658 & 9.4 & 12.9 & 10.9 & 79.5 & 104.0 & 92.9 \\
\hline & Other & 34,147 & 0.0 & 3.0 & 1.2 & 28.0 & 156.6 & 72.9 \\
\hline & Total & 239,027 & 62.8 & 260.2 & 194.6 & $1,463.9$ & $2,054.7$ & $1,760.5$ \\
\hline \multirow{3}{*}{$\begin{array}{l}\text { Southeastern USA } \\
\text { Plains }\end{array}$} & Forests & 507,236 & 811.0 & $1,976.3$ & $1,407.2$ & $5,162.3$ & $11,613.9$ & $8,576.2$ \\
\hline & Grass/shrub & 10,377 & 0.0 & 15.3 & 8.1 & 32.0 & 78.6 & 62.4 \\
\hline & Agriculture & 313,514 & 0.0 & 410.7 & 199.6 & 697.0 & $1,919.5$ & $1,261.8$ \\
\hline \multirow{2}{*}{$\begin{array}{l}\text { Ozark, Ouachita- } \\
\text { Appalachian } \\
\text { Forests }\end{array}$} & Other & 31,128 & 0.0 & 10.3 & 4.7 & 21.8 & 64.2 & 38.6 \\
\hline & Total & 520,486 & 758.0 & $1,377.8$ & $1,057.2$ & $4,847.3$ & $8,328.1$ & $6,779.1$ \\
\hline \multirow{6}{*}{$\begin{array}{l}\text { Mississippi Alluvial } \\
\text { and Southeast } \\
\text { USA Coastal } \\
\text { Plains }\end{array}$} & Forests & 87,495 & 156.7 & 396.2 & 288 & $1,097.6$ & $2,472.3$ & $1,967.1$ \\
\hline & Grass/shrub & 26,811 & 0 & 28.8 & 16.1 & 108.1 & 169.7 & 140.2 \\
\hline & Agriculture & 139,412 & 0 & 231.4 & 113.4 & 487.9 & $1,079.6$ & 760.1 \\
\hline & Wetlands & 113,617 & 137.3 & 291.8 & 216.6 & $1,799.1$ & $2,665.1$ & $2,376.0$ \\
\hline & Other & 139,424 & 0 & 20.7 & 9 & 56.9 & 311 & 130.2 \\
\hline & Total & 506,758 & 294 & 968.9 & 643.1 & $3,549.6$ & $6,697.7$ & $5,373.6$ \\
\hline \multirow{6}{*}{$\begin{array}{l}\text { Eastern United } \\
\quad \text { States }\end{array}$} & Forests & $1,363,153$ & $2,982.6$ & $5,337.8$ & $4,233.9$ & $17,108.1$ & $31,419.3$ & $25,464.3$ \\
\hline & Grass/shrub & 47,992 & 0 & 55.9 & 31.7 & 194.6 & 330.8 & 273.3 \\
\hline & Agriculture & 964,948 & 0 & $1,196.40$ & 635.2 & $3,449.5$ & $6,625.0$ & $4,921.4$ \\
\hline & Wetlands & 271,717 & 486.5 & 813.3 & 652.8 & $4,502.4$ & $6,600.5$ & $5,922.7$ \\
\hline & Other & 404,813 & 0 & 90.3 & 39.9 & 256.9 & $1,026.6$ & 501.5 \\
\hline & Total & $3,052,623$ & $3,469.2$ & $7,493.7$ & $5,593.5$ & $25,511.6$ & $46,002.2$ & $37,083.2$ \\
\hline
\end{tabular}




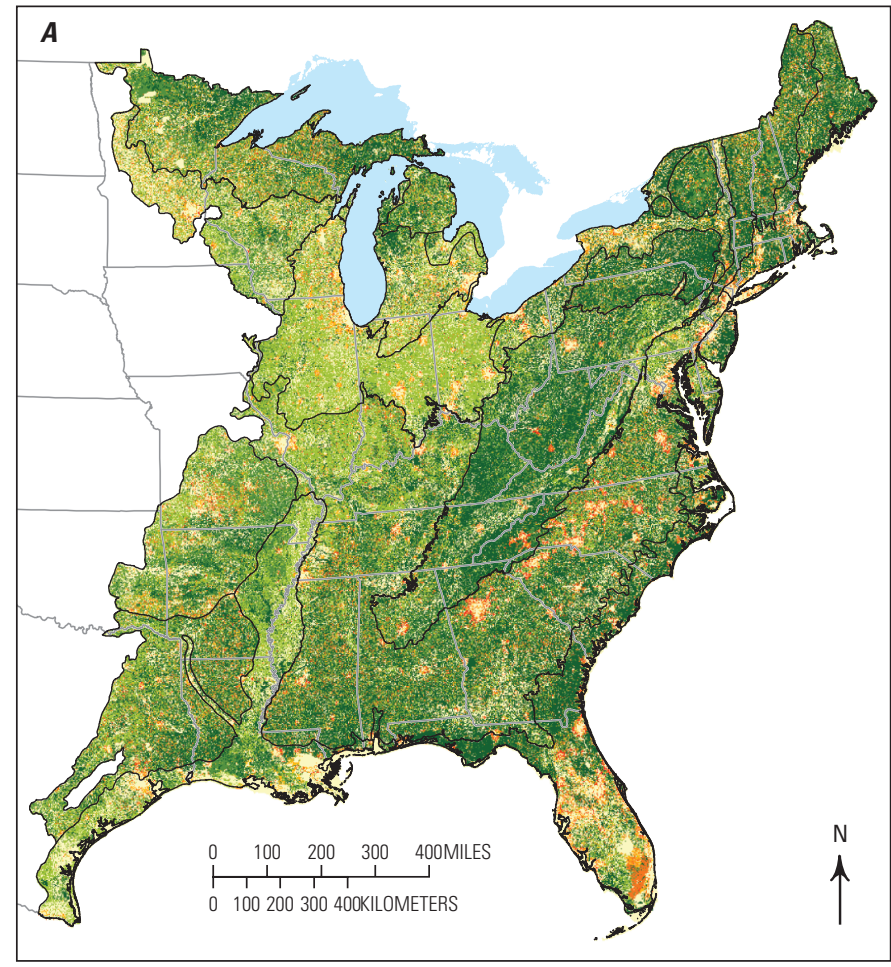

EXPLANATION

Total mean net carbon flux averaged annually from 2006 to 2050, in kilograms of carbon per square meter per year

\begin{tabular}{l|l}
\hline$\leq-5$ & 0.5 to 1.9 \\
-5 to -2.1 & 2.0 to 4.9 \\
-2 to -0.6 & $\geq 5$ \\
-0.5 to 0.4 & \\
\hline & Level II ecoregion boundary
\end{tabular}
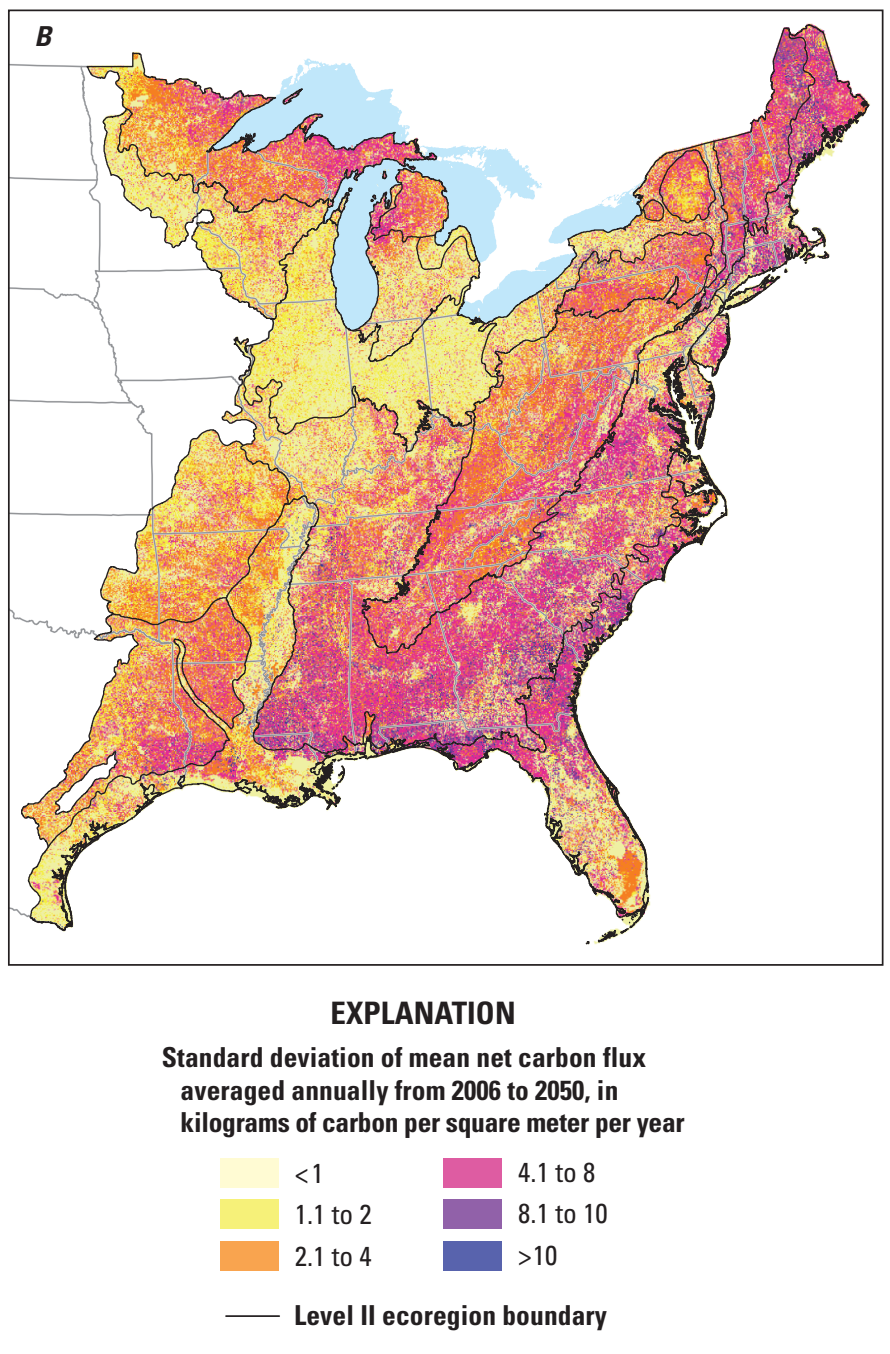

Figure 7-9. Maps showing the projected $A$, average annual and $B$, standard deviation of net ecosystem carbon balance (NECB) in the Eastern United States, averaged annually from 2006 to 2050. Projected average annual NECB was derived from 21 simulation model runs using biogeochemical models Land GHG Accounting Tool, Century, and Erosion Deposition Carbon Model, Intergovernmental Panel on Climate Change Special Report on Emissions Scenarios (Nakićenović and others, 2000) scenarios A1B, A2, and B1, and general circulation models Third Generation Coupled Global Climate Model of the Canadian Centre for Climate Modelling and Analysis, Australia's Commonwealth Scientific and Industrial Research Organisation Mark 3.0, and Model for Interdisciplinary Research on Climate 3.2, medium resolution. Negative average annual NECB values indicate projected carbon sinks or carbon gains by terrestrial ecosystems, and positive values denote projected carbon losses. Level II ecoregions are shown in figure 1-1.

agricultural lands $\left(-22 \mathrm{gC} / \mathrm{m}^{2} / \mathrm{yr}\right)$, grasslands/shrublands $\left(-16.7 \mathrm{gC} / \mathrm{m}^{2} / \mathrm{yr}\right)$, and other lands $\left(-11.1 \mathrm{gC} / \mathrm{m}^{2} / \mathrm{yr}\right)$. On average, about 64.3 percent of the total carbon was projected to accumulate in live biomass, 20.3 percent in soil organic carbon, and about 15.4 percent in dead biomass (forest litter and dead, woody debris). Forests were projected to be the primary carbon sink with $-157.6 \mathrm{TgC} / \mathrm{yr}$ in the Eastern United States in the future.

\subsubsection{Mixed Wood Shield}

In the Mixed Wood Shield ecoregion, the projected mean annual net ecosystem carbon balance (NECB) values between 2006 and 2050 of the 21 model simulations used in this assessment ranged from -26 to $0.6 \mathrm{TgC} / \mathrm{yr}$, depending on land-use and land-cover scenario, climate-change projection, and biogeochemical model (table 7-8). On average, this ecoregion can be a carbon sink with the sequestration rate of $-16.3 \mathrm{TgC} / \mathrm{yr}$. Among the different ecosystems, wetlands were projected to gain $-8.1 \mathrm{TgC} / \mathrm{yr}$ (49.7 percent of the total) averaged across all model runs, followed by forests with an average of $-7.3 \mathrm{TgC} / \mathrm{yr}$ (44.8 percent of the total), agricultural lands with an average of $-0.8 \mathrm{TgC} / \mathrm{yr}$ ( 4.9 percent of the total), and the sum of the rest of the ecosystems averaging $-0.2 \mathrm{TgC} / \mathrm{yr}$ (less than 1 percent of the total). 


\subsubsection{Atlantic Highlands}

The projected mean annual NECB values in the Atlantic Highlands ecoregion between 2006 and 2050 ranged from -34.8 to $-1.8 \mathrm{TgC} / \mathrm{yr}$ across 21 model simulations used in this assessment (table 7-8) with an average of $-23.5 \mathrm{TgC} / \mathrm{yr}$. The projected mean annual NECB for forests in this ecoregion was $-22.1 \mathrm{TgC} / \mathrm{yr}$ (or 94 percent of the total) across all model runs, followed by wetlands (3.8 percent of the total) and agricultural lands (1.3 percent of the total).

\subsubsection{Mixed Wood Plains}

The projected mean annual NECB values in the Mixed Wood Plains between 2006 and 2050 ranged from -41.7 to $2.5 \mathrm{TgC} / \mathrm{yr}$ across all 21 model simulations used in this assessment (table 7-8). The projected mean annual NECB for forests $(-18 \mathrm{TgC} / \mathrm{yr})$ in this ecoregion accounted for 76.9 percent of the total, followed by wetlands (12 percent of the total) and agricultural lands (8.1 percent of the total).

\subsubsection{Central USA Plains}

The projected means of annual NECB in the Central USA Plains ecoregion between 2006 and 2050 ranged from -11.7 to $0.6 \mathrm{TgC} / \mathrm{yr}$ (table $7-8$ ) across all 21 model simulations used in this assessment. Generally, this ecoregion was projected to be a carbon sink, with a mean carbon sequestration rate of $-5.8 \mathrm{TgC} / \mathrm{yr}$. The dominant ecosystem in the ecoregion, agricultural lands, was projected to contribute about 50 percent of the total carbon sequestration, followed by forests (31 percent of the total), other lands (10.4 percent), and wetlands (8.6 percent).

\subsubsection{Southeastern USA Plains}

The projected means of annual NECB in the Southeastern USA Plains ecoregion between 2006 and 2050 ranged from -157.3 to $5 \mathrm{TgC} / \mathrm{yr}$ according to 21 model simulations used in this assessment. The projected average NECB of $-79.4 \mathrm{TgC} / \mathrm{yr}$ makes this ecoregion the greatest carbon sink in the Eastern United States. Among different ecosystems, forests were projected to accumulate the most carbon (70.7 percent of the total), followed by wetlands (17.1 percent), agricultural lands (10.2 percent), and grasslands/shrublands ( 0.4 percent). The total carbon sequestration the rest ecosystems contributed about 2 percent.

\subsubsection{Ozark, Ouachita-Appalachian Forests}

In the Ozark, Ouachita-Appalachian Forests ecoregion, the projected means of annual NECB between 2006 and 2050 as simulated by the 21 model runs used in this assessment ranged from -76.9 to $-5.7 \mathrm{TgC} / \mathrm{yr}$ (table $7-8$ ) with an average estimate of $-44.2 \mathrm{TgC} / \mathrm{yr}$, which makes this ecoregion the second largest carbon sink in the Eastern United States. Among the different ecosystems, forests were projected to gain $-40 \mathrm{TgC} / \mathrm{yr}$, which contributed 90.1 percent of the total carbon sequestration, and agricultural lands, which accounted for about 7.5 percent.

\subsubsection{Mississippi Alluvial and Southeast USA Coastal Plains}

In the Mississippi Alluvial and Southeast USA Coastal Plains ecoregion, the projected meansof annual NECB between 2006 and 2050 representing the 21 model simulations used in this assessment ranged from -55.3 to $0.2 \mathrm{TgC} / \mathrm{yr}$. Of this total, wetlands were projected to accumulate the most carbon $(45.3$ percent of the total), followed by forests ( 37.9 percent) and agricultural lands (12.1 percent). Grasslands/shrublands and other lands were projected to account for about 4.7 percent of the total mean annual NECB in this ecoregion.

\subsubsection{Projected GHG Fluxes}

The projected minimum, maximum, and average of annual GHG fluxes from 2006 to 2050 are listed by ecoregion and ecosystem in table 7-9. Temporal trends of the projected future fluxes of the three GHG between 2000 and 2050 are shown in figure 7-10. The projected future $\mathrm{GHG}$ fluxes for $\mathrm{CO}_{2}, \mathrm{~N}_{2} \mathrm{O}$, and $\mathrm{CH}_{4}$ averaged $-824.6 \mathrm{TgCO}_{2}$-eq/yr, 174.7 $\mathrm{TgCO}_{2}$-eq/yr, and 198.71 $\mathrm{TgCO}_{2}$-eq/yr, respectively. The overall GWP from 2006 through 2050 averaged $-451.2 \mathrm{TgCO}_{2}$-eq/yr.

\subsection{Discussion}

\subsubsection{Effects of Uncertainty of Models, LULC Scenarios, and GCMs on Carbon Sequestration Estimates}

Table 7-10 lists the projected estimates of average carbon stocks in 2050, average annual NECB from 2006 to 2050 , and corresponding relative variability (variability index, as described in the Definitions of Carbon Stocks and Fluxes and Uncertainty section) by model, LULC scenario, and GCM. The variability index of the carbon stocks and NECB estimated by the three models indicates the uncertainty introduced by these models. Among the three biogeochemical models for the Eastern United States, the Century model and the LGAT gave a highest and lowest projected estimates, respectively, whereas the projection by the EDCM model fell generally in the middle although a lot closer to that of the Century model. For simulating carbon stock, the models performed differently across ecoregions with the smallest discrepancy found in the Central USA Plains ecoregion (15.1 percent variability across three models), and the highest, in the Southeastern USA Plains ecoregion (49.1 percent). For 
Table 7-8. Projected net ecosystem carbon balance values simulated in 21 model runs and averaged between 2006 and 2050 in the Eastern United States.

[Negative net ecosystem carbon balance (NECB) values indicate carbon uptake or sequestration by ecosystems. Only soil organic carbon (SOC) in the top $20 \mathrm{~cm}$ of the soil layer was calculated. Data may not add to totals shown due to independent rounding. $\mathrm{km}^{2}$, square kilometers; max, maximum; min, minimum; $\mathrm{TgC}$, teragrams (or $10^{12}$ grams) of carbon]

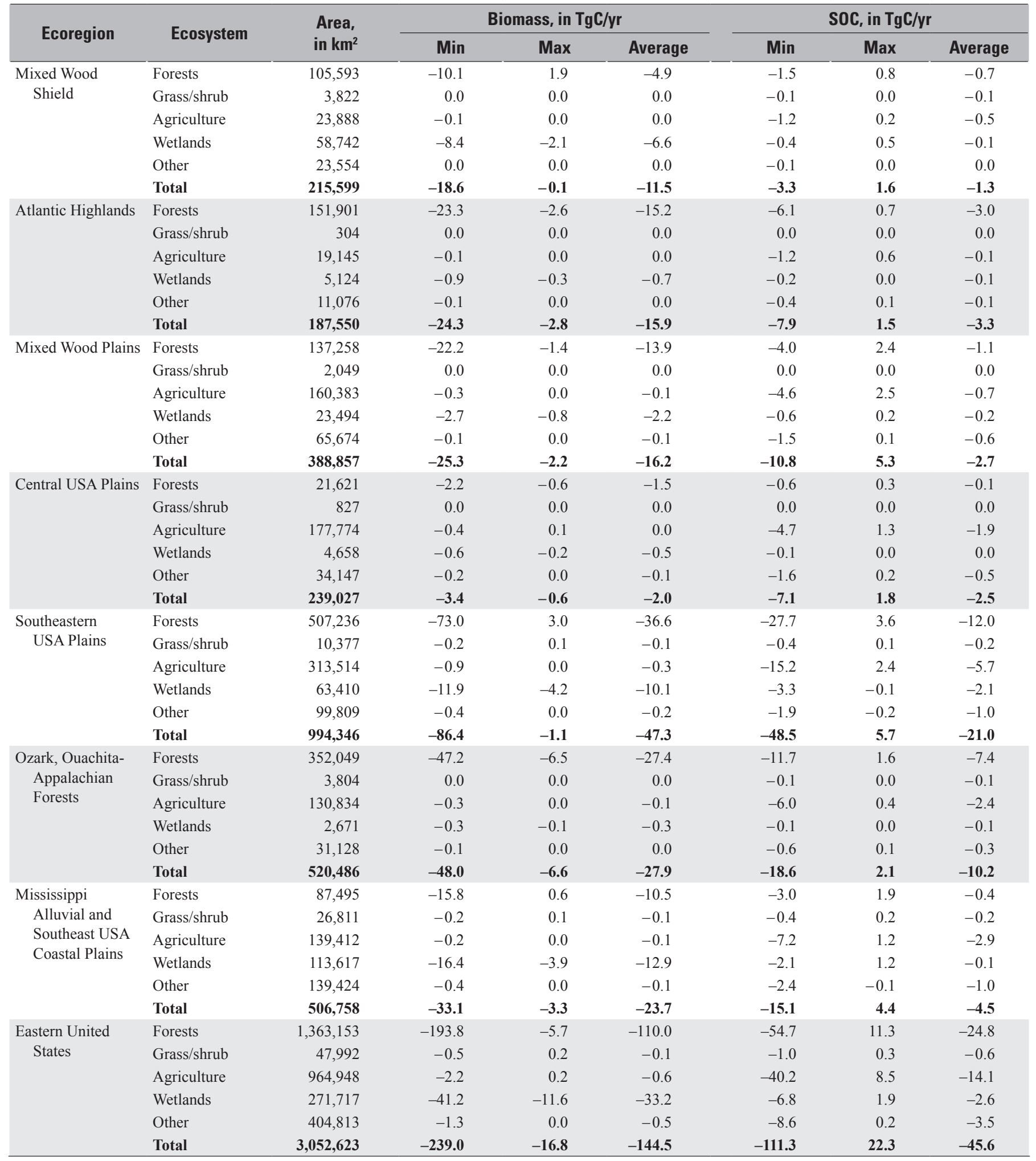


Table 7-8. Projected net ecosystem carbon balance values simulated in 21 model runs and averaged between 2006 and 2050 in the Eastern United States.-Continued

[Negative net ecosystem carbon balance (NECB) values indicate carbon uptake or sequestration by ecosystems. Only soil organic carbon (SOC) in the top $20 \mathrm{~cm}$ of the soil layer was calculated. Data may not add to totals shown due to independent rounding. $\mathrm{km}^{2}$, square kilometers; max, maximum; min, minimum; $\mathrm{TgC}$, teragrams (or $10^{12}$ grams) of carbon]

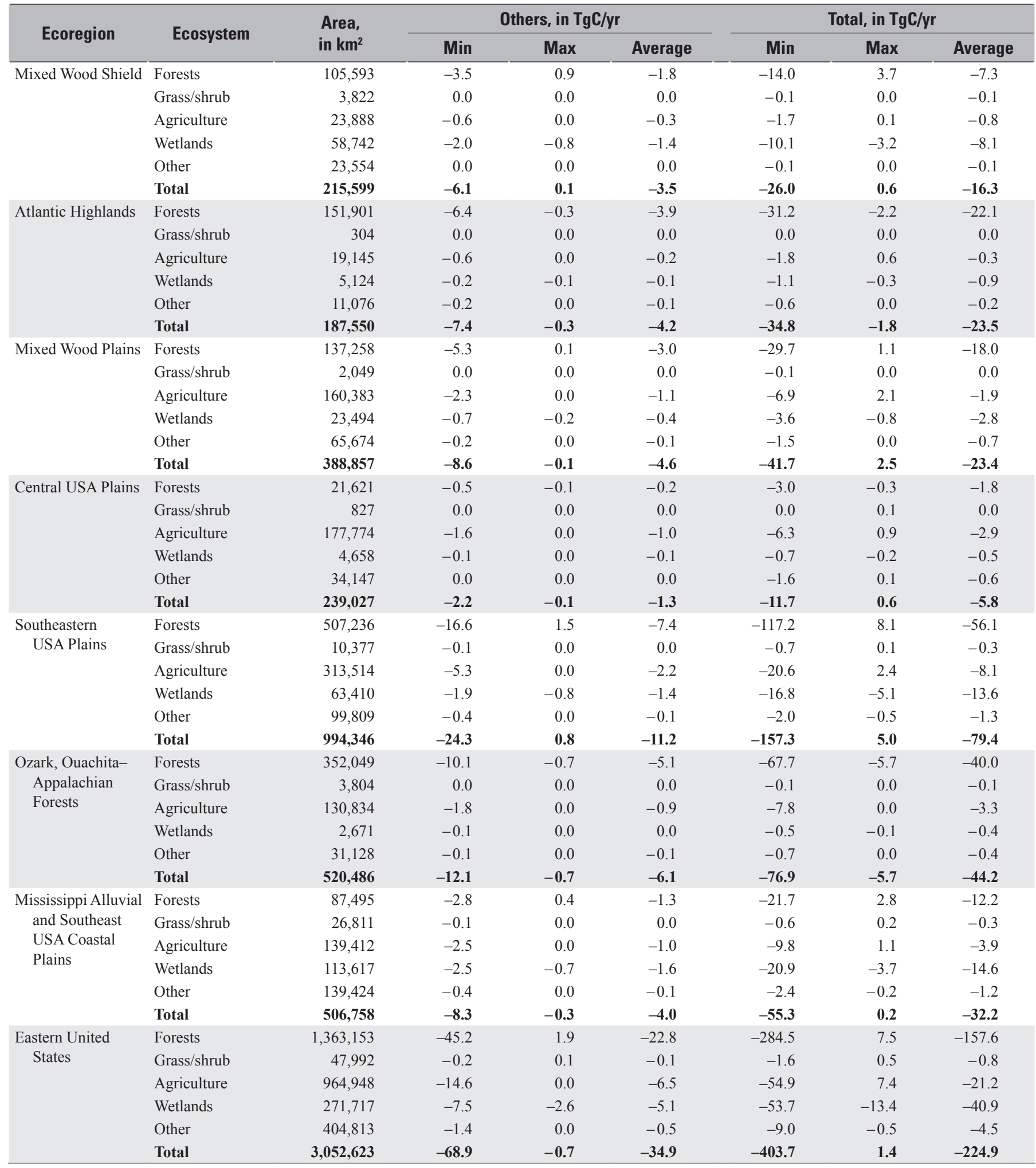


Table 7-9. Projected average annual nutrient fluxes and total global warming potential (GWP), averaged from 2006 to 2050, in the Eastern United States.

[Nutrient fluxes are for carbon dioxide $\left(\mathrm{CO}_{2}\right)$, methane $\left(\mathrm{CH}_{4}\right)$, and nitrous oxide $\left(\mathrm{N}_{2} \mathrm{O}\right)$. Projected fluxes of methane and nitrous oxide were estimated by the land GHG accounting tool (LGAT), and projected flux of carbon dioxide was calculated using net ecosystem carbon balance (NECB) values from table 7-8. $\mathrm{TgCO}_{2}$-eq, teragrams (or $10^{12}$ grams) of carbon dioxide equivalent per year]

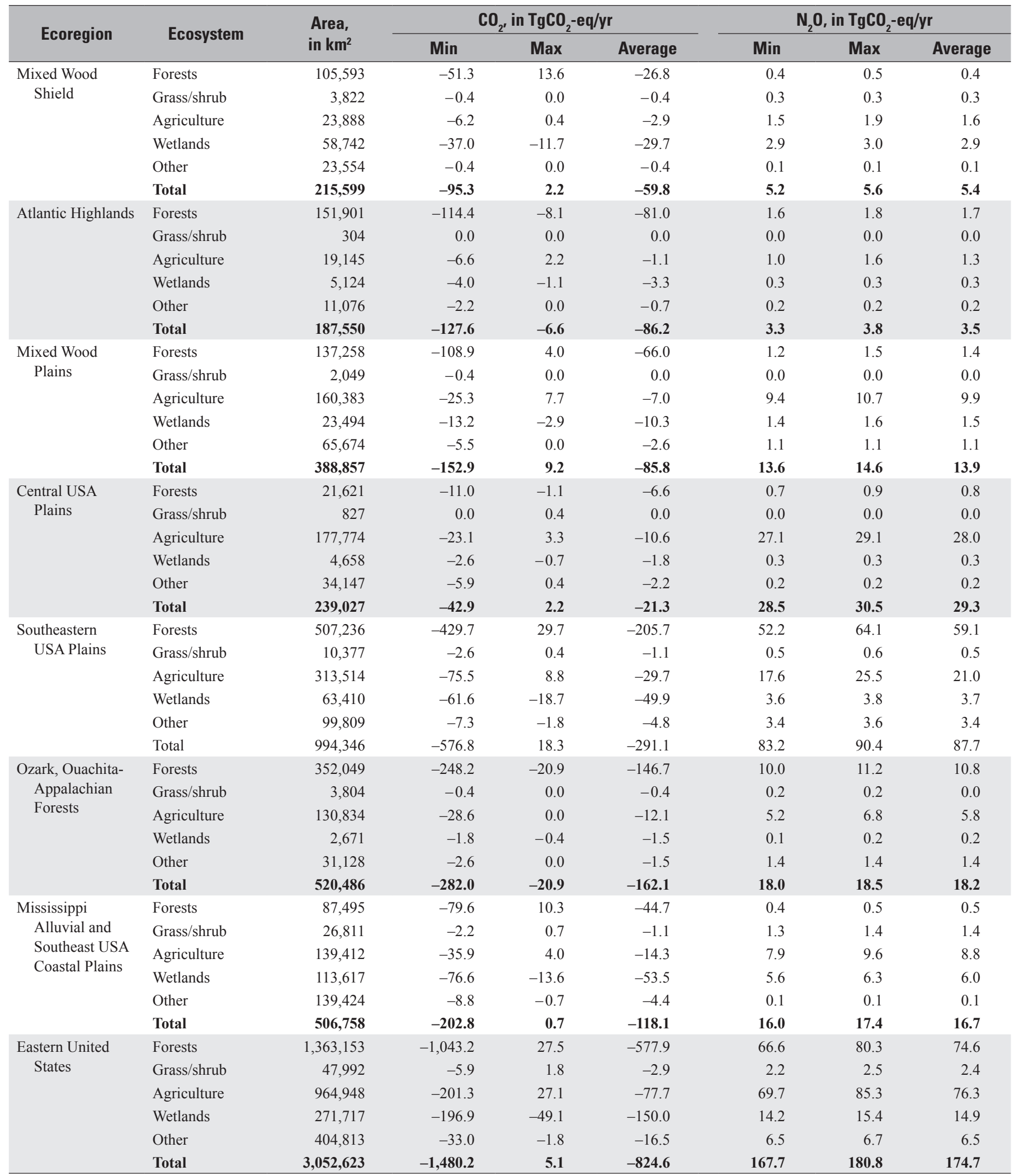


Table 7-9. Projected average annual nutrient fluxes and total global warming potential (GWP), averaged from 2006 to 2050, in the Eastern United States.-Continued

[Nutrient fluxes are for carbon dioxide $\left(\mathrm{CO}_{2}\right)$, methane $\left(\mathrm{CH}_{4}\right)$, and nitrous oxide $\left(\mathrm{N}_{2} \mathrm{O}\right)$. Projected fluxes of methane and nitrous oxide were estimated by the land GHG accounting tool (LGAT), and projected flux of carbon dioxide was calculated using net ecosystem carbon balance (NECB) values from table 7-8.

$\mathrm{TgCO}_{2}$-eq, teragrams (or $10^{12}$ grams) of carbon dioxide equivalent per year]

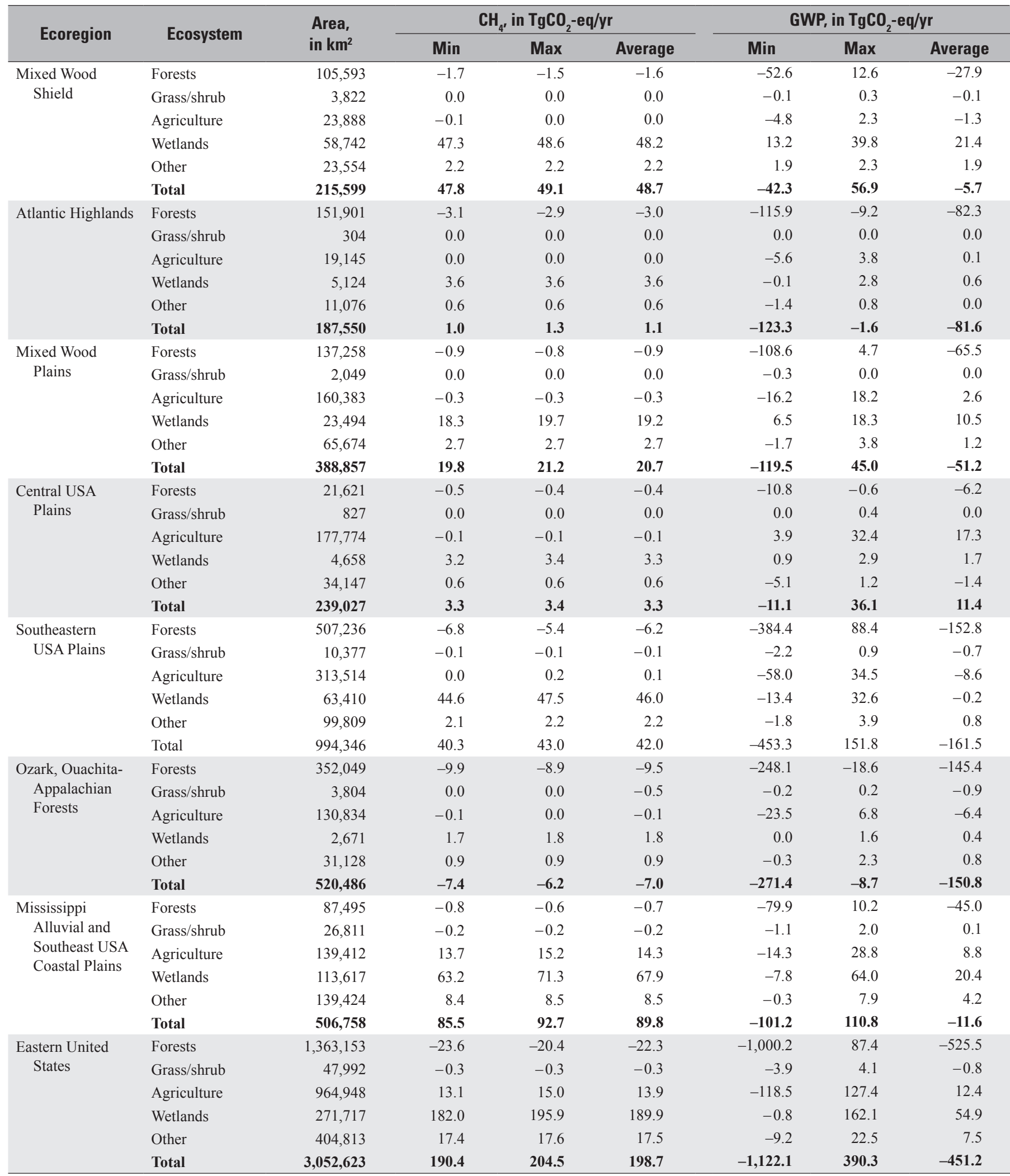



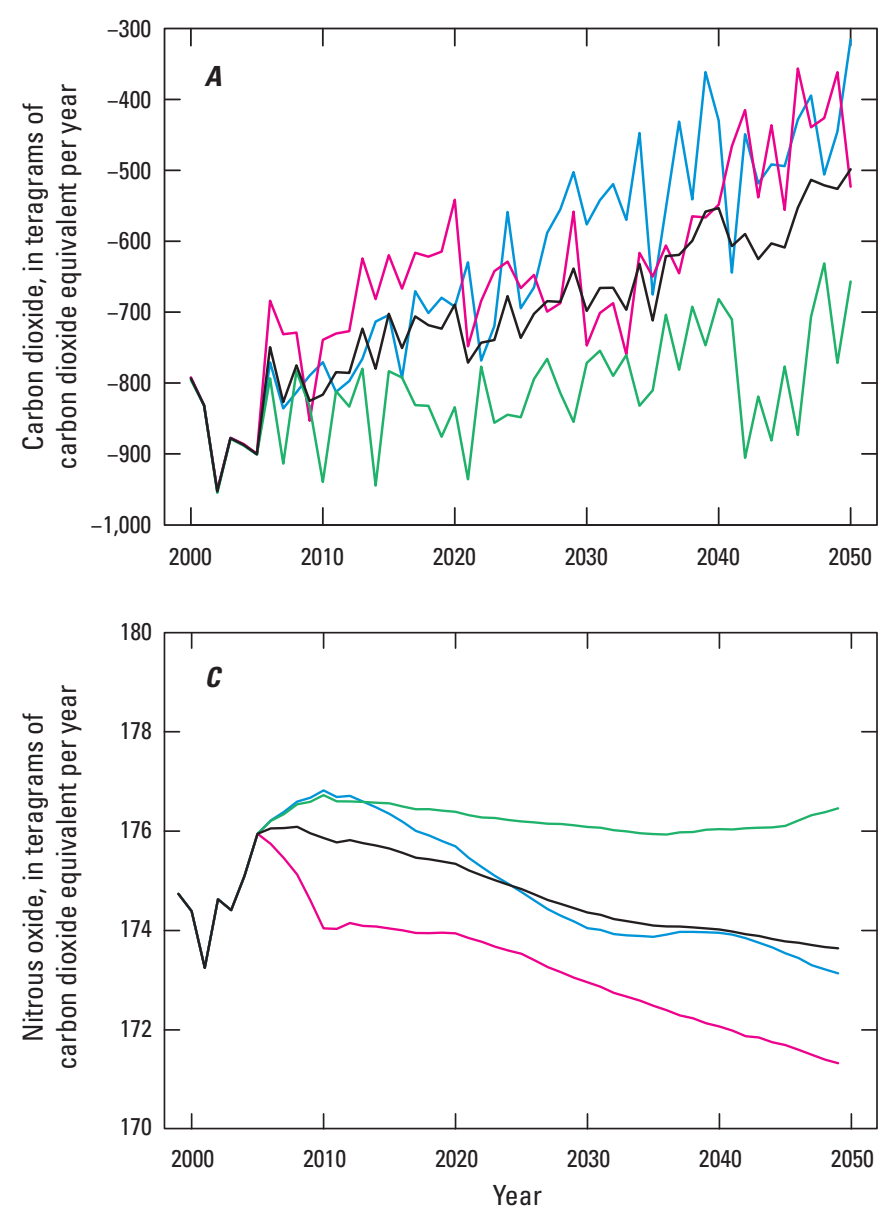

the projected average annual NECB estimates, the Century model almost always yielded the highest estimates, followed by the EDCM and the LGAT. The relative variability among the models in projecting the average annual NECB was very high, ranging from 110.2 percent in the Mixed Wood Plains to 154.6 percent in the Central USA Plains.

The three LULC scenarios (A1B, A2, and B1) were adapted for the assessment based on social, economic, and biophysical conditions embedded in the SRES scenarios (chaps. 2 and 3). Among the three scenarios, the relative variability of the estimated carbon stock was small, ranging from 2.9 to 12.1 percent across the ecoregions. The relative variability of the projected average annual NECB under these scenarios, higher than that of carbon stock, ranged from 13.3 percent in the Central USA Plains to 32.5 percent in the Southeastern USA Plains ecoregion. The higher variability of the projected average annual NECB across scenarios in some ecoregions compared with the carbon stock variability did not necessarily indicate that there was a large difference among the results of the scenario modeling. The high variability may have been simply related to the low projected average annual NECB estimates and how the percent variability was defined.

The effect of climate uncertainty introduced by the GCMs on projected carbon sequestration is reflected by the variability of carbon estimates across GCMs. The relative
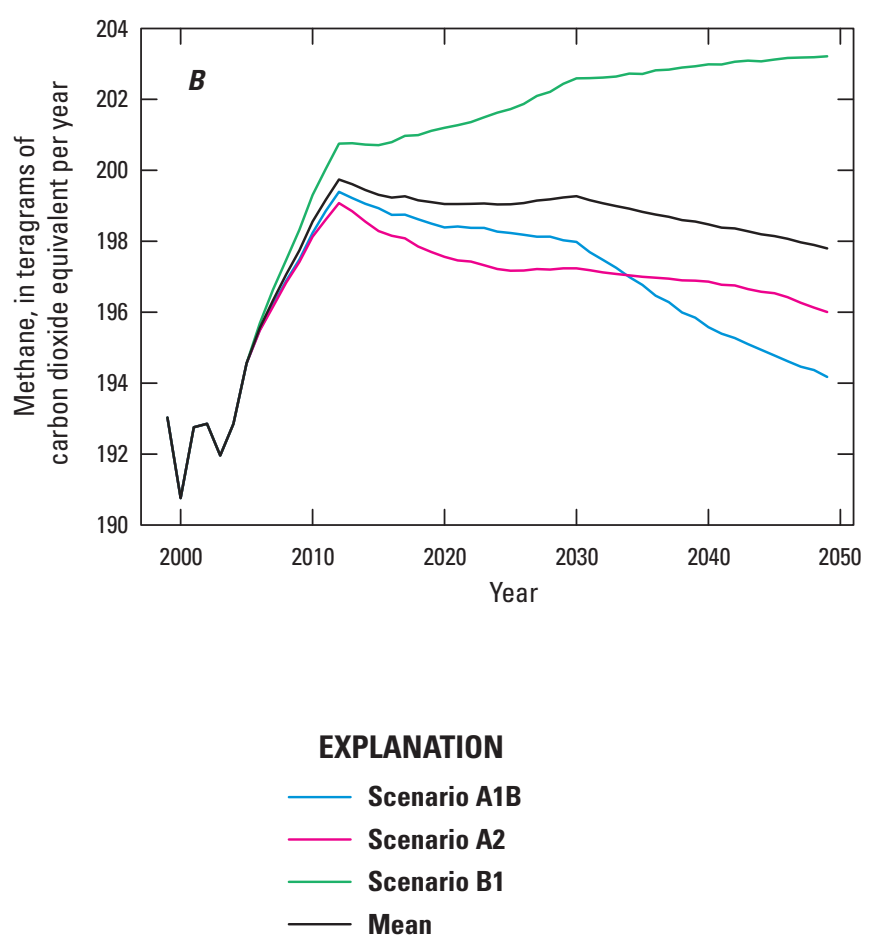

Figure 7-10. Graphs showing the baseline and projected temporal changes in global warming potential of $A$, carbon dioxide, $B$, methane, and $C$, nitrous oxide fluxes in the Eastern United States from 2006 through 2050. $\mathrm{TgCO}_{2}$-eq/yr, teragrams of carbon dioxide equivalent per year.

variability that may be attributed to GCM uncertainty ranged from 1 to 4.1 percent for projected carbon stocks and from 7.9 to 15.9 percent for the projected average annual NECB across the ecoregions (table 7-10).

Comparing the relative variability or uncertainty of carbon estimates demonstrated by the models, LULC scenarios, and GCMs (table 7-10), the biogeochemical models introduced the highest relative uncertainty, varying from 110.2 to 148.8 percent, followed by LULC scenarios (from 13.3 to 32.5 percent) and GCMs (from 7.9 to 15.9 percent). The uncertainty of biogeochemical models overwhelmed the uncertainty from the other two.

\subsubsection{Comparison of Results With Other Studies}

On average, the terrestrial ecosystems (forests, agricultural lands, grasslands and shrublands, wetlands, and other lands) in the seven ecoregions of the Eastern United States stored a total $26,962 \mathrm{TgC}$ (table 7-4) during the baseline period. Carbon in biomass pools (such as live and dead vegetative materials aboveground and belowground, except for those removed from agricultural fields and forests) accounted for $15,352 \mathrm{TgC}$ ( 57 percent) of the total, and the rest was stored in the top $20 \mathrm{~cm}$ of the soil layer. Carbon stored in other pools (such as grain and woody biomass removed from the 
Table 7-10. Comparison of projected average carbon stocks in 2050 and projected average annual net ecosystem carbon balance from 2006 to 2050 in the Eastern United States.

[Derived from combinations of three biogeochemical models, three land-use and land-change scenarios, and three general circulation models. The "variability index," which is also presented, was calculated as a percentage measure for each of the three subsets of the model runs by dividing the range of the minimum and maximum estimates of the subset by their average and multiplying by 100]

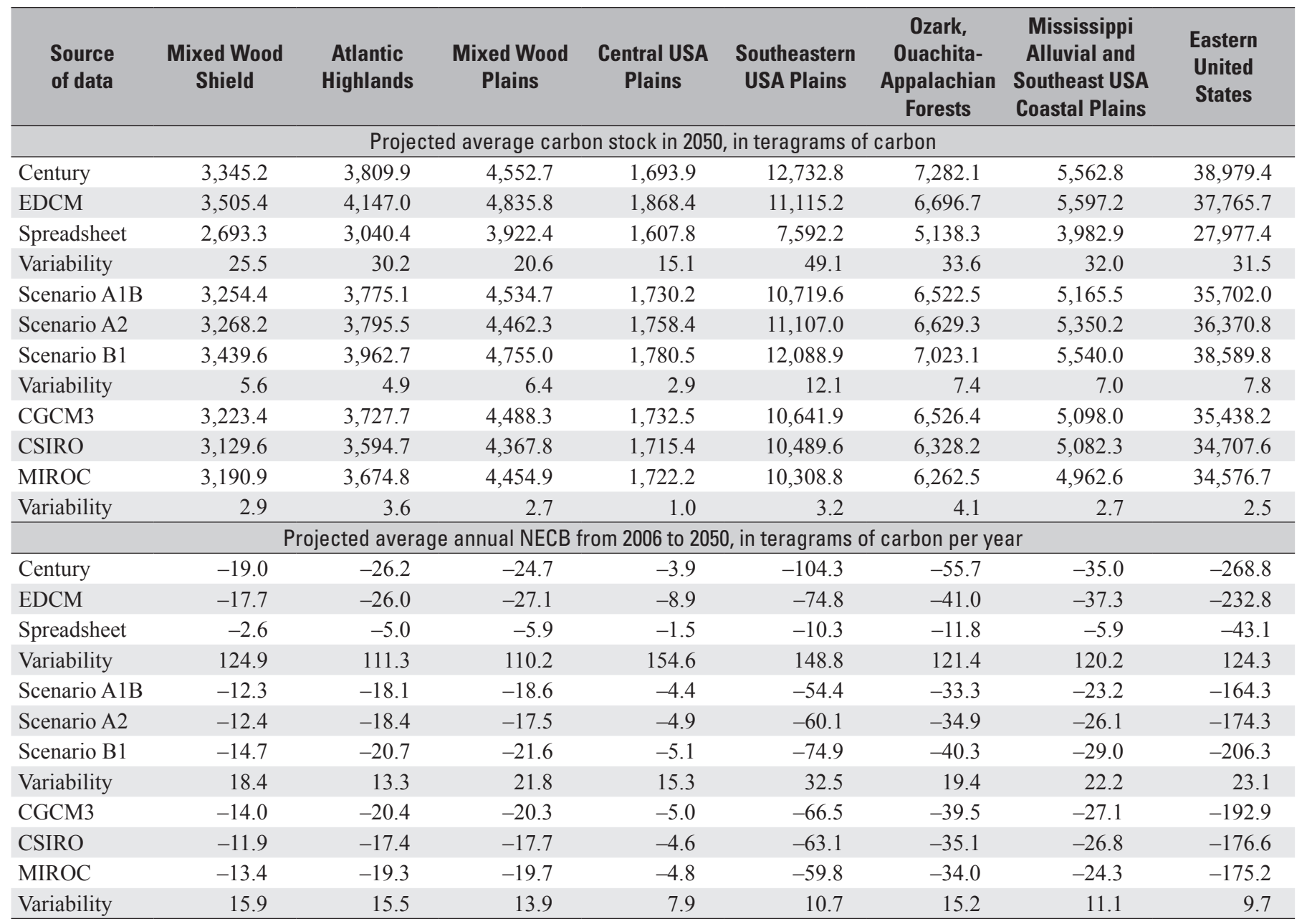

landscape) was not estimated in this assessment, although its influx was calculated.

For the baseline period, the estimated forest live biomass carbon for the entire Eastern United States was 9,686 TgC on $1.461 \mathrm{Mkm}^{2}$ (146.1 million hectares (Mha)) of forested areas, which was lower than a recent Forest Service estimate of $11,249 \mathrm{TgC}$ on a larger land base of 155.4 Mha (U.S. Department of Agriculture, 2008). In terms of carbon density, forest live biomass from this assessment $\left(6.6 \mathrm{kgC} / \mathrm{m}^{2}\right)$ was about 10 percent lower than that of the Forest Service study at $7.3 \mathrm{kgC} / \mathrm{m}^{2}$. The dead biomass (dead wood and forest floor) from this assessment was estimated to be $3,209 \mathrm{TgC}\left(2.2 \mathrm{kgC} / \mathrm{m}^{2}\right)$, which was very close to the Forest Service estimate of $3,188 \mathrm{TgC}\left(2.1 \mathrm{kgC} / \mathrm{m}^{2}\right)$.

The average carbon sequestration rate or NECB of all terrestrial ecosystems in the Eastern United States was estimated to decline from $-279.4 \mathrm{TgC} / \mathrm{yr}$ during the baseline period to $-224.9 \mathrm{TgC} / \mathrm{yr}$ during the projection period. The decrease of the carbon sink strength of Eastern United States over time may be attributed largely to potential forest aging and reduced soil organic carbon accumulation. Several studies have noted the maturity of recovered forest lands in the Eastern United States (particularly in the northeastern region) since the early 20 th century, hence the reduced contribution of active carbon production by the forests. Major processes contributing to the reduced SOC accumulation in the Eastern United States may include (1) the re-equilibration of soils to the rates of addition of organic matter as soils slowly recover from the soil organic matter that was lost following abandonment of agriculture around the beginning of the 20th century, (2) acceleration of the waning of the sink strength due to climate warming (as soil temperatures and biological activities increase with climate warming, rates of soil organic matter decomposition increase northwards; Melvin and Goodale, 
2013), and (3) genetic improvement of plants, especially crops, that will enhance organic matter production and therefore likely increase carbon storage in soils.

The average rate of sequestration by forests in the Eastern United States estimated in this assessment was $-155 \mathrm{gC} / \mathrm{m}^{2} / \mathrm{yr}$ ( $-226.2 \mathrm{TgC} / \mathrm{yr}$ on $146.1 \mathrm{Mha}$ ), including $-36 \mathrm{gC} / \mathrm{m}^{2} / \mathrm{yr}$ for soil carbon increase and $-119 \mathrm{gC} / \mathrm{m}^{2} / \mathrm{yr}$ for live and dead biomass carbon increase. By comparison, the Forest Service estimate (U.S. Department of Agriculture, 2008) estimated the forest sequestration rate in combined aboveground and belowground live and dead biomass pool to be $-60 \mathrm{gC} / \mathrm{m}^{2} / \mathrm{yr}$ ( $-93.3 \mathrm{TgC} / \mathrm{yr}$ on $155.4 \mathrm{Mha})$. Therefore, the per-unit-area estimate for carbon sequestration in the biomass pool is twice as large from this assessment compared with that from the Forest Service study. Causes to the difference in the estimates of carbon sequestration are many, including different forest areas, definitions, years of studies, and methods, and can be complex; the variability and associated uncertainties in many existing studies summarized in table 1-2 range from $-82.8 \mathrm{gC} / \mathrm{m}^{2} / \mathrm{yr}$ for major forest types in the Eastern United States (Williams and others, 2012) to $-243 \mathrm{gC} / \mathrm{m}^{2} / \mathrm{yr}$ for all forests in the Eastern United States (Turner and others, 1995). Carbon removals, especially clearcutting and thinning, are also critical components that affect the calculation of the rate of sequestration. The carbon removal amount (clear and partial cuttings) was estimated in this assessment to be $41 \mathrm{TgC} / \mathrm{yr}$ for the baseline period, which is significantly lower than in some earlier studies; for example, Williams and others (2012) estimated carbon removal to be about $100 \mathrm{TgC} / \mathrm{yr}$ in the Eastern United States.

NPP values from MODIS for 2001 through 2005 were used to constrain the spatial variability of GEMS NPP simulations. For the entire Eastern United States, the average baseline NPP was about $640 \mathrm{gC} / \mathrm{m}^{2} / \mathrm{yr}$, generally matching that of other regional studies. Mickler and others (2002) reported that forest NPP of the Southeastern United States was between 644 and $711 \mathrm{gC} / \mathrm{m}^{2} / \mathrm{yr}$ (converted from biomass according to a standard conversion factor of 0.5 given by Eggleston and others (2006)). One challenge in validating NPP simulations is the scarcity of the NPP estimates compared with the aboveground NPP (ANPP) estimates because of the difficulties in measuring belowground NPP. In order to compare belowground NPP estimates with available ANPP estimates, ANPP from this assessment was estimated to be $448 \mathrm{gC} / \mathrm{m}^{2} / \mathrm{yr}$, using the forest NPP estimate of $640 \mathrm{gC} / \mathrm{m}^{2} / \mathrm{yr}$ and a conversion factor of 0.7 from forest NPP to ANPP according to field studies (Whittaker and Woodwell, 1969; Harris and others, 1975; Benecke and Nordmeyer, 1982; Gholz and Fisher, 1982; Ryan and others, 1996, 1997; Curtis and others, 2002; Maier and others, 2004). This value for ANPP would agree well with other estimations generated using inventory or site-specific methods. For example, Brown and Schroeder (1999) reported that the ANPP in forests in the Eastern United States averaged $435 \mathrm{gC} / \mathrm{m}^{2} / \mathrm{yr}$ and $485 \mathrm{gC} / \mathrm{m}^{2} / \mathrm{yr}$ for hardwood and softwood types, respectively. Jenkins and others (2001) reported that the average forest ANPPs in the mid-Atlantic region were $393 \mathrm{gC} / \mathrm{m}^{2} / \mathrm{yr}$ and $430 \mathrm{gC} / \mathrm{m}^{2} / \mathrm{yr}$ for hardwood and softwood types, respectively.

Another comparison for ecosystem carbon sequestration may be made with $\mathrm{CO}_{2} \mathrm{NEE}$ for an entire ecosystem, estimated with the eddy covariance technique (table 7-11). The eddy covariance technique has been central to measuring the magnitude and variation of NEE in various ecosystems and the effects of disturbances and climate change (Loescher and others, 2006). Although NEE values listed in table 7-11 showed large variations across sites, most ecosystems showed

Table 7-11. Net ecosystem exchange of carbon dioxide measured in various ecosystems in the Eastern United States using eddy covariance techniques.

[Negative net ecosystem exchange (NEE) of carbon dioxide $\left(\mathrm{CO}_{2}\right)$ indicates carbon uptake by ecosystems. $\mathrm{gC} / \mathrm{m}^{2} / \mathrm{yr}$, grams per square meter per year]

\begin{tabular}{|c|c|c|c|c|}
\hline Forest ecosystem & $\begin{array}{l}\text { NEE, in } \\
\mathrm{gC} / \mathrm{m}^{2} / \mathrm{yr}\end{array}$ & Location of site & Location & Reference \\
\hline Deciduous broad-leaved forest & -370 & Harvard Forest, Mass. & $42^{\circ} 54^{\prime} \mathrm{N}, 72^{\circ} 18^{\prime} \mathrm{W}$ & Wofsy and others (1993) \\
\hline Deciduous broad-leaved forest & -140 & Harvard Forest, Mass. & $42^{\circ} 54 \mathrm{~N}, 72^{\circ} 18^{\prime} \mathrm{W}$ & Goulden and others (1996) \\
\hline Slash pine plantation & -740 & Gainesville, Fla. & $29^{\circ} 44 \mathrm{~N}, 82^{\circ} 09^{\prime} \mathrm{W}$ & Clark and others (1999) \\
\hline Scrub oak ecosystem & -287 & Kissimmee-St. Cloud, Fla. & $28^{\circ} 36^{\prime} \mathrm{N}, 80^{\circ} 42^{\prime} \mathrm{W}$ & Powell and others (2006) \\
\hline Deciduous forest & -525 & Oak Ridge, Tenn. & $35^{\circ} 57^{\prime} \mathrm{N}, 84^{\circ} 17^{\prime} \mathrm{W}$ & Greco and Baldocchi (1996) \\
\hline Mixed hardwood and boreal forests & -119 & $\begin{array}{l}\text { University of Michigan } \\
\text { Biological Station, Mich. }\end{array}$ & $45^{\circ} 35^{\prime} \mathrm{N}, 84^{\circ} 42^{\prime} \mathrm{W}$ & Curtis and others (2002) \\
\hline Mix of upland forests and wetlands & -220 & Willow Creek, Wisc. & $45^{\circ} 47^{\prime} \mathrm{N}, 90^{\circ} 05^{\prime} \mathrm{W}$ & Curtis and others (2002) \\
\hline Deciduous broad-leaved forest & -280 & Harvard Forest, Mass. & $42^{\circ} 54^{\prime} \mathrm{N}, 72^{\circ} 17^{\prime} \mathrm{W}$ & Urbanski and others (2007) \\
\hline Loblolly pine plantation & 106 & $\begin{array}{l}\text { Southeast Tree Research and } \\
\text { Education Site, Scotland } \\
\text { County, N.C. }\end{array}$ & $34^{\circ} 48^{\prime} \mathrm{N}, 79^{\circ} 12^{\prime} \mathrm{W}$ & Lai and others (2002) \\
\hline
\end{tabular}


carbon sequestration. For example, Wofsy and others (1993) reported an NEE of $-370 \mathrm{gC} / \mathrm{m}^{2} / \mathrm{yr}$ at the Harvard Forest. Goulden and others (1996) reported that the annual net uptake of $\mathrm{CO}_{2}$ by a deciduous forest in New England (the Atlantic Highlands and Mixed Wood Plains ecoregions) ranged from $-140 \mathrm{gC} / \mathrm{m}^{2} / \mathrm{yr}$ to $280 \mathrm{gC} / \mathrm{m}^{2} / \mathrm{yr}$. Falge and others (2002) estimated the NEE of a temperate deciduous forest to be $-181 \mathrm{gC} / \mathrm{m}^{2} / \mathrm{yr}$.

Bracho and others (2012) used eddy covariance and biometric approaches to measure carbon dynamics in two slash pine plantations (Pinus elliottii var. elliottii Englm) in northern Florida (in the Mississippi Alluvial and Southeast USA Coastal Plains ecoregion) over 9 years with frequent drought events and observed that the NEE magnitude fluctuated with environmental conditions (for example, drought events) from -800 to $-400 \mathrm{gC} / \mathrm{m}^{2} / \mathrm{yr}$ and documented a drought-induced reduction of 20 percent in NEE. Similarly, Clark and others (2010) reported that invasive insects led to defoliation in a mixed stand in New Jersey (in the Mississippi Alluvial and Southeast USA Coastal Plains ecoregion) from 2005 through 2007 and resulted in a 20 to 41 percent NEE reduction.

After analyzing a global database, Luyssaert and others (2007) found that the average NEP was $-311 \mathrm{gC} / \mathrm{m}^{2} / \mathrm{yr}$ $\pm 38 \mathrm{gC} / \mathrm{m}^{2} / \mathrm{yr}$ for temperate humid deciduous forests. In addition, the study found that the global pattern for NEP was insensitive to climate and was mainly determined by nonclimatic conditions, such as successional stage, site management, site history, and site disturbance.

In the USGS assessment of the Eastern United States, the average forest carbon sequestration in the baseline period was $-155 \mathrm{gC} / \mathrm{m}^{2} / \mathrm{yr}$, with soil carbon change contributing $-36 \mathrm{gC} / \mathrm{m}^{2} / \mathrm{yr}$ and the live and dead biomass carbon increase representing $-119 \mathrm{gC} / \mathrm{m}^{2} / \mathrm{yr}$. This average value was in the lower range of the measurements made by eddy covariance in the Eastern United States (table 7-11). With support of data obtained from 128 cold temperate and boreal forests across the United States, Reich (2012) found that stand-scale forest productivity is a function of leaf area index and canopy nitrogen concentration, which together explain more than 75 percent of the variation in ANPP among forests.

\subsubsection{Soil Carbon Sequestration Measurements in Agricultural Ecosystems}

The agricultural soils were estimated to be a small SOC sink at an average rate of $-4 \mathrm{gC} / \mathrm{m}^{2} / \mathrm{yr}$ (derived from table 7-5) ranging from a small source of $10 \mathrm{gC} / \mathrm{m}^{2} / \mathrm{yr}$ to a sink of $-21 \mathrm{gC} / \mathrm{m}^{2} / \mathrm{yr}$ for the baseline years. The average value is somewhat smaller than the observed values reported by Tan and others (2006) and Franzluebbers (2010) but shows a relatively higher uncertainty than the reported field measurements. These estimated rates from previous studies came with an assumption that all cropped lands were under conservation tillage, but in reality only about 70 percent of all cropped soils were managed with conservation practices (Conservation Technology Information Center, 2012). The estimated values from this assessment included cropped soils that would be managed with conventional tillage, which likely led to higher SOC carbon source estimates (West and Post, 2002). Projected average net carbon flux in SOC pool for the agricultural lands was a $\mathrm{SOC}$ sink at $-15 \mathrm{gC} / \mathrm{m}^{2} / \mathrm{yr}$, ranging from an almost neutral state to a moderate SOC sink of $-36 \mathrm{gC} / \mathrm{m}^{2} / \mathrm{yr}$.

\subsubsection{Carbon Removal From Forest Harvesting}

Carbon removal from clearcutting and partial forest cuts was estimated to be $41 \mathrm{TgC} / \mathrm{yr}$ from 2001 through 2005, which was lower than an estimate by the Forest Service (Adams and others, 2006) that showed about 110 to $120 \mathrm{TgC} / \mathrm{yr}$ of clearcutting and partial forest cuts by the end of the 1990s. Comparing annual harvest statistics from 2001 through 2005 between the Forest Service RPA studies (Smith and others, 2004, 2009) for the north and south regions of the Forest Service and this assessment (table 7-12) clearly indicates that the issue was the difference in estimating areas of harvesting.

Although forest areas used in the two studies were similar, annual areas harvested were quite different, with Smith and others (2009) reporting approximately 2.5 times the harvest area in this assessment. Area affected from clearcutting and partial cutting in the RPA was reported as $38,091 \mathrm{~km}^{2}$ or 2.45 percent of the total forest area, whereas it was $15,037 \mathrm{~km}^{2}$ or 1.03 percent of the total forest area used in this assessment. Both clear cutting and partial cutting were more than twice as high in the RPA study as in this assessment. The RPA study relied on the approach of forest inventory to estimate harvesting area (Smith and others, 2009), whereas this assessment used datasets derived from remote sensing techniques as described in chapter 3 of this report.

Carbon removal rates, on the other hand, were similar between the RPA study and this assessment at 2.8 kilograms of carbon per square meter per event $\left(\mathrm{kgC} / \mathrm{m}^{2} /\right.$ event $)$ and $2.7 \mathrm{kgC} / \mathrm{m}^{2} /$ event, respectively. The RPA study used $3.6 \mathrm{kgC} / \mathrm{m}^{2} /$ event and $2.3 \mathrm{kgC} / \mathrm{m}^{2} /$ event for clearcutting and partial cutting, compared with $3.8 \mathrm{kgC} / \mathrm{m}^{2} /$ event and $1.8 \mathrm{kgC} / \mathrm{m}^{2} /$ event used in this assessment.

As the result, using the approach described in McKinley and others (2011) and the data from the RPA (Smith and others, 2009), the total carbon removal from the RPA study would be approximately $108 \mathrm{TgC} / \mathrm{yr}$ for the two Forest Service regions in the Eastern United States, compared with $41 \mathrm{TgC} / \mathrm{yr}$ reported in this assessment. The magnitude of difference is similar for both clearcutting and partial cutting (table 7-12).

Evidence from this assessment shows that the effect of discrepancies in estimating areas of forest cutting (clearcutting and partial cutting) on estimating net forest carbon flux is substantial. Current efforts that merge remotely sensed spatial forest cutting footprints with estimates derived from forest inventories have shown promising results (Hicke and others, 2007; Goward and others, 2008; Huang and others, 2010; 
Table 7-12. Annual average forest harvests from 2001 through 2005 in the Eastern United States.

[Comparison of forest harvest results between the Forest Service Resource Planning Act (RPA) results reported in Smith and others $(2004 ; 2009)$ for the Forest Service north and south regions and produced for the U.S. Geological Survey (USGS) assessment. $\mathrm{km}^{2}$, square kilometers; gC/ $\mathrm{m}^{2} /$ event, grams of carbon per square meter per event; $\mathrm{TgC} / \mathrm{yr}$, teragrams of carbon per year]

\begin{tabular}{|c|c|c|}
\hline Forest harvest variable & RPA & $\begin{array}{c}\text { USGS } \\
\text { assessment }\end{array}$ \\
\hline Forest area, in $\mathrm{km}^{2}$ & $1,555,163$ & $1,461,458$ \\
\hline Clearcut and partial cut area, in $\mathrm{km}^{2}$ & 38,091 & 15,037 \\
\hline $\begin{array}{l}\text { Forest area clearcut and partial cut, in } \\
\text { percent }\end{array}$ & 2.45 & 1.03 \\
\hline Clearcut area, in $\mathrm{km}^{2}$ & 14,810 & 6,683 \\
\hline Forest area clearcut, in percent & 0.95 & 0.46 \\
\hline Partial cut area, in $\mathrm{km}^{2}$ & 23,280 & 8,354 \\
\hline Forest area partial cut, in percent & 1.50 & 0.57 \\
\hline $\begin{array}{l}\text { Carbon removal from clearcut and } \\
\text { partial cut, in } \mathrm{TgC} / \mathrm{yr}\end{array}$ & 108 & 41.4 \\
\hline $\begin{array}{l}\text { Carbon removal from clearcut, in } \\
\mathrm{TgC} / \mathrm{yr}\end{array}$ & 54.0 & 25.4 \\
\hline $\begin{array}{l}\text { Carbon removal from partial cut, in } \\
\mathrm{TgC} / \mathrm{yr}\end{array}$ & 54.0 & 15.6 \\
\hline $\begin{array}{l}\text { Rate of carbon removal from clearcut } \\
\text { and partial cut, in } \mathrm{gC} / \mathrm{m}^{2} \text { per event }\end{array}$ & 2,830 & 2,750 \\
\hline $\begin{array}{l}\text { Rate of carbon removal from clearcut, } \\
\text { in } \mathrm{gC} / \mathrm{m}^{2} \text { per event }\end{array}$ & 3,640 & 3,800 \\
\hline $\begin{array}{l}\text { Rate of carbon removal from partial } \\
\text { cut, in } \mathrm{gC} / \mathrm{m}^{2} \text { per event }\end{array}$ & 2,320 & 1,800 \\
\hline
\end{tabular}

Turner and others, 2011; Williams and others, 2012). The combined approach is one that was used for this assessment (described in chapter 3 of this report). Both remotely sensed products and ground-based estimation carry uncertainties in their results. This kind of uncertainty is one of the major areas that deserve much attention to reduce the uncertainty in estimating carbon dynamics over large areas (Liu and others, 2012b; Kasischke and others, 2013).

\subsubsection{Summary of Baseline Carbon Fluxes in the Assessment of the Eastern United States}

On average, the terrestrial ecosystems (forests, croplands, grasslands, shrublands, wetlands, and other lands) in the seven ecoregions of the Eastern United States stored a total of 26,962 TgC during the baseline period (2001-2005). Carbon in biomass pools (such as live and dead vegetative materials aboveground and belowground, except for those removed from agricultural fields and forests) accounted for 15,352 TgC (57 percent) of the total, and the rest was stored in the top $20 \mathrm{~cm}$ of the soil layer. Carbon stored in other pools (such as grain and woody biomass removed from the landscape) was not estimated in this assessment, although the influx of carbon from these sources was calculated. The regional NECB was estimated to be $-288.6 \mathrm{TgC} / \mathrm{yr}$, including NECB from lacustrine systems (9.2 TgC/yr) in the Eastern United States. This estimate represented the sum of carbon sequestered in terrestrial pools and in sediments in aquatic ecosystems in this region; however, carbon removal from rivers and coastal waters was not included in this assessment. Of the total NECB in the region, the terrestrial ecosystems were responsible for an average of $-279.4 \mathrm{TgC} / \mathrm{yr}$, including $-214 \mathrm{TgC} / \mathrm{yr}$ and $-65.4 \mathrm{TgC} / \mathrm{yr}$ in biomass and soils, respectively (fig. 7-11).

Carbon fluxes and burials from major terrestrial sources (this chapter) and in inland waters and coastal waters (chaps. 5 and 6) for baseline years are summarized together in figure 7-11. For simplicity, the estimated carbon stocks in all terrestrial ecosystems are lumped together in this diagram within two carbon pools: one for biomass carbon and one for soil organic carbon. The baseline years varied for different components of the assessment as limited by available input data (chap. 1). As the result, figure 7-11 should be interpreted as a composite representation of contemporary carbon cycle processes in the region estimated using different methods described in various chapters of this report. The common time period for all the components was from 2001 to 2005, which is the nominal baseline period for this assessment.

Among the various fluxes, the largest were NPP and heterotrophic respiration of the terrestrial ecosystems (fig. 7-11). The NPP and heterotrophic respiration were 1,690.1 TgC/yr and 1,369.1 TgC/yr, respectively. About 16.5 percent of the annual NPP was sequestered in biomass and soils. The amount of carbon removed by grain harvesting from agricultural lands was $103.8 \mathrm{TgC} / \mathrm{yr}$. The amount of carbon removed by timber harvesting from forest lands was 41.4 TgC/yr. Wildland fires also emitted an average of 1.6 $\mathrm{TgC} / \mathrm{yr}$ from ecosystems in the Eastern United States. On the aquatic side, rivers and streams transported an average of 36.5 $\mathrm{TgC} / \mathrm{yr}$ through various ecosystems in the Eastern United States, and 51.3 TgC/yr was emitted from all inland water bodies.

\subsubsection{Limitation of This Assessment and Future Directions}

For this assessment, efforts were made to process and produce spatially and temporally explicit input data of LULC (chaps. 2 and 3), wildland fire (chap. 4), and land management activities (this chapter) and to include the effects of these processes in carbon estimates presented in this chapter. Nevertheless, only a partial attribution analysis was produced on effects of controlling processes (for example, effects of wildland fire (chap. 4), effects of timber production (this chapter), general attribution of LULC change (chap. 3 and this chapter), and uncertainty contribution from the three biogeochemical models, LULC scenarios, and GCMs (this chapter).

Other ecosystem processes and land-use activities not included in this assessment could also potentially introduce uncertainties in the results. Although carbon fluxes related to timber and grain harvesting were estimated, the offsite 


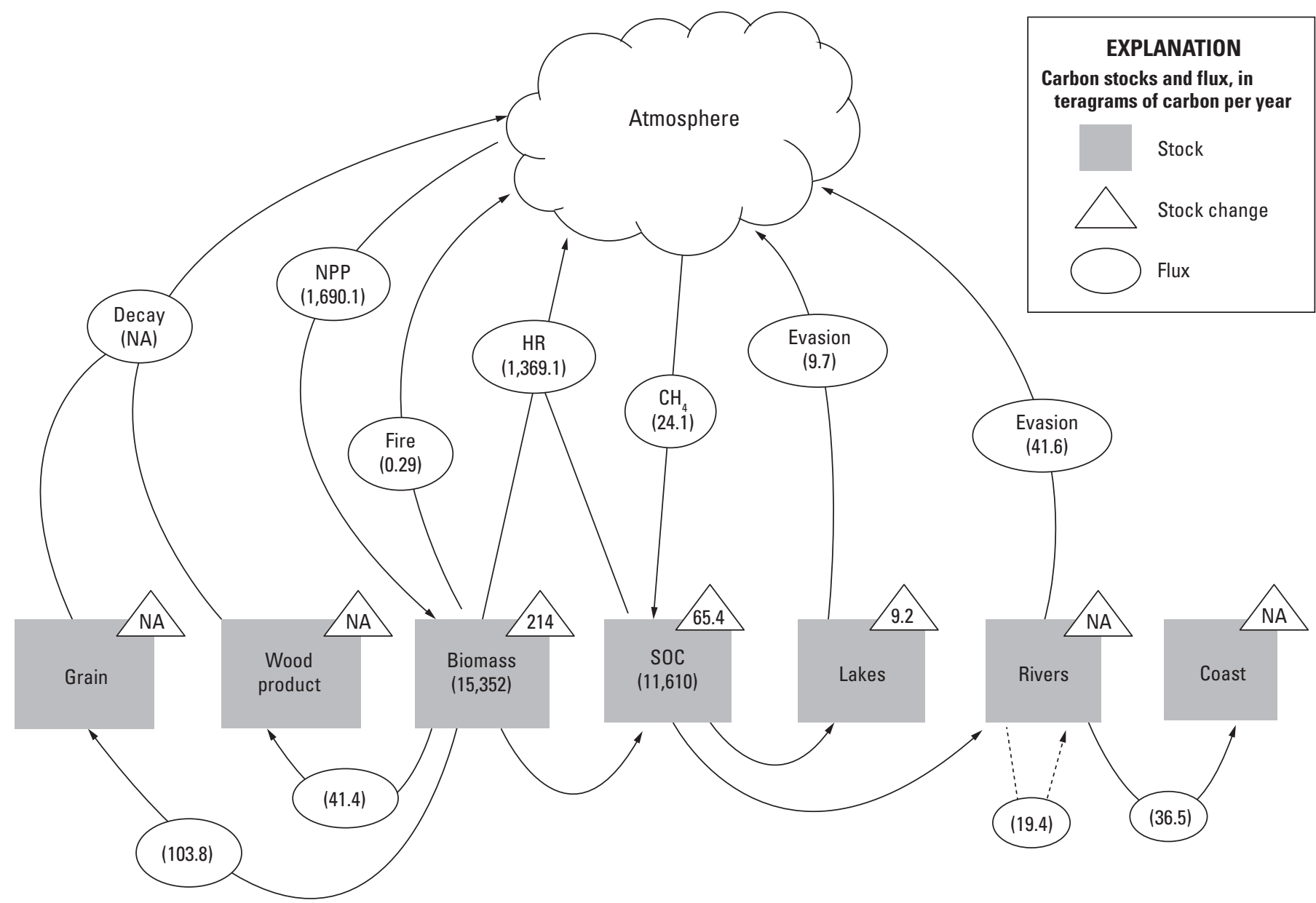

Figure 7-11. Flow diagram showing average carbon stocks and fluxes and changes in average carbon stock for primary carbon pools in the Eastern United States during the baseline years (2001 through 2005). Only those carbon stocks and fluxes that were examined in the assessment are shown. Changes in carbon storage rates in lacustrine systems (lakes and reservoirs) and in coastal waters (by burial in sediment) were included, but the carbon stocks in these ecosystems were not included. In quantifying the changes in average carbon stocks of soils and biomass (all dead and live biomass), carbon combustion by fire and transfer to products by harvesting were considered, but not their export to the aquatic ecosystems. There was no coupling between the estimates of carbon stocks in the terrestrial and aquatic systems. Positive carbon stock change indicates a carbon storage increase and therefore represents carbon sequestration. The arrow with the dashed line under the "Rivers" box indicates the lateral flux of carbon within the streams and rivers. $\mathrm{CH}_{4^{\prime}}$ methane; $\mathrm{HR}$, heterotrophic respiration of terrestrial ecosystems; $\mathrm{NA}$, not applicable, due to either a lack of input data or the choice of methods; NPP, net primary production of terrestrial ecosystems; SOC, soil organic carbon.

dynamics of timber and grain products were not accounted in this assessment because no life-cycle analysis was conducted to evaluate the long-term decomposition rates of the harvests. Also not explicitly included in this assessment were the carbon implications of other ecosystem disturbances, such as the carbon fluxes related to the temporal dynamics of forest defoliation and mortality from insects and windstorm-caused mortalities, particularly in the Great Lake and southern States. The dynamics of these land-management activities and natural disturbances, although highly relevant to the carbon cycle in the Eastern United States, were not supported with sufficient input data and scientific understanding. As a result, their exclusion introduced uncertainty in the assessment.
Results of this assessment suggested a wide range of uncertainty in the estimated carbon sequestration rates across models, LULC scenarios, and GCM projections in ecoregions and in the Eastern United States. In addition, the results showed that the uncertainty from models dominated the uncertainties from LULC and GCMs. These results are important but they are high-level observations without a detailed cause-and-effect analysis, which require a further effort to explain the differences among models, LULC scenarios, and GCM projections.

It should be recognized that the uncertainty analysis presented in this chapter is partial and conditional to the methods and input data used, specifically, the three biogeochemical models, climate projections of the three GCMs, 
and the three LULC scenarios. For example, the general analysis did not include uncertainties from input data layers and model parameters. Model simulations were constrained by nationally consistent ground-based measurements and census data (for example, forest inventory data from FIA and grain yield and crop management practices from the USDA) and satellite-derived estimates of processes such as NPP and disturbances. The development of additional data layers should be beneficial in constraining model simulations. For example, GEMS models should be calibrated and validated, with measures of parameter uncertainty, at site scales, using various measurements collected from diverse ecosystems and are available from FLUXNET (http://fluxnet.ornl.gov/). Developing additional data layers from FIA data through collaboration with the Forest Service and from literature review and meta-analysis may help reduce uncertainties in the data. It is also important to develop a scheme that can improve the understanding and quantification of the export of carbon from terrestrial to aquatic systems using the law of mass conservation, which was not implemented in this assessment. A continuing national effort should be undertaken to add more data streams and fields to constrain GEMS model behavior more tightly and therefore improve the understanding and quantification of the carbon cycle and reduce the uncertainty of the estimated carbon sources and sinks over large areas in the United States.

This assessment has created a nationwide and consistent framework capacity for quantifying carbon dynamics and GHG emissions under the effects of LULC, disturbances, and climate for the Eastern United States at 250-m resolution. Future efforts should be orchestrated around the following major themes to strengthen this capacity: (1) improving understanding and quantification of the carbon cycle at landscape to national scales, as described earlier in this section, with fundamental advancement in process understanding, and (2) transitioning GEMS into a real-time carbon dynamics monitoring system for the country and the ecoregions. With regard to the second theme, efforts should replace part of the databases developed in this assessment. Specifically, the model simulated dynamics of climate, land use, and disturbances from 2006 to present (part of the projection period in the assessment) should be replaced with real observations. 


\section{Selected References}

Ackerman, D.J., 1989, Hydrology of the Mississippi River Valley alluvial aquifer, south-central United StatesA preliminary assessment of the regional flow system: U.S. Geological Survey Water Resources Investigations Report 88-4028, 74 p.

Ackerman, K.V., Mixon, D.M., Sundquist, E.T., Stallard, R.F., Schwarz, G.E., and Stewart, D.W., 2009, RESIS-II; An updated version of the original reservoir sedimentation survey information system (RESIS) database: U.S. Geological Survey Data Series 434, accessed July 11, 2012, at http://pubs.usgs.gov/ds/ds434/.

Adams, D.M., Haynes, R.W., and Daigneault, A.J., 2006, Estimated timber harvest by U.S. region and ownership, 1950-2002: U.S. Department of Agriculture General Technical Report PNW-GTR-659, 64 p. (Also available at http://www.fs.fed.us/pnw/pubs/pnw_gtr659.pdf.)

Albani, Marco, Medvigy, David, Hurtt, G.C., and Moorcroft, P.R., 2006, The contributions of land-use change, $\mathrm{CO}_{2}$ fertilization, and climate variability to the eastern U.S. carbon sink: Global Change Biology, v. 12, no. 12, p. 2370-2390, accessed September 30, 2013, at http://dx.doi.org/10.1111/ j.1365-2486.2006.01254.x.

Albaugh, T.J., Allen, H.L., Dougherty, P.M., Kress, L.W., and King, J.S., 1998, Leaf area and above- and belowground growth responses of loblolly pine to nutrient and water additions: Forest Science, v. 44, no. 2, p. 317-328. (Also available at $h t t p: / / w w w$.ingentaconnect.com/content/saf/ $\left.f_{S} / 1998 / 00000044 / 00000002 / a r t 00016.\right)$

Albert, D.A., 1995, Regional landscape ecosystems of Michigan, Minnesota, and Wisconsin - A working map and classification: U.S. Department of Agriculture, Forest Service General Technical Report NC-178, 250 p., accessed November 13, 2013, at http://www.npwrc.usgs.gov/resource/ habitat/rlandscp/.

Albini, F.A., and Reinhardt, E.D., 1995, Model ignition and burning rate of large woody natural fuels: International Journal of Wildland Fire, v. 5, no. 2, p. 81-91.

Albini, F.A., and Reinhardt, E.D., 1997, Improved calibration of a large fuel burnout model: International Journal of Wildland Fire, v. 7, no. 1, p. 21-28.

Albini, F.A., Brown, J.K., Reinhardt, E.D., and Ottmar, R.D., 1995, Calibration of a large fuel burnout model: International Journal of Wildland Fire, v. 5, no. 3, p. 173-192.

Alcamo, Joseph, Leemans, Rick, and Kreileman, Eric, 1998, Global change scenarios of the 21 st century-Results from the IMAGE 2.1 model: Elsevier Science Ltd., Oxford, United Kingdom, 296 p.
Alexander, R.B., Smith, R.A., Schwarz, G.E., Boyer, E.W., Nolan, J.V., and Brakebill, J.W., 2008, Differences in phosphorus and nitrogen delivery to the gulf of Mexico from the Mississippi River basin: Environmental Science and Technology, v. 42, no. 3, p. 822-830.

Allan, J.D., 2004, Landscapes and riverscapes-The influence of land use on stream ecosystems: Annual Review of Ecology, Evolution, and Systematics, v. 35, no. 1, p. 257-284.

Allison, M.A., Bianchi, T.S., McKee, B.A., and Sampere, T.P., 2007, Carbon burial on river-dominated continental shelves - Impact of historical changes in sediment loading adjacent to the Mississippi River: Geophysical Research Letters, v. 34, no. 1, L01606, accessed October 30, 2013, at http://dx.doi.org/10.1029/2006GL028362.

Alperin, M.J., Suayah, I.B., Benninger, L.K., and Martens, C.S., 2002, Modern organic carbon burial fluxes, recent sedimentation rates, and particle mixing rates from the upper continental slope near Cape Hatteras, North Carolina (USA): Deep-Sea Research Part II: Topical Studies in Oceanography, v. 49, no. 20, p. 4645-4665.

Anderson, D.M., Glibert, P.M., and Burkholder, J.M., 2002, Harmful algal blooms and eutrophication-Nutrient sources, composition, and consequences: Estuaries, v. 25, no. 4B, p. 704-726.

Anderson, L.A., and Sarmiento, J.L., 1994, Redfield ratios of remineralization determined by nutrient data-analysis: Global Biogeochemical Cycles, v. 8, no. 1, p. 65-80.

Armentano, T.V., and Menges, E.S., 1986, Patterns of change in the carbon balance of organic soil-wetlands of the temperate zone: Journal of Ecology, v. 74, no. 3, 755-774.

Armstrong, R.A., Lee, Cindy, Hedges, J.I., Honjo, Susumu, and Wakeham, S.G., 2001, A new, mechanistic model for organic carbon fluxes in the ocean based on the quantitative association of POC with ballast minerals: Deep-Sea Research Part II: Topical Studies in Oceanography, v. 49, nos. 1-3, p. 219-236.

Auch, R.F., Napton, D.E., Kambly, Steven, Moreland, T.R., Jr., and Sayler, K.L., 2012, The driving forces of land change in the northern Piedmont of the United States: Geographical Review, v. 102, no. 1, p. 53-75.

Aufdenkampe, A.K., Mayorga, Emilio, Raymond, P.A., Melack, J.M., Doney, S.C., Alin, S.R., Aalto, R.E., and Yoo, Kyungsoo, 2011, Riverine coupling of biogeochemical cycles between land, oceans, and atmosphere: Frontiers in Ecology and the Environment, v. 9, no. 1, p. 53-60.

Bachelet, Dominique, Neilson, R.P., Hickler, Thomas, Drapek, R.J., Lenihan, J.M., Sykes, M.T., Smith, Benjamin, Sitch, Stephen, and Thonicke, Kirsten, 2003, Simulating 
past and future dynamics of natural ecosystems in the United States: Global Biogeochemical Cycles, v. 17, no. 2, 1045, 21 p., accessed October 30, 2013, at http://dx.doi. org/10.1029/2001GB001508.

Bachelet, Dominique, Neilson, R.P., Lenihan, J.M., and Drapek, R.J., 2001, Climate change effects on vegetation distribution and carbon budget in the United States: Ecosystems, v. 4, no. 3, p. 164-185.

Balshi, M.S., McGuire, A.D., Duffy, P., Flannigan, M., Kicklighter, D.W., and Melillo, J., 2009a, Vulnerability of carbon storage in North American boreal forests to wildfires during the 21 st century: Global Change Biology, v. 15 , no. 6 , p. 1491-1510.

Balshi, M.S., McGuire, A.D., Duffy, Paul, Flannigan, Mike, Walsh, John, and Melillo, Jerry, 2009b, Assessing the response of area burned to changing climate in western boreal North America using a multivariate adaptive regression splines (MARS) approach: Global Change Biology, v. 15 , no. 3, p. 578-600.

Barnes, R.T., and Raymond, P.A., 2009, The contribution of agricultural and urban activities to inorganic carbon fluxes within temperate watersheds: Chemical Geology, v. 266, nos. 3-4, p. 318-327.

Battin, T.J., Luyssaert, Sebastiaan, Kaplan, L.A., Aufdenkampe, A.K., Richter, Andreas, and Tranvik, L J., 2009, The boundless carbon cycle: Nature Geoscience, v. 2, p. 598-600. (Also available at $h t t p: / / d x . d o i . o r g / 10.1038 /$ ngeo618.)

Behrenfeld, M.J., and Falkowski, P. G., 1997, Photosynthetic rates derived from satellite-based chlorophyll concentration: Limnology and Oceanography, v. 42, no. 1, p. 1-20.

Benecke, Udo, and Nordmeyer, A.H., 1982, Carbon uptake and allocation by Nothofagus solandri var. cliffortioides (Hook f.) Poole and Pinus contorta Douglas ex Loudon ssp. contorta at montane and subalpine altitudes, in Waring, R.H., ed., Carbon uptake and allocation in subalpine ecosystems as a key to management, Proceedings of an IUFRO workshop: Corvallis, Oreg., Oregon State University, p. 9-21.

Bennington, Val, McKinley, G.A., Urban, N.R., and McDonald, C.P., 2012, Can spatial heterogeneity explain the perceived imbalance in Lake Superior's carbon budget? A model study: Journal of Geophysical Research: Biogeosciences, v. 117, no. G3, G03020, 20 p., accessed February 4, 2014, at $h t t p: / / d x$.doi.org/10.1029/2011JG001895.

Bergamaschi, B.A., Tsamakis, Elizabeth, Keil, R.G., Eglinton, T.I., Montluçon, D.B., and Hedges, J.I., 1997, The effect of grain size and surface area on organic matter, lignin and carbohydrate concentration, and molecular compositions in Peru margin sediments: Geochimica Et Cosmochimica Acta, v. 61, no. 6, p. 1247-1260.

Bianchi, T.S., DiMarco, S.F., Cowan, J.H., Jr., Hetland, R.D., Chapman, P., Day, J.W., and Allison, M.A., 2010, The science of hypoxia in the northern gulf of Mexico-A review: Science of the Total Environment, v. 408, no. 7 , p. 1471-1484.

Binford, M.W., Gholz, H.L., Starr, Gregory, and Martin, T.A., Regional carbon dynamics in the southeastern coastal plain-Balancing land cover type, timber harvesting, fire, and environmental variation: Journal of Geophysical Research: Atmospheres, v. 111, no. D24, 12 p., accessed February 6, 2014, at $h t t p: / / d x$.doi.org/10.1029/2005JD006820.

Birdsey, Richard, Pregitzer, Kurt, and Lucier, Alan, 2006, Forest carbon management in the United States-1600-2100: Journal of Environmental Quality, v. 35, no. 4, p. 1461-1469.

Blair, N.E., Leithold, E.L., and Aller, R.C., 2004, From bedrock to burial-The evolution of particulate organic carbon across coupled watershed-continental margin systems: Marine Chemistry, v. 92, no. 1-4, p. 141-156.

Blair, N.E., Leithold, E.L., Ford, S.T., Peeler, K.A., Holmes, J.C., and Perkey, D.W., 2003, The persistence of memoryThe fate of ancient sedimentary organic carbon in a modern sedimentary system: Geochimica Et Cosmochimica Acta, v. 67 , no. 1 , p. $63-73$.

Boudreau, B.P., and Ruddick, B.R., 1991, On a reactive continuum representation of organic-matter diagenesis: American Journal of Science, v. 291, no. 5, p. 507-538.

Boyer, E.W., Howarth, R.W., Galloway, J.N., Dentener, F.J., Green, P. A., and Vörösmarty, C.J., 2006, Riverine nitrogen export from the continents to the coasts: Global Biogeochemical Cycles, v. 20, no. 1, 9 p., accessed October 30, 2013, at http://dx.doi.org/10.1029/2005GB002537.

Bracho, Rosvel, Starr, Gregogry, Gholz, H.L., Martin, T.A., Cropper, W.P., and Loescher, H.W., 2012, Controls on carbon dynamics by ecosystem structure and climate for southeastern U.S. slash pine plantations: Ecological Monographs, v. 82 , no. 1 , p. $101-128$.

Bradshaw, L.S., Deeming, J.E., Burgan, R.E., and Cohen, J.D., 1983, The 1978 national fire-danger rating system-Technical documentation: U.S. Department of Agriculture, Forest Service, General Technical Report INT-169, 44 p., accessed October 29, 2013, at http://www.fs.fed.us/rm/pubs_int/ int_gtr169.pdf.

Braun, E.L., 1950, Deciduous forests of eastern North America: New York, Hafner Publishing Company, 596 p.

Breitburg, D.L., Craig, J.K., Fulford, R.S., Rose, K.A., Boynton, W.R., Brady, D.C., Ciotti, B.J., Diaz, R.J., Friedland, K.D., Hagy, J.D., III, Hart, D.R., Hines, A.H., Houde, E.D., Kolesar, S.E., Nixon, S.W., Rice, J.A., Secor, D.H., and Targett, T.E., 2009, Nutrient enrichment and fisheries exploitation-Interactive effects on estuarine living resources and their management: Hydrobiologia, v. 629, no. 1, p. 31-47.

Bridgham, S.D., Megonigal, J.P., Keller, J.K., Bliss, N.B., and Trettin, Carl, 2006, The carbon balance of North American wetlands: Wetlands, v. 26, no. 4, p. 889-916. 
Brown, D.G., Johnson, K.M., Loveland, T.R., and Theobald, D.M., 2005, Rural land-use trends in the conterminous United States, 1950-2000: Ecological Applications, v. 15, no. 6, p. 1851-1863. (Also available at http://dx.doi.org/10.1890/03-5220.)

Brown, T.J., Hall, B.L., Mohrle, C.R., and Reinbold, H.J., 2002, Coarse assessment of federal wildland fire occurrence data: Reno, Nevada, Desert Research Institute Climate, Ecosystem, and Fire Applications Program Report 02-04, 31 p., accessed October 29, 2013, at http://cefa.dri.edu/ Publications/fireoccurrencereport.pdf.

Burakowski, E.A., Wake, C.P., Braswell, Bobby, and Brown, D.P., 2008, Trends in wintertime climate in the northeastern United States -1965-2005: Journal of Geophysical Research: Atmospheres, v. 113, no. D20, D20114, 12 p., accessed October 30, 2013, at http://dx.doi.org/10.1029/2008JD009870.

Burdige, D.J., 2005, Burial of terrestrial organic matter in marine sediments - A re-assessment: Global Biogeochemical Cycles, v. 19, no. 4, 7 p., accessed October 30, 2013, at http://dx.doi.org/10.1029/2004GB002368.

Burdige, D.J., 2007, Preservation of organic matter in marine sediments - Controls, mechanisms, and an imbalance in sediment organic carbon budgets?: Chemical Reviews, v. 107 , no. 2 , p. $467-485$.

Burgan, R.E., 1988, 1988 revisions to the 1978 national firedanger rating system: U.S. Department of Agriculture, Forest Service, Research Paper SE-273, 144 p., accessed October 30, 2013, at http://www.treesearch.fs.fed.us/pubs/593.

Burgin, A.J., and Hamilton, S.K., 2007, Have we overemphasized the role of denitrification in aquatic ecosystems?-A review of nitrate removal pathways: Frontiers in Ecology and Environmental Science, v. 5, no. 2, p. 89-96.

Butman, David, and Raymond, P.A., 2011, Significant efflux of carbon dioxide from streams and rivers in the United States: Nature Geoscience, v. 4, no. 12, p. 839-842.

Calkin, D.E., Thompson, M.P., Finney, M.A., and Hyde, K.D., 2011, A real-time risk assessment tool supporting wildland fire decisionmaking: Journal of Forestry, v. 109, no. 5, p. 274-280.

Campbell, John, Donato, Dan, Azuma, David, and Law, Beverly, 2007, Pyrogenic carbon emission from a large wildfire in Oregon, United States: Journal of Geophysical Research, v. 112, no. G4, G04014, 11 p., accessed October 30, 2013, at http://dx.doi.org/10.1029/2007JG000451.

Canadian Forest Service, 2012, Climate change scenarios data, in Regional, national and international climate modeling: Canadian Forest Service database, accessed May 31, 2012, at http://cfs.nrcan.gc.ca/projects/3/5.

Canham, C.D., and Loucks, O.L., 1984, Catastrophic windthrow in the presettlement forests of Wisconsin: Ecology, v. 65 , no. 3 , p. $803-809$.
Cardille, J.A., Ventura, S.J., and Turner, M.G., 2001, Environmental and social factors influencing wildfires in the Upper Midwest, United States: Ecological Applications, v. 11, no. 1, p. 111-127.

Cary, G.J., Flannigan, M.D., Keane, R.E., Bradstock, R.A., Davies, I.D., Lenihan, J.M., Li, Chao, Logan, K.A., and Parsons, R.A., 2009, Relative importance of fuel management, ignition management and weather for area burnedEvidence from five landscape-fire-succession models: International Journal of Wildland Fire, v. 18, no. 2, p. 147-156.

Chapin, F.S., III, Woodwell, G.M., Randerson, J.T., Rastetter, E.B., Lovett, G.M., Baldocchi, D.D., Clark, D.A., Harmon, M.E., Schimel, D.S., Valentini, R., Wirth, C., Aber, J.D., Cole, J.J., Goulden, M.L., Harden, J.W., Heimann, M., Howarth, R.W., Matson, P.A., McGuire, A.D., Melillo, J.M., Mooney, H.A., Neff, J.C., Houghton, R.A., Pace, M.L., Ryan, M.G., Running, S.W., Sala, O.E., Schlesinger, W.H., and Schulze, E.D., 2006, Reconciling carbon-cycle concepts, terminology, and methods: Ecosystems, v. 9, p. 1041-1050, accessed October 30, 2013, at http://dx.doi.org/10.1007/s10021-005-0105-7.

Chen, Guangsheng, Tian, Hanqin, Zhang, Chi, Liu, Mingliang, Ren, Wwi, Zhu, Wenquan, Chappelka, A.H., Prior, S.A., and Lockaby, G.B., 2012, Drought in the southern United States over the 20th century-Variability and its impacts on terrestrial ecosystem productivity and carbon storage: Climatic Change, v. 114, no. 2, p. 379-397, accessed October 28, 2013, at http://dx.doi.org/10.1007/s10584-012-0410-z.

Chen, Hua, Tian, Hanqin, Liu, Mingliang, Melillo, Jerry, Pan, Shufen, and Zhang, Chi, 2006, Effect of land-cover change on terrestrial carbon dynamics in the southern United States: Journal of Environmental Quality, v. 35, no. 4, p. 1533-1547.

Chmura, G.L., Anisfeld, S.C., Cahoon, D.R., and Lynch, J.C., 2003, Global carbon sequestration in tidal, saline wetland soils: Global Biogeochemical Cycles, v. 17, no. 4, 1111, 12 p., accessed October 28, 2013, at http://dx.doi.org/10.1029/2002GB001917.

Christensen, N.L., 1988, Vegetation of the southeastern Coastal Plain, in Barbour, M.G., and Billings, W.D., eds., North American terrestrial vegetation: Cambridge, United Kingdom, Cambridge University Press, p. 317-363.

Christensen, N.L., 1999, Vegetation of the Southeastern Coastal Plain, chap. 11 of Barbour, M.G., and Billings, W.D., eds., North American terrestrial vegetation, 2d ed.: Cambridge, United Kingdom, Cambridge University Press, p. 397-448.

Christopher, S.F., Lal, Rattan, and Mishra, Umakant, 2009, Regional study of no-till effects on carbon sequestration in the midwestern United States: Soil Science Society of America Journal, v. 73, no. 1, p. 207-216, accessed October 28, 2013, at http://dx.doi.org/10.2136/sssaj2007.0336. 
Claggett, P.R., Jantz, C.A., Goetz, S.J., and Bisland, Carin, 2004, Assessing development pressure in the Chesapeake Bay watershed; an evaluation of two land-use change models: Environmental Monitoring and Assessment, v. 94, nos. 1-3, p. 129-146.

Clark, K.L., Skowronski, Nicholas, and Hom, John, 2010, Invasive insects impact forest carbon dynamics: Global Change Biology, v. 16, no. 1, p. 88-101.

Clark, K.L., Gholz, H.L., Moncrieff, J.B., Cropley, Ford, and Loescher, H.W., 1999, Environmental controls over net exchanges of carbon dioxide from contrasting Florida ecosystems: Ecological Applications, v. 9, no. 3, p. 936-948.

Cleary, M.B., Pendall, Elise, and Ewers, B.E., 2010, Aboveground and belowground carbon pools after fire in mountain big sagebrush steppe: Rangeland Ecology and Management, v. 63 , no. 2, p. 187-196.

Cleland, D.T., Crow, T.R., Saunders, S.C., Dickmann, D.I., Maclean, A.L., Jordan, J.K., Watson, R.L., Sloan, A.M., and Brosofske, K.D., 2004, Characterizing historical and modern fire regimes in Michigan (USA) - A landscape ecosystem approach: Landscape Ecology, v. 19, no. 3, p. 311-325.

Clilverd, H.M., Jones, J.B., Jr., and Kielland, Knut, 2008, Nitrogen retention in the hyporheic zone of a glacial river in interior Alaska: Biogeochemistry, v. 88, no. 1, p. 31-46.

Cohn, T.A., Caulder, D.L., Gilroy, E.J., Zynzuk, L.D., and Summers, R.M., 1992, The validity of a simple statistical model for estimating fluvial constituent loads-An empirical study involving nutrient loads entering Chesapeake Bay: Water Resources Research, v. 28, no. 9, p. 2353-2363.

Cole, J.J., and Caraco, N.F., 1998, Atmospheric exchange of carbon dioxide in a low-wind oligotrophic lake measured by the addition of $\mathrm{SF}_{6}$ : Limnology and Oceanography, v. 43, no. 4, p. 647-656.

Cole , J.J., Prairie, Y.T., Caraco, N.F., McDowell, W.H., Tranvik, L.J., Striegl, R.G., Duarte, C.M., Kortelainen, P., Downing, J.A., Middelburg, J.J., and Melack, J., 2007, Plumbing the global carbon cycle-Integrating inland waters into the terrestrial carbon budget: Ecosystems, v. 10 , no. 1 , p. $172-185$, accessed October 31,2013 , at http://dx.doi.org/10.1007/s10021-006-9013-8.

Commission for Environmental Cooperation, 1997, Ecological regions of North America-Toward a common perspective: Montréal, Canada, Commission for Environmental Cooperation, 71 p., accessed November 13, 2013, at http://www3.cec.org/islandora/en/item/1701-ecologicalregions-north-america-toward-common-perspective-en.pdf.

Commission for Environmental Cooperation, 2006, Ecological regions of North America-Level I-III: Montréal, Canada, Commission for Environmental Cooperation map, 1 sh., scale 1:10,000,000, accessed November 13, 2013, at http://www3.cec.org/islandora/en/item/2560-ecologicalregions-north-america-level-i-iii-en.pdf.
Commission for Environmental Cooperation, 2012, Terrestrial ecoregions, 2009: Commission for Environmental Cooperation Web page, accessed November 12, 2013, at http://www.cec.org/Page. asp? PageID $=122 \&$ Content $I D=1329$.

Conservation Technology Information Center, 2012, Crop residue management (CRM) survey data: Conservation Technology Information Center dataset, accessed May 31, 2012, at http://www.ctic.purdue.edu/CRM/crm_search/.

Craine, J. M., Fierer, Noah, and McLauchlan, K.K., 2010, Widespread coupling between the rate and temperature sensitivity of organic matter decay: Nature Geoscience, v. 3, no. 12 , p. $854-857$.

Creed, I.F., Beall, F D., Clair, T.A., Dillon, P.J., and Hesslein, R.H., 2008, Predicting export of dissolved organic carbon from forested catchments in glaciated landscapes with shallow soils: Global Biogeochemical Cycles, v. 22, no. 4, GB4024, 14 p., accessed February 4, 2014, at http://dx.doi.org/10.1029/2008GB003294.

Crowder, B.M, 1987, Economic costs of reservoir sedimentation-A regional approach to estimating cropland erosion damage. Journal of Soil and Water Conservation, v. 42, no. 3, p. 194-197. (Also available at http://www.jswconline.org/content/42/3/194.abstract.)

Curtis, H.T., 1959, The vegetation of Wisconsin-An ordination of plant communities: Madison, Wisconsin, The University of Wisconsin Press, $657 \mathrm{p}$.

Curtis, P.S., Hanson, P.J., Bolstad, Paul, Barford, Carol, Randolph, J.C., Schmid, H.P., and Wilson, K.B., 2002, Biometric and eddy-covariance based estimates of annual carbon storage in five eastern North American deciduous forests: Agricultural and Forest Meteorology, v. 113, nos. 1-4, p. 3-19.

da Cunha, L.C., Buitenhuis, E.T., Le Quéré, Corinne, Giraud, Xavier, and Ludwig, Wolfgang, 2007, Potential impact of changes in river nutrient supply on global ocean biogeochemistry: Global Biogeochemical Cycles, v. 21, no. 4, 15 p., accessed October 31, 2013, at http://dx.doi.org/10.1029/2006GB002718.

Dagg, M., Benner, R., Lohrenz, S., and Lawrence, D., 2004, Transformation of dissolved and particulate materials on continental shelves influenced by large rivers - Plume processes: Continental Shelf Research, v. 24, nos. 7-8, p. 833-858.

Davidson, E.A., and Janssens, I.A., 2006, Temperature sensitivity of soil carbon decomposition and feedbacks to climate change: Nature, v. 440, p. 165-173.

de Boyer Montégut, Clément, Madec, Gurvan, Fischer, A.S., Lazar, Alban, and Iudicone, Daniele, 2004, Mixed layer depth over the global ocean-An examination of profile data and a profile-based climatology: Journal of Geophysical Research: Oceans, v. 109, no. C12, 20 p., accessed October 31, 2013, at http://dx.doi.org/10.1029/2004JC002378. 
Dean, W.E., and Gorham, Eville, 1998, Magnitude and significance of carbon burial in lakes, reservoirs, and peatlands: Geology, v. 26, no. 6, p. 535-538. (Also available at http://digitalcommons.unl.edu/cgi/viewcontent.cgi?article $=$ $1307 \&$ context $=$ usgsstaffpub.)

Deeming, J.E., Burgan, R.E., and Cohen, J.D., 1977, The national fire-danger rating system-1978: U.S. Department of Agriculture, Forest Service General Technical Report INT-39, $63 \mathrm{p}$.

Dendocker, N., Schmit, C., and Rounsevell, M., 2008, Exploring spatial data uncertainties in land-use change scenarios: International Journal of Geographical Information Science, v. 22, no. 9, p. 1013-1030. (Also available at http://dx.doi.org/10.1080/13658810701812836.)

Downing, J.A., Cole, J.J., Duarte, C.M., Middelburg, J.J., Melack, J.M., Prairie, Y.T., Kortelainen, Pirrko, Striegl, R.G., McDowell, W.H., and Tranvik, L.J., 2012, Global abundance and size distribution of streams and rivers: Inland Waters, v. 2, no. 4, p. 229-236.

Drummond, M.A., and Loveland T.R., 2010, Land-use pressure and a transition to forest-cover loss in the eastern United States: Bioscience, v. 60, no. 4, p. 286-298.

Duan, Qingyun, Sorooshian, Soroosh, and Gupta, Vijai, 1992, Effective and efficient global optimization for conceptual rainfall-runoff models: Water Resources Research, v. 28, no. 4, p. 1015-1031. (Also available at http://dx.doi.org/10.1029/91WR02985.)

Dunne, J.P., Armstrong, R.A., Gnanadesikan, Anand, and Sarmiento, J.L., 2005, Empirical and mechanistic models for the particle export ratio: Global Biogeochemical Cycles, v. 19, no. 4, 16 p., accessed October 31, 2013, at http://dx.doi.org/10.1029/2004GB002390.

Dunne, J.P., Sarmiento, J.L., and Gnanadesikan, Anand, 2007, A synthesis of global particle export from the surface ocean and cycling through the ocean interior and on the seafloor: Global Biogeochemical Cycles, v. 21, no. 4, 16 p., accessed October 31, 2013, at http://dx.doi.org/10.1029/2006GB002907.

Earley, L.S., 2004, Looking for longleaf-The fall and rise of an American forest: Chapel Hill, North Carolina, University of North Carolina Press, 336 p.

Efron, Bradley, and Tibshirani, R.J., 1993, An introduction to the bootstrap: New York, Chapman \& Hall, 456 p.

Eggleston, Simon, Buenda, Leandro, Miwa, Kyoko, Ngara, Todd, and Tanabe, Kiyoto, 2006, 2006 IPCC guidelines for national greenhouse gas inventories: Intergovernmental Panel on Climate Change, 5 v., [variously paged].

Eidenshink, Jeff, Schwind, Brian, Brewer, Ken, Zhu, Zhiliang, Quayle, Brad, and Howard, Stephen, 2007, A project for monitoring trends in burn severity: Fire Ecology, v. 3, no .1, p. 3-21.
Falge, Eva, Baldocchi, Dennis, Tenhunen, John, Aubinet, Marc, Bakwin, Peter, Berbigier, Paul, Bernhofer, Christian, Burba, George, Clement, Robert, Davis, K.J., Elbers, J.A., Goldstein, A.H., Grelle, Achim, Granier, André, Guðmundsson, Jón, Hollinger, David, Kowalski, A.S., Katul, Gabriel, Law, B.E., Malhi, Yadvinder, Meyers, Tilden, Monson, R.K., Munger, J.W., Oechel, Walt, Paw U, K.T., Pilegaard, Kim, Rannik, Üllar, Rebmann, Corinna, Suyker, Andrew, Valentini, Riccardo, Wilson, Kell, and Wofsy, Steve, 2002, Seasonality of ecosystem respiration and gross primary production as derived from FLUXNET measurements: Agricultural and Forest Meteorology, v. 113, nos. 1-4, p. 53-74. (Also available at $h t t p: / / d x$. doi.org/10.1016/ S0168-1923(02)00102-8.)

Falk, D.A., Miller, Carol, McKenzie, Donald, and Black, A.E., 2007, Cross-scale analysis of fire regimes: Ecosystems, v. 10 , p. $809-823$.

Finney, M.A., 2002, Fire growth using minimum travel time methods: Canadian Journal of Forest Research, v. 32, no. 8, p. 1420-1424.

Finney, M.A., McHugh, C.W., Grenfell, I.C., Riley, K.L., and Short, K.C., 2011, A simulation of probabilistic wildfire risk components for the continental United States: Stochastic Environmental Research and Risk Assessment, v. 25, no. 7, p. $973-1000$.

Flannigan, M.D., Krawchuk, M.A., de Groot, W.J., Wotton, B.M., and Gowman, L.M., 2009, Implications of changing climate for global wildland fire: International Journal of Wildland Fire, v. 18, no. 5, p. 483-507.

Flato, G.M., and Boer, G.J., 2001, Warming asymmetry in climate change simulations: Geophysical Research Letters, v. 28 , no. 1, p. 195-198.

Forman, R.T.T., ed., 1998, Pine barrens-Ecosystem and landscape: New Brunswick, New Jersey, Rutgers University Press, $654 \mathrm{p}$.

Foster, D.R., Motzkin, Glenn, and Slater, Benjamin, 1998, Land-use history as long-term broad-scale disturbanceRegional forest dynamics in central New England: Ecosystems, v. 1, no. 1, p. 96-119.

Franzluebbers, A.J., 2010, Achieving soil organic carbon sequestration with conservation agricultural systems in the southeastern United States: Soil Science Society of America Journal, v. 74, no. 2, p. 347-357. (Also available at http://dx.doi.org/10.2136/sssaj2009.0079.)

Freeman, C., Fenner, N., Ostle, N.J., Kang, H., Dowrick, D.J., Reynolds, B., Lock, M.A., Sleep, D., Hughes, S., and Hudson, J., 2004. Export of dissolved organic carbon from peatlands under elevated carbon dioxide levels: Nature, v. 430, p. 195-198.

Frelich, L.E., and Lorimer, C.G., 1991, Natural disturbance regimes in hemlock-hardwood forests of the upper Great Lakes region: Ecological Monographs, v. 61, no. 2, p. 145-164. 
French, N.H.F., de Groot, W.J., Jenkins, L.K., Rogers, B.M., Alvarado, Ernesto, Amiro, Brian, de Jong, Bernardus, Goetz, Scott, Hoy, Elizabeth, Hyer, Edward, Keane, Robert, Law, B.E., McKenzie, Donald, McNulty, S.G., Ottmar, Roger, Pérez-Salicrup, D.R., Randerson, James, Robertson, K.M., and Turetsky, Merritt, 2011, Model comparisons for estimating carbon emissions from North American wildland fire: Journal of Geophysical Research: Biogeosciences, v. 116, no. G4, 21 p., accessed October 31, 2013, at http://dx.doi.org/10.1029/2010JG001469.

Friedman, S.K., and Reich, P.B., 2005, Regional legacies of logging-Departure from presettlement forest conditions in northern Minnesota: Ecological Applications, v. 15, no. 2, p. 727-744.

Gallant, A.L., Loveland, T.R., Sohl, T.L., and Napton, D.E., 2004, Using an ecoregion framework to analyze land-cover and land-use dynamics: Environmental Management, v. 34, supplement 1, p. S89-S110.

Gedalof, Ze'ev, Peterson, D.L., and Mantua, N.J., 2005, Atmospheric, climatic, and ecological controls on extreme wildfire years in the northwestern United States: Ecological Applications, v. 15, no. 1, p. 154-174.

Geis, J.W., and Boggess, W.R., 1968, The prairie peninsula; its origin and significance in the vegetational history of central Illinois, in Bergstrom, R.E., ed., The Quaternary of Illinois: University of Illinois College of Agriculture Special Publication 14, p. 89-96.

Gholz, H.L., and Fisher, R.F., 1982, Organic matter production and distribution in slash pine (Pinus elliottii) plantations: Ecology, v. 63, no. 6, p. 1827-1839.

Gibson, Campbell, 1998, Population of the 100 largest cities and other urban places in the United States_-1790 to 1990: U.S. Census Bureau Population Division Working Paper 27, accessed October 31, 2013, at http://www.census.gov/ population/www/documentation/twps0027/twps0027.html.

Giglio, Louis, Descloitres, Jacques, Justice, C.O., and Kaufman, Y.J., 2003, An enhanced contextual fire detection algorithm for MODIS: Remote Sensing of Environment, v. 87 , nos. 2-3, p. 273-282.

Giglio, Louis, Randerson, J.T., van der Werf, G.R., Kasibhatla, P.S., Collatz, G.J., Morton, D.C., and DeFries, R.S., 2010, Assessing variability and long-term trends in burned area by merging multiple satellite fire products: Biogeosciences, v. 7, no. 3, p. 1171-1186.

Glassy, J. M., and Running, S.W., 1994, Validating diurnal climatology logic of the MT-CLIM model across a climatic gradient in Oregon: Ecological Applications, v. 4, no. 2, p. 248-257.

Glibert, P.M., 2010, Long-term changes in nutrient loading and stoichiometry and their relationships with changes in the food web and dominant pelagic fish species in the San Francisco estuary, California: Reviews in Fisheries Science, v. 18 , no. 2, p. 211-232.
Glibert, P.M., Seitzinger, Sybil, Heil, C.A., Burkholder, J.M., Parrow, M.W., Codispoti, L.A., and Kelly, Vince, 2005, The role of eutrophication in the global proliferation of harmful algal blooms: Oceanography, v. 18, no. 2, p. 198-209.

Goetz, S.J., Bond-Lamberty, B., Law, B.E., Hicke, J.A., Huang, C., Houghton, R.A., McNulty, S., O’Halloran, T., Harmon, M., Meddens, A.J.H., Pfeifer, E.M., Mildrexler, D., and Kasischke, E.S., 2012, Observations and assessment of forest carbon dynamics following disturbance in North America: Journal of Geophysical Research: Biogeosciences, v. 117, no. G2, 17 p., accessed October 31, 2013, at http://dx.doi.org/10.1029/2011JG001733.

Goldblum, David, and Rigg, L.S., 2010, The deciduous forest-Boreal forest ecotone: Geography Compass, v. 4, no. 7, p. 704-717.

Gonzalez, Patrick, Neilson, R.P., Lenihan, J.M., and Drapek, R.J., 2010, Global patterns in the vulnerability of ecosystems to vegetation shifts due to climate change: Global Ecology and Biogeography, v. 19, no. 6, p. 755-768. (Also available at http://dx.doi.org/10.1111/j.14668238.2010.00558.x.)

Gordon, C., Cooper, C., Senior, C.A., Banks, H.T., Gregory, J.M., Johns, T.C., Mitchell, J.F.B., and Wood, R.A., 2000, The simulation of SST, sea ice extents and ocean heat transports in a version of the Hadley Centre coupled model without flux adjustments: Climate Dynamics, v. 16, nos. 2-3, p. 147-168.

Gordon, E.S., Goni, M.A., Roberts, Q.N., Kineke, G.C., and Allison, M.A., 2001, Organic matter distribution and accumulation on the inner Louisiana shelf west of the Atchafalaya River: Continental Shelf Research, v. 21, nos. 16-17, p. 1691-1721.

Goulden, M.L., Munger, J.W., Fan, S.-M., Daube, B.C., and Wofsy, S.C., 1996, Exchange of carbon dioxide by a deciduous forest-Response to interannual climate variability: Science, v. 271, no. 5255, p. 1576-1578. (Also available at http://dx.doi.org/10.1126/science.271.5255.1576.)

Goward, S.N., Masek, J.G., Cohen, Warren, Moisen, Gretchen, Collatz, G.J., Healey, Sean, Houghton, R.A., Huang, Chengquan, Kennedy, Robert, Law, Beverly, Powell, Scott, Turner, David, and Wulder, M.A., 2008, Forest disturbance and north American carbon flux: Eos Transactions American Geophysical Union, v. 89, no. 11, p. 105-106. (Also available at $h$ ttp://dx.doi.org/10.1029/2008EO110001.)

Greco, Susanna, and Baldocchi, D.D., 1996, Seasonal variations of $\mathrm{CO}_{2}$ and water vapour exchange rates over a temperate deciduous forest: Global Change Biology, v. 2, no. 3, p. 183-197. (Also available at http://dx.doi. org/10.1111/j.1365-2486.1996.tb00071.x.

Green, R.E., Bianchi, T.S., Dagg, M.J., Walker, N.D., and Breed, G.A., 2006, An organic carbon budget for the Mississippi River turbidity plume and plume contributions to air-sea $\mathrm{CO}_{2}$ fluxes and bottom water hypoxia: Estuaries and Coasts, v. 29, no. 4, p. 579-597. 
Griffith, G.E., Omernik, J.M., and Azevedo, S.H., 1997, Ecoregions of Tennessee: U.S. Environmental Protection Agency EPA/600/R-97/022, 51 p.

Hair, J.F., Black, W.C., Babin, Barry, Anderson, R.E., and Tatham, R.L., 2005, Multivariate data analysis (6th ed.): Upper Saddle River, N.J., Prentice Hall, 928 p.

Hales, Burke, Cai, W.J., Mitchell, B.G., Sabine, C.L., and Schofield, Oscar, eds., 2008, North American continental margins-A synthesis and planning workshop: Washington, D.C., U.S. Carbon Cycle Science Program, 115 p.

Hall, R.O., Jr., Kennedy, T.A., and Rosi-Marshall, E.J., 2012, Air-water oxygen exchange in a large whitewater river: Limnology and Oceanography: Fluids and Environments, v. 2, no. 1, p. 1-11. (Also available at http://dx.doi.org/10.1215/21573689-1572535.)

Hanley, J.A., and McNeil, B.J., 1982, The meaning and use of the area under a receiver operating characteristic (ROC) curve: Radiology, v. 143, no. 1, p. 29-36.

Harris, W.F., Sollins, P., Edwards, N.T., Dinger, B.E., and Shugart, H.H., 1975, Analysis of carbon flow and productivity in a temperate deciduous forest ecosystem, in Reichle, D.E., Franklin, J.F., and Goodall, D.W., eds., Productivity of world ecosystems: Washington, D.C., National Academy of Sciences, p. 116-122.

Hart, J.F., 1968, Loss and abandonment of cleared farm land in the eastern United States: Annals of the Association of American Geographers, v. 58, no. 3, p. 417-440.

Hart, J.F., 1978, Cropland concentrations in the South: Annals of the Association of American Geographers, v. 68, no. 4, p. 505-517.

Hastie, Trevor, Tibshirani, Robert, and Friedman, Jerome, 2009, The elements of statistical learning-Data mining, inference, and prediction ( $2 \mathrm{~d}$ ed.): New York, New York, Springer, $745 \mathrm{p}$.

Hasumi, Hiroyashu, and Emori, Seita, eds., 2004, K-1 coupled GCM (MIROC) description: University of Tokyo Center for Climate System Research, National Institute for Environmental Studies, and Frontier Research Center for Global Change, 34 p., accessed November 6, 2013, at http://ccsr.aori.u-tokyo.ac.jp/ hasumi/miroc_description.pdf.

Hawbaker, T.J, and Zhu, Zhiliang, 2012, Baseline wildland fires and emissions for the Western United States, chap. 3 of Zhu, Zhiliang, and Reed, B.C., eds., Baseline and projected future carbon storage and greenhouse-gas fluxes in ecosystems of the Western United States: U.S. Geological Survey Professional Paper 1797, p. 29-37. (Also available at http://pubs.usgs.gov/pp/1797/.)

Hayhoe, Katharine, Wake, C.P., Huntington, T.G., Luo, Lifeng, Schwartz, M.D., Sheffield, Justin, Wood, Eric, Anderson, Bruce, Bradbury, James, DeGaetano, Art, Troy, T.J., and Wolfe, David, 2007, Past and future changes in climate and hydrological indicators in the US northeast: Climate Dynamics, v. 28, no 4, p. 381-407.

Haynes, R.W., 2003, An analysis of the timber situation in the United States-1952 to 2050: U.S. Department of Agriculture, Forest Service General Technical Report PNWGTR-560, 254 p. (Also available at $h t t p: / / w w w . f s . f e d . u s /$ pnw/pubs/gtr560/.)

Heath, L.S., Smith, J.E., Skog, K.E., Nowak, D.J., and Woodall, C.W., 2011a, Managed forest carbon estimates for the U.S. greenhouse gas inventory, 1990-2008: Journal of Forestry, April/May, p. 167-173.

Heath, L.S., Smith, J.E., Woodall, C.W., Azuma, D.L., and Waddell, K.L., 2011b, Carbon stocks on forestland of the United States with emphasis on USDA Forest Service ownership: Ecosphere, v. 2, no. 1, article 6, 21 p., accessed October 31, 2013, at http://dx.doi.org/10.1890/ES1000126.1.

Hedges, J.I., and Keil, R.G., 1995, Sedimentary organic matter preservation-An assessment and speculative synthesis: Marine Chemistry, v. 49, nos. 2-3, p. 81-115.

Hedges, J.I., Keil, R.G., and Benner, R., 1997, What happens to terrestrial organic matter in the ocean?: Organic Geochemistry, v. 27, nos. 5-6, p. 195-212.

Heinselman, M.L., 1973, Fire in the virgin forests of the Boundary Waters Canoe Area, Minnesota: Quaternary Research, v. 3, no. 3, p. 329-382.

Herbert, R.A., 1999, Nitrogen cycling in coastal marine ecosystems: FEMS Microbiology Reviews, v. 23, no. 5, p. 563-590.

Hessl, A.E., 2011, Pathways for climate change effects on fire-Models, data, and uncertainties: Progress in Physical Geography, v. 35, no. 3, p. 393-407.

Hesterberg, Tim, Moore, D.S., Monaghan, Shaun, Clipson, Ashley, and Epstein, Rachel, 2010, Bootstrap methods and permutation tests, chap. 16 of Moore, D.S., McCabe, G.P., and Craig, Bruce, eds., Introduction to the practice of statistics (7 ed.): New York, W.H. Freeman \& Company, p. 16.1-16.60.

Hicke, J.A., Allen, C.D., Desai, A.R., Dietze, M.C., Hall, R.J., Hogg, E.H., Kashian, D.M., Moore, David, Raffa, K.F., Sturrock, R.N., and Vogelmann, James, 2012, Effects of biotic disturbances on forest carbon cycling in the United States and Canada: Global Change Biology, v. 18, no. 1, p. 7-34. (Also available at $h t t p: / / d x$.doi.org/10.1111/j.13652486.2011.02543.x.)

Hicke, J.A., Jenkins, J.C., Ojima, D.S., and Ducey, Mark, 2007, Spatial patterns of forest characteristics in the western United States derived from inventories: Ecological Applications, v. 17, no. 8, p. 2387-2402. (Also available at http://dx.doi.org/10.1890/06-1951.1.)

Hofmann, E.E., Cahill, Bronwyn, Fennel, Katja, Friedrichs, M.A.M., Hyde, Kimberly, Lee, Cindy, Mannino, Antonio, 
Najjar, R.G., O’Reilly, J.E., Wilkin, John, and Xue, Jianhong, 2011, Modeling the dynamics of continental shelf carbon: Annual Review of Marine Science, v. 3, p. 93-122.

Homer, Collin, Dewitz, Jon, Fry, Joyce, Coan, Michael, Hossain, Nazmul, Larson, Charles, Herold, Nate, McKerrow, Alexa, Van Driel, J.N., and Wickham, James, 2007, Completion of the 2001 national land cover database for the conterminous United States: Photogrammetric Engineering and Remote Sensing, v. 73, no. 4, p. 337-341. (Also available at http://www.asprs.org/a/publications/pers/2007journal/april/ highlight.pdf.).

Horizon Systems Corporation, 2005, NHDPlus, version 2: Horizon Systems Corporation Web site accessed October 1, 2012, at http://www.horizon-systems.com/nhdplus/.

Houghton, R.A., 2010, How well do we know the flux of $\mathrm{CO}_{2}$ from land-use change?: Tellus B, v. 62, no. 5, p. 337-351, accessed October 31, 2013, at http://dx.doi.org/10.1111/ j.1600-0889.2010.00473.x.

Houghton, R.A., and Hackler, J.L., 2000, Changes in terrestrial carbon storage in the United States. 1. The roles of agriculture and forestry: Global Ecology and Biogeography, v. 9, no. 2, p. 125-144, accessed December 10, 2013, at http://dx.doi.org/10.1046/j.1365-2699.2000.00166.x.

Houghton, R.A., Hackler, J.L., and Lawrence, K.T., 1999, The U.S. carbon budget - Contributions from land-use change: Science, v. 285 , no. 5427 , p. 574-578, accessed October 31 , 2013, at $h t t p: / / d x$.doi.org/10.1126/science.285.5427.574.

Howarth, R.W., 2008, Coastal nitrogen pollution-A review of sources and trends globally and regionally: Harmful Algae, v. 8 , no. 1, p. 14-20.

Howarth, R.W., Billen, G., Swaney, D., Townsend, A., Jaworski, N., Lajtha, K., Downing, J.A., Elmgren, R., Caraco, N., Jordan, T., Berendse, F., Freney, J., Kudeyarov, V., Murdoch, P., and Zhu Zhao-Liang, 1996, Regional nitrogen budgets and riverine $\mathrm{N} \& \mathrm{P}$ fluxes for the drainages to the North Atlantic Ocean-Natural and human influences: Biogeochemistry, v. 35, no. 1, p. 75-139.

Huang, Chengquan, Goward, S.N., Masek, J.G., Thomas, Nancy, Zhu, Zhiliang, and Vogelmann, J.E., 2010, An automated approach for reconstructing recent forest disturbance history using dense Landsat time series stacks: Remote Sensing of Environment, v. 114, no. 1, p. 183-198. (Also available at $h t t p: / / d x . d o i . o r g / 10.1016 / j . r s e .2009 .08 .017$.

Huang, Cho-ying, Asner, G.P., Barger, N.N., Neff, J.C., and Floyd, M.L., 2010, Regional aboveground live carbon losses due to drought-induced tree dieback in piñon-juniper ecosystems: Remote Sensing of Environment, v. 114, no. 7, p. 1471-1479. (Also available at $h t t p: / / d x . d o i . o r g / 10.1016 / j$. rse.2010.02.003.)

Hunt, R.J., Walker, J.F., and Krabbenhoft, D.P., 1999, Characterizing hydrology and the importance of groundwater discharge in natural and constructed wetlands:
Wetlands, v. 19, no. 2, p. 458-472. (Also available at http://users.ipfw.edu/isiorho/20010114-12.pdf.)

Hunt, C.W., Salisbury, J.E., and Vandemark, D., 2011, Contribution of non-carbonate anions to total alkalinity and overestimation of $p \mathrm{CO}_{2}$ in New England and New Brunswick rivers: Biogeosciences, v. 8, no. 10, p. 3069-3076. (Also available at $h t t p: / / d x$.doi.org/10.5194/bg-8-3069-2011.)

Huntington, T.G., Richardson, A.D., McGuire, K.J., and Hayhoe, Katharine, 2009, Climate and hydrological changes in the northeastern United States-Recent trends and implications for forested and aquatic ecosystems: Canadian Journal of Forest Research, v. 39, no. 2, p. 199-212.

Huntzinger, D.N., Post, W.M., Wei, Y., Michalak, A.M., West, T.O., Jacobson, A.R., Baker, I.T., Chen, J.M., Davis, K.J., Hayes, D.J., Hoffman, F.M., Jain, A.K., Liu, S., McGuire, A.D., Neilson, R.P., Potter, Chris, Poulter, B., Price, David, Raczka, B.M., Tian, H.Q., Thornton, P., Tomelleri, E., Viovy, N., Xiaos, J., Yuant, W., Zengu, N., Zhaov, M., and Cook, R., 2012. North American carbon project (NACP) regional interim synthesis-Terrestrial biospheric model intercomparison: Ecological Modelling, v. 232, p. 144-157. (Also available at http://dx.doi.org/10.1016/j.ecolmodel.2012.02.004.)

Hurteau, M.D., and Brooks, M.L., 2011, Short- and long-term effects of fire on carbon in US dry temperate forest systems: BioScience, v. 61, no. 2, p. 139-146.

Hurtt, G.C., Pacala, S.W., Moorcroft, P.R., Caspersen, J., Shevliakova, E., Houghton, R.A., and Moore, B., III, 2002, Projecting the future of the U.S. carbon sink: Proceedings of the National Academy of Sciences of the United States of America, v. 99, no. 3, p. 1389-1394, accessed October 31, 2013, at http://dx.doi.org/10.1073/pnas.012249999.

International Organization for Standardization, 1995, Guide to the expression of uncertainty in measurements: Geneva, International Organization for Standardization Guide 98-3: 1995, $120 \mathrm{p}$.

Jenkins, J.C., Birdsey, R.A., and Pan, Yude, 2001, Biomass and NPP estimation for the mid-Atlantic region (USA) using plot-level forest inventory data: Ecological Applications, v. 11, no. 4, p. 1174-1193.

Jensen, O.P., Benson, B.J., Magnuson, J.J., Card, V.M., Futter, M.N., Soranno, P.A., and Stewart, K.M., 2007, Spatial analysis of ice phenology trends across the Laurentian Great Lakes region during a recent warming period: Limnology and Oceanography, v. 52, no. 5, p. 2013-2026.

Jeon, S.B., Olofsson, Pontus, and Woodcock, C.E., 2012, Land use change in New England-A reversal of the forest transition: Journal of Land Use Science, v. 9, no. 1, p. 105-130.

Jolly, W.M., Nemani, Ramakrishna, and Running, S.W., 2005, A generalized, bioclimatic index to predict foliar phenology in response to climate: Global Change Biology, v. 11, no. 4, p. 619-632. 
Jones, J.B., Jr., and Mulholland, P., 1998, Influence of drainage basin topography and elevation on carbon dioxide and methane supersaturation of stream water: Biogeochemistry, v. 40 , no. 1, p. 57-72.

Joyce, L.A., Price, D.T., McKenney, D.W., Siltanen, R.M., Papadopol, Pia, Lawrence, Kevin, and Coulson, D.P., 2011, High resolution interpolation of climate scenarios for the conterminous USA and Alaska derived from general circulation model simulations: Fort Collins, Colo., U.S. Department of Agriculture, Forest Service General Technical Report RMRS-GTR-263, 87 p.

Kara, A.B., Rochford, P.A., and Hurlburt, H.E., 2000, An optimal definition for ocean mixed layer depth: Journal of Geophysical Research: Oceans, v. 105, no. C7, p. 16803-16821.

Kashian, D.M., Romme, W.H., Tinker, D.B., Turner, M.G., and Ryan, M.G., 2012, Post-fire changes in forest carbon storage over a 300-year chronosequence of Pinus contortadominated forests: Ecological Monographs, v. 83, no. 1, p. 49-66 plus appendixes.

Kasischke, E.S., Amiro, B.D., Barger, N.N., French, N.H.F., Grosse, Guido, Goetz, S.J., Harmon, M.E., Hicke, J.A., Liu, Shuguang, and Masek, J.G., 2013. Impacts of disturbance on the terrestrial carbon budget of North America: Journal of Geophysical Research: Biogeosciences, v. 118, no. 1, p. 1-14. (Also available at http://dx.doi.org/10.1002/ jgrg.20027.)

Keane, R.E., Cary, G.J., and Parsons, R., 2003, Using simulation to map fire regimes-An evaluation of approaches, strategies, and limitations: International Journal of Wildland Fire, v. 12, nos. 3-4, p. 309-322.

Keenan, T.F., Davidson, Eric, Moffat, A.M., Munger, William, and Richardson, A.D., 2012, Using model-data fusion to interpret past trends, and quantify uncertainties in future projections, of terrestrial ecosystem carbon cycling: Global Change Biology, v. 18, no. 8, p. 2555-2569.

Keil, R.G., Mayer, L.M., Quay, P.D., Richey, J.E., and Hedges, J.I., 1997, Loss of organic matter from riverine particles in deltas: Geochimica et Cosmochimica Acta, v. 61, no. 7, p. 1507-1511.

Keim, B.D., Fischer, M.R., and Wilson, A.M., 2005, Are there spurious precipitation trends in the United States climate division database?: Geophysical Research Letters, v. 32, no. 4, L04702, 3 p., accessed November 6, 2013, at http://dx.doi.org/10.1029/2004GL021985.

Kellndorfer, Josef, Walker, Wayne, Pierce, Leland, Dobson, Craig, Fites, Jo Ann, Hunsaker, Carolyn, Vona, John, and Clutter, Michael, 2004, Vegetation height estimation from shuttle radar topography mission and national elevation datasets: Remote Sensing of Environment, v. 93, no. 3, p. 339-358. (Also available at http://dx.doi.org/10.1016/j.rse.2004.07.017.)

Kellndorfer, Josef, Walker, W.S., Kirsch, Katherine, Fiske, G.J., Bishop, J.B., LaPoint, Liz, Hoppus, Mike, and West- fall, Jim, 2013, NACP aboveground biomass and carbon baseline data, ver. 2 (NBCD 2000), U.S.A., 2000: Oak Ridge National Laboratory dataset, accessed January 14, 2014, at $h t t p: / / d x$.doi.org/10.3334/ORNLDAAC/1161.

Kimball, J.S., Running, S.W., and Nemani, R., 1997, An improved method for estimating surface humidity from daily minimum temperature: Agricultural and Forest Meteorology, v. 85, nos. 1-2, p. 87-98.

Korontzi, Stefania, McCarty, Jessica, Loboda, Tatiana, Kumar, Suresh, and Justice, Chris, 2006, Global distribution of agricultural fires in croplands from 3 years of Moderate Resolution Imaging Spectroradiometer (MODIS) data: Global Biogeochemical Cycles, v. 20, no. 2, GB2021, 15 p., accessed November 6, 2013, at http://dx.doi.org/10.1029/2005GB002529.

Kuchler, A.W., 1964, Potential natural vegetation of the conterminous United States: New York, American Geographical Society Special Publication 36, 116 p., scale 1:3,168,000.

Lai, C.-T., Katul, G., Butnor, J., Siqueira, M., Ellsworth, D., Maier, C., Johnsen, K., McKeand, S., and Oren, R., 2002, Modelling the limits on the response of net carbon exchange to fertilization in a south-eastern pine forest: Plant, Cell and Environment, v. 25, no. 9, p. 1095-1119. (Also available at http://dx.doi.org/10.1046/j.1365-3040.2002.00896.x.)

Larkin, N.K., O'Neill, S.M., Solomon, Robert, Raffuse, Sean, Strand, Tara, Sullivan, D.C., Krull, Candace, Rorig, Miriam, Peterson, J.L., and Ferguson, S.A., 2009, The BlueSky smoke modeling framework: International Journal of Wildland Fire, v. 18, no. 8, p. 906-920.

Lauerwald, Ronny, Hartmann, Jens, Ludwig, Wolfgang, and Moosdorf, Nils, 2012, Assessing the nonconservative fluvial fluxes of dissolved organic carbon in North America: Journal of Geophysical Research, v. 117, no. G1, G01027, 19 p. accessed February 4, 2014, at http://dx.doi.org/10.1029/2011JG001820.

Law, B.E., Turner, D., Campbell, J., Sun, O.J., Van Tuyl, S., Ritts, W.D., and Cohen, W.B., 2004, Disturbance and climate effects on carbon stocks and fluxes across western Oregon USA: Global Change Biology, v. 10, no. 9, p. 1429-1444.

Lee, C., Murray, D.W., Barber, R.T., Buesseler, K.O., Dymond, J., Hedges, J.I., Honjo, S., Manganini, S.J., Marra, J., Moser, C., Peterson, M.L., Prell, W.L., and Wakeham, S.G., 1998, Particulate organic carbon fluxes - Compilation of results from the 1995 US JGOFS Arabian Sea process study: Deep-Sea Research Part II: Topical Studies in Oceanography, v. 45, nos. 10-11, p. 2489-2501.

Lee, J.J., and Dodson, Rusty, 1996, Potential carbon sequestration by afforestation of pasture in the south-central United States: Agronomy Journal, v. 88, no. 3, p. 381-384, accessed November 6, 2013, at https://www.soils.org/ publications/aj/abstracts/88/3/AJ0880030381. 
Leithold, E.L., Perkey, D.W., Blair, N.E., and Creamer, T.N., 2005, Sedimentation and carbon burial on the northern California continental shelf - The signatures of land-use change: Continental Shelf Research, v. 25, no. 3, p. 349-371.

Leopold, L.B., and Maddock, Thomas, Jr., 1953, The hydraulic geometry of stream channels and some physiographic implications: U.S. Geological Survey Professional Paper 252, 57 p. (Also available at http://pubs.usgs.gov/pp/0252/ report.pdf.)

Lillesand, Thomas, Kiefer, R.W., and Chipman, Jonathan, 2007, Remote sensing and image interpretation (6th ed.): New York, Wiley, 804 p.

Litchman, E., Klausmeier, C.A., Miller, J.R., Schofield, O.M., and Falkowski, P. G., 2006, Multi-nutrient, multi-group model of present and future oceanic phytoplankton communities: Biogeosciences, v. 3, no. 4, p. 585-606.

Liu, Shuguang, 2009, Quantifying the spatial details of carbon sequestration potential and performance, in McPherson, B.J., and Sundquist, E.T., eds., Carbon sequestration and its role in the global carbon cycle: American Geophysical Union Monograph 183, p. 117-128. (Also available at http://dx.doi.org/10.1029/2006GM000524.)

Liu, Shuguang, Bond-Lamberty, Ben, Hicke, J.A., Vargas, Rodrigo, Zhao, Shuqing, Chen, Jing, Edburg, S.L., Hu, Yueming, Liu, Jinxun, McGuire, A.D., Xiao, Jingfeng, Keane, Robert, Yuan, Wenping, Tang, Jianwu, Luo, Yiqi, Potter, Christopher, and Oeding, Jennifer, 2011, Simulating the impacts of disturbances on forest carbon cycling in North America; processes, data, models, and challenges: Journal of Geophysical Research, v. 116, no. G4, G00K08, 22 p., accessed March 25, 2014, at http://dx.doi.org/10.1029/2010JG001585.

Liu, Shuguang, Liu, Jinxun, Young, C.J., Werner, J.M., Wu, Yiping, Li, Zhengpeng, Dahal, Devendra, Oeding, Jennifer, Schmidt, G.L., Sohl, T.L., Hawbaker, T.J., and Sleeter, B.M., 2012a, Baseline carbon storage, carbon sequestration, and greenhouse-gas fluxes in terrestrial ecosystems of the western United States, chap. 5 of Zhu, Zhiliang, and Reed, B.C., eds., Baseline and projected future carbon storage and greenhouse-gas fluxes in ecosystems of the western United States: U.S. Geological Survey Professional Paper 1797, p. 45-63. (Also available at http://pubs.usgs.gov/pp/1797/.)

Liu, Shuguang, Loveland, T.R., and Kurtz, R.M., 2004, Contemporary carbon dynamics in terrestrial ecosystems in the southeastern plains of the United States: Environmental Management, v. 33, supplement 1, p. S442-S456, accessed October 31, 2013, at http://dx.doi.org/10.1007/ s00267-003-9152-z.

Liu, Shuguang, Tan, Zhengxi, Chen, Mingshi, Liu, Jinxun, Wein, Anne, Li, Zhengpeng, Huang, Shengli, Oeding, Jennifer, Young, Claudia, Verma, S.B., Suyker, A.E., Faulkner, Stephen, and McCarty, G.W., 2012b, The general ensemble biogeochemical modeling system (GEMS) and its applica- tions to agricultural systems in the United States, chap. 18 of Liebig, Mark, Franzluebbers, A.J., and Follett, Ronald, eds., Managing agricultural greenhouse gases - Coordinated agricultural research through GRACEnet to address our changing climate: London, Academic Press, p. 309-323. (Also available at http://dx.doi.org/10.1016/B978-0-12386897-8.00018-8.)

Liu, Shuguang, Wu, Yiping, Young, C.J., Dahal, Devendra, Werner, J.M., Liu, Jinxun, Li, Zhengpeng, Tan, Zhengxi, Schmidt, G.L., Oeding, Jennifer, Sohl, T.L., Hawbaker, T.J., and Sleeter, B.M., 2012c, Projected future carbon storage and greenhouse-gas fluxes of terrestrial ecosystems in the western United States, chap. 9 of Zhu, Zhiliang, and Reed, B.C., eds., Baseline and projected future carbon storage and greenhouse-gas fluxes in ecosystems of the western United States: U.S. Geological Survey Professional Paper 1797, p. 109-124. (Also available at http://pubs.usgs.gov/ pp/1797/.)

Liu, Shuguang, Bliss, Norman, Sundquist, Eric, and Huntington, T.G., 2003, Modeling carbon dynamics in vegetation and soil under the impact of soil erosion and deposition: Global Biogeochemical Cycles, v. 17, no. 2, 1074, 24 p., accessed January 14, 2014, at http://dx.doi.org/10.1029/2002GB002010.

Liu, Yongqiang, 2004, Variability of wildland fire emissions across the contiguous United States: Atmospheric Environment, v. 38, no. 21, p. 3489-3499.

Loescher, H.W., Law, B.E., Mahrt, L., Hollinger, D.Y., Campbell, J., and Wofsy, S.C., 2006, Uncertainties in, and interpretation of, carbon flux estimates using the eddy covariance technique: Journal of Geophysical Research, v. 111, no. D12, D21S90, 19 p., accessed February 12, 2014, at http://dx.doi.org/10.1029/2005JD006932.

Loveland, T.R., Sohl, T.L., Stehman, S.V., Gallant, A.L., Sayler, K.L., Napton, D.E., 2002, A strategy for estimating the rates of recent United States land-cover changes: Photogrammetric Engineering and Remote Sensing, v. 68, no. 10, p. 1091-1099.

Lozovik, P.A., 2005, Contribution of organic acid anions to the alkalinity of natural humic water: Journal of Analytical Chemistry, v. 60, no. 11, p. 1000-1004.

Lutes, D.C., Keane, R.E., and Caratti, J.F., 2009, A surface fuel classification for estimating fire effects: International Journal of Wildland Fire, v. 18, no. 7, p. 802-814.

Luyssaert, S., and others, 2007, $\mathrm{CO}_{2}$ balance of boreal, temperate, and tropical forests derived from a global database: Global Change Biology, v. 13, no. 12, p. 2509-2537.

Magnuson, J.J., Robertson, D.M., Benson, B.J., Wynne, R.H., Livingstone, D.M., Arai, Tadashi, Assel, R.A., Barry, R.G., Card, Virginia, Kuusisto, Esko, Granin, N.G., Prowse, T.D., Stewart, K.M., and Vuglinski, V.S., 2000, Historical trends in lake and river ice cover in the Northern Hemisphere: Science, v. 289, no. 5485, p. 1743-1746. 
Maier, C.A., Albaugh, T.J., Allen, H.L., and Dougherty, P.M., 2004, Respiratory carbon use and carbon storage in midrotation loblolly pine (Pinus taeda L.) plantations-The effect of site resources on the stand carbon balance: Global Change Biology, v. 10, p. 1335-1350.

Malone, T.C., Conley, D.J., Fisher, T.R., Glibert, P.M., Harding, L.W., and Sellner, K.G., 1996, Scales of nutrientlimited phytoplankton productivity in Chesapeake Bay: Estuaries, v. 19, no. 2, p. 371-385.

Martin, J.H., Knauer, G.A., Karl, D.M., and Broenkow, W.W., 1987, Vertex - Carbon cycling in the northeast Pacific: Deep-Sea Research Part I: Oceanographic Research Papers, v. 34 , no. 2 , p. $267-285$.

Maurer, E.P., Brekke, Levi, Pruitt, Tom, and Duffy, P.B., 2007, Fine-resolution climate projections enhance regional climate change impact studies: EOS, Transactions, American Geophysical Union, v. 88, no. 47, p. 504.

Maurer, E.P., Wood, A.W., Adam, J.C., Lettenmaier, D.P., and Nijssen, B., 2002, A long-term hydrologically based dataset of land surface fluxes and states for the conterminous United States: Journal of Climate, v. 15, no. 22, p. 3237-3251.

Mayorga, Emilio, Seitzinger, S.P., Harrison, J.A., Dumont, Egon, Beusen, A.H.W., Bouwman, A.F., Fekete, B.M., Kroeze, Carolien, and Van Drecht, Gerard, 2010, Global nutrient export from WaterSheds 2 (NEWS 2)- Model development and implementation: Environmental Modelling and Software, v. 25, no. 7, p. 837-853.

McDonald, C.P, Rover, J.A., Stets, E.G., and Striegl R.G., 2012, The regional abundance and size distribution of lakes and reservoirs in the United States and implications for estimates of global lake extent: Limnology and Oceanography, v. 57 , no. 2 , p. $597-606$.

McIntyre, S.C. 1993, Reservoir sedimentation rates linked to long-term changes in agricultural land use: Journal of the American Water Resources Association, v. 29, no. 3, p. 487-495. (Also available at http://dx.doi.org/10.1111/j.1752-1688.1993.tb03226.x.)

McKinley, Galen, Urban, Noel, Bennington, Val, Pilcher, Darren, and McDonald, Cory, 2011, Preliminary carbon budgets for the Laurentian Great Lakes: Ocean Carbon and Biogeochemistry News, v. 4, no. 2, p. 1-7. (Also available at $h t t p: / / w w w . u s-o c b . o r g / p u b l i c a t i o n s / O C B \_N E W S \_S P R \_$ SUM11.pdf.)

Mearns, L.O., Giorgi, F., McDaniel, L., and Shields, C., 2003. Climate scenarios for the southeastern U.S. based on GCM and regional model simulations: Climatic Change, v. 60, nos. 1-2, p. 7-35.

Meehl, G.A., Covey, Curt, Delworth, Thomas, Latif, Mojib, McAvaney, Bryant, Mitchell, J.F.B., Taylor, K.E., and Stouffer, R.J., 2007, The WCRP CMIP3 multimodel dataset-A new era in climate change research: Bulle- tin of the American Meteorological Society, v. 88, no. 9, p. 1383-1394.

Meigs, G.W., Donato, D.C., Campbell, J.L., Martin, J.G., and Law, B.E., 2009, Forest fire impacts on carbon uptake, storage, and emission-The role of burn severity in the eastern Cascades, Oregon: Ecosystems, v. 12, no. 8, p. 1246-1267.

Melching, C.S., and Flores, H.E., 1999, Reaeration equations derived from U.S. Geological Survey database: Journal of Environmental Engineering, v. 125, no. 5, p. 407-414. (Also available at http://solon.er.usgs.gov/pubs/rearation_ equations_melching_flores.pdf.)

Melvin, A.M., and Goodale, C.L., 2013, Tree species and earthworm effects on soil nutrient distribution and turnover in a northeastern U.S. common garden: Canadian Journal of Forest Research, v. 43, no. 2, p. 180-187.

Mesinger, Fedor, DiMego, Geoff, Kalnay, Eugenia, Mitchell, Kenneth, Shafran, P.C., Ebisuzaki, Wesley, Jović, Dušan, Woollen, Jack, Rogers, Eric, Berbery, E.H., Ek, M.B., Fan, Yun, Grumbine, Robert, Higgins, Wayne, Li, Hong, Lin, Ying, Manikin, Geoff, Parrish, David, and Shi, Wei, 2006, North American regional reanalysis: Bulletin of the American Meteorological Society, v. 87, no. 3, p. 343-360.

Messina, M.G., and Conner, W.H., 1998, Southern forested wetlands-Ecology and management: Boca Raton, Florida, CRC Press LLC, $640 \mathrm{p}$.

Metherell, A.K., Harding, L.A., Cole, C.V., and Parton, W.J., 1993, CENTURY soil organic matter model environment, technical documentation, Agroecosystem version 4.0: U.S. Department of Agriculture Technical Report 4, accessed December 16, 2013, at http://www.nrel.colostate.edu/ projects/century/.

Meybeck, Michel, Dürr, H.H., and Vörösmarty, C.J., 2006, Global coastal segmentation and its river catchment contributors - A new look at land-ocean linkage: Global Biogeochemical Cycles, v. 20, no. 1, GB1S90, 15 p., accessed November 6, 2013, at http://dx.doi. org/10.1029/2005GB002540.

Michalak, A.M., Jackson, R.B., Marland, Gregg, Sabine, C.L., and the Carbon Cycle Science Working Group, 2011, A U.S. carbon cycle science plan: Washington, D.C., U.S. Carbon Cycle Science Program, 69 p., accessed November 6, 2013, at $h t t p: / / w w w . c a r b o n c y c l e s c i e n c e . g o v /$ sites/default/files/ documents/USCarbonCycleSciencePlan-2011.pdf.

Michigan Tech Research Institute, 2012, Wildland fire emissions information system: Michigan Technological University, Michigan Tech Research Institute database, accessed August 3, 2012, at http://wfeis.mtri.org/.

Michmerhuizen, C.M., Striegl, R.G., and McDonald, M.E., 1996, Potential methane emission from north-temperate lakes following ice melt: Limnology and Oceanography, v. 41, no. 5, p. 985-991. 
Mickler, R.A., Earnhardt, T.S., and Moore, J.A., 2002, Modeling and spatially distributing forest net primary production at regional scale: Journal of the Air and Waste Management Association, v. 52, no.4, p. 174-185. (Also available at http://www.srs.fs.usda.gov/pubs/ja/ja_mickler002.pdf.)

Middelburg, J.J., and Levin, L.A., 2009, Coastal hypoxia and sediment biogeochemistry: Biogeosciences, v. 6, no. 7, p. 1273-1293.

Milesi, Cristina, Elvidge, C.D., Nemani, R.R., and Running, S.W., 2003, Assessing the impact of urban land development on net primary productivity in the southeastern United States: Remote Sensing of Environment, v. 86 , no. 13 , p. 401-410, accessed November 6, 2013, at http://dx.doi.org/10.1016/S0034-4257(03)00081-6.

Millero, F.J., 1979, Thermodynamics of the carbonate system in seawater: Geochimica et Cosmochimica Acta, v. 43, no. 10, p. 1651-1661. (Also available at http://dx.doi.org/10.1016/0016-7037(79)90184-4.)

Milliman, J.D., and Syvitski, J.P.M., 1992, Geomorphic/ tectonic control of sediment discharge to the ocean-The importance of small mountainous rivers: The Journal of Geology, v. 100, no. 5, p. 525-544.

Mixon, D.M., Kinner, D.A., Stallard, R.F., and Syvitski, J.P.M., 2008, Geolocation of man-made reservoirs across terrains of varying complexity using GIS: Computers and Geosciences, v. 34, no. 10, p. 1184-1197. (Also available at http://dx.doi.org/10.1016/j.cageo.2008.02.015.)

Mulholland, P.J., 2003. Large-scale patterns in dissolved organic carbon concentration, flux, and sources, in Findlay, S.E.G., and Sinsabaugh, R.L., eds., Aquatic ecosystems - Interactivity of dissolved organic matter: Elsevier Science, p. 139-159.

Mulholland, P.J., and Elwood, J.W., 1982, The role of lake and reservoir sediments as sinks in the perturbed global carbon cycle: Tellus, v. 34, no. 5, p. 490-499.

Mulholland, P.J., and Watts, J.A., 1982, Transport of organic carbon to the oceans by rivers of North America-A synthesis of existing data: Tellus, v. 34, no. 2, p. 176-186.

Murray, A.G., and Parslow, J.S., 1999, The analysis of alternative formulations in a simple model of a coastal ecosystem: Ecological Modelling, v. 119, nos. 2-3, p. 149-166.

Najjar, R.G., Pyke, C.R., Adams, M.B., Breitburg, Denise, Hershner, Carl, Kemp, Michael, Howarth, Robert, Mulholland, M.R., Paolisso, Michael, Secor, David, Sellner, Kevin, Wardrop, Denice, and Wood, Robert, 2010, Potential climate-change impacts on the Chesapeake Bay: Estuarine, Coastal, and Shelf Science, v. 86, no. 1, p. 1-20.

Najjar, R.G., Walker, H.A., Anderson, P.J., Barron, E.J., Bord, R.J., Gibson, J.R., Kennedy, V.S., Knight, C.G., Megonigal, J.P., O’Connor, R.E., Polsky, C.D., Psuty, N.P., Richards, B.A., Sorenson, L.G., Steele, E.M., and Swanson, R.S., 2000, The potential impacts of climate change on the mid-
Atlantic coastal region: Climate Research, v. 14, no. 3, p. 219-233.

Nakićenović, Nebojša, Alcamo, Joseph, Davis, Gerald, de Vries, Bert, Fenhann, Joergen, Gaffin, Stuart, Gregory, Kenneth, Grübler, Arnulf, Jung, T.Y., Kram, Tom, La Rovere, E.L., Michaelis, Laurie, Mori, Shunsuke, Morita, Tsuneyuki, Pepper, William, Pitcher, Hugh, Price, Lynn, Riahi, Keywan, Roehrl, Alexander, Rogner, H.H., Sankovski, Alexei, Schlesinger, Michael, Shukla, Priyararshi, Smith, Steven, Swart, Robert, van Rooijen, Sascha, Victor, Nadejda, and Zhou Dadi, 2000, Special report on emissions scenarios; A special report of Working Group III of the Intergovernmental Panel on Climate Change: Cambridge, United Kingdom, Cambridge University Press, 599 p., accessed November 15, 2011, at http://www.grida.no/publications/other/ ipcc\% $\%$ Fsr/? src=/climate/ipcc/emission/index.htm.

Napton, D.E., Auch, R.F., Headley, Rachel, and Taylor, J.L., 2010, Land changes and their driving forces in the southeastern United States: Regional Environmental Change, v.10, no. 1, p. 37-53.

National Aeronautics and Space Administration, 2012, Surface meteorology and solar energy: National Aeronautics and Space Administration, accessed May 31, 2012, at http://eosweb.larc.nasa.gov/sse/.

National Interagency Fire Center, [undated], Wildland fire statistics: Bureau of Land Management Web site, accessed May 3, 2013, at http://www.nifc.gov/fireInfo/fireInfo_ statistics.html.

Nixon, S.W., Ammerman, J.W., Atkinson, L.P., Berounsky, V. M., Billen, G., Boicourt, W.C., Boynton, W.R., Church, T.M., Ditoro, D.M., Elmgren, R., Garber, J.H., Giblin, A.E., Jahnke, R.A., Owens, N.J.P., Pilson, M.E.Q., and Seitzinger, S.P., 1996, The fate of nitrogen and phosphorus at the landsea margin of the North Atlantic Ocean: Biogeochemistry, v. 35 , no. 1 , p. 141-180.

Nowacki, G.J., and Abrams, M.D., 2008, The demise of fire and "mesophication" of forests in the eastern United States: Bioscience, v. 58, no. 2, p. 123-138. (Also available at http://dx.doi.org/10.1641/B580207.)

Nowak, D.J., and Crane, D.E., 2002, Carbon storage and sequestration by urban trees in the USA: Environmental Pollution, v. 116, no. 3, p. 381-389, accessed November 7, 2013, at http://www.ncbi.nlm.nih.gov/pubmed/11822716.

Oak Ridge National Laboratory, 2012, Global fire emissions database, version 2.1: Oak Ridge National Laboratory Distributed Active Archive Center database, accessed August 9, 2012, at http://daac.ornl.gov/VEGETATION/guides/global_ fire_emissions_v2.1.html.

Oczkowski, Autumn, and Nixon, Scott, 2008, Increasing nutrient concentrations and the rise and fall of a coastal fishery; a review of data from the Nile Delta, Egypt: Estuarine, Coastal, and Shelf Science, v. 77, no. 3, p. 309-319. 
Oliver, B.G., Thurman, E.M., and Malcolm, R.L., 1983, The contribution of humic substances to the acidity of colored natural waters: Geochimica et Cosmochimica Acta, v. 47, no. 11, p. 2031-2035. (Also available at http://dx.doi.org/10.1016/0016-7037(83)90218-1.)

Omernik, J.M., 1987, Ecoregions of the conterminous United States: Annals of the Association of American Geographers, v. 77 , no. 1 , p. $118-125$.

Oren, Ram, Hsieh, Cheng-I, Stoy, Paul, Albertson, John, McCarthy, H.R., Harrell, Peter, and Katul, G.G., 2006, Estimating the uncertainty in annual net ecosystem carbon exchange-Spatial variation in turbulent fluxes and sampling errors in eddy-covariance measurements: Global Change Biology, v. 12, no. 5, p. 883-896. (Also available at http://dx.doi.org/10.1111/j.1365-2486.2006.01131.x.)

Ottmar, R.D., Prichard, S.J., Vihnanek, R.E., and Sandberg, D.V., 2008, Modification and validation of fuel consumption models for shrub and forested lands in the Southwest, Pacific Northwest, Rockies, Midwest, Southeast and Alaska: Seattle, Washington, Joint Fire Science Program Project 98-1-9-06 final report, 14 p. plus appendixes, accessed November 7, 2013, at http://www.firescience.gov/ projects/98-1-9-06/project/98-1-9-06_final_report.pdf.

Ottmar, R.D., Sandberg, D.V., Riccardi, C.L., and Prichard, S.J., 2007, An overview of the fuel characteristic classification system - Quantifying, classifying, and creating fuelbeds for resource planning: Canadian Journal of Forest Research, v. 37, no. 12, p. 2383-2393.

Outcalt, K.W., and Wade, D.D., 2004, Fuels management reduces tree mortality from wildfires in southeastern United States: Journal of Applied Forestry, v. 28, no. 1, p. 28-34.

Pacala, S.W., Hurtt, G.C., Baker, D., Peylin, P., Houghton, R.A., Birdsey, R.A., Heath, L., Sundquist, E.T., Stallard, R.F., Ciais, P., Moorcroft, P., Caspersen, J.P., Shevliakova, E., Moore, B., Kohlmaier, G., Holland, E., Gloor, M., Harmon, M.E., Fan, S.-M., Sarmiento, J.L., Goodale, C.L., Schimel, D., and Field, C.B., 2001, Consistent land- and atmosphere-based U.S. carbon sink estimates: Science, v. 292, no. 5525, p. 2316-2320, accessed October 31, 2013, at http://dx.doi.org/10.1126/science.1057320.

Pacala, Stephen, Birdsey, R.A., Bridgham, S.D., Conant, R.T., Davis, Kenneth, Hales, Burke, Houghton, R.A., Jenkins, J.C., Johnston, Mark, Marland, Gregg, Paustian, Keith, Caspersen, John, Socolow, Robert, and Tol, R.S.J., 2007, The North American carbon budget past and present, chap. 3 of King, A.W., Dilling, Lisa, Zimmerman, G.P., Fairman, D.M., Houghton, R.A., Marland, Gregg, Rose, A.Z., and Wilbanks, T.J., eds., The first state of the carbon cycle report (SOCCR) - The North American carbon budget and implications for the global carbon cycle, U.S. Climate Change Committee Synthesis and Assessment Product 2.2: Asheville, North Carolina, National Oceanic and Atmospheric Administration, p. 29-36, accessed November
7, 2013, at http://downloads.globalchange.gov/sap/sap2-2/ sap2-2-final-all.pdf.

Paerl, H.W., 2006, Assessing and managing nutrient-enhanced eutrophication in estuarine and coastal waters-Interactive effects of human and climatic perturbations: Ecological Engineering, v. 26, no. 1, p. 40-54.

Pan, Yude, Birdsey, R.A., Fang, Jingyun, Houghton, Richard, Kauppi, P.E., Kurz, W.A., Phillips, O.L., Shvidenko, Anatoly, Lewis, S.L., Canadell, J.G., Ciais, Philippe, Jackson, R.B., Pacala, S.W., McGuire, A.D., Piao, Shilong, Rautiainen, Aapo, Sitch, Stephen, and Hayes, Daniel, 2011, A large and persistent carbon sink in the world's forests: Science, v. 333, no. 6045, p. 988-993, accessed October 31, 2013, at http://dx.doi.org/10.1126/science.1201609.

Park, C.C., 1977, World-wide variations in hydraulic geometry exponents of stream channels - An analysis and some observations: Journal of Hydrology, v. 33, no. 1-2, p. 133-146.

Parkhurst, D.L., and Appelo, C.A.J., 1999, User's guide to PHREEQC (version 2) -A computer program for speciation, batch-reaction, one-dimensional transport, and inverse geochemical calculations: U.S. Geological Survey WaterResources Investigations Report 99-4259, 312 p.

Parton, W.J., Ojima, D.S., and Schimel, D.S., 1994, Environmental change in grasslands-Assessment using models: Climatic Change, v. 28, no. 1, p. 111-141. (Also available at http://dx.doi.org/10.1007/BF01094103.)

Parton, W.J., Schimel, D.S., Cole, C.V., and Ojima, D.S., 1987, Analysis of factors controlling soil organic-matter levels in great plains grasslands: Soil Science Society of America Journal, v. 51, no. 5, p. 1173-1179. (Also available at $h t t p: / / d x$. doi.org/10.2136/ sssaj1987.03615995005100050015x.)

Peet, R.K., and Allard, D.J., 1993, Longleaf pine vegetation of the southern Atlantic and eastern Gulf Coast regions-A preliminary classification, in Herman, S.M., ed., The longleaf pine ecosystem-Ecology, restoration and management, Tall Timbers Fire Ecology Conference, 18th, Tallahassee, Fla., May 30-June 2, 1991, Proceedings: Tallahassee, Fla., Tall Timbers Research Station, p. 45-81.

Piña-Ochoa, E., and Álvarez-Cobelas, M., 2006, Denitrification in aquatic environments-A cross-system analysis: Biogeochemistry, v. 81, no. 1, p. 111-130.

Planbureau voor de Leefomgeving [Netherlands Environmental Assessment Agency], 2001, The IMAGE 2.2 implementation of the SRES scenarios-A comprehensive analysis of emissions, climate change and impacts in the 21 st century: The Hague, Netherlands, Netherlands Environmental Assessment Agency CD-ROM 481508018.

Poffenbarger, H.J., Needelman, B.A., and Megonigal, J.P., 2011, Salinity influence on methane emissions from tidal marshes: Wetlands, v. 31, no. 5, p. 831-842, accessed 
October 31, 2013, at http://dx.doi.org/10.1007/s13157-0110197-0.

Pontius, R.G., Jr., and Millones, Marco, 2012, Death to Kappa- Birth of quantity disagreement and allocation disagreement for accuracy assessment: International Journal of Remote Sensing, v. 32, no. 15, p. 4407-4429. (Also available at $h t t p: / / d x$.doi.org/10.1080/01431161.2011.552923.)

Post, W.M., Emanuel, W.R., Zinke, P.J., and Stangenberger, A.G., 1982, Soil carbon pools and world life zones: Nature, v. 298, p. 156-159. (Also available at http://dx.doi.org/10.1038/298156a0.)

Potter, C.S., Randerson, J.T., Field, C.B., Matson, P.A., Vitousek, P.M., Mooney, H.A., and Klooster, S.A., 1993, Terrestrial ecosystem production-A process model based on global satellite and surface data: Global Biogeochemical Cycles, v. 7, no. 4, p. 811-841.

Potter, Christopher, Klooster, Steven, Genovese, Vanessa, Hiatt, Cyrus, Boriah, Shyam, Kumar, Vipin, Mithal, Varun, and Garg, Ashish, 2012, Terrestrial ecosystem carbon fluxes predicted from MODIS satellite data and large-scale disturbance modeling: International Journal of Geosciences, v. 3, no. 3, p. 469-479.

Poulter, Benjamin, Christensen, N.L., Jr., and Halpin, P.N., 2006, Carbon emissions from a temperate peat fire and its relevance to interannual variability of trace atmospheric greenhouse gases: Journal of Geophysical Research: Atmospheres, v. 111, no. D6, D06301, 11 p., accessed November 7, 2013, at $h t t p: / / d x$.doi.org/10.1029/2005JD006455.

Powell, T.L., Bracho, Rosvel, Li, Jiahong, Dore, Sabina, Hinkle, C.R., and Drake, B.G., 2006, Environmental controls over net ecosystem carbon exchange of scrub oak in central Florida: Agricultural and Forest Meteorology, v. 141, no. 1, p. 19-34. (Also available at http://dx.doi.org/10.1016/j.agrformet.2006.09.002.)

Preisler, H.K., Brillinger, D.R., Burgan, R.E., and Benoit, J.W., 2004, Probability based models for estimation of wildfire risk: International Journal of Wildland Fire, v. 13, no. 2, p. 133-142.

Preston, S.D., Alexander, R.B., and Wolock, D.M., 2011, SPARROW modeling to understand water-quality conditions in major regions of the United States-A featured collection introduction: Journal of the American Water Resources Association, v. 47, no. 5, p. 887-890.

PRISM Climate Group, 2012, PRISM data: PRISM Climate Group dataset, accessed October 23, 2012, at http://www.prism.oregonstate.edu/.

Protected Areas Database of the United States Partnership, 2009, A map for the future - Creating the next generation of protected area inventories in the United States: Protected Areas Database of the United States Partnership, 20 p., accessed June 18, 2010, at http://www.protectedlands.net/ images/PADUS_FinalJuly2009LowRes.pdf.
Rabalais, N.N., Díaz, R.J., Levin, L.A., Turner, R.E., Gilbert, D., and Zhang, J., 2010, Dynamics and distribution of natural and human-caused hypoxia: Biogeosciences, v. 7, no. 2, p. 585-619.

Rabalais, N.N., Turner, R.E., Justić, Dubravko, Dortch, Quay, Wiseman, W.J., Jr., and Sen Gupta, B.K., 1996, Nutrient changes in the Mississippi River and system responses on the adjacent continental shelf: Estuaries, v. 19, no. 2B, p. 386-407.

Radeloff, V.C., Mladenoff, D.J., and Boyce, M.S., 2000, A historical perspective and future outlook on landscape scale restoration in the northwest Wisconsin pine barrens: Restoration Ecology, v. 8, no. 2, p. 119-126.

Raymond, P.A., and Cole, J.J., 2003, Increase in the export of alkalinity from North America's largest river: Science, v.301, no. 5629 , p. $88-91$.

Raymond, P.A., Zappa, C.J., Butman, David, Bott, T.L., Potter, Jody, Mulholland, Patrick, Laursen, A.E., McDowell, W.H., and Newbold, Dennis, 2012, Scaling the gas transfer velocity and hydraulic geometry in streams and small rivers: Limnology and Oceanography-Fluids and Environments, v. 2, p. 41-53. (Also available at http://dx.doi.org/10.1215/21573689-1597669.)

Reich, P.B., 2012, Key canopy traits drive forest productivity: Proceedings of the Royal Society B: Biological Sciences, v. 279 , no. 1736 , p. $2128-2134$.

Reinhardt, E.D., Keane, R.E., and Brown, J.K., 1997, First order fire effect model-FOFEM 4.0, user's guide: U.S. Department of Agriculture, Forest Service General Technical Report INT-GTR-344, 65 p., accessed November 7, 2013, at http://www.fs.fed.us/rm/pubs_int/int_gtr344.pdf.

Reinhardt, Elizabeth, and Keane, Bob, 2009, FOFEM-The first-order fire effects model adapts to the 21 st century: Fire Science Brief, no. 62, p. 1-6, accessed November 7, 2013, at http://www.firescience.gov/projects/98-1-8-03/ supdocs/98-1-8-03_fsbrief62-final.pdf.

Rhemtulla, J.M., Mladenoff, D.J., and Clayton, M.K., 2009, Legacies of historical land use on regional forest composition and structure in Wisconsin, USA (mid-1800s-1930s2000s): Ecological Applications, v. 19, no. 4, p. 1061-1078.

Riera, J.L., Schindler, J.E., and Kratz, T.K., 1999, Seasonal dynamics of carbon dioxide and methane in two clear-water lakes and two bog lakes in northern Wisconsin, U.S.A.: Canadian Journal of Fisheries and Aquatic Sciences, v. 56, no. 2, p. 265-274.

Robinson, D.T., Brown, D.G., French, N.H.F., and Reed, B.C., 2013, Linking land use and the carbon cycle, chap. 1 of Brown, D.G., Robinson, D.T., French, N.H.F., and Reed, B.C., eds., Land use and the carbon cycle: Advances in integrated science, management, and policy: New York, N.Y., Cambridge University Press, p. 3-23. 
Rollins, M.G., 2009, LANDFIRE-A nationally consistent vegetation, wildland fire, and fuel assessment: International Journal of Wildland Fire, v. 18, no. 3, p. 235-249.

Roy, D.P., Lewis, P.E., and Justice, C.O., 2002, Burned area mapping using multi-temporal moderate spatial resolution data-A bi-directional reflectance model-based expectation approach: Remote Sensing of Environment, v. 83, nos. 1-2, p. 263-286.

Runkel, R.L., Crawford, C.G., and Cohn, T.A., 2004, Load estimator (LOADEST) - A FORTRAN program for estimating constituent loads in streams and rivers: U.S. Geological Survey Techniques and Methods, book 4, chap. A5, 69 p., accessed November 7, 2013, at http://pubs.usgs.gov/ tm/2005/tm4A5/.

Running, S.W., 2008, Ecosystem disturbance, carbon, and climate: Science, v. 321, no. 5889, p. 652-653, accessed October 31, 2013, at http://dx.doi.org/10.1126/science.1159607.

Ryan, M.G., Binkley, D., and Fownes, J.H., 1997, Agerelated decline in forest productivity-Pattern and process: Advances in Ecological Research, v. 27, p. 213-262.

Ryan, M.G., Hubbard, R.M., Pongracic, Silvia, Raison, R.J., and McMurtrie, R.E., 1996, Foliage, fine-root, woody-tissue and stand respiration in Pinus radiata in relation to nutrient status: Tree Physiology, v. 16, no. 3, p. 333-343.

Rykiel, E.J., Jr., 1996, Testing ecological models-The meaning of validation: Ecological Modelling, v. 90, no. 3, p. 229-244. (Also available at $h t t p: / / d x$.doi.org/10.1016/03043800(95)00152-2.)

Sampere, T.P., Bianchi, T.S., Wakeham, S.G., and Allison, M.A., 2008, Sources of organic matter in surface sediments of the Louisiana continental margin-Effects of major depositional/transport pathways and Hurricane Ivan: Continental Shelf Research, v. 28, no. 17, p. 2472-2487.

Sarmiento, J.L., and Gruber, Nicolas, 2002, Sinks for anthropogenic carbon: Physics Today, v. 55, no. 8, p. 30-36.

Sauer, M.J., Roesler, C.S., Werdell, P.J., and Barnard, A., 2012, Under the hood of satellite empirical chlorophyll $a$ algorithms - Revealing the dependencies of maximum band ratio algorithms on inherent optical properties: Optics Express, v. 20, no. 19, p. 20920-20933.

Schmidt, Gail, Liu, Shuguang, and Oeding, Jennifer, 2011, Derived crop management data for the land carbon project: U.S. Geological Survey Open-File Report 2011-1303, 15 p., accessed February 12, 2014, at http://pubs.usgs.gov/ of/2011/1303/.

Schulte, L.A., Mladenoff, D.J., Crow, T.R., Merrick, L.C., and Cleland, D.T., 2007, Homogenization of northern U.S. Great Lakes forests due to land use: Landscape Ecology, v. 22 , no. 7, p. 1089-1103.

Schwalm, C.R., Williams, C.A., Schaefer, Kevin, Anderson, Ryan, Arain, M.A., Baker, Ian, Barr, Alan, Black, T.A., Chen, Guangsheng, Chen, J.M., Ciais, Phillippe, Davis,
K.J., Desai, Ankur, Dietze, Michael, Dragoni, Danilo, Fischer, M.L., Flanagan, L.B., Grant, Robert, Gu, Lianhong, Hollinger, David, Izaurralde, R.C., Kucharik, Chris, Lafleur, Peter, Law, B.E., Li, Longhui, Li, Zhengpeng, Liu, Shuguang, Lokupitiya, Erandanthie, Luo, Yiqi, Ma, Siyan, Margolis, Hank, Matamala, Roser, McCaughey, Harry, Monson, R.K., Oechel, W.C., Peng, Changhui, Poulter, Benjamin, Price, D.T., Riciutto, D.M., Riley, William, Sahoo, A.K., Sprintsin, Michael, Sun, Jianfeng, Tian, Hanqin, Tonitto, Christina, Verbeeck, Hans, and Verma, S.B., 2010, A modeldata intercomparison of $\mathrm{CO}_{2}$ exchange across North America-Results from the North American carbon program site synthesis: Journal of Geophysical Research: Biogeosciences, v. 115, no. G3, G00H05, 22 p., accessed February 25, 2014, at $h t t p: / / d x$.doi.org/10.1029/2009JG001229.

Schwarz, G.E., Hoos, A.B., Alexander, R.B., and Smith, R.A., 2006, The SPARROW surface water-quality model-Theory, application, and user documentation: U.S. Geological Survey Techniques and Methods, book 6, chap. B3., 248 p., accessed November 7, 2013, at http://pubs.usgs.gov/ $\mathrm{tm} / 2006 / \mathrm{tm} 6 \mathrm{b3} /$.

Seiler, Wolfgang, and Crutzen, P.J., 1980, Estimates of gross and net fluxes of carbon between the biosphere and the atmosphere from biomass burning: Climatic Change, v. 2, no. 3, p. 207-247.

Seitzinger, S., Harrison, J.A., Böhlke, J.K., Bouwman, A.F., Lowrance, R., Peterson, B., Tobias, C., and Van Drecht, G., 2006, Denitrification across landscapes and waterscapes-A synthesis: Ecological Applications, v. 16, no. 6, p. 2064-2090.

Seitzinger, S.P., and Giblin, A.E., 1996, Estimating denitrification in North Atlantic continental shelf sediments: Biogeochemistry, v. 35, no. 1, p. 235-260.

Seitzinger, S.P., Harrison, J.A., Dumont, Egon, Beusen, A.H.W., and Bouwman, A.F., 2005, Sources and delivery of carbon, nitrogen, and phosphorus to the coastal zone An overview of global nutrient export from watersheds (NEWS) models and their application: Global Biogeochemical Cycles, v. 19, no. 4, 11 p., accessed November 7, 2013, at $h t t p: / / d x$.doi.org/10.1029/2005GB002606.

Seitzinger, S.P., Mayorga, E., Bouwman, A.F., Kroeze, C., Beusen, A.H.W., Billen, G., Van Drecht, G., Dumont, E., Fekete, B.M., Garnier, J., and Harrison, J.A., 2010, Global river nutrient export-A scenario analysis of past and future trends: Global Biogeochemical Cycles, v. 24, no. 2, 16 p., accessed November 7, 2013, at http://dx.doi. org/10.1029/2009GB003587.

Sharitz, R.R., and Mitsch, W.J., 1993, Southern floodplain forests, in Martin, W.H., Boyce, S.G., and Echternacht, A.C., eds., Biodiversity of the southeastern United States-Lowland terrestrial communities: New York, John Wiley and Sons, p. 311-372. 
Shepherd, D., Burgess, D., Jickells, T., Andrews, J., Cave, R., Turner, R.K., Aldridge, J., Parker, E.R., and Young, E., 2007, Modelling the effects and economics of managed realignment on the cycling and storage of nutrients, carbon and sediments in the Blackwater estuary UK: Estuarine, Coastal, and Shelf Science, v. 73, nos. 3-4, p. 355-367.

Shih, J.S., Alexander, R.B., Smith, R.A., Boyer, E.W., Schwarz, G.E., and Chung, Susie, 2010, An initial SPARROW model of land use and in-stream controls on total organic carbon in streams of the conterminous United States: U.S. Geological Survey Open-File Report 2010-1276, 22 p., accessed November 7, 2013, at http://pubs.usgs.gov/of/2010/1276/.

Siegel, D.A., Behrenfeld, M.J., Maritorena, S., McClain, C.R., Antoine, D., Bailey, S.W., Bontempi, P.S., Boss, E.S., Dierssen, H.M., Doney, S.C., Eplee, R.E., Jr., Evans, R.H., Feldman, G.C., Fields, E., Franz, B.A., Kuring, N.A., Mengelt, C., Nelson, N.B., Patt, F.S., Robinson, W.D., Sarmiento, J.L., Swan, C.M., Werdell, P.J., Westberry, T.K., Wilding, J.G., and Yoder, J.A., 2013, Regional to global assessments of phytoplankton dynamics from the SeaWiFS mission: Remote Sensing of Environment, v. 135, p. 77-91.

Sleeter, B.M., Sohl, T.L., Bouchard, M.A., Reker, R.R., Soulard, C.E., Acevedo, William, Griffith, G.E., Sleeter, R.R., Auch, R.F., Sayler, K.L., Prisley, Stephen, and Zhu, Zhiliang, 2012a, Scenarios of land use and land cover change in the conterminous United States-Utilizing the special report on emission scenarios at ecoregional scales: Global Environmental Change, v. 22, no. 4, p. 896-914.

Sleeter, B.M., Sohl, T.L., Loveland, T.R., Auch, R.F., Acevedo, William, Drummond, M.A., Sayler, K.L., and Stehman, S.V., 2013, Land-cover change in the conterminous United States from 1973 to 2000: Global Environmental Change, v. 23 , no. 4 , p. $733-748$.

Sleeter, B.M., Wilson, T.S., and Acevedo, William, eds., $2012 \mathrm{~b}$, Status and trends of land change in the western United States-1973 to 2000: U.S. Geological Survey Professional Paper 1794-A, 324 p. (Also available at http://pubs.usgs.gov/pp/1794/a/.)

Smith, J.E., and Heath, L.S., 2008, Carbon stocks and stock changes in U.S. forests, chap. 4 of U.S. agriculture and forestry greenhouse gas inventory-1990-2005: U.S. Department of Agriculture Technical Bulletin 1921, p. 65-80 plus appendix C, accessed November 7, 2013, at $h t t p: / / w w w . n r s . f s . f e d . u s / p u b s / j r n l / 2008 / n r s \_2008$ smith-j_001.pdf.

Smith, R.A., Schwarz, G.E., and Alexander, R.B., 1997, Regional interpretation of water-quality monitoring data: Water Resources Research, v. 33, no. 12, p. 2781-2798.

Smith, S.V., and Hollibaugh, J.T., 1993, Coastal metabolism and the oceanic organic-carbon balance: Reviews of Geophysics, v. 31, no. 1, p. 75-89.
Smith, W.B., Miles, P.D., Perry, C.H., and Pugh, S.A., 2009, Forest resources of the United States, 2007: U.S. Department of Agriculture, Forest Service, General Technical Report WO-78. 336 p., accessed February 12, 2014, at http://www.fs.fed.us/nrs/pubs/gtr/gtr_wo78.pdf.

Smith, W.B., Miles, P.D., Vissage, J.S., and Pugh, S.A., 2004, Forest resources of the United States, 2002: U.S. Department of Agriculture, Forest Service, General Technical Report NC-241, 137 p. (Also available at http://nrs.fs.fed.us/pubs/gtr/gtr_nc241.pdf.)

Soetaert, Karline, and Petzoldt, Thomas, 2010. Inverse modelling, sensitivity and Monte Carlo analysis in R using package FME: Journal of Statistical Software, v. 33, no. 3, p. 1-28. (Also available at http://www.jstatsoft.org/v33/i03.)

Sohl, T.L., Sleeter, B.M., Sayler, K.L., Bouchard, M.A., Reker, R.R., Bennett, S.L., Sleeter, R.L., Kanengieter, R.L., and Zhu, Zhiliang, 2012a, Spatially explicit land-use and landcover scenarios for the Great Plains of the United States: Agriculture, Ecosystems \& Environment, v. 153, p. 1-15, accessed October 31, 2013, at $h t t p: / / d x$. doi.org/10.1016/j. agee.2012.02.019.

Sohl, T.L., Sleeter, B.M., Zhu, Zhiliang, Sayler, K.L., Bennett, Stacie, Bouchard, Michelle, Reker, Ryan, Hawbaker, Todd, Wein, Anne, Liu, Shuguang, Kanengieter, Ronald, and Acevedo, William, 2012b, A land-use and land-cover modeling strategy to support a national assessment of carbon stocks and fluxes: Applied Geography, v. 34, p. 111-124, accessed October 31, 2013, at $h t t p: / / d x$.doi.org/10.1016/j. apgeog.2011.10.019.

Sohl, Terry, and Sayler, Kristi, 2008, Using the FORE-SCE model to project land-cover change in the southeastern United States: Ecological Modelling, v. 219, nos. 1-2, p. 49-65, accessed October 31, 2013, at http://dx.doi. org/10.1016/j.ecolmodel.2008.08.003.

Spracklen, D.V., Mickley, L.J., Logan, J.A., Hudman, R.C., Yevich, R., Flannigan, M.D., and Westerling, A.L., 2009, Impacts of climate change from 2000 to 2050 on wildfire activity and carbonaceous aerosol concentrations in the western United States: Journal of Geophysical Research: Atmospheres, v. 114, no. D20, 17 p., accessed November 7, 2013, at $h t t p: / / d x$.doi.org/10.1029/2008JD010966.

Stackpoole, S.M., Butman, David, Clow, D.W., McDonald, C.P., Stets, E.G., and Striegl, R.G., 2012, Baseline carbon sequestration, transport, and emission from inland aquatic ecosystems in the western United States, chap. 10 of Zhu, Zhiliang, and Reed, B.C., eds., Baseline and projected future carbon storage and greenhouse-gas fluxes in ecosystems of the western United States: U.S. Geological Survey Professional Paper 1797, p. 125-141. (Also available at http://pubs.usgs.gov/pp/1797/.)

Stephenson, S.L., Ash, A.N., and Stauffer, D.F.,1993, Appalachian oak forests, in Martin, W.H., Boyce, S.G., and Echternacht, A.C., eds., Biodiversity of the southeastern United 
States-Upland terrestrial communities: New York, John Wiley and Sons, p. 255-303.

Stets, E.G., and Striegl, R.G., 2012, Carbon export by rivers draining the conterminous United States: Inland Waters, v. 2 , no. 4, p. 177-184.

Stets, E.G., Striegl, R.G., Aiken, G.R., Rosenberry, D.O., and Winter, T.C., 2009, Hydrologic support of carbon dioxide flux revealed by whole-lake carbon budgets: Journal of Geophysical Research: Biosciences, v. 114, no. G1, G01008, 14 p., accessed November 7, 2013, at http://dx.doi.org/10.1029/2008JG000783.

Stocks, B.J., Mason, J.A., Todd, J.B., Bosch, E.M., Wotton, B.M., Amiro, B.D., Flannigan, M.D., Hirsch, K.G., Logan, K.A., Martell, D.L., and Skinner, W.R., 2002, Large forest fires in Canada, 1959-1997: Journal of Geophysical Research: Atmospheres, v. 108, no. D1, 8149, 12 p., accessed November 7, 2013, at http://dx.doi.org/10.1029/2001JD000484.

Strahler, A.N., 1952, Dynamic basis of geomorphology: Geological Society of America Bulletin, v. 63, no. 9, p. 923-938.

Strauss, David, Bednar, Larry, and Mees, Romain, 1989, Do one percent of the forest fires cause ninety-nine percent of the damage?: Forest Science, v. 35, no. 2, p. 319-328.

Strengers, Bart, Leemans, Rik, Eickhout, Bas, de Vries, Bert, and Bouwman, Lex, 2004, The land-use projections and resulting emissions in the IPCC SRES scenarios as simulated by the IMAGE 2.2 model: GeoJournal, v. 61, no. 4, p. 381-393.

Striegl, R.G., Dornblaser, M.M., Aiken, G.R., Wickland, K.P., and Raymond, P.A., 2007, Carbon export and cycling by the Yukon, Tanana, and Porcupine rivers, Alaska, 2001-2005: Water Resources Research, v. 43, no. 2, W02411, 9 p., accessed February 4, 2014, at http://dx.doi.org/10.1029/2006WR005201.

Striegl, R.G., Dornblaser, M.M., McDonald, C.P., Rover, J.R., and Stets, E.G., 2012, Carbon dioxide and methane emissions from the Yukon River system: Global Biogeochemical Cycles, v. 26, no. 4, GB0E05, 11 p., accessed February 4, 2014, at http://dx.doi.org/10.1029/2012GB004306.

Swaney, D.P., Hong, Bongghi, Ti, Chaopu, Howarth, R.W., and Humborg, Christoph, 2012, Net anthropogenic nitrogen inputs to watersheds and riverine $\mathrm{N}$ export to coastal waters-A brief overview: Current Opinion in Environmental Sustainability, v. 4, no. 2, p. 203-211.

Swetnam, T.W., and Betancourt, J.L., 1990, Fire-Southern oscillation relations in the southwestern United States: Science, v. 249, no. 4972, p. 1017-1020.

Syphard, A.D., Radeloff, V.C., Keeley, J.E., Hawbaker, T.J., Clayton, M.K., Stewart, S.I., and Hammer, R.B., 2007, Human influence on California fire regimes: Ecological Applications, v. 17, no. 5, p. 1388-1402.
Syvitski, J.P.M., Vörösmarty, C.J., Kettner, A.J., and Green, Pamela, 2005, Impact of humans on the flux of terrestrial sediment to the global coastal ocean: Science, v. 308, no. 5720, p. 376-380.

Szeto, M., Werdell, P.J., Moore, T.S., and Campbell, J.W., 2011, Are the world's oceans optically different?: Journal of Geophysical Research: Oceans, v. 116, no. C7, C00H04, 14 p., accessed November 7, 2013, at http://dx.doi.org/10.1029/2011JC007230.

Tan, Zhenxi, Lal, Rattan, and Liu, Shuguang, 2006, Using experimental and geospatial data to estimate regional carbon sequestration potential under no-till management: Soil Science, v. 171, no. 12, p. 950-959.

Thomas, C.J., Blair, N.E., Alperin, M.J., DeMaster, D.J., Jahnke, R.A., Martens, C.S., and Mayer, L., 2002, Organic carbon deposition on the North Carolina continental slope off Cape Hatteras (USA): Deep-Sea Research Part II: Topical Studies in Oceanography, v. 49, no. 20, p. 4687-4709.

Thomas, Helmuth, Bozec, Yann, Elkalay, Khalid, and de Baar, H.J.W., 2004, Enhanced open ocean storage of $\mathrm{CO}_{2}$ from shelf sea pumping: Science, v. 304, no. 5673, p. 1005-1008.

Tian, Hanqin, Chen, Guangsheng, Liu, Mingliang, Zhang, Chi, Sun, Ge, Lu, Chaoqun, Xu, Xiaofeng, Ren, Wei, Pan, Shufen, and Chappelka, Arthur, 2010, Model estimates of net primary productivity, evapotranspiration, and water use efficiency in the terrestrial ecosystems of the southern United States during 1895-2007: Forest Ecology and Management, v. 259, no. 7, p. 1311-1327, accessed November 7, 2013, at http://dx.doi.org/10.1016/j.foreco.2009.10.009.

Tian, Hanqin, Chen, Guangsheng, Zhang, Chi, Liu, Mingliang, Sun, Ge, Chappelka, Arthur, Ren, Wei, Xu, Xiaofeng, Lu, Choaqun, Pan, Shufen, Chen, Hua, Hui, Dafeng, McNulty, Steven, Lockaby, Graeme, and Vance, Eric, 2012, Centuryscale responses of ecosystem carbon storage and flux to multiple environmental changes in the southern United States: Ecosystems, v. 15, no. 4, p. 674-694.

Tishchenko, P.Ya., Wallmann, K., Vasilevskaya, N.A., Volkova, T.I., Zvalinskii, V.I., Khodorenko, N.D., and Shkirnikova, E.M.,2006, The contribution of organic matter to the alkaline reserve of natural waters: Oceanology, v. 46, no. 2, p. 192-199. (Also available at http://dx.doi.org/10.1134/S0001437006020068.)

Transeau, E.N., 1935, The prairie peninsula: Ecology, v. 16, no. 3, p. 423-437.

Tranvik, L.J., Downing, J.A., Cotner, J.B., Loiselle, S.A., Striegl, R.G., Ballatore, T.J., Dillon, Peter, Finlay, Kerri, Fortino, Kenneth, Knoll, L.B., Kortelainen, P.L., Kutser, Tiit, Larsen, Soren, Laurion, Isabelle, Leech, D.M., McCallister, S.L., McKnight, D.M., Melack, J.M., Overholt, Erin, Porter, J.A., Prairie, Yves, Renwick, W.H., Roland, Fabio, Sherman, B.S., Schindler, D.W., Sobek, Sebastian, Tremblay, Alain, Vanni, M.J., Verschoor, A.M., von Wachenfeldt, Eddie, and Weyhenmeyer, G.A., 2009, Lakes and reservoirs 
as regulators of carbon cycling and climate: Limnology and Oceanography, v. 54, no. 6, part 2, p. 2298-2314, accessed November 7, 2013, at http://dx.doi.org/10.4319/ lo.2009.54.6 part 2.2298.

Trimmer, Mark, and Engström, Pia, 2011, Distribution, activity, and ecology of anammox bacteria in aquatic environments, chap. 9 of Ward, B.B., Arp, D.J., and Klotz, M.G., eds., Nitrification: Washington, D.C., ASM Press, p. 201-236.

Trombulak, S.C., and Wolfson, Richard, 2004, Twentiethcentury climate change in New England and New York, USA: Geophysical Research Letters, v. 31, no. 19, L19202, 4 p., accessed November 7, 2013, at http://dx.doi.org/10.1029/2004GL020574.

Tulbure, Mirela, Wimberly, Michael, Roy, David, and Henebry, Geoffrey, 2011, Spatial and temporal heterogeneity of agricultural fires in the central United States in relation to land cover and land use: Landscape Ecology, v. 26, no. 2, p. 211-224.

Turner, D.P., Göckede, M., Law, B.E., Ritts, W.D., Cohen, W.B., Yang, Z., Hudiburg, T., Kennedy, R., and Duane, M., 2011, Multiple constraint analysis of regional land-surface carbon flux: Tellus, v. 63B, no. 2, p. 207-221. (Also available at $h t t p: / / d x$.doi.org/10.1111/j.1600-0889.2011.00525.x.)

Turner, D.P., Koerper, G.J., Harmon, M.E., and Lee, J.J., 1995, A carbon budget for forests of the conterminous United States: Ecological Applications, v. 5, no. 2, p. 421-436.

Turner, M.G., Baker, W.L., Peterson, C.J., and Peet, R.K., 1998, Factors influencing succession-Lessons from large, infrequent natural disturbances: Ecosystems, v. 1, no. 6, p. 511-523.

Turner, R.E., and Rabalais, N.N., 2004, Suspended sediment, C, N, P, and Si yields from the Mississippi River basin: Hydrobiologia, v. 511, nos. 1-3, p. 79-89.

Turner, R.E., Rabalais, N.N., Alexander, R.B., McIsaac, G., and Howarth, R.W., 2007, Characterization of nutrient, organic carbon, and sediment loads and concentrations from the Mississippi River into the northern Gulf of Mexico: Estuaries and Coasts, v. 30, no. 5, p. 773-790.

Tyson, R.V., 2001, Sedimentation rate, dilution, preservation and total organic carbon-Some results of a modelling study: Organic Geochemistry, v. 32, no. 2, p. 333-339.

U.S. Army Corps of Engineers, 2012, National inventory of dams: U.S. Army Corps of Engineers Web site, accessed June 22, 2012, at http://geo.usace.army.mil/ pgis/f? $p=397: 12$.

U.S. Census Bureau, 2012, TIGER products: U.S. Census Bureau Web page, accessed August 5, 2012, at http://www.census.gov/geo/www/tiger/.

U.S. Congress, 2007, Energy independence and security act of 2007-Public Law 110-140: U.S. Congress, 311 p., accessed November 7, 2013, at http://frwebgate.access.gpo.gov/cgi-bin/getdoc. cgi?dbname=110_cong_public laws\&docid=f:publ140.110. $p d f$.

U.S. Department of Agriculture, 2008, U.S. agriculture and forestry greenhouse gas inventory-1990-2005: U.S. Department of Agriculture Technical Bulletin 1921, [variously paged]. (Also available at $h t t p: / / w w w . u s d a . g o v / o c e /$ climate_change/AFGGInventory1990_2005.htm.)

U.S. Department of Agriculture, 2011, USDA agriculture and forestry greenhouse gas inventory-1990-2008: U.S. Department of Agriculture Technical Bulletin 1930, 115 p. plus appendixes, accessed November 7, 2013, at http://www.usda.gov/oce/climate_change/AFGG_ Inventory/USDA_GHG_Inv_1990-2008_June2011.pdf.

U.S. Department of Agriculture, Economic Research Service, 2011a, ARMS farm financial and crop production practices - Tailored reports: U.S. Department of Agriculture, Economic Research Service database, accessed August 16, 2011, at http://www.ers.usda.gov/Data/ARMS/ app/. [Database moved and accessed June 6, 2014, at http://www.ers.usda.gov/data-products/arms-farm-financialand-crop-production-practices/tailored-reports-farmstructure-and-finance.aspx\#.U5GYp_mwLMo.]

U.S. Department of Agriculture, Economic Research Service, 2011b, Fertilizer use and price: U.S. Department of Agriculture, Economic Research Service database, accessed August 16, 2011, at http://www.ers.usda.gov/Data/FertilizerUse/. [Database moved and accessed March 25, 2014, at http://www.ers.usda.gov/data-products/fertilizer-use-andprice.aspx\#.UzGMH_ldV8E.]

U.S. Department of Agriculture, Forest Service, [2009], Timber products output studies: U.S. Department of Agriculture, Forest Service Web page, accessed February 12, 2014, at http://www.fia.fs.fed.us/program-features/tpo.

U.S. Department of Agriculture, Forest Service, 2012a, Forest biomass across the lower 48 states and Alaska: U.S. Department of Agriculture, Forest Service database, accessed September 5, 2012, at http://fsgeodata.fs.fed.us/rastergateway/ biomass/.

U.S. Department of Agriculture, Forest Service, 2012b, Forest inventory and analysis national program: U.S. Department of Agriculture, Forest Service database, accessed November 25, 2012, at http://www.fia.fs.fed.us/tools-data.

U.S. Department of Agriculture, Forest Service, 2012c, Future of America's forests and rangelands: U.S. Department of Agriculture General Technical Report WO-87, 197 p., accessed November 7, 2013, at http://www.fs.fed.us/ research/publications/gtr/gtr_wo87.pdf.

U.S. Department of Agriculture, National Agricultural Statistics Service, 2011, Quick stats: U.S. Department of Agriculture, National Agricultural Statistics Service database, accessed September 5, 2012, at http://www.nass.usda.gov/QuickStats/. [Web site moved to http://quickstats.nass.usda.gov/.] 
U.S. Department of Agriculture, Natural Resources Conservation Service, 2009, Soil survey geographic (SSURGO) database: U.S. Department of Agriculture, Natural Resources Conservations Service database, accessed August 14, 2012, at http://soildatamart.nrcs. usda.gov/. [At the time of publication, the soil data mart functionality had been incorporated into the soil survey Web site at http://websoilsurvey.nrcs.usda.gov and http://datagateway.nrcs.usda.gov/.]

U.S. Department of Agriculture, Natural Resources Conservation Service, 2012, Watershed boundary dataset: U.S. Department of Agriculture, Natural Resources Conservation Service Web site, accessed October 3, 2012, at http://www.nrcs.usda.gov/wps/portal/nrcs/main/national/ water/watersheds/dataset/.

U.S. Department of Interior, 2012, Federal wildland fire occurrence data: U.S. Department of the Interior database, accessed August 12, 2012, at http://wildfire.cr.usgs.gov/ firehistory/data.html.

U.S. Environmental Protection Agency, 1999, Level III ecoregions of the continental United States: U.S. Environmental Protection Agency, scale 1:7,500,000.

U.S. Environmental Protection Agency, 2009, National lakes assessment-A collaborative survey of the nation's lakes: U.S. Environmental Protection Agency, Office of Water and Office of Research and Development EPA 841-R-09-001, 103 p., accessed October 23, 2012, at http://www.epa.gov/ owow/LAKES/lakessurvey/pdf/nla_report_low_res.pdf.

U.S. Environmental Protection Agency, 2012, Inventory of U.S. greenhouse gas emissions and sinks - 1990-2010: U.S. Environmental Protection Agency EPA 430-R12-001, [variously paged], accessed November 8 , 2013, at http://www.epa.gov/climatechange/Downloads/ ghgemissions/US-GHG-Inventory-2012-Main-Text.pdf.

U.S. Environmental Protection Agency, 2013a, Ecoregions of North America: U.S. Environmental Protection Agency, accessed November 13, 2013, at http://www.epa.gov/wed/ pages/ecoregions/na_eco.htm.

U.S. Environmental Protection Agency, 2013b, Inventory of U.S. greenhouse gas emissions and sinks-19902011: U.S. Environmental Protection Agency EPA 430-R-13-001, [variously paged], accessed April 29, 2013, at http://www.epa.gov/climatechange/Downloads/ ghgemissions/US-GHG-Inventory-2013-Main-Text.pdf.

U.S. Geological Survey, [undated], National water information service: U.S. Geological Survey Web site, accessed October 1, 2012, at http://waterdata.usgs.gov/nwis.

U.S. Geological Survey, 2010, Moderate resolution imaging spectroradiometer (MODIS) irrigated agriculture dataset for the United States (MIrAD-US): U.S. Geological Survey Web site, accessed February 12, 2014, at http://earlywarning.usgs.gov/USirrigation/.
U.S. Geological Survey, 2012a, Land cover trends: U.S. Geological Survey database, accessed May 31, 2012, at http://landcovertrends.usgs.gov/.

U.S. Geological Survey, 2012b, National elevation dataset: U.S. Geological Survey database, accessed August 5, 2012, at http://ned.usgs.gov/.

U.S. Geological Survey, 2012c, National hydrography dataset: U.S. Geological Survey database, accessed August 6, 2012, at $h t t p: / / n h d . u s g s . g o v /$.

United Nations Framework Convention on Climate Change, 1998, Kyoto protocol to the United Nations Framework Convention on Climate Change: Bonn, Germany, United Nations Framework Convention on Climate Change, 20 p. (Also available at $h t t p: / / u n f c c c . i n t / r e s o u r c e / d o c s / c o n v k p /$ kpeng.pdf.)

Urbanski, S., Barford, C., Wofsy, S., Kucharik, C., Pyle, E., Budney, J., McKain, K., Fitzjarrald, D., Czikowsky, M., and Munger, J.W., 2007, Factors controlling $\mathrm{CO}_{2}$ exchange on timescales from hourly to decadal at Harvard Forest: Journal of Geophysical Research, v. 112, no. G2, G02020, 25 p., accessed January 23, 2014, at http://dx.doi.org/10.1029/2006JG000293.

van der Werf, G.R., Randerson, J.T., Giglio, L., Collatz, G.J., Mu, M., Kasibhatla, P.S., Morton, D.C., DeFries, R.S., Jin, Y., and van Leeuwen, T.T., 2010, Global fire emissions and the contribution of deforestation, savanna, forest, agricultural, and peat fires (1997-2009): Atmospheric Chemistry and Physics, v. 10, no. 23, p. 11707-11735.

van Heuven, Steven, Pierrot, Denis, Lewis, Ernie, and Wallace, D.W.R., 2009, CO2SYS v 1.1-MATLAB program developed for $\mathrm{CO} 2$ system calculations: U.S. Department of Energy, Oak Ridge National Laboratory ORNL/CDIAC105b, accessed February 4, 2014, at http://cdiac.ornl.gov/ ftp/co2sys/CO2SYS_calc_MATLAB_v1.1/.

van Vuuren, D.P., Lucas, P.L., and Hilderink, Henk, 2007, Downscaling drivers of global environmental change scenarios-Enabling use of global SRES scenarios at the national and grid level: Global Environmental Change, v. 17, no. 1, p. 114-130.

van Vuuren, D.P., Smith, S.J., and Riahi, Keywan, 2010, Downscaling socioeconomic and emissions scenarios for global environmental change research - A review: Climate Change, v. 1, no. 3, p. 393-404.

Verburg, P.H., Kok, Kasper, Pontius, R.G., Jr., and Veldkamp, A., 2006, Modeling land-use and land-cover change, in Lambin, E.F., and Geist, H.J., eds., Land-use and landcover change-Local processes and global impacts: Berlin, Springer-Verlag, p.117-135.

Verburg, P.H., Tabeau, Andrzej, and Hatna, Erez, 2013, Assessing spatial uncertainties of land allocation using a scenario approach and sensitivity analysis-A study for land use in Europe: Journal of Environmental Manage- 
ment, v. 127, supplement, p. S132-S144. (Also available at http://dx.doi.org/10.1016/j.jenvman.2012.08.038.)

Verburg, P.S.J., and Johnson, D.W., 2001, A spreadsheet-based biogeochemical model to simulate nutrient cycling processes in forest ecosystems: Ecological Modelling, v. 141, nos. 1-3, p. 185-200, accessed December 10, 2013, at http://dx.doi.org/10.1016/S0304-3800(01)00273-3.

Vogelmann, J.E., Howard, S.M., Yang, Limin, Larson, C.R., Wylie, B.K., and Van Driel, Nick, 2001, Completion of the 1990s National Land Cover Data Set for the conterminous United States from Landsat thematic mapper data and ancillary data sources: Photogrammetric Engineering and Remote Sensing, v. 67, no. 6, p. 650-662. (Also available at $h$ ttp://eserv.asprs.org/PERS/2001journal/jun/2001 jun_ highlight.pdf.)

Vörösmarty, C.J., McIntyre, P. B., Gessner, M.O., Dudgeon, D., Prusevich, A., Green, P., Glidden, S., Bunn, S.E., Sullivan, C.A., Liermann, C.R., and Davies, P. M., 2010, Global threats to human water security and river biodiversity: Nature, v. 467, no. 7315 , p. 555-561.

Walsh, J.J., Premuzic, E.T., Gaffney, J.S., Rowe, G.T., Harbottle, G., Stoenner, R.W., Balsam, W.L., Betzer, P. R., and Macko, S.A., 1985, Organic storage of $\mathrm{CO}_{2}$ on the continental slope off the mid-Atlantic bight, the southeastern Bering Sea, and the Peru coast: Deep-Sea Research Part I: Oceanographic Research Papers, v. 32, no. 7, p. 853-883.

Wanninkhof, Rik, 1992, Relationship between wind speed and gas exchange over the ocean: Journal of Geophysical Research, v. 97, no. C5, p. 7373-7382. (Also available at http://dx.doi.org/10.1029/92JC00188.)

Watson, R.T., Noble, I.R., Bolin, Bert, Ravindranath, N.H., Verardo, D.J., and Dokken, D.J., 2000, Land use, land-use change, and forestry: Geneva, Intergovernmental Panel on Climate Change, 375 p.

West, T.O, and Marland, Gregg, 2002, A synthesis of carbon sequestration, carbon emissions, and net carbon flux in agriculture - Comparing tillage practices in the United States: Agriculture, Ecosystems \& Environment, v. 91, nos. 1-3, p. 217-232.

West, T.O., and Post, W.M., 2002, Soil organic carbon sequestration rates by tillage and crop rotation- $\mathrm{A}$ global data analysis: Soil Science Society of America Journal, v. 66, no. 6, p. 1930-1946. (Also available at http://dx.doi.org/10.3334/CDIAC/tcm.002.)

Westerling, A.L., Hidalgo, H.G., Cayan, D.R., and Swetnam, T.W., 2006, Warming and earlier spring increase western US forest wildfire activity: Science, v. 313, no. 5789, p. 940-943.

Whitehead, P. G., Wilby, R.L., Battarbee, R.W., Kernan, M., and Wade, A.J., 2009, A review of the potential impacts of climate change on surface water quality: Hydrological Sciences Journal, v. 54, no. 1, p. 101-123.
Whittaker, R.H., and Woodwell, G.M., 1969, Structure, production and diversity of the oak-pine forest at Brookhaven, New York: Journal of Ecology, v. 57, no. 1, p. 155-174.

Wiedinmeyer, Christine, and Neff, J.C., 2007, Estimates of $\mathrm{CO}_{2}$ from fires in the United States-Implications for carbon management: Carbon Balance and Management, v. 2, no. 10, 12 p., accessed November 8, 2013, at http://dx.doi.org/10.1186/1750-0680-2-10.

Wiken, Ed, Nava, F.J., and Griffith, Glenn, 2011, North American terrestrial ecoregions-Level III: Montréal, Canada, Commission for Environmental Cooperation, 149 p., accessed November 13, 2013, at http://www3.cec.org/islandora/en/item/10415-northamerican-terrestrial-ecoregionslevel-iii-en.pdf.

Williams, C.A., Collatz, G.J., Masek, Jeffrey, and Goward, S.N., 2012, Carbon consequences of forest disturbance and recovery across the conterminous United States: Global Biogeochemical Cycles, v. 26, no. 1, 13 p., accessed November 8, 2013, at http://dx.doi.org/10.1029/2010GB003947.

Williams, J.R., Mooney, Siân, and Peterson, J.M., 2009, What is the carbon market-Is there a final answer?: Journal of Soil and Water Conservation, v. 64, no. 1, p. 27A-35A.

Wilson, K.B., and Baldocchi, D.D., 2000, Seasonal and interannual variability of energy fluxes over a broadleaved temperate deciduous forest in North America: Agricultural and Forest Meteorology, v. 100, no. 1, p. 1-18. (Also available at $h t t p: / / d x$.doi.org/10.1016/S0168-1923(99)00088-X.)

Wilson, T.S., Sleeter, B.M., Sohl, T.S., Griffith, Glenn, Acevedo, William, Bennett, Stacie, Bouchard, Michelle, Reker, Ryan, Ryan, Christy, Sayler, K.L., Sleeter, Rachel, and Soulard, C.E., 2012, Future scenarios of land-use and landcover change in the United States-The marine west coast forests ecoregion: U.S. Geological Survey Open File Report 2012-1252, 14 p. and appendixes, accessed February 6, 2014, at http://pubs.usgs.gov/of/2012/1252/.

Wofsy, S.C., Goulden, M.L., Munger, J.W., Fan, S.-M., Bakwin, P.S., Daube, B.C., Bassow, S.L., and Bazzaz, F.A., 1993, Net exchange of $\mathrm{CO}_{2}$ in a mid-latitude forest: Science, v. 260, no. 5112, p. 1314-1317. (Also available at http://dx.doi.org/10.1126/science.260.5112.1314.)

Wood, A.W., Maurer, E.P., Kumar, Arun, and Lettenmaier, D.P., 2002, Long-range experimental hydrologic forecasting for the eastern United States: Journal of Geophysical Research: Atmospheres, v. 107, no. D20, 4459, p. ACL 6-1-ACL 6-15, accessed November 8, 2013, at http://dx.doi.org/10.1029/2001JD000659.

Woodbury, P.B., Heath, L.S., and Smith, J.E., 2006, Land use change effects on forest carbon cycling throughout the southern United States: Journal of Environmental Quality, v. 35, p. 1348-1363, accessed October 31, 2013, at http://dx.doi.org/10.2134/jeq2005.0148. 
Woodbury, P.B., Smith, J.E., and Heath, L.S., 2007, Carbon sequestration in the U.S. forest sector from 1990 to 2010: Forest Ecology and Management, v. 241, nos. 1-3, p. 14-27. (Also available at http://dx.doi.org/10.1016/j.foreco.2006.12.008.)

Wrona, F.J., Prowse, T.D., Reist, J.D., Hobbie, J.E., Lévesque, L.M.J., and Vincent, W.F., 2006, Climate change effects on aquatic biota, ecosystem structure and function: Ambio, v 35, no. 7, p. 359-369, accessed November 8, 2013, at $h$ ttp://dx.doi.org/10.1579/0044-7447(2006)35[359: CCEOAB]2.0.CO;2.

Wu, Yiping, and Liu, Shuguang, 2012. Automating calibration, sensitivity and uncertainty analysis of complex models using the R package flexible modeling environment (FME) - SWAT as an example: Environmental Modelling and Software, v. 31, p. 99-109. (Also available at http://dx.doi.org/10.1016/j.envsoft.2011.11.013.)

Xian, George, Homer, Collin, and Fry, Joyce, 2009, Updating the 2001 national land cover database land cover classification to 2006 by using landsat imagery change detection methods: Remote Sensing of Environment, v. 113, no. 6, p. 1133-1147. (Also available at http://dx.doi.org/10.1016/j.rse.2009.02.004.)

Yu, Z.C., 2012, Northern peatland carbon stocks and dynamics-A review: Biogeosciences, v. 9, p. 4071-4085.

Zappa, C.J., McGillis, W.R., Raymond, P.A., Edson, J.B., Hintsa, E.J., Zemmelink, H.J., Dacey, J.W.H., and Ho, D.T., 2007, Environmental turbulent mixing controls on air-water gas exchange in marine and aquatic systems: Geophysical Research Letters, v. 34, no. 10, L10601, 6 p., accessed February 4, 2014, at http://dx.doi.org/10.1029/2006GL028790.

Zhang, Chi, Tian, Hanqin, Chen, Guangsheng, Chappelka, Arthur, Xu, Xiaofeng, Ren, Wei, Hui, Dafeng, Liu, Mingliang, Lu, Chaoqun, Pan, Shufen, and Lockaby, Greame, 2012, Impacts of urbanization on carbon balance in terrestrial ecosystems of the southern United States: Environmental Pollution, v. 164, p. 89-101.

Zhang, J., Gilbert, D., Gooday, A.J., Levin, L., Naqvi, S.W.A., Middelburg, J.J., Scranton, M., Ekau, W., Peña, A., Dewitte, B., Oguz, T., Monteiro, P.M.S., Urban, E., Rabalais, N.N., Ittekkot, V., Kemp, W.M., Ulloa, O., Elmgren, R., EscobarBriones, E., and Van der Plas, A.K., 2010, Natural and human-induced hypoxia and consequences for coastal areas-Synthesis and future development: Biogeosciences, v. 7 , no. 5 , p. $1443-1467$.
Zhang, Quanfa, Pregitzer, K.S., and Reed, D.D., 2000, Historical changes in the forests of the Luce district of the Upper Peninsula of Michigan: The American Midland Naturalist, v. 143 , no. 1, p. 94-110.

Zhao Maosheng, Heinsch F.A., Nemani R.R., and Running S.W., 2005, Improvements of the MODIS terrestrial gross and net primary production global data set: Remote Sensing of Environment, v. 95, no. 2, p. 164-176. (Also available at http://dx.doi.org/10.1016/j.rse.2004.12.011.)

Zheng, Daolan, Heath, L.S., Ducey, M.J., and Smith, J.E., 2011, Carbon changes in conterminous US forests associated with growth and major disturbances-1992-2001: Environmental Research Letters, v. 6, no. 1, 014012, 10 p., accessed November 8, 2013, at http://dx.doi.org/10.1088/1748-9326/6/1/014012.

Zhu, Zhiliang, and Reed, B.C., eds., 2012, Baseline and projected future carbon storage and greenhouse-gas fluxes in ecosystems of the western United States: U.S. Geological Survey Professional Paper 1797, 192 p. (Also available at http://pubs.usgs.gov/pp/1797/.)

Zhu, Zhiliang, ed., Bergamaschi, Brian, Bernknopf, Richard, Clow, David, Dye, Dennis, Faulkner, Stephen, Forney, William, Gleason, Robert, Hawbaker, Todd, Liu, Jinxun, Liu, Shuguang, Prisley, Stephen, Reed, Bradley, Reeves, Matthew, Rollins, Matthew, Sleeter, Benjamin, Sohl, Terry, Stackpoole, Sarah, Stehman, Stephen, Striegl, Robert, Wein, Anne, and Zhu, Zhiliang, 2010, A method for assessing carbon stocks, carbon sequestration, and greenhouse-gas fluxes in ecosystems of the United States under present conditions and future scenarios: U.S. Geological Survey Scientific Investigations Report 2010-5233, 190 p. (Also available at $h t t p: / / p u b s . u s g s . g o v /$ sir/2010/5233/.) (Supersedes U.S. Geological Survey Open-File Report 2010-1144.)

Zhu, Zhiliang, ed., Bouchard, Michelle, Butman, David, Hawbaker, Todd, Li, Zhengpeng, Liu, Jinxun, Liu, Shuguang, McDonald, Cory, Reker, Ryan, Sayler, Kristi, Sleeter, Benjamin, Sohl, Terry, Stackpoole, Sarah, Wein, Anne, and Zhu, Zhiliang, 2011, Baseline and projected future carbon storage and greenhouse-gas fluxes in the Great Plains region of the United States: U.S. Geological Survey Professional Paper 1787, 28 p. (Also available at http://pubs.usgs.gov/ pp/1787/.) 



\section{Appendixes 1-6}

Appendix 1. The Erosion Deposition Carbon Model

Appendix 2. The Land Greenhouse-Gas Accounting Tool

Appendix 3. Coefficients of Forest Partial Cutting and Biomass Mortality

Appendix 4. Optimized Maximum Monthly Gross Primary Production

Appendix 5. Comparison of Sampling-Based and Per-Pixel Model Runs

Appendix 6. Emission Factors of Nitrous Oxide and Methane in the Eastern United States 


\section{Appendix 1. The Erosion Deposition Carbon Model}

The Erosion Deposition Carbon Model (EDCM; Liu and others, 2003) is an ecosystem biogeochemical model developed from the well-established ecosystem model Century version 4.0 (Parton and others, 1987, 1994). Although the EDCM retains the basic input and output file structures of Century, major changes have been made on model structure and underlying biogeochemical processes.

A new algorithm has been implemented in EDCM for this national assessment to account for the effects of cropping improvement on the carbon cycle of an ecosystem. Crop biomass production, crop yield, and residue return to the soil greatly affect the carbon cycle in cropland systems. Crop yield has experienced continuous improvement over the past century and continuing into the future due to genetic engineering and improved management practices.

We analyzed the temporal trends of yield from 1866 through 2009 for 23 major crops in the United States based on the census data of the U.S. Department of Agriculture at the State and county levels (U.S. Department of Agriculture, Economic Research Service, 2011). To quantify the overall temporal change of each crop, the reported yield for a given crop was averaged across the country and normalized to the yield in 2000 . In addition, the projected yield changes from Integrated Model to Assess the Greenhouse Effect (IMAGE) for various crops (Alcamo and others, 1998) were used to constrain the future paths and potentials of these crops for the next 50 years. These normalized yields of any given crop were then fitted to the following logistic growth curve:

$$
Y_{n}(t)=c+\frac{k}{1+a \times \exp (b \times(t-d))},
$$

where

$$
c, k, a, b \text {, and } d \quad \text { are fitted coefficients (table A1-1), and }
$$$$
Y_{n}(t) \quad \text { is the yield in year } t \text { normalized to } 2000 \text {. }
$$

After examining the normalized temporal yield curves of the all the crops, these changes were grouped into seven major categories (table A1-1). It should be noted that the curves (fig. A1-1) were developed for applications across the country, and some crops (for example, sugarcane and rice) might not exist in all ecoregions across the country. These curves are embedded in the General Ensemble Biogeochemical Modeling System (GEMS; Liu, 2009; Liu and others, 2012).
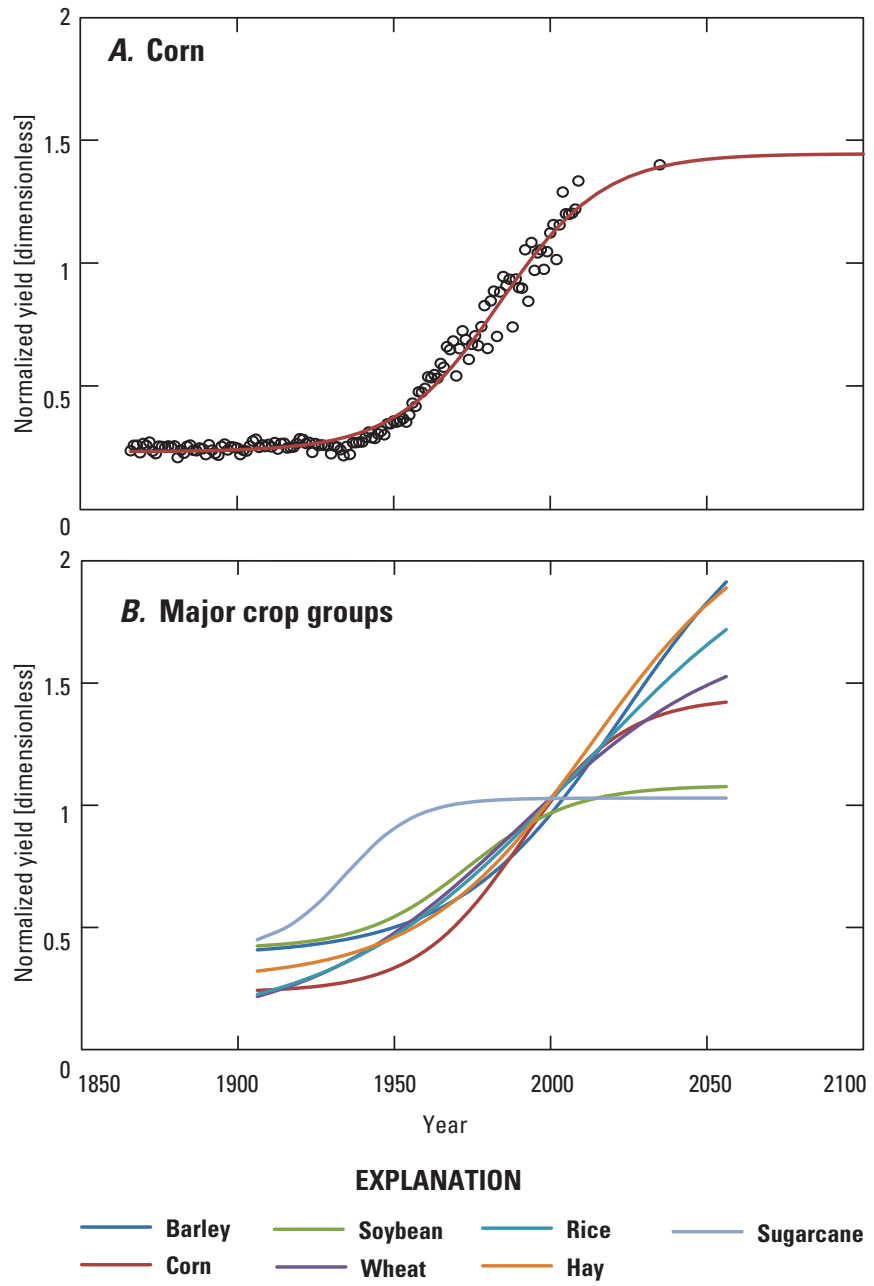

Figure A1-1. Normalized curves of grain yield in the United States for $A$, corn and $B$, major crop groups. 
Table A1-1. Coefficients of the logistic curves describing the grain yield change for major crops in the United States.

[Values of c, k, a, b, and d are fitted coefficients of the logistic growth curves; see text for the equation]

\begin{tabular}{|c|c|c|c|c|c|c|}
\hline Group & c & k & a & b & d & Crops in the group \\
\hline Barley & 0.3853 & 1.9614 & 8.6459 & -0.038 & 1960 & Barley, oats \\
\hline Corn & 0.235 & 1.2095 & 4.2095 & -0.0602 & 1960 & $\begin{array}{l}\text { Corn, corn silage, sugar beets, sweet corn, potatoes, tomatoes, cot- } \\
\text { ton }\end{array}$ \\
\hline Soybean & 0.413 & 0.6681 & 1.5526 & -0.06 & 1960 & Soybeans, peanuts \\
\hline Wheat & 0.0852 & 1.6525 & 2.3209 & -0.0291 & 1955 & Winter wheat, spring wheat, durum wheat, sunflowers \\
\hline Rice & 0.0846 & 2.1279 & 3.4339 & -0.0256 & 1955 & Rice, sorghum \\
\hline Hay & 0.2832 & 1.939 & 6.6342 & -0.0365 & 1955 & Hay, rye, tobacco, beans \\
\hline Sugarcane & 0.4044 & 0.6252 & 0.0575 & -0.09 & 1960 & Sugarcane, sorghum silage \\
\hline
\end{tabular}

\section{References Cited}

Alcamo, Joseph, Leemans, Rick, and Kreileman, Eric, 1998, Global change scenarios of the 21 st century-Results from the IMAGE 2.1 model: Oxford, Elsevier Science Ltd., 296 p.

Liu, Shuguang, 2009, Quantifying the spatial details of carbon sequestration potential and performance, in McPherson, B.J., and Sundquist, E.T., eds., Carbon sequestration and its role in the global carbon cycle: American Geophysical Union Monograph 183, p. 117-128, http://dx.doi.org/10.1029/2006GM000524.

Liu, Shuguang, Bliss, Norman, Sundquist, Eric, and Huntington, T.G., 2003, Modeling carbon dynamics in vegetation and soil under the impact of soil erosion and deposition: Global Biogeochemical Cycles, v. 17, no. 2, 1074, 24 p., http://dx.doi.org/10.1029/2002GB002010.

Liu, Shuguang, Tan, Zhengxi, Chen, Mingshi, Liu, Jinxun, Wein, Anne, Li, Zhengpeng, Huang, Shengli, Oeding, Jennifer, Young, Claudia, Verma, S.B., Suyker, A.E., Faulkner, Stephen, and McCarty, G.W., 2012, The general ensemble biogeochemical modeling system (GEMS) and its applications to agricultural systems in the United States, chap. 18 of Liebig, Mark, Franzluebbers, A.J., and Follett, Ronald, eds., Managing agricultural greenhouse gases - Coordinated agricultural research through GRACEnet to address our changing climate: London, Academic Press, p. 309-323. (Also available at http://dx.doi.org/10.1016/ B978-0-12-386897-8.00018-8.)

Parton, W.J., Schimel, D.S., Cole, C.V., and Ojima, D.S., 1987, Analysis of factors controlling soil organic-matter levels in Great Plains grasslands: Soil Science Society of America Journal, v. 51, no. 5, p. 1173-1179, http://dx.doi. org/10.2136/sssaj1987.03615995005100050015x.

Parton, W.J., Ojima, D.S., and Schimel, D.S., 1994, Environmental change in grasslands-Assessment using models: Climatic Change, v. 28, nos. 1-2, p. 111-141, http://dx.doi.org/10.1007/BF01094103.

U.S. Department of Agriculture, Economic Research Service, 2011a, ARMS farm financial and crop production practicesTailored reports: U.S. Department of Agriculture, Economic Research Service database, accessed August 16, 2011, at http://www.ers.usda.gov/Data/ARMS/app/. [Database moved and accessed June 6, 2014, at http://www.ers.usda.gov/data-products/arms-farm-financialand-crop-production-practices/tailored-reports-farmstructure-and-finance.aspx\#.U5GYp_mwLMo.] 


\section{Appendix 2. The Land Greenhouse-Gas Accounting Tool}

Spreadsheet-based or bookkeeping models have been used to simulate various biogeochemical processes (for example, Houghton and Hackler, 2000; Verburg and Johnson, 2001). The Land Greenhouse-Gas Accounting Tool (LGAT) is developed based on a set of rules and implemented using $\mathrm{C}++$ to calculate carbon budgets and greenhouse gas (GHG) emissions, similar to a spreadsheet model in algorithms but different in form. Instead of performing calculations according to tables in a spreadsheet environment, the LGAT generates spatial data layers of carbon stocks and GHG emissions on a pixel basis according to the rules and conditions of each pixel. Changes in pixel conditions can lead to changes in carbon stocks and GHG emissions over time.

The LGAT requires the following input data:

- land cover map

- forest age distribution map

- soil carbon map

- potential aboveground and belowground biomass maps for grassland and shrubland

- forest carbon density by age and forest type

- lookup tables for methane $\left(\mathrm{CH}_{4}\right)$ and nitrous oxide $\left(\mathrm{N}_{2} \mathrm{O}\right)$ emission factors by region and land cover

The LGAT generates maps of 12 variables on an annual basis (table A2-1). Additional data layers, such as temporal changes of total carbon, can be calculated handily at the pixel level by looking at the differences between years. The LGAT calculates carbon stocks and GHG fluxes of all pixels in a region using the following rules:

- Soil organic carbon (SOC) stocks. - Assign SOC stocks according to static map (no SOC change is tracked because lack of data at present).
- Biomass carbon stocks.-

- If the land cover is forest-

- If there is no disturbance, assign carbon stock values according to region (for example, the U.S. Forest Service Forest Inventory and Analysis (FIA) unit), forest type, and age.

- If forest harvesting occurs-

- Calculate carbon removal (as $\beta \times \mathrm{C}_{\mathrm{AGLB}}$, where $\beta$ is the mass transfer coefficient from aboveground live carbon to harvested wood and $\mathrm{C}_{\mathrm{AGLB}}$ is the aboveground live biomass carbon).

- Assign carbon stock values according to region (for example, FIA unit), forest type, and age $(=0)$.

- No procedure has been implemented for other disturbances.

- If the land cover is cropland-

- If cover is corn, assign corn-specific constant carbon stock values.

- If cover is not corn, assign specific constant carbon stock values.

- If the land cover is grassland, assign carbon stock values according to a potential grassland biomass carbon stock map.

- If land cover is shrubland, assign carbon stock values according to a potential shrubland biomass carbon stock map.

- $\mathrm{CH}_{4}$ flux.-Assign $\mathrm{CH}_{4}$ emission factor according to region and land cover.

- $\mathrm{N}_{2} \mathrm{O}$ flux.-Assign $\mathrm{N}_{2} \mathrm{O}$ emission factor according to region and land cover.

Table A2-1. List of output variables from the Land Greenhouse-Gas Accounting Tool.

$\left[\mathrm{CH}_{4}\right.$, methane; $\mathrm{gC} / \mathrm{ha} / \mathrm{yr}$, grams of nitrogen per hectare per year; $\mathrm{MgC} / \mathrm{ha}$, megagrams of carbon per hectare; $\mathrm{MgC} / \mathrm{ha} / \mathrm{yr}$, megagrams of carbon per hectare per year; $\mathrm{N}_{2} \mathrm{O}$, nitrous oxide]

\begin{tabular}{llllll}
\multicolumn{1}{c}{ Index } & \multicolumn{1}{c}{ Variable } & \multicolumn{1}{c}{ Definition } & \multicolumn{1}{c}{ Unit } & Pool/flux & Scale \\
\hline 1 & Aglc_tr & Aboveground live carbon & $\mathrm{MgC} / \mathrm{ha}$ & Pool & Pixel \\
2 & Bglc_tr & Belowground live carbon & $\mathrm{MgC} / \mathrm{ha}$ & Pool & Pixel \\
3 & Aglc_ntr & Understory aboveground carbon & $\mathrm{MgC} / \mathrm{ha}$ & Pool & Pixel \\
4 & Bglc_ntr & Understory belowground carbon & $\mathrm{MgC} / \mathrm{ha}$ & Pool & Pixel \\
\hline 5 & CWD_st & Standing dead carbon & $\mathrm{MgC} / \mathrm{ha}$ & Pool & Pixel \\
6 & CWD_dn & Down wood carbon & $\mathrm{MgC} / \mathrm{ha}$ & Pool & Pixel \\
7 & Litter & Litter carbon & $\mathrm{MgC} / \mathrm{ha}$ & Pool & Pixel \\
8 & roots_dead & Dead roots & $\mathrm{MgC} / \mathrm{ha}$ & Pool & Pixel \\
9 & soc & Soil organic carbon & $\mathrm{MgC} / \mathrm{ha}$ & Pool & Pixel \\
10 & systemc & Total system carbon & $\mathrm{MgC} / \mathrm{ha}$ & Pool & Pixel \\
11 & $\mathrm{~N}_{2} \mathrm{O}$ & $\mathrm{N}_{2} \mathrm{O}$ emissions & $\mathrm{gN} / \mathrm{ha} / \mathrm{yr}$ & Flux & Pixel \\
12 & $\mathrm{CH}_{4}$ & $\mathrm{CH}_{4}$ flux & $\mathrm{MgC} / \mathrm{ha} / \mathrm{yr}$ & Flux & Pixel \\
\hline
\end{tabular}




\section{References Cited}

Houghton, R.A., and Hackler, J.L., 2000, Changes in terrestrial carbon storage in the United States. 1. The roles of agriculture and forestry: Global Ecology and Biogeography, v. 9, no. 2, p. 125-144, accessed December 10, 2013, at http://dx.doi.org/10.1046/j.1365-2699.2000.00166.x.
Verburg, P.S.J., and Johnson, D.W., 2001, A spreadsheet-based biogeochemical model to simulate nutrient cycling processes in forest ecosystems: Ecological Modelling, v. 141, nos. 1-3, p. 185-200, accessed December 10, 2013, at http://dx.doi.org/10.1016/S0304-3800(01)00273-3. 


\section{Appendix 3. Coefficients of Forest Partial Cutting and Biomass Mortality}

The U.S. Forest Service Forest Inventory and Analysis (FIA) Program is known to provide forest inventory data for the United States. The FIA database for each individual State can be downloaded from the FIA DataMart (http://fia.fs.fed.us/tools-data) as a Microsoft Access database. We downloaded the forest inventory information for the period that reported the annualized data (from 2002 through 2010) to estimate the coefficients related to partial cutting and biomass mortality in the Eastern United States at FIA plot level. These coefficients were then averaged by FIA unit, defined as a group of counties by State, and delineated by forest type (tables A3-1 to A3-4). This work was primarily done by Decheng Zhou from Beijing University and Jennifer Oeding of Stinger Ghaffarian Technolgoes Inc. under contract for the U.S. Geological Survey, in consultation with FIA staff.

Table A3-1. Forest partial cutting and biomass mortality in the Eastern United States.

[Forest partial cutting is the percent of forestland area being partially cut per year, and biomass mortality is the percentage of live biomass becoming dead each year, averaged from Forest Inventory and Analysis (FIA) observations from 2002 through 2010. FIPS ID, Federal Information Processing Standard identification number]

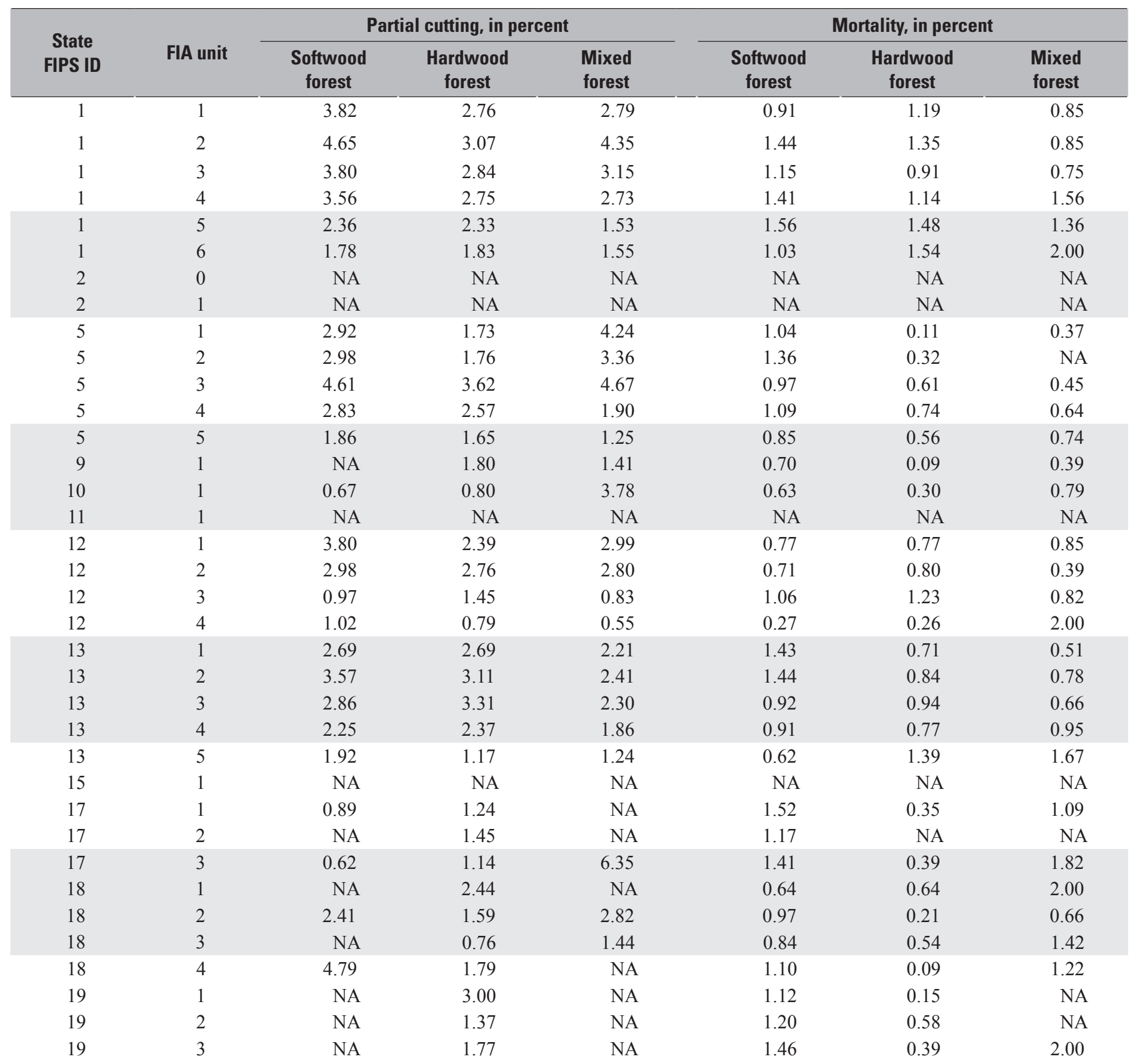


Table A3-1. Forest partial cutting and biomass mortality in the Eastern United States._Continued

[Forest partial cutting is the percent of forestland area being partially cut per year, and biomass mortality is the percentage of live biomass becoming dead each year, averaged from Forest Inventory and Analysis (FIA) observations from 2002 through 2010. FIPS ID, Federal Information Processing Standard identification number]

\begin{tabular}{|c|c|c|c|c|c|c|c|}
\hline \multirow{2}{*}{$\begin{array}{c}\text { State } \\
\text { FIPS ID }\end{array}$} & \multirow[b]{2}{*}{ FIA unit } & \multicolumn{3}{|c|}{ Partial cutting, in percent } & \multicolumn{3}{|c|}{ Mortality, in percent } \\
\hline & & $\begin{array}{l}\text { Softwood } \\
\text { forest }\end{array}$ & $\begin{array}{l}\text { Hardwood } \\
\text { forest }\end{array}$ & $\begin{array}{l}\text { Mixed } \\
\text { forest }\end{array}$ & $\begin{array}{l}\text { Softwood } \\
\text { forest }\end{array}$ & $\begin{array}{l}\text { Hardwood } \\
\text { forest }\end{array}$ & $\begin{array}{l}\text { Mixed } \\
\text { forest }\end{array}$ \\
\hline 20 & 1 & 2.26 & 1.29 & NA & 1.30 & 1.12 & 2.00 \\
\hline 20 & 2 & 1.11 & 1.00 & 2.49 & 1.00 & NA & 0.78 \\
\hline 20 & 3 & NA & 0.59 & NA & 2.00 & 1.06 & NA \\
\hline 21 & 2 & 1.82 & 1.35 & NA & 1.28 & 0.97 & 0.99 \\
\hline 21 & 3 & NA & 1.46 & 0.90 & 0.77 & 1.72 & 2.00 \\
\hline 21 & 4 & 1.18 & 0.86 & 0.81 & 0.80 & 0.54 & 1.75 \\
\hline 21 & 5 & 2.71 & 1.32 & 1.19 & 0.72 & 0.77 & 1.40 \\
\hline 21 & 6 & 0.65 & 1.07 & 1.80 & 0.50 & 1.08 & 0.73 \\
\hline 22 & 1 & 4.41 & 1.34 & 2.07 & 1.16 & 0.64 & 0.45 \\
\hline 22 & 2 & 3.45 & 1.24 & 5.68 & 1.57 & NA & 2.00 \\
\hline 22 & 3 & 4.33 & 2.79 & 3.86 & 1.55 & 1.56 & 1.54 \\
\hline 22 & 4 & 3.42 & 2.25 & 4.80 & 2.00 & 1.49 & 0.49 \\
\hline 22 & 5 & 4.94 & 3.97 & 4.77 & 0.68 & 0.08 & 0.43 \\
\hline 23 & 1 & 3.60 & 2.52 & 10.00 & 0.89 & 2.00 & 0.76 \\
\hline 23 & 2 & 2.22 & 3.27 & NA & 1.28 & NA & 0.99 \\
\hline 23 & 3 & 3.09 & 3.04 & 6.78 & 0.99 & 0.12 & 0.87 \\
\hline 23 & 4 & 1.94 & 3.02 & NA & 1.37 & 0.05 & 1.15 \\
\hline 23 & 5 & 2.54 & 3.07 & NA & 1.32 & 1.89 & 1.02 \\
\hline 23 & 6 & 2.67 & 2.03 & 2.01 & 1.00 & 0.63 & 1.33 \\
\hline 23 & 7 & 1.87 & 4.05 & 3.64 & 1.48 & 1.19 & 0.99 \\
\hline 23 & 8 & 3.64 & 2.99 & 3.40 & 0.52 & 0.98 & 0.74 \\
\hline 23 & 9 & 2.77 & 3.09 & 3.80 & 1.06 & 0.33 & 0.85 \\
\hline 24 & 2 & 1.47 & 1.98 & 2.82 & 1.00 & 0.62 & 0.49 \\
\hline 24 & 3 & 2.50 & 1.73 & 4.26 & 0.51 & 1.84 & 1.02 \\
\hline 24 & 4 & 3.81 & 1.86 & 4.66 & 0.95 & 0.67 & 0.67 \\
\hline 24 & 5 & NA & 1.94 & 11.35 & 0.99 & 1.03 & 0.19 \\
\hline 25 & 1 & 1.29 & 1.71 & 1.65 & 0.76 & 0.68 & 0.52 \\
\hline 26 & 1 & 0.74 & 2.03 & 1.51 & 0.99 & 0.43 & 0.95 \\
\hline 26 & 2 & 0.87 & 1.97 & 1.59 & 0.85 & 0.59 & 1.18 \\
\hline 26 & 3 & 1.12 & 1.66 & 1.29 & 0.75 & 0.66 & 0.71 \\
\hline 26 & 4 & 0.57 & 1.46 & 1.76 & 1.24 & 1.15 & 2.00 \\
\hline 27 & 1 & 0.65 & 1.99 & 1.34 & 2.00 & 2.00 & 1.61 \\
\hline 27 & 2 & 1.09 & 2.43 & 1.86 & 1.41 & 1.22 & 1.23 \\
\hline 27 & 3 & 1.26 & 1.95 & 3.44 & 1.25 & 1.46 & 1.28 \\
\hline 27 & 4 & NA & 1.32 & NA & 1.31 & 0.27 & 0.75 \\
\hline 28 & 1 & 1.60 & 2.29 & 3.87 & 0.95 & 1.30 & 0.08 \\
\hline 28 & 2 & 3.56 & 2.40 & 2.10 & 0.83 & 1.38 & 0.34 \\
\hline 28 & 3 & 3.98 & 3.17 & 3.26 & 1.27 & 0.88 & 0.95 \\
\hline 28 & 4 & 3.47 & 2.87 & 3.60 & 2.00 & 2.00 & 1.56 \\
\hline 28 & 5 & 3.63 & 2.59 & 3.57 & 2.00 & 0.41 & 0.46 \\
\hline 29 & 1 & 1.58 & 2.39 & 2.39 & 0.94 & 0.68 & 0.33 \\
\hline 29 & 2 & 2.98 & 3.19 & 1.78 & 0.92 & 0.51 & 0.50 \\
\hline 29 & 3 & 2.04 & 2.36 & 1.72 & 1.43 & 0.37 & 0.06 \\
\hline 29 & 4 & NA & 1.96 & 2.01 & 1.16 & 1.47 & 0.92 \\
\hline
\end{tabular}


Table A3-1. Forest partial cutting and biomass mortality in the Eastern United States.—Continued

[Forest partial cutting is the percent of forestland area being partially cut per year, and biomass mortality is the percentage of live biomass becoming dead each year, averaged from Forest Inventory and Analysis (FIA) observations from 2002 through 2010. FIPS ID, Federal Information Processing Standard identification number]

\begin{tabular}{|c|c|c|c|c|c|c|c|}
\hline \multirow{2}{*}{$\begin{array}{l}\text { State } \\
\text { FIPS ID }\end{array}$} & \multirow[b]{2}{*}{ FIA unit } & \multicolumn{3}{|c|}{ Partial cutting, in percent } & \multicolumn{3}{|c|}{ Mortality, in percent } \\
\hline & & $\begin{array}{c}\text { Softwood } \\
\text { forest }\end{array}$ & $\begin{array}{l}\text { Hardwood } \\
\text { forest }\end{array}$ & $\begin{array}{l}\text { Mixed } \\
\text { forest }\end{array}$ & $\begin{array}{c}\text { Softwood } \\
\text { forest }\end{array}$ & $\begin{array}{l}\text { Hardwood } \\
\text { forest }\end{array}$ & $\begin{array}{r}\text { Mixed } \\
\text { forest }\end{array}$ \\
\hline 31 & 1 & 1.18 & 0.84 & 2.57 & 1.35 & 1.44 & 0.41 \\
\hline 31 & 2 & 0.29 & 0.58 & NA & 2.00 & 0.83 & 0.86 \\
\hline 33 & 2 & 2.10 & 2.24 & 2.87 & 1.05 & 1.15 & 2.00 \\
\hline 34 & 1 & 0.19 & 1.01 & 1.43 & 0.81 & 0.61 & 0.59 \\
\hline 36 & 1 & 0.99 & 1.76 & 2.21 & 1.26 & 1.17 & 1.16 \\
\hline 36 & 2 & 0.57 & 1.64 & 3.77 & 0.70 & 0.30 & 1.22 \\
\hline 36 & 3 & 1.46 & 1.53 & NA & 0.95 & 0.95 & 0.84 \\
\hline 36 & 4 & 0.46 & 0.92 & 2.52 & 1.12 & 0.90 & 0.88 \\
\hline 36 & 6 & 1.19 & 2.33 & 3.22 & 0.60 & 0.79 & 0.67 \\
\hline 36 & 7 & 1.37 & 2.05 & 1.51 & 0.58 & 0.50 & 0.52 \\
\hline 36 & 8 & 0.98 & 1.00 & NA & 0.84 & 0.22 & 0.78 \\
\hline 37 & 1 & 4.61 & 3.14 & 3.24 & 1.76 & 1.00 & 0.69 \\
\hline 37 & 2 & 3.31 & 2.93 & 3.58 & 1.24 & 1.68 & 1.14 \\
\hline 37 & 3 & 1.69 & 2.10 & 2.50 & 0.95 & 1.49 & 1.53 \\
\hline 37 & 4 & 0.98 & 1.12 & 1.83 & 0.64 & 1.28 & 1.41 \\
\hline 38 & 1 & NA & 0.59 & NA & 2.00 & NA & 0.74 \\
\hline 39 & 1 & 0.37 & 1.23 & 2.79 & 1.00 & 1.14 & 0.41 \\
\hline 39 & 2 & NA & 1.15 & 2.12 & 0.90 & 2.00 & 0.48 \\
\hline 39 & 3 & NA & 1.01 & NA & 1.11 & 2.00 & 0.81 \\
\hline 39 & 4 & 2.84 & 1.22 & NA & 1.08 & NA & 0.31 \\
\hline 39 & 5 & NA & 0.48 & NA & 0.86 & 0.65 & NA \\
\hline 39 & 6 & 2.73 & 1.10 & NA & 0.95 & 1.89 & 1.70 \\
\hline 40 & 1 & 4.57 & 1.89 & 2.97 & 0.83 & 0.23 & 0.71 \\
\hline 40 & 2 & 2.31 & 0.98 & 1.52 & 2.00 & 2.00 & NA \\
\hline 40 & 3 & NA & NA & NA & 1.07 & 0.87 & 0.92 \\
\hline 40 & 4 & NA & NA & NA & 1.07 & 0.87 & 0.92 \\
\hline 40 & 5 & NA & NA & NA & 1.07 & 0.87 & 0.92 \\
\hline 40 & 6 & NA & NA & NA & 1.07 & 0.87 & 0.92 \\
\hline 40 & 7 & NA & NA & NA & 1.07 & 0.87 & 0.92 \\
\hline 42 & 0 & NA & 1.97 & NA & 1.14 & 1.66 & 0.33 \\
\hline 42 & 5 & 2.68 & 2.24 & NA & 0.86 & 2.00 & 1.00 \\
\hline 42 & 6 & 0.66 & 1.65 & 1.02 & 0.70 & 0.50 & 0.71 \\
\hline 42 & 7 & NA & 2.13 & 4.87 & 0.69 & 0.42 & 2.00 \\
\hline 42 & 8 & 3.28 & 1.41 & 1.86 & 0.79 & 2.00 & 1.34 \\
\hline 42 & 9 & NA & 1.90 & NA & 0.76 & 0.07 & 0.89 \\
\hline 44 & 1 & 0.49 & 0.96 & NA & 0.51 & 0.08 & 0.72 \\
\hline 45 & 1 & 3.24 & 1.92 & 1.91 & 0.82 & 0.79 & 0.61 \\
\hline 45 & 2 & 2.85 & 2.37 & 2.37 & 0.75 & 0.60 & 0.59 \\
\hline 45 & 3 & 3.01 & 1.95 & 2.02 & 0.88 & 1.12 & 0.96 \\
\hline 46 & 1 & NA & 0.59 & NA & 2.00 & NA & 0.22 \\
\hline 46 & 2 & 2.08 & 3.40 & NA & 1.18 & NA & 1.14 \\
\hline 47 & 1 & 1.67 & 2.09 & 2.25 & 1.15 & 0.70 & 0.82 \\
\hline 47 & 2 & 3.44 & 2.03 & 2.29 & 0.88 & 0.96 & 0.28 \\
\hline 47 & 3 & 0.56 & 1.87 & 1.20 & 0.82 & 0.56 & 0.40 \\
\hline
\end{tabular}


Table A3-1. Forest partial cutting and biomass mortality in the Eastern United States._Continued

[Forest partial cutting is the percent of forestland area being partially cut per year, and biomass mortality is the percentage of live biomass becoming dead each year, averaged from Forest Inventory and Analysis (FIA) observations from 2002 through 2010. FIPS ID, Federal Information Processing Standard identification number]

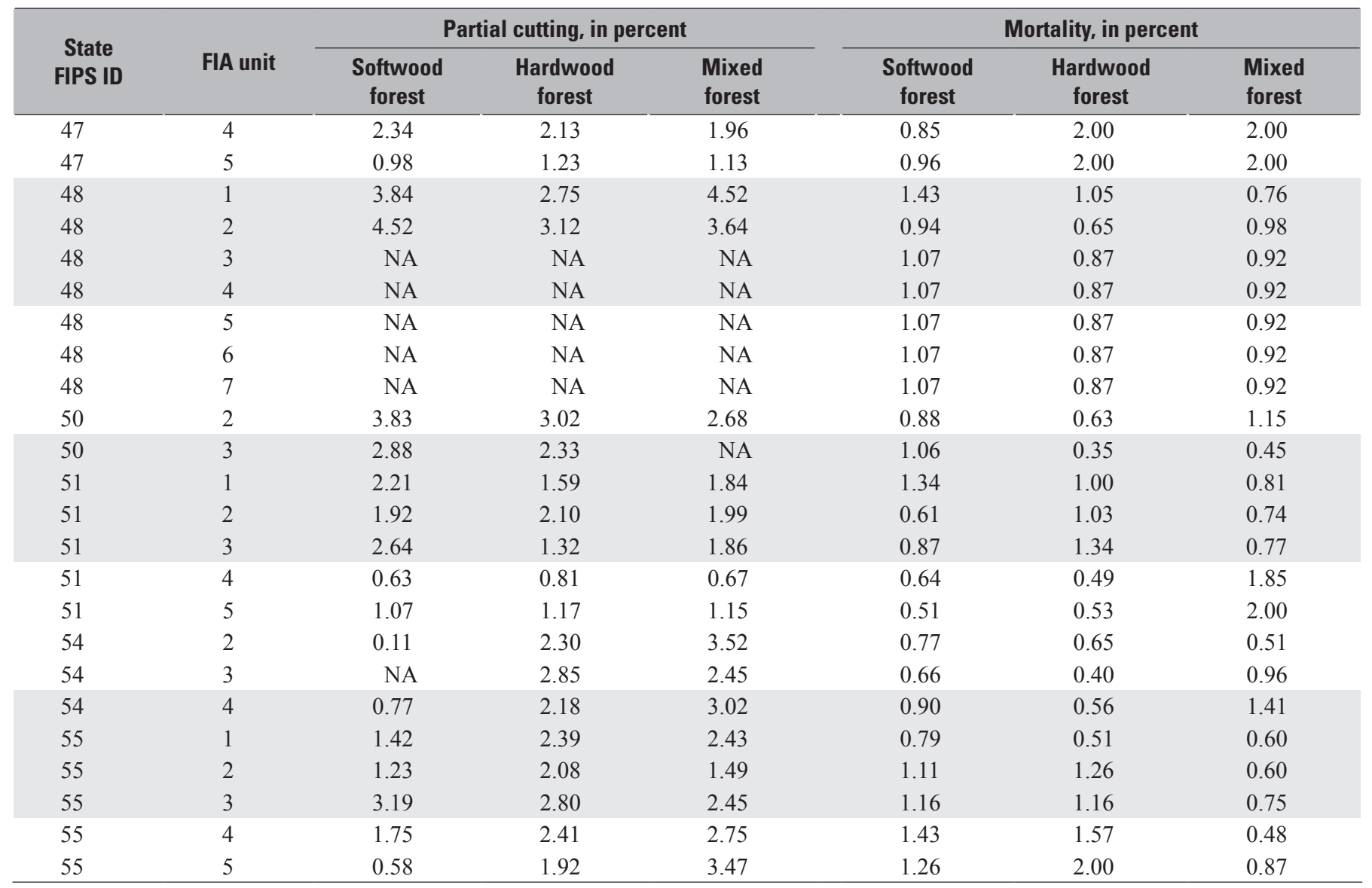

Table A3-2. Age distribution of forest mortality in the Eastern United States.

[Values are as a percentage of the total forest type. Columns represent age class: age10, 0 to 10 years old; age20, 11 to 20 years old; age 30 , 21 to 30 years old; age $40=31$ to 40 years old; age 50, 41 to 50 years old; age 60,51 to 60 years old; age 70,61 to 70 years old; age 80,71 to 80 years old; age 90,81 to 90 years old; age 100, 91 to 100 years old; age $110,>100$ years old]

\begin{tabular}{lrrrrrrrrrrrrr}
\multicolumn{1}{c}{ Forest type } & age10 & age20 & age30 & age40 & age50 & age60 & age70 & age80 & age90 & age100 & age110 \\
\hline Hardwood & 0.69 & 1.42 & 2.74 & 6.82 & 13.61 & 17.24 & 20.29 & 15.39 & 10.74 & 5.77 & 5.29 \\
Mixed & 1.19 & 3.25 & 5.08 & 8.87 & 18.29 & 23.47 & 15.71 & 13.29 & 8.10 & 1.71 & 1.03 \\
Softwood & 1.45 & 6.78 & 15.57 & 10.94 & 16.59 & 15.52 & 12.25 & 9.24 & 4.74 & 2.45 & 4.48 \\
\hline
\end{tabular}

Table A3-3. Age distribution of partial forest cutting in the Eastern United States.

[Values are as a percentage of the total forest type. Columns represent age class: age10, 0 to 10 years old; age20, 11 to 20 years old; age 30,21 to 30 years old; age $40=31$ to 40 years old; age 50,41 to 50 years old; age 60,51 to 60 years old; age 70,61 to 70 years old; age 80,71 to 80 years old; age 90,81 to 90 years old; age 100, 91 to 100 years old; age 110 , more than 100 years old]

\begin{tabular}{|c|c|c|c|c|c|c|c|c|c|c|c|}
\hline Forest type & age10 & age20 & age30 & age40 & age50 & age60 & age70 & age80 & age90 & age100 & age110 \\
\hline Hardwood & 1.23 & 1.29 & 3.05 & 7.22 & 12.50 & 19.43 & 20.93 & 15.48 & 8.94 & 4.39 & 5.56 \\
\hline Mixed & 0.92 & 3.30 & 11.19 & 16.93 & 16.35 & 24.84 & 10.33 & 8.23 & 3.06 & 2.47 & 2.39 \\
\hline
\end{tabular}


Table A3-4. Frequency distribution of forest cutting in the Eastern United States.

[Values are as a percentage of the total forest type. Columns represent removal rate of aboveground biomass: ci0, 0 to 10 percent removal; ci20, 11 to 20 percent removal; ci30, 21 to 30 percent removal; ci $40=31$ to 40 percent removal; ci50, 41 to 50 percent removal; ci60, 51 to 60 percent removal; ci70, 61 to 70 percent removal; ci80, 71 to 80 percent removal; ci90, 81 to 90 percent removal; ci100, 91 to 100 percent removal (that is, clearcut).

\begin{tabular}{lllllllllll}
\hline Forest Type & ci10 & ci20 & ci30 & ci40 & ci50 & ci60 & ci70 & ci80 & ci90 & ci100 \\
\hline Hardwood & 3.741 & 7.489 & 9.647 & 9.486 & 10.44 & 11.15 & 9.335 & 7.911 & 13.1 & 17.7 \\
Mixed & 3.286 & 5.521 & 4.801 & 6.879 & 10.25 & 6.89 & 15.08 & 11.35 & 16.53 & 19.41 \\
Softwood & 1.018 & 2.897 & 5.83 & 7.527 & 9.354 & 9.768 & 8.314 & 9.152 & 9.948 & 36.19 \\
\hline
\end{tabular}




\section{Appendix 4. Optimized Maximum Monthly Gross Primary Production}

The maximum gross primary production rates (PRDX) for all land cover types within each county in the Eastern United States were calibrated using county-based grainyield-survey data by crop type and 250-meter resolution net primary production data from the moderate resolution imaging spectroradiometer (MODIS) for other land-use and land-cover types such as forests and grasslands from 2001 through 2005. Figure A4-1 shows the distribution of PRDX for the major land cover types across more than 1,990 counties in the Eastern United States.

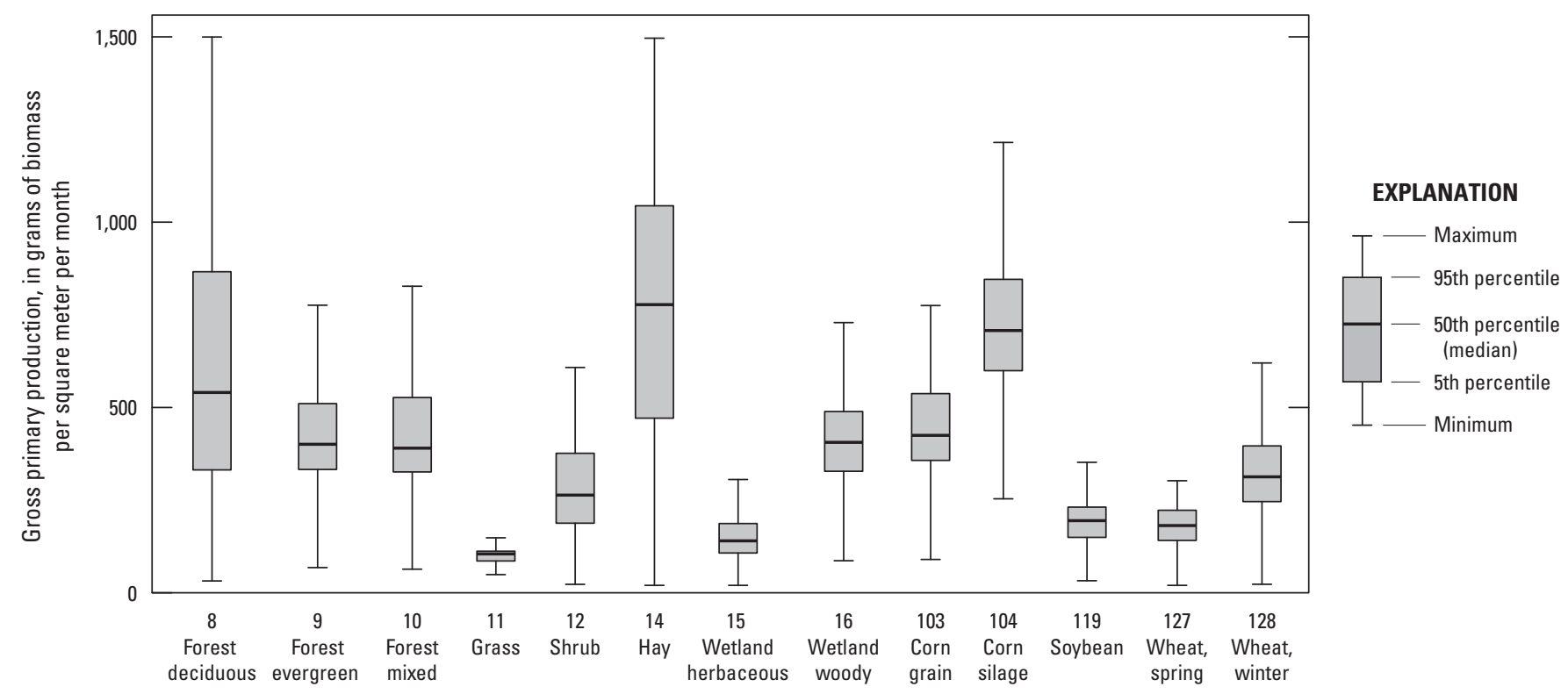

Figure A4-1. Graph showing the distribution of the optimized parameter potential monthly gross primary production (PRDX), in grams of biomass per square meter per month, in the Erosion Deposition Carbon Model (EDCM) for each major land cover across 1,990 counties in the Eastern United States. Each box-and-whisker represents the distribution of the PRDX values derived for 1,990 counties. The line inside the box shows the median, the upper and lower ends of the box are the 75th and 25th percentiles, respectively, and the whiskers show the maximum and minimum values. 


\section{Appendix 5. Comparison of Sampling-Based and Per-Pixel Model Runs}

Biogeochemical modeling over large areas is computationally intensive. In order to accelerate turnover time of modeling results for repeated analysis and debugging, sampling-based model simulations are implemented in the General Ensemble Biogeochemical Modeling System (GEMS; Liu, 2009; Liu and others, 2012). Not all pixels will be simulated using the sampling approach. Instead, GEMS systematically selects the pixels to simulate according to user input. For example, simulating every fifth pixel in both $\mathrm{x}$ and $y$ directions would result in a sampling rate of $1: 25$, every tenth pixel would result in a rate of 1:100, and so on. Users can select sampling rates according to situation (for example, the size of study area and the running time they can afford). The running time for the Century version 4.0 model (Parton and others, 1987, 1994; Metherell and others, 1993) and the Erosion Deposition Carbon Model (EDCM; appendix 1; Liu and others, 2003) can be shortened by more than 98 percent with a sampling rate of 1:100.

To illustrate the effects of sampling on model simulations, figures A5-1 and A5-2 compare model-simulated carbon stocks and fluxes using sampling-based and per-pixel simulation approaches in the Mixed Wood Shield ecoregion (other ecoregions showed similar results). The sampling rate of 1:100 used for this assessment was sufficient to represent the overall dynamics of carbon stocks and fluxes compared with the per-pixel simulation approach.

\section{References Cited}

Liu, Shuguang, 2009, Quantifying the spatial details of carbon sequestration potential and performance, in McPherson, B.J., and Sundquist, E.T., eds., Carbon sequestration and its role in the global carbon cycle: American Geophysical Union Monograph 183, p. 117-128, http://dx.doi.org/10.1029/2006GM000524.
Liu, Shuguang, Bliss, Norman, Sundquist, Eric, and Huntington, T.G., 2003, Modeling carbon dynamics in vegetation and soil under the impact of soil erosion and deposition: Global Biogeochemical Cycles, v. 17, no. 2, 1074, 24 p., http://dx.doi.org/10.1029/2002GB002010.

Liu, Shuguang, Tan, Zhengxi, Chen, Mingshi, Liu, Jinxun, Wein, Anne, Li, Zhengpeng, Huang, Shengli, Oeding, Jennifer, Young, Claudia, Verma, S.B., Suyker, A.E., Faulkner, Stephen, and McCarty, G.W., 2012, The general ensemble biogeochemical modeling system (GEMS) and its applications to agricultural systems in the United States, chap. 18 of Liebig, Mark, Franzluebbers, A.J., and Follett, Ronald, eds., Managing agricultural greenhouse gases - Coordinated agricultural research through GRACEnet to address our changing climate: London, Academic Press, p. 309-323. (Also available at $h t t p: / / d x$.doi.org/10.1016/B978-0-12386897-8.00018-8.)

Metherell, A.K., Harding, L.A., Cole, C.V., and Parton, W.J., 1993, Century soil organic matter model environment, technical documentation, Agroecosystem version 4.0: U.S. Department of Agriculture Technical Report 4, accessed December 16, 2013, at http://www.nrel.colostate.edu/ projects/century/.

Parton, W.J., Schimel, D.S., Cole, C.V., and Ojima, D.S., 1987, Analysis of factors controlling soil organic-matter levels in Great Plains grasslands: Soil Science Society of America Journal, v. 51, no. 5, p. 1173-1179, http://dx.doi.org/10.2136/sssaj1987.036159950051000500 $15 x$.

Parton, W.J., Ojima, D.S., and Schimel, D.S., 1994, Environmental change in grasslands-Assessment using models: Climatic Change, v. 28, nos. 1-2, p. 111-141, http://dx.doi.org/10.1007/BF01094103. 


\section{A. NPP, in $\mathrm{kg} / \mathrm{m}^{2} / \mathrm{yr}$}

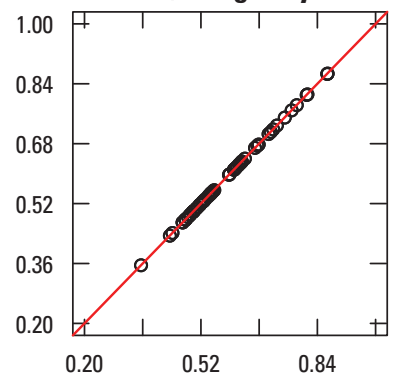

B. Grain yield, in $\mathrm{kg} / \mathrm{m}^{2} / \mathrm{yr}$

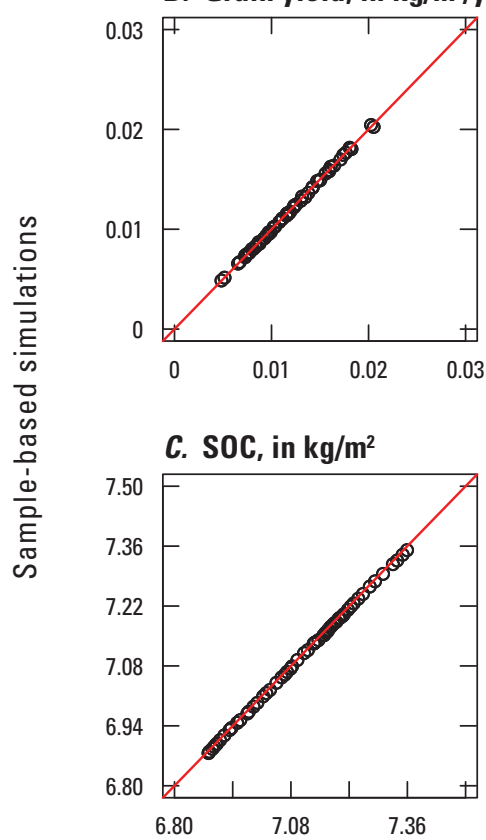

D. Carbon stock, in $\mathrm{kg} / \mathrm{m}^{2}$

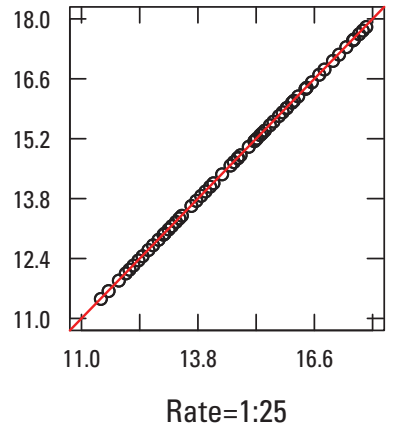

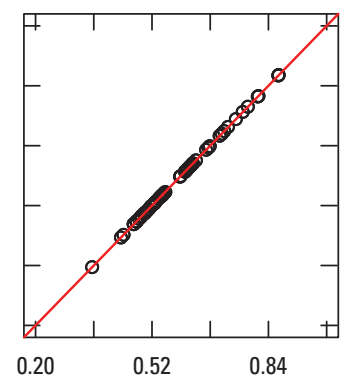
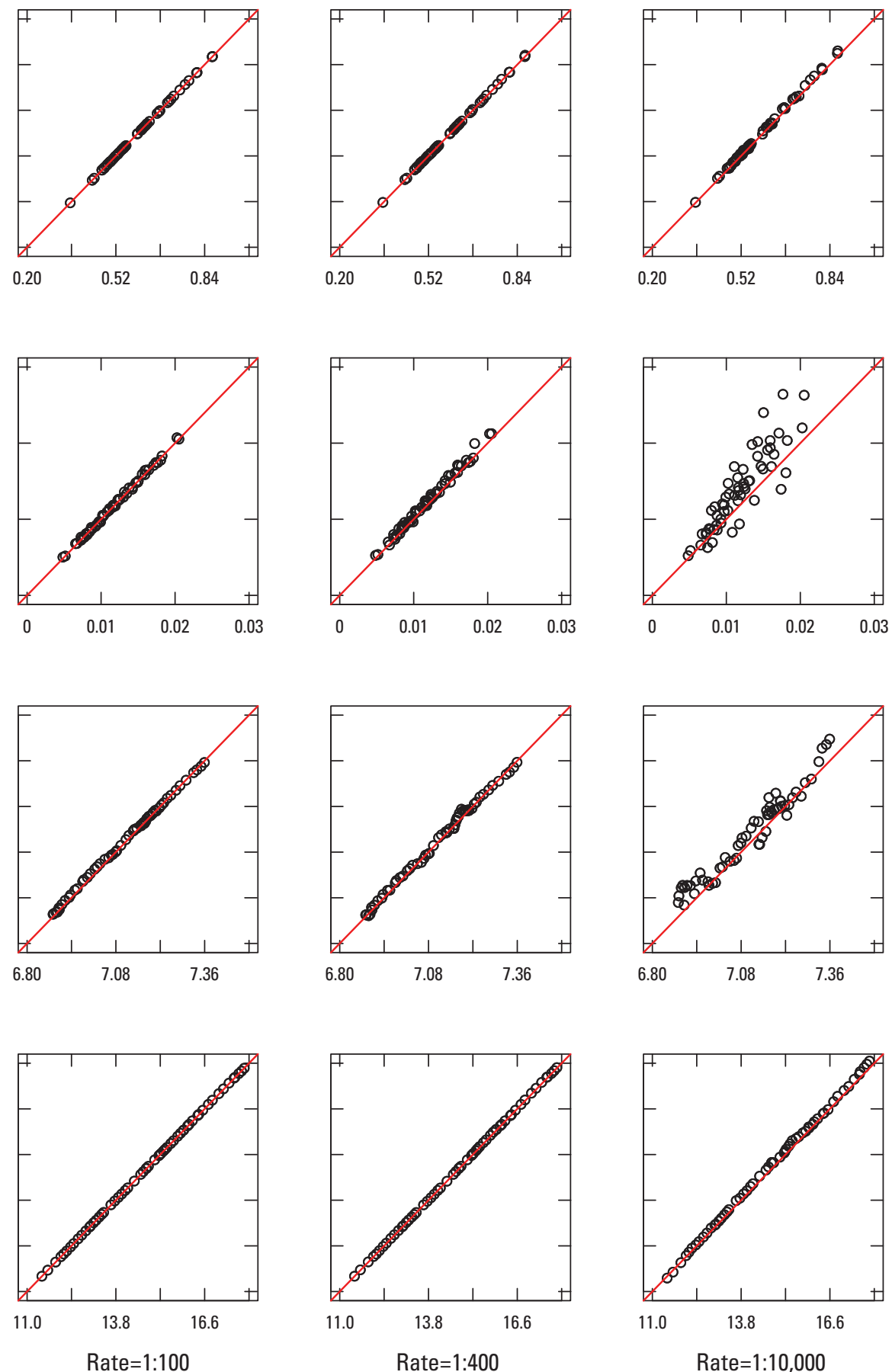

Per-pixel simulations

Figure A5-1. Comparison of simulations in the Century version 4.0 model (Parton and others, 1987, 1994; Metherell and others, 1993) of net primary production (NPP), grain yield, soil organic carbon (SOC), and total ecoregion carbon storage in the Mixed Wood Shield ecoregion using per-pixel and sampling-based approaches. Each circle represents the carbon stock or flux for a given year between 1992 and 1950; the circles on or near the per-pixel simulation trend (red line) show the deviation of results of the samplingbased simulations compared with results from the per-pixel simulation. $\mathrm{kg} / \mathrm{m}^{2} / \mathrm{yr}$, kilograms per square meter per year. 
A. NPP, in $\mathrm{kg} / \mathrm{m}^{2} / \mathrm{yr}$

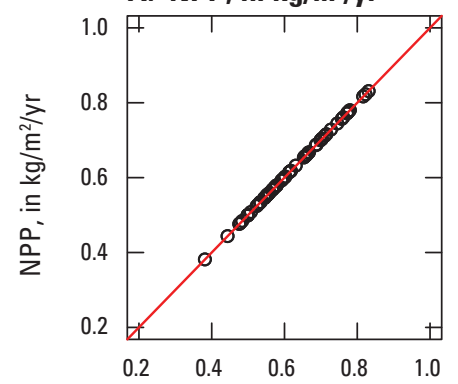

B. Grain yield, in $\mathrm{kg} / \mathrm{m}^{2} / \mathrm{yr}$

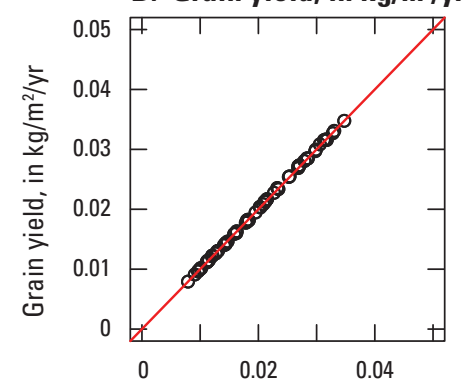

C. $\mathrm{SOC}$, in $\mathrm{kg} / \mathrm{m}^{2}$

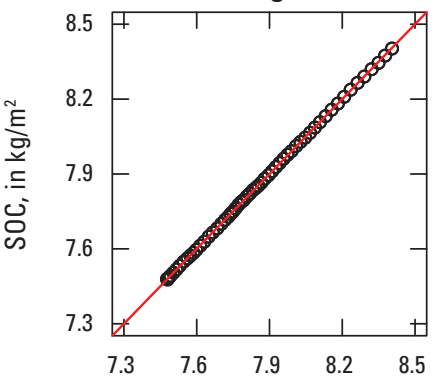

D. Carbon stock, in $\mathrm{kg} / \mathrm{m}^{2}$

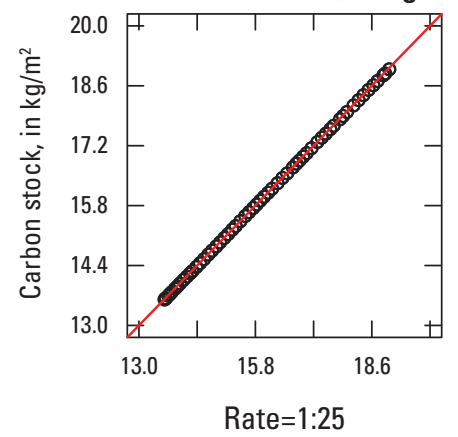

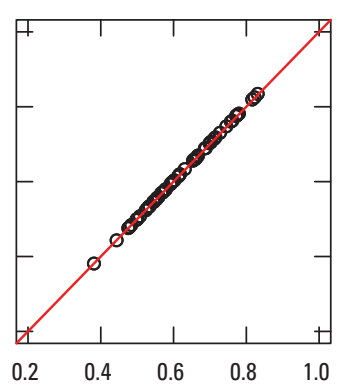
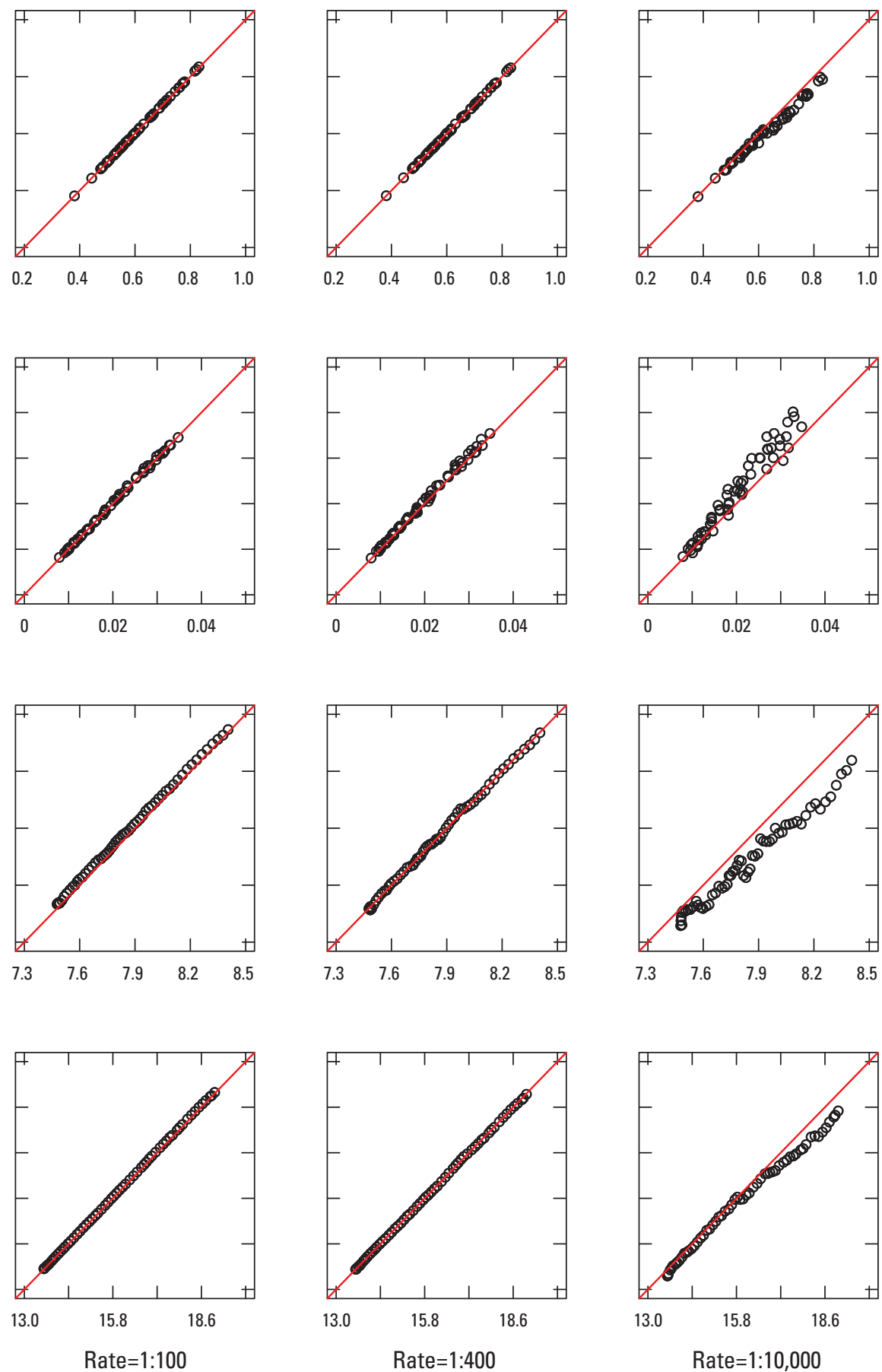

Per-pixel simulations

Figure A5-2. Comparison of simulations from the Erosion Deposition Carbon Model (EDCM; appendix 1; Liu and others, 2003) of net primary production (NPP), grain yield, soil organic carbon (SOC), and total ecoregion carbon storage in the Mixed Wood Shield ecoregion using per-pixel and sampling-based approaches. Each circle represents the carbon stock or flux for a given year between 1992 and 1950; the circles on or near the per-pixel simulation trend (red line) show the deviation of results of the sampling-based simulations compared with results from the per-pixel simulation. $\mathrm{kg} / \mathrm{m}^{2} / \mathrm{yr}$, kilograms per square meter per year. 


\section{Appendix 6. Emission Factors of Nitrous Oxide and Methane in the Eastern United States}

Nitrous oxide $\left(\mathrm{N}_{2} \mathrm{O}\right)$ and methane $\left(\mathrm{CH}_{4}\right)$ are major greenhouse gases; in terms of global warming potentials (GWP), $\mathrm{N}_{2} \mathrm{O}$ and $\mathrm{CH}_{4}$ have 310 and 21 times, respectively, more of an effect than carbon dioxide $\left(\mathrm{CO}_{2}\right.$; U.S. Environmental Protection Agency, 2012). Atmospheric concentrations of these gases are increasing in exponential rate (Corre and others, 1999); human activities are the only reason for these increases. Agricultural activities are major emitter of anthropogenic $\mathrm{CH}_{4}\left(27\right.$ percent) and $\mathrm{N}_{2} \mathrm{O}$ (70 percent) to the global atmosphere, although natural systems, such as wetlands and forests, emit a significant amount of these gases (Smith and others, 2007).

$\mathrm{N}_{2} \mathrm{O}$ flux is highly dependent on nitrogen input and precipitation and only slightly on temperature. However, soil parameters, including $\mathrm{pH}$, organic carbon content, and nitrogen content, have a significant effect (Mosier and others, 1997b; Gleason and others, 2009; Anderson and others, 2010). $\mathrm{CH}_{4}$ is produced when organic materials decompose in oxygen-deprived conditions, notably from fermentative digestion by ruminant livestock, from stored manures, and from rice grown under flooded conditions (Mosier and others, 1998).

The compilation of the emission factors was conducted using an Intergovernmental Panel on Climate Change data collection approach (Goodwin and others, 2006). For this approach, published emission factors of various land use and land cover types in the United States were collected, and type of land use (types of crop, forest, wetland, or grassland), management practice, annual mean flux (if multiple years were reported, we took average annual flux), and location were recorded. Collected values were averaged when there were multiple values for any ecoregion and ecosystem. If no published value was found for any particular region, the value for a nearby similar region was used. Tables A6-1 and A6-2 list the compiled results of $\mathrm{N}_{2} \mathrm{O}$ and $\mathrm{CH}_{4}$ emission factors by ecoregion and ecosystem type with data source flag. 
Table A6-1. $\quad \mathrm{N}_{2} \mathrm{O}$ emission factors by ecosystem and level II ecoregion.

[LC ID, land cover name and identification (U.S. Geological Survey Land Carbon Project designation for the purposes of the assessment). Values are in kilograms of nitrous oxide as nitrogen per hectare per year. Values in flag columns explain if mean is measured or surrogated: 0 , measured, 1 , assumed, 2, average of all measured value for the land cover type. Data are from the sources listed in the References Cited section of this appendix]

\begin{tabular}{|c|c|c|c|c|c|c|c|c|c|c|c|c|c|c|c|}
\hline LC name & LC ID & ER_52 & Flag_52 & ER_53 & Flag_53 & ER_62 & Flag_62 & ER_71 & Flag_71 & ER_81 & Flag_81 & ER_82 & Flag_82 & ER_83 & Flag_83 \\
\hline Water & 1 & 0.080 & 0 & 0.825 & 2 & 0.825 & 2 & 1.581 & 0 & 0.880 & 0 & 0.880 & 0 & 3.430 & 0 \\
\hline Developed & 2 & 0.001 & 1 & 0.001 & 1 & 0.001 & 1 & 0.001 & 1 & 0.001 & 1 & 0.001 & 1 & 0.001 & 1 \\
\hline $\begin{array}{l}\text { Mechanically } \\
\text { disturbed, } \\
\text { national forest }\end{array}$ & 3 & 0.001 & 1 & 0.001 & 1 & 0.001 & 1 & 0.001 & 1 & 0.001 & 1 & 0.001 & 1 & 0.001 & 1 \\
\hline $\begin{array}{l}\text { Mechanically } \\
\text { disturbed, other } \\
\text { public lands }\end{array}$ & 4 & 0.001 & 1 & 0.001 & 1 & 0.001 & 1 & 0.001 & 1 & 0.001 & 1 & 0.001 & 1 & 0.001 & 1 \\
\hline Mining & 6 & 0.001 & 1 & 0.001 & 1 & 0.001 & 1 & 0.001 & 1 & 0.001 & 1 & 0.001 & 1 & 0.001 & 1 \\
\hline Barren & 7 & 0.484 & 2 & 0.484 & 2 & 0.484 & 2 & 0.484 & 2 & 0.484 & 2 & 0.484 & 2 & 0.484 & 2 \\
\hline Deciduous forest & 8 & 0.020 & 0 & 0.253 & 0 & 0.649 & 2 & 0.649 & 2 & 0.110 & 0 & 0.649 & 2 & 0.420 & 0 \\
\hline Agriculture & 13 & 1.300 & 2 & 1.300 & 2 & 1.300 & 2 & 1.300 & 2 & 1.300 & 2 & 1.300 & 2 & 1.300 & 2 \\
\hline Hay pasture & 14 & 0.813 & 2 & 0.813 & 2 & 0.813 & 2 & 0.813 & 2 & 0.813 & 2 & 0.813 & 2 & 0.813 & 2 \\
\hline $\begin{array}{c}\text { Herbaceous } \\
\text { wetland }\end{array}$ & 15 & 0.010 & 0 & 0.846 & 2 & 0.846 & 2 & 0.846 & 2 & 1.450 & 0 & 1.450 & 0 & 0.846 & 2 \\
\hline Woody wetland & 16 & 1.222 & 2 & 1.222 & 2 & 1.222 & 2 & 1.222 & 2 & 1.222 & 2 & 1.222 & 2 & 1.222 & 2 \\
\hline Perennial ice/snow & 17 & 0.001 & 1 & 0.001 & 1 & 0.001 & 1 & 0.001 & 1 & 0.001 & 1 & 0.001 & 1 & 0.001 & 1 \\
\hline Barley & 100 & 2.459 & 2 & 2.459 & 2 & 2.459 & 2 & 2.459 & 2 & 2.800 & 0 & 0.900 & 0 & 2.459 & 2 \\
\hline Beans & 101 & 1.310 & 2 & 1.310 & 2 & 1.310 & 2 & 1.310 & 2 & 1.310 & 2 & 1.310 & 2 & 1.310 & 2 \\
\hline Canola & 102 & 2.400 & 2 & 2.400 & 2 & 2.400 & 2 & 2.400 & 2 & 2.500 & 0 & 2.400 & 2 & 2.400 & 2 \\
\hline Corn grain & 103 & 2.680 & 2 & 2.680 & 2 & 2.680 & 2 & 2.680 & 2 & 1.873 & 0 & 5.111 & 0 & 2.680 & 2 \\
\hline Corn silage & 104 & 2.680 & 2 & 2.680 & 2 & 2.680 & 2 & 2.680 & 2 & 1.873 & 0 & 5.111 & 0 & 2.680 & 2 \\
\hline Peanuts & 112 & 6.200 & 1 & 6.200 & 1 & 6.200 & 1 & 6.200 & 1 & 6.200 & 1 & 6.200 & 1 & 6.200 & 1 \\
\hline Peas & 113 & 0.510 & 2 & 0.510 & 2 & 0.510 & 2 & 0.510 & 2 & 0.510 & 2 & 0.510 & 2 & 0.510 & 2 \\
\hline Potatoes & 114 & 3.095 & 2 & 3.095 & 2 & 3.095 & 2 & 3.095 & 2 & 3.095 & 2 & 3.095 & 2 & 3.095 & 2 \\
\hline Rice & 115 & 0.117 & 2 & 0.117 & 2 & 0.117 & 2 & 0.117 & 2 & 0.117 & 2 & 0.117 & 2 & 0.117 & 2 \\
\hline Rye & 116 & 0.038 & 2 & 0.038 & 2 & 0.038 & 2 & 0.038 & 2 & 0.038 & 2 & 0.038 & 2 & 0.038 & 2 \\
\hline Safflower & 117 & 1.200 & 2 & 1.200 & 2 & 1.200 & 2 & 1.200 & 2 & 1.200 & 2 & 1.200 & 2 & 1.200 & 2 \\
\hline Sorghum & 118 & 2.200 & 2 & 2.200 & 2 & 2.200 & 2 & 2.200 & 2 & 2.200 & 2 & 2.200 & 2 & 2.200 & 2 \\
\hline Soybeans & 119 & 1.981 & 2 & 1.981 & 2 & 1.981 & 2 & 1.981 & 2 & 1.070 & 0 & 1.981 & 2 & 1.981 & 2 \\
\hline Sugarbeets & 120 & 1.000 & 1 & 1.000 & 1 & 1.000 & 1 & 1.000 & 1 & 1.000 & 1 & 1.000 & 1 & 1.000 & 1 \\
\hline Sugarcane & 121 & 0.280 & 2 & 0.280 & 2 & 0.280 & 2 & 0.280 & 2 & 0.280 & 2 & 0.280 & 2 & 0.280 & 2 \\
\hline Sunflowers & 122 & 2.000 & 1 & 2.000 & 1 & 2.000 & 1 & 2.000 & 1 & 2.000 & 1 & 2.000 & 1 & 2.000 & 1 \\
\hline Sweet corn & 123 & 3.790 & 2 & 3.790 & 2 & 3.790 & 2 & 3.790 & 2 & 3.790 & 2 & 3.790 & 2 & 3.790 & 2 \\
\hline Tobacco & 124 & 2.258 & 2 & 2.258 & 2 & 2.258 & 2 & 2.258 & 2 & 2.258 & 2 & 2.258 & 0 & 2.258 & 2 \\
\hline Tomatoes & 125 & 7.375 & 2 & 7.375 & 2 & 7.375 & 2 & 7.375 & 2 & 7.375 & 2 & 0.750 & 0 & 7.375 & 2 \\
\hline Wheat durum & 126 & 2.011 & 2 & 2.011 & 2 & 2.011 & 2 & 2.011 & 2 & 2.265 & 0 & 2.011 & 2 & 2.011 & 2 \\
\hline Wheat, spring & 127 & 2.011 & 2 & 2.011 & 2 & 2.011 & 2 & 2.011 & 2 & 2.265 & 0 & 2.011 & 2 & 2.011 & 2 \\
\hline Wheat, winter & 128 & 2.011 & 2 & 2.011 & 2 & 2.011 & 2 & 2.011 & 2 & 2.265 & 0 & 2.011 & 2 & 2.011 & 2 \\
\hline
\end{tabular}


Table A6-1. $\quad \mathrm{N}_{2} \mathrm{O}$ emission factors by ecosystem and level II ecoregion.-Continued

[LC ID, land cover name and identification (U.S. Geological Survey Land Carbon Project designation for the purposes of the assessment). Values are in kilograms of nitrous oxide as nitrogen per hectare per year. Values in flag columns explain if mean is measured or surrogated: 0 , measured, 1 , assumed, 2, average of all measured value for the land cover type. Data are from the sources listed in the References Cited section of this appendix]

\begin{tabular}{|c|c|c|c|c|c|c|c|c|c|c|c|c|c|c|c|}
\hline ER_84 & Flag_84 & ER_85 & Flag_85 & ER_92 & Flag_92 & ER_93 & Flag_93 & ER_94 & Flag_94 & ER_101 & Flag_101 & ER_102 & Flag_102 & ER_111 & Flag_111 \\
\hline 3.430 & 2 & 0.022 & 0 & 2.370 & 0 & 0.850 & 0 & 0.825 & 2 & 0.825 & 2 & 0.825 & 2 & 0.825 & 2 \\
\hline 0.001 & 1 & 0.001 & 1 & 0.001 & 1 & 0.001 & 1 & 0.001 & 1 & 0.001 & 1 & 0.001 & 1 & 0.001 & 1 \\
\hline 0.001 & 1 & 0.001 & 1 & 0.001 & 1 & 0.001 & 1 & 0.001 & 1 & 0.001 & 1 & 0.001 & 1 & 0.001 & 1 \\
\hline
\end{tabular}

$\begin{array}{lllllllllllllllllll}0.001 & 1 & 0.001 & 1 & 0.001 & 1 & 0.001 & 1 & 0.001 & 1 & 0.001 & 1 & 0.001 & 1 & 0.001 & 1 \\ 0.001 & 1 & 0.001 & 1 & 0.001 & 1 & 0.001 & 1 & 0.001 & 1 & 0.001 & 1 & 0.001 & 1 & 0.001 & 1\end{array}$

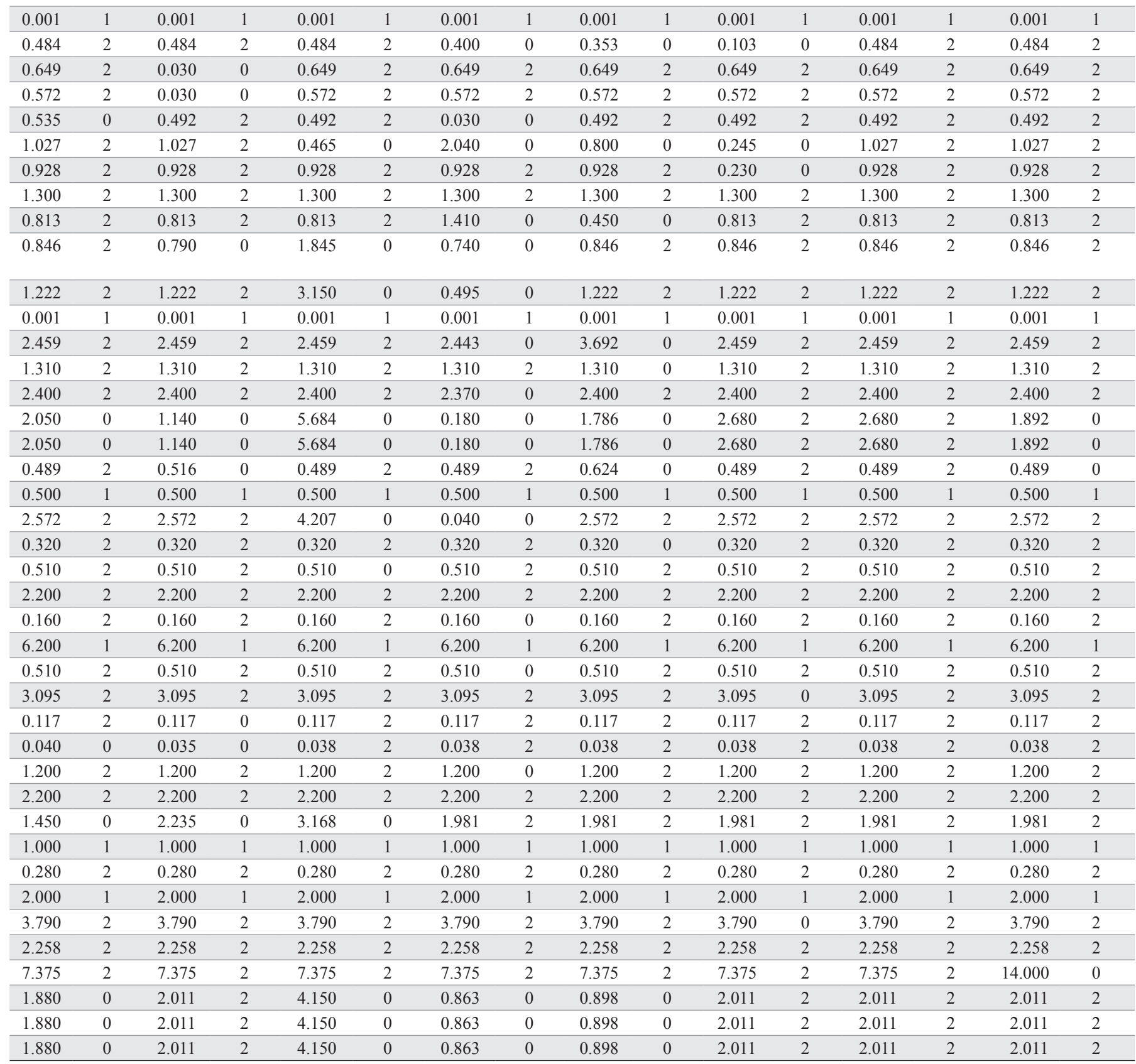


Table A6-2. $\quad \mathrm{CH}_{4}$ emission factors by ecosystem and level Il ecoregion.

[LC ID, land cover name and identification (U.S. Geological Survey Land Carbon Project designation for the purposes of the assessment). Values are in kilograms of nitrous oxide as nitrogen per hectare per year. Values in flag columns explain if mean is measured or surrogated: 0 , measured, 1, assumed, 2, average of all measured value for the land cover type. Data are from the sources listed in the References Cited section of this appendix]

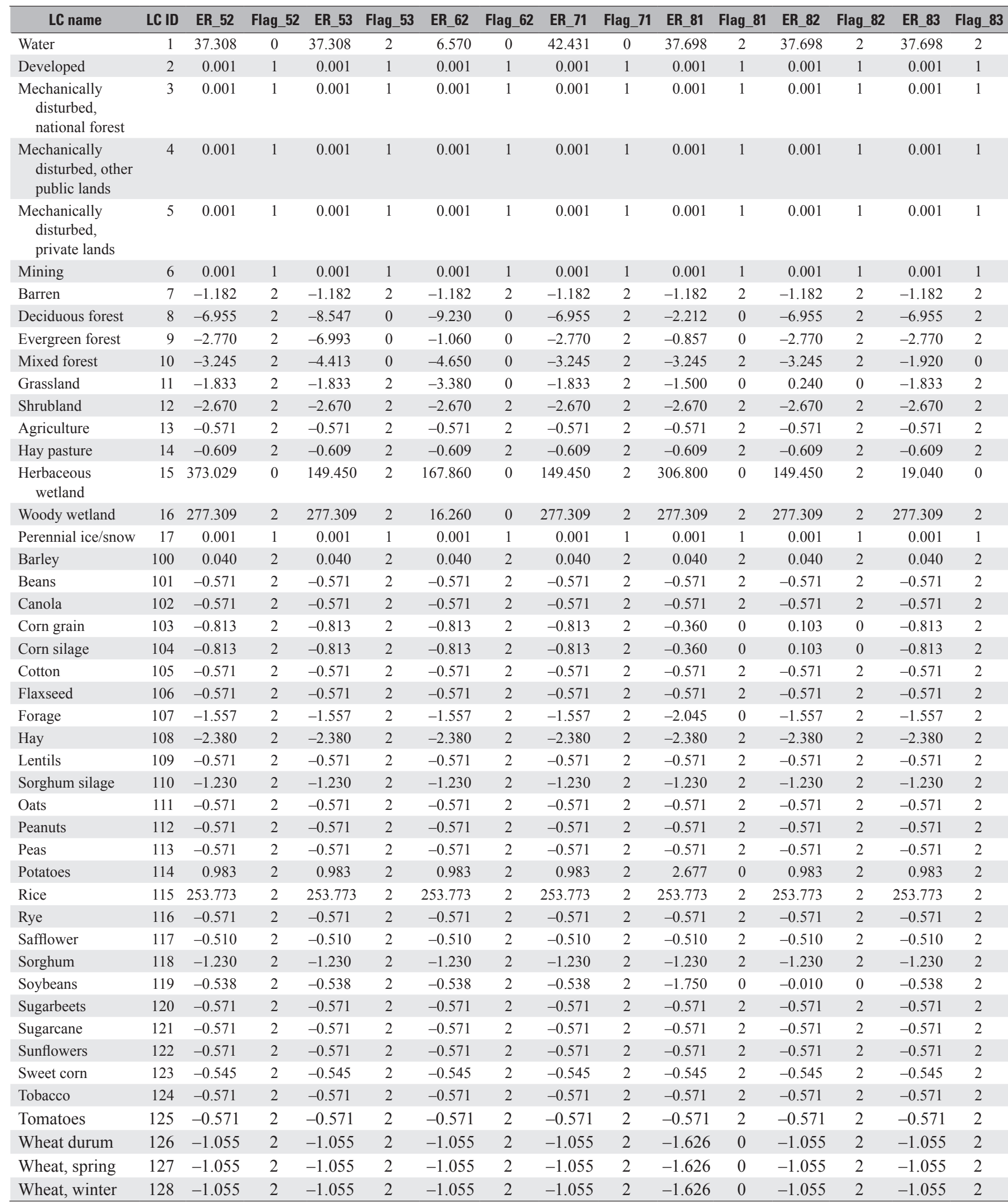


Table A6-2. $\quad \mathrm{CH}_{4}$ emission factors by ecosystem and level II ecoregion.-Continued

[LC ID, land cover name and identification (U.S. Geological Survey Land Carbon Project designation for the purposes of the assessment). Values are in kilograms of nitrous oxide as nitrogen per hectare per year. Values in flag columns explain if mean is measured or surrogated: 0 , measured, 1 , assumed, 2, average of all measured value for the land cover type. Data are from the sources listed in the References Cited section of this appendix]

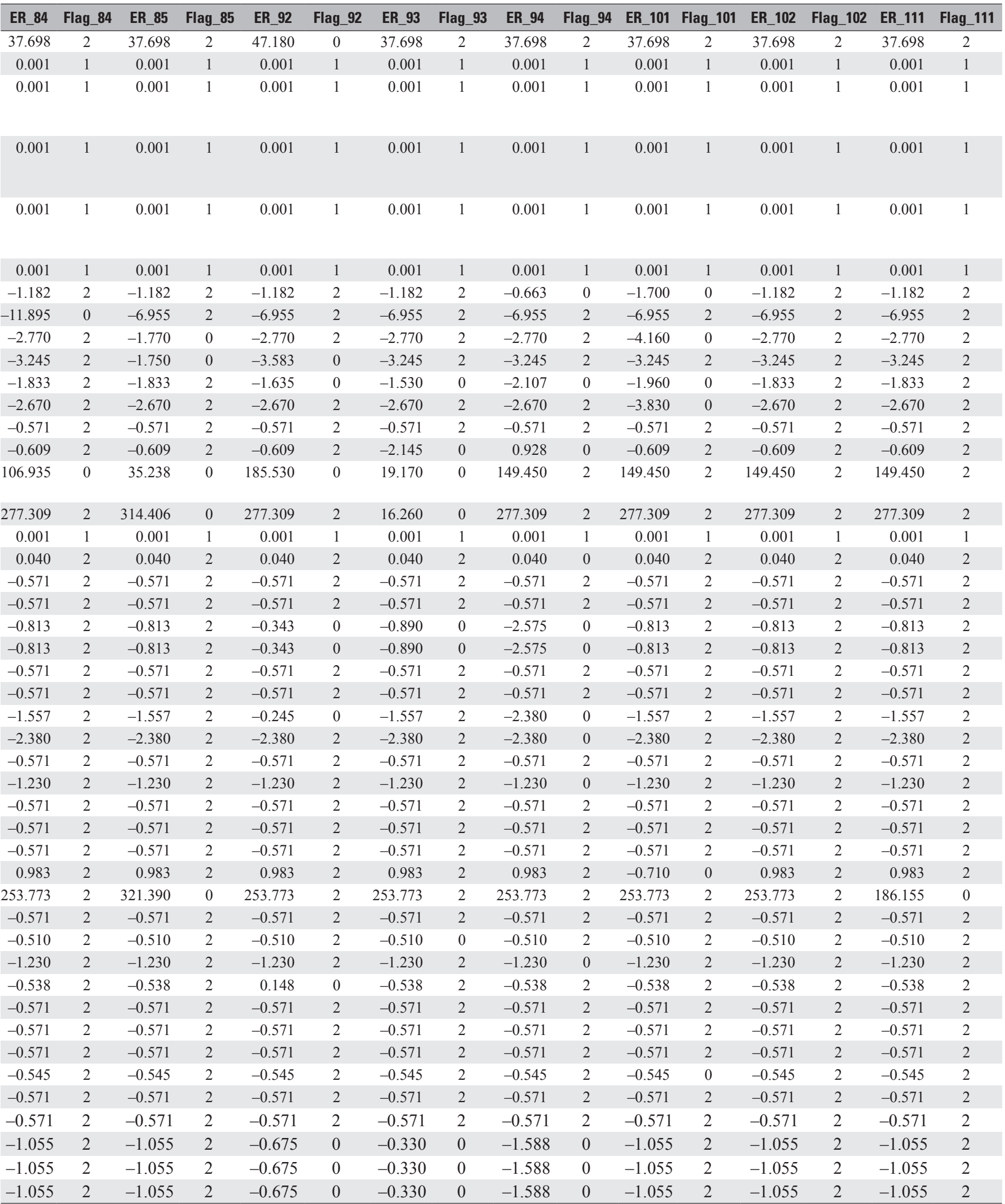




\section{Selected References}

Adviento-Borbe, M.A.A., Haddix, M.L., Binder, D.L., Walters, D.T., and Dobermann, A., 2007, Soil greenhouse gas fluxes and global warming potential in four highyielding maize systems: Global Change Biology, v. 13, no. 9, p. 1972-1988, accessed December 16, 2013, at http://dx.doi.org/10.1111/j.1365-2486.2007.01421.x.

Alford, D.P., DeLaune, R.D., and Lindau, C.W., 1997, Methane flux from Mississippi River deltaic plain wetlands: Biogeochemistry, v. 37, no. 3, p. 227-236. (Also available at http://dx.doi.org/10.1023/A:1005762023795.

Alluvione, Francesco, Halvorson, A.D., and Del Grosso, S.J., 2009, Nitrogen, tillage, and crop rotation effects on carbon dioxide and methane fluxes from irrigated cropping systems: Journal of Environmental Quality, v. 38, no. 5, p. 2023-2033. (Also available at http://dx.doi.org/10.2134/ jeq2008.0517.)

Altor, A.E., and Mitsch, W.J., 2006, Methane flux from created riparian marshes-Relationship to intermittent versus continuous inundation and emergent macrophytes: Ecological Engineering, v. 28, no. 3, p. 224-234, accessed December 16, 2013, at http://dx.doi.org/10.1016/j.ecoleng.2006.06.006.

Ambus, P., and Robertson, G.P., 2006, The effect of increased $\mathrm{N}$ deposition on nitrous oxide, methane and carbon dioxide fluxes from unmanaged forest and grassland communities in Michigan: Biogeochemistry, v. 79, no. 3, p. 315-337, accessed December 16, 2013, at http://dx.doi.org/10.1007/ s10533-005-5313-x.

Amos, Bridgit, Arkebauer, T.J., and Doran, J.W., 2005, Soil surface fluxes of greenhouse gases in an irrigated maizebased agroecosystem: Soil Science Society of America Journal, v. 69, no. 2, p. 387-395. (Also available at http://digitalcommons.unl.edu/cgi/viewcontent.cgi? article= 1314 \& context $=$ agronomyfacpub.)

Anderson, Brian, Bartlett, Karen, Frolking, Steven, Hayhoe, Katharine, Jenkins, Jennifer, and Salas, William, 2010, Methane and nitrous oxide emissions from natural sources: U.S. Environmental Protection Agency EPA 430-R-10001, [variously paged], accessed December 18, 2013, at http://www.epa.gov/outreach/pdfs/Methane-and-NitrousOxide-Emissions-From-Natural-Sources.pdf.

Badiou, Pascal, McDougal, Rhonda, Pennock, Dan, and Clark, Bob, 2011, Greenhouse gas emissions and carbon sequestration potential in restored wetlands of the Canadian prairie pothole region: Wetlands Ecology and Management, v. 19, no. 3, p. 237-256, accessed December 16, 2013, at http://dx.doi.org/10.1007/s11273-011-9214-6.

Bowden, R.D., Steudler, P.A., Melillo, J.M., and Aber, J.D., 1990, Annual nitrous oxide fluxes from temperate forest soils in the northeastern United States: Journal of Geophysical Research, v. 95, no. D9, p. 13997-14005. (Also available at http://dx.doi.org/10.1029/JD095iD09p13997.)
Bowden, R.D., Castro, M.S., Melillo, J.M., Steudler, P.A., and Aber, J.D., 1993, Fluxes of greenhouse gases between soils and the atmosphere in a temperate forest following a simulated hurricane blowdown: Biogeochemistry, v. 21, no. 2, p. 61-71. (Also available at http://dx.doi.org/10.1007/ BF00000871.)

Bowden, R.D., Rullo, G., Stevens, G.R., and Steudler, P.A., 2000, Soil fluxes of carbon dioxide, nitrous oxide, and methane at a productive temperate deciduous forest: Journal of Environment Quality, v. 29, no. 1, p. 268-276. (Also available at http://dx.doi.org/10.2134/ jeq2000.00472425002900010034x.)

Breitenbeck, G.A., Blackmer, A.M., and Bremner, J.M., 1980, Effects of different nitrogen fertilizers on emission of nitrous oxide from soil: Geophysical Research Letters, v. 7, no. 1, p. 85-88. (Also available at http://dx.doi.org/10.1029/ GL007i001p00085.)

Breitenbeck, G.A., and Bremner, J.M., 1986, Effects of rate and depth of fertilizer application on emission of nitrous oxide from soil fertilized with anhydrous ammonia: Biology and Fertility of Soils, v. 2, no. 4, p. 201-204. (Also available at http://dx.doi.org/10.1007/BF00260844.)

Bremer, D.J., 2006, Nitrous oxide fluxes in turfgrass: Journal of Environmental Quality, v. 35, no. 5, p. 1678-1685. (Also available at $h t t p: / / d x$. doi.org/10.2134/jeq2005.0387.)

Bremer, E., and van Kessel, C., 1990, Appraisal of the nitrogen-15 natural-abundance method for quantifying dinitrogen fixation: Soil Science Society of America Journal, v. 54, no. 2, p. 404-411. (Also available at http://dx.doi.org/10.2136/sssaj1990.036159950054000200 $18 x$.)

Bronson, K.F., Mosier, A.R., and Bishnoi, S.R., 1992, Nitrous oxide emissions in irrigated corn as affected by nitrification inhibitors: Soil Science Society of America Journal, v. 56, no. 1, p. 161-165. (Also available at http://dx.doi.org/10.2136/sssaj1992.036159950056000100 $25 x$.)

Castro, M.S., Steudler, P.A., Melillo, J.M., Aber, J.D., and Millham, Sarah, 1993, Exchange of $\mathrm{N}_{2} \mathrm{O}$ and $\mathrm{CH}_{4}$ between the atmosphere and soils in spruce-fir forests in the northeastern United States: Biogeochemistry, v. 18, no. 3, p. 119-135. (Also available at http://dx.doi.org/10.1007/ BF00003273.)

Castro, M.S., Peterjohn, W.T., Melillo, J.M., Steudler, P.A., Gholz, H.L., and Lewis, David, 1994, Effects of nitrogen fertilization on the fluxes of $\mathrm{N}_{2} \mathrm{O}, \mathrm{CH}_{4}$, and $\mathrm{CO}_{2}$ from soils in a Florida slash pine plantation: Canadian Journal of Forest Research, v. 24, no. 1, p. 9-13. (Also available at http://dx.doi.org/10.1139/x94-002.)

Castro, M.S., Steudler, P.A., and Melillo, J.M., Aber, J.D., and Bowden, R.D., 1995, Factors controlling atmospheric methane consumption by temperate forest soils: Global Biogeochemical Cycles, v. 9, no. 1, p. 1-10. (Also available at http://dx.doi.org/10.1029/94GB02651.) 
Castro, M.S., Gholz, H.L., Clark, K.L., and Steudler, P.A., 2000, Effects of forest harvesting on soil methane fluxes in Florida slash pine plantations: Canadian Journal of Forest Research, v. 30, no. 10, p. 1534-1542. (Also available at http://dx.doi.org/10.1139/x00-084.)

Cates, R.L., and Keeney, D.R., 1987, Nitrous oxide production throughout the year from fertilized and manured maize fields: Journal of Environmental Quality, v. 16, no. 4, p. 443-447. (Also available at http://dx.doi.org/10.2134/ jeq1987.00472425001600040026x.)

Chan, A.S.K., and Parkin, T.B., 2001, Methane oxidation and production activity in soils from natural and agricultural ecosystems: Journal of Environmental Quality, v. 30, no. 6, p. 1896-1903. (Also available at http://dx.doi.org/10.2134/ jeq2001.1896.)

Chang, C., Janzen, H.H., and Cho, C.M., 1998, Nitrous oxide emission from long-term manured soils: Soil Science Society of America Journal, v. 62, no. 3, p. 677-682. (Also available at http://dx.doi.org/10.2136/sssaj1998.036159950 06200030019x.)

Cochran, V.L., Elliott, L.F., and Papendick, R.I., 1981, Nitrous oxide emissions from a fallow field fertilized with anhydrous ammonia: Soil Science Society of America Journal, v. 45, no. 2, p. 307-310. (Also available at http://dx.doi.org/ 10.2136/sssaj1981.03615995004500020016x.)

Collins, H.P., Haile-Mariam, Shawel, Higgins, Stewart, Kruger, Chad, and Granatstein, David, 2008, Monitoring greenhouse gas fluxes from an irrigated agroecosystem: Sustaining the Pacific Northwest-Food, Farm, and Natural Resource Systems, v. 6, no. 2, p. 1-7, accessed December 16, 2013, at http://csanr.wsu.edu/publications/SPNW/ SPNW-v6-n2.pdf.

Corre, M.D., Pennock, D.J., Van Kessel, Chris, and Elliott, D.K., 1999, Estimation of annual nitrous oxide emissions from a transitional grassland-forest region in Saskatchewan, Canada: Biogeochemistry, v. 44, no. 1, p. 29-49. (Also available at $h$ ttp://dx.doi.org/10.1007/BF00992997.)

Crill, P.M., 1991, Seasonal patterns of methane uptake and carbon dioxide release by a temperate woodland soil: Global Biogeochemical Cycles, v. 5, no. 4, p. 319-334. (Also available at $h t t p: / / d x . d o i . o r g / 10.1029 / 91 G B 02466$.

de Angelis, M.A., and Gordon, L.I., 1985, Upwelling and river runoff as sources of dissolved nitrous oxide to the Alsea estuary, Oregon: Estuarine, Coastal and Shelf Science, v. 20, no. 4, p. 375-386. (Also available at http://dx.doi.org/10.1016/0272-7714(85)90082-4.)

de Angelis, M.A., and Lilley, M.D., 1987, Methane in surface waters of Oregon estuaries and rivers: Limnology and Oceanography, v. 32, no. 3, p. 716-722. (Also available at http://aslo.org/lo/toc/vol_32/issue_3/0716.pdf.)

DeLaune, R.D., Smith, C.J., and Patrick, W.H., Jr., 1983, Methane release from gulf coast wetlands:
Tellus, v. 35B, no. 1, p. 8-15. (Also available at http://dx.doi.org/10.1111/j.1600-0889.1983.tb00002.x.)

DeLaune, R.D., Feijtel, T.C., and Patrick, W.H., Jr., 1989, Nitrogen flows in Louisiana Gulf Coast salt marsh-Spatial considerations: Biogeochemistry, v. 8, no. 1, p. 25-37. (Also available at $h t t p: / / d x . d o i . o r g / 10.1007 / B F 02180165$.

DeLaune, R.D., Lindau, C.W., Sulaeman, E., and Jugsujinda, A., 1998, Nitrification and denitrification estimates in a Louisiana swamp forest soil as assessed by ${ }^{15} \mathrm{~N}$ isotope dilution and direct gaseous measurements: Water, Air, and Soil Pollution, v. 106, nos. 1-2, p. 149-161. (Also available at http://dx.doi.org/10.1023/A:1004953626415.)

DeLaune, R.D., and Pezeshki, S.R., 2003, The role of soil organic carbon in maintaining surface elevation in rapidly subsiding U.S. Gulf of Mexico coastal marshes: Water, Air, and Soil Pollution: Focus, v. 3, no. 1, p. 167-179. (Also available at $h t t p: / / d x$.doi.org/10.1023/A:1022136328105.)

Delgado, J.A., and Mosier, A.R., 1996, Mitigation alternatives to decrease nitrous oxides emissions and ureanitrogen loss and their effect on methane flux: Journal of Environmental Quality, v. 25, no. 5, p. 1105-1111. (Also available at $h t t p: / / d x . d o i . o r g / 10.2134 /$ jeq1996.00472425002500050025x.)

Dubbs, L.L., and Whalen, S.C., 2010, Reduced net atmospheric $\mathrm{CH}_{4}$ consumption is a sustained response to elevated $\mathrm{CO}_{2}$ in a temperate forest: Biology and Fertility of Soils, v. 46, no. 6, p. 597-606. (Also available at http://dx.doi.org/10.1007/s00374-010-0467-7.)

Duxbury, J.M., Bouldin, D.R., Terry, R.E., and Tate, R.L., III, 1982, Emissions of nitrous oxide from soils: Nature, v. 298, no. 5873, p. 462-464. (Also available at http://dx.doi.org/10.1038/298462a0.).

Erickson, Heather, and Perakis, Steve, 2010, Methane, nitrous oxide, and nitric oxide fluxes from douglas-fir forests in the Oregon coast range: Corvallis, Oregon, Oregon Climate Change Research Institute presentation, 18 p., accessed July 26, 2013, at http://occri.net/wp-content/ uploads/2010/09/0955-Tue-Erickson.pdf.

Galbally, I.E., Kirstine, W.V., Meyer, C.P., and Wang, Y.P., 2008, Soil-atmosphere trace gas exchange in semiarid and arid zones: Journal of Environment Quality, v. 37, no. 2, p. 599-607, accessed December 16, 2013, at http://dx.doi. org/10.2134/jeq2006.0445.

Ginting, Daniel, and Eghball, Bahman, 2005, Nitrous oxide emission from no-till irrigated corn: Soil Science Society of America Journal, v. 69, no. 3, p. 915-924, accessed December 16, 2013, at http://dx.doi.org/10.2136/sssaj2004.0292.

Gleason, R.A., Tangen, B.A., Browne, B.A., and Euliss, N.H., Jr., 2009, Greenhouse gas flux from cropland and restored wetlands in the prairie pothole region: Soil Biology and Biochemistry, v. 41, no. 12, p. 2501-2507, accessed December 16, 2013, at http://dx.doi.org/10.1016/j.soilbio.2009.09.008. 
Goodroad, L.L., and Keeney, D.R., 1984, Nitrous oxide emission from forest, marsh, and prairie ecosystems: Journal of Environmental Quality, v. 13, no. 3, p. 448-452. (Also available at $h t t p: / / d x$. doi.org/10.2134/ jeq1984.00472425001300030024x.)

Goodroad, L.L., Keeney, D.R., and Peterson, L.A., 1984, Nitrous oxide emissions from agricultural soils in Wisconsin: Journal of Environmental Quality, v. 13, no. 4, p. 557-561. (Also available at $h t t p: / / d x$. doi.org/10.2134/ jeq1984.00472425001300040010x.)

Goodwin, Justin, Woodfield, Mike, Ibnoaf, Mirghani, Koch, Matthias, and Yan, Hong, 2006, Approaches to data collection, chap. 2 of Eggleston, Simon, Buendia, Leandro, Miwa, Kyoto, Ngara, Todd, and Tanabe, Kiyoto, eds., General guidance and reporting: Intergovernmental Panel on Climate Change 2006 IPCC Guidelines for National Greenhouse Gas Inventories, v. 1, p. 2.1-2.24, accessed December 16, 2013, at http://www.ipcc-nggip.iges.or.jp/public/2006gl/ voll.html.

Grandy, A.S., Loecke, T.D., Parr, Sara, and Robertson, G.P., 2006, Long-term trends in nitrous oxide emissions, soil nitrogen, and crop yields of till and no-till cropping systems: Journal of Environmental Quality, v. 35, no. 4, p. 1487-1495. (Also available at $h t t p: / / d x . d o i . o r g / 10.2134 /$ jeq2005.0166.)

Groffman, P.M., and Turner, C.L., 1995, Plant productivity and nitrogen gas fluxes in a tallgrass prairie landscape: Landscape Ecology, v. 10, no. 5, p. 255-266. (Also available at $h t t p: / / d x$.doi.org/10.1007/BF00128993.)

Guilbault, M.R., and Matthias, A.D., 1998, Emissions of $\mathrm{N}_{2} \mathrm{O}$ from Sonoran Desert and effluent-irrigated grass ecosystems: Journal of Arid Environments, v. 38, no. 1, p. 87-98. (Also available at $h t t p: / / d x$.doi.org/10.1006/ jare.1997.0300.)

Halvorson, A.D., Del Grosso, S.J., and Reule, C.A., 2008, Nitrogen, tillage, and crop rotation effects on nitrous oxide emissions from irrigated cropping systems: Journal of Environmental Quality, v. 37, no. 4, p. 1337-1344. (Also available at $h t t p: / / d x$.doi.org/10.2134/jeq2007.0268.)

Hernandez-Ramirez, Guillermo, Brouder, S.M., Smith, D.R., and Van Scoyoc, G.E., 2009, Greenhouse gas fluxes in an eastern Corn Belt soil-Weather, nitrogen source, and rotation: Journal of Environmental Quality, v. 38, no. 3, p. 841-854. (Also available at $h t t p: / / d x . d o i . o r g / 10.2134 /$ jeq2007.0565.)

Hernandez, M.E., and Mitsch, W.J., 2006, Influence of hydrologic pulses, flooding frequency, and vegetation on nitrous oxide emissions from created riparian marshes: Wetlands, v. 26, no. 3, p. 862-877. (Also available at http://dx.doi.org/10.1672/0277-5212(2006)26[862:IOHPF F]2.0.CO;2.).

Hopfensperger, K.N., Gault, C.M., and Groffman, P.M., 2009, Influence of plant communities and soil proper- ties on trace gas fluxes in riparian northern hardwood forests: Forest Ecology and Management, v. 258, no. 9, p. 2076-2082, accessed December 16, 2013, at http://dx.doi.org/10.1016/j.foreco.2009.08.004.

Hutchinson, G.L., and Brams, E.A., 1992, NO versus $\mathrm{N}_{2} \mathrm{O}$ emissions from an $\mathrm{NH}_{4}^{+}$-amended Bermuda grass pasture: Journal of Geophysical Research: Atmospheres, v. 97, no. D9, p. 9889-9896. (Also available at http://dx.doi.org/10.1029/92JD00713.)

Hutchinson, G.L., and Mosier, A.R., 1979, Nitrous oxide emissions from an irrigated cornfield: Science, v. 205, no. 4411, p. 1125-1127. (Also available at $h t t p: / / d x$.doi.org/10.1126/ science.205.4411.1125.)

Hyatt, C.R., Venterea, R.T., Rosen, C.J., McNearney, Matthew, Wilson, M.L., and Dolan, M.S., 2010, Polymer-coated urea maintains potato yields and reduces nitrous oxide emissions in a Minnesota loamy sand: Soil Science Society of America Journal, v. 74, no. 2, p. 419-428, accessed December 16, 2013, at $h t t p: / / d x$.doi.org/10.2136/sssaj2009.0126.

Jacinthe, P.A., and Dick, W.A., 1997, Soil management and nitrous oxide emissions from cultivated fields in southern Ohio: Soil and Tillage Research, v. 41, nos. 3-4, p. 221235. (Also available at $h t t p: / / d x . d o i . o r g / 10.1016 / S 0167-$ 1987(96)01094-X.)

Johnson, J.M.F., Archer, David, and Barbour, Nancy, 2010, Greenhouse gas emission from contrasting management scenarios in the northern Corn Belt: Soil Science Society of America Journal, v. 74, no. 2, p. 396-406, accessed December 16, 2013, at http://dx.doi.org/10.2136/sssaj2009.0008.

Kaye, J.P., Burke, I.C., Mosier, A.R., and Guerschman, J.P., 2004, Methane and nitrous oxide fluxes from urban soils to the atmosphere: Ecological Applications, v. 14, no. 4, p. 975-981. (Also available at http://dx.doi.org/10.1890/03-5115.)

Kessavalou, Anabayan, Doran, J.W., Mosier, A.R., and Drijber, R.A., 1998a, Greenhouse gas fluxes following tillage and wetting in a wheat-fallow cropping system: Journal of Environment Quality, v. 27, no. 5, p. 1105-1116. (Also available at http://naldc.nal.usda.gov/download/16845/ $P D F$.)

Kessavalou, Anabayan, Mosier, A.R., Doran, J.W., Drijber, R.A., Lyon, D.J., and Heinemeyer, O., 1998b, Fluxes of carbon dioxide, nitrous oxide, and methane in grass sod and winter wheat-fallow tillage management: Journal of Environment Quality, v. 27, no. 5, p. 1094-1104. (Also available at http://dx.doi.org/10.2134/ jeq1998.00472425002700050015x.)

Kim, D.G., Isenhart, T.M., Parkin, T.B., Schultz, R.C., Loynachan, T.E., and Raich, J.W., 2009, Nitrous oxide emissions from riparian forest buffers, warm-season and cool-season grass filters, and crop fields: Biogeosciences Discussions, v. 6, no. 1, p. 607-650. (Also available at http://dx.doi.org/10.5194/bgd-6-607-2009.) 
Koh, H.S., Ochs, C.A., and Yu, Kewei, 2009, Hydrologic gradient and vegetation controls on $\mathrm{CH}_{4}$ and $\mathrm{CO}_{2}$ fluxes in a spring-fed forested wetland: Hydrobiologia, v. 630, no. 1, p. 271-286. (Also available at $h t t p: / / d x$.doi.org/10.1007/ s10750-009-9821-x.)

Kong, A.Y.Y., Fonte, S.J., van Kessel, Chris, and Six, Johan, 2009, Transitioning from standard to minimum tillageTrade-offs between soil organic matter stabilization, nitrous oxide emissions, and $\mathrm{N}$ availability in irrigated cropping systems: Soil and Tillage Research, v. 104, no. 2, p. 256-262, accessed December 16, 2013, at http://dx.doi.org/10.1016/j.still.2009.03.004.

Lee, Juhwan, Hopmans, J.W., van Kessel, Chris, King, A.P., Evatt, K.J., Louie, Dianne, Rolston, D.E., and Six, Johan, 2009, Tillage and seasonal emissions of $\mathrm{CO}_{2}$, $\mathrm{N}_{2} \mathrm{O}$ and $\mathrm{NO}$ across a seed bed and at the field scale in a Mediterranean climate: Agriculture, Ecosystems, and Environment, v. 129, no. 4, p. 378-390. (Also available at http://dx.doi.org/10.1016/j.agee.2008.10.012.)

Li, Changsheng, Frolking, S.E., Harriss, R.C., and Terry, R.E., 1994, Modeling nitrous oxide emissions from agricultureA Florida case study: Chemosphere, v. 28, no. 7, p. 14011415. (Also available at $h t t p: / / d x$.doi.org/10.1016/00456535(94)90081-7.)

Liebig, M.A., Gross, J.R., Kronberg, S.L., and Phillips, R.L., 2010a, Grazing management contributions to net global warming potential - A long-term evaluation in the northern Great Plains: Journal of Environmental Quality, v. 39, no. 3, p. 799-809. (Also available at $h t t p: / / d x . d o i . o r g / 10.2134 /$ jeq2009.0272.)

Liebig, M.A., Tanaka, D.L., and Gross, J.R., 2010b, Fallow effects on soil carbon and greenhouse gas flux in central North Dakota: Soil Science Society of America Journal, v. 74 , no. 2, p. 358-365, accessed December 16, 2013, at http://dx.doi.org/10.2136/sssaj2008.0368.

Lindau, C.W., DeLaune, R.D., and Jones, G.L., 1988, Fate of added nitrate and ammonium-nitrogen entering a Louisiana gulf coast swamp forest: Water Pollution Control Federation Journal, v. 60, no. 3, p. 386-390. (Also available at http://www.jstor.org/stable/25043507.)

Lindau, C.W., DeLaune, R.D., Patrick, W.H., and Bollich, P.K., 1990a, Fertilizer effects on dinitrogen, nitrous oxide, and methane emissions from lowland rice: Soil Science Society of America Journal, v. 54, no. 6, p. 1789-1794. (Also available at $h t t p: / / d x$.doi.org/10.2136/sssaj1990.0361 5995005400060048x.)

Lindau, C.W., Patrick, W.H., Jr., DeLaune, R.D., and Reddy, K.R., 1990b, Rate of accumulation and emission of $\mathrm{N}_{2}, \mathrm{~N}_{2} \mathrm{O}$ and $\mathrm{CH}_{4}$ from a flooded rice soil: Plant and Soil, v. 129, no. 2, p. 269-276. (Also available at http://link.springer.com/article/10.1007/BF00032422.)

Lindau, C.W., Bollich, P.K., DeLaune, R.D., Patrick, W.H., Jr., and Law, V.J., 1991, Effect of urea fertilizer and environ- mental factors on $\mathrm{CH}_{4}$ emissions from a Louisiana, USA rice field: Plant and Soil, v. 136, no. 2, p. 195-203. (Also available at $h t t p: / / d x$.doi.org/10.1007/BF02150050.)

Lindau, C.W., Bollich, P.K., DeLaune, R.D., Mosier, A.R., and Bronson, K.F., 1993, Methane mitigation in flooded Louisiana rice fields: Biology and Fertility of Soils, v. 15, no. 3 , p. 174-178. (Also available at $h t t p: / / d x . d o i . o r g / 10.1007 /$ BF00361607.)

Lindau, C.W., Bollich, P.K., and DeLaune, R.D., 1995, Effect of rice variety on methane emission from Louisiana rice: Agriculture, Ecosystems, and Environment, v. 54, nos. 1-2, p. 109-114. (Also available at http://dx.doi.org/10.1016/0167-8809(95)00587-I.)

Lindau, C.W., Wickersham, P., DeLaune, R.D., Collins, J.W., Bollick, P.K., Scott, L.M., and Lambremont, E.N., 1998, Methane and nitrous oxide evolution and ${ }^{15} \mathrm{~N}$ and ${ }^{226} \mathrm{Ra}$ uptake as affected by application of gypsum and phosphogypsum to Louisiana rice: Agriculture, Ecosystems, and Environment, v. 68, nos. 1-2, p. 165-173. (Also available at http://dx.doi.org/10.1016/S0167-8809(97)00154-0.)

Lowrance, Richard, Vellidis, George, and Hubbard, R.K., 1995, Denitrification in a restored riparian forest wetland: Journal of Environmental Quality, v. 24, no. 5, p. 808-815. (Also available at $h t t p: / / d x . d o i . o r g / 10.2134 /$ jeq1995.00472425002400050003x.)

Martens, D.A., Emmerich, William, McLain, J.E.T., and Johnsen, T.N., 2005, Atmospheric carbon mitigation potential of agricultural management in the southwestern USA: Soil and Tillage Research, v. 83, no. 1, p. 95-119, accessed December 16, 2013, at http://dx.doi.org/10.1016/j.still.2005.02.011.

Mast, M.A., Wickland, K.P., Striegl, R.T., and Clow, D.W., 1998, Winter fluxes of $\mathrm{CO}_{2}$ and $\mathrm{CH}_{4}$ from subalpine soils in Rocky Mountain National Park, Colorado: Global Biogeochemical Cycles, v. 12, no. 4, p. 607-620. (Also available at http://dx.doi.org/10.1029/98GB02313.)

Matson, P.A., Gower, S.T., Volkmann, Carol, Billow, Christine, and Grier, C.C., 1992, Soil nitrogen cycling and nitrous oxide flux in a Rocky Mountain douglas-fir forest-Effects of fertilization, irrigation and carbon addition: Biogeochemistry, v. 18 , no. 2, p. 101-117. (Also available at http://dx.doi.org/10.1007/BF00002705.)

McLain, J.E.T., and Martens, D.A., 2006, $\mathrm{N}_{2} \mathrm{O}$ production by heterotrophic $\mathrm{N}$ transformations in a semiarid soil: Applied Soil Ecology, v. 32, no. 2, p. 253-263, accessed December 16, 2013, at http://dx.doi.org/10.1016/j.apsoil.2005.06.005.

Mosier, A.R., and Hutchinson, G.L., 1981, Nitrous oxide emissions from cropped fields: Journal of Environmental Quality, v. 10, no. 2, p. 169-173. (Also available at $h t t p: / / d x$.doi.org/10.2134/ jeq1981.00472425001000020009x.)

Mosier, A.R., Hutchinson, G.L., Sabey, B.R., and Baxter, J., 1982, Nitrous oxide emissions from barley plots treated with ammonium nitrate or sewage 
sludge: Journal of Environmental Quality, v. 11, no. 1, p. 78-81. (Also available at $h t t p: / / d x$.doi.org/10.2134/ jeq1982.00472425001100010019x.)

Mosier, A.R., Parton, W.J., Valentine, D.W., Ojima, D.S., Schimel, D.S., and Heinemeyer, O., 1997a, $\mathrm{CH}_{4}$ and $\mathrm{N}_{2} \mathrm{O}$ fluxes in the Colorado shortgrass steppe; 2. Longterm impact of land use change: Global Biogeochemical Cycles, v. 11, no. 1, p. 29-42. (Also available at http://dx.doi.org/10.1029/96GB03612.)

Mosier, A.R., Delgado, J.A., Cochran, V.L., Valentine, D.W., and Parton, W.J., 1997b, Impact of agriculture on soil consumption of atmospheric $\mathrm{CH}_{4}$ and a comparison of $\mathrm{CH}_{4}$ and $\mathrm{N}_{2} \mathrm{O}$ flux in subarctic, temperate and tropical grasslands: Nutrient Cycling in Agroecosystems, v. 49, nos. 1-3, p. 71-83. (Also available at $h t t p: / / d x$.doi.org/ 10.1023/A:1009754207548.

Mosier, A.R., Peterson, G.A., and Sherrod, L.A., 2003, Mitigating net global warming potential $\left(\mathrm{CO}_{2}, \mathrm{CH}_{4}\right.$ and $\left.\mathrm{N}_{2} \mathrm{O}\right)$ in upland crop production: International Methane and Nitrous Oxide Mitigation Conference, 3, Beijing, China, September 14-19, 2003, paper, 8 p., accessed December 18, 2013, at http://www.coalinfo.net.cn/coalbed/meeting/2203/papers/ agriculture/AG005.pdf.

Mummey, D.L., Smith, J.L., and Bolton, H., Jr., 1994, Nitrous oxide flux from a shrub-steppe ecosystem-Sources and regulation: Soil Biology and Biochemistry, v. 26, no. 2, p. 279-286. (Also available at http://dx.doi.org/10.1016/0038-0717(94)90168-6.)

Mummey, D.L., Smith, J.L., and Bolton, Harvey, Jr., 1997, Small-scale spatial and temporal variability of $\mathrm{N}_{2} \mathrm{O}$ flux from a shrub-steppe ecosystem: Soil Biology and Biochemistry, v. 29, nos. 11-12, p. 1699-1706. (Also available at http://dx.doi.org/10.1016/S0038-0717(97)00077-1.)

Neff, J.C., Bowman, W.D., Holland, E.A., Fisk, M.C., and Schmidt, S.K., 1994, Fluxes of nitrous oxide and methane from nitrogen-amended soils in a Colorado alpine ecosystem: Biogeochemistry, v. 27, no. 1, p. 23-33. (Also available at $h t t p: / / d x$.doi.org/10.1007/BF00002569.)

Omonode, R.A., Vyn, T.J., Smith, D.R., Hegymegi, Péter, and Gál, Anita, 2007, Soil carbon dioxide and methane fluxes from long-term tillage systems in continuous corn and corn-soybean rotations: Soil and Tillage Research, v. 95, nos. 1-2, p. 182-195. (Also available at http://dx.doi.org/10.1016/j.still.2006.12.004.)

Parkin, T.B., and Kaspar, T.C., 2006, Nitrous oxide emissions from corn-soybean systems in the Midwest: Journal of Environmental Quality, v. 35, no. 4, p. 1496-1506. (Also available at $h t t p: / / d x$.doi.org/10.2134/jeq2005.0183.)

Parton, W.J., Mosier, A.R., and Schimel, D.S., 1988, Rates and pathways of nitrous oxide production in a shortgrass steppe: Biogeochemistry, v. 6, no. 1, p. 45-58. (Also available at http://dx.doi.org/10.1007/BF00002932.)
Pearson, Timothy, Grimland, Sean, and Brown, Sandra, 2010, A spatial analysis of greenhouse gas emissions from agricultural fertilizer usage in the US: Arlington, Va., Winrock International, David and Lucile Packard Foundation Grant \#2008-32689, 38 p., accessed December 18, 2013, at http://americancarbonregistry.org/carbon-accounting/ emissions-reductions-through-changes-in-fertilizermanagement/Spatial\%20analysis\%20of\%20GHG\%20 emissions $\% 20$ from\%20agricultural\%20fertilizer $\% 20$ usage\%20in\%20the\%20US\%20-April\%202010.pdf.

Pennock, Dan, Yates, Thomas, Bedard-Haughn, Angela, Phipps, Kim, Farrell, Richard, and McDougal, Rhonda, 2010, Landscape controls on $\mathrm{N}_{2} \mathrm{O}$ and $\mathrm{CH} 4$ emissions from freshwater mineral soil wetlands of the Canadian Prairie Pothole region: Geoderma, v. 155, nos. 3-4, p. 308-319, accessed December 16, 2013, at http://dx.doi. org/10.1016/j.geoderma.2009.12.015.

Peterjohn, W.T., McGervey, R.J., Sexstone, A.J., Christ, M.J., Foster, C.J., and Adams, M.B., 1998, Nitrous oxide production in two forested watersheds exhibiting symptoms of nitrogen saturation: Canadian Journal of Forest Research, v. 28, no. 11, p. 1723-1732. (Also available at http://dx.doi.org/10.1139/cjfr-28-11-1723.)

Phillips, R.L., Whalen, S.C., and Schlesinger, W.H., 2001, Influence of atmospheric $\mathrm{CO}_{2}$ enrichment on nitrous oxide flux in a temperate forest ecosystem: Global Biogeochemical Cycles, v. 15, no. 3, p. 741-752. (Also available at http://dx.doi.org/10.1029/2000GB001372.)

Phillips, Rebecca, and Beeri, Ofer, 2008, The role of hydropedologic vegetation zones in greenhouse gas emissions for agricultural wetland landscapes: Catena, v. 72, no. 3, p. 386-394. (Also available at http://dx.doi.org/10.1016/j.catena.2007.07.007.)

Phillips, R.L., Tanaka, D.L., Archer, D.W., and Hanson, J.D., 2009, Fertilizer application timing influences greenhouse gas fluxes over a growing season: Journal of Environmental Quality, v. 38, no. 4, p. 1569-1579. (Also available at http://dx.doi.org/10.2134/jeq2008.0483.)

Pulliam, W.M., 1993, Carbon dioxide and methane exports from a southeastern floodplain swamp: Ecological Monographs, v. 63, no. 1, p. 29-53. (Also available at http://dx.doi.org/10.2307/2937122.)

Redeker, K.R., Wang, N.-Y., Low, J.C., McMillan, A., Tyler, S.C., and Cicerone, R.J., 2000, Emissions of methyl halides and methane from rice paddies: Science, v. 290, no. 5493, p. 966-969. (Also available at $h t t p: / / d x . d o i . o r g / 10.1126 /$ science.290.5493.966.)

Riera, J.L., Schindler, J.E., and Kratz, T.K., 1999, Seasonal dynamics of carbon dioxide and methane in two clear-water lakes and two bog lakes in northern Wisconsin, U.S.A.: Canadian Journal of Fisheries and Aquatic Sciences, v. 56, no. 2, p. 265-274. (Also available at http://dx.doi.org/10.1139/f98-182.) 
Robertson, G.P., Paul, E.A., and Harwood, R.R., 2000, Greenhouse gases in intensive agriculture-Contributions of individual gases to the radiative forcing of the atmosphere: Science, v. 289, no. 5486, p. 1922-1925, accessed December 16, 2013, at http://dx.doi.org/10.1126/ science.289.5486.1922.

Rochette, Philippe, Worth, D.E., Lemke, R.L., McConkey, B.G., Pennock, D.J., Wagner-Riddle, Claudia, and Desjardins, R.L., 2008, Estimation of $\mathrm{N}_{2} \mathrm{O}$ emissions from agricultural soils in Canada; I. Development of a country-specific methodology: Canadian Journal of Soil Science, v. 88, no. 5, p. 641-654. (Also available at http://dx.doi.org/10.4141/ CJSS07025.)

Ryden, J.C., and Lund, L.J., 1980, Nature and extent of directly measured denitrification losses from some irrigated vegetable crop production units: Soil Science Society of America Journal, v. 44, no. 3, p. 505-511. (Also available at http://dx.doi.org/10.2136/sssaj1980.0361599500440003 0013x.)

Sainju, U.M., 2010, Management practices impact on soil nitrous oxide emission in the northern Great Plains, USA: World Congress of Soil Science, Soil Solutions for a Changing World, 19, Brisbane, Australia, August 1-6, 2010, proceedings, p. 140-143, accessed December 18, 2013, at http://www.iuss.org/19th WCSS/Symposium/pdf/1779.pdf.)

Sauer, T.J., Compston, S.R., West, C.P., Hernandez-Ramirez, Guillermo, Gbur, E.E., and Parkin, T.B., 2009, Nitrous oxide emissions from a bermudagrass pasture-Interseeded winter rye and poultry litter: Soil Biology and Biochemistry, v. 41, no. 7, p. 1417-1424. (Also available at http://dx.doi.org/10.1016/j.soilbio.2009.03.019.)

Smith, C.J., DeLaune, R.D., and Patrick, W.H., Jr., 1983, Nitrous oxide emission from Gulf Coast wetlands: Geochimica et Cosmochimica Acta, v. 47, no. 10, p. 1805-1814. (Also available at http://dx.doi.org/10.1016/00167037(83)90028-5.)

Smith, Pete, Martino, Daniel, Cai, Zucong, Gwary, Daniel, Janzen, Henry, Kumar, Pushpam, McCarl, Bruce, Ogle, Stephen, O’Mara, Frank, Rice, Charles, Scholes, Bob, and Sirotenko, Oleg, 2007, Agriculture, chap. 8 of Metz, Bert, Davidson, Ogunlade, Bosch, Peter, Dave, Rutu, and Meyer, Leo, eds., Climate change 2007-Mitigation of climate change, Contribution of Working Group III to the Fourth Assessment Report of the Intergovernmental Panel on Climate Change: Cambridge, United Kingdom, and New York, Cambridge University Press, p. 497-540. (Also available at http://www.ipcc.ch/publications_and_data/publications_ ipcc_fourth_assessment_report_wg 3 _report_mitigation_of climate_change.htm.)

Striegl, R.G., McConnaughey, T.A., Thorstenson, D.C., Weeks, E.P., and Woodward, J.C., 1992, Consumption of atmospheric methane by desert soils: Nature, v. 357, no. 6374, p. 145-147. (Also available at http://dx.doi.org/10.1038/357145a0.)
Sullivan, B.W., Kolb, T.E., Hart, S.C., Kaye, J.P., Dore, S., and Montes-Helu, M., 2008, Thinning reduces soil carbon dioxide but not methane flux from southwestern USA ponderosa pine forests: Forest Ecology and Management, v. 255, no. 12, p. 4047-4055. (Also available at http://dx.doi.org/10.1016/j.foreco.2008.03.051.)

Suwanwaree, Pongthep, and Robertson, G.P., 2005, Methane oxidation in forest, successional, and no-till agricultural ecosystems: Soil Science Society of America Journal, v. 69, no. 6, p. 1722-1729, accessed December 16, 2013, at http://dx.doi.org/10.2136/sssaj2004.0223.

Tate, C.M., and Striegl, R.G., 1993, Methane consumption and carbon dioxide emission in tallgrass prairie - Effects of biomass burning and conversion to agriculture: Global Biogeochemical Cycles, v. 7, no. 4, p. 735-748. (Also available at http://dx.doi.org/10.1029/93GB02560.)

Terry, R.E., Tate, R.L., III, and Duxbury, J.M., 1981, The effect of flooding on nitrous oxide emissions from an organic soil: Soil Science, v. 132, no. 3, p. 228-232. (Also available at http://www.researchgate.net) publication/232212111_The_Effect_of_Flooding_on_ Nitrous_Oxide_Emissions_From_An_Organic_Soil.)

Torn, M.S., and Harte, John, 1996, Methane consumption by montane soils - Implications for positive and negative feedback with climatic change: Biogeochemistry, v. 32, no. 1, p. 53-67. (Also available at http://dx.doi.org/10.1007/ BF00001532.)

Ullah, Sami, Breitenbeck, G.A., and Faulkner, S.P., 2005, Denitrification and $\mathrm{N}_{2} \mathrm{O}$ emission from forested and cultivated alluvial clay soil: Biogeochemistry, v. 73, no. 3, p. 499-513, accessed December 16, 2013, at http://dx.doi.org/10.1007/s10533-004-1565-0.

U.S. Environmental Protection Agency, 2012, Inventory of U.S. greenhouse gas emissions and sinks - 1990-2010: U.S. Environmental Protection Agency EPA 430-R-12001, [variously paged], accessed December 18, 2013, at http://www.epa.gov/climatechange/Downloads/ ghgemissions/US-GHG-Inventory-2012-Main-Text.pdf.

Venterea, R.T., and Rolston, D.E., 2000, Nitric and nitrous oxide emission following fertilizer application to agricultural soil-Biotic and abiotic mechanisms and kinetics: Journal of Geophysical Research, v. 105, no. D12, p. 15117-15129. (Also available at http://dx.doi.org/10.1029/2000JD900025.)

Venterea, R.T., Groffman, P.M., Verchot, L.V., Magill, A.H., Aber, J.D., and Steudler, P.A., 2003, Nitrogen oxide gas emissions from temperate forest soils receiving long-term nitrogen inputs: Global Change Biology, v. 9, no. 3, p. 346357. (Also available at http://dx.doi.org/10.1046/j.13652486.2003.00591.x.)

Venterea, R.T., Burger, Martin, and Spokas, K.A., 2005, Nitrogen oxide and methane emissions under varying tillage and fertilizer management: Journal of Environmental Quality, 
v. 34 , no. 5 , p. $1467-1477$. (Also available at $h t t p: / / d x . d o i$. org/10.2134/jeq2005.0018.)

Walker, J.T., Geron, C.D., Vose, J.M., and Swank, W.T., 2002, Nitrogen trace gas emissions from a riparian ecosystem in southern Appalachia: Chemosphere, v. 49, no. 10, p. 13891398. (Also available at $h t t p: / / d x$.doi.org/10.1016/S00456535(02)00320-X.)

Whiting, G.J., and Chanton, J.P., 2001, Greenhouse carbon balance of wetlands-Methane emission versus carbon sequestration: Tellus, v. 53B, no. 5, p. 521-528. (Also available at $h t t p: / / d x . d o i . o r g / 10.1034 / j .1600-$ 0889.2001.530501.x.)

Yavitt, J.B., Simmons, J.A., and Fahey, T.J., 1993, Methane fluxes in a northern hardwood forest ecosystem in relation to acid precipitation: Chemosphere, v. 26, nos. 1-4, p. 721-730. (Also available at http://dx.doi.org/10.1016/0045-6535(93)90456-F.) 



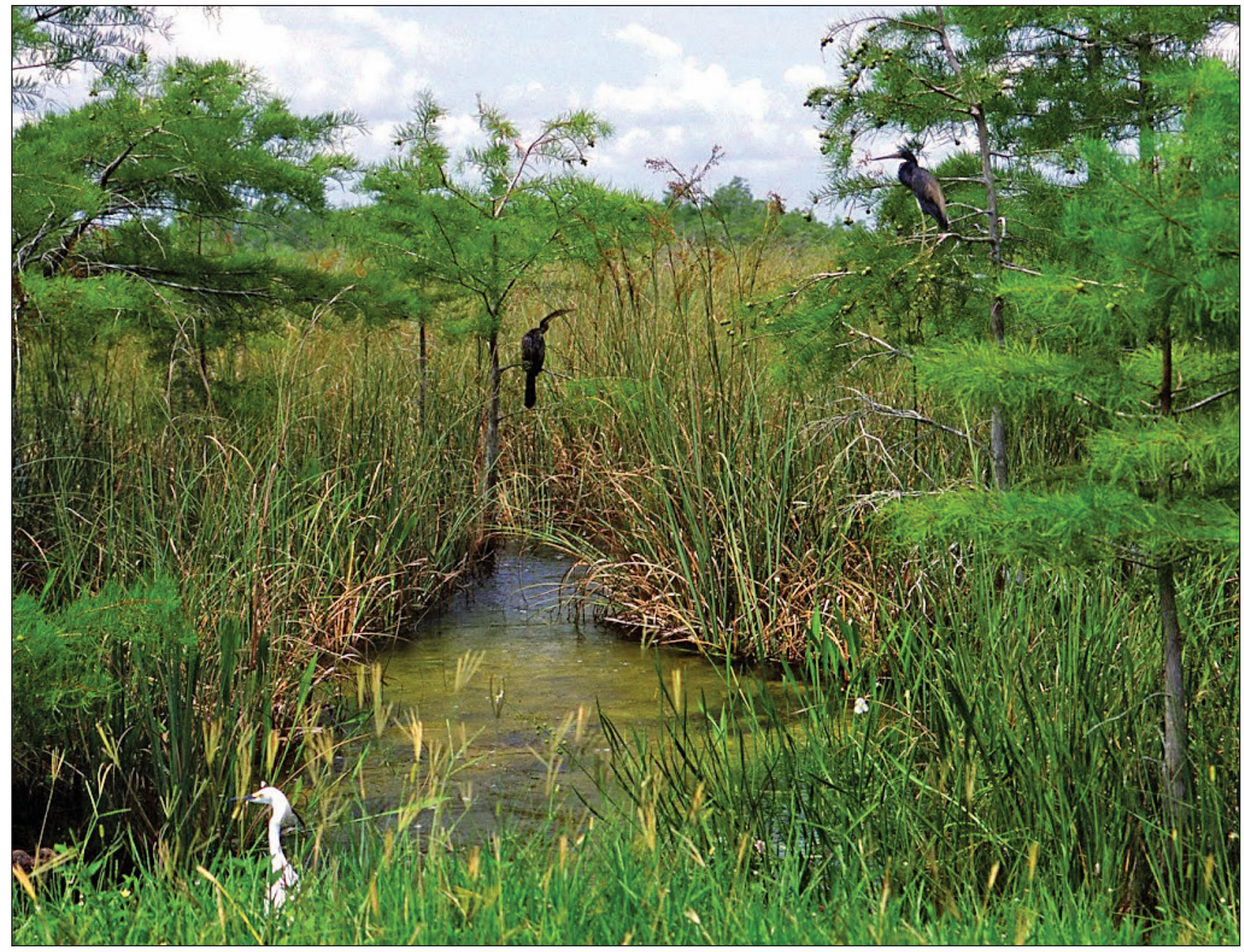

ISSN 1044-9612 (print)

ISBN 978-1-41133-3794-? 